ANDRÉ LUIZ MOLISANI

SINTERIZAÇÃO E CARACTERIZAÇÃO DE PROPRIEDADES MECÂNICAS DE CERÂMICAS DE NITRETO DE ALUMÍNIO 


\section{SINTERIZAÇÃO E CARACTERIZAÇÃO DE PROPRIEDADES MECÂNICAS DE CERÂMICAS DE NITRETO DE ALUMÍNIO}

Tese apresentada à Escola Politécnica da Universidade de São Paulo para obtenção do título de Doutorado em Engenharia

Área de concentração:

Engenharia Metalúrgica e de Materiais

Orientador:

Prof. Titular Dr. Hélio Goldenstein 
FICHA CATALOGRÁFICA

Molisani, André Luiz

Sinterização e caracterização de propriedades mecânicas de cerâmicas de nitreto de alumínio / A.L. Molisani. - São Paulo, 2009.

$215 \mathrm{p}$.

Tese (Doutorado) - Escola Politécnica da Universidade de São Paulo. Departamento de Engenharia Metalúrgica e de Materiais.

1. Cerâmica avançada 2. Sinterização 3. Propriedades dos materiais I. Universidade de São Paulo. Escola Politécnica. Departamento de Engenharia Metalúrgica e de Materiais II. t. 


\section{DEDICATÓRIA}

Aos meus pais, Maria de Lourdes e Luiz Carlos

À minha futura esposa Patrícia 


\section{AGRADECIMENTOS}

A consolidação do presente trabalho dependeu do apoio, incentivo e orientação das seguintes pessoas:

- Professor Titular Dr. Hélio Goldenstein: Departamento de Engenharia Metalúrgica e de Materiais da Escola Politécnica da Universidade de São Paulo;

- Dr. Humberto Nayouki Yoshimura: Ex-pesquisador do Laboratório de Metalurgia e Materiais Cerâmicos do Centro de Tecnologia de Processos e Produtos do Instituto de Pesquisas Tecnológicas do Estado de São Paulo e atual Professor do Centro de Engenharia, Modelagem e Ciências Sociais Aplicadas da Universidade Federal do ABC;

- PhD. Ana Helena de Almeida Bressiani: Responsável pelo Laboratório de Cerâmicas Estruturais do Centro de Ciência e Tecnologia de Materiais do Instituto de Pesquisas Energéticas e Nucleares;

- Dra. Catia Fredericci: Pesquisadora do Laboratório de Metalurgia e Materiais Cerâmicos do Centro de Tecnologia de Processos e Produtos do Instituto de Pesquisas Tecnológicas do Estado de São Paulo.

Em relação ao suporte técnico e financeiro, agradeço:

- Ao Departamento de Engenharia Metalúrgica e de Materiais da Escola Politécnica da Universidade de São Paulo;

- Ao Centro de Tecnologia de Processos e Produtos do Instituto de Pesquisas Tecnológicas do Estado de São Paulo;

- Ao Centro de Metrologia Química do Instituto de Pesquisas Tecnológicas do Estado de São Paulo;

- Ao Centro de Ciência e Tecnologia de Materiais do Instituto de Pesquisas Energéticas e Nucleares;

- À Fundação de Amparo à Pesquisa do Estado de São Paulo (FAPESP);

- Ao Conselho Nacional de Desenvolvimento Científico e Tecnológico (CNPq). 


\section{RESUMO}

Os objetivos gerais deste trabalho foram estudar o comportamento de densificação e as propriedades mecânicas do nitreto de alumínio (AlN) com aditivo de sinterização. Os objetivos específicos foram estudar: 1) o efeito do teor de $\mathrm{Y}_{2} \mathrm{O}_{3}$ na densificação do $\mathrm{AlN}$; 2) o efeito da adição de carbono na densificação do $\mathrm{AlN}$ com $\mathrm{CaO}$; 3) o efeito da adição simultânea de $\mathrm{Y}_{2} \mathrm{O}_{3}$ e $\mathrm{CaO}$ na densificação do $\mathrm{AlN}$; 4) o efeito da porosidade nas propriedades elásticas do AlN com $\mathrm{Y}_{2} \mathrm{O}_{3}$ ou $\mathrm{CaO}$; e 5) o efeito do teor de $\mathrm{Y}_{2} \mathrm{O}_{3}$ ou $\mathrm{CaO}$ nas propriedades mecânicas do AlN. As amostras foram sinterizadas sob atmosfera inerte em várias temperaturas $\left(1100-2000^{\circ} \mathrm{C}\right)$ e analisadas por determinação de densidade, difração de raios X e microscopia eletrônica de varredura. As propriedades determinadas à temperatura ambiente foram: constantes elásticas pelo método de pulso-eco ultra-sônico, resistência à flexão biaxial, dureza Vickers e tenacidade à fratura pelos métodos Indentation Fracture $\left(\mathrm{K}_{\mathrm{Ic}-\mathrm{IF}}\right)$ e Indentation Strength $\left(\mathrm{K}_{\mathrm{Ic}-\mathrm{IS}}\right)$. $\mathrm{O}$ AlN com $\mathrm{Y}_{2} \mathrm{O}_{3}$ apresentou significativa densificação por sinterização no estado sólido, mas completa densificação ocorreu somente por sinterização via fase líquida. A densificação do AlN não foi influenciada pelo aumento de $0,5 \%$ a $4 \%$ de $\mathrm{Y}_{2} \mathrm{O}_{3}$, pois a temperatura de formação da fase líquida $\left(\sim 1725^{\circ} \mathrm{C}\right)$ não variou nesta faixa de teor de aditivo. Porém, a adição de carbono levou à formação de segundas-fases refratárias no AlN com $4 \%$ de $\mathrm{Y}_{2} \mathrm{O}_{3}$, o que atrasou sua densificação devido ao aumento da temperatura de formação da fase líquida. A adição de carbono não mudou a temperatura de formação da fase líquida do $\mathrm{AlN}$ com $4 \%$ de $\mathrm{CaO}$ sinterizado acima de $1650^{\circ} \mathrm{C}$, mas sua densificação também atrasou devido à diminuição da fração de fase líquida e ao aprisionamento de gás nos poros fechados. A adição simultânea de $\mathrm{CaO}$ e $\mathrm{Y}_{2} \mathrm{O}_{3}$ diminuiu significativamente a temperatura de sinterização do AlN em relação às adições individuais destes aditivos. O AlN com mistura de $\mathrm{CaO}$ e $\mathrm{Y}_{2} \mathrm{O}_{3}$ atingiu quase completa densificação a partir de $1650^{\circ} \mathrm{C}$ devido à formação de fase líquida com composição próxima da fase $\mathrm{CaYAl}_{3} \mathrm{O}_{7}$, que apresentou boas características de molhamento e espalhamento nesta temperatura de sinterização. A adição de carbono mudou a composição das segundas-fases de $\mathrm{CaYAl}_{3} \mathrm{O}_{7}$ para $\mathrm{CaYAlO}_{4}$ e, então, para YAM $\left(2 \mathrm{Y}_{2} \mathrm{O}_{3} \cdot \mathrm{Al}_{2} \mathrm{O}_{3}\right)$ no AlN com mistura de $\mathrm{CaO}$ e $\mathrm{Y}_{2} \mathrm{O}_{3}$, o que atrasou sua densificação em baixas temperaturas de sinterização $\left(<1700^{\circ} \mathrm{C}\right)$ devido à alta viscosidade e/ou baixa molhabilidade da fase $\mathrm{CaYAlO}_{4}$ e à alta refratariedade da fase YAM. As propriedades elásticas, bem como a dureza Vickers do AlN foram influenciadas pela porosidade, mas não foram influenciadas pelo tipo $\left(\mathrm{CaO}\right.$ e $\left.\mathrm{Y}_{2} \mathrm{O}_{3}\right)$ e teor $(0,5 \%$ a $8 \%$ em massa $)$ de aditivo de sinterização. A resistência 
à flexão foi influenciada pelo tipo e teor de aditivo de sinterização, sendo observado um teor crítico de aditivo, acima do qual esta propriedade diminuiu significativamente e, então, tendeu a permanecer constante em função do teor de aditivo. Não se observou correlação entre tenacidade à fratura e resistência à flexão. Os valores de $\mathrm{K}_{\mathrm{Ic}-\mathrm{IS}}$, que não variaram com o tipo e teor de aditivo de sinterização, foram considerados mais consistentes do que os valores de $\mathrm{K}_{\text {Ic-IF. }}$

Palavras-chave: AlN. $\mathrm{Y}_{2} \mathrm{O}_{3}$. CaO. Sinterização. Porosidade. Propriedades Mecânicas. 


\section{ABSTRACT}

The general objectives of this work were to study the densification behavior and the mechanical properties of aluminum nitride (AlN) with sintering aid. The specific objectives studied were: 1) the effect of $\mathrm{Y}_{2} \mathrm{O}_{3}$ content on the densification of $\mathrm{AlN}, 2$ ) the effect of carbon addition on the densification of AlN with $\mathrm{CaO}, 3)$ the effect of simultaneous addition of $\mathrm{Y}_{2} \mathrm{O}_{3}$ and $\mathrm{CaO}$ on the densification of $\mathrm{AlN}$; 4) the effect of porosity on elastic properties of $\mathrm{AlN}$ with $\mathrm{CaO}$ or $\mathrm{Y}_{2} \mathrm{O}_{3}$, and 5) the effect of $\mathrm{Y}_{2} \mathrm{O}_{3}$ or $\mathrm{CaO}$ content on the mechanical properties of AlN. The samples were sintered under inert atmosphere at various temperatures $\left(1100^{\circ} \mathrm{C}\right.$ $2000^{\circ} \mathrm{C}$ ) and analyzed by density measurement, X-ray diffraction and scanning electron microscopy. The properties measured at room temperature were: elastic constants by the ultrasound pulse-echo method, biaxial flexural strength, Vickers hardness and fracture toughness by the Indentation Fracture (IF) and Indentation Strength (IS) methods. AlN with $\mathrm{Y}_{2} \mathrm{O}_{3}$ presented significant densification by solid-state sintering, but full densification occurred only by liquid-phase sintering. The densification of AIN was not influenced by the increase of $0.5 \%$ to $4 \% \mathrm{Y}_{2} \mathrm{O}_{3}$, since the liquid-phase formation temperature $\left(\sim 1725^{\circ} \mathrm{C}\right)$ did not change in this range of additive content. However, the addition of carbon to AlN with $4 \%$ $\mathrm{Y}_{2} \mathrm{O}_{3}$ led to formation of refractory second-phases, which delayed the densification due to an increase of the liquid-phase formation temperature. The addition of carbon did not change the liquid-phase formation temperature of $\mathrm{AlN}$ with $4 \% \mathrm{CaO}$ sintered above $1650^{\circ} \mathrm{C}$, but its densification delayed significantly due to the diminution of liquid-phase fraction and trapped gas in closed pores. The simultaneous addition of $\mathrm{CaO}$ and $\mathrm{Y}_{2} \mathrm{O}_{3}$ significantly diminished the sintering temperature of AlN in relation to the individual additions of these additives. AIN with simultaneous addition of $\mathrm{CaO}$ and $\mathrm{Y}_{2} \mathrm{O}_{3}$ achieved almost full densification at $1650^{\circ} \mathrm{C}$ due to formation of liquid-phase with composition close to $\mathrm{CaYAl}_{3} \mathrm{O}_{7}$ phase, which had good wetting and spreading characteristics at this temperature. The addition of carbon changed the composition of second-phases from $\mathrm{CaYAl}_{3} \mathrm{O}_{7}$ to $\mathrm{CaYAlO}$ and then to $\mathrm{YAM}\left(2 \mathrm{Y}_{2} \mathrm{O}_{3} \cdot \mathrm{Al}_{2} \mathrm{O}_{3}\right)$ in AlN with simultaneous addition of $\mathrm{CaO}$ and $\mathrm{Y}_{2} \mathrm{O}_{3}$, delaying its densification at low sintering temperatures $\left(<1700^{\circ} \mathrm{C}\right)$ due to the high viscosity and/or low wettability of $\mathrm{CaYAlO}_{4}$ phase and high refractoriness of YAM phase. The elastic properties, as well as Vickers hardness were influenced by the increase of porosity, but were not influenced by type $\left(\mathrm{CaO}\right.$ and $\left.\mathrm{Y}_{2} \mathrm{O}_{3}\right)$ and content $(0.5 \%$ to $8 \%$ in mass) of sintering aid. Flexure strength was influenced by the type and content of sintering aid. It was observed a critical additive content, 
above which the strength decreased significantly and then tended to remain almost constant as a function of additive content. No relationship was observed between fracture toughness and flexure strength. The $\mathrm{K}_{\mathrm{Ic}-\mathrm{IS}}$ values, which did not vary with type and content of sintering aid, were found to be more consistent than the $\mathrm{K}_{\mathrm{Ic}-\mathrm{IF}}$ values.

Key-words: AlN. $\mathrm{Y}_{2} \mathrm{O}_{3}$. CaO. Sintering. Porosity. Mechanical Properties. 


\section{LISTA DE ILUSTRAÇÕES}

Figura 1.1 - Ilustração da seqüência de montagem de um dispositivo eletrônico pela tecnologia DBC.

Figura 1.2 - Ilustração mostrando as principais etapas de um processo de produção de dispositivos eletrônicos pela tecnologia HTCC.

Figura 2.1 - Ilustração esquemática dos possíveis mecanismos de transporte de matéria, que podem atuar durante a sinterização no estado sólido: 1) difusão pela superfície; 2) difusão pela rede (a partir da superfície); 3) transporte por evaporação e condensação; 4) difusão pelo contorno de grão; 5) difusão pela rede (a partir do contorno de grão); e 6) fluxo plástico (por meio de discordâncias).

Figura 2.2 - Ilustração esquemática da geometria dos poros no estágio final da sinterização no estado sólido.

Figura 2.3 - Ilustração esquemática mostrando o ângulo diedro ( $\Psi)$ formado na interseção entre dois grãos e a fase líquida. $\gamma_{S S}$ é a energia interfacial sólido-sólido e $\gamma_{S L}$ é a energia interfacial sólido-líquido.

Figura 2.4 - Ilustração esquemática dos mecanismos de acomodação de forma e crescimento de pescoço durante o estágio intermediário da sinterização via fase líquida: (a) achatamento de contato; (b) dissolução de grãos finos; e (c) difusão no estado sólido.

Figura 2.5 - Ilustração esquemática de uma placa sujeita a uma tensão uniforme de tração $(\sigma)$ aplicada paralelamente ao semi-eixo a da cavidade elíptica. A região PC indica a ponta da cavidade elíptica, cujo raio de curvatura é $\tau=\mathrm{a}^{2} / \mathrm{c}$.

Figura 2.6 - Ilustração esquemática dos modos de carregamento: (a) modo I ou de abertura;

(b) modo II ou de deslizamento; e (c) modo III ou de cisalhamento fora do plano. 41

Figura 2.7 - Esquema de um gráfico mostrando o efeito do tamanho da trinca (c) na tenacidade à fratura $\left(\mathrm{K}_{\mathrm{Ic}}\right)$ de materiais cerâmicos que exibem ou não comportamento de curva $\mathrm{R}$. 44

Figura 2.8 - Imagens de microscópio eletrônico de varredura da superfície polida de amostras de alumina submetidas ao ensaio de determinação da curva $\mathrm{R}$ a partir de trincas longas. Amostras com tamanho de grão de $18 \mu \mathrm{m}$ (a) e de $39 \mu \mathrm{m}$ (b), onde se observa a ocorrência de engastamento mecânico e escorregamento com atrito; ${ }^{126}$ imagem mostrando a ocorrência de desprendimento (pullout) de grão (c).

Figura 2.9 - (a) esquema da célula unitária do AlN e (b) esquema das ligações entre os átomos de alumínio e nitrogênio. Estrutura cristalina hexagonal $2 \mathrm{H}$ similar a da würstita. Parâmetros de rede: $\alpha=3,111 \AA, \delta=4,978 \AA$ e $\delta / \alpha=1,600$.

Figura 2.10 - Diagrama de equilíbrio de fases do sistema $\mathrm{AlN}-\mathrm{Al}_{2} \mathrm{O}_{3}$. 
Figura 2.11 - Diagrama de avaliação da estabilidade térmica do AlN na presença de vários aditivos óxidos. As energias $\Delta \mathrm{F}_{7}{ }^{\circ}, \Delta \mathrm{F}_{8}{ }^{\circ}$ e $\Delta \mathrm{F}_{9}{ }^{\mathrm{o}}$ indicam as energias livres padrões de formação das reações 2.7 a 2.9, respectivamente. Estas energias foram calculadas a partir de dados termodinâmicos para a temperatura de $1530^{\circ} \mathrm{C}$. Os óxidos metálicos, localizados dentro da área demarcada, não induzem a oxidação do AlN durante a sinterização.

Figura 3.1 - Diagrama de equilíbrio de fases do sistema $\mathrm{Y}_{2} \mathrm{O}_{3}-\mathrm{Al}_{2} \mathrm{O}_{3}$. $\mathrm{YAG}\left(3 \mathrm{Y}_{2} \mathrm{O}_{3} \cdot 5 \mathrm{Al}_{2} \mathrm{O}_{3}\right)$, YAM $\left(2 \mathrm{Y}_{2} \mathrm{O}_{3} \cdot \mathrm{Al}_{2} \mathrm{O}_{3}\right)$ e YAP $\left(\mathrm{Y}_{2} \mathrm{O}_{3} \cdot \mathrm{Al}_{2} \mathrm{O}_{3}\right)$. As setas indicam as composições inicias esperadas nos corpos conformados de pó de AlN com $0,85 \%$ em massa de oxigênio e adição de $0,5 \%, 2 \%$ e $4 \%$ em massa de $\mathrm{Y}_{2} \mathrm{O}_{3}$.

Figura 3.2 - Distribuição granulométrica dos pós de partida de $\mathrm{AlN}$ e $\mathrm{Y}_{2} \mathrm{O}_{3}$. .66

Figura 3.3 - Imagens de MEV dos pós de partida: (a) AlN, (b) $\mathrm{Y}_{2} \mathrm{O}_{3}$, e (c) grafita (C). .66

Figura 3.4 - Densidade relativa em função da temperatura de sinterização do AlN sem aditivo e com $\mathrm{Y}_{2} \mathrm{O}_{3}$.

Figura 3.5 - Curvas de retração linear (a) e de taxa de retração (b) em função da temperatura de sinterização. Estas curvas foram traçadas com os dados experimentais obtidos por dilatometria.

Figura 3.6 - Difratogramas de raios $\mathrm{X}$ das amostras $05 \mathrm{Y}, 2 \mathrm{Y}$ e $4 \mathrm{Y}$ sinterizadas a $1650^{\circ} \mathrm{C}$ (a), $1750^{\circ} \mathrm{C}$ (b) e $2000^{\circ} \mathrm{C}$ (c). Fases cristalinas: (1) AlN, (2) YAG $\left[3 \mathrm{Y}_{2} \mathrm{O}_{3} \cdot 5 \mathrm{Al}_{2} \mathrm{O}_{3}\right]$, (3) YAP $\left[\mathrm{Y}_{2} \mathrm{O}_{3} \cdot \mathrm{Al}_{2} \mathrm{O}_{3}\right]$, (4) YAM $\left[2 \mathrm{Y}_{2} \mathrm{O}_{3} \cdot \mathrm{Al}_{2} \mathrm{O}_{3}\right]$, (5) não identificada e (6) $\mathrm{Y}_{2} \mathrm{O}_{3}$ .70

Figura 3.7 - Imagens de MEV da superfície de fratura do AIN sem aditivo sinterizado a $1650^{\circ} \mathrm{C}(\mathrm{a}), 1850^{\circ} \mathrm{C}$ (b) e $2000^{\circ} \mathrm{C}$ (c) por $1 \mathrm{~h} . .$. 71

Figura 3.8 - Imagens de MEV de amostras sinterizadas a $1700^{\circ} \mathrm{C}$ por $1 \mathrm{~h}$ : (a) superfície de fratura e (b) superfície polida da amostra 05Y, (c) superfície de fratura e (d) superfície polida da amostra 4Y, e (e) espectro da análise por EDS realizada em uma das partículas claras da Figura 3.8d. As regiões claras nas Figuras $3.8 \mathrm{~b}$ e $3.8 \mathrm{~d}$ são partículas de segundas-fases.........72

Figura 3.9 - Imagens de MEV da superfície de fratura das amostras com $\mathrm{Y}_{2} \mathrm{O}_{3}$ sinterizadas em várias temperaturas: (a) amostra $05 \mathrm{Y}-1725^{\circ} \mathrm{C} / 1 \mathrm{~min}$, (b) amostra $05 \mathrm{Y}-1725^{\circ} \mathrm{C} / 1 \mathrm{~h}$ e (c) amostra $4 \mathrm{Y}-1750^{\circ} \mathrm{C} / 1 \mathrm{~h}$.

Figura 3.10 - Imagens de MEV da superfície polida da amostra 05Y sinterizada em várias temperaturas por $1 \mathrm{~h}$ : (a) $1750^{\circ} \mathrm{C}$; (b) $1850^{\circ} \mathrm{C}$; e (c) $1900^{\circ} \mathrm{C}$. A seta indica uma partícula pequena de segunda-fase.

Figura 3.11-Imagens de MEV da superfície polida das amostras de AlN com $\mathrm{Y}_{2} \mathrm{O}_{3}$ sinterizadas em várias temperaturas por $1 \mathrm{~h}$ : (a) amostra $2 \mathrm{Y}-1800^{\circ} \mathrm{C}$; (b) amostra $4 \mathrm{Y}$ $1850^{\circ} \mathrm{C}$; (c) amostra $4 \mathrm{Y}-1900^{\circ} \mathrm{C}$; (d) amostra $05 \mathrm{Y}-1950^{\circ} \mathrm{C}$; (e) amostra $4 \mathrm{Y}-1950^{\circ} \mathrm{C}$; e (f) amostra $2 \mathrm{Y}-2000^{\circ} \mathrm{C}$. A seta indica uma partícula grande de segunda-fase.

Figura 3.12 - Densidade relativa em função da temperatura de sinterização das amostras 4Y, $4 \mathrm{Y} 05 \mathrm{C}$ e $4 \mathrm{Y} 1 \mathrm{C}$.

Figura 3.13 - Perda de massa em função da temperatura de sinterização das amostras 4Y, 4Y05C e 4Y1C. 
Figura 3.14 - Imagens de MEV da superfície polida das amostras sinterizadas em várias temperaturas por $1 \mathrm{~h}$ : (a) $4 \mathrm{Y} 05 \mathrm{C}-1750^{\circ} \mathrm{C}$, (b) $4 \mathrm{Y} 05 \mathrm{C}-1800^{\circ} \mathrm{C}$, (c) $4 \mathrm{Y} 1 \mathrm{C}-1800^{\circ} \mathrm{C}$, (d) $4 Y 1 \mathrm{C}-1850^{\circ} \mathrm{C}$ e (e) espectro da análise por EDS realizada em uma das partículas de segundas-fases observadas na Figura 3.14d. As regiões claras observadas nas Figuras 3.14a a 3.14d são partículas de segundas-fases.

Figura 4.1 - Diagrama de equilíbrio de fases do sistema $\mathrm{CaO}-\mathrm{Al}_{2} \mathrm{O}_{3} \cdot \mathrm{C}_{3} \mathrm{~A}\left(3 \mathrm{CaO} \cdot \mathrm{Al}_{2} \mathrm{O}_{3}\right)$, $\mathrm{C}_{12} \mathrm{~A}_{7}\left(12 \mathrm{CaO}_{2} 7 \mathrm{Al}_{2} \mathrm{O}_{3}\right), \mathrm{C}_{5} \mathrm{~A}_{3}\left(5 \mathrm{CaO} .3 \mathrm{Al}_{2} \mathrm{O}_{3}\right), \mathrm{CA}\left(\mathrm{CaO} . \mathrm{Al}_{2} \mathrm{O}_{3}\right), \mathrm{CA}_{2}\left(\mathrm{CaO} .2 \mathrm{Al}_{2} \mathrm{O}_{3}\right), \mathrm{C}_{3} \mathrm{~A}_{5}$ $\left(3 \mathrm{CaO} .5 \mathrm{Al}_{2} \mathrm{O}_{3}\right)$ e $\mathrm{CA}_{6}\left(\mathrm{CaO} .6 \mathrm{Al}_{2} \mathrm{O}_{3}\right)$. As setas indicam as composições inicias esperadas nos corpos conformados de AlN com $0,5 \%, 1 \%, 2 \%, 4 \%$ e $8 \%$ em massa de $\mathrm{CaO}$.

Figura 4.2-Dados compilados da literatura referente à densidade em função do teor equivalente de $\mathrm{CaO}$ para amostras de $\mathrm{AlN}$ sinterizadas a $1650^{\circ} \mathrm{C}$ e $1700^{\circ} \mathrm{C}$.

Figura 4.3 - Imagens de MEV da superfície de fratura do AlN com 13,5\% em massa de $\mathrm{CaCO}_{3}$ sinterizado a $1500^{\circ} \mathrm{C}$ (a) e $7 \%$ em massa de $\mathrm{CaCO}_{3}$ sinterizado a $1750^{\circ} \mathrm{C}$ (b). 98

Figura 4.4 - Diagrama esquemático da evolução das segundas-fases no AlN com $\mathrm{CaCO}_{3}$ sinterizado em várias temperaturas. Os teores $0,9 \%, 1,8 \%, 3,5 \%, 7,0 \%$ e $13,5 \%$ em massa de $\mathrm{CaCO}_{3}$ correspondem a $0,5 \%, 1 \%, 2 \%, 4 \%$ e $8 \%$ em massa de $\mathrm{CaO}$, respectivamente. $\mathrm{O}$ símbolo \# indica a presença de uma pequena fração da fase $\mathrm{C}_{5} \mathrm{~A}_{3}$, que é metaestável e apresenta composição próxima da fase $\mathrm{C}_{12} \mathrm{~A}_{7}$. $\mathrm{O}$ símbolo * indica a presença de uma pequena fração da fase $\mathrm{Al}_{2} \mathrm{O}_{3}$. As fases $\mathrm{C}_{3} \mathrm{~A}, \mathrm{C}_{12} \mathrm{~A}_{7}, \mathrm{CA}, \mathrm{CA}_{2}$ e $\mathrm{CA}_{6}$ correspondem aos compostos $3 \mathrm{CaO} . \mathrm{Al}_{2} \mathrm{O}_{3}, 12 \mathrm{CaO} .7 \mathrm{Al}_{2} \mathrm{O}_{3}, \mathrm{CaO} . \mathrm{Al}_{2} \mathrm{O}_{3}, \mathrm{CaO} .2 \mathrm{Al}_{2} \mathrm{O}_{3}$ e $\mathrm{CaO} .6 \mathrm{Al}_{2} \mathrm{O}_{3}$, respectivamente..... 101

Figura 4.5 - Distribuição granulométrica dos pós de partida de $\mathrm{AlN}$ e $\mathrm{CaCO}_{3}$ (a) e imagem de MEV das partículas do pó de $\mathrm{CaCO}_{3}$ (b). 102

Figura 4.6 - Densidade relativa em função da temperatura de sinterização das amostras $4 \mathrm{Ca}$, $4 \mathrm{Ca} 05 \mathrm{C}$ e $4 \mathrm{Ca} 1 \mathrm{C}$.

Figura 4.7 - Perda de massa em função da temperatura de sinterização das amostras $4 \mathrm{Ca}$, $4 \mathrm{Ca} 05 \mathrm{C}$ e $4 \mathrm{Ca} 1 \mathrm{C}$. 104

Figura 4.8 - Imagens de MEV: superfícies polidas da amostra $4 \mathrm{Ca}$ sinterizada a $1650^{\circ} \mathrm{C}$ (a) e $1700^{\circ} \mathrm{C}(\mathrm{b})$, e superfície de fratura a $1800^{\circ} \mathrm{C}$ (c); superfícies polidas das amostras $4 \mathrm{Ca} 05 \mathrm{C}$ (d) e $4 \mathrm{Ca} 1 \mathrm{C}$ (e) sinterizadas a $1700^{\circ} \mathrm{C}$, e superfície de fratura da amostra $4 \mathrm{Ca} 1 \mathrm{C}$ sinterizada a $1800^{\circ} \mathrm{C}(\mathrm{f})$. 106

Figura 5.1 - Diagrama de equilíbrio de fases do sistema $\mathrm{CaO}-\mathrm{Al}_{2} \mathrm{O}_{3}-\mathrm{Y}_{2} \mathrm{O}_{3}$. As temperaturas eutéticas mais baixas ocorrem a $1375^{\circ} \mathrm{C}\left(\mathrm{n}^{\circ} 8\right), 1395^{\circ} \mathrm{C}\left(\mathrm{n}^{\circ}\right.$ 9), $1420^{\circ} \mathrm{C}\left(\mathrm{n}^{\circ} 7\right)$ e $1535^{\circ} \mathrm{C}\left(\mathrm{n}^{\circ} 6 \mathrm{e}\right.$ 6'). Fases de interesse: $\mathrm{CaYAl}_{3} \mathrm{O}_{7}, \mathrm{CaYAlO}_{4}, \mathrm{YAM}\left(\mathrm{Y}_{4} \mathrm{Al}_{2} \mathrm{O}_{9}\right)$, YAP $\left(\mathrm{YAlO}_{3}\right)$, YAG $\left(\mathrm{Y}_{3} \mathrm{Al}_{5} \mathrm{O}_{12}\right), \mathrm{C}_{3} \mathrm{~A}\left(\mathrm{Ca}_{3} \mathrm{Al}_{2} \mathrm{O}_{6}\right), \mathrm{C}_{12} \mathrm{~A}_{7}\left(\mathrm{Ca}_{12} \mathrm{Al}_{14} \mathrm{O}_{33}\right), \mathrm{CA}\left(\mathrm{CaAl}_{2} \mathrm{O}_{4}\right), \mathrm{CA}_{2}\left(\mathrm{CaAl}_{4} \mathrm{O}_{7}\right), \mathrm{CA}_{6}$ $\left(\mathrm{CaAl}_{12} \mathrm{O}_{19}\right)$. Os símbolos indicam as composições iniciais esperadas nos corpos conformados de pó de AlN com 0,85\% em massa de oxigênio e adições, em \% massa, de 1\% CaO-3\% $\mathrm{Y}_{2} \mathrm{O}_{3}(\boldsymbol{\bullet}), 2 \% \mathrm{CaO}-2 \% \mathrm{Y}_{2} \mathrm{O}_{3}(\bullet)$ e $3 \% \mathrm{CaO}-1 \% \mathrm{Y}_{2} \mathrm{O}_{3}(\boldsymbol{\Delta})$ 114

Figura 5.2 - Resultados de densidade relativa das amostras de AlN com $\mathrm{Y}_{2} \mathrm{O}_{3}$ e/ou CaO. As amostras $4 \mathrm{Y}$ e $4 \mathrm{Ca}$ se referem ao AlN com $4 \%$ de $\mathrm{Y}_{2} \mathrm{O}_{3}$ e $4 \%$ de $\mathrm{CaO}$, respectivamente. Já as amostras $1 \mathrm{Ca} 3 \mathrm{Y}, 2 \mathrm{Ca} 2 \mathrm{Y}$ e $3 \mathrm{Ca} 1 \mathrm{Y}$ se referem ao $\mathrm{AlN}$ com $1 \% \mathrm{CaO}-3 \% \mathrm{Y}_{2} \mathrm{O}_{3}, 2 \% \mathrm{CaO}-2 \%$ $\mathrm{Y}_{2} \mathrm{O}_{3}$ e $3 \% \mathrm{CaO}-1 \% \mathrm{Y}_{2} \mathrm{O}_{3}$, respectivamente. 
Figura 5.3 - Perda de massa em função da temperatura de sinterização das amostras $1 \mathrm{Ca} 3 \mathrm{Y}$, $2 \mathrm{Ca} 2 \mathrm{Y}$ e $3 \mathrm{Ca} 1 \mathrm{Y}$.

Figura 5.4-Difratogramas de raios $\mathrm{X}$ das amostras $1 \mathrm{Ca} 3 \mathrm{Y}, 2 \mathrm{Ca} 2 \mathrm{Y}$ e $3 \mathrm{Ca} 1 \mathrm{Y}$. Fases cristalinas: (1) AlN, (2) YAG $\left[5 \mathrm{Al}_{2} \mathrm{O}_{3} .3 \mathrm{Y}_{2} \mathrm{O}_{3}\right]$, (3) $\mathrm{CaYAl}_{3} \mathrm{O}_{7}$, (4) YAM $\left[\mathrm{Al}_{2} \mathrm{O}_{3} \cdot 2 \mathrm{Y}_{2} \mathrm{O}_{3}\right]$, (5) $\mathrm{CaYAlO}_{4}$ e (6) não identificada....

Figura 5.5 - Imagens de MEV da superfície polida da amostra $1 \mathrm{Ca} 3 \mathrm{Y}$ sinterizada a $1650^{\circ} \mathrm{C}$ (a e b) e $1850^{\circ} \mathrm{C}$ (c) por $1 \mathrm{~h}$. As regiões claras observadas nas Figuras 5.5a a 5.5c são partículas de segundas-fases. Resultados das análises por EDS realizadas na partícula grande de segunda-fase (d) e na matriz (e)

Figura 5.6 - Imagens de MEV das superfícies de fratura das amostras 2Ca2Y (a) e 3Ca1Y (c) sinterizadas a $1650^{\circ} \mathrm{C}$, das superfícies polidas das amostras $2 \mathrm{Ca} 2 \mathrm{Y}$ (b) e $3 \mathrm{Ca} 1 \mathrm{Y}$ (d) sinterizadas a $1700^{\circ} \mathrm{C}$ e das superfícies de fratura das amostras $2 \mathrm{Ca} 2 \mathrm{Y}$ (e) e $3 \mathrm{Ca} 1 \mathrm{Y}$ (f) sinterizadas a $1800^{\circ} \mathrm{C}$

Figura 5.7-Densidade em função da temperatura de sinterização das amostras 2Ca2Y, 2Ca2Y05C e 2Ca2Y1C.

Figura 5.8 - Perda de massa em função da temperatura de sinterização das amostras $2 \mathrm{Ca} 2 \mathrm{Y}$, $2 \mathrm{Ca} 2 \mathrm{Y} 05 \mathrm{C}$ e $2 \mathrm{Ca} 2 \mathrm{Y} 1 \mathrm{C}$

Figura 5.9 - Imagens de MEV da superfície polida das amostras 2Ca2Y05C (a) e 2Ca2Y1C (c) sinterizadas a $1650^{\circ} \mathrm{C}$, e $2 \mathrm{Ca} 2 \mathrm{Y} 05 \mathrm{C}$ (d) sinterizada a $1700^{\circ} \mathrm{C}$. Imagem de $\mathrm{MEV}$ da superfície de fratura da amostra $2 \mathrm{Ca} 2 \mathrm{Y} 1 \mathrm{C}$ (e) sinterizada a $1850^{\circ} \mathrm{C}$. Espectro de EDS (b) de uma partícula grande de segundas-fases observada na amostra $2 \mathrm{Ca} 2 \mathrm{Y} 05 \mathrm{C}$.

Figura 6.1 - Relação entre fração de área sólida mínima e fração volumétrica de poros determinada para vários tipos de modelo: (1) regra das misturas; (2) partículas esféricas com empilhamento rômbico; (3) partículas esféricas com empilhamento cúbico simples; (4) poros esféricos com empilhamento cúbico simples; (5) poros cilíndricos com empilhamento cúbico simples alinhado transversalmente à tensão aplicada; e (6) poros cilíndricos com empilhamento cúbico simples alinhado paralelamente à tensão aplicada. As linhas tracejadas representam curvas exponenciais $\left(\mathrm{e}_{-}{ }^{\mathrm{bP}}\right)$, que foram ajustadas para diferentes valores de b... 139

Figura 6.2-Resultados de fração volumétrica de poros em função da temperatura de sinterização. O coeficiente de variação foi menor do que $0,3 \%$.

Figura 6.3 - Imagens de MEV da superfície de fratura das amostras de AlN. Amostras 1Ca (a) e $4 \mathrm{Ca}$ (b) sinterizadas a $1650^{\circ} \mathrm{C}$ e amostra $2 \mathrm{Ca}$ sinterizada a $1800^{\circ} \mathrm{C}$. Amostra $4 \mathrm{Y}$ (d) sinterizada a $1700^{\circ} \mathrm{C}$ e amostras $05 \mathrm{Y}$ e $2 \mathrm{Y}$ sinterizadas a $1800^{\circ} \mathrm{C}$.

Figura 6.4 - Resultados de módulo de Young (E) em função da temperatura de sinterização (a) e módulos elásticos ( $\mathrm{E}, \mathrm{G}$ e $\left.\mathrm{K}_{\mathrm{V}}\right)$ em função da fração volumétrica de poros, $f_{\mathrm{P}}(\mathrm{b})$. Módulos de cisalhamento $(\mathrm{G})$ e geométrico $\left(\mathrm{K}_{\mathrm{V}}\right)$. Os coeficientes de variação das constantes elásticas foram menores do que $5 \%$. 148

Figura 6.5-Módulos elásticos (a) e velocidades sônicas e coeficiente de Poisson (b) em função da fração volumétrica de poros $\left(f_{\mathrm{P}}\right)$ para todas as amostras sinterizadas entre $1650^{\circ} \mathrm{C}$ e $2000^{\circ} \mathrm{C}$. As curvas foram obtidas a partir do ajuste dos dados experimentais a equação de Phani-Niyogi (eq. 6.7, Tabela 6.1). 
Figura 6.6 - Dados experimentais de coeficiente de Poisson em função da fração volumétrica de poros.

Figura 6.7 - Propriedades relativas $\left(\mathrm{M} / \mathrm{M}_{0}=\mathrm{E} / \mathrm{E}_{0}, \mathrm{G} / \mathrm{G}_{0}, \mathrm{~K}_{\mathrm{V}} / \mathrm{K}_{\mathrm{V} 0}, v / \mathrm{v}_{0}, \mathrm{v}_{\mathrm{L}} / \mathrm{v}_{\mathrm{L} 0}\right.$ e $\left.\mathrm{v}_{\mathrm{T}} / \mathrm{v}_{\mathrm{T} 0}\right)$ em função da fração volumétrica de poros. As curvas tracejadas indicadas com número se referem aos vários tipos de modelos. A curva 1 se refere ao modelo de regra das misturas. As demais curvas se referem aos modelos de área sólida mínima (ASM): (2) partículas esféricas com empilhamento rômbico; (3) partículas esféricas com empilhamento cúbico simples; (4) poros esféricos com empilhamento cúbico simples; (5) poros cilíndricos com empilhamento cúbico simples alinhado transversalmente à tensão aplicada; e (6) poros cilíndricos com empilhamento cúbico simples alinhado paralelamente à tensão aplicada.

Figura 6.8 - Módulos elásticos normalizados em função da fração volumétrica de poros: (a) módulo de Young (E), (b) módulo de cisalhamento $(\mathrm{G})$ e (c) módulo volumétrico $\left(\mathrm{K}_{\mathrm{V}}\right)$. As curvas se referem aos modelos analíticos baseados em concentração de tensão ao redor dos poros (Tabela 6.2).

Figura 6.9 - Módulo elástico relativo $\left(\mathrm{M} / \mathrm{M}_{0}\right)$ e fração relativa dos modelos de ASM em função da fração volumétrica de poros. Os modelos 3 e 4 se referem aos respectivos modelos de partículas esféricas em empilhamento cúbico simples (curva 3, Fig. 6.7) e poros esféricos em empilhamento cúbico simples (curva 4, Fig. 6.7)....

Figura 7.1 - Dispositivo de teste de resistência à flexão biaxial do tipo pistão sobre três esferas (a), imagem do pistão de aplicação de carga com diâmetro de $1,65 \mathrm{~mm}$ e do portaamostra com esferas metálicas (diâmetro $=1,58 \mathrm{~mm}$ ) arranjadas de tal modo a formar ângulos de $120^{\circ}$ (b), e imagem de um disco cerâmico colocado no porta-amostra para realização do ensaio (c).

Figura 7.2 - Esquema do sistema de fratura produzido por indentação Vickers, onde $C_{a p}$ é a carga aplicada e 2 c é o comprimento da trinca radial-mediana (a), e vista de topo da região indentada, onde $2 \mathrm{u}$ é o comprimento da diagonal da indentação Vickers (região de deformação plástica) (b).

Figura 7.3 - Imagens replicadas da superfície de fraturas das amostras de AlN sinterizadas a $1800^{\circ} \mathrm{C}$, onde se delimitou os contornos de grão para determinação do tamanho de grão por meio de análise de imagens: (a) AlN-0,5\% CaO, (b) AlN-4\% CaO, (c) AlN-0,5\% $\mathrm{Y}_{2} \mathrm{O}_{3}$ e (d) $\mathrm{AlN}-4 \% \mathrm{Y}_{2} \mathrm{O}_{3}$.

Figura 7.4-Ilustração esquemática da superfície de fratura mostrando as três regiões características da propagação da trinca (mirror, mist e hackle), bem como a origem da fratura, profundidade do defeito (a) e comprimento do defeito (2c).

Figura 7.5-Módulo de Young (E) e porosidade (P) em função do teor de aditivo de sinterização: (a) $\mathrm{CaO}$ e (b) $\mathrm{Y}_{2} \mathrm{O}_{3}$. As amostras de $\mathrm{AlN}$ foram sinterizadas a $1800^{\circ} \mathrm{C}$ por $1 \mathrm{~h}$.

Figura 7.6 - Resistência à flexão biaxial $\left(\sigma_{\mathrm{f}, \mathrm{b}}\right)$ do AlN em função do teor de aditivo de sinterização. As amostras de AlN foram sinterizadas a $1800^{\circ} \mathrm{C}$ por $1 \mathrm{~h}$. 
Figura 7.7 - Imagens de MEV da superfície de fratura das amostras de AlN sinterizadas a $1800^{\circ} \mathrm{C}$ e submetidas ao ensaio de resistência à flexão biaxial. As setas indicam poros grandes residuais.

Figura 7.8 - Tamanho médio de grão (a) e fração de grãos com fratura transgranular (b) em função do teor de aditivo de sinterização. As amostras de $\mathrm{AlN}$ foram sinterizadas a $1800^{\circ} \mathrm{C}$ por $1 \mathrm{~h}$

Figura 7.9 - Dureza Vickers ( $\left.\mathrm{H}_{\mathrm{V}^{-0}, 5 \mathrm{kgf}}\right)$ em função do teor de aditivo de sinterização (a) e da carga de indentação (b). As amostras de AlN foram sinterizadas a $1800^{\circ} \mathrm{C}$ por $1 \mathrm{~h}$.............. 174

Figura 7.10 - Tenacidade à fratura determinada pelo método IF - Indentation Fracture $\left(\mathrm{K}_{\mathrm{Ic}-\mathrm{IF}}\right)$ do AlN em função do teor de aditivo de sinterização. As amostras de AlN foram sinterizadas a $1800^{\circ} \mathrm{C}$ por $1 \mathrm{~h}$

Figura 7.11 - Imagens de MEV do perfil da trinca gerada por indentação Vickers (carga de $0,5 \mathrm{kgf}$ ) na superfície polida de amostras de $\mathrm{AlN}$ com $\mathrm{CaO}$ sinterizadas a $1800^{\circ} \mathrm{C}$ por $1 \mathrm{~h}$. As indicações referem-se aos mecanismos de tenacificação: (1) engastamento (interlocking) mecânico e escorregamento (sliding) com atrito das superfícies de fratura e (2) ponteamento de trinca (crack bridging).

Figura 7.12 - Imagens de MEV do perfil da trinca gerada por indentação Vickers (carga de $0,5 \mathrm{kgf}$ ) na superfície polida de amostras de $\mathrm{AlN}$ com $\mathrm{Y}_{2} \mathrm{O}_{3}$ sinterizadas a $1800^{\circ} \mathrm{C}$ por $1 \mathrm{~h}$. As indicações 1 e 2 referem-se aos mecanismos de tenacificação: (1) engastamento (interlocking) mecânico e escorregamento (sliding) com atrito das superfícies de fratura e (2) ponteamento de trinca (crack bridging). Já a indicação $\mathrm{P}$ refere-se às partículas grandes de aluminatos de ítrio.

Figura 7.13 - Tenacidade à fratura determinada pelo método IS - Indentation Strength ( $\left.\mathrm{K}_{\mathrm{Ic}-\mathrm{IS}}\right)$ do AlN em função do teor de aditivo de sinterização. As amostras de AlN foram sinterizadas a $1800^{\circ} \mathrm{C}$ por $1 \mathrm{~h}$. 179

Figura 7.14 - Imagens dos principais padrões macroscópicos de fratura das amostras de AlN submetidas ao ensaio de resistência à flexão biaxial. As setas nas Figuras 7.14a e 7.14b indicam a direção de propagação da trinca e o ponto $O$ indica a região em que se localiza provavelmente a origem da fratura. Os diâmetros dos corpos-de-prova foram próximos de 11 $\mathrm{mm}$.

Figura 7.15 - Relação entre resistência à flexão biaxial $\left(\sigma_{\mathrm{f}, \mathrm{b}}\right)$ e número de fragmentos de fratura $\left(\mathrm{N}_{\mathrm{ff}}\right)$ das amostras de AlN sinterizadas a $1800^{\circ} \mathrm{C}$ por $1 \mathrm{~h}$.

Figura 7.16 - Imagens de MEV mostrando a origem de fratura $(\mathrm{O})$ dos corpos-de-prova de AlN submetidos ao ensaio de resistência à flexão biaxial. As regiões demarcadas nas imagens indicam o tamanho do defeito iniciador da fratura.

Figura 7.17 - Imagens de MEV mostrando defeitos (poros grandes) de processamento nas superfícies de fratura de amostras de AlN submetidas ao ensaio de resistência à flexão biaxial. Os defeitos foram localizados no interior (volume) do corpo.

Figura 7.18 - Comprimento de trinca calculado $\left(\mathrm{c}_{\text {calc }}\right)$ pela equação 2.22 a partir dos dados de $\mathrm{K}_{\text {Ic-IF }}$ e $\mathrm{K}_{\text {Ic-IS }}$ em função do comprimento de trinca determinado ( $\mathrm{c}_{\mathrm{det}}$ ) pela análise fractográfica. A curva linear corresponde à condição $\mathrm{c}_{\mathrm{calc}}=\mathrm{c}_{\mathrm{det}}$. 


\section{LISTA DE TABELAS}

Tabela 2.1 - Características técnicas dos pós de AlN produzidos por redução carbotérmica e nitretação do pó de $\mathrm{Al}_{2} \mathrm{O}_{3}$ (Tokuyama Soda Corp., Japão) e por nitretação direta de alumínio metálico (H.C. Starck, Alemanha).

Tabela 2.2 - Valores de energia livre padrão de formação $\left(\Delta \mathrm{F}_{\mathrm{f}}{ }^{\mathrm{o}}\right)$ de algumas fases de aluminato que podem se formar durante a sinterização do AlN com aditivo...........................55

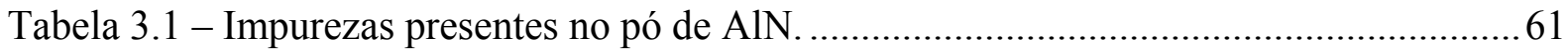

Tabela 3.2 - Composições e identificações das amostras de AlN ...........................................61

Tabela 3.3 - Resultados de DRX das segundas-fases nas amostras de AlN com $\mathrm{Y}_{2} \mathrm{O}_{3} \ldots \ldots \ldots . .70$

Tabela 3.4 - Resultados de DRX das segundas-fases nas amostras 4Y, 4Y05C e 4Y1C........78

Tabela 4.1 - Composições e identificações das amostras de AlN.......................................... 101

Tabela 4.2 - Resultados de DRX das segundas-fases nas amostras 4Ca, 4Ca05C e 4Ca1C. 105

Tabela 5.1 - Composições e identificações das amostras de AlN......................................... 117

Tabela 5.2-Resultados de DRX das segundas-fases nas amostras $1 \mathrm{Ca} 3 \mathrm{Y}, 2 \mathrm{Ca} 2 \mathrm{Y}$ e $3 \mathrm{Ca} 1 \mathrm{Y}$.

Tabela 5.3-Resultados de DRX das segundas-fases nas amostras 2Ca2Y, 2Ca2 Y05C e $2 \mathrm{Ca} 2 \mathrm{Y} 1 \mathrm{C}$.

Tabela 6.1 - Equações semi-empíricas de constantes elásticas em função da porosidade. ... 141

Tabela 3.2 - Equações analíticas de constantes elásticas em função da porosidade.

Tabela 6.3 - Composições e identificações das amostras de AlN.

Tabela 6.4-Resultados do ajuste matemático dos resultados de módulos elásticos (E, G e $\left.\mathrm{K}_{\mathrm{V}}\right)$, coeficiente Poisson $(v)$ e velocidades sônicas $\left(\mathrm{v}_{\mathrm{L}} \mathrm{e} \mathrm{v}_{\mathrm{T}}\right)$. $\mathrm{O}$ índice 0 se refere à propriedade de interesse na condição de porosidade igual a zero. VE é a variável b para as equações 6.1, 6.3, 6.4 e 6.5 (Tabela 6.1 ), $\mathrm{b}_{1} / \mathrm{b}_{2}$ para as equações 6.2 e $6.6, \mathrm{P}_{\text {crit }} / \mathrm{n}$ para a equação 6.7 e $\mathrm{P}_{\text {crit }}$ para equação 6.9. Os melhores ajustes, ou seja, os resultados com maior valor de $\mathrm{R}^{2}$ foram obtidos para as equações 6.2 e 6.7 .

Tabela 7.1 - Propriedades do AlN sem aditivo de sinterização.

Tabela 7.2 - Propriedades do AlN com adição individual de $\mathrm{Y}_{2} \mathrm{O}_{3}$ ou CaO. 163

Tabela 7.3 - Propriedade mecânicas (média \pm desvio-padrão) das amostras de AlN com adição tanto de $\mathrm{CaO}$ como de $\mathrm{Y}_{2} \mathrm{O}_{3}$ sinterizadas a $1800^{\circ} \mathrm{C}$. 
LISTA DE ABREVIATURAS E SIGLAS

$\begin{array}{ll}\text { ASM } & \text { Área Sólida Mínima } \\ \text { ASE } & \text { Área de Superfície Específica } \\ \text { DBC } & \text { Direct Bonding Copper } \\ \text { DRX } & \text { Difração de Raios X } \\ \text { EDS } & \text { Espectrômetro de Energia Dispersiva } \\ \text { HTCC } & \text { High Temperature Cofired Ceramic } \\ \text { MEV } & \text { Micrscópio Eletrônico de Varredura } \\ \text { MFLE } & \text { Mecânica de Fratura Linear Elástica } \\ \text { MO } & \text { Microscópio Óptico } \\ \text { PEG } & \text { Polietileno Glicol }\end{array}$




\section{LISTA DE SÍMBOLOS}

a

A

$b, b_{1}$ e $b_{2}$

B

C

$\mathrm{c}_{0}$

$\mathrm{C}$

$\mathrm{C}_{\mathrm{ap}}$

$\mathrm{C}_{\text {rup }}$

$\mathrm{d}_{0}$

E

$\mathrm{E}_{0}$

$\mathrm{F}$

$f_{\mathrm{P}}$

$f_{\mathrm{T}}$

G

$\mathrm{G}_{0}$

$\mathrm{H}_{\mathrm{V}}$

K

$\mathrm{K}_{\mathrm{Ic}}$

$\mathrm{K}_{\text {Ic-IF }}$

$\mathrm{K}_{\text {Ic-IS }}$

$\mathrm{K}_{\mathrm{Ic}-\mathrm{SCF}}$

$\mathrm{K}_{\text {Ic-SEPB }}$

$\mathrm{K}_{\mathrm{V}}$

$\mathrm{K}_{\mathrm{V} 0}$

M

$\mathrm{M}_{0}$

semi-eixo menor de uma elipse

raio do círculo formado pela disposição das esferas do porta-amostra do ensaio de resistência à flexão biaxial

constantes

raio da área carregada ou ponta do pistão do dispositivo de ensaio de resistência à flexão biaixial

metade do semi-eixo maior de uma elipse ou comprimento de trinca tamanho crítico de trinca

raio do corpo-de-prova usado no ensaio de resistência à flexão biaxial carga aplicada na indentação Vickers

carga de ruptura

espaçamento interatômico

módulo de Young

módulo de Young do corpo livre de poros

taxa de liberação de energia

fração volumétrica de poros

fração de grãos com fratura transgranular

módulo de cisalhamento

módulo de cisalhamento do corpo livre de poros

dureza Vickers

fator de intensidade de tensão

fator de intensidade de tensão crítico ou tenacidade à fratura

tenacidade à fratura determinada por Indentation Fracture

tenacidade à fratura determinada por Indentation Strength

tenacidade à fratura determinada por Surface Crack in Flexure

tenacidade à fratura determinada por Single Edge Pre-cracked Beam

Módulo volumétrico

módulo volumétrico do corpo livre de poros

forma genérica para indicar as constantes elásticas $\left(E, G\right.$ e $\left.K_{V}\right)$

forma genérica para indicar as constantes elásticas $\left(\mathrm{E}, \mathrm{G}\right.$ e $\left.\mathrm{K}_{\mathrm{V}}\right)$ do corpo livre de poros 


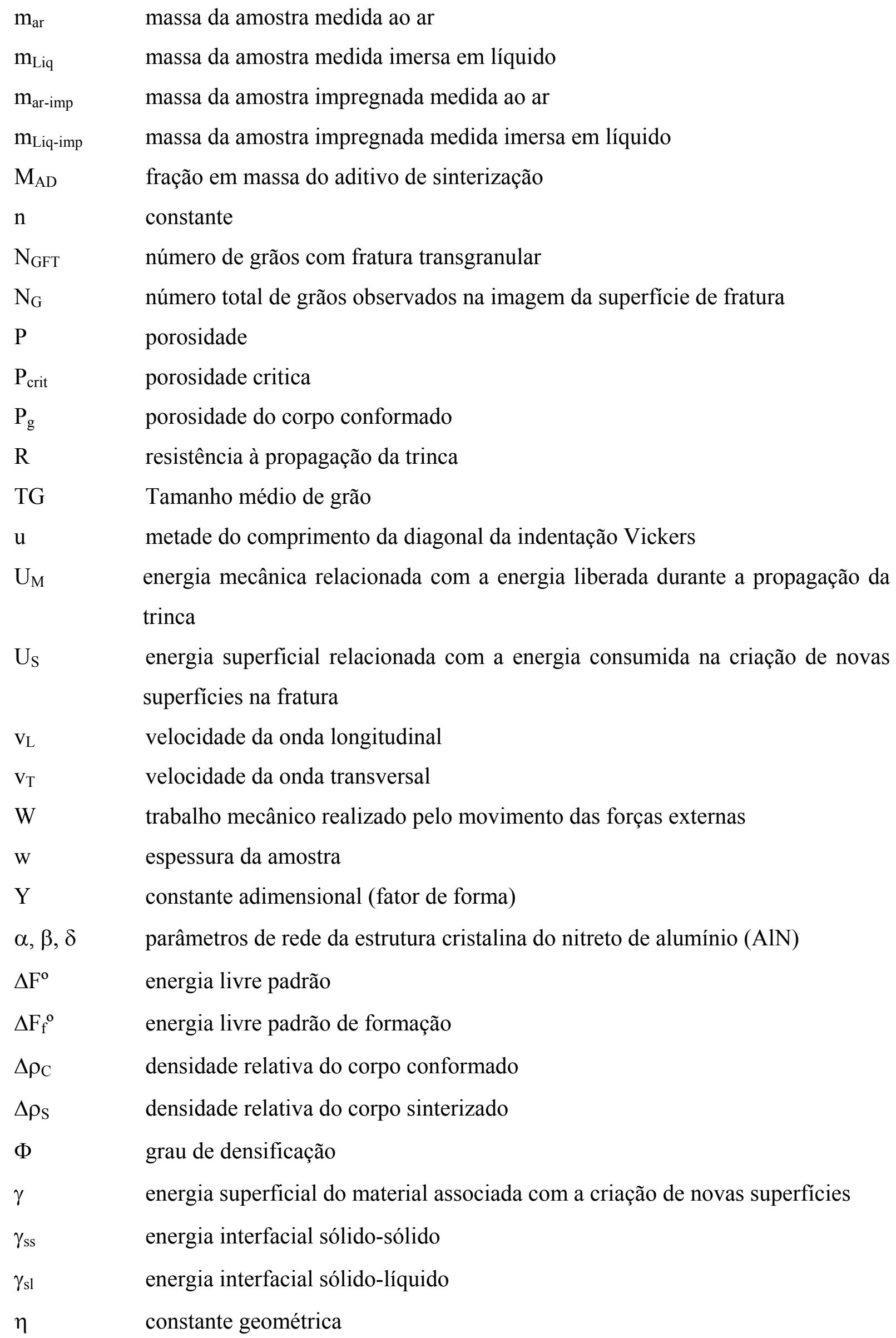




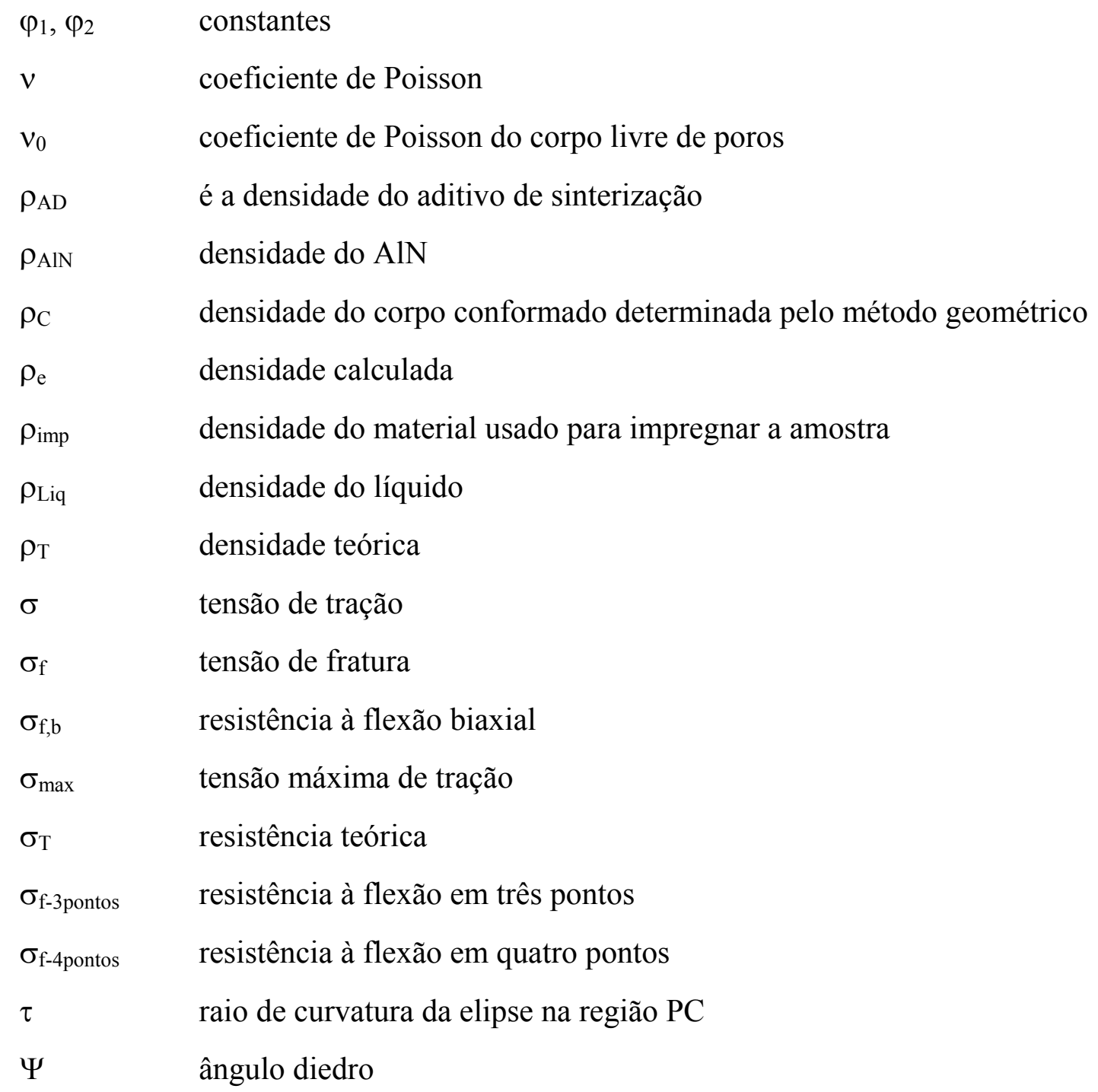




\section{SUMÁRIO}

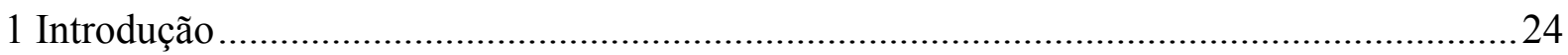

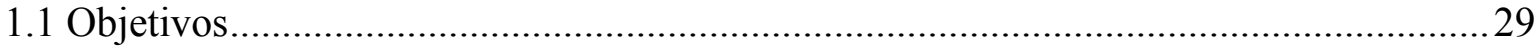

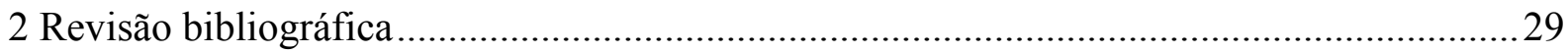

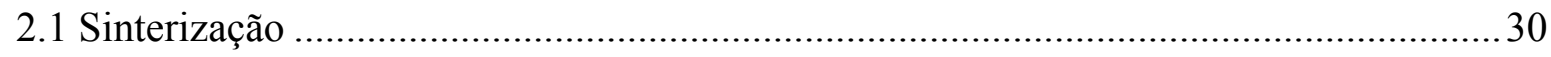

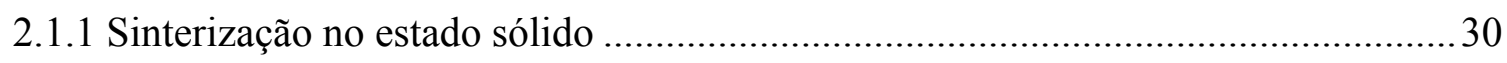

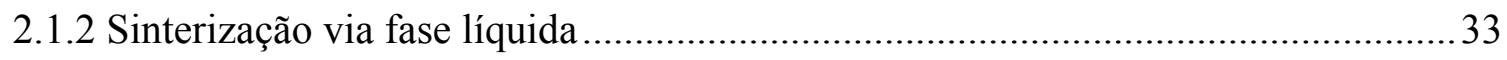

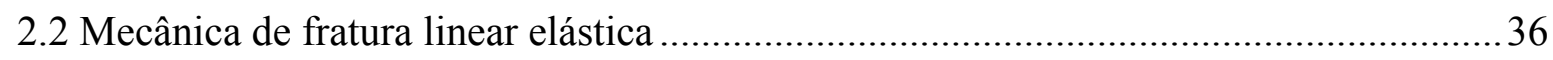

2.2.1 Tenacificação em materiais cerâmicos ....................................................................... 44

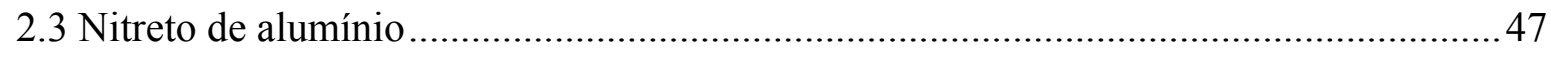

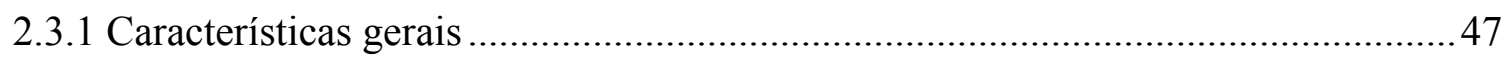

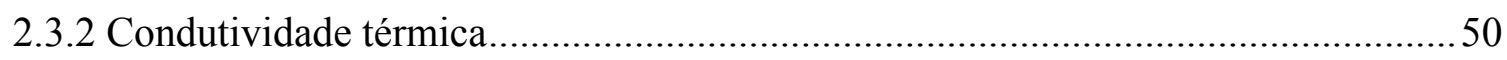

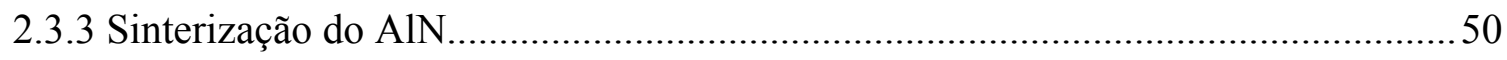

2.3.4 Efeito do aditivo de sinterização na densificação do AlN .......................................53

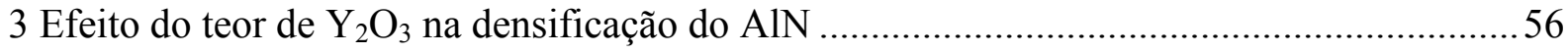

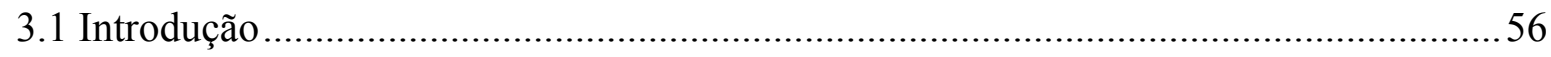

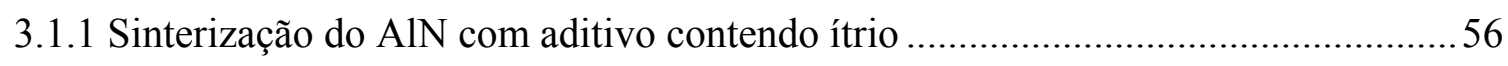

3.1.2 Evolução das segundas-fases do AlN com aditivo contendo ítrio...........................59

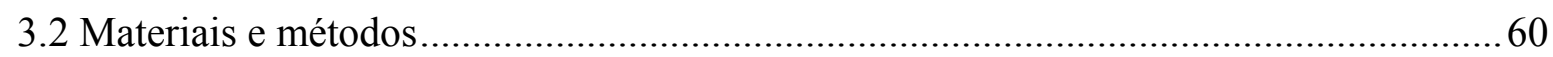

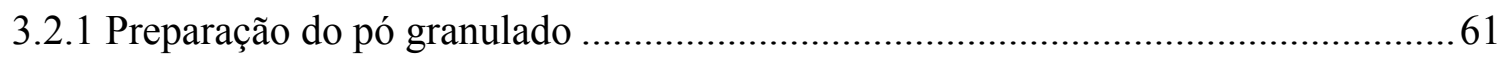

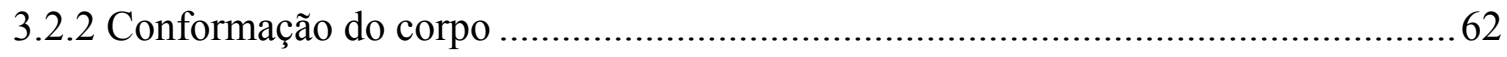

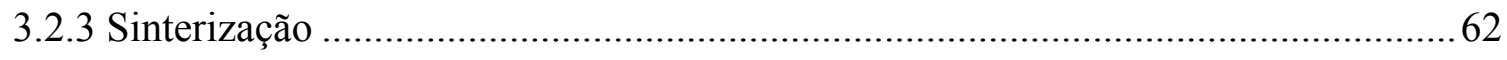

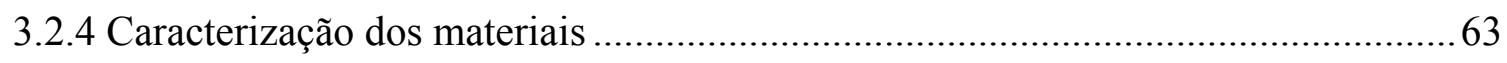

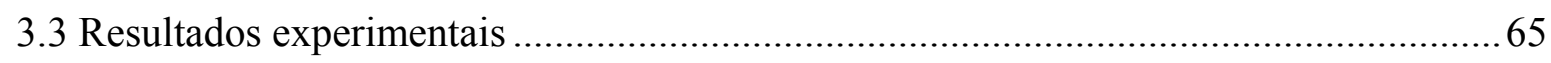

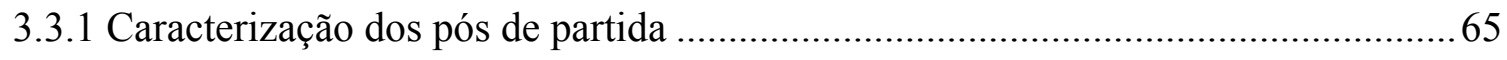

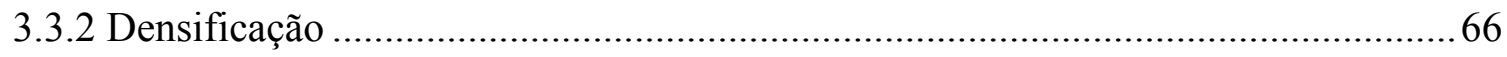

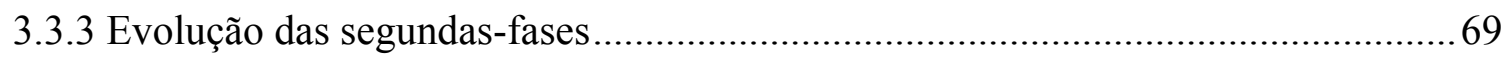

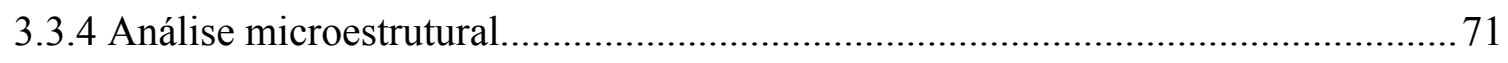

3.3.5 Efeito do carbono na densificação do AlN com $\mathrm{Y}_{2} \mathrm{O}_{3}$....................................... 75

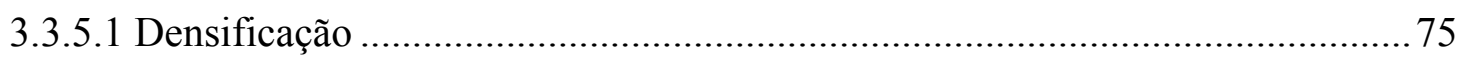

3.3.5.2 Perda de massa e evolução das segundas-fases ............................................... 76

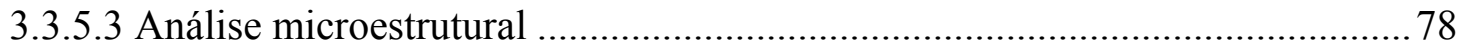

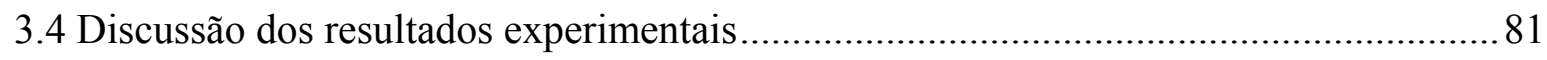

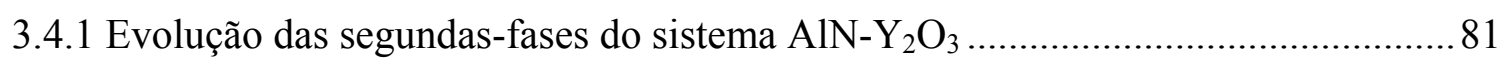

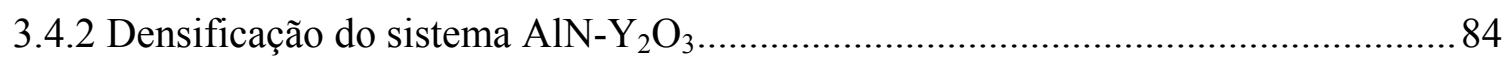


3.4.3 Formação de partículas grandes de segundas-fases no sistema $\mathrm{AlN}-\mathrm{Y}_{2} \mathrm{O}_{3}$ 89

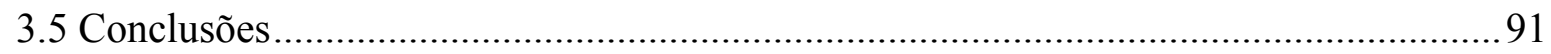

4 Efeito do carbono na densificação do AlN com CaO........................................................93

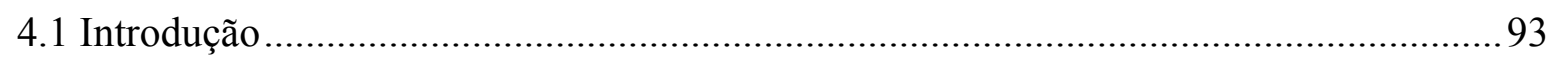

4.1.1 Sinterização do AIN com aditivo contendo cálcio ............................................... 94

4.1.2 Evolução das segundas-fases do AlN com aditivo contendo cálcio........................99

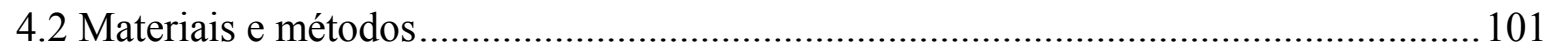

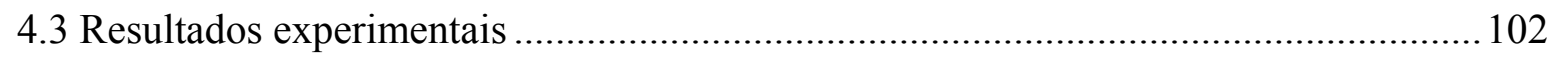

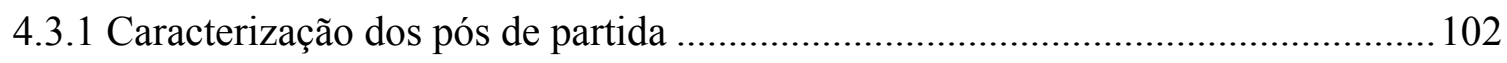

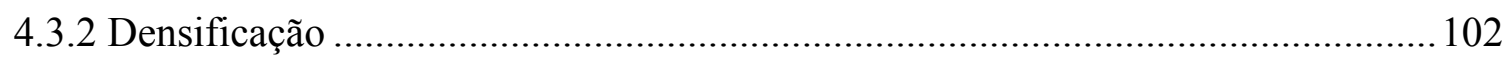

4.3.3 Perda de massa e evolução das segundas-fases .................................................... 103

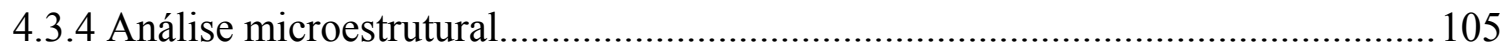

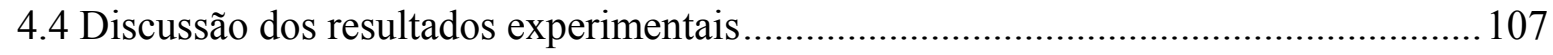

4.4.1 Efeito do carbono na evolução das segundas-fases do sistema $\mathrm{AlN}-\mathrm{CaO}$............ 107

4.4.2 Efeito do carbono na densificação do sistema $\mathrm{AlN}-\mathrm{CaO}$..................................... 109

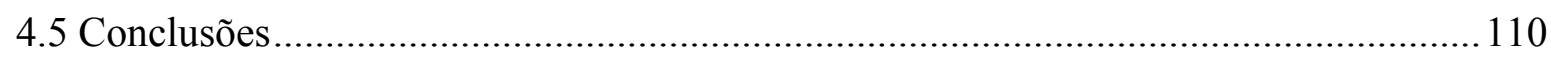

5. Efeito da adição simultânea de $\mathrm{Y}_{2} \mathrm{O}_{3}$ e $\mathrm{CaO}$ na densificação do $\mathrm{AlN}$............................... 112

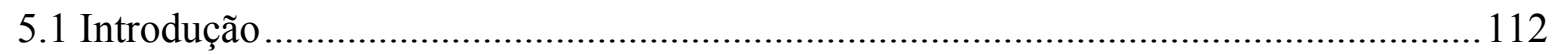

5.1.1 Sinterização do AlN com adição simultânea de $\mathrm{Y}_{2} \mathrm{O}_{3}$ e $\mathrm{CaO}$............................... 112

5.1.2 Evolução das segundas-fases do AlN com adição simultânea de $\mathrm{Y}_{2} \mathrm{O}_{3}$ e $\mathrm{CaO}$..... 115

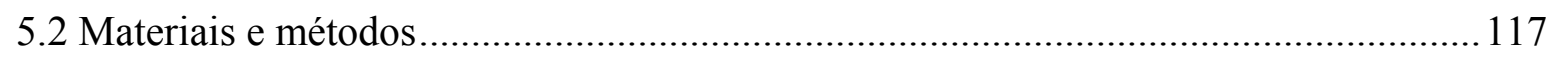

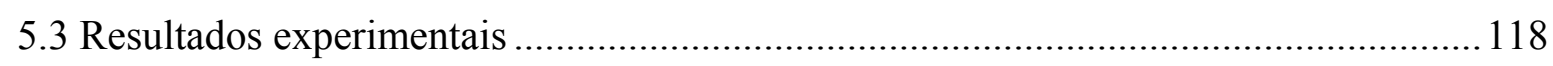

5.3.1 Efeito da adição simultânea de $\mathrm{Y}_{2} \mathrm{O}_{3}$ e $\mathrm{CaO}$ na densificação do AlN .................... 118

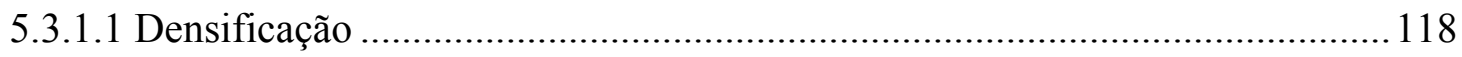

5.3.1.2 Perda de massa e evolução das segundas-fases .............................................. 119

5.3.1.3 Análise microestrutural ............................................................................ 122

5.3.2 Efeito do carbono na densificação do AlN com adição simultânea de $\mathrm{Y}_{2} \mathrm{O}_{3}$ e $\mathrm{CaO}$

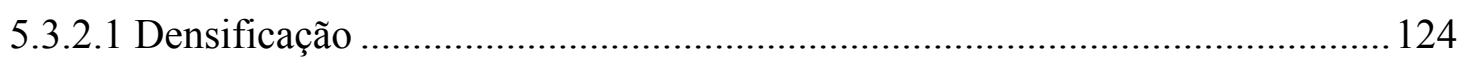

5.3.2.2 Perda de massa e evolução das segundas-fases .......................................... 125

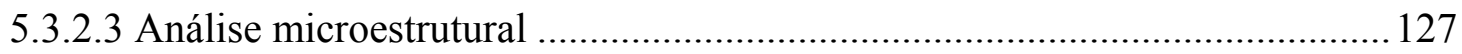

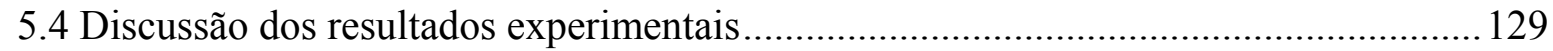

5.4.1 Evolução das segundas-fases do sistema AlN- $\mathrm{Y}_{2} \mathrm{O}_{3}-\mathrm{CaO}$................................... 129

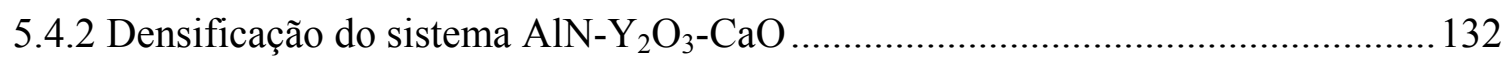

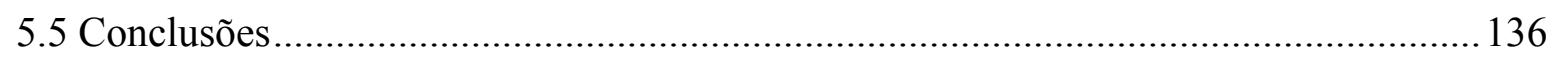

6 Efeito da porosidade nas propriedades elásticas do AlN ................................................. 138

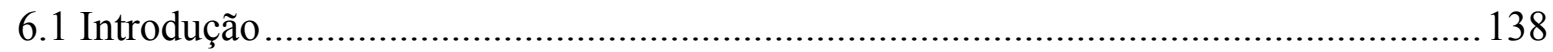

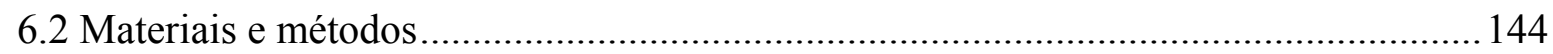




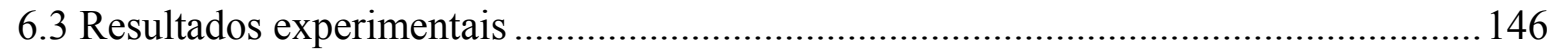

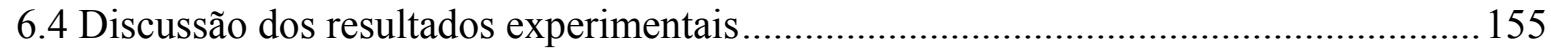

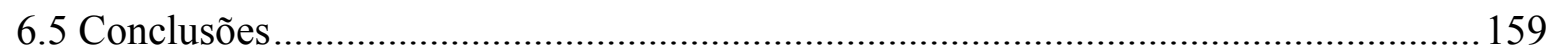

7 Efeito do teor de $\mathrm{Y}_{2} \mathrm{O}_{3}$ ou $\mathrm{CaO}$ nas propriedades mecânicas do AlN …………………........ 160

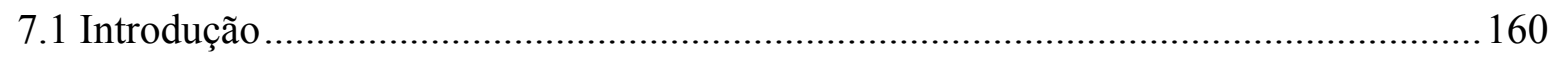

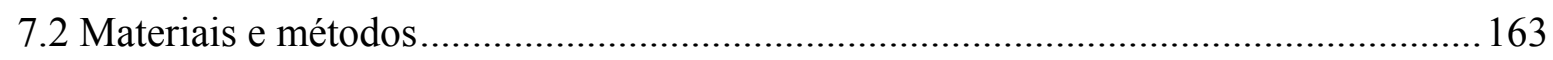

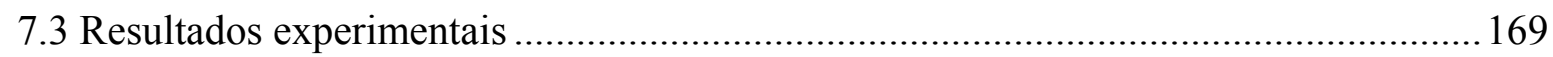

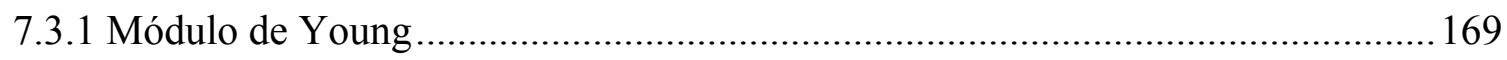

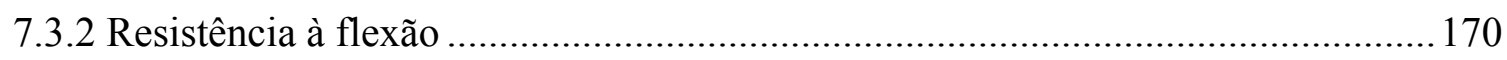

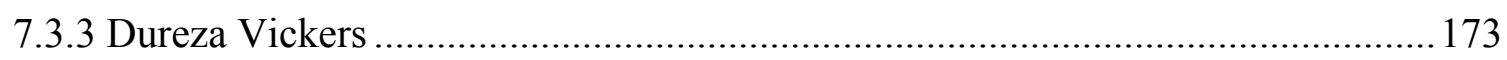

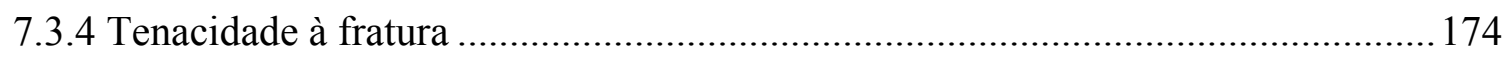

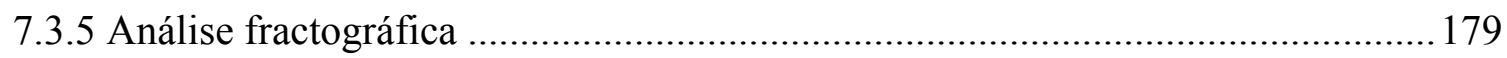

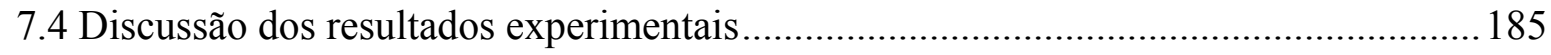

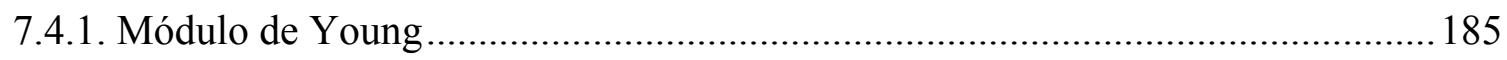

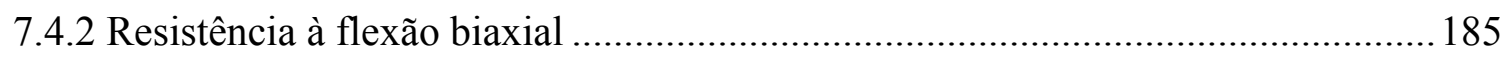

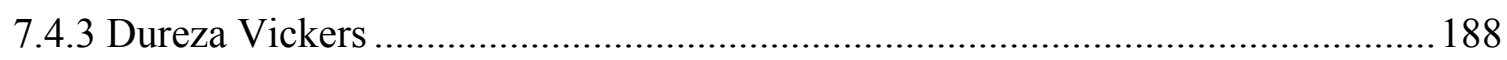

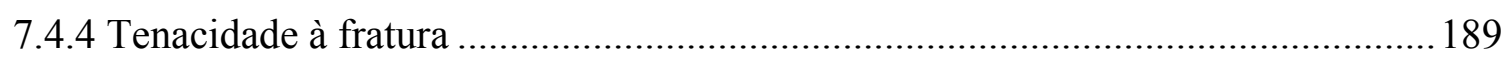

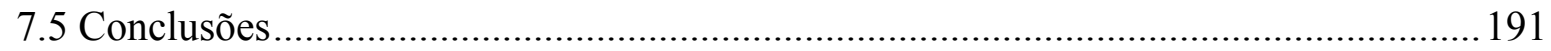

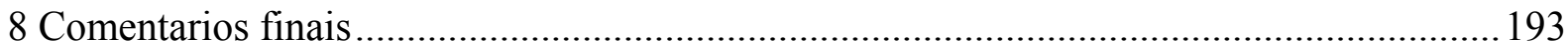

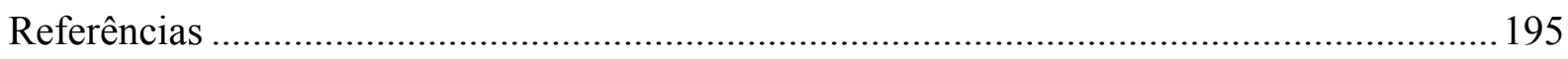




\section{Introdução}

A engenharia de microeletrônica desenvolveu técnicas de processamento que possibilitaram a fabricação de dispositivos eletrônicos em miniatura (circuitos integrados ou chips) e com elevada eficiência funcional. No entanto, a flexibilidade funcional e os custos efetivos se tornaram os principais problemas relacionados com a produção de circuitos eletrônicos complexos dentro do próprio chip de silício. ${ }^{1}$ Em decorrência destas dificuldades, surgiu a tecnologia de componentes passivos, que desenvolveu circuitos complexos com alto desempenho e baixos custos de produção e manutenção. Esta tecnologia é responsável pelo desenvolvimento de substratos e dispositivos de encapsulamento, que fornecem interconexão, sustentação e proteção aos circuitos integrados. ${ }^{2}$

A tecnologia de componentes passivos possibilitou o desenvolvimento de substratos integrados fabricados pelo processo Direct Bonding Copper (DBC). Esta rota de processamento consiste na colagem de lâminas finas de cobre na superfície de substratos cerâmicos por tratamento térmico (Fig. 1.1a). Um filme polimérico, resistente ao ataque químico, é aplicado na superfície metalizada do substrato cerâmico pelo método de impressão por serigrafia (silk-screen), o que resulta em uma máscara contendo a configuração (layout) do circuito eletrônico. As áreas metálicas não protegidas pelo filme polimérico são removidas por ataque químico (Fig. 1.1b) e, então, sistemas multicamadas, produzidos pela tecnologia de filme espesso, podem ser fixados por meio de adesivo na superfície do substrato cerâmico (Figs. 1.1c e 11d). Os dispositivos eletrônicos ativos (capacitores, resistores, transistores e outros) são obtidos pela associação ou não de diversas camadas de filmes espessos com composições químicas distintas. A fixação dos contatos elétricos, assim como a interconexão via fio, é realizada por soldagem (Figs. 1.1e e 1.1f). Os substratos de AlN podem ser usados na produção de circuito controlador de potência para automóvel, módulo semicondutor de alta potência, diodo de potência para emissão de luz e outras aplicações envolvendo alta potência. $^{3}$

O processo High Temperature Cofired Ceramic (HTCC) também foi desenvolvido pela tecnologia de componentes passivos. Este processo consiste basicamente em aplicar multicamadas de filmes espessos, com composição química variável, sobre a superfície de substratos cerâmicos não sinterizados produzidos por colagem de fita (tape casting). As camadas de filme espesso podem ser aplicadas pela técnica de impressão por serigrafia. $\mathrm{O}$ termo cofired significa que o substrato cerâmico, juntamente com as multicamadas de filme 
espesso, são sinterizadas ao mesmo tempo, produzindo um único módulo eletrônico (circuito híbrido). Deste modo, é possível produzir dispositivos eletrônicos complexos com menor número de etapas de processamento, o que reduz significativamente os custos de produção. A Figura 1.2 ilustra esquematicamente a seqüência de produção de dispositivos eletrônicos pela tecnologia HTCC.

Folha de cobre aplicada por DBC

\section{Substrato de AIN}

(a)

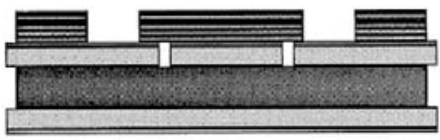

(d)

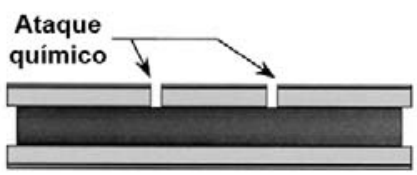

(b)

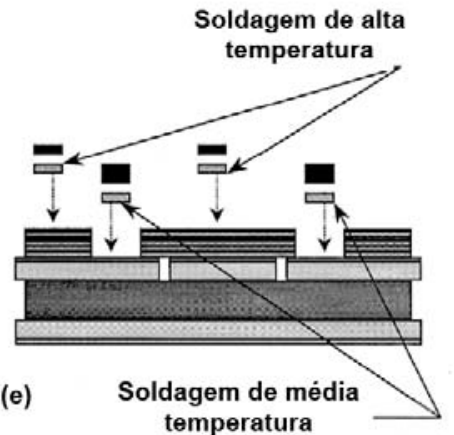

Sistema multicamadas
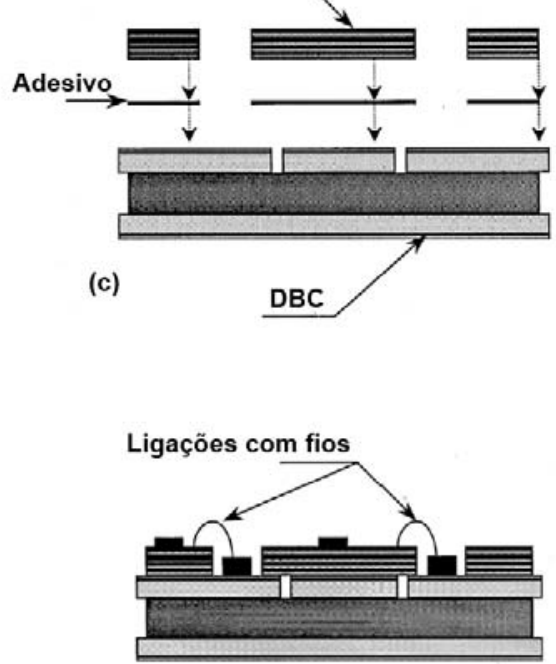

(f)

Figura 1.1 - Ilustração da seqüência de montagem de um dispositivo eletrônico pela tecnologia DBC. ${ }^{4}$

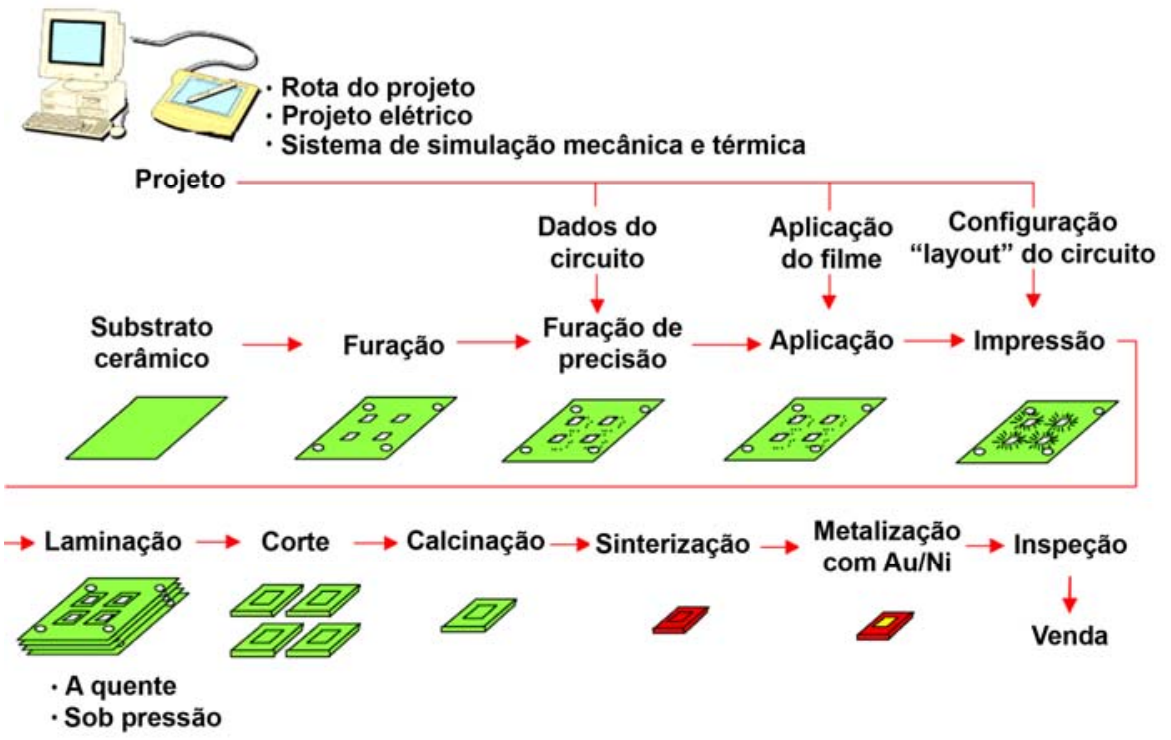

Figura 1.2 - Ilustração mostrando as principais etapas de um processo de produção de dispositivos eletrônicos pela tecnologia HTCC. ${ }^{5}$ 
A diminuição de tamanho do circuito integrado (chip) promove naturalmente o adensamento de dispositivos eletrônicos ativos (capacitores, resistores, transistores e outros), o que pode gerar elevada dissipação térmica local, quando este é submetido a condições de trabalho em alta potência e/ou alta freqüência. ${ }^{6}$ Isto mostra que o componente passivo (substrato e/ou material de encapsulamento), usado na montagem do módulo eletrônico de alto desempenho, deve apresentar elevada condutividade térmica para promover rápida dissipação de calor, o que evita a geração de falhas (trincas) por superaquecimento. Outras propriedades de interesse para o componente passivo são: ${ }^{7}$ boa resistência mecânica para suportar o chip e a metalização; alta resistividade para isolar eletricamente o chip; estabilidade química para evitar reações com os demais dispositivos eletrônicos; coeficiente de expansão térmica próximo do silício para evitar a formação de trincas por superaquecimento durante a produção e/ou funcionamento; baixa constante dielétrica para diminuir perdas por microondas; e bom acabamento superficial para facilitar a deposição de filme espesso.

$\mathrm{O}$ processo DBC foi desenvolvido inicialmente para a cerâmica de alumina $\left(\mathrm{Al}_{2} \mathrm{O}_{3}\right),{ }^{8,9}$ pois este material apresenta baixo custo de produção e boas propriedades elétricas e mecânicas. ${ }^{10-14}$ A alumina $\left(\mathrm{Al}_{2} \mathrm{O}_{3}\right)$ preparada com adição de sílica $\left(\mathrm{SiO}_{2}\right)$, magnésia $(\mathrm{MgO})$ e cálcia $(\mathrm{CaO})$, cuja fração de $\mathrm{Al}_{2} \mathrm{O}_{3}$ varia de $90 \%$ a $96 \%$, é a cerâmica mais usada na fabricação de dispositivos passivos. ${ }^{5}$ Os aditivos $\left(\mathrm{SiO}_{2}, \mathrm{MgO}\right.$ e $\left.\mathrm{CaO}\right)$ são usados para promover densificação em menor temperatura $\left(1400^{\circ} \mathrm{C}-1600^{\circ} \mathrm{C}\right),{ }^{5}$ assim como melhorar a adesão da lâmina metálica à superfície do substrato cerâmico. Porém, o $\mathrm{Al}_{2} \mathrm{O}_{3}$ tem baixa condutividade térmica $(\sim 20 \mathrm{~W} / \mathrm{mK})$ e alto coeficiente de expansão térmica $\left(7,2 \times 10^{-6} /{ }^{\circ} \mathrm{C}\right) \mathrm{em}$ relação àquele observado para o silício $\left(3,2 \times 10^{-6} /{ }^{\circ} \mathrm{C}\right),{ }^{15} \mathrm{o}$ que limita sua aplicação em dispositivos eletrônicos com elevada dissipação térmica. A berília $(\mathrm{BeO})$ vem sendo usada na fabricação de dispositivos eletrônicos de alto desempenho, pois apresenta elevada condutividade térmica $(240-260 \mathrm{~W} / \mathrm{mK}),{ }^{2,15}$ mas sua utilização está diminuindo em decorrência do seu elevado coeficiente de expansão térmica $\left(8 \times 10^{-6} /{ }^{\circ} \mathrm{C}\right)$ e da sua toxicidade. ${ }^{1,16} \mathrm{O}$ nitreto de alumínio (A1N) vem chamando a atenção do meio industrial e científico devido à sua elevada condutividade térmica $(80-200 \mathrm{~W} / \mathrm{mK})$, além de outras boas propriedades, tais como: ${ }^{17}$ elevada resistência à ruptura dielétrica, baixa perda de energia em alta freqüência, elevada resistividade elétrica e coeficiente de expansão térmica $\left(4,4 \times 10^{-6} /{ }^{\circ} \mathrm{C}\right)$ próximo daquele observado para o silício. Este conjunto de propriedades torna o AlN um forte candidato a substituir o $\mathrm{Al}_{2} \mathrm{O}_{3}$ e o $\mathrm{BeO}$ na fabricação de dispositivos eletrônicos com elevada dissipação térmica. ${ }^{1,6,15,18,19}$ 
Embora o AlN seja reconhecido por sua elevada condutividade térmica, esta propriedade é fortemente influenciada pelo teor de oxigênio presente no pó de partida. ${ }^{20-23}$ Esta impureza é inerente ao AlN, pois o pó apresenta uma camada de hidróxido ou óxido amorfo de alumínio, cuja origem é decorrente da reação de hidrólise causada pela exposição do pó à umidade do meio ambiente. ${ }^{24,25}$ Durante a sinterização, o oxigênio entra em solução sólida na rede cristalina do $\mathrm{AlN},{ }^{21,22}$ causando uma diminuição significativa de condutividade térmica. A cerâmica policristalina de AIN sem aditivo de sinterização apresenta condutividade térmica entre 50 e $85 \mathrm{~W} / \mathrm{mK},{ }^{26,27}$ muito abaixo do valor previsto teoricamente para o monocristal de AlN isento de oxigênio $(320 \mathrm{~W} / \mathrm{mK}) .{ }^{22}$ Em decorrência dos baixos valores de condutividade térmica alcançados pela cerâmica de AlN sem aditivo de sinterização, vários estudos foram realizados, principalmente nas décadas de 80 e 90, com o objetivo de otimizar esta propriedade, quer seja pela: melhora na qualidade do pó de partida; ${ }^{28-35}$ adição de aditivos de sinterização; ${ }^{23,36-44}$ mudança na atmosfera de sinterização; ${ }^{45-50}$ e utilização de tratamentos térmicos pós-sinterização (annealing). ${ }^{23,39,51-53}$

A ítria $\left(\mathrm{Y}_{2} \mathrm{O}_{3}\right)$ e a cálcia $(\mathrm{CaO})$ são os aditivos de sinterização mais usados nos estudos sobre a cerâmica de AlN. Porém, o $\mathrm{Y}_{2} \mathrm{O}_{3}$ se tornou mais popular porque sua utilização resulta em valores maiores de condutividade térmica. No caso do $\mathrm{AlN}$ com $\mathrm{Y}_{2} \mathrm{O}_{3}$, verificou-se que a formação de uma atmosfera redutora, proveniente da grafita do cadinho e do elemento de aquecimento do forno ${ }^{18,50}$ ou da adição de pó de grafita como aditivo de sinterização ${ }^{18,49,54,55}$, pode promover um aumento significativo de condutividade térmica. Porém, a formação de uma atmosfera fortemente redutora pode inibir a densificação do $\mathrm{AlN}$ com $\mathrm{Y}_{2} \mathrm{O}_{3} .{ }^{18}$ Isto ocorre porque as segundas-fases de contorno de grão (aluminatos) se tornam mais refratárias em decorrência da desoxidação causada pela atmosfera redutora, ${ }^{56}$ o que aumenta a temperatura de formação de fase líquida e, conseqüentemente, retarda o processo de densificação. Já o AlN com $\mathrm{CaO}$ apresenta evaporação de compostos durante a sinterização tanto em atmosfera redutora ${ }^{57-59}$ como inerte ${ }^{60,61}$. Alguns estudos ${ }^{26,62-64}$ utilizaram aditivos contendo cálcio e carbono $\left(\mathrm{CaC}_{2}\right.$ e $\left.\mathrm{CaCN}_{2}\right)$ para formar uma atmosfera redutora no interior do corpo conformado durante a sinterização. Entretanto, não se observou a utilização de sistemas de aditivos de sinterização contendo pós de grafita e cálcia.

Algumas empresas (Sumitomo Electric USA Inc., Toshiba Ceramics Co. Ltd., Kyocera Corporation e AdTech Ceramics) estão comercializando substratos de $\mathrm{AlN}$ com $\mathrm{Y}_{2} \mathrm{O}_{3}$, cuja condutividade térmica varia de 100 a $170 \mathrm{~W} / \mathrm{mK}$. Apesar da rota de fabricação do AlN com $\mathrm{Y}_{2} \mathrm{O}_{3}$ ou $\mathrm{CaO}$ já estar estabelecida, há várias lacunas na literatura no que diz respeito aos mecanismos de sinterização envolvidos na densificação do AlN. Há alguns trabalhos que 
estudaram o comportamento de densificação do $\mathrm{AlN}$ com $\mathrm{Y}_{2} \mathrm{O}_{3}{ }^{56,65-68}$ ou $\mathrm{CaO}^{26,59-61,69}$, os quais elucidaram parcialmente os mecanismos de sinterização envolvidos na densificação destas cerâmicas.

Substratos de alumina 96\% são comumente usados na produção de componentes passivos pelo processo $\mathrm{HTCC},{ }^{5,70}$ sendo estes circuitos híbridos sinterizados entre $1400^{\circ} \mathrm{C}$ e $1600^{\circ} \mathrm{C}$. Como o AlN com $\mathrm{Y}_{2} \mathrm{O}_{3}$ ou $\mathrm{CaO}$ é usualmente sinterizado ao redor de $1800^{\circ} \mathrm{C},{ }^{43} \mathrm{a}$ adaptação destas cerâmicas ao processo HTCC é praticamente inviável até o presente momento. Com o intuito de abaixar a temperatura de sinterização do AlN, vêm sendo desenvolvidos sistemas de aditivos baseados na mistura de diferentes compostos. Os sistemas $\mathrm{Y}_{2} \mathrm{O}_{3}-\mathrm{CaO}-\mathrm{La}_{2} \mathrm{O}_{3}-\mathrm{CeO}_{2}-\mathrm{SiO}_{2}{ }^{71}$ e $\mathrm{Y}_{2} \mathrm{O}_{3}-\mathrm{CaO}-\mathrm{LaB}_{6}-\mathrm{W}^{72}$ promoveram a densificação do $\mathrm{AlN} \mathrm{a}$ $1600^{\circ} \mathrm{C}$, mas a condutividade térmica foi considerada relativamente baixa ( $\left.\sim 98 \mathrm{~W} / \mathrm{mK}\right)$. A adição simultânea de compostos à base de ítrio e cálcio tem promovido a densificação do AlN entre $1650^{\circ} \mathrm{C}$ e $1750^{\circ} \mathrm{C},{ }^{73-76}$ além de resultar em valores de condutividade térmica da ordem de $180 \mathrm{~W} / \mathrm{mK} .{ }^{73,76}$ Estes resultados indicaram que é possível obter cerâmicas de AlN com elevada condutividade térmica a partir de $1650^{\circ} \mathrm{C}$, o que favorece sua aplicação na produção de componentes passivos pelo processo HTCC. No entanto, há poucos estudos direcionados ao comportamento de densificação do AlN com adição simultânea de compostos à base de ítrio e cálcio. ${ }^{42-44,75-77}$

Asai \& Takahashi ${ }^{78}$ estudaram o efeito da composição das segundas-fases na resistência mecânica de substratos cerâmicos de AlN usados na fabricação de dispositivos eletrônicos. Outros trabalhos determinaram a resistência mecânica e/ou tenacidade à fratura de cerâmicas de AlN com elevada condutividade térmica, ${ }^{41,79,80}$ pois as cerâmicas usadas na fabricação de dispositivos eletrônicos devem apresentar boas propriedades mecânicas. Porém, alguns trabalhos ${ }^{81-83}$ propõem que a condutividade térmica do AlN pode ser aumentada, acima de $200 \mathrm{~W} / \mathrm{mK}$, pela realização de tratamentos térmicos pós-sinterização em atmosfera redutora. Este tipo de tratamento térmico promove a "limpeza" (evaporação) das segundasfases localizadas nos contornos de grão, o que resulta no aumento da condutividade térmica do AlN $(\sim 270 \mathrm{~W} / \mathrm{mK})$. Por outro lado, este procedimento pode causar um aumento significativo do tamanho de grão do AlN, o que afeta drasticamente as propriedades mecânicas do produto final. Este tipo de visão mostra claramente que os estudos relacionados com a condutividade térmica do AlN não se preocuparam com a otimização de outras propriedades como, por exemplo, a resistência mecânica e a tenacidade à fratura, que são propriedades importantes para a tecnologia de componentes passivos, pois o substrato e o material de encapsulamento devem fornecer sustentação e integridade física ao chip. 
Nos últimos dez anos, alguns trabalhos mostraram que é possível produzir AlN com alta condutividade térmica em baixa temperatura, ${ }^{43,73-76}$ o que resultou em cerâmicas com boas propriedades mecânicas. ${ }^{43}$ Apesar da tecnologia de componentes passivos solicitar a produção de substrato cerâmico e material de encapsulamento com boas propriedades mecânicas, somente nos últimos quatro anos tem surgido trabalhos em que se relaciona as variáveis de processamento cerâmico do AlN com as propriedades mecânicas. ${ }^{84-86}$ Alguns destes trabalhos foram desenvolvidos em parceria com grandes empresas de microeletrônica, mostrando que os estudos sobre o AlN estão sendo direcionados para o aumento da confiabilidade mecânica do substrato cerâmico. Estes trabalhos têm mostrado que a formação de defeitos de processamento (poros grandes) causou pouca influência na condutividade térmica da cerâmica de $\mathrm{AlN}$ com $\mathrm{Y}_{2} \mathrm{O}_{3},{ }^{84}$ mas causou uma diminuição significativamente na resistência mecânica. ${ }^{84,87}$ Há poucos trabalhos que caracterizaram as propriedades mecânicas

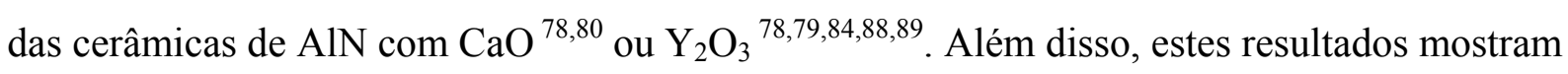
apenas uma tendência do comportamento mecânico do AlN, pois é difícil correlacionar estes resultados devido ao emprego de diferentes métodos de determinação das propriedades mecânicas, bem como dos diferentes métodos de processamento cerâmico. Por exemplo, é conhecido que há um teor ótimo de aditivo de sinterização, na faixa de 3\% a 5\% em massa, para maximização da condutividade térmica do AlN com $\mathrm{Y}_{2} \mathrm{O}_{3}$ ou $\mathrm{CaO}$, mas poucos trabalhos ${ }^{41}$ estudaram o efeito do teor destes aditivos nas propriedades mecânicas. A mesma carência de estudos foi observada com relação ao efeito da porosidade nas propriedades elásticas do AlN.

\subsection{Objetivos}

Este trabalho tem como objetivos gerais estudar os mecanismos de sinterização e as propriedades mecânicas da cerâmica de $\mathrm{AlN}$ com $\mathrm{Y}_{2} \mathrm{O}_{3}$ e/ou $\mathrm{CaO}$, tendo como objetivos específicos estudar:

i) o efeito do teor de $\mathrm{Y}_{2} \mathrm{O}_{3}$ na densificação do $\mathrm{AlN}$;

ii) o efeito da adição de carbono na densificação do $\mathrm{AlN}$ com $\mathrm{CaO}$;

iii) o efeito da adição simultânea de $\mathrm{Y}_{2} \mathrm{O}_{3}$ e $\mathrm{CaO}$ na densificação do $\mathrm{AlN}$;

iv) o efeito da porosidade nas propriedades elásticas do $\mathrm{AlN}$ com $\mathrm{Y}_{2} \mathrm{O}_{3}$ ou $\mathrm{CaO}$;

v) o efeito do teor de $\mathrm{Y}_{2} \mathrm{O}_{3}$ ou $\mathrm{CaO}$ nas propriedades mecânicas do AlN. 


\section{Revisão bibliográfica}

Neste capítulo, apresentam-se algumas bases conceituais, que foram fundamentais para o desenvolvimento deste trabalho. Estas bases conceituais foram divididas em três assuntos específicos:

- Sinterização

- Mecânica de fratura linear elástica

- Nitreto de alumínio

\subsection{Sinterização}

Sinterização pode ser definida como um fenômeno, ativado termicamente, que transforma um corpo conformado, constituído por partículas cristalinas e/ou amorfas, em um corpo rígido devido a eventos de transporte de matéria, ${ }^{90,91}$ que ocorrem freqüentemente em escala atômica. Uma característica comum, observada em todos os tipos de sinterização, é a diminuição da área de superfície das partículas (ou grãos) com simultâneo aumento de resistência do corpo conformado. ${ }^{90}$ Em relação aos materiais cerâmicos, a sinterização pode ser dividida em: ${ }^{92}$ i) sinterização no estado sólido; ii) sinterização via fase líquida; e iii) sinterização viscosa. Neste trabalho foram abordados os temas de sinterização no estado sólido e via fase líquida, pois a densificação da cerâmica de AlN envolve apenas estes dois processos de sinterização.

\subsubsection{Sinterização no estado sólido}

A sinterização no estado sólido pode ser dividida em três estágios, ${ }^{93-96}$ que são caracterizados por mudanças na microestrutura durante o processo de densificação. 


\section{Estágio inicial}

Este estágio é caracterizado pelo crescimento de pescoço e formação de um contorno de grão na região de contato entre as partículas. ${ }^{93}$ A movimentação de material para a região do pescoço acontece por diferentes mecanismos de transporte de matéria (Fig. 2.1). ${ }^{96,97} \mathrm{O}$ pescoço pode crescer até que a razão entre os raios do pescoço e da partícula atinja um valor próximo de $0,3^{95}$ ou o raio do pescoço atinja um valor entre 0,4 e 0,5 do raio da partícula ${ }^{96}$.

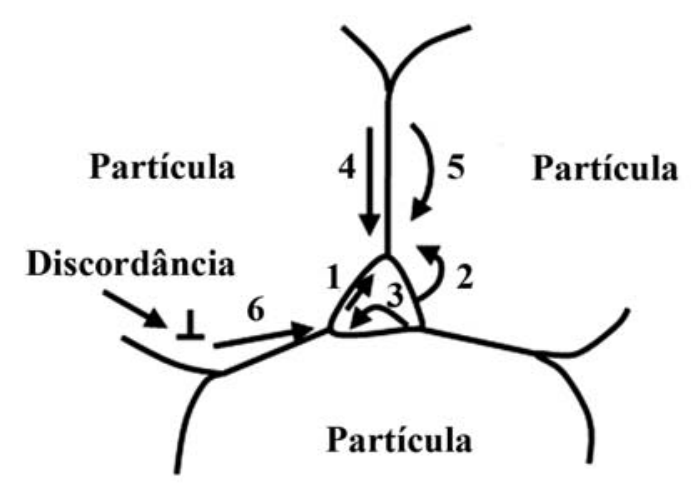

Figura 2.1 - Ilustração esquemática dos possíveis mecanismos de transporte de matéria, que podem atuar durante a sinterização no estado sólido: 1) difusão pela superfície; 2) difusão pela rede (a partir da superfície); 3) transporte por evaporação e condensação; 4) difusão pelo contorno de grão; 5) difusão pela rede (a partir do contorno de grão); e 6) fluxo plástico (por meio de discordâncias). ${ }^{96}$

\section{Estágio intermediário}

Este estágio permanece ativado durante a maior parte do processo de sinterização. ${ }^{96} \mathrm{~A}$ microestrutura é caracterizada pela presença de canais contínuos de poros situados ao longo das junções de três grãos. ${ }^{97}$ Os mecanismos 4 a 6 (Fig. 2.1) promovem retração e densificação no corpo conformado e, portanto, são denominados de mecanismos de densificação. ${ }^{96,98}$ Os mecanismos 1 a 3 (Fig. 2.1) não promovem densificação, pois somente aumentam a curvatura da superfície do pescoço, causando uma redução no potencial termodinâmico de densificação. ${ }^{96}$ Entretanto, a sinterização no estado sólido é controlada por um conjunto de mecanismos de transporte de matéria (Fig. 2.1), que atuam de forma cooperativa entre si, promovendo mudanças microestruturais que levam o corpo conformado a uma condição mais estável. $^{95}$ 


\section{Estágio final}

A microestrutura é caracterizada pela presença de poros isolados, cuja morfologia varia em função da sua disposição na microestrutura (Fig. 2.2): i) poros situados no interior dos grãos tendem a forma esférica; ii) poros situados nas faces e arestas dos grãos tendem a forma lenticular; e iii) poros situados nos cantos dos grãos tendem para a forma de tetraedros arredondados. Os poros isolados podem ser eliminados por um ou mais mecanismos de transporte de matéria (Fig. 2.1), dependendo da sua localização sobre o grão. ${ }^{95}$ Se o poro tem mobilidade mais lenta do que o contorno de grão durante a sinterização, o poro tende a permanecer isolado no interior do grão, resultando em lenta densificação porque sua eliminação acontece somente por difusão pela rede. ${ }^{95}$ Por outro lado, se o poro tem elevada mobilidade, este pode permanecer unido ao contorno de grão, resultando em rápida densificação porque sua eliminação acontece por difusão pela rede e pelo contorno de grão. ${ }^{95}$ A mobilidade do contorno de grão depende da taxa de difusão na região do contorno de grão, enquanto a mobilidade do poro depende da curvatura do poro (tamanho do poro) e dos mecanismos de transporte de matéria. ${ }^{95}$

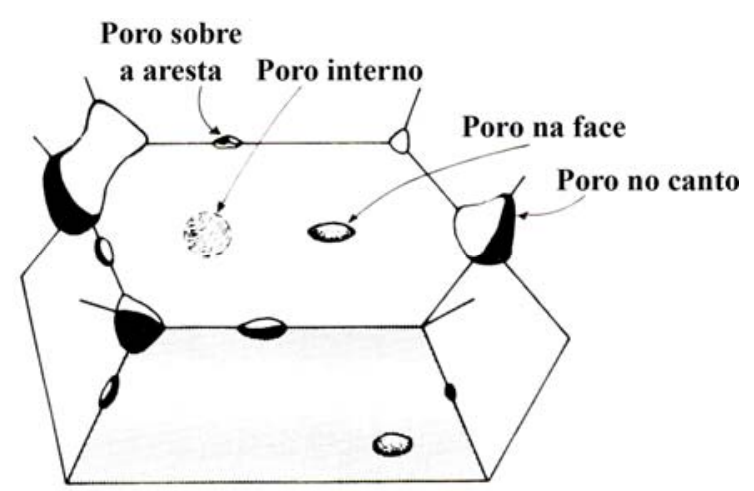

Figura 2.2 - Ilustração esquemática da geometria dos poros no estágio final da sinterização no estado sólido. ${ }^{95}$

O potencial termodinâmico para o crescimento de grão é a diminuição de energia interfacial por unidade de área. O número total de grãos em um determinado sistema deve diminuir durante o crescimento de grão, visando à conservação de volume no sistema. Em decorrência da curvatura dos contornos de grão, os grãos com mais de seis lados tendem a crescer, enquanto os grãos com menos de seis lados tendem a retrair. A taxa de crescimento de grão pode ser influenciada pela presença de poros, inclusões e solutos, que inibem ou dificultam a movimentação dos contornos de grão. ${ }^{95,97}$ 


\subsubsection{Sinterização via fase líquida}

A sinterização via fase líquida envolve a coexistência simultânea de líquido e partículas sólidas durante um determinado período do tratamento térmico (queima). O líquido formado durante a sinterização pode ser transiente ou persistente, dependendo do grau de solubilidade entre os materiais que constituem o corpo conformado. ${ }^{90,99} \mathrm{O}$ processo de sinterização via fase líquida pode ser dividido em três estágios: ${ }^{100}$ rearranjo de partículas, solução-difusão-precipitação e remoção de poros. O estágio final (remoção de poros) da sinterização via fase líquida também é denominado de sinterização no estado sólido. ${ }^{90,99}$

\section{Estágio inicial}

Uma rápida densificação pode acontecer logo após a formação de líquido, caso haja elevada solubilidade do sólido no líquido e boa molhabilidade do líquido no sólido. ${ }^{90,99}$ Isto ocorre porque a fase líquida vai se espalhar por entre as partículas do corpo conformado, gerando forças capilares, que promovem o rearranjo destas partículas para uma condição de máximo empacotamento. ${ }^{101,102}$ Quando a solubilidade do sólido no líquido é baixa, a densificação por rearranjo de partículas pode ser inibida, se houver a formação de um esqueleto rígido de partículas devido à sinterização no estado sólido durante o aquecimento até a temperatura de formação de fase líquida. ${ }^{90,99}$ Neste caso, a densificação acontecerá durante o estágio intermediário e final da sinterização via fase líquida. ${ }^{90}$ A molhabilidade da fase líquida sobre as partículas sólidas ou grãos pode ser determinada pelo ângulo diedro ( $\Psi),{ }^{90,103}$ que é definido em função das tensões interfaciais localizadas na região de interseção entre dois grãos e a fase líquida (Fig. 2.3). Deste modo, o ângulo diedro ( $\Psi$ ) pode ser expresso como:

$$
\psi=2 \arccos \frac{\gamma_{\mathrm{SS}}}{2 \gamma_{\mathrm{SL}}}
$$

onde, $\gamma_{\mathrm{SS}}$ é a energia interfacial sólido-sólido e $\gamma_{\mathrm{SL}}$ é a energia interfacial sólido-líquido. $\mathrm{Na}$ condição $\gamma_{\mathrm{SS}} / \gamma_{\mathrm{SL}}<2$ o ângulo diedro varia de $0^{\circ}$ a $180^{\circ}$. Quanto mais próximo de $180^{\circ}$, 
menor será a penetração de líquido no contorno de grão. A condição $\gamma_{S S} / \gamma_{S L}=2$ representa a condição em que o líquido penetra completamente no contorno de grão. A condição $\gamma_{\mathrm{SS}} / \gamma_{\mathrm{SL}}>$ 2 não se aplica à equação $2.1 .^{103}$

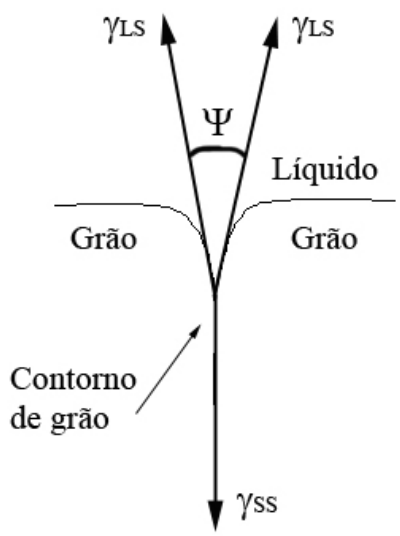

Figura 2.3 - Ilustração esquemática mostrando o ângulo diedro ( $\Psi)$ formado na interseção entre dois grãos e a fase líquida. ${ }^{103} \gamma_{\mathrm{SS}}$ é a energia interfacial sólido-sólido e $\gamma_{\mathrm{SL}}$ é a energia interfacial sólido-líquido.

A fração volumétrica de fase líquida presente durante a sinterização influencia a densificação por rearranjo de partículas. ${ }^{101,102}$ Supondo que o líquido apresente boas características de molhamento e espalhamento, é previsto que o corpo conformado pode atingir completa densificação apenas pelo mecanismo de rearranjo de partículas com a presença de $35 \%$ em volume de líquido. ${ }^{101}$ Porém, Kwon \& Messing ${ }^{104}$ indicaram um teor próximo de $26 \%$ em volume de líquido para promover completa densificação por rearranjo de partículas em uma cerâmica de alumina $\left(\mathrm{Al}_{2} \mathrm{O}_{3}\right)$ com adição de um vidro de silicato de alumínio-magnésio.

\section{Estágio intermediário}

O estágio de solução-difusão-precipitação depende da solubilidade do sólido no líquido, pois a taxa de densificação depende da taxa de transporte de matéria pelo líquido. ${ }^{90}$ Este estágio é caracterizado por densificação, acomodação de forma dos grãos, achatamento de contatos, eliminação parcial de poros e coalescimento de pescoços. ${ }^{90}$ A Figura 2.4 mostra esquematicamente os possíveis mecanismos de densificação que podem atuar durante o estágio intermediário da sinterização via fase líquida. O primeiro mecanismo (Fig. 2.4a), denominado de achatamento de contato (contact flattening), foi proposto por Kingery ${ }^{101}$. Este 
processo persiste até que o pescoço atinja uma condição de equilíbrio definida pelo tamanho de grão e o ângulo diedro. ${ }^{99} \mathrm{O}$ segundo mecanismo (Fig. 2.4b), que envolve a dissolução de pequenos grãos, seguida pela difusão e precipitação do material dissolvido sobre os grãos maiores, promove a ocupação dos espaços vazios por acomodação de forma dos grãos, além de favorecer o preenchimento dos poros restantes pelo líquido. ${ }^{99} \mathrm{O}$ terceiro mecanismo envolve o crescimento de pescoço entre as partículas (Fig. 2.4c), que é análogo ao mecanismo relacionado com o estágio inicial da sinterização no estado sólido. Em geral, este último mecanismo tem grande importância em sistemas que apresentam baixa solubilidade do sólido no líquido. ${ }^{99}$
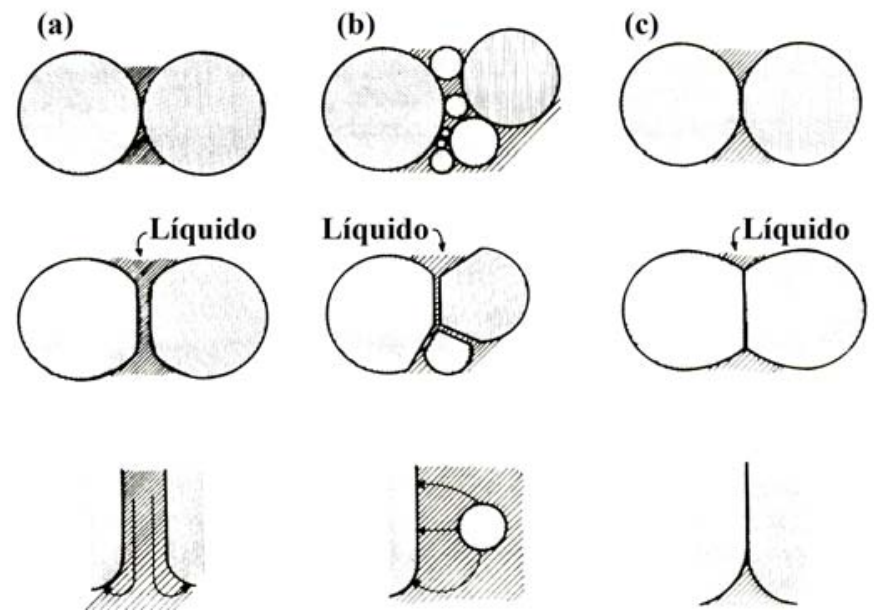

Figura 2.4 - Ilustração esquemática dos mecanismos de acomodação de forma e crescimento de pescoço durante o estágio intermediário da sinterização via fase líquida: (a) achatamento de contato; (b) dissolução de grãos finos; e (c) difusão no estado sólido. ${ }^{99}$

\section{Estágio final}

O mecanismo de solução-difusão-precipitação continua durante o estágio final da sinterização via fase líquida. ${ }^{99,103}$ Este estágio é caracterizado pela baixa taxa de densificação e pela remoção de poros residuais. ${ }^{100}$ Há duas vertentes de mecanismos usados para descrever o processo de eliminação de poros residuais durante a sinterização via fase líquida: 1) achatamento de contato ${ }^{101,102,105}$ e 2) preenchimento de poros ${ }^{106-108}$. Embora os dois mecanismos de eliminação de poros sejam dependentes do crescimento de grão, ${ }^{108} \mathrm{o}$ mecanismo de preenchimento de poros é considerado mais rápido do que o mecanismo de achatamento de contato. ${ }^{107,108}$ A principal justificativa é que o crescimento de grão causado por achatamento de contatos é mais lento em comparação com a cinética global de 
crescimento de grão, que leva em consideração os mecanismos de achatamento de contato, dissolução de grãos finos e difusão no estado sólido (Fig. 2.4). O mecanismo de preenchimento de poros se baseia na eliminação dos poros em função do crescimento de grão,

que promove o deslocamento de líquido para a superfície dos poros. ${ }^{107}$ Isto causa o molhamento da superfície dos poros pelo líquido, fazendo com que os grãos cresçam em direção ao centro dos poros. Por outro lado, se a fração volumétrica de líquido é muito baixa, o mecanismo de acomodação de forma dos grãos por achatamento de contato pode ser um importante mecanismo para promover densificação durante o estágio final da sinterização via fase líquida. ${ }^{107}$

No estágio final da sinterização via fase líquida, os poros são fechados ${ }^{93} \mathrm{e}$, portanto, pode acontecer o aprisionamento de gás no seu interior. Supondo que o gás aprisionado seja solúvel na matriz, a taxa de densificação ou eliminação de poros pode ser controlada pela taxa de difusão de gás para fora do poro ou pela solubilidade do gás na matriz. Porém, se o gás é insolúvel na matriz, a retração e/ou eliminação de poros é inibida devido ao aumento da pressão de gás no interior dos poros, o que resulta na diminuição da taxa de densificação. ${ }^{90,100,106,109-111}$

\subsection{Mecânica de fratura linear elástica}

A mecânica de fratura linear elástica (MFLE) segue a lei de Hooke, ou seja, é válida apenas no regime elástico, onde o material não está sujeito à deformação plástica permanente. Os materiais cerâmicos são caracterizados por apresentar fratura frágil e, portanto, exibem um comportamento de fratura baseado na MFLE.

Para sólidos livres de defeitos, a resistência teórica $\left(\sigma_{\mathrm{T}}\right)$ de um corpo pode ser definida como a tensão necessária para separá-lo em duas partes através do rompimento de suas ligações interatômicas, ${ }^{97,112}$ sendo expressa como:

$$
\sigma_{\mathrm{T}}=\sqrt{\frac{E \gamma}{d_{0}}}
$$


onde, E é o módulo de Young, $\gamma$ é a energia superficial do material associada com a criação de novas superfícies e $\mathrm{d}_{0}$ é a distância interatômica.

A resistência teórica $\left(\sigma_{\mathrm{T}}\right)$ é significativamente maior do que a resistência à fratura observada freqüentemente em materiais frágeis. ${ }^{97,112-114}$ Por exemplo, a cerâmica de alumina tem resistência teórica $\left(\sigma_{\mathrm{T}}\right)$ próxima de $3 \times 10^{4} \mathrm{MPa},{ }^{112}$ enquanto sua resistência à fratura varia comumente de 275 a $425 \mathrm{MPa}$. Esta diferença significativa entre os valores de resistência foi atribuída à presença de defeitos (flaws) no material, ${ }^{97,113-117}$ que induz a fratura abaixo do valor previsto pela resistência teórica $\left(\sigma_{\mathrm{T}}\right) .{ }^{97}$ Os defeitos encontrados nos materiais cerâmicos manufaturados podem ser introduzidos durante o processamento do pó cerâmico (síntese, preparação do pó para conformação, conformação e sinterização), acabamento final (usinagem, lapidação e/ou polimento) e utilização do componente. ${ }^{114,116,118}$

Os conceitos de concentração de tensão na ponta de uma trinca, tratado por Inglis ${ }^{*}$, e balanço de energia termodinâmico aplicado na propagação da trinca, tratado por Griffith ${ }^{\dagger}$, são considerados fundamentais para a mecânica de fratura. ${ }^{114,119,120} \mathrm{O}$ modelo de Inglis considera uma placa com cavidade elíptica de semi-eixos a e c (Fig. 2.5), que está sujeita a uma tensão uniforme de tração $(\sigma)$ aplicada paralelamente ao semi-eixo a da cavidade. ${ }^{119}$ Supondo que o sistema está em regime elástico linear (lei de Hooke), Inglis mostrou que a tensão, presente na extremidade da cavidade (região PC, Fig. 2.5), pode aumentar significativamente em relação à tensão aplicada na placa. ${ }^{119}$ Assim, na região PC da cavidade (Fig. 2.5), a tensão de tração será máxima $\left(\sigma_{\text {máx }}\right)$, sendo expressa como:

$$
\sigma_{\text {máx }}=\sigma\left(1+\frac{2 \mathrm{c}}{\mathrm{a}}\right)
$$

Se a cavidade apresentar o semi-eixo a significativamente menor do que o semi-eixo $\underline{\mathrm{c}}$, e sabendo que o raio de curvatura na extremidade da cavidade é $\tau=\mathrm{a}^{2} / \mathrm{c}$, pode-se dizer que a tensão de tração máxima $\left(\sigma_{\text {máx }}\right)$ na região PC da cavidade (Fig. 2.5) é: ${ }^{113,119}$

$$
\sigma_{\text {máx }}=2 \sigma \sqrt{\frac{\mathrm{c}}{\tau}}
$$

\footnotetext{
* INGLIS, C.E. Stress in a plate due to the presence of cracks and sharp corners. In: Proceedings Institute Naval Architects, 1913, London, p. 219-241.

$\dagger$ GRIFFITH, A.A. The Phenomena of rupture and flow in solids. In: Philosophical Transactions Royal Society, 1920, London, p. 163-198.
} 
O critério de falha pode ser obtido pela combinação das equações 2.2 e $2.4,{ }^{117}$ sendo expresso como:

$$
\sigma_{\mathrm{f}}=\sqrt{\frac{E \gamma \tau}{4 \mathrm{~cd}}}
$$

onde, $\sigma_{\mathrm{f}}$ é a tensão de fratura, E é o módulo de Young, $\gamma$ é a energia superficial do material associada com a criação de novas superfícies na fratura, $\tau$ é o raio de curvatura da cavidade elíptica, c é o comprimento da trinca e $\mathrm{d}_{0}$ é a distância interatômica.

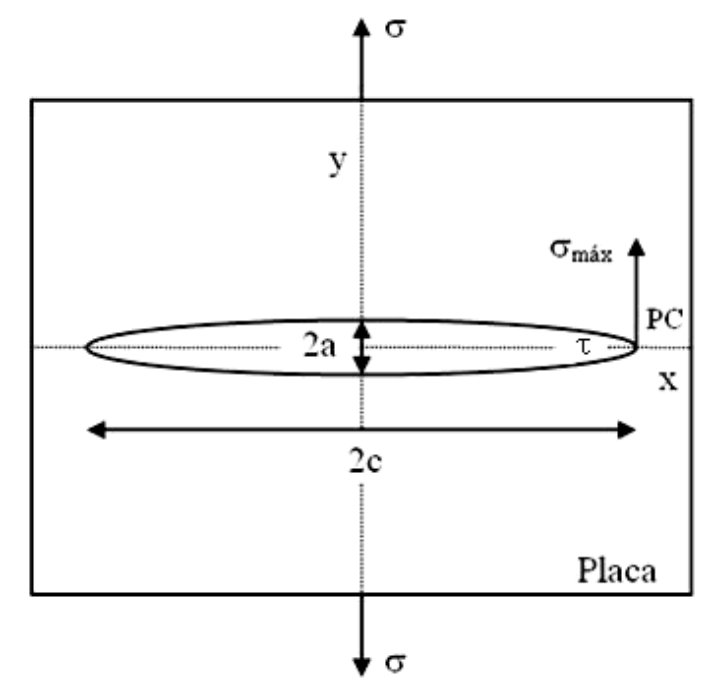

Figura 2.5 - Ilustração esquemática de uma placa sujeita a uma tensão uniforme de tração $(\sigma)$ aplicada paralelamente ao semi-eixo a da cavidade elíptica. A região PC indica a ponta da cavidade elíptica, cujo raio de curvatura é $\tau=\mathrm{a}^{2} / \mathrm{c}$. ${ }^{119}$

O modelo de Inglis falhou ao ser usado como critério de falha, pois este prevê que a tensão concentrada na extremidade da cavidade tende a infinito quando o raio de curvatura da elipse tende a zero, ou seja, da ordem de um espaçamento interatômico. ${ }^{117,119}$ Como é comum a presença de defeitos microscópicos em materiais cerâmicos, uma tensão com valor nominal próximo de zero poderia levar à fratura um corpo sólido de acordo com o modelo proposto por Inglis.

Griffith propôs um modelo de propagação de trinca baseado no conceito da primeira lei da termodinâmica ${ }^{114,117,119}$ e, então, estabeleceu a seguinte condição de balanço de energia: 


$$
\frac{\mathrm{d}\left(\mathrm{U}_{\mathrm{M}}+\mathrm{U}_{\mathrm{S}}+\mathrm{W}\right)}{\mathrm{dc}}=0
$$

onde, $U_{M}$ é a energia mecânica elástica relacionada com a energia liberada durante a propagação da trinca, $U_{S}$ é a energia superficial relacionada com a energia consumida na criação de novas superfícies na fratura, W é o trabalho mecânico realizado pelo movimento das forças externas e c é o comprimento da trinca.

Sabendo que o sistema está sob carregamento constante e obedece à MFLE, o trabalho (W) realizado pela forças externas, que resulta no crescimento da trinca, ${ }^{119}$ pode ser expresso como:

$$
\mathrm{dW}=-2 \mathrm{dU}_{\mathrm{M}}
$$

Rearranjando as equações 2.6 e 2.7, tem-se a condição do balanço de energia de Griffith para crescimento de trinca sob carregamento constante:

$$
\frac{\mathrm{dU}_{\mathrm{M}}}{\mathrm{dc}}=\frac{\mathrm{dU}_{\mathrm{S}}}{\mathrm{dc}}
$$

Supondo uma cavidade elíptica infinitamente estreita $(a \rightarrow 0)$, com comprimento (c) e sujeita a uma tensão de tração constante dentro do regime elástico linear, Griffith mostrou que a energia mecânica $\left(\mathrm{U}_{\mathrm{M}}\right)$ pode ser expressa como: ${ }^{119}$

$$
\begin{aligned}
& U_{M}=-\frac{\pi c^{2} \sigma^{2}}{E} \text { (placa fina) } \\
& U_{M}=-\frac{\pi\left(1-v^{2}\right) c^{2} \sigma^{2}}{E} \quad \text { (placa espessa) }
\end{aligned}
$$

onde, c é o comprimento da trinca (equivale à metade do comprimento do maior semi-eixo da elipse da Figura 2.5), $\sigma$ é a tensão de tração, E é o módulo de Young e $v$ é o coeficiente de Poisson. Os sinais negativos nas equações 2.9 e 2.10 indicam uma diminuição de energia mecânica $\left(\mathrm{U}_{\mathrm{M}}\right)$ com a formação da trinca. ${ }^{119}$ 
A energia superficial $\left(U_{S}\right)$ relacionada com a energia consumida na criação de duas superfícies na fratura pode ser expressa como: ${ }^{119}$

$$
\mathrm{U}_{\mathrm{S}}=4 \mathrm{c} \gamma
$$

onde, c é o comprimento da trinca (equivale à metade do comprimento do maior semi-eixo da elipse da Figura 2.5) e $\gamma$ é a energia superficial por unidade de área.

Derivando $U_{M}$ (eq. 2.9 e 2.10) e $U_{S}$ (eq. 2.11) em função do comprimento da trinca ( $\mathrm{dU}_{\mathrm{M}} / \mathrm{dc}$ e $\mathrm{dU}_{\mathrm{S}} / \mathrm{dc}$, respectivamente), e realizando o balanço de energia de Griffith (eq. 2.8), determina-se o critério de falha de Griffith para propagação de trinca: ${ }^{114,119}$

$$
\begin{aligned}
& \sigma_{\mathrm{f}}=\sqrt{\frac{2 \gamma \mathrm{E}}{\pi \mathrm{c}}} \text { (estado plano de tensão) } \\
& \sigma_{\mathrm{f}}=\sqrt{\frac{2 \gamma \mathrm{E}}{\pi\left(1-v^{2}\right) \mathrm{c}}} \text { (estado plano de deformação) }
\end{aligned}
$$

onde, $\sigma_{\mathrm{f}}$ é a tensão de fratura, $\gamma$ é a energia superficial por unidade de área, E é o módulo de Young e c é o comprimento da trinca (equivale à metade do comprimento do maior semi-eixo da elipse da Figura 2.5). O modelo de Griffith considera que a energia total de um sistema associado com a formação da trinca é transformada apenas em energia superficial $\left(U_{S}\right)$ durante a fratura. ${ }^{114}$ Embora haja outros fatores que podem induzir dissipação de energia durante a propagação da trinca, ${ }^{114}$ o modelo de Griffith vem sendo aplicado com sucesso na análise de materiais com fratura frágil.

Os campos de tensões localizados na vizinhança da ponta de uma trinca podem ser divididos em: ${ }^{119}$ modo I: corresponde à separação das superfícies da trinca pela ação de uma tensão de tração (Fig. 2.6a); modo II: corresponde ao cisalhamento longitudinal das superfícies da trinca em uma direção normal ao plano da trinca (Fig. 2.6b); e modo III: corresponde ao cisalhamento lateral em uma direção paralela ao plano da trinca (Fig. 2.6c). O plano de propagação da trinca pode mudar com o crescimento da trinca, ${ }^{114}$ dando origem a 
um tipo misto de modo de carregamento. Porém, o modo I é mais pertinente para propagação de trincas em materiais com fratura frágil. ${ }^{114,117,119}$
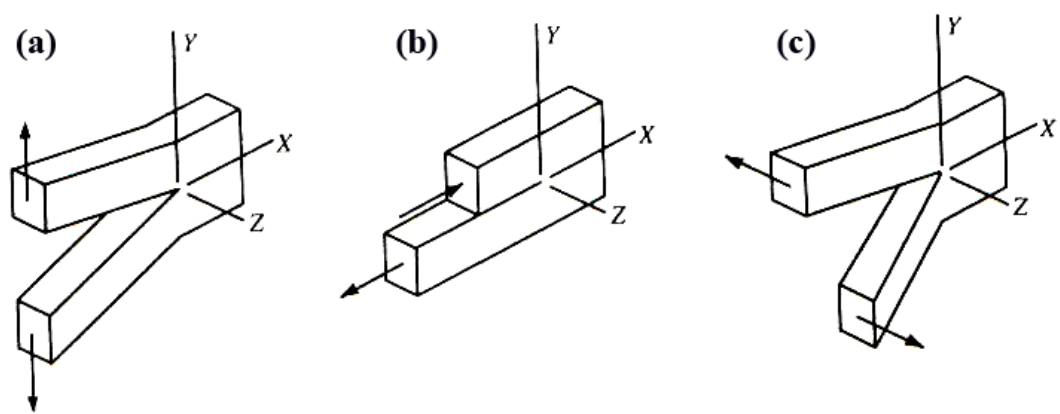

Figura 2.6 - Ilustração esquemática dos modos de carregamento: (a) modo I ou de abertura; (b) modo II ou de deslizamento; e (c) modo III ou de cisalhamento fora do plano. ${ }^{115}$

Irwin $^{\ddagger}$ apud Lawn ${ }^{119}$ desenvolveu soluções analíticas para os campos de tensão e deslocamento ao redor da ponta de uma trinca e identificou nestas equações uma constante de proporcionalidade, que recebeu a denominação de fator de intensidade de tensão $(\mathrm{K})$. Este fator é comumente denominado de $\mathrm{K}_{\mathrm{I}}, \mathrm{K}_{\mathrm{II}}$ e $\mathrm{K}_{\mathrm{III}}$, pois é dependente do modo de carregamento (Fig. 2.6). Irwin também correlacionou os conceitos de Inglis e Griffith e mostrou que a taxa de liberação de energia (F) em função do fator de intensidade de tensão (K) pode ser expressa como: ${ }^{114,117}$

$$
\begin{aligned}
& \mathrm{F}=\frac{\mathrm{K}_{\mathrm{I}}^{2}}{\mathrm{E}}+\frac{\mathrm{K}_{\mathrm{II}}^{2}}{\mathrm{E}}+\frac{\mathrm{K}_{\mathrm{III}}^{2}(1+v)}{\mathrm{E}} \text { (estado plano de tensão) } \\
& \mathrm{F}=\frac{\mathrm{K}_{\mathrm{I}}^{2}\left(1-v^{2}\right)}{\mathrm{E}}+\frac{\mathrm{K}_{\mathrm{II}}^{2}\left(1-v^{2}\right)}{\mathrm{E}}+\frac{\mathrm{K}_{\mathrm{III}}^{2}(1+v)}{\mathrm{E}} \text { (estado plano de deformação) }
\end{aligned}
$$

onde, o índice subscrito em K indica o modo de carregamento da MFLE para trincas (Fig. 2.6), v é o coeficiente de Poisson e E é o módulo de Young.

O balanço de energia de Griffith (eq. 2.8) pode ser reformulado em termos de energia: ${ }^{117,121}$

$$
\mathrm{F}=\mathrm{R}
$$

\footnotetext{
*IRWIN, G.R. Fracture. In: Handbuch der Physik, 1958, Springer-Verlag, Berlin, p. 557.
} 
onde, $\mathrm{F}$ é a taxa de liberação de energia e $\mathrm{R}$ é a resistência à propagação da trinca. Para materiais frágeis, a resistência à propagação da trinca é igual à energia de superfície $(\gamma)^{121} \mathrm{e}$, portanto, a taxa de liberação de energia $(\mathrm{F})$ pode ser expressa como:

$$
\mathrm{F}=2 \gamma
$$

Substituindo a equação 2.17 nas equações 2.14 e 2.15 , e sabendo que as falhas em materiais cerâmicos acontecem preferencialmente em modo I de carregamento, ${ }^{114,117,119}$ temse:

$$
\begin{aligned}
& \mathrm{K}_{\mathrm{I}}=\sqrt{2 \gamma \mathrm{E}} \text { (estado plano de tensão) } \\
& \mathrm{K}_{\mathrm{I}}=\sqrt{\frac{2 \gamma \mathrm{E}}{\left(1-v^{2}\right)}} \text { (estado plano de deformação) }
\end{aligned}
$$

Segundo a MFLE, cada material apresenta um valor crítico de $\mathrm{K}_{\mathrm{I}}$, denominado de fator de intensidade de tensão crítico $\left(\mathrm{K}_{\mathrm{Ic}}\right)$, acima do qual a trinca propaga de forma catastrófica. ${ }^{117}$ Deste modo, a condição de falha pode ser expressa como: ${ }^{115}$

$$
\mathrm{K}_{\mathrm{I}} \geq \mathrm{K}_{\mathrm{Ic}}
$$

Rearranjando a equação do critério de falha de Griffith (eq. 2.12) para o estado plano de tensão, tem-se:

$$
\sqrt{2 \gamma \mathrm{E}}=\sigma_{\mathrm{f}} \sqrt{\pi \mathrm{c}}
$$

O termo do lado esquerdo da equação 2.21 é o fator de intensidade de tensão na ponta da trinca para modo I de carregamento (eq. 2.18). Como a condição de falha é dada pela equação 2.20, pode-se dizer que o termo do lado direito da equação 2.21 é o fator de intensidade de tensão crítico $\left(\mathrm{K}_{\mathrm{Ic}}\right)$ para modo I de carregamento. $\mathrm{O}$ termo $\mathrm{K}_{\mathrm{Ic}}$, também conhecido por tenacidade à fratura, é uma propriedade intrínseca do material e pode ser definido como sendo o fator de intensidade de tensão crítico na ponta de uma trinca pré- 
existente. A tenacidade à fratura $\left(\mathrm{K}_{\mathrm{Ic}}\right)$ ou critério de falha de Irwin-Griffith pode ser expressa genericamente como:

$$
\mathrm{K}_{\mathrm{Ic}}=\sigma_{\mathrm{f}} \cdot \mathrm{Y} \cdot \sqrt{\mathrm{c}}
$$

onde, $\sigma_{\mathrm{f}}$ é a tensão de fratura, $\mathrm{Y}$ é uma constante adimensional que depende de vários fatores (modo de carregamento, forma e dimensões do corpo e geometria e comprimento da trinca) e c é o tamanho crítico da trinca a partir do qual a fratura propaga.

Como a tenacidade à fratura (eq. 2.22) é dependente do comprimento da trinca, a variação de resistência nos materiais cerâmicos deve estar associada com a distribuição do tamanho de defeitos. Os defeitos gerados por usinagem, impacto, desgaste e choque térmico podem levar à formação de microtrincas superficiais, que são consideradas o principal fator que controla a resistência mecânica nos materiais cerâmicos. ${ }^{114}$ Por outro lado, Lange ${ }^{116}$ indicou que cada etapa do processamento cerâmico tem um potencial para introduzir defeitos que podem persistir e/ou originar novos defeitos durante as etapas subseqüentes do processamento. Quando um defeito de processamento (poro, inclusão. grão grande) é considerado a fonte de falha no material, ${ }^{122}$ o fator dominante, que leva ao início da falha, é o tamanho do defeito presente em um plano aproximadamente perpendicular à tensão aplicada, sendo considerados os fatores secundários a forma do defeito e sua orientação relativa para o eixo de aplicação de tensão. Como os poros localizados próximos da superfície tensionada podem atuar como uma trinca aguda, ou podem estar associados com trincas superficiais oriundas de usinagem, os mesmos são comumente vinculados a algum tipo de trinca, ${ }^{122}$ que pode resultar na falha do material, pois a concentração de tensão na trinca deve provavelmente exceder aquela prevista para o poro isolado. Os poros grandes são considerados atípicos em relação à forma média dos poros presentes na microestrutura e, portanto, os poros localizados próximos da superfície, que são freqüentemente vinculados a algum tipo de trinca, são considerados a principal fonte de falha atribuída à presença do referido defeito. 


\subsubsection{Tenacificação em materiais cerâmicos}

As cerâmicas têm sua aplicação limitada como material estrutural de engenharia devido à sua fragilidade. Esta fragilidade torna-as susceptíveis à presença de defeitos (flaws), ${ }^{114,115,118,119}$ que são usualmente introduzidos nas etapas de processamento cerâmico, usinagem e polimento ou durante a utilização do componente. ${ }^{116,118}$ Entretanto, a confiabilidade mecânica dos materiais cerâmicos pode ser aumentada por meio de controle microestrutural. ${ }^{123}$ Modificações nas características microestruturais (microstructural design) podem resultar no impedimento da propagação da trinca, ${ }^{118,123}$ o que implica no aumento da tenacidade à fratura. Alguns tipos de microestruturas causam no material um comportamento denominado de curva $\mathrm{R}$ (curva de resistência à propagação da trinca), que é caracterizado pelo aumento da tenacidade à fratura em função do aumento do comprimento da trinca. Neste caso, a taxa de liberação de energia (eq. 2.17) deve apresentar um termo adicional $\left(\mathrm{R}_{\mathrm{a}}\right),{ }^{121}$ que está relacionado com a contribuição da microestrutura para o aumento da resistência à propagação da trinca. A Figura 2.7 mostra esquematicamente o efeito do tamanho da trinca (c) na tenacidade à fratura de materiais cerâmicos que exibem ou não comportamento de curva $\mathrm{R}$.

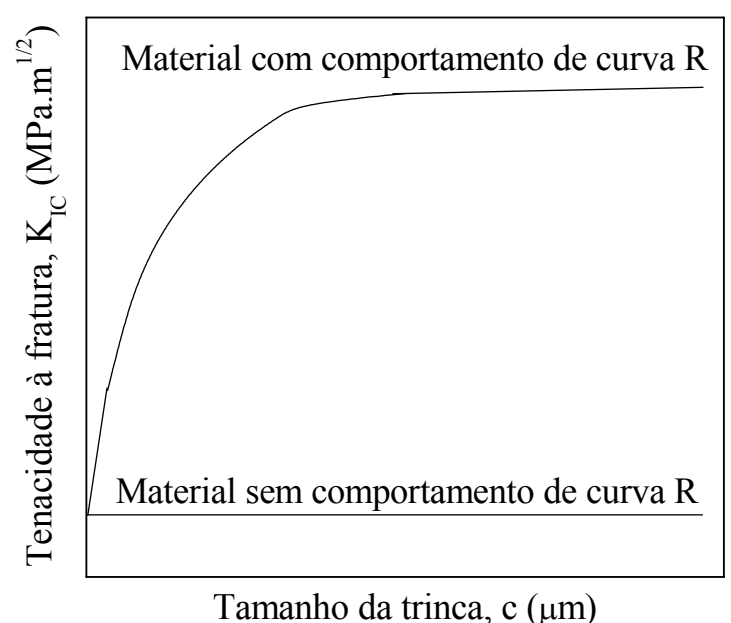

Figura 2.7 - Esquema de um gráfico mostrando o efeito do tamanho da trinca (c) na tenacidade à fratura $\left(\mathrm{K}_{\mathrm{Ic}}\right)$ de materiais cerâmicos que exibem ou não comportamento de curva R. ${ }^{115}$

O mecanismo de tenacificação que ocorre com mais freqüência nos materiais cerâmicos é a deflexão de trinca. Este mecanismo é caracterizado pela mudança sistemática da direção de propagação da trinca, fazendo com que a tensão aplicada deixe de ser normal à superfície da trinca, o que implica na diminuição da intensidade de tensão na ponta da trinca 
$\left(\mathrm{K}_{\mathrm{I}}\right)$. Deste modo, a energia do sistema deve ser aumentada para promover o crescimento da trinca até um tamanho crítico em que sua propagação se torna catastrófica ou instável. O caso mais comum de tenacificação por deflexão de trinca é a propagação da trinca pela região de contorno de grão. A utilização de aditivos de sinterização pode levar à formação de contornos de grãos suficientemente fracos, ${ }^{123}$ favorecendo a propagação intergranular da trinca, o que pode resultar no aumento da tenacidade à fratura por deflexão de trinca, principalmente se a microestrutura apresentar uma distribuição bimodal de grãos ou grãos com alta razão de aspecto (grãos alongados). A presença de partículas de segundas-fases, na forma de fibra, plaqueta, bastonete ou whisker, pode mudar a direção de propagação da trinca e, então, promover a tenacificação por deflexão de trinca. ${ }^{115}$

Os materiais cerâmicos monofásicos com estrutura cristalina não cúbica (p.e. $\mathrm{Al}_{2} \mathrm{O}_{3} \mathrm{e}$ $\mathrm{Si}_{3} \mathrm{~N}_{4}$ ) podem apresentar tensões residuais internas nos contornos de grão em decorrência da anisotropia de expansão térmica do cristal. ${ }^{124-127}$ Estas tensões internas são de tração e/ou compressão e, portanto, podem influenciar significativamente na propagação da trinca em materiais cerâmicos com baixa porosidade $(\leq 3 \%) .{ }^{125,126}$ Quando a microestrutura apresenta grãos com tamanho acima de certo valor crítico, as tensões internas geradas por diferença de expansão térmica entre os grãos adjacentes levam à formação de microtrincas na região de contorno de grão. ${ }^{125}$ A formação de microtrincas na região adjacente à ponta da trinca pode diminuir a energia de deformação nesta região, ${ }^{125}$ o que dificulta a propagação da trinca, ou seja, aumenta a tenacidade à fratura. Este mecanismo é denominado de microtrincamento. Entretanto, o aumento do tamanho de grão, muito acima do valor limite especificado para um determinado material, promove a nucleação excessiva de microtrincas, ${ }^{125}$ que podem coalescer e, então, formar macrotrincas, que diminuem significativamente tanto a resistência mecânica como a tenacidade à fratura. A presença de segundas-fases também pode nuclear microtrincas devido à diferença de coeficiente de expansão térmica entre os constituintes da microestrutura, ${ }^{126,128}$ mas o próprio crescimento da trinca pode levar à formação de microtrincas na zona de processo frontal (frontal process zone). ${ }^{129}$

Para alguns materiais cerâmicos que não apresentam transformação de fase, o aumento da resistência à propagação da trinca tem sido associado com a zona de processo da cauda da trinca (crack wake process zone). ${ }^{129-133}$ Em materiais cerâmicos com grãos grandes, a ocorrência de fratura intergranular leva à formação de superfícies de fratura irregulares (tortuosas), que favorecem o engastamento (interlocking) mecânico e/ou escorregamento (sliding) com atrito na zona de processo da cauda da trinca. ${ }^{118,123,130-133} \mathrm{O}$ mecanismo de desprendimento (pullout) de grãos engastados também contribui para aumentar o atrito entre 
as superfícies de fratura, ${ }^{127}$ o que impede a propagação da trinca, ou seja, aumenta a tenacidade à fratura. $\mathrm{O}$ aumento do tamanho de grão em cerâmicas de alumina intensifica a ocorrência do mecanismo de tenacificação por engastamento mecânico e escorregamento com atrito das superfícies de fratura na região da cauda da trinca (Figs. 2.8a e 2.8b). Na Figura 2.8c, observa-se o desprendimento de grão causado pela ativação do mecanismo de engastamento mecânico e escorregamento com atrito das superfícies de fratura na região da cauda da trinca.
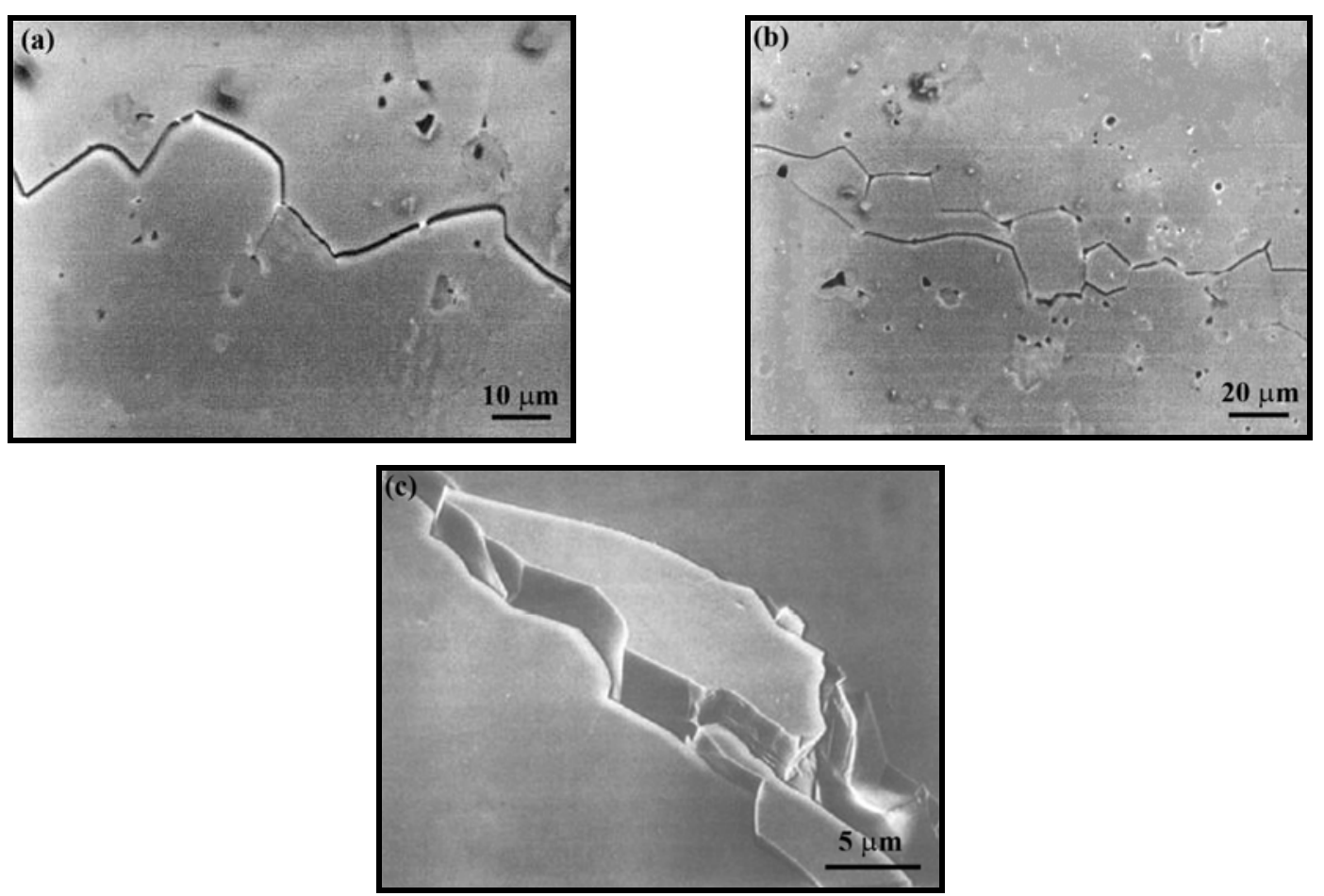

Figura 2.8 - Imagens de microscópio eletrônico de varredura da superfície polida de amostras de alumina submetidas ao ensaio de determinação da curva $\mathrm{R}$ a partir de trincas longas. Amostras com tamanho de grão de $18 \mu \mathrm{m}$ (a) e de $39 \mu \mathrm{m}$ (b), onde se observa a ocorrência de engastamento mecânico e escorregamento com atrito; ${ }^{127}$ imagem mostrando a ocorrência de desprendimento (pullout) de grão (c). ${ }^{134}$

O mecanismo de tenacificação por ponteamento de trinca (crack bridging) é observado comumente em materiais cerâmicos contendo fibras. ${ }^{97}$ Neste caso, a trinca propaga de tal modo que não ocorre a fratura das fibras. Assim, a energia de fratura é diminuída pelo atrito na região em que houve o desprendimento da interface fibra-matriz e pelo ponteamento da trinca pelas fibras. A incorporação de partículas de material dúctil em cerâmicas pode aumentar a tenacidade à fratura, ${ }^{135,136}$ seguindo o mesmo princípio do mecanismo de ponteamento observado em materiais cerâmicos com incorporação de fibras. Por exemplo, a incorporação de partículas de molibdênio (Mo) na cerâmica de AlN aumentou a tenacidade à 
fratura em aproximadamente $167 \%$ em comparação com o material sem reforço metálico. ${ }^{136}$ Durante a propagação da trinca, a energia de fratura perde intensidade devido à interação da ponta da trinca com as partículas de material dúctil. A deformação das partículas metálicas na ponta da trinca age como um sorvedouro de energia, além de causar o ponteamento da trinca.

A zona de processo frontal apresenta pouca influência sobre a propagação da trinca em materiais cerâmicos sem transformação de fase. ${ }^{118,129,131,132}$ Por outro lado, esta zona de processo é responsável pelo impedimento da propagação da trinca em materiais cerâmicos com transformação de fase induzida por tensão. ${ }^{114,118}$ Por exemplo, algumas cerâmicas de zircônica $\left(\mathrm{ZrO}_{2}\right)$ podem apresentar uma estrutura cristalina tetragonal metaestável à temperatura ambiente, ${ }^{137}$ mas a presença de elevadas tensões na ponta da trinca induz uma transformação de fase do tipo martensítica (displaciva) na zona de processo frontal, ${ }^{114,118}$ que leva à formação da fase monoclínica de $\mathrm{ZrO}_{2}$. Esta transformação de fase implica na expansão volumétrica local, ${ }^{114,118}$ que resulta no impedimento da propagação da trinca em decorrência da formação de tensões de compressão na zona de processo frontal. ${ }^{114}$ Embora as duas zonas de processo (cauda e frontal) contribuam para o impedimento da propagação da trinca em materiais cerâmicos, o aumento da fração volumétrica de microtrincas na zona de processo frontal causa uma degradação local das propriedades do material, o que pode levar à diminuição da tenacidade à fratura.

\subsection{Nitreto de alumínio}

\subsubsection{Características gerais}

A estrutura cristalina do nitreto de alumínio (AlN) é constituída por ânions $\left(\mathrm{N}^{3-}\right)$ arranjados na forma hexagonal compacta com cátions $\left(\mathrm{Al}^{3+}\right)$ ocupando a metade dos sítios tetraédricos (Fig. 2.9). Embora o AlN seja considerado uma cerâmica covalente, ${ }^{76,138,139}$ sua estrutura é constituída por ligações tanto covalentes (60\%) como iônicas (40\%). ${ }^{140,141} \mathrm{O}$ AlN não apresenta ponto de fusão, mas se dissocia em alumínio (Al) e nitrogênio $(\mathrm{N})$ acima de $2230^{\circ} \mathrm{C} .{ }^{142}$ 

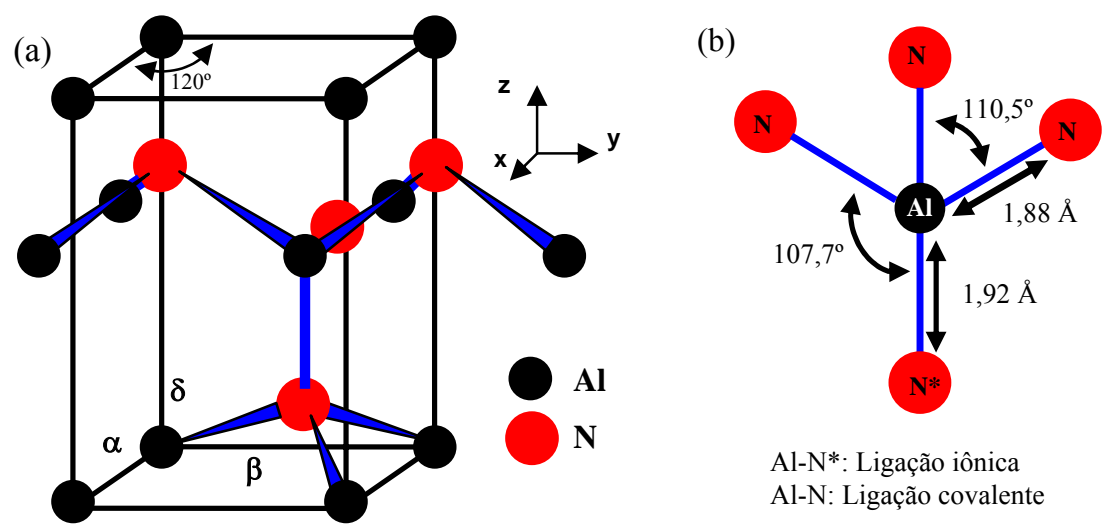

Al-N*: Ligação iônica Al-N: Ligação covalente

Figura 2.9 - (a) esquema da célula unitária do AlN e (b) esquema das ligações entre os átomos de alumínio e nitrogênio. Estrutura cristalina hexagonal $2 \mathrm{H}$ similar a da würstita. Parâmetros de rede: $\alpha=3,111 \AA, \delta=4,978 \AA$ e $\delta / \alpha=1,600 .^{142}$

O AlN não é encontrado na natureza e, portanto, deve ser sintetizado a partir de matérias-primas industrializadas como, por exemplo, pó de alumínio ou de alumina $\left(\mathrm{Al}_{2} \mathrm{O}_{3}\right)$. Embora haja vários métodos de síntese do pó de AlN, tais como deposição química a vapor $^{143,144}$, plasma ${ }^{145,146}$ e pirólise a partir de compostos à base de alumínio [Al(NO) $)_{3}$, $\left.\mathrm{Al}(\mathrm{OH})_{3}, \quad \mathrm{Al}(\mathrm{OH}) \cdot\left(\mathrm{O}_{2} \mathrm{CCH} .\left(\mathrm{C}_{2} \mathrm{H}_{5}\right) \cdot\left(\mathrm{C}_{4} \mathrm{H}_{9}\right)\right)_{2}\right]^{147,148}$, os métodos usados comumente na indústria são os processos de redução carbotérmica e nitretação do pó de $\mathrm{Al}_{2} \mathrm{O}_{3}$ e de nitretação direta de alumínio metálico. ${ }^{149} \mathrm{Na}$ síntese por redução carbotérmica e nitretação, o pós de $\mathrm{Al}_{2} \mathrm{O}_{3}$ e carbono (C) são misturados em meio aquoso ou em solvente orgânico para obter uma mistura homogênea. ${ }^{33}$ Após a secagem, a mistura de pós é tratada termicamente em forno com fluxo de gás nitrogênio ou amônia entre $1400^{\circ} \mathrm{C}$ e $1700^{\circ} \mathrm{C}$. ${ }^{33,150}$ Uma subseqüente calcinação ao ar ou em atmosfera de oxigênio é realizada entre $400^{\circ} \mathrm{C}$ e $800^{\circ} \mathrm{C}$ para remoção do carbono não reagido. ${ }^{33} \mathrm{~A}$ calcinação não deve ser realizada acima de $800^{\circ} \mathrm{C}$ devido ao problema de oxidação do pó de AlN. ${ }^{33,151}$

Apesar da temperatura de fusão do alumínio metálico ser ao redor $660^{\circ} \mathrm{C},{ }^{32}$ o processo de síntese por nitretação direta de alumínio metálico é realizado em temperaturas tão altas quanto $1150^{\circ} \mathrm{C} .^{32,33} \mathrm{O}$ alumínio metálico, normalmente usado na forma de pó, é fundido em altas temperaturas e, então, injeta-se gás nitrogênio ou amônia para promover a nitretação. $\mathrm{O}$ AlN sintetizado por nitretação direta deve ser submetido a um processo de moagem, ${ }^{16,17}$ o que pode resultar no aumento do teor de oxigênio presente na superfície do pó de partida. A Tabela 2.1 mostra algumas características técnicas dos pós de AlN produzidos por redução carbotérmica e nitretação do pó de $\mathrm{Al}_{2} \mathrm{O}_{3}$ e por nitretação direta de alumínio metálico. 
Tabela 2.1 - Características técnicas dos pós de AlN produzidos por redução carbotérmica e nitretação do pó de $\mathrm{Al}_{2} \mathrm{O}_{3}$ (Tokuyama Soda Corp., Japão) e por nitretação direta de alumínio metálico (H.C. Starck, Alemanha). ${ }^{152}$

\begin{tabular}{l|c|c|c|c}
\hline \multirow{2}{*}{ Características } & \multicolumn{2}{|c|}{ Tokuyama Soda } & \multicolumn{2}{c}{ H.C. Starck } \\
\cline { 2 - 5 } & Grau F & Grau H & Grau B & Grau C \\
\hline $\begin{array}{l}\text { Área de superfície } \\
\text { específica (m²) }\end{array}$ & 3,31 & 2,63 & 2,80 & 4,00 \\
\hline $\begin{array}{l}\text { Tamanho médio de } \\
\text { partícula ( } \mu \text { m) }\end{array}$ & 1,31 & 1,55 & 3,25 & 2,41 \\
\hline O (\% massa) & 0,89 & 0,83 & 1,14 & 1,60 \\
\hline C (\% massa) & 0,04 & 0,02 & 0,05 & 0,04 \\
\hline Si (ppm massa) & $<9$ & 38 & 0 & 0 \\
\hline Fé (ppm massa) & $<10$ & 10 & $<20$ & 20 \\
\hline Ca (ppm massa) & 6 & 220 & 0 & 0 \\
\hline
\end{tabular}

O AlN é hidrolisado ao ser exposto à umidade do meio ambiente, ${ }^{152-154}$ sendo formada uma camada de hidróxido de alumínio na superfície do pó. Bowen et al. ${ }^{153}$ estudaram a hidrólise do pó de AlN em solução aquosa à temperatura ambiente. Inicialmente, observaram a formação de uma camada amorfa de hidróxido de alumínio (bohemita, AlOOH) sobre o pó de AlN, a qual se transformou em bayerita cristalina $\left[\mathrm{Al}\left(\mathrm{OH}_{3}\right)\right]$ após longos períodos de exposição à água. Além disso, observaram a formação de amônia, que é um produto tóxico. ${ }^{153,155}$ As possíveis reações químicas que podem ocorrer durante o processo de hidrólise do pó de AlN são: ${ }^{153}$

$$
\begin{aligned}
& \mathrm{AlN}+2 \mathrm{H}_{2} \mathrm{O} \leftrightarrow \mathrm{AlOOH}_{\text {amorfo }}+\mathrm{NH}_{3} \\
& \mathrm{NH}_{3}+\mathrm{H}_{2} \mathrm{O} \leftrightarrow \mathrm{NH}_{4}^{+}+\mathrm{OH}^{-} \\
& \mathrm{AlOOH}_{\text {amorfo }}+\mathrm{H}_{2} \mathrm{O} \leftrightarrow \mathrm{Al}(\mathrm{OH})_{3}
\end{aligned}
$$

Recentemente, Kocjan et al. ${ }^{156}$ estudaram o efeito da temperatura no comportamento de hidrólise do pó de AlN. Eles indicaram que, para qualquer temperatura (de ambiente até $90^{\circ} \mathrm{C}$ ), o primeiro produto de reação formado na superfície do pó de AlN é a fase pseudobohemita $\left(\mathrm{AlOOH}_{\mathrm{amorfa}}\right)$. Uma vez formada esta fase, uma parte se transforma em bohemita cristalina, enquanto a outra parte reage com água para formar bayerita cristalina. Deste modo, Kocjan et al. ${ }^{156}$ propuseram que, em altas temperaturas $\left(\leq 90^{\circ} \mathrm{C}\right)$, o processo de hidrólise do pó de AlN pode ocorrer de acordo com a reação 2.4, que acontece simultaneamente com a reação 2.3 . 


$$
\mathrm{AlOOH}_{\text {amorfo }} \leftrightarrow \mathrm{AlOOH}_{\text {cristalina }}
$$

Os dados da literatura mostram que o AlN tem grande afinidade por oxigênio e, portanto, o teor de oxigênio presente no pó, principalmente na superfície, depende do método de síntese, da condição de armazenamento e da rota de processamento cerâmico.

\subsubsection{Condutividade térmica}

A condutividade térmica da cerâmica policristalina de AlN sem aditivo de sinterização pode variar de 40 a $85 \mathrm{~W} / \mathrm{mK} \cdot{ }^{26,157,158}$ Estes valores de condutividade térmica são significativamente menores em comparação com o monocristal de AlN isento de oxigênio, cuja condutividade térmica teórica foi estimada em $320 \mathrm{~W} / \mathrm{mK}$ à temperatura ambiente. ${ }^{22} \mathrm{O}$ oxigênio, presente de forma inerente na superfície do pó de AlN, entra em solução sólida na rede cristalina durante a sinterização, formando lacunas de alumínio devido à compensação de carga produzida pela substituição de nitrogênio por oxigênio. ${ }^{21,22} \mathrm{O}$ aumento da concentração de lacunas de alumínio na rede cristalina do AIN diminui a condutividade térmica, ${ }^{21,22}$ pois o livre caminho médio dos fônons diminui com o aumento do número de espalhamentos causados pelas interações lacuna-fônon. Além das lacunas de alumínio, a entrada de oxigênio na rede cristalina do AlN pode promover a formação de outros defeitos como, por exemplo, falhas de empilhamento e discordâncias, ${ }^{159-161}$ que podem afetar significativamente a condutividade térmica. Há vários trabalhos mostrando que a condutividade térmica do AlN aumenta em função da diminuição do teor de oxigênio presente na sua rede cristalina, ${ }^{20,162,163}$ indicando que tal impureza deve ser rigidamente controlada, visando à produção de substratos cerâmicos com alta condutividade térmica.

\subsubsection{Sinterização do AIN}

A forte ligação covalente Al-N dificulta a mobilidade dos respectivos átomos pela rede cristalina, ${ }^{164}$ o que resulta na diminuição do coeficiente de autodifusão do AlN e, conseqüentemente, na diminuição da sinterabilidade da cerâmica de AlN. ${ }^{139,164,165}$ Porém, 
Sakai \& Iwata ${ }^{24}$ observaram que o coeficiente de autodifusão do AlN pode ser aumentado em função do aumento do teor de oxigênio presente na superfície do pó de partida. O coeficiente de autodifusão aumenta devido à entrada de oxigênio em solução sólida na rede cristalina do $\mathrm{AlN}$, que leva à formação de lacunas de alumínio em decorrência da compensação de carga entre oxigênio e nitrogênio. ${ }^{21}$ Sakai \& Iwata ${ }^{24}$ indicaram um teor mínimo de $2 \%$ em massa de oxigênio para densificar o $\mathrm{AlN}$ a $1800^{\circ} \mathrm{C}$ por prensagem a quente.

Já Kurokawa et al. ${ }^{26}$ observaram que a adição de carbono, acima de $0,5 \%$ em massa, inibiu a densificação do $\mathrm{AlN}$ sem aditivo por prensagem a quente na temperatura de $1800^{\circ} \mathrm{C}$. Eles indicaram que esta inibição foi causada pelo excesso de carbono, que promoveu uma desoxidação excessiva dos compostos óxidos presentes na superfície do pó de AlN. Estes resultados indicaram que, mesmo tendo um efeito deletério em relação à condutividade térmica, ${ }^{21,40}$ a presença de oxigênio na superfície do pó de AlN implica no aumento de sua sinterabilidade.

$\mathrm{O}$ diagrama de equilíbrio de fases do sistema $\mathrm{AlN}-\mathrm{Al}_{2} \mathrm{O}_{3}$ é apresentado na Figura 2.10. Com base neste diagrama de fases, Sakai et al. ${ }^{25}$ propuseram um mecanismo de sinterização para a cerâmica de AlN sem aditivo. Eles indicaram que a camada de óxido amorfo sobre as partículas de AlN, cuja espessura é da ordem de 40 a $120 \AA$, começa a cristalizar em $\alpha-\mathrm{Al}_{2} \mathrm{O}_{3}$ durante o aquecimento, principalmente acima de $1200^{\circ} \mathrm{C}$. Em seguida, as partículas de AIN reagem com a camada de $\alpha-\mathrm{Al}_{2} \mathrm{O}_{3}$, formando uma fase espinélio de oxinitreto de alumínio ( $\gamma$ $\mathrm{AlON}, \mathrm{Al}_{23} \mathrm{O}_{27} \mathrm{~N}_{5}$ ) acima de $1650^{\circ} \mathrm{C}$ (Fig. 2.10), que melhora a densificação devido ao aumento do coeficiente de autodifusão. Apesar do diagrama de fases do sistema $\mathrm{AlN}-\mathrm{Al}_{2} \mathrm{O}_{3}$ prever a formação de várias fases de oxinitreto de alumínio (Fig. 2.10), Sakai et al. ${ }^{25}$ indicaram que a formação do pseudo-politipo $27 \mathrm{R}\left(\mathrm{Al}_{9} \mathrm{O}_{3} \mathrm{~N}_{7}\right)$ acima de $1800^{\circ} \mathrm{C}$ também pode auxiliar na densificação do AlN. Estes resultados indicaram que a densificação do AlN sem aditivo ocorre por sinterização no estado sólido. Entretanto, outros trabalhos ${ }^{65,166}$ sugeriram que a densificação do AlN sem aditivo foi assistida por sinterização via fase líquida acima de $1850^{\circ} \mathrm{C}$. A formação de fase líquida ao redor de $1850^{\circ} \mathrm{C}$ foi correlacionada com a reação eutética $\mathrm{L} \rightarrow \gamma-\mathrm{AlON}+\alpha-\mathrm{Al}_{2} \mathrm{O}_{3}$ (Fig. 2.10).

No final da década de 60 , Komeya \& Inoue ${ }^{167}$ estudaram o efeito do tamanho de partícula na densificação do AlN sem aditivo. Eles observaram que a sinterabilidade do AlN foi fortemente influenciada pelo tamanho da partícula do pó de partida. Apesar das evidências de melhora da sinterabilidade com a diminuição do tamanho de partícula do AlN, ${ }^{167}$ somente na década de 80, sugiram outros relatos $59,168,169$ indicando que a sinterabilidade desta 
cerâmica é dependente das características do pó de partida e, então, estabeleceu-se que a utilização de pó fino de estreita distribuição granulométrica $(\leq 1 \mu \mathrm{m})$ e com baixo teor de oxigênio $(\sim 1 \%$ em massa) pode promover a densificação do AlN $(\geq 90 \%$ da densidade teórica) por sinterização sem pressão a partir de $1900^{\circ} \mathrm{C} .{ }^{27,169}$

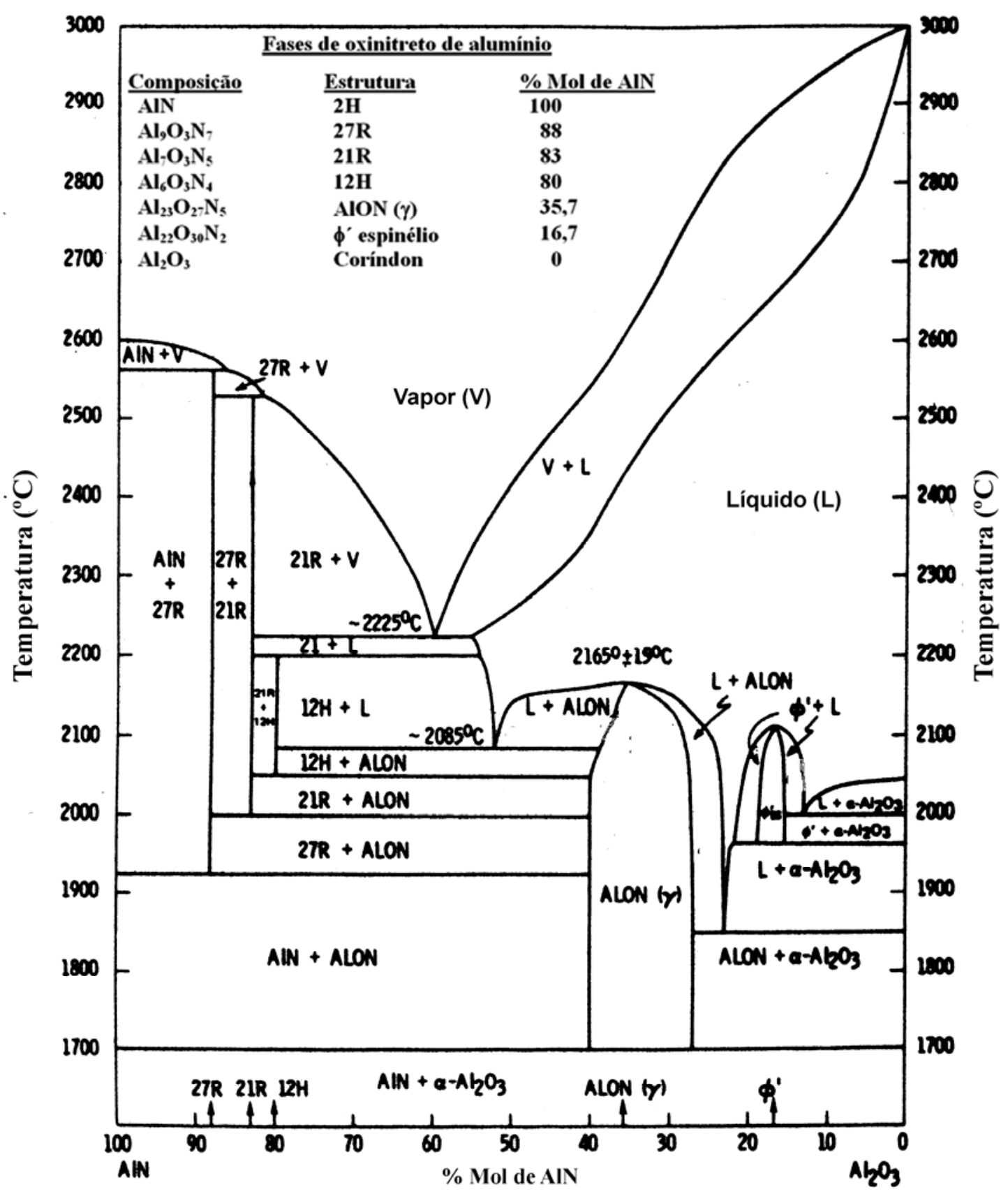

Figura 2.10 - Diagrama de equilíbrio de fases do sistema $\mathrm{AlN}-\mathrm{Al}_{2} \mathrm{O}_{3} .{ }^{170}$ 


\subsubsection{Efeito do aditivo de sinterização na densificação do AlN}

A qualidade do pó de AlN melhorou com o passar do tempo, mas sua temperatura de sinterização continuou relativamente alta $\left(\geq 1900^{\circ} \mathrm{C}\right)$, o que resultou na busca de novas metodologias de processamento para diminuir a temperatura de sinterização. Os primeiros estudos em que se utilizou aditivo de sinterização para diminuir a temperatura de sinterização do AlN surgiram na década de $70 .{ }^{171,172}$ Komeya et al. ${ }^{171}$ observaram que a adição de $\mathrm{Y}_{2} \mathrm{O}_{3}$ melhorou significativamente a densificação do AlN em comparação com o material sem aditivo. Prochazka \& Bobik ${ }^{172}$ analisaram vários aditivos $\left(\mathrm{Be}_{3} \mathrm{~N}_{2}, \mathrm{ZnO}, \mathrm{NiO}, \mathrm{BaCO}_{3}, \mathrm{SrCO}_{3}\right.$ e $\left.\mathrm{CaCO}_{3}\right)$ e verificaram que somente os aditivos $\mathrm{SrCO}_{3}$ e $\mathrm{CaCO}_{3}$ foram eficientes para promover densificação no AlN ( $98 \%$ da densidade teórica) por sinterização sem pressão a partir de $1850^{\circ} \mathrm{C}$.

A melhora na densificação do AlN, isto é, a diminuição da temperatura de sinterização em função da utilização de aditivos óxidos foi atribuída ao aumento da difusividade no estado sólido ${ }^{19}$ e à formação de fase líquida em baixas temperaturas ${ }^{19,41}$. Somente no final da década de 80 surgiu uma proposição para explicar o mecanismo de densificação do AlN com aditivo de sinterização. ${ }^{23,59}$ Esta proposição se baseou no fato de que o aditivo óxido reage com a camada de óxido $\left(\mathrm{Al}_{2} \mathrm{O}_{3}\right)$ presente na superfície do pó de $\mathrm{AlN}$, formando fases de aluminato, que fundem durante a sinterização ${ }^{23,59}$ e, então, promovem densificação no AlN pela ativação dos mecanismos de rearranjo de partículas e solução-difusão-precipitação da sinterização via fase líquida. ${ }^{59}$ Além de abaixar a temperatura de sinterização, os aditivos também melhoram a condutividade térmica do $\mathrm{AlN},{ }^{23,59}$ pois o oxigênio presente na superfície do pó de AlN é capturado na forma de segundas-fases de contorno de grão, o que evita a entrada de oxigênio por solução sólida na rede cristalina do AlN. Porém, há relatos indicando que alguns óxidos metálicos podem promover oxidação no AlN durante a sinterização, ${ }^{42,44}$ resultando no aumento da quantidade de oxigênio $\left(\mathrm{Al}_{2} \mathrm{O}_{3}\right)$ e, conseqüentemente, na diminuição da condutividade térmica. As reações que descrevem o processo de oxidação do AlN durante a sinterização são: ${ }^{42,44}$

$$
\begin{aligned}
& 4 / 3 \mathrm{AlN}_{(\mathrm{s})}+b \mathrm{M}_{\mathrm{x}} \mathrm{O}_{\mathrm{y}(\mathrm{s}, \mathrm{l})} \rightarrow 2 / 3 \mathrm{Al}_{2} \mathrm{O}_{3(\mathrm{~s})}+2 / 3 \mathrm{~N}_{2(\mathrm{~g})}+a \mathrm{M}_{(\mathrm{s}, \mathrm{l})} \\
& 4 / 3 \mathrm{AlN}_{(\mathrm{s})}+d \mathrm{M}_{\mathrm{x}}{ }^{\prime \prime} \mathrm{O}_{\mathrm{y}}^{\prime \prime}(\mathrm{s}, \mathrm{l}) \rightarrow 2 / 3 \mathrm{Al}_{2} \mathrm{O}_{3(\mathrm{~s})}+c \mathrm{M}_{\mathrm{x}}^{\prime} \mathrm{N}_{\mathrm{y}(\mathrm{s}, \mathrm{l})}^{\prime}+e \mathrm{~N}_{2(\mathrm{~g})}
\end{aligned}
$$


onde, $\mathrm{M}_{\mathrm{x}} \mathrm{O}_{\mathrm{y}}$ e $\mathrm{M}_{\mathrm{x}}{ }^{\prime \prime} \mathrm{O}_{\mathrm{y}}{ }^{\prime \prime}$ são óxidos metálicos, $\mathrm{M}$ é o metal e $\mathrm{M}_{\mathrm{x}}^{\prime} \mathrm{N}_{\mathrm{y}}^{\prime}$ é o nitreto metálico. As constantes $a, b, c, d$ e $e$ dependem dos compostos envolvidos nas reações.

As reações 2.5 e 2.6 foram obtidas a partir das reações 2.7 a 2.9 e, portanto, a possibilidade de reação entre o AlN e o aditivo óxido pode ser analisada pela mudança nas energias livres $\Delta \mathrm{F}_{7}{ }^{\mathrm{o}}, \Delta \mathrm{F}_{8}{ }^{\mathrm{o}}$ e $\Delta \mathrm{F}_{9}{ }^{\mathrm{o}}$ relacionadas com as reações 2.7 a 2.9 , respectivamente.

$$
\begin{aligned}
& 4 / 3 \mathrm{AlN}_{(\mathrm{s})}+\mathrm{O}_{2(\mathrm{~g})} \rightarrow 2 / 3 \mathrm{Al}_{2} \mathrm{O}_{3(\mathrm{~s})}+2 / 3 \mathrm{~N}_{2(\mathrm{~g})} \\
& a \mathrm{M}_{(\mathrm{s}, \mathrm{l})}+\mathrm{O}_{2(\mathrm{~g})} \rightarrow b \mathrm{M}_{\mathrm{x}} \mathrm{O}_{\mathrm{y}(\mathrm{s}, \mathrm{l})} \\
& c \mathrm{M}_{\mathrm{x}}^{\prime} \mathrm{N}_{\mathrm{y}(\mathrm{s}, \mathrm{l})}^{\prime}+\mathrm{O}_{2(\mathrm{~g})} \rightarrow d \mathrm{M}_{\mathrm{x}}{ }^{\prime \prime} \mathrm{O}_{\mathrm{y}}{ }^{\prime \prime}(\mathrm{s}, \mathrm{l})+\mathrm{N}_{2(\mathrm{~g})}
\end{aligned}
$$

A Figura 2.11 mostra o diagrama de avaliação da estabilidade do AlN na presença de vários compostos óxidos. A área demarcada na Figura 2.11 indica a condição termodinâmica $\left(\Delta \mathrm{F}_{7}{ }^{\mathrm{o}}>\Delta \mathrm{F}_{8}{ }^{\mathrm{o}}\right.$ e $\left.\Delta \mathrm{F}_{7}{ }^{\mathrm{o}}>\Delta \mathrm{F}_{9}{ }^{\mathrm{o}}\right)$ em que o AlN não é oxidado durante a sinterização. Por outro lado, o AlN será oxidado durante a sinterização quando $\Delta \mathrm{F}_{7}{ }^{\circ}<\Delta \mathrm{F}_{8}{ }^{\mathrm{o}}$ e $\Delta \mathrm{F}_{7}{ }^{\mathrm{o}}<\Delta \mathrm{F}_{9}{ }^{\mathrm{o}}$. Isto mostra que os aditivos óxidos, localizados na área demarcada (Fig. 2.11), não promovem oxidação no AlN e, portanto, podem ser usados para produzir cerâmicas de alta condutividade térmica. ${ }^{42,44}$

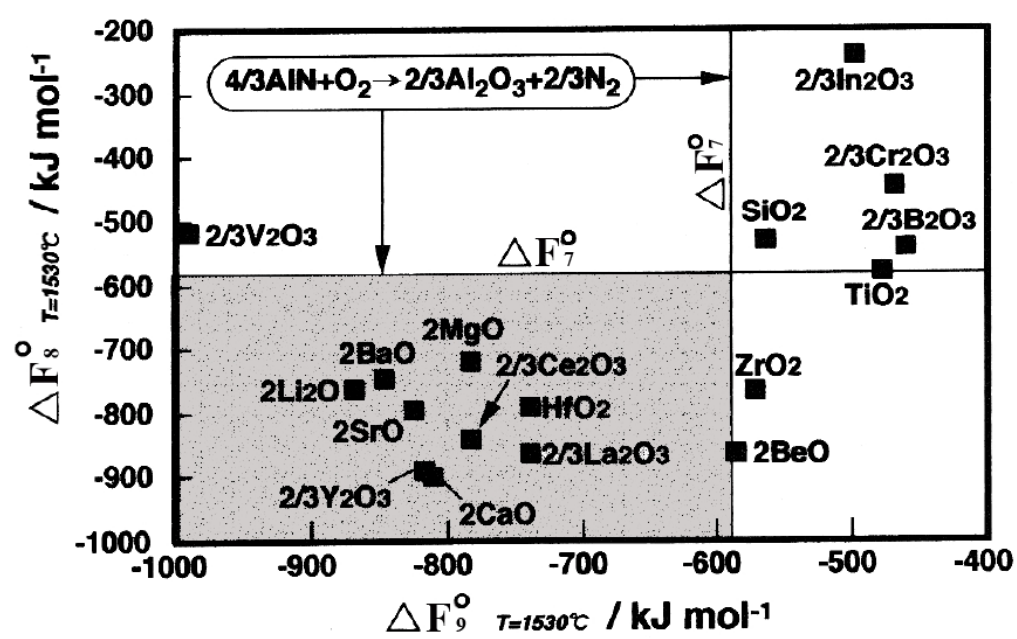

Figura 2.11 - Diagrama de avaliação da estabilidade térmica do AlN na presença de vários aditivos óxidos. As energias $\Delta \mathrm{F}_{7}{ }^{\circ}, \Delta \mathrm{F}_{8}{ }^{\circ}$ e $\Delta \mathrm{F}_{9}{ }^{\circ}$ indicam as energias livres padrões de formação das reações 2.7 a 2.9 , respectivamente. Estas energias foram calculadas a partir de dados termodinâmicos para a temperatura de $1530^{\circ} \mathrm{C}$. Os óxidos metálicos, localizados dentro da área demarcada, não promovem oxidação no AlN durante a sinterização. ${ }^{42}$ 
Virkar et al. ${ }^{23}$ indicaram que a habilidade de um aditivo de sinterização capturar oxigênio $\left(\mathrm{Al}_{2} \mathrm{O}_{3}\right)$ da superfície do pó de AlN pode ser determinada em função da energia livre padrão de formação $\left(\Delta \mathrm{F}_{\mathrm{f}}{ }^{\mathrm{o}}\right)$ da fase aluminato. A Tabela 2.3 apresenta valores de $\Delta \mathrm{F}_{\mathrm{f}}^{\mathrm{o}}$ de alguns aluminatos relacionados com os compostos óxidos presentes na área demarcada da Figura 2.11. $\mathrm{O}$ aluminato de ítrio $\left(\mathrm{Al}_{2} \mathrm{Y}_{4} \mathrm{O}_{9}\right)$ tem menor valor de $\Delta \mathrm{F}_{\mathrm{f}}{ }^{\mathrm{o}}$ do que os demais aluminatos (Tabela 2.3), indicando que o sistema $\mathrm{Al}_{2} \mathrm{O}_{3}-\mathrm{Y}_{2} \mathrm{O}_{3}$ é mais estável termodinamicamente em relação aos outros sistemas $\mathrm{Al}_{2} \mathrm{O}_{3}$-aditivo. Portanto, o $\mathrm{Y}_{2} \mathrm{O}_{3}$ pode ser usado como um aditivo de sinterização efetivo na produção de cerâmicas de AlN com alta condutividade térmica. ${ }^{43}$ Embora o $\mathrm{Y}_{2} \mathrm{O}_{3}$ seja o aditivo de sinterização habitualmente usado na produção de cerâmicas de AlN com alta condutividade térmica, ${ }^{47,52,54}$ os aditivos $\mathrm{CaO}$ ou mistura simultânea de $\mathrm{Y}_{2} \mathrm{O}_{3}$ e $\mathrm{CaO}$ também são usados nos estudos sobre a densificação e/ou condutividade térmica. $57,61,69$

Tabela 2.2 - Valores de energia livre padrão de formação $\left(\Delta \mathrm{F}_{\mathrm{f}}{ }^{\mathrm{o}}\right)$ de algumas fases de aluminato que podem se formar durante a sinterização do AlN com aditivo. ${ }^{43}$

\begin{tabular}{c|c}
\hline Fases de Aluminato & $\Delta \mathrm{F}_{\mathrm{f}}^{\mathrm{o}} / \mathrm{kJ} . \mathrm{mol}^{-1}\left(1530^{\circ} \mathrm{C}\right)$ \\
\hline $\mathrm{Al}_{2} \mathrm{Y}_{4} \mathrm{O}_{9}$ & -1980 \\
\hline $\mathrm{Al}_{2} \mathrm{CaO}_{4}$ & -1620 \\
\hline $\mathrm{Al}_{2} \mathrm{BaO}_{4}$ & -1617 \\
\hline $\mathrm{Al}_{2} \mathrm{BeO}_{4}$ & -1550 \\
\hline $\mathrm{Al}_{2} \mathrm{MgO}_{4}$ & -1492 \\
\hline
\end{tabular}




\section{Efeito do teor de $\mathrm{Y}_{2} \mathrm{O}_{3}$ na densificação do AIN}

\subsection{Introdução}

O comportamento de densificação do AlN foi pouco estudado em comparação com outras cerâmicas técnicas $\left(\mathrm{Al}_{2} \mathrm{O}_{3}, \mathrm{SiC}, \mathrm{Si}_{3} \mathrm{~N}_{4}\right)$. Embora haja alguns estudos sobre a densificação do AlN com $\mathrm{Y}_{2} \mathrm{O}_{3},{ }^{56,65-68}$ os mecanismos envolvidos na sua sinterização foram parcialmente elucidados. Há informações relevantes sobre a sinterização do AlN com $\mathrm{Y}_{2} \mathrm{O}_{3}$ em alguns trabalhos relacionados com a otimização da condutividade térmica, mas que também não são suficientes para esclarecer o comportamento de densificação do AlN. Vários trabalhos estudaram o efeito do teor de $\mathrm{Y}_{2} \mathrm{O}_{3}{ }^{23,39,47}$ e da adição simultânea de carbono e $\mathrm{Y}_{2} \mathrm{O}_{3}{ }^{18,26,49,55,56}$ na condutividade térmica do AlN, mas poucos estudos ${ }^{56}$ relacionaram as referidas variáveis de processamento com o comportamento de densificação do AlN. Assim, este capítulo teve como objetivo estudar o efeito do teor de $\mathrm{Y}_{2} \mathrm{O}_{3}$ na densificação do AlN.

\subsubsection{Sinterização do AIN com aditivo contendo ítrio}

$\mathrm{O}$ aditivo de sinterização à base de ítrio é adicionado comumente na forma de óxido $\left(\mathrm{Y}_{2} \mathrm{O}_{3}\right)^{38,53,76,82,138,173-176}$, mas também pode ser adicionado na forma de aluminato (YAG, $\left.3 \mathrm{Y}_{2} \mathrm{O}_{3} .5 \mathrm{Al}_{2} \mathrm{O}_{3}\right){ }^{54}$ ou na forma de fluoreto $\left(\mathrm{YF}_{3}\right)^{20,47,74,75,177-179}$. Como relatado anteriormente, $\mathrm{o}$ aditivo de sinterização reage com a camada de óxido $\left(\mathrm{Al}_{2} \mathrm{O}_{3}\right)$ presente na superfície do pó de $\mathrm{AlN}$, formando segundas-fases do sistema $\mathrm{Al}_{2} \mathrm{O}_{3}$-aditivo, as quais fundem em altas temperaturas, favorecendo a densificação do AlN por sinterização via fase líquida. No caso dos aditivos à base de ítrio, observou-se a formação de aluminatos de ítrio a partir de $1125^{\circ} \mathrm{C}^{38}$ ou $1200^{\circ} \mathrm{C}^{66,68}$, indicando que a formação destas segundas-fases aconteceu durante o aquecimento até a temperatura de sinterização. Koestler et al. ${ }^{66}$ observaram que a nucleação (início de formação) dos aluminatos de ítrio ocorreu no contato entre a camada de óxido $\left(\mathrm{Al}_{2} \mathrm{O}_{3}\right)$ presente no pó de $\mathrm{AlN}$ e a partícula de $\mathrm{Y}_{2} \mathrm{O}_{3}$. Com o aumento de temperatura, as partículas de $\mathrm{Y}_{2} \mathrm{O}_{3}$ foram sendo gradativamente transformadas para aluminatos de ítrio por sinterização no estado sólido. As novas partículas de aluminatos de ítrio permaneceram nos 
sítios anteriormente ocupados pelas partículas de $\mathrm{Y}_{2} \mathrm{O}_{3}$ até a formação de fase líquida. A composição das segundas-fases dependeu tanto da quantidade de aditivo de sinterização como da quantidade de oxigênio presente na superfície do pó de AlN. ${ }^{51,66}$

Alguns trabalhos ${ }^{65-68,180}$ estudaram o comportamento de densificação do AlN com $\mathrm{Y}_{2} \mathrm{O}_{3}$ por dilatometria, utilizando principalmente pós de AlN com elevada área de superfície específica (ASE). Estes estudos mostraram que o início de retração linear do AlN com $\mathrm{Y}_{2} \mathrm{O}_{3}$ ocorreu entre $1125^{\circ} \mathrm{C}$ e $1450^{\circ} \mathrm{C}$. O AlN com $\mathrm{Y}_{2} \mathrm{O}_{3}$ apresentou larga faixa de temperatura de início de retração linear devido à utilização de pós de AlN com diferentes ASE (3 a 48 $\left.\mathrm{m}^{2} / \mathrm{g}\right),{ }^{67,68}$ pois a utilização de pós mais finos favorece a densificação em menores temperaturas de sinterização. $\mathrm{O}$ início de retração linear do $\mathrm{AlN}$ com $\mathrm{Y}_{2} \mathrm{O}_{3}$ foi correlacionado com a formação de aluminatos de ítrio por sinterização no estado sólido. ${ }^{66}$

A curva de taxa de retração, determinada pela derivada da curva de retração linear em função da temperatura ou tempo, pode apresentar vários picos característicos, que representam fenômenos físico-químicos ativados durante a sinterização. De maneira geral, a curva de taxa de retração do $\mathrm{AlN}$ com $\mathrm{Y}_{2} \mathrm{O}_{3}$ apresentou dois picos de máxima taxa de retração. As temperaturas em que ocorreram estes picos foram deslocadas para menores temperaturas em função do aumento da $\operatorname{ASE}\left(3\right.$ a $48 \mathrm{~m}^{2} / \mathrm{g}$ ). ${ }^{65,67,68,180}$ Porém, alguns pós comerciais de $\operatorname{AlN}\left(\right.$ ASE $\approx 3 \mathrm{~m}^{2} / \mathrm{g}$ ) preparados com $\mathrm{Y}_{2} \mathrm{O}_{3}$ apresentaram apenas um pico de máxima taxa de retração. ${ }^{66,68}$ Nestes trabalhos, o único pico de máxima taxa de retração ocorreu na mesma faixa de temperatura em que ocorreu o segundo pico de máxima taxa de retração observado nos demais trabalhos. O primeiro pico de máxima taxa de retração do AlN com $\mathrm{Y}_{2} \mathrm{O}_{3}$ ocorreu entre $1400^{\circ} \mathrm{C}$ e $1550^{\circ} \mathrm{C} .{ }^{67,68,180}$ Segundo Tajika et al. ${ }^{67}$, a faixa de temperatura em que ocorreu o início de retração e o primeiro pico de máxima taxa de retração $\left(1300^{\circ} \mathrm{C}\right.$ e $\left.1500^{\circ} \mathrm{C}\right)$ ficou abaixo da temperatura prevista para formação de líquido no diagrama de equilíbrio de fases do sistema $\mathrm{Y}_{2} \mathrm{O}_{3}-\mathrm{Al}_{2} \mathrm{O}_{3}\left(1760^{\circ} \mathrm{C}\right.$, Fig. 3.1). Assim, eles indicaram que a retração linear até cerca de $1500^{\circ} \mathrm{C}$ está relacionada com a formação de compostos óxidos por reação no estado sólido. A formação de compostos óxidos (aluminatos de ítrio) causou rearranjo de partículas no estado sólido, ${ }^{67}$ o que levou à retração do AIN durante a sinterização entre $1300^{\circ} \mathrm{C}$ e $1500^{\circ} \mathrm{C}$. Outros trabalhos, ${ }^{65,68}$ que utilizaram pós com elevada ASE, também indicaram que a densificação em baixa temperatura $\left(\leq 1600^{\circ} \mathrm{C}\right)$ está relacionada com a formação de aluminatos de ítrio por sinterização no estado sólido. 


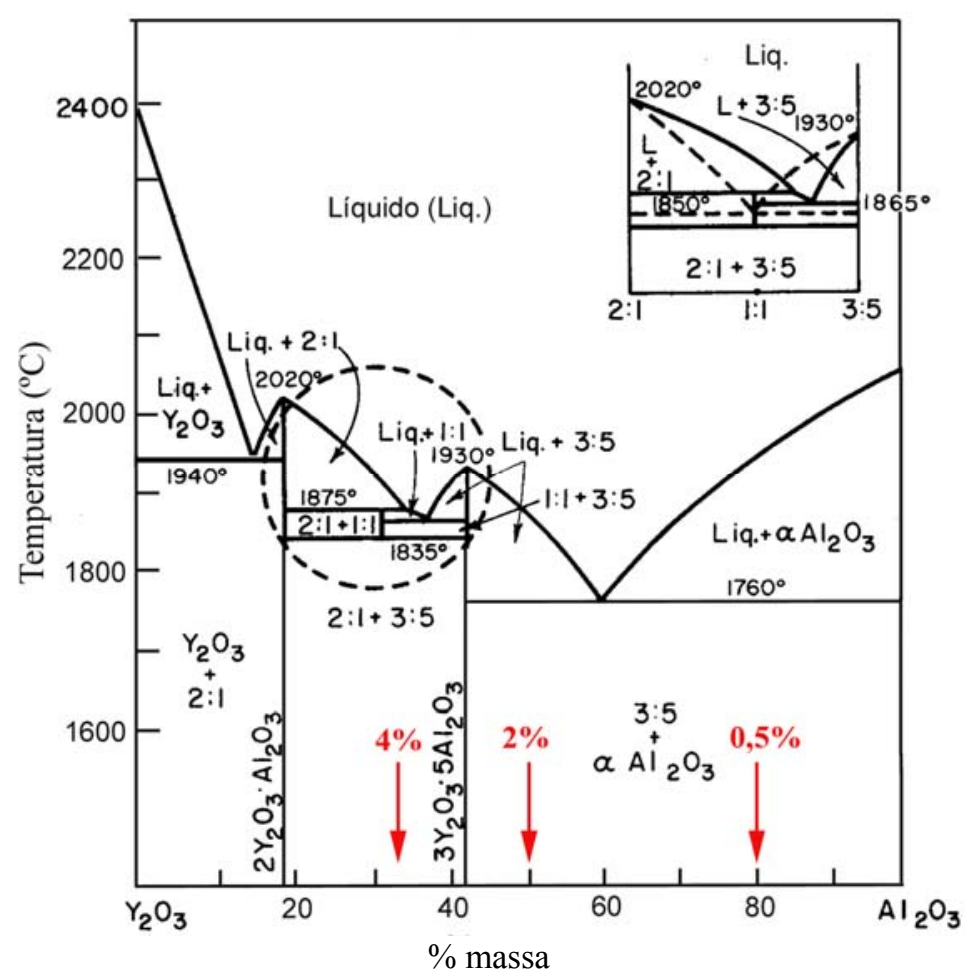

Figura 3.1 - Diagrama de equilíbrio de fases do sistema $\mathrm{Y}_{2} \mathrm{O}_{3}-\mathrm{Al}_{2} \mathrm{O}_{3}$. ${ }^{181}$ YAG $\left(3 \mathrm{Y}_{2} \mathrm{O}_{3} .5 \mathrm{Al}_{2} \mathrm{O}_{3}\right)$, $\mathrm{YAM}$ $\left(2 \mathrm{Y}_{2} \mathrm{O}_{3} \cdot \mathrm{Al}_{2} \mathrm{O}_{3}\right)$ e YAP $\left(\mathrm{Y}_{2} \mathrm{O}_{3} \cdot \mathrm{Al}_{2} \mathrm{O}_{3}\right)$. As setas indicam as composições inicias esperadas nos corpos conformados de pó de AlN com $0,85 \%$ em massa de oxigênio e adição de $0,5 \%, 2 \%$ e $4 \%$ em massa de $\mathrm{Y}_{2} \mathrm{O}_{3}$.

Já o segundo pico de máxima taxa de retração do $\mathrm{AlN}$ com $\mathrm{Y}_{2} \mathrm{O}_{3}$ ocorreu entre $1720^{\circ} \mathrm{C}$ e $1900^{\circ} \mathrm{C} .{ }^{66-68,180} \mathrm{O}$ segundo pico de máxima taxa de retração foi correlacionado com a formação de fase líquida, ${ }^{66,67}$ pois a formação de líquido é prevista a partir de $1686^{\circ} \mathrm{C}{ }^{43}$ ou $1720^{\circ} \mathrm{C}{ }^{182}$ para o sistema ternário $\mathrm{AlN}-\mathrm{Y}_{2} \mathrm{O}_{3}-\mathrm{Al}_{2} \mathrm{O}_{3}$ ou $1760^{\circ} \mathrm{C}{ }^{181}$ para o sistema binário $\mathrm{Y}_{2} \mathrm{O}_{3}-\mathrm{Al}_{2} \mathrm{O}_{3}$ (Fig. 3.1). Estas temperaturas estão associadas com a reação eutética $\mathrm{L} \leftrightarrow$ YAG $+\alpha-\mathrm{Al}_{2} \mathrm{O}_{3}$, como observado no diagrama de fases da Figura 3.1. Como a cerâmica de AlN com aditivo contendo ítrio atinge máxima densidade ao redor de $1800^{\circ} \mathrm{C}^{47,54,76} \mathrm{e}$, sabendo que a menor temperatura eutética deste sistema pode ocorrer entre $1686^{\circ} \mathrm{C}$ e $1760^{\circ} \mathrm{C}$, pode-se dizer que esta cerâmica atinge máxima densificação com "pequenos" superaquecimentos $\left(\leq 114^{\circ} \mathrm{C}\right)$ acima da sua menor temperatura eutética. Já o pó ultrafino de $\mathrm{AlN}$ com $\mathrm{Y}_{2} \mathrm{O}_{3}$ apresentou temperatura de segundo pico de máxima taxa de retração ao redor de $1650^{\circ} \mathrm{C}$. ${ }^{65}$ Como esta temperatura foi menor do que a temperatura de formação de líquido mais baixa prevista na literatura $\left(\sim 1686^{\circ} \mathrm{C}\right)$, Hashimoto et al. ${ }^{65}$ sugeriram que a densificação do AlN ocorreu em decorrência de reações no estado sólido entre o AlN e os aluminatos de ítrio formados em menores temperaturas. 
Buhr et al. ${ }^{180}$ indicaram que pequenas adições de $\mathrm{Y}_{2} \mathrm{O}_{3}(\sim 1 \%$ em massa) são suficientes para promover densificação no AlN, mas que seria necessário o uso de maior teor de aditivo, até certo valor, para atingir valores máximos de condutividade térmica. Outros trabalhos ${ }^{23,39,47}$ observaram que a condutividade térmica do AlN aumentou até atingir um valor máximo com $3 \%$ a $5 \%$ em massa de $\mathrm{Y}_{2} \mathrm{O}_{3}$ e, então, apresentou uma diminuição significativa com o subseqüente aumento do teor de $\mathrm{Y}_{2} \mathrm{O}_{3}$. Kim et al. ${ }^{183}$ observaram que o aumento de $5 \%$ para $10 \%$ em massa de $\mathrm{Y}_{2} \mathrm{O}_{3}$ causou um atraso significativo na densificação do AlN. Eles sugeriram que a presença de $\mathrm{Y}_{2} \mathrm{O}_{3}$ não reagido pode ter atrasado a densificação do AlN, mas não observaram evidências sobre tal suposição.

\subsubsection{Evolução das segundas-fases do AIN com aditivo contendo ítrio}

A cerâmica de AlN é freqüentemente sinterizada em forno com elemento resistivo de grafita e sob atmosfera de gás nitrogênio. Deste modo, estabelece-se uma atmosfera de nitrogênio parcialmente redutora durante a sinterização, que é considerada como um dos mecanismos responsáveis pela melhora da condutividade térmica do AlN. ${ }^{48-50,54,81-83,180} \mathrm{~A}$ atmosfera redutora promove a desoxidação das fases de contorno de grão, melhorando a condutividade térmica devido à limpeza (cleanness) da microestrutura ${ }^{18,47,50,54,82,158}$. Reações químicas, que descrevem o processo de desoxidação das segundas-fases durante a sinterização, foram propostas para o $\mathrm{AlN} \operatorname{com~} \mathrm{Y}_{2} \mathrm{O}_{3}:{ }^{50}$

$$
\begin{aligned}
& \mathrm{Al}_{2} \mathrm{O}_{3(\mathrm{~s})}+\mathrm{N}_{2(\mathrm{~g})}+3 \mathrm{CO}_{(\mathrm{g})} \leftrightarrow 2 \mathrm{AlN}_{(\mathrm{s})}+3 \mathrm{CO}_{2(\mathrm{~g})} \\
& \mathrm{Al}_{2} \mathrm{Y}_{4} \mathrm{O}_{9(\mathrm{~s})}{ }^{\S}+\mathrm{N}_{2(\mathrm{~g})}+3 \mathrm{CO}_{(\mathrm{g})} \leftrightarrow 2 \mathrm{AlN}_{(\mathrm{s})}+2 \mathrm{Y}_{2} \mathrm{O}_{3(\mathrm{~s})}+3 \mathrm{CO}_{2(\mathrm{~g})} \\
& \mathrm{Y}_{2} \mathrm{O}_{3(\mathrm{~s})}+\mathrm{N}_{2(\mathrm{~g})}+3 \mathrm{CO}_{(\mathrm{g})} \leftrightarrow 2 \mathrm{YN}_{(\mathrm{s})}+3 \mathrm{CO}_{2(\mathrm{~g})}
\end{aligned}
$$

Parte do gás $\mathrm{CO}_{2}$ produzido durante o processo de desoxidação das segundas-fases (reações 3.1 a 3.3) pode ser convertida em gás CO (reação 3.4) devido à presença de carbono proveniente da grafita do cadinho e do elemento de aquecimento do forno. Deste modo, a atmosfera redutora pode ser mantida durante a sinterização.

$$
\mathrm{CO}_{2(\mathrm{~g})}+\mathrm{C}_{(\mathrm{s})} \leftrightarrow 2 \mathrm{CO}_{(\mathrm{g})}
$$

\footnotetext{
${ }^{\S} \mathrm{A}$ fase $\mathrm{Al}_{2} \mathrm{Y}_{4} \mathrm{O}_{9}$ corresponde à fase $\mathrm{YAM}\left(2 \mathrm{Y}_{2} \mathrm{O}_{3} \cdot \mathrm{Al}_{2} \mathrm{O}_{3}\right)$ apresentada no diagrama de fases da Figura 3.1.
} 
Embora haja um consenso para utilizar uma atmosfera redutora na otimização da condutividade térmica do AlN com $\mathrm{Y}_{2} \mathrm{O}_{3}$, observou-se que a presença de uma atmosfera fortemente redutora pode inibir a densificação e, assim, diminuir drasticamente a condutividade térmica. ${ }^{18}$ Há procedimentos comumente usados para impedir a formação de uma atmosfera excessivamente redutora, tais como: ${ }^{18}$ utilização de cadinho de nitreto de boro $(\mathrm{BN})$ ou cadinho de grafita com uma camada protetora de pó de $\mathrm{BN}$ ou AlN.

Alguns estudos ${ }^{18,49,55,184}$ utilizaram pó de grafita ou de negro de fumo como aditivo de sinterização, objetivando a formação in situ de uma atmosfera redutora no interior do corpo conformado de $\mathrm{AlN}$ com $\mathrm{Y}_{2} \mathrm{O}_{3}$. A utilização de até 0,5\% em massa de carbono $(\mathrm{C})$ aumentou consideravelmente a condutividade térmica do AlN com $\mathrm{Y}_{2} \mathrm{O}_{3}$ em relação à cerâmica

preparada sem adição de C. ${ }^{49,55}$ Yan et al. ${ }^{56}$ propuseram uma condição limite (threshold) para que aconteça a densificação do $\mathrm{AlN}$ com $\mathrm{Y}_{2} \mathrm{O}_{3}$ na presença de C. Esta condição limite é dada pela razão atômica entre $\mathrm{C}$ e oxigênio $(\mathrm{O})$ e deve ser igual a 1 . A densificação do AlN somente acontece na condição em que a razão $\mathrm{C} / \mathrm{O}$ é menor do que 1. A condutividade térmica aumenta conforme aumenta a razão $\mathrm{C} / \mathrm{O}$, na faixa menor do que 1 , e se aproxima da condição limite $(\mathrm{C} / \mathrm{O}=1)$, onde as segundas-fases apresentam uma tendência para formar fases ricas em $\mathrm{Y}_{2} \mathrm{O}_{3}$. A composição do aluminato de ítrio depende do teor de aditivo de sinterização e do teor de oxigênio $\left(\mathrm{Al}_{2} \mathrm{O}_{3}\right)$ presente na superfície do pó de AlN. ${ }^{51,66}$ Por exemplo, o AlN com 1,8\% em massa de $\mathrm{Y}_{2} \mathrm{O}_{3}$ apresentou somente a fase $\mathrm{YAG},{ }^{51}$ enquanto o AlN com 4,2\% em massa de $\mathrm{Y}_{2} \mathrm{O}_{3}$ apresentou em ordem de preponderância as fases YAM, YAP e YAG. Assim, durante a sinterização sob atmosfera redutora, a composição das segundas-fases muda gradualmente de $\mathrm{xAl}_{2} \mathrm{O}_{3} \cdot \mathrm{yY}_{2} \mathrm{O}_{3}$ para $\mathrm{Y}_{2} \mathrm{O}_{3}$ devido à maior pressão parcial de oxigênio do $\mathrm{Al}_{2} \mathrm{O}_{3}$ em relação ao do $\mathrm{Y}_{2} \mathrm{O}_{3} \cdot{ }^{49,56}$ Outros trabalhos indicaram que os aluminatos de ítrio podem ser decompostos em $\mathrm{Al}_{2} \mathrm{O}_{3}$ e $\mathrm{Y}_{2} \mathrm{O}_{3}$ durante a sinterização; ${ }^{50,82}$ conforme migram para a superfície do corpo se transformam em AlN e YN (reações 3.1 e 3.3), respectivamente.

\subsection{Materiais e métodos}

As matérias-primas usadas na preparação dos corpos sinterizados foram: pó de nitreto de alumínio (AlN, Tokuyama Soda - grau F, Japão); pós de $\mathrm{Y}_{2} \mathrm{O}_{3}$ (Aldrich Chemical Co., Alemanha) e de grafita (C, Grafite de Lubrificação, Brasil) como aditivos de sinterização; 
polietileno glicol (PEG, Nacalai Tesque, Japão) como ligante; álcool isopropílico PA como meio de mistura; e tinta de nitreto de boro (BN, Union Carbide, USA) como revestimento do cadinho. A Tabela 3.1 apresenta os dados fornecidos pelo fabricante sobre o teor de impurezas presentes no pó de AlN.

Tabela 3.1 - Impurezas presentes no pó de AlN (fração em massa).

\begin{tabular}{l|c|c|c|c|c}
\hline Impurezas & Oxigênio & Carbono & Cálcio & Silício & Ferro \\
\hline Teor & $0,85 \%$ & $310 \mathrm{ppm}$ & $10 \mathrm{ppm}$ & $<9 \mathrm{ppm}$ & $<10 \mathrm{ppm}$ \\
\hline
\end{tabular}

\subsubsection{Preparação do pó granulado}

Os pós de partida foram misturados em álcool isopropílico para evitar o problema de degradação do pó de AlN em ambiente aquoso. O ligante (PEG) foi dissolvido em álcool isopropílico a $45^{\circ} \mathrm{C}$ na seguinte proporção em peso: $20 \%$ de $\mathrm{PEG}$ e $80 \%$ de álcool isopropílico. A dispersão de pó foi preparada em recipiente cilíndrico de material polimérico com $300 \mathrm{ml}$ de álcool isopropílico e $250 \mathrm{~g}$ de esferas de material polimérico (diâmetro de 6 $\mathrm{mm}$ ) para $100 \mathrm{~g}$ de material sólido. Dois lotes de pó granulado foram produzidos para cada composição estudada neste trabalho.

A mistura da dispersão de pós foi realizada em moinho de bolas (Yamato, UB32) com velocidade de $80 \mathrm{rpm}$ por cerca de $20 \mathrm{~h}$. Em seguida, adicionaram-se $10 \mathrm{~g}$ de solução de PEG ( $1 \%$ em massa de ligante) à dispersão de pó, que retornou para o moinho por mais $2 \mathrm{~h}$. Após a mistura, a dispersão foi vertida em béquer de polímero (Nalgen) e, então, foi secada em placa quente a $100^{\circ} \mathrm{C}$ por $12 \mathrm{~h}$. O material seco foi granulado em peneira com tela de náilon de 80 mesh e armazenado em recipiente de vidro em dessecador. A Tabela 3.2 apresenta as composições e identificações das amostras de AlN preparadas no presente trabalho.

Tabela 3.2 - Composições e identificações das amostras de AlN.

\begin{tabular}{l|c}
\hline Composição (\% em massa) & Identificação da amostra \\
\hline $0,5 \% \mathrm{Y}_{2} \mathrm{O}_{3}$ & $05 \mathrm{Y}$ \\
\hline $2 \% \mathrm{Y}_{2} \mathrm{O}_{3}$ & $2 \mathrm{Y}$ \\
\hline $4 \% \mathrm{Y}_{2} \mathrm{O}_{3}$ & $4 \mathrm{Y}$ \\
\hline $4 \% \mathrm{Y}_{2} \mathrm{O}_{3}$ e $0,5 \% \mathrm{C}$ & $4 \mathrm{Y} 05 \mathrm{C}$ \\
\hline $4 \% \mathrm{Y}_{2} \mathrm{O}_{3}$ e $1,0 \% \mathrm{C}$ & $4 \mathrm{Y} 1 \mathrm{C}$ \\
\hline
\end{tabular}




\subsubsection{Conformação do corpo}

A conformação foi realizada em duas etapas: prensagem uniaxial com pressão de 10 $\mathrm{MPa}$ por $30 \mathrm{~s}$ (Gardelin) e prensagem isostática com pressão de $150 \mathrm{MPa}$ por $15 \mathrm{~s}$ (Yuken Rubber Press, YRDW-26-100-R). O corpo sinterizado em dilatômetro foi compactado em matriz cilíndrica de aço com diâmetro de $7 \mathrm{~mm}$. Depois da prensagem isostática, o corpo apresentou altura próxima de $12 \mathrm{~mm}$ e diâmetro próximo de $6 \mathrm{~mm}$. O corpo sinterizado em forno convencional com elemento resistivo de tungstênio foi compactado em matriz cilíndrica de carbeto de tungstênio com diâmetro de $15 \mathrm{~mm}$. Depois da prensagem isostática, o corpo apresentou espessura próxima de $5 \mathrm{~mm}$ e diâmetro próximo de 14,5 mm.

\subsubsection{Sinterização}

\section{Dilatômetro}

Os corpos conformados de AlN sem aditivo e com adição de 4\% de $\mathrm{Y}_{2} \mathrm{O}_{3}$ foram acondicionados em cadinho de grafita recoberto com tinta de $\mathrm{BN}$ e, então, calcinados em forno convencional com elemento resistivo de grafita (Thermal Technology, 1000-560FP20). Os corpos conformados foram calcinados a $600^{\circ} \mathrm{C}$ por $0,5 \mathrm{~h}$ em atmosfera de gás nitrogênio. A sinterização em dilatômetro (Netsch, 402), que possibilita mensurar continuamente a variação linear em função do tempo e da temperatura, foi realizada a $1850^{\circ} \mathrm{C}$ por $1 \mathrm{~h}$ sob fluxo de gás nitrogênio. As taxas de aquecimento e resfriamento foram respectivamente $10^{\circ} \mathrm{C} / \mathrm{min}$ e $30^{\circ} \mathrm{C} /$ min tanto para a calcinação como para a sinterização.

\section{Forno convencional}

Os corpos conformados de AlN com diferentes composições (Tabela 3.2) foram sinterizados em forno com elemento resistivo de tungstênio (Nems, NM 15), usando o seguintes parâmetros: 1) taxa de aquecimento de $10^{\circ} \mathrm{C} / \mathrm{min}$; 2) primeiro patamar a $500^{\circ} \mathrm{C}$ por $0,5 \mathrm{~h}$; 3) segundo patamar na temperatura de sinterização $\left(1650^{\circ} \mathrm{C}\right.$ a $\left.2000^{\circ} \mathrm{C}\right)$ por $\left.1 \mathrm{~h} ; 4\right)$ taxa 
de resfriamento de $30^{\circ} \mathrm{C} / \mathrm{min}$; 5) fluxo constante de $2 \mathrm{~L} / \mathrm{min}$ de gás nitrogênio; e 6) pressão positiva ao redor de $0,15 \mathrm{kgf} / \mathrm{cm}^{2}$. Os corpos com formato de pastilha foram acondicionados sobre chapas de molibdênio recobertas com BN e com camada de pó de AlN.

\subsubsection{Caracterização dos materiais}

\section{Análise granulométrica}

A distribuição granulométrica dos pós de partida foi determinada por duas técnicas de análise. $\mathrm{O}$ pó de $\mathrm{AlN}$ foi analisado por sedimentação com contagem por raios $\mathrm{X}$ (Micromeritics, Sedigraph 5100), enquanto o pó de $\mathrm{Y}_{2} \mathrm{O}_{3}$ foi analisado por difração de raios laser (Malvern, Mastersizer 2000).

\section{Densidade}

A densidade do corpo conformado foi determinada pelo método geométrico (a partir das medidas de dimensão e massa), enquanto a densidade do corpo sinterizado foi determinada pelo método de imersão em líquido (método de Arquimedes). A equação 3.1 foi usada para calcular a densidade do corpo denso. Já o corpo poroso, com baixa densidade, foi recoberto (impregnado) com esmalte para pintar unhas e, então, a densidade foi determinada com a equação 3.2 .

$$
\begin{aligned}
& \rho_{\mathrm{e}}=\frac{\mathrm{m}_{\mathrm{ar}}}{\mathrm{m}_{\mathrm{ar}}-\mathrm{m}_{\text {Liq }}} \rho_{\text {Liq }} \\
& \rho_{\mathrm{e}}=\frac{\mathrm{m}_{\mathrm{ar}}}{\left(\frac{\mathrm{m}_{\mathrm{ar}-\mathrm{imp}}-\mathrm{m}_{\text {Liq-imp }}}{\rho_{\text {Liq }}}\right)-\left(\frac{\mathrm{m}_{\mathrm{ar}-\mathrm{imp}}-\mathrm{m}_{\mathrm{ar}}}{\rho_{\text {imp }}}\right)}
\end{aligned}
$$

onde, $\rho_{\mathrm{e}}$ é a densidade calculada, $\mathrm{m}_{\mathrm{ar}}$ é a massa da amostra medida ao ar, $\mathrm{m}_{\mathrm{Liq}}$ é a massa da amostra medida imersa em líquido, $\rho_{\text {Liq }}$ é a densidade do líquido (álcool isopropílico) em função da temperatura, $m_{\text {ar-imp }}$ é a massa da amostra impregnada medida ao ar, $m_{\text {Liq-imp }}$ é a 
massa da amostra impregnada medida imersa em líquido e $\rho_{\text {imp }}$ é a densidade do material usado para impregnar a amostra $\left(\rho_{\text {esmalte }} \approx 1,31 \mathrm{~g} / \mathrm{cm}^{3}\right)$.

A densidade relativa e o grau de densificação ${ }^{185}$ foram determinados pelas seguintes equações:

$$
\begin{aligned}
& \Delta \rho_{\mathrm{C}}=\left(\frac{\rho_{\mathrm{C}}}{\rho_{\mathrm{AIN}}}\right) \times 100 \\
& \Delta \rho_{\mathrm{S}}=\left(\frac{\rho_{\mathrm{e}}}{\rho_{\mathrm{T}}}\right) \times 100 \\
& \rho_{\mathrm{T}}=\rho_{\mathrm{AIN}} \cdot\left(1-\mathrm{M}_{\mathrm{AD}}\right)+\rho_{\mathrm{AD}} \cdot \mathrm{M}_{\mathrm{AD}} \\
& \Phi=\left(\frac{\Delta \rho_{\mathrm{S}}-\Delta \rho_{\mathrm{C}}}{100-\Delta \rho_{\mathrm{C}}}\right)
\end{aligned}
$$

onde, $\Delta \rho_{\mathrm{C}}$ e $\Delta \rho_{\mathrm{S}}$ são as respectivas densidades relativas dos corpos conformado e sinterizado, $\rho_{\mathrm{C}}$ é a densidade geométrica do corpo conformado, $\rho_{\mathrm{e}}$ é a densidade calculada (eq. 3.1 e 3.2), $\rho_{\mathrm{T}}$ é a densidade teórica, $\rho_{\mathrm{AlN}}$ é a densidade do $\operatorname{AlN}\left(3,26 \mathrm{~g} / \mathrm{cm}^{3}\right), \rho_{\mathrm{AD}}$ é a densidade do aditivo de sinterização $\left(\rho_{\mathrm{Y}_{2} \mathrm{O}_{3}}=5,03 \mathrm{~g} / \mathrm{cm}^{3}\right.$ e $\left.\rho_{\mathrm{CaO}}=3,31 \mathrm{~g} / \mathrm{cm}^{3}\right), \mathrm{M}_{\mathrm{AD}}$ é a fração em massa do aditivo de sinterização e $\Phi$ é o grau de densificação.

\section{Preparação ceramográfica}

O corpo sinterizado na forma de disco foi cortado transversalmente, próximo da região central, em uma cortadeira de alta rotação (Buehler, Isomet-2000) com disco de corte adiamantado e, então, polido em uma politriz semi-automática (Buehler, Ecomet 3) com suspensões aquosas de diamante $(45 \mu \mathrm{m}$ a $1 \mu \mathrm{m})$ e sílica coloidal para acabamento final. 


\section{Difratometria de raios $X$}

$A$ análise por difração de raios $\mathrm{X}(\mathrm{DRX})$ foi realizada com radiação do cobre $\left(\mathrm{Cu}-\mathrm{K}_{\alpha 1}\right)$ e velocidade de varredura de $0,5^{\circ} / \mathrm{min}$ (difratômetro Rigaku, RINT 2000). As análises por DRX foram realizadas nas seções transversais polidas das amostras com alta densidade. Já as amostras com baixa densidade foram moídas em moinho de anéis de carbeto de tungstênio (Shatterbox, SPEX 8500) e, então, compactadas e analisadas por DRX. Os cartões JCPDS utilizados foram: 25-1133 (AlN), 33-0040 (YAG, 3 $\mathrm{Y}_{2} \mathrm{O}_{3} .5 \mathrm{Al}_{2} \mathrm{O}_{3}$ ), 34-0368 (YAM, $\left.2 \mathrm{Y}_{2} \mathrm{O}_{3} \cdot \mathrm{Al}_{2} \mathrm{O}_{3}\right), 33-0041$ (YAP, $\left.\mathrm{Y}_{2} \mathrm{O}_{3} \cdot \mathrm{Al}_{2} \mathrm{O}_{3}\right), 41-1105\left(\mathrm{Y}_{2} \mathrm{O}_{3}\right)$ e $76-2495(\mathrm{YN})$.

\section{Microscopia eletrônica de varredura}

As análises dos pós de partida e das superfícies de fratura e polidas dos corpos sinterizados foram realizadas em um microscópio eletrônico de varredura (MEV, Jeol, JSM 6300, Japão), sendo as microanálises químicas realizadas com espectrômetro de energia dispersa (EDS, Noram, USA) acoplado ao MEV. As amostras foram recobertas com ouro em uma campânula a vácuo e, então, foram analisadas com tensão de trabalho de $15 \mathrm{kV}$.

\subsection{Resultados experimentais}

\subsubsection{Caracterização dos pós de partida}

$\mathrm{O}$ pó de $\mathrm{AlN}$ apresentou estreita distribuição granulométrica em relação ao pó de $\mathrm{Y}_{2} \mathrm{O}_{3}$ (Fig. 3.2). O tamanho médio de partícula do AlN foi $0,9 \mu \mathrm{m}$ (valor referente a $50 \%$ em volume acumulado, Fig. 3.2), enquanto o pó de $\mathrm{Y}_{2} \mathrm{O}_{3}$ apresentou tamanho médio de partícula de $5,3 \mu \mathrm{m}$. O pó de AlN apresentou partículas com tamanho igual a $2 \mu \mathrm{m}$ para $90 \%$ em volume acumulado (Fig. 3.2), enquanto o pó de $\mathrm{Y}_{2} \mathrm{O}_{3}$ apresentou partículas com tamanho superior a $20 \mu \mathrm{m}$ para a mesma porcentagem em volume. 


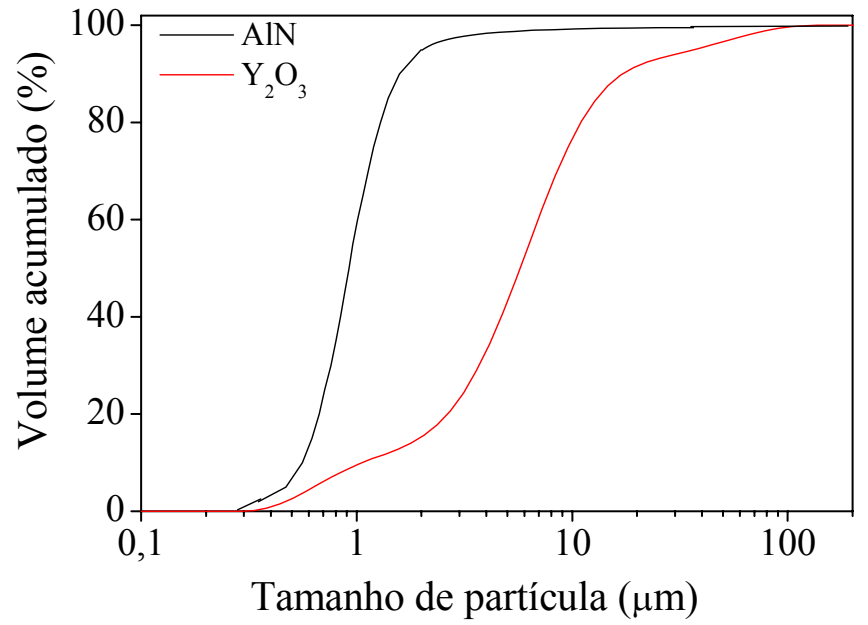

Figura 3.2 - Distribuição granulométrica dos pós de partida de $\mathrm{AlN}$ e $\mathrm{Y}_{2} \mathrm{O}_{3}$.

As partículas primárias do pó de AlN tenderam a forma isométrica (Fig. 3.3a), enquanto as partículas do pó de $\mathrm{Y}_{2} \mathrm{O}_{3}$ tenderam a forma de placas irregulares (Fig. 3.3b). Já as partículas do pó de grafita $(\mathrm{C})$ também tenderam a forma de placas irregulares, cujo tamanho variou de alguns poucos micrometros até cerca de $20 \mu \mathrm{m}$ (Fig. 3.3c).
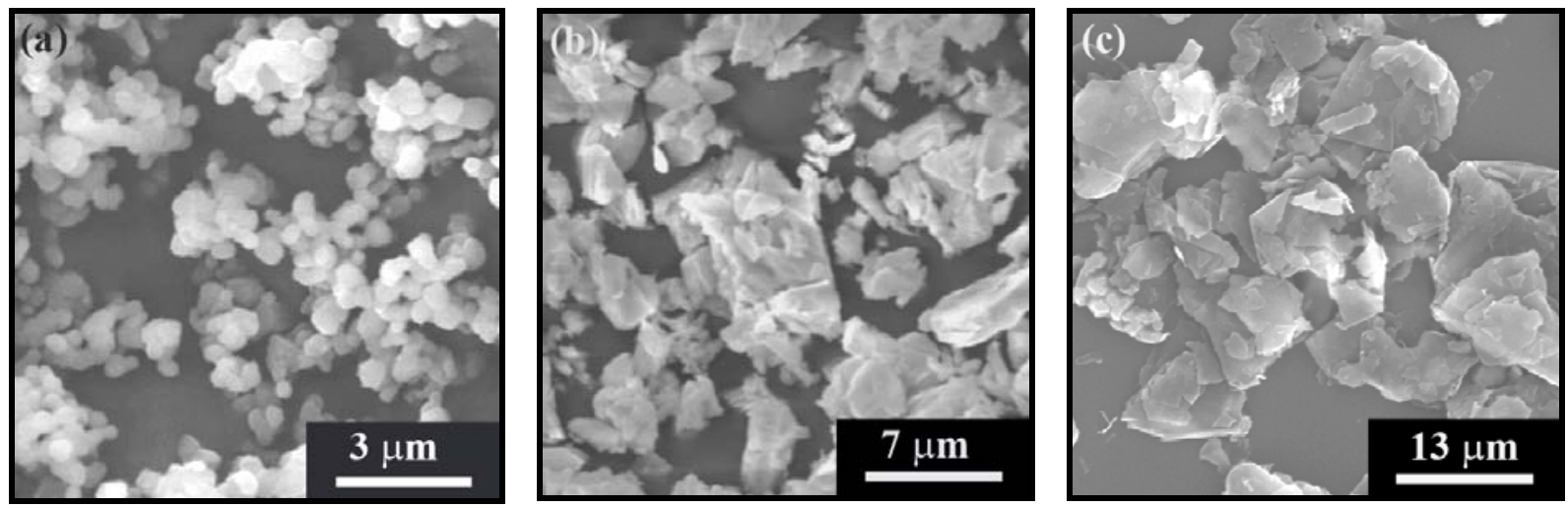

Figura 3.3 - Imagens de MEV dos pós de partida: (a) AlN, (b) $\mathrm{Y}_{2} \mathrm{O}_{3}$ e (c) grafita (C).

\subsubsection{Densificação}

\section{Sinterização em forno convencional}

Os corpos compactados apresentaram densidade relativa ao redor de $55 \%$ da densidade teórica (DT). Os resultados de densidade relativa em função da temperatura de sinterização 
são apresentados na Figura 3.4. O AlN sem aditivo aumentou sua densidade de $62 \%$ para $75 \%$ DT entre $1650^{\circ} \mathrm{C}$ e $1850^{\circ} \mathrm{C}$ (Fig. 3.4), o que mostrou a ocorrência de pouca densificação nesta faixa de temperatura. O AlN sem aditivo sinterizado a $1850^{\circ} \mathrm{C}$ apresentou somente $44 \%$ de densificação total. Entretanto, esta amostra teve um aumento significativo de densidade acima de $1850^{\circ} \mathrm{C}$ (Fig. 3.4), pois atingiu densidade ao redor de $98 \%$ DT a $1950^{\circ} \mathrm{C}$. Este valor de densidade correspondeu a 95\% de densificação total.

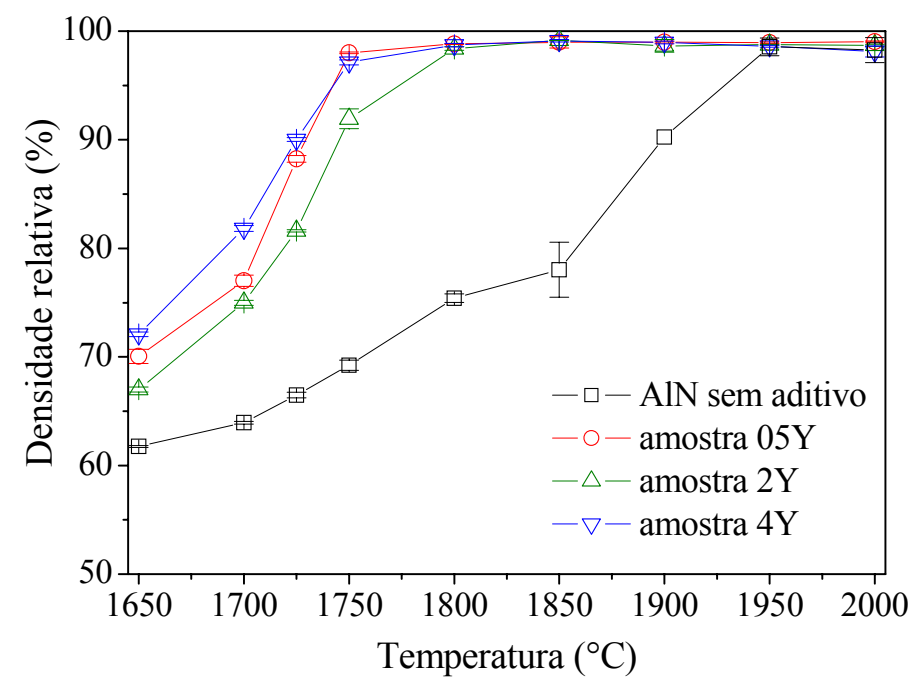

Figura 3.4 - Densidade relativa em função da temperatura de sinterização do AlN sem aditivo e com $\mathrm{Y}_{2} \mathrm{O}_{3}$.

A adição de $0,5 \%$ de $\mathrm{Y}_{2} \mathrm{O}_{3}$ (amostra $05 \mathrm{Y}$ ) deslocou a curva de densificação do AlN para menores temperaturas (Fig. 3.4). As curvas de densificação das amostras $05 \mathrm{Y}$ e $4 \mathrm{Y}$ foram próximas na faixa de temperatura estudada. Já a amostra $2 \mathrm{Y}$ teve sua curva de densificação levemente deslocada para maiores temperaturas em relação às amostras $05 \mathrm{Y}$ e $4 \mathrm{Y}$ entre $1650^{\circ} \mathrm{C}$ e $1750^{\circ} \mathrm{C}$ (Fig. 3.4). As amostras $05 \mathrm{Y}$ e $4 \mathrm{Y}$ sinterizadas a $1750^{\circ} \mathrm{C}$ apresentaram densidades de 97\% DT (Fig. 3.4), que correspondeu a 93\% de densificação total. Embora a amostra $2 \mathrm{Y}$ sinterizada a $1750^{\circ} \mathrm{C}$ tenha atingido apenas $82 \%$ de densificação total (Fig. 3.4), as três amostras com $\mathrm{Y}_{2} \mathrm{O}_{3}$ sinterizadas a partir de $1800^{\circ} \mathrm{C}$ apresentaram densidades próximas ( $\sim 99 \%$ DT) e praticamente constantes. Sabendo que o AlN sem aditivo sinterizado a partir de $1950^{\circ} \mathrm{C}$ atingiu $95 \%$ de densificação total (Fig. 3.4), pode-se dizer que o $\mathrm{Y}_{2} \mathrm{O}_{3}$ diminuiu a temperatura de sinterização do $\mathrm{AlN}$ em cerca de $200^{\circ} \mathrm{C}$, pois este aditivo de sinterização pode promover $93 \%$ de densificação total no AlN sinterizado a partir de $1750^{\circ} \mathrm{C}$. 


\section{Sinterização em dilatômetro}

O AlN sem aditivo apresentou retração linear ao redor de 5\% no final do tratamento isotérmico a $1850^{\circ} \mathrm{C}$ (Fig. 3.5a), o que indicou a ocorrência de pouca densificação até esta temperatura de sinterização. Este resultado foi similar ao observado para o AlN sem aditivo sinterizado em forno convencional (Fig. 3.4). Após a sinterização na temperatura de $1850^{\circ} \mathrm{C}$, o AlN sem aditivo sinterizado tanto em forno convencional como em dilatômetro apresentou densidade próxima de $80 \%$ DT. A adição de 4\% de $\mathrm{Y}_{2} \mathrm{O}_{3}$ (amostra $4 \mathrm{Y}$ ) deslocou a curva de retração linear do AIN para menores temperaturas (Fig. 3.5a), sendo este resultado similar ao observado na sinterização em forno convencional (Fig. 3.4). A amostra 4Y apresentou temperatura de início de retração ao redor de $1200^{\circ} \mathrm{C}$ (Fig. 3.5a), enquanto o AlN sem aditivo iniciou sua retração ao redor de $1460^{\circ} \mathrm{C}$. Um patamar entre $1500^{\circ} \mathrm{C}$ e $1540^{\circ} \mathrm{C}$ foi observado na curva de retração linear da amostra 4Y (Fig. 3.5a). Esta amostra atingiu máxima retração linear ao redor de $1800^{\circ} \mathrm{C}(\sim 17 \%$, Fig. 3.5a), pois sua retração aumentou apenas $1 \%$ até o final do tratamento isotérmico a $1850^{\circ} \mathrm{C}$.
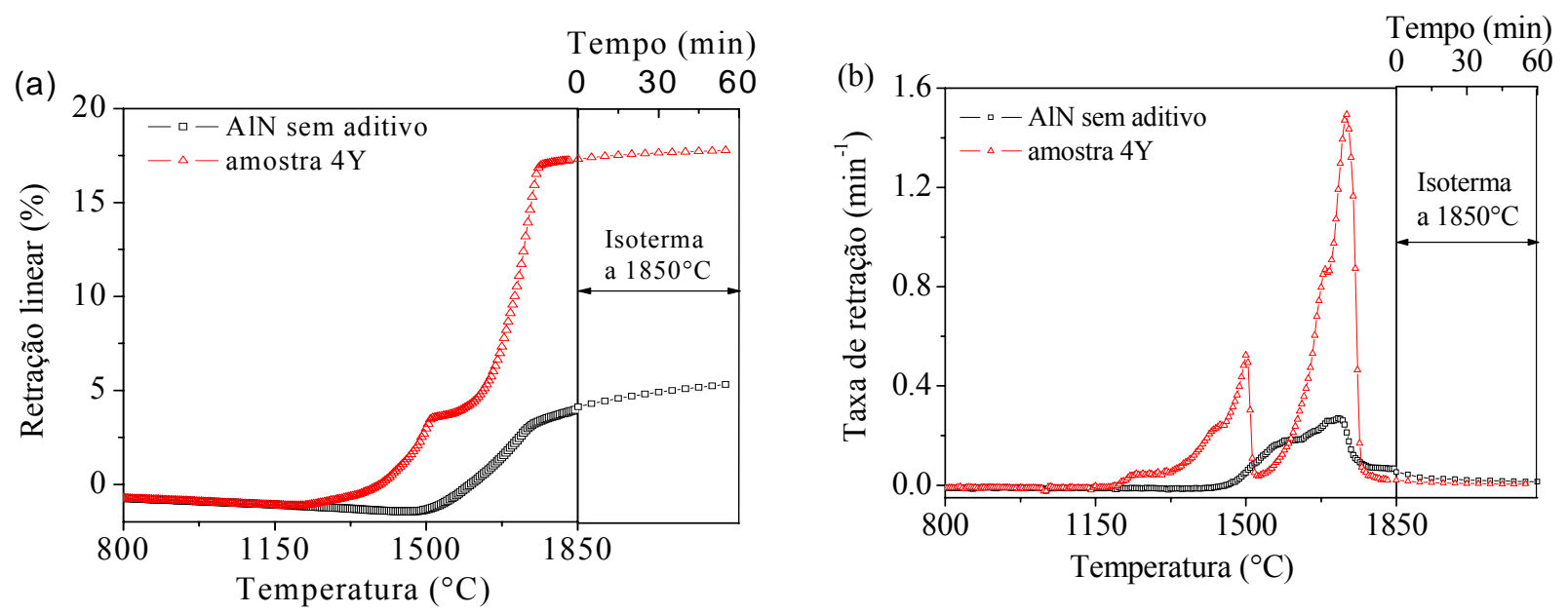

Figura 3.5 - Curvas de retração linear (a) e de taxa de retração (b) em função da temperatura de sinterização. Estas curvas foram traçadas com os dados experimentais obtidos por dilatometria.

As curvas de taxa de retração do AlN sem aditivo e da amostra $4 \mathrm{Y}$ apresentaram vários picos (Fig. 3.5b), indicando a ocorrência de vários fenômenos físico-químicos durante a sinterização até $1850^{\circ} \mathrm{C}$. O AlN sem aditivo apresentou dois picos de máxima taxa de retração (Fig. 3.5b), sendo que o primeiro pico se apresentou na forma de uma inflexão (ombro) na região da curva associada com o segundo pico de máxima taxa de retração. As temperaturas em que ocorreram os dois picos de máxima taxa de retração foram $1600^{\circ} \mathrm{C}$ e $1715^{\circ} \mathrm{C}$, 
respectivamente. A amostra $4 \mathrm{Y}$ apresentou dois picos bem definidos de máxima taxa de retração (Fig. 3.5b). Estes dois picos ocorreram nas temperaturas de $1500^{\circ} \mathrm{C}$ e $1730^{\circ} \mathrm{C}$, respectivamente. Porém, observaram-se várias inflexões (ombros) na curva de taxa retração da amostra 4Y (Fig. 3.5b), principalmente nas regiões associadas com os picos de máxima taxa de retração. Duas inflexões foram observadas na região da curva associada com o primeiro pico de máxima taxa de retração (Fig. 3.5b). As temperaturas em que ocorreram estas duas inflexões foram $1240^{\circ} \mathrm{C}$ e $1440^{\circ} \mathrm{C}$, respectivamente. Outra inflexão foi observada na região da curva associada com o segundo pico de máxima taxa de retração $\left(1685^{\circ} \mathrm{C}\right.$, Fig. $3.5 b)$.

\subsubsection{Evolução das segundas-fases}

Os resultados apresentados neste tópico são provenientes da caracterização do AlN sem e com $\mathrm{Y}_{2} \mathrm{O}_{3}$ sinterizado em forno convencional. A análise de DRX não revelou a presença de segundas-fases no AlN sem aditivo sinterizado a $1850^{\circ} \mathrm{C}$ e $2000^{\circ} \mathrm{C}$. A Figura 3.6 apresenta alguns difratogramas de raios $\mathrm{X}$ das amostras $05 \mathrm{Y}, 2 \mathrm{Y}$ e $4 \mathrm{Y}$ sinterizadas a $1650^{\circ} \mathrm{C}$, $1750^{\circ} \mathrm{C}$ e $2000^{\circ} \mathrm{C}$. A Tabela 3.3 apresenta os resultados de DRX de todas as amostras de AlN com $\mathrm{Y}_{2} \mathrm{O}_{3}$ sinterizadas entre $1650^{\circ} \mathrm{C}$ e $2000^{\circ} \mathrm{C}$. A amostra $05 \mathrm{Y}$ sinterizada entre $1650^{\circ} \mathrm{C}$ e $1950^{\circ} \mathrm{C}$ apresentou a fase YAG (Tabela 3.3), mas apresentou a fase $\mathrm{Y}_{2} \mathrm{O}_{3}$ após a sinterização na temperatura de $2000^{\circ} \mathrm{C}$. A amostra $2 \mathrm{Y}$ sinterizada entre $1650^{\circ} \mathrm{C}$ e $1900^{\circ} \mathrm{C}$ também apresentou a fase YAG (Tabela 3.3), mas a fase YAP foi identificada na referida amostra sinterizada a $1950^{\circ} \mathrm{C}$ e $2000^{\circ} \mathrm{C}$. A amostra $4 \mathrm{Y}$ sinterizada a $1650^{\circ} \mathrm{C}$ e $1700^{\circ} \mathrm{C}$ apresentou em ordem de preponderância as fases YAG, YAM e YAP (Tabela 3.3). Porém, o aumento da temperatura de sinterização causou uma inversão na ordem de preponderância das segundasfases identificadas na amostra $4 \mathrm{Y}$. Esta amostra sinterizada a $1750^{\circ} \mathrm{C}$ apresentou maior quantidade da fase YAP, seguida por YAG e YAM (Tabela 3.3). Quando sinterizada entre $1800^{\circ} \mathrm{C}$ e $1900^{\circ} \mathrm{C}$, apresentou em ordem de preponderância as fases YAP e YAG (Tabela 3.3), mas somente a fase YAP foi identificada após a sinterização nas temperaturas de $1950^{\circ} \mathrm{C}$ e $2000^{\circ} \mathrm{C}$. Embora a fase YAP seja estável somente entre $1835^{\circ} \mathrm{C}$ e $1865^{\circ} \mathrm{C}$ (Fig. 3.1), esta segunda-fase é freqüentemente identificada em amostras de $\mathrm{AlN}$ com $\mathrm{Y}_{2} \mathrm{O}_{3}$. ${ }^{37,38,56}$

Os resultados de DRX mostraram uma tendência para formar fases mais ricas em $\mathrm{Y}_{2} \mathrm{O}_{3}$ com o aumento da temperatura de sinterização, principalmente acima de $1850^{\circ} \mathrm{C}$. Isto pode 
estar relacionado com a evaporação de compostos durante a sinterização em altas temperaturas $\left(>1850^{\circ} \mathrm{C}\right)$. No entanto, as três amostras apresentaram perda de massa menor ou igual a $0,8 \%$ entre $1650^{\circ} \mathrm{C}$ e $2000^{\circ} \mathrm{C}$.
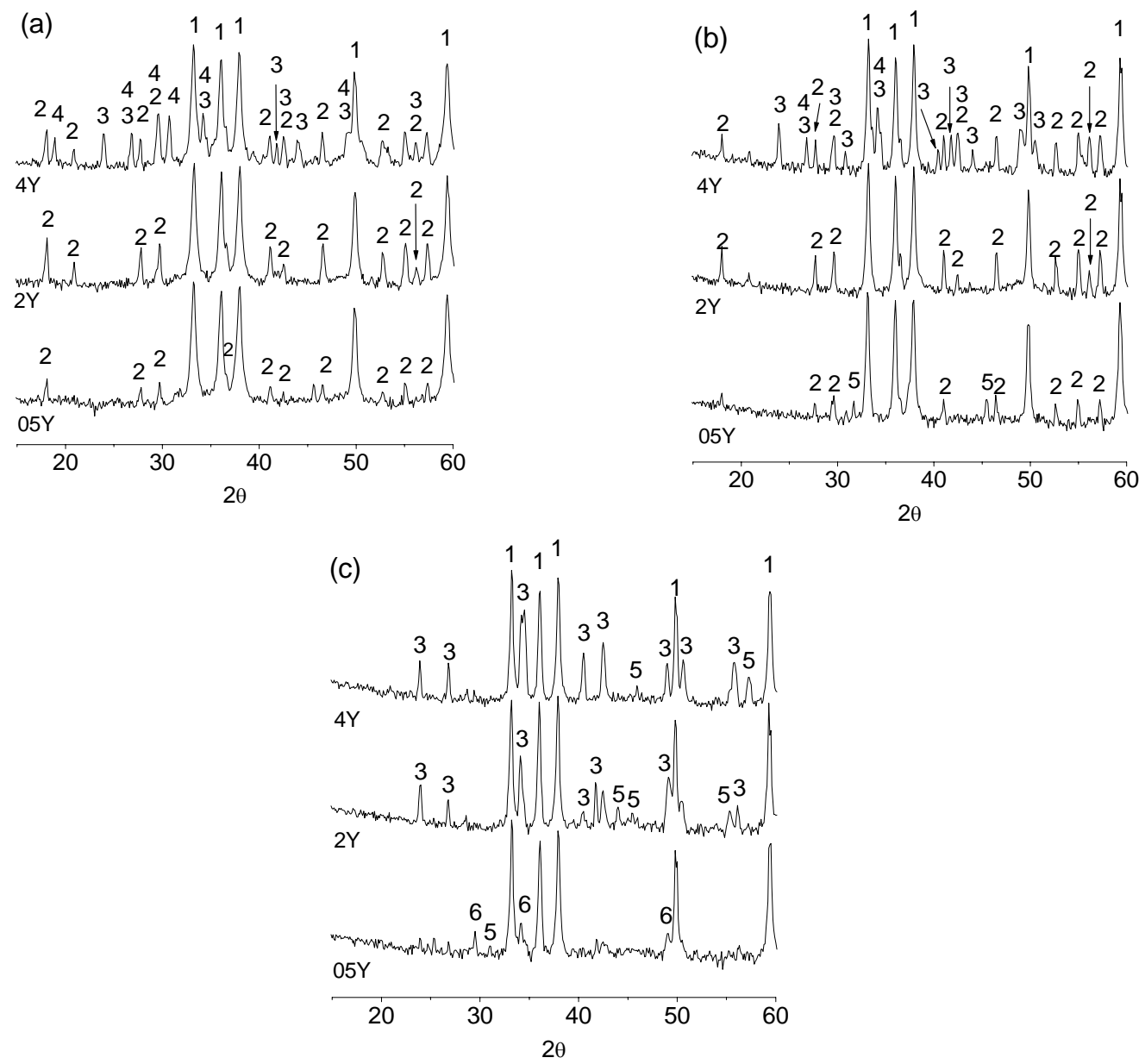

Figura 3.6 - Difratogramas de raios $\mathrm{X}$ das amostras $05 \mathrm{Y}, 2 \mathrm{Y}$ e $4 \mathrm{Y}$ sinterizadas a $1650^{\circ} \mathrm{C}$ (a), $1750^{\circ} \mathrm{C}$ (b) e $2000^{\circ} \mathrm{C}$ (c). Fases cristalinas: (1) AlN, (2) $\mathrm{YAG}\left[3 \mathrm{Y}_{2} \mathrm{O}_{3} \cdot 5 \mathrm{Al}_{2} \mathrm{O}_{3}\right]$, (3) $\mathrm{YAP}\left[\mathrm{Y}_{2} \mathrm{O}_{3} \cdot \mathrm{Al}_{2} \mathrm{O}_{3}\right]$, (4) $\mathrm{YAM}$ $\left[2 \mathrm{Y}_{2} \mathrm{O}_{3} \cdot \mathrm{Al}_{2} \mathrm{O}_{3}\right]$, (5) não identificada e (6) $\mathrm{Y}_{2} \mathrm{O}_{3}$.

Tabela 3.3 - Resultados de DRX das segundas-fases nas amostras de AlN com $\mathrm{Y}_{2} \mathrm{O}_{3}$.

\begin{tabular}{c|c|c|c}
\hline $\begin{array}{c}\text { Temperatura } \\
(\mathbf{(} \mathbf{C})\end{array}$ & \multicolumn{3}{|c}{ Segundas-fases em ordem de preponderância } \\
\cline { 2 - 4 } & $\mathbf{0 5 Y}$ & $\mathbf{2 Y}$ & $\mathbf{4 Y}$ \\
\hline $\mathbf{1 6 5 0}$ & YAG & YAG & YAG, YAM, YAP \\
\hline $\mathbf{1 7 0 0}$ & YAG & YAG & YAG, YAM, YAP \\
\hline $\mathbf{1 7 2 5}$ & YAG & YAG & Não analisada \\
\hline $\mathbf{1 7 5 0}$ & YAG & YAG & YAP, YAG, YAM \\
\hline $\mathbf{1 8 0 0}$ & YAG & YAG & YAP, YAG \\
\hline $\mathbf{1 8 5 0}$ & YAG & YAG & YAP, YAG \\
\hline $\mathbf{1 9 0 0}$ & YAG & YAG & YAP, YAG \\
\hline $\mathbf{1 9 5 0}$ & YAG & YAP & YAP \\
\hline $\mathbf{2 0 0 0}$ & $\mathrm{Y}_{2} \mathrm{O}_{3}$ & YAP & YAP \\
\hline
\end{tabular}




\subsubsection{Análise microestrutural}

Os resultados apresentados neste tópico são provenientes da caracterização do AlN sem e com $\mathrm{Y}_{2} \mathrm{O}_{3}$ sinterizado em forno convencional. $\mathrm{O}$ AlN sem aditivo sinterizado entre $1650^{\circ} \mathrm{C}$ e $1850^{\circ} \mathrm{C}$ apresentou pouca densificação (Figs. 3.7a e 3.7b), onde se observou somente a formação de pescoço entre as partículas primárias. Este tipo de morfologia microestrutural é peculiar do estágio inicial da sinterização no estado sólido. Mesmo na faixa de temperatura em que ocorreu uma significativa densificação $\left(>1850^{\circ} \mathrm{C}\right.$, Fig. 3.4), não se observaram evidências de formação de fase líquida durante a sinterização do AlN sem aditivo (Fig. 3.7c). Os grãos de AlN começaram a crescer de forma mais significativa acima de $1850^{\circ} \mathrm{C}$.
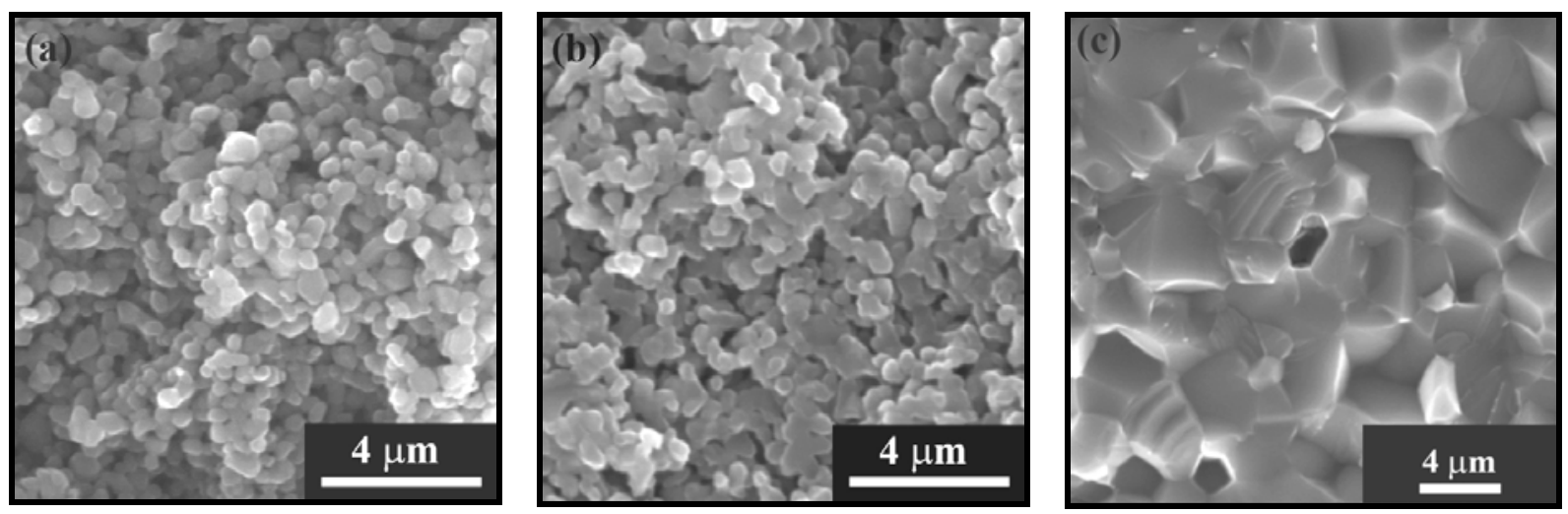

Figura 3.7 - Imagens de MEV da superfície de fratura do AlN sem aditivo sinterizado a $1650^{\circ} \mathrm{C}(\mathrm{a}), 1850^{\circ} \mathrm{C}$ (b) e $2000^{\circ} \mathrm{C}(\mathrm{c})$ por $1 \mathrm{~h}$.

$\mathrm{O}$ AlN com $\mathrm{Y}_{2} \mathrm{O}_{3}$ sinterizado até $1700^{\circ} \mathrm{C}$ apresentou apenas formação de pescoço entre as partículas primárias (Figs. 3.8a a 3.8d), sendo tal morfologia similar àquela observada para o AlN sem aditivo sinterizado até $1850^{\circ} \mathrm{C}$ (Fig. 3.7b). Esta característica microestrutural indicou que a densificação do $\mathrm{AlN}$ com $\mathrm{Y}_{2} \mathrm{O}_{3}$ ocorreu por sinterização no estado sólido até $1700^{\circ} \mathrm{C}$. A presença de poros interconectados (Figs. 3.8b e 3.8d) é outro forte indicativo de que a densificação parcial do $\mathrm{AlN}$ com $\mathrm{Y}_{2} \mathrm{O}_{3}$ ocorreu por sinterização no estado sólido. As imagens de $\mathrm{MEV}$, com maior magnitude, mostraram uma coesão significativa entre as partículas primárias (Figs. 3.8b e 3.8d), o que indicou uma expressiva densificação por sinterização no estado sólido. As amostras $05 \mathrm{Y}, 2 \mathrm{Y}$ e $4 \mathrm{Y}$ sinterizadas até $1700^{\circ} \mathrm{C}$ apresentaram partículas de segundas-fases dispersas pela microestrutura (Figs. 3.8b e 3.8d), cuja quantidade aumentou em função do aumento do teor de $\mathrm{Y}_{2} \mathrm{O}_{3}$. Estas partículas de 
segundas-fases tiveram larga distribuição de tamanho (Figs. 3.8b e 3.8d), pois se observaram partículas com tamanho da ordem de nanômetros até cerca de $3 \mu \mathrm{m}$. As partículas de segundas-fases foram constituídas por oxigênio $(\mathrm{O})$, alumínio (Al) e ítrio (Y) (Fig. 3.8e), indicando serem partículas de aluminato de ítrio. Este resultado está de acordo com os resultados de DRX (Tabela 3.3).
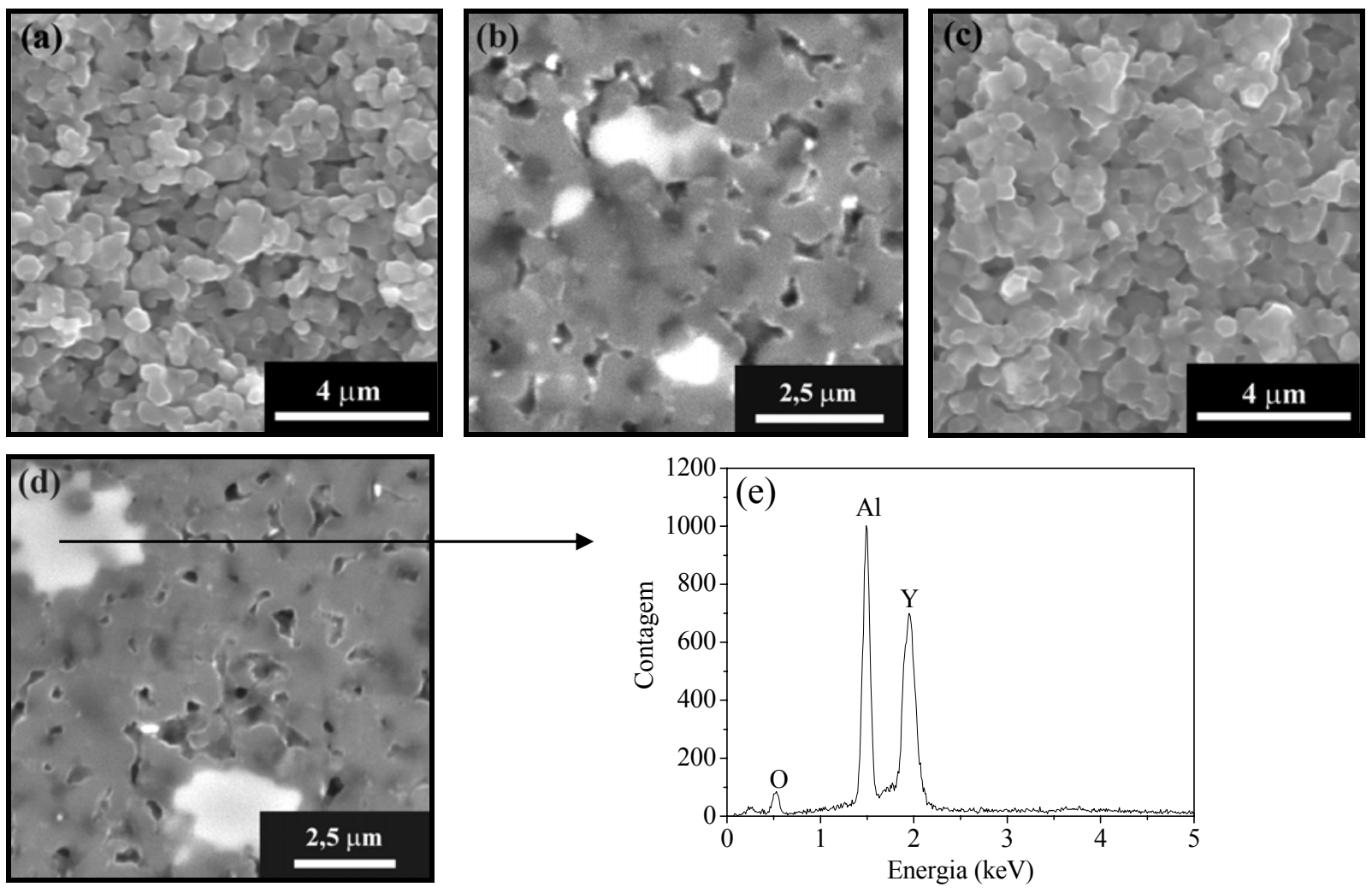

Figura 3.8 -Imagens de MEV de amostras sinterizadas a $1700^{\circ} \mathrm{C}$ por $1 \mathrm{~h}$ : (a) superfície de fratura e (b) superfície polida da amostra $05 \mathrm{Y}$, (c) superfície de fratura e (d) superfície polida da amostra 4Y, e (e) espectro da análise por EDS realizada em uma das partículas claras da Figura 3.8d. As regiões claras nas Figuras 3.8b e $3.8 \mathrm{~d}$ são partículas de segundas-fases.

Aglomerados densos de partículas foram observados nas amostras 05Y, 2Y e 4Y sinterizadas a $1725^{\circ} \mathrm{C}$ por 1 min (Fig. 3.9a), cuja quantidade aumentou levemente em função do teor de $\mathrm{Y}_{2} \mathrm{O}_{3}$. A presença destes aglomerados de partículas indicou a ocorrência de formação de fase líquida, que ativou o mecanismo de rearranjo de partículas da sinterização via fase líquida. A $1725^{\circ} \mathrm{C}$, o aumento do tempo de sinterização (1 para 60 minutos) promoveu rápida densificação nas amostras com $\mathrm{Y}_{2} \mathrm{O}_{3}$ (Figs. 3.9a e 3.9b). As amostras $05 \mathrm{Y}$ e 4Y alcançaram quase completa densificação a $1750^{\circ} \mathrm{C}$ (Figs. 3.4 e $3.9 \mathrm{c}$ ), o que mostrou a necessidade de um pequeno superaquecimento, acima da sua temperatura de formação de fase 
líquida, para promover a densificação do $\mathrm{AlN}$ com $\mathrm{Y}_{2} \mathrm{O}_{3}$. Entretanto, a amostra $2 \mathrm{Y}$ teve uma densificação levemente atrasada em relação às demais amostras com $\mathrm{Y}_{2} \mathrm{O}_{3}$ (Fig. 3.4).
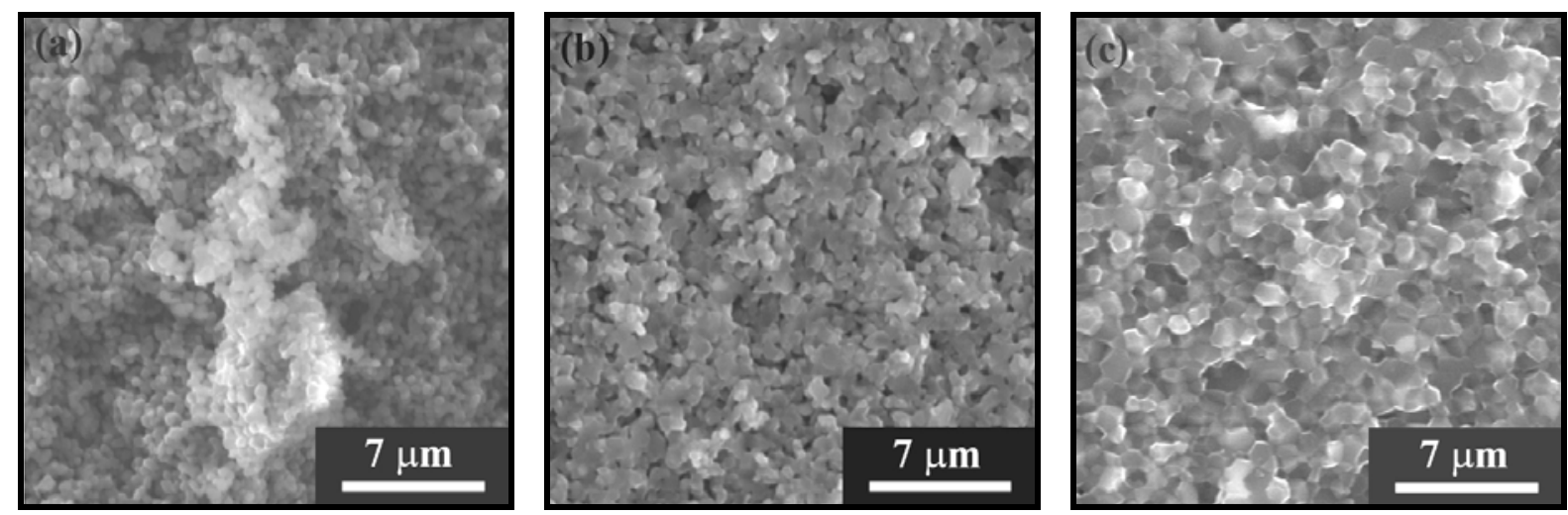

Figura 3.9-Imagens de MEV da superfície de fratura das amostras com $\mathrm{Y}_{2} \mathrm{O}_{3}$ sinterizadas em várias temperaturas: (a) amostra $05 \mathrm{Y}-1725^{\circ} \mathrm{C} / 1 \mathrm{~min}$, (b) amostra $05 \mathrm{Y}-1725^{\circ} \mathrm{C} / 1 \mathrm{~h}$ e (c) amostra $4 \mathrm{Y}-1750^{\circ} \mathrm{C} / 1 \mathrm{~h}$.

A amostra $05 \mathrm{Y}$ sinterizada acima de $1700^{\circ} \mathrm{C}$ não apresentou partículas grandes de segundas-fases (Figs. 3.8b e 3.10a). Pequenos poros residuais foram observados na amostra $05 \mathrm{Y}$ sinterizada a $1750^{\circ} \mathrm{C}$ (Fig. 3.10a). Estes poros residuais, praticamente, não foram observados acima de $1750^{\circ} \mathrm{C}$ (Figs. $3.10 \mathrm{~b}$ e $3.10 \mathrm{c}$ ), mas observaram-se pequenas partículas de segundas-fases localizadas preferencialmente nas junções de três grãos.
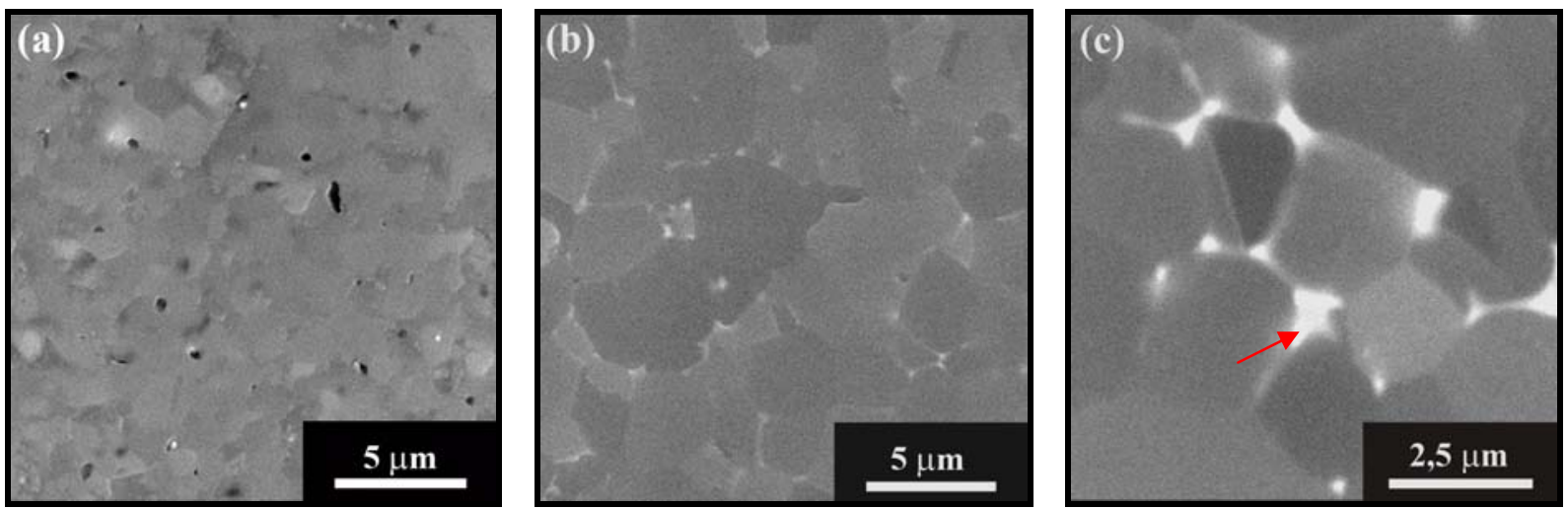

Figura 3.10 - Imagens de MEV da superfície polida da amostra $05 \mathrm{Y}$ sinterizada em várias temperaturas por $1 \mathrm{~h}$ : (a) $1750^{\circ} \mathrm{C}$; (b) $1850^{\circ} \mathrm{C}$; e (c) $1900^{\circ} \mathrm{C}$. A seta indica uma partícula pequena de segunda-fase.

A amostra $05 \mathrm{Y}$ apresentou grãos facetados com alto ângulo diedro após sua completa densificação (Figs. 3.10), o que sugeriu a presença de fase líquida com más características de molhamento e espalhamento durante a sinterização. Embora estes resultados levem à indicação de que a sinterização foi afetada pelas características de molhamento e espalhamento da fase líquida, a amostra $05 \mathrm{Y}$ apresentou rápida densificação após a formação 
de fase líquida (Figs. 3.9a e 3.10a), isto é, atingiu quase completa densificação com um superaquecimento próximo de $25^{\circ} \mathrm{C}$ acima da temperatura em que se observaram evidências de formação de fase líquida $\left(1725^{\circ} \mathrm{C}\right.$, Fig. 3.9a).

Partículas de segundas-fases foram observadas nas amostras $2 \mathrm{Y}$ e $4 \mathrm{Y}$ sinterizadas entre $1650^{\circ} \mathrm{C}$ e $1800^{\circ} \mathrm{C}$ (Figs. 3.8d e 3.11a), cuja quantidade aumentou levemente em função do teor de $\mathrm{Y}_{2} \mathrm{O}_{3}$. Esta morfologia microestrutural também foi observada em amostras de AlN preparadas com $\mathrm{Y}_{2} \mathrm{O}_{3}$ ou óxidos de terras raras. ${ }^{23,37,47,54}$ Alguns autores ${ }^{37,39}$ indicaram que estas partículas de segundas-fases se formaram em decorrência da alta viscosidade e/ou baixa molhabilidade da fase líquida presente durante a sinterização do AlN. As partículas grandes de segundas-fases não foram observadas nas amostras $2 \mathrm{Y}$ e $4 \mathrm{Y}$ sinterizadas acima de $1800^{\circ} \mathrm{C}$ (Figs. 3.11a e 3.11b), mas pequenas partículas de segundas-fases foram observadas nas regiões de contorno de grão. Estes resultados indicaram que houve uma mudança no comportamento de viscosidade e/ou molhabilidade das segundas-fases com formato de partícula acima de $1800^{\circ} \mathrm{C}$, o que favoreceu o seu espalhamento por entre os grãos de AlN.
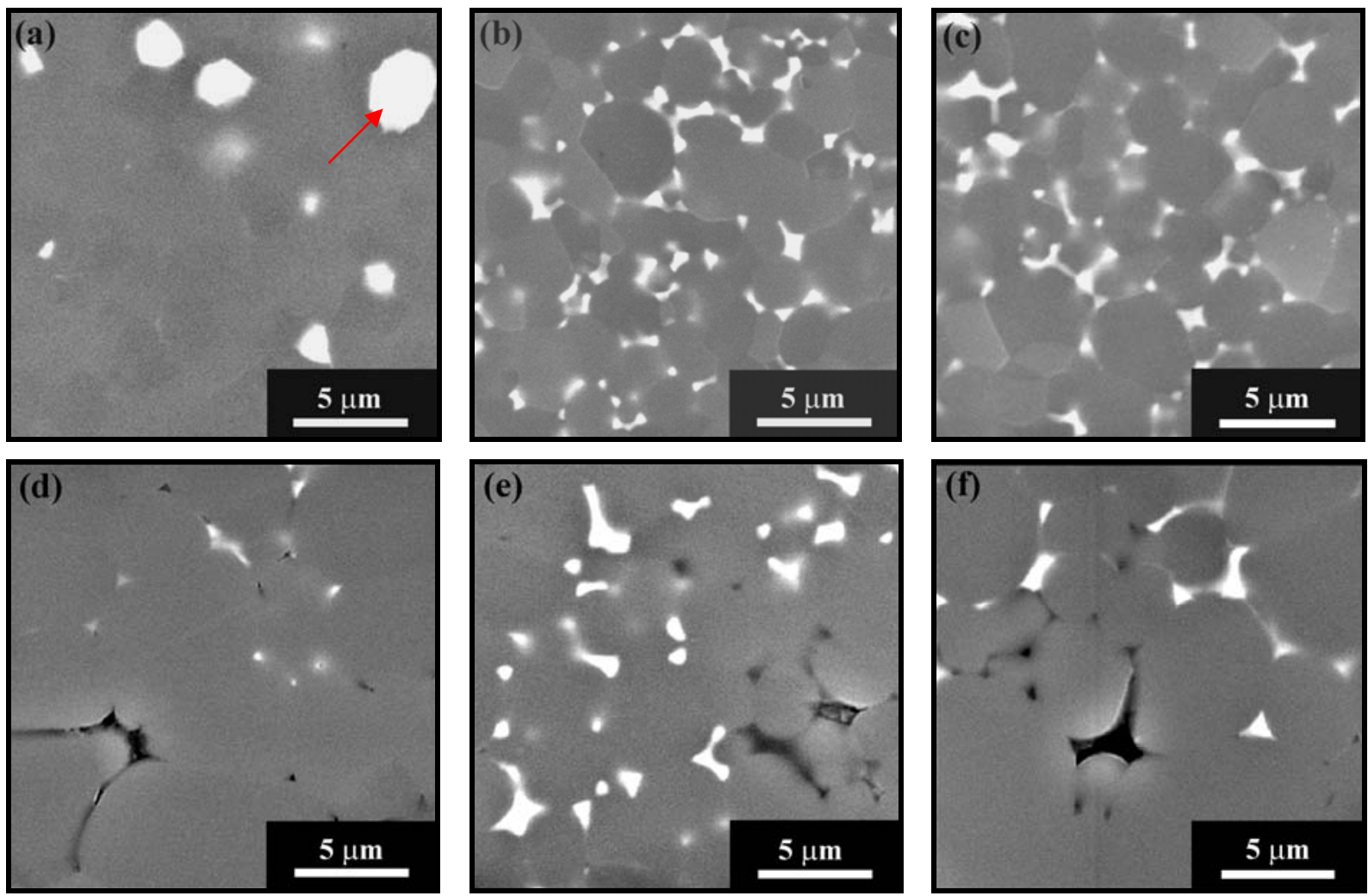

Figura 3.11 - Imagens de MEV da superfície polida das amostras de $\mathrm{AlN}$ com $\mathrm{Y}_{2} \mathrm{O}_{3}$ sinterizadas em várias temperaturas por $1 \mathrm{~h}$ : (a) amostra $2 \mathrm{Y}-1800^{\circ} \mathrm{C}$; (b) amostra $4 \mathrm{Y}-1850^{\circ} \mathrm{C}$; (c) amostra $4 \mathrm{Y}-1900^{\circ} \mathrm{C}$; (d) amostra $05 \mathrm{Y}-1950^{\circ} \mathrm{C}$; (e) amostra $4 \mathrm{Y}-1950^{\circ} \mathrm{C}$; e (f) amostra $2 \mathrm{Y}-2000^{\circ} \mathrm{C}$. A seta indica uma partícula grande de segunda-fase. 
O espalhamento da fase líquida proveniente das segundas-fases com formato de partículas não levou à formação de poros grandes até $1900^{\circ} \mathrm{C}$ (Figs. 3.11a a 3.11c). Porém, acima desta temperatura de sinterização, as três amostras com $\mathrm{Y}_{2} \mathrm{O}_{3}$ apresentaram poros na região de contorno de grão (Figs. 3.11d a 3.11f). A formação destes poros sugeriu que as segundas-fases de contorno de grão evaporaram gradativamente com o aumento da temperatura de sinterização $\left(\geq 1900^{\circ} \mathrm{C}\right)$. Os resultados de DRX mostraram uma tendência para formar fases mais ricas em $\mathrm{Y}_{2} \mathrm{O}_{3}$ acima de $1850^{\circ} \mathrm{C}$ (Tabela 3.3), indicando uma evaporação preferencial de $\mathrm{Al}_{2} \mathrm{O}_{3}$ das fases de aluminato de ítrio. Isto reforça a interpretação de que ocorreu evaporação de segundas-fases de contorno de grão durante a sinterização em alta temperatura $\left(>1850^{\circ} \mathrm{C}\right)$.

As amostras $2 \mathrm{Y}$ e $4 \mathrm{Y}$ sinterizadas a $1750^{\circ} \mathrm{C}$ e $1800^{\circ} \mathrm{C}$ apresentaram grãos facetados com alto ângulo diedro. Porém, a morfologia dos grãos mudou gradativamente de facetada para arredondada (Fig. 3.11), principalmente após o espalhamento da fase líquida oriunda das partículas grandes de segundas-fases. Os grãos continuaram facetados e com alto ângulo diedro nas regiões com pouca concentração de segundas-fases de contornos de grão. $\mathrm{O}$ arredondamento dos grãos ocorreu principalmente nas regiões com alta concentração de segundas-fases de contornos de grão.

\subsubsection{Efeito do carbono na densificação do $\mathrm{AIN} \operatorname{com} \mathrm{Y}_{2} \mathrm{O}_{3}$}

Neste tópico, estudou-se o efeito da formação in situ de uma atmosfera redutora com carbono (C) no interior do corpo conformado de AlN sinterizado sob atmosfera inerte de gás nitrogênio. Um teor de $4 \%$ de $\mathrm{Y}_{2} \mathrm{O}_{3}$ foi estabelecido e, então, prepararam-se amostras com adições de $0,5 \%$ e $1 \%$ de $\mathrm{C}$ (amostras 4Y05C e 4Y1C, respectivamente). Os resultados da amostra $4 \mathrm{Y}\left(4 \%\right.$ de $\left.\mathrm{Y}_{2} \mathrm{O}_{3}\right)$ foram usados como referência $(0 \%$ de $\mathrm{C})$.

\subsubsection{Densificação}

A adição de $0,5 \%$ de C (amostra 4Y05C) limitou a densificação da amostra 4Y entre $1650^{\circ} \mathrm{C}$ e $1750^{\circ} \mathrm{C}$ (Fig. 3.12), enquanto a adição de $1 \%$ de $\mathrm{C}$ (amostra 4Y1C) inibiu a ação 
efetiva do $\mathrm{Y}_{2} \mathrm{O}_{3}$ em promover densificação no AlN nesta faixa de temperatura. A amostra 4Y1C apresentou densidade (Fig. 3.12) próxima daquela observada para o AlN sem aditivo após a sinterização entre $1650^{\circ} \mathrm{C}$ e $1750^{\circ} \mathrm{C}$ (Fig. 3.4). Porém, a amostra $4 \mathrm{Y} 1 \mathrm{C}$ e, também, a amostra 4Y05C atingiram quase completa densificação após a sinterização na temperatura de $1800^{\circ} \mathrm{C}$ ( $\sim 99 \%$ DT, Fig. 3.12). Isto mostrou que o aumento de temperatura minimizou o efeito prejudicial do $\mathrm{C}$ na densificação do $\mathrm{AlN} \operatorname{com} \mathrm{Y}_{2} \mathrm{O}_{3}$. $\mathrm{O}$ aumento da temperatura de sinterização de $1800^{\circ} \mathrm{C}$ para $1850^{\circ} \mathrm{C}$ não mudou o comportamento de densificação da amostra 4Y05C ( 99\% DT, Fig. 3.12), mas causou uma diminuição significativa de densidade na amostra 4 Y 1C ( $\sim 98 \%$ para $\sim 90 \%$ DT).

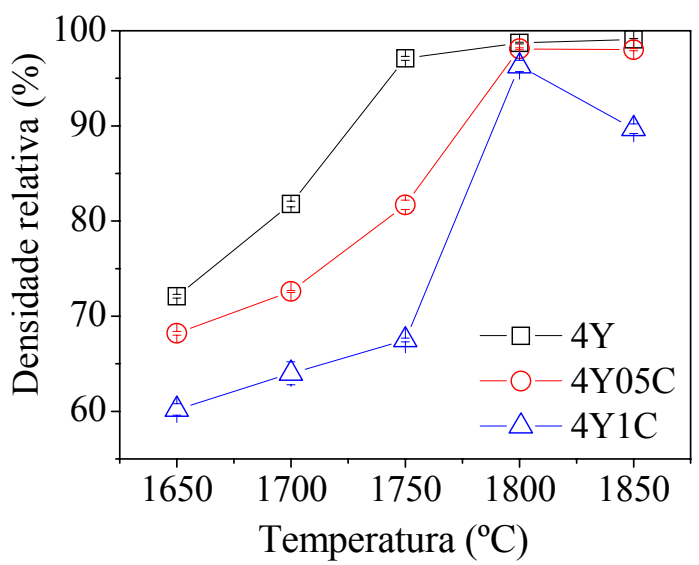

Figura 3.12 - Densidade relativa em função da temperatura de sinterização das amostras 4Y, 4Y05C e 4Y1C.

\subsubsection{Perda de massa e evolução das segundas-fases}

A amostra $4 \mathrm{Y}$ sinterizada entre $1650^{\circ} \mathrm{C}$ e $1850^{\circ} \mathrm{C}$ apresentou perda de massa abaixo de 1\% (Fig. 3.13), o que indicou a ocorrência de pouca evaporação de compostos durante sinterização sob atmosfera não redutora. Já as amostras 4Y05C e 4Y1C sinterizadas entre $1650^{\circ} \mathrm{C}$ e $1850^{\circ} \mathrm{C}$ apresentaram perdas de massa significativamente maiores do que a amostra 4Y (Fig. 3.13). Isto mostrou que a formação de uma atmosfera redutora com $\mathrm{C}$ causou uma evaporação significativa de compostos durante as sinterizações do $\mathrm{AlN}$ com $\mathrm{Y}_{2} \mathrm{O}_{3}$. A amostra 4Y05C sinterizada entre $1650^{\circ} \mathrm{C}$ e $1850^{\circ} \mathrm{C}$ apresentou valores de perda de massa na faixa de 2,8\% a 3,7\% (Fig. 3.13). Estes valores de perda de massa foram maiores do que o valor de perda teórica de $\mathrm{CO}_{2}$ proveniente da reação de desoxidação de $0,5 \%$ de $\mathrm{C}(\sim 2 \%)^{* *}$. Já a

${ }^{* *} \mathrm{C}+\mathrm{O}_{2} \leftrightarrow \mathrm{CO}_{2}$ 
amostra 4Y1C apresentou valores de perda de massa (3,3\% a 4\%, Fig. 3.13) abaixo ou próximos do valor de perda teórica de $\mathrm{CO}_{2}$ proveniente da reação de desoxidação de $1 \%$ de $\mathrm{C}$ $(\sim 4 \%)$. Estes resultados indicaram que a adição de $C$ causou uma diminuição significativa na fração de segunda-fase líquida presente durante a sinterização do AlN com 4\% de $\mathrm{Y}_{2} \mathrm{O}_{3}$. Após a sinterização na temperatura de $1800^{\circ} \mathrm{C}$, as amostras com $\mathrm{C}$ apresentaram valores próximos de perda de massa (Fig. 3.13), fato que não aconteceu nas demais temperaturas de sinterização. Isto pode ter influenciado o comportamento de densificação das amostras com C, pois as duas amostras atingiram valores próximos de densidade somente na temperatura de $1800^{\circ} \mathrm{C}$ (Fig. 3.12).

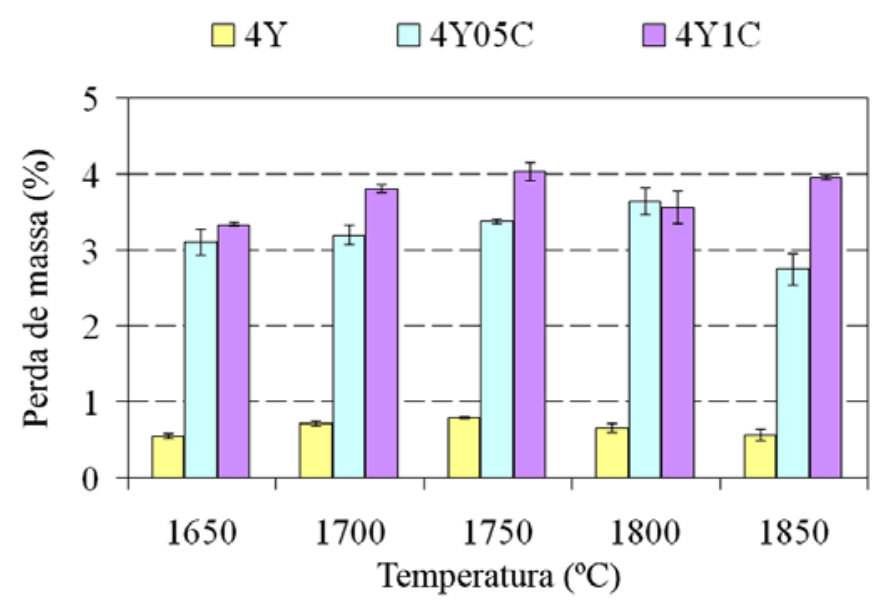

Figura 3.13 - Perda de massa em função da temperatura de sinterização das amostras 4Y, 4Y05C e 4Y1C.

Os resultados de DRX das amostras 4Y, 4Y05C e 4Y1C sinterizadas entre $1650^{\circ} \mathrm{C}$ e $1850^{\circ} \mathrm{C}$ são apresentados na Tabela 3.4. A adição de $\mathrm{C}$ levou à formação de segundas-fases ricas em $\mathrm{Y}_{2} \mathrm{O}_{3}$ em relação à amostra $4 \mathrm{Y}$ (Tabela 3.4). A amostra 4Y05C apresentou em ordem de preponderância as fases $\mathrm{YAM}$ e $\mathrm{Y}_{2} \mathrm{O}_{3}$ entre $1650^{\circ} \mathrm{C}$ e $1750^{\circ} \mathrm{C}$. Já a amostra $4 \mathrm{Y} 1 \mathrm{C}$ apresentou em ordem de preponderância as fases $\mathrm{Y}_{2} \mathrm{O}_{3}$ e $\mathrm{YN}$ (Tabela 3.4), mostrando que a adição de $1 \%$ de $\mathrm{C}$ inibiu a formação de aluminatos de ítrio entre $1650^{\circ} \mathrm{C}$ e $1750^{\circ} \mathrm{C}$. Estes resultados indicaram que aconteceu uma evaporação preferencial de $\mathrm{Al}_{2} \mathrm{O}_{3}$ durante a sinterização até pelo menos $1750^{\circ} \mathrm{C}$. Isto está de acordo como os resultados de perda de massa (Fig. 3.13), que indicaram uma evaporação significativa de compostos durante a sinterização das amostras 4Y05C e 4Y1C. O aumento de temperatura de sinterização, acima de $1750^{\circ} \mathrm{C}$, levou somente à formação da fase YAP na amostra 4Y05C (Tabela 3.4). A amostra 4Y1C sinterizada a $1800^{\circ} \mathrm{C}$ apresentou em ordem de preponderância as fases YAP e $\mathrm{Y}_{2} \mathrm{O}_{3}$ (Tabela 3.4). Porém, esta amostra voltou a formar as fases $\mathrm{Y}_{2} \mathrm{O}_{3}$ e $\mathrm{YN}$ após a sinterização na 
temperatura de $1850^{\circ} \mathrm{C}$. Estes resultados indicaram que a amostra $4 \mathrm{Y} 1 \mathrm{C}$ sinterizada a $1800^{\circ} \mathrm{C}$ apresentou uma mudança significativa na sua evolução de segundas-fases (Tabela 3.4), pois aconteceu a formação de uma fase de aluminato de ítrio. Nesta temperatura de sinterização, as duas amostras com $\mathrm{C}$ atingiram valores de densidade próximos daquele observado para a amostra sem $\mathrm{C}$ (Fig. 3.12). Isto indicou que a densificação do AlN com $\mathrm{Y}_{2} \mathrm{O}_{3}$ foi favorecida pela formação de aluminatos de ítrio mais ricos em $\mathrm{Al}_{2} \mathrm{O}_{3}$.

Tabela 3.4 - Resultados de DRX das segundas-fases nas amostras 4Y, 4Y05C e 4Y1C.

\begin{tabular}{c|c|c|c}
\hline \multirow{2}{*}{ Temperatura $\left({ }^{\circ} \mathbf{C}\right)$} & \multicolumn{3}{|c}{ Segundas-fases em ordem de preponderância } \\
\cline { 2 - 4 } & $\mathbf{4 Y}$ & 4Y05C & 4Y1C \\
\hline $\mathbf{1 6 5 0}$ & YAG, YAM, YAP & YAM, $\mathrm{Y}_{2} \mathrm{O}_{3}$ & $\mathrm{Y}_{2} \mathrm{O}_{3}, \mathrm{YN}$ \\
\hline $\mathbf{1 7 0 0}$ & YAG, YAM, YAP & YAM, $\mathrm{Y}_{2} \mathrm{O}_{3}$ & $\mathrm{Y}_{2} \mathrm{O}_{3}, \mathrm{YN}$ \\
\hline $\mathbf{1 7 5 0}$ & YAP, YAG, YAM & YAM, $\mathrm{Y}_{2} \mathrm{O}_{3}$ & $\mathrm{Y}_{2} \mathrm{O}_{3}, \mathrm{YN}$ \\
\hline $\mathbf{1 8 0 0}$ & YAP, YAG & YAP & $\mathrm{YAP}_{2} \mathrm{Y}_{2} \mathrm{O}_{3}$ \\
\hline $\mathbf{1 8 5 0}$ & YAP, YAG & YAP & $\mathrm{Y}_{2} \mathrm{O}_{3}, \mathrm{YN}$ \\
\hline
\end{tabular}

Note: $\mathrm{YAG}\left(3 \mathrm{Y}_{2} \mathrm{O}_{3} \cdot 5 \mathrm{Al}_{2} \mathrm{O}_{3}\right)$, YAM $\left(2 \mathrm{Y}_{2} \mathrm{O}_{3} \cdot \mathrm{Al}_{2} \mathrm{O}_{3}\right)$ e $\mathrm{YAP}\left(\mathrm{Y}_{2} \mathrm{O}_{3} \cdot \mathrm{Al}_{2} \mathrm{O}_{3}\right)$.

\subsubsection{Análise microestrutural}

As amostras $4 \mathrm{Y} 05 \mathrm{C}$ e $4 \mathrm{Y} 1 \mathrm{C}$ sinterizadas a $1750^{\circ} \mathrm{C}$ apresentaram microestruturas com poros tendendo a forma alongada (Fig. 3.14a), cuja porosidade aumentou em função do teor de C. A presença de poros interconectados sugeriu que a densificação destas amostras aconteceu por sinterização no estado sólido até $1750^{\circ} \mathrm{C}$. Como a amostra $4 \mathrm{Y}$ sinterizada a $1750^{\circ} \mathrm{C}$ apresentou uma microestrutura praticamente densa (Fig. 3.9c), pode-se dizer que a adição de $\mathrm{C}$ retardou a densificação, isto é, aumentou a temperatura de sinterização do AlN com $\mathrm{Y}_{2} \mathrm{O}_{3}$. As amostras com $\mathrm{C}$ sinterizadas a $1800^{\circ} \mathrm{C}$ apresentaram microestruturas praticamente densas (Figs. 3.14b e 3.14c). Isto mostrou que o aumento da temperatura de sinterização minimizou o efeito prejudicial do $\mathrm{C}$ na densificação do $\mathrm{AlN}$ com $\mathrm{Y}_{2} \mathrm{O}_{3}$. Porém, estas amostras apresentaram uma pequena quantidade de poros residuais (Figs. 3.14b e 3.14c), cuja fração foi maior nas amostras com maior teor de C. Isto explica a pequena diferença de densidade entre as amostras sinterizadas a $1800^{\circ} \mathrm{C}$ (Fig. 3.12).

A microestrutura da amostra 4Y05C permaneceu densa com o aumento da temperatura de sinterização de $1800^{\circ} \mathrm{C}$ para $1850^{\circ} \mathrm{C}$. Já a microestrutura da amostra $4 \mathrm{Y} 1 \mathrm{C}$ apresentou um 
aumento significativo de porosidade com o aumento da temperatura de $1800^{\circ} \mathrm{C}$ para $1850^{\circ} \mathrm{C}$ (Figs. 3.14c e 3.14d, respectivamente), o que resultou na diminuição significativa de densidade nesta faixa de temperatura (Fig. 3.12). A presença de poros interconectados (Fig. 3.14d) sugeriu que a densificação da amostra 4Y1C ocorreu por sinterização no estado sólido na temperatura de $1850^{\circ} \mathrm{C}$. Supondo que não houve formação de fase líquida durante a sinterização na temperatura de $1850^{\circ} \mathrm{C}$, pode-se dizer que a amostra $4 \mathrm{Y} 1 \mathrm{C}$ atingiu $78 \%$ de densificação total por sinterização no estado sólido (Fig. 3.12). Estes resultados indicaram que o AlN com $\mathrm{Y}_{2} \mathrm{O}_{3}$ pode atingir uma densificação significativa por sinterização no estado sólido, mas completa densificação pode acontecer somente com a formação de fase líquida proveniente da fusão dos aluminatos de ítrio.
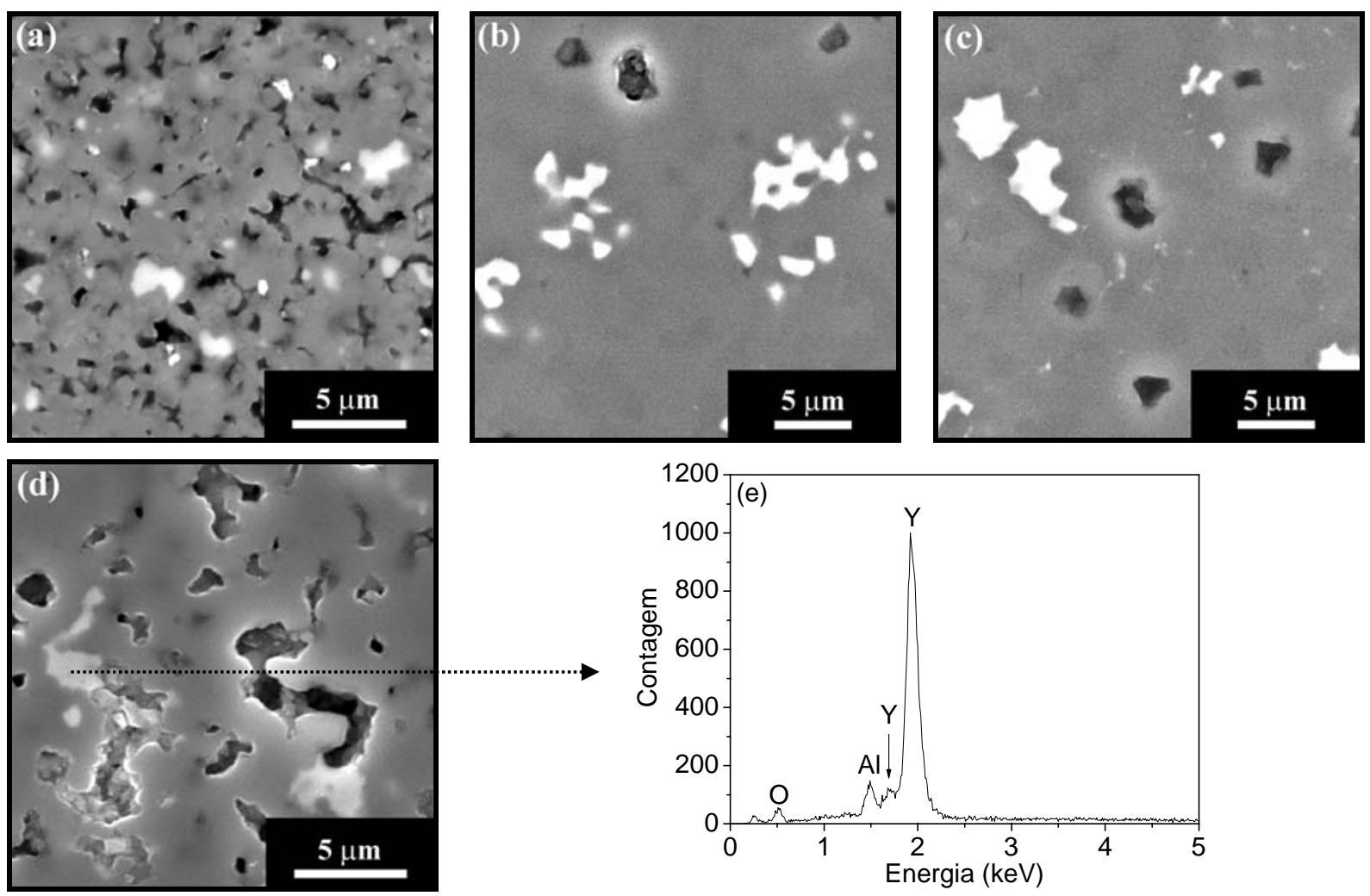

Figura 3.14 - Imagens de MEV da superfície polida das amostras sinterizadas em várias temperaturas por $1 \mathrm{~h}$ : (a) $4 \mathrm{Y} 05 \mathrm{C}-1750^{\circ} \mathrm{C}$, (b) $4 \mathrm{Y} 05 \mathrm{C}-1800^{\circ} \mathrm{C}$, (c) $4 \mathrm{Y} 1 \mathrm{C}-1800^{\circ} \mathrm{C}$, (d) $4 \mathrm{Y} 1 \mathrm{C}-1850^{\circ} \mathrm{C}$ e (e) espectro da análise por EDS realizada em uma das partículas de segundas-fases observadas na Figura 3.14d. As regiões claras observadas nas Figuras 3.14a a 3.14d são partículas de segundas-fases.

A amostra $4 \mathrm{Y} 05 \mathrm{C}$ sinterizada entre $1650^{\circ} \mathrm{C}$ e $1800^{\circ} \mathrm{C}$ apresentou partículas grandes de segundas-fases (Figs. 3.14a e 3.14b) compostas por oxigênio, alumínio e ítrio (espectro de EDS similar ao da Figura 3.8e). Isto indicou que estas partículas foram constituídas por aluminatos de ítrio, pois os resultados de DRX mostraram a presença de aluminatos de ítrio na 
amostra 4Y05C sinterizada entre $1650^{\circ} \mathrm{C}$ e $1850^{\circ} \mathrm{C}$ (Tabela 3.4). Estas partículas grandes de segundas-fases foram similares àquelas observadas nas amostras $2 \mathrm{Y}$ e $4 \mathrm{Y}$ sinterizadas entre $1650^{\circ} \mathrm{C}$ e $1800^{\circ} \mathrm{C}$ (Figs. 3.8b, 3.8d e 3.11a). As partículas grandes de segundas-fases desapareceram da microestrutura da amostra 4Y05C com o aumento da temperatura de sinterização de $1800^{\circ} \mathrm{C}$ para $1850^{\circ} \mathrm{C}$, mas surgiram partículas pequenas localizadas preferencialmente nas junções de três grãos. Estes resultados são similares àqueles observados nas amostras $2 \mathrm{Y}$ e $4 \mathrm{Y}$ sinterizadas acima de $1800^{\circ} \mathrm{C}$ (Figs. $3.11 \mathrm{a}$ e $3.11 \mathrm{~b}$ ).

Já a amostra $4 \mathrm{Y} 1 \mathrm{C}$ sinterizada entre $1650^{\circ} \mathrm{C}$ e $1750^{\circ} \mathrm{C}$ apresentou partículas grandes de segundas-fases com alto teor de ítrio $(\mathrm{Y})$ e baixos teores de oxigênio $(\mathrm{O})$ e alumínio (Al) (Fig. 3.14e). Estes resultados indicaram que estas partículas tiveram uma composição química diferente daquelas partículas observadas nas amostras 2Y, 4Y e 4Y05C (Fig. 3.8e). Isto sugeriu que as partículas grandes da amostra 4Y1C não foram constituídas por aluminatos de ítrio entre $1650^{\circ} \mathrm{C}$ e $1750^{\circ} \mathrm{C}$, o que está de acordo com os resultados de DRX (Tabela 3.4), que não mostraram fases de aluminato de ítrio na amostra $4 \mathrm{Y} 1 \mathrm{C}$ sinterizada abaixo de $1800^{\circ} \mathrm{C}$. Porém, a composição das partículas grandes de segundas-fases mudou com o aumento da temperatura de sinterização de $1750^{\circ} \mathrm{C}$ para $1800^{\circ} \mathrm{C}$ (Fig. $3.14 \mathrm{c}$ ), pois os espectros de EDS foram similares ao observado na Figura 3.8e, o que indicou a formação de aluminatos de ítrio. Isto está de acordo com os resultados de DRX da amostra 4Y1C (Tabela 3.4), que mostraram a presença da fase YAP na amostra sinterizada a $1800^{\circ} \mathrm{C}$. As partículas grandes de segundasfases permaneceram na microestrutura da amostra $4 \mathrm{Y} 1 \mathrm{C}$ sinterizada a $1850^{\circ} \mathrm{C}$ (Figs. $3.14 \mathrm{c} \mathrm{e}$ 3.14d), diferindo dos resultados observados para as amostras 2Y, 4Y e 4Y05C sinterizadas acima de $1800^{\circ} \mathrm{C}$ (Figs. 3.11a a 3.11c). Após a sinterização na temperatura de $1850^{\circ} \mathrm{C}$, as partículas grandes de segundas-fases da amostra 4Y1C apresentaram elevado teor de ítrio (Y) e baixos teores de oxigênio $(\mathrm{O})$ e alumínio (Al) (Fig. 3.14e). Isto mostrou que a composição das partículas de segundas-fases mudou novamente entre $1800^{\circ} \mathrm{C}$ e $1850^{\circ} \mathrm{C}$, o que está de acordo com os resultados de DRX da amostra 4Y1C (Tabela 3.4). Provavelmente, estas partículas ricas em $\mathrm{Y}_{2} \mathrm{O}_{3}$ permaneceram na microestrutura da amostra $4 \mathrm{Y} 1 \mathrm{C}$ sinterizada acima de $1800^{\circ} \mathrm{C}$ porque foram mais refratárias do que os aluminatos de ítrio. 


\subsection{Discussão dos resultados experimentais}

\subsubsection{Evolução das segundas-fases do sistema $\mathrm{AIN}-\mathrm{Y}_{2} \mathrm{O}_{3}$}

\section{Sob atmosfera inerte}

Alguns trabalhos ${ }^{51,66}$ têm sugerido que as composições dos aluminatos de ítrio variam em função da quantidade de aditivo de sinterização e do teor de oxigênio presente na superfície do pó de AlN. Com base nesta proposição, estimaram-se as composições iniciais das amostras $05 \mathrm{Y}, 2 \mathrm{Y}$ e $4 \mathrm{Y}$, que foram indicadas no diagrama de equilíbrio de fases do sistema $\mathrm{Y}_{2} \mathrm{O}_{3}-\mathrm{Al}_{2} \mathrm{O}_{3}$ (Fig. 3.1). As composições das amostras $05 \mathrm{Y}$ e $2 \mathrm{Y}$ ficaram dentro do campo YAG $+\alpha-\mathrm{Al}_{2} \mathrm{O}_{3}$, enquanto a composição da amostra $4 \mathrm{Y}$ ficou dentro do campo YAM + YAG. Como as sinterizações foram realizadas sob atmosfera não redutora (inerte), esperava-se que as composições das segundas-fases formadas durante a sinterização das amostras $05 \mathrm{Y}$ a $4 \mathrm{Y}$ permanecessem iguais ou próximas das composições inicias (Fig. 3.1). No caso das amostras $05 \mathrm{Y}$ e $2 \mathrm{Y}$, observou-se somente a fase YAG nas amostras sinterizadas entre $1650^{\circ} \mathrm{C}$ e $1900^{\circ} \mathrm{C}$ (Tabela 3.3). Estes resultados ficaram próximos das composições previstas para as amostras $05 \mathrm{Y}$ e $2 \mathrm{Y}$ (YAG e $\alpha-\mathrm{Al}_{2} \mathrm{O}_{3}$, Fig. 3.1). Provavelmente, a fase $\alpha-\mathrm{Al}_{2} \mathrm{O}_{3}$ não foi identificada porque seu teor ficou abaixo do limite de detecção do equipamento de DRX.

Já o aumento da temperatura de sinterização, acima de $1950^{\circ} \mathrm{C}$, levou à formação da fase $\mathrm{Y}_{2} \mathrm{O}_{3}$ na amostra $05 \mathrm{Y}$ (Tabela 3.3). Estes resultados mostraram a ocorrência de uma evaporação preferencial de $\mathrm{Al}_{2} \mathrm{O}_{3}$ da fase $\mathrm{YAG}$, o que indicou a diminuição da estabilidade desta fase durante a sinterização do AlN em altas temperaturas. O aumento da temperatura de sinterização, acima de $1900^{\circ} \mathrm{C}$, também mudou a evolução das segundas-fases na amostra $2 \mathrm{Y}$ (Tabela 3.3). Neste caso, a composição da segunda-fase mudou de YAG para YAP, o que sugeriu uma evaporação preferencial de $\mathrm{Al}_{2} \mathrm{O}_{3}$, como observado para a amostra $05 \mathrm{Y}$. Como a fase YAP é mais estável do que as demais fases de aluminato de ítrio em altas temperaturas ( $\geq 1835^{\circ} \mathrm{C}$, Fig. 3.1 ), pode-se dizer que, durante a sinterização do AlN acima de $1900^{\circ} \mathrm{C}$, a fase líquida perdeu mais $\mathrm{Al}_{2} \mathrm{O}_{3}$ para atingir uma composição igual ou próxima da fase YAP. A presença da fase YAP é comum em cerâmicas de AlN e a sua presença à temperatura ambiente foi decorrente do resfriamento fora do equilíbrio durante o processo de sinterização. 
A amostra $4 \mathrm{Y}$ sinterizada até $1700^{\circ} \mathrm{C}$ apresentou, em ordem de preponderância, as fases YAG, YAM e YAP (Tabela 3.3). Em relação à composição prevista no corpo conformado (Fig. 3.1), a amostra $4 \mathrm{Y}$ sinterizada até $1700^{\circ} \mathrm{C}$ apresentou a fase adicional YAP, que é metaestável abaixo de $1835^{\circ} \mathrm{C}$. Após a formação de fase líquida $\left(\sim 1725^{\circ} \mathrm{C}\right)$, a evolução das segundas-fases na amostra 4Y apresentou tendência para formar, em maior fração, a fase YAP com o aumento da temperatura de sinterização (Tabela 3.3). Estes resultados reforçam a interpretação de que a fase líquida perde compostos por evaporação para atingir uma composição igual ou próxima da fase YAP durante a sinterização do AlN em altas temperaturas $\left(>1900^{\circ} \mathrm{C}\right)$. Os resultados da análise microestrutural corroboram com a interpretação acima, pois as amostras $05 \mathrm{Y}, 2 \mathrm{Y}$ e $4 \mathrm{Y}$ sinterizadas entre $1800^{\circ} \mathrm{C}$ e $1900^{\circ} \mathrm{C}$ não apresentaram poros residuais na região de contorno de grão (Figs. 3.10b, 3.10c e 3.11a a 3.11c). Porém, o aumento da temperatura de sinterização, acima de $1900^{\circ} \mathrm{C}$, levou à formação de poros residuais na região de contorno de grão (Figs. 3.11e a 3.11f). Estes resultados indicaram que as segundas-fases de contorno de grão começaram a evaporar de forma significativa em altas temperaturas $\left(>1900^{\circ} \mathrm{C}\right)$, mesmo em atmosfera de sinterização inerte.

\section{Sob atmosfera redutora}

O processo de desoxidação das segundas-fases durante a sinterização do AlN com $\mathrm{Y}_{2} \mathrm{O}_{3}$ tem sido proposto para ocorrer pela desoxidação inicial dos aluminatos de ítrio, seguida pela desoxidação das fases remanescentes contendo $\mathrm{Al}_{2} \mathrm{O}_{3}$ e $\mathrm{Y}_{2} \mathrm{O}_{3}$, conforme sugerido nas reações 3.1 a 3.3 e 3.5 a 3.7. ${ }^{49,54,82}$ A mudança gradativa da composição das segundas-fases de $\mathrm{xAl}_{2} \mathrm{O}_{3} \cdot \mathrm{yY}_{2} \mathrm{O}_{3}$ para $\mathrm{Y}_{2} \mathrm{O}_{3}$ ocorre devido à maior pressão parcial de oxigênio do $\mathrm{Al}_{2} \mathrm{O}_{3}$ em relação ao $\mathrm{Y}_{2} \mathrm{O}_{3} \cdot{ }^{49,56}$

$$
\begin{aligned}
& 4 \mathrm{Al}_{5} \mathrm{Y}_{3} \mathrm{O}_{12(\mathrm{~s})}+7 \mathrm{~N}_{2(\mathrm{~g})}+21 \mathrm{C}_{(\mathrm{s})} \rightleftarrows 14 \mathrm{AlN}_{(\mathrm{s})}+3 \mathrm{Al}_{2} \mathrm{Y}_{4} \mathrm{O}_{9(\mathrm{~s})}+21 \mathrm{CO}_{(\mathrm{g})} \\
& \mathrm{Al}_{2} \mathrm{Y}_{4} \mathrm{O}_{9(\mathrm{~s})}+\mathrm{N}_{2(\mathrm{~g})}+3 \mathrm{C}_{(\mathrm{s})} \rightleftarrows 2 \mathrm{AlN}_{(\mathrm{s})}+2 \mathrm{Y}_{2} \mathrm{O}_{3(\mathrm{~s})}+3 \mathrm{CO}_{(\mathrm{g})} \\
& \mathrm{Y}_{2} \mathrm{O}_{3(\mathrm{~s})}+\mathrm{N}_{2(\mathrm{~g})}+3 \mathrm{C}_{(\mathrm{s})} \rightleftarrows 2 \mathrm{YN}_{(\mathrm{s})}+3 \mathrm{CO}_{(\mathrm{g})}
\end{aligned}
$$

Apesar de ser admissível que a desoxidação das segundas-fases do AlN com $\mathrm{Y}_{2} \mathrm{O}_{3}$ ocorra de acordo com as reações $3.2,3.3$ e 3.5 a 3.7, no presente trabalho propõe-se um mecanismo alternativo para o processo de desoxidação das segundas-fases durante a 
sinterização sob atmosfera redutora com carbono. Sabendo que o $\mathrm{Y}_{2} \mathrm{O}_{3}$ é mais estável do que o $\mathrm{Al}_{2} \mathrm{O}_{3},{ }^{44}$ estabeleceu-se que, antes da formação dos aluminatos de ítrio, o carbono promove a desoxidação da camada de óxido $\left(\mathrm{Al}_{2} \mathrm{O}_{3}\right)$ presente na superfície do pó de $\mathrm{AlN}$, segundo a reação 3.8:

$$
\mathrm{Al}_{2} \mathrm{O}_{3(\mathrm{~s})}+\mathrm{C}_{(\mathrm{s})}+\mathrm{N}_{2(\mathrm{~g})} \leftrightarrow 2 \mathrm{AlN}_{(\mathrm{s})}+3 \mathrm{CO}_{(\mathrm{g})}
$$

Dependendo do teor de carbono adicionado, a formação de aluminatos de ítrio pode ser inibida devido à falta de $\mathrm{Al}_{2} \mathrm{O}_{3}$ para reagir com o $\mathrm{Y}_{2} \mathrm{O}_{3}$, o que pode resultar na presença de $\mathrm{Y}_{2} \mathrm{O}_{3}$ não reagido. Este óxido remanescente pode reagir com o $\mathrm{C}$ livre, levando à formação da fase YN (reação 3.7). Os resultados de DRX (Tabela 3.4) corroboram com o mecanismo proposto no presente trabalho (reação 3.8). A amostra $4 \mathrm{Y} 05 \mathrm{C}$ sinterizada entre $1650^{\circ} \mathrm{C}$ e $1750^{\circ} \mathrm{C}$ apresentou as fases $\mathrm{YAM}$ e $\mathrm{Y}_{2} \mathrm{O}_{3}$ (Tabela 3.4), enquanto a amostra $4 \mathrm{Y}$ sinterizada na mesma faixa de temperatura apresentou as fases YAP, YAG, YAM. Estes resultados mostraram que a adição de $0,5 \%$ de $\mathrm{C}$ levou à formação de fases mais ricas em $\mathrm{Y}_{2} \mathrm{O}_{3}$ na amostra sinterizada até $1750^{\circ} \mathrm{C}$. Isto indicou que o carbono causou a desoxidação de uma fração significativa de $\mathrm{Al}_{2} \mathrm{O}_{3}$ presente na superfície do pó de $\mathrm{AlN}$ (reação 3.8), diminuindo a quantidade de $\mathrm{Al}_{2} \mathrm{O}_{3}$ disponível para reagir com o $\mathrm{Y}_{2} \mathrm{O}_{3}$ adicionado, o que resultou na formação de aluminatos ricos em $\mathrm{Y}_{2} \mathrm{O}_{3}$ e na presença de $\mathrm{Y}_{2} \mathrm{O}_{3}$ não reagido. Já a adição de $1 \%$ de $\mathrm{C}$ (amostra 4Y1C) levou à formação das fases $\mathrm{Y}_{2} \mathrm{O}_{3}$ e $\mathrm{YN}$ entre $1650^{\circ} \mathrm{C}$ e $1750^{\circ} \mathrm{C}$ (Tabela 3.4). Isto indicou que o carbono foi adicionado em excesso, o que resultou na completa desoxidação da superfície do pó de $\mathrm{AlN}$ (reação 3.8) e na parcial desoxidação do $\mathrm{Y}_{2} \mathrm{O}_{3}$ adicionado (reação 3.7$)$.

Há outros resultados que corroboram com o mecanismo proposto no presente trabalho. Estes resultados estão relacionados com o comportamento de densificação do AlN. A adição de $\mathrm{Y}_{2} \mathrm{O}_{3}$ deslocou a curva de densificação do AlN para menores temperaturas (Fig. 3.4), o que mostrou que este aditivo aumentou significativamente a sinterabilidade do AlN. Porém, a amostra 4Y1C apresentou um comportamento de densificação próximo daquele observado para o AlN sem aditivo entre $1650^{\circ} \mathrm{C}$ e $1750^{\circ} \mathrm{C}$ (Figs. 3.12 e 3.4, respectivamente). Estes resultados indicaram que a adição de $1 \%$ de $\mathrm{C}$ diminuiu significativamente a ação efetiva do $\mathrm{Y}_{2} \mathrm{O}_{3}$ em promover a densificação do AlN em menores temperaturas de sinterização. Como a amostra 4Y1C não apresentou fases de aluminato de ítrio entre $1650^{\circ} \mathrm{C}$ e $1750^{\circ} \mathrm{C}$ (Tabela 3.4) e, sabendo que a formação de aluminatos de ítrio promove uma densificação significativa no AlN por sinterização no estado sólido, ${ }^{66,67,186}$ pode-se dizer que o AlN apresentou pouca 
densificação em decorrência da não formação de aluminatos de ítrio durante a sinterização. Estes resultados reforçam a interpretação de que a adição de carbono causa a desoxidação do $\mathrm{Al}_{2} \mathrm{O}_{3}$ presente na superfície do pó de $\mathrm{AlN}$, o que pode inibir a formação de aluminatos, caso não haja $\mathrm{Al}_{2} \mathrm{O}_{3}$ suficiente para reagir com o aditivo de sinterização $\left(\mathrm{Y}_{2} \mathrm{O}_{3}\right)$.

\subsubsection{Densificação do sistema $\mathrm{AlN}-\mathrm{Y}_{2} \mathrm{O}_{3}$}

Neste tópico, apresenta-se uma releitura do processo de sinterização do AlN com adição de $\mathrm{Y}_{2} \mathrm{O}_{3}$, com base na literatura e nos resultados obtidos no presente trabalho. Os resultados da série com adição de carbono possibilitaram confirmar interpretações sobre os mecanismos de densificação, que não foram possíveis apenas com a série de variação do teor de $\mathrm{Y}_{2} \mathrm{O}_{3}$. Nesta discussão, ressalta-se a importância do processo de sinterização no estado sólido, que antecede o processo de sinterização via fase líquida.

\section{Estágio inicial}

A temperatura de início de retração linear da amostra $4 \mathrm{Y}$ ocorreu próximo de $1200^{\circ} \mathrm{C}$ (Fig. 3.5a). Este resultado indicou que o estágio inicial da densificação do AlN com $\mathrm{Y}_{2} \mathrm{O}_{3}$ foi ativado próximo desta temperatura de sinterização. Outros trabalhos observaram que o início de retração linear do $\mathrm{AlN}$ com $\mathrm{Y}_{2} \mathrm{O}_{3}$ ocorreu entre $1125^{\circ} \mathrm{C}$ e $1450^{\circ} \mathrm{C}$. ${ }^{65-68,180} \mathrm{O}$ início de retração linear do $\mathrm{AlN}$ com $\mathrm{Y}_{2} \mathrm{O}_{3}$ foi relacionado com a formação de aluminatos de ítrio por sinterização no estado sólido. ${ }^{66}$ No presente trabalho, a curva de taxa de retração apresentou duas inflexões (ombros) nas temperaturas de $1240^{\circ} \mathrm{C}$ e $1440^{\circ} \mathrm{C}$ (Fig. 3.5b). Estes resultados indicaram que estas inflexões podem estar relacionadas com a formação de diferentes fases de aluminato de ítrio, pois a amostra $4 \mathrm{Y}$ sinterizada a $1650^{\circ} \mathrm{C}$ apresentou três fases distintas de aluminato de ítrio (Tabela 3.3).

Na curva de taxa de retração da amostra 4Y (Fig. 3.5b), observou-se que o primeiro pico de máxima taxa de retração ocorreu na temperatura de $1500^{\circ} \mathrm{C}$, mas o início e final deste pico ocorreu nas temperaturas de $1200^{\circ} \mathrm{C}$ e $1540^{\circ} \mathrm{C}$, respectivamente. Esta faixa de temperatura está abaixo da menor temperatura eutética prevista para o sistema binário $\mathrm{Y}_{2} \mathrm{O}_{3}$ $\mathrm{Al}_{2} \mathrm{O}_{3}\left(1760^{\circ} \mathrm{C}\right.$, Fig. 3.1), assim como para o sistema ternário $\mathrm{AlN}-\mathrm{Y}_{2} \mathrm{O}_{3}-\mathrm{Al}_{2} \mathrm{O}_{3}$, que indica 
formação de fase líquida a partir de $1686^{\circ} \mathrm{C}^{43}$ ou $1720^{\circ} \mathrm{C}^{182}$. Estes resultados indicaram que o início de retração linear, bem como o primeiro pico de máxima taxa de retração não estão relacionados com a formação de fase líquida durante a sinterização do $\mathrm{AlN}$ com $\mathrm{Y}_{2} \mathrm{O}_{3}$. Tajika et al. ${ }^{67}$ indicaram que a formação de compostos óxidos (aluminatos de ítrio) causou rearranjo de partículas no estado sólido, o que resultou na retração do AlN durante a sinterização entre $1300^{\circ} \mathrm{C}$ e $1500^{\circ} \mathrm{C}$. Outros trabalhos também sugeriram que a densificação do AlN em baixa temperatura $\left(\leq 1600^{\circ} \mathrm{C}\right)$ está relacionada com a formação de aluminatos de ítrio por sinterização no estado sólido. ${ }^{65,68,186}$

As amostras $05 \mathrm{Y}, 2 \mathrm{Y}$ e $4 \mathrm{Y}$ sinterizadas até $1700^{\circ} \mathrm{C}$ apresentaram microestruturas com formação de pescoço entre as partículas primárias (Figs. 3.8a e 3.8c). Esta característica microestrutural é observada em materiais submetidos ao estágio inicial da sinterização no estado sólido. Como estas amostras apresentaram densidades entre 75\% e 82\% DT (Fig. 3.4), pode-se dizer que elas alcançaram até cerca de $50 \%$ de densificação total por sinterização no estado sólido. ${ }^{186} \mathrm{~A}$ adição de $\mathrm{Y}_{2} \mathrm{O}_{3}$ causou uma diminuição significativa na temperatura de sinterização do AlN, ${ }^{186,187}$ pois a amostra sem aditivo atingiu densidade próxima de $80 \%$ DT somente após a sinterização na temperatura de $1850^{\circ} \mathrm{C}$ (Fig. 3.4). Porém, a amostra 4Y1C sinterizada entre $1650^{\circ} \mathrm{C}$ e $1750^{\circ} \mathrm{C}$ apresentou valores de densidade próximos daqueles observados para o AlN sem aditivo sinterizado na mesma faixa de temperatura (Figs. $3.4 \mathrm{e}$ 3.12). Isto mostrou que a adição de $1 \%$ de $\mathrm{C}$ inibiu praticamente a ação do $\mathrm{Y}_{2} \mathrm{O}_{3}$ em promover a densificação do AlN entre $1650^{\circ} \mathrm{C}$ e $1750^{\circ} \mathrm{C}$. Embora tenha ocorrido uma diferença significativa de densidade entre as amostras $4 \mathrm{Y}$ e 4Y05C (Fig. 3.12), a amostra 4Y05C apresentou valores de densidade significativamente maiores do que a amostra 4Y1C abaixo de $1800^{\circ} \mathrm{C}$. Analisando as evoluções das segundas-fases das amostras sem e com C (Tabela 3.4), observou-se que a amostra $4 \mathrm{Y} 1 \mathrm{C}$ não apresentou fases de aluminato de ítrio entre $1650^{\circ} \mathrm{C} \mathrm{e}$ $1750^{\circ} \mathrm{C}$. Como os valores de densidade da amostra 4 Y $1 \mathrm{C}$ foram próximos dos valores obtidos para o AlN sem aditivo entre $1650^{\circ} \mathrm{C}$ e $1750^{\circ} \mathrm{C}$ (Figs. 3.12 e 3.4, respectivamente), e sabendo que a amostra 4Y1C não apresentou fases de aluminato de ítrio nesta faixa de temperatura (Tabela 3.4), pode-se dizer que a amostra 4Y1C apresentou pouca densificação nos estágios iniciais da sinterização em decorrência da não formação de aluminatos de ítrio. Outros trabalhos também indicaram que a formação de aluminatos de ítrio por sinterização no estado sólido promove uma densificação significativa no AlN. ${ }^{66,67}$ Estes resultados indicaram que a formação de aluminatos de ítrio e a subseqüente reação destas segundas-fases com o AlN podem induzir uma significativa densificação no AlN antes da formação de fase líquida. ${ }^{186,187}$ 


\section{Estágios intermediário e final}

A presença de aglomerados densos de partículas na microestrutura das amostras de AlN com $\mathrm{Y}_{2} \mathrm{O}_{3}$ sinterizadas a $1725^{\circ} \mathrm{C}$ por 1 min (Fig. 3.9a) foi um indicativo de que ocorreu formação de fase líquida, que ativou o mecanismo de rearranjo de partículas da sinterização via fase líquida. A temperatura eutética do sistema ternário $\mathrm{AlN}-\mathrm{Y}_{2} \mathrm{O}_{3}-\mathrm{Al}_{2} \mathrm{O}_{3}$ é prevista ao redor de $1720^{\circ} \mathrm{C},{ }^{182} \mathrm{o}$ que corrobora com a indicação de que a densificação das amostras $05 \mathrm{Y}$, $2 \mathrm{Y}$ e $4 \mathrm{Y}$ foi assistida por sinterização via fase líquida na temperatura de $1725^{\circ} \mathrm{C}$. Como o segundo pico de máxima taxa de retração da amostra $4 \mathrm{Y}$ ocorreu na temperatura de $1730^{\circ} \mathrm{C}$ (Fig. 3.5b), pode-se dizer que este pico está associado com a formação de fase líquida durante a sinterização do AlN com $\mathrm{Y}_{2} \mathrm{O}_{3}$. Entretanto, o segundo pico de máxima taxa de retração teve seu início e final nas temperaturas de $1540^{\circ} \mathrm{C}$ e $1800^{\circ} \mathrm{C}$ (Fig. 3.5b), respectivamente. Estes resultados indicaram que ocorreu um aumento significativo na taxa de retração da amostra 4Y na faixa de temperatura em que não é prevista a formação de fase líquida, pois as temperaturas de formação da fase líquida no sistema ternário $\mathrm{AlN}-\mathrm{Y}_{2} \mathrm{O}_{3}-\mathrm{Al}_{2} \mathrm{O}_{3}$ são previstas a $1686^{\circ} \mathrm{C}^{43}$ ou $1720^{\circ} \mathrm{C}{ }^{182}$. Embora tenha ocorrido uma inflexão (ombro) na curva de taxa de retração da amostra $4 \mathrm{Y}\left(\sim 1685^{\circ} \mathrm{C}\right.$, Fig. $\left.3.5 \mathrm{~b}\right)$, esta inflexão não pode ser relacionada com o início da formação de fase líquida, pois as amostras $05 \mathrm{Y}, 2 \mathrm{Y}$ e $4 \mathrm{Y}$ apresentaram microestruturas com apenas formação de pescoços entre as partículas primárias até $1700^{\circ} \mathrm{C}$ (Figs. 3.8). Supondo que a formação de fase líquida ocorreu entre $1685^{\circ} \mathrm{C}$ e $1730^{\circ} \mathrm{C}$, o aumento na taxa de retração observado entre $1540^{\circ} \mathrm{C}$ e $1685^{\circ} \mathrm{C}$ (Fig. 3.5b) pode ser atribuído aos mecanismos de sinterização no estado sólido. Este resultado sugeriu que o aumento da temperatura de sinterização entre $1540^{\circ} \mathrm{C}$ e $1685^{\circ} \mathrm{C}$ pode promover uma densificação significativa no AlN com $\mathrm{Y}_{2} \mathrm{O}_{3}$ por sinterização no estado sólido. Esta proposição é plausível, visto que as amostras $05 \mathrm{Y}, 2 \mathrm{Y}$ e $4 \mathrm{Y}$ atingiram, em média, $50 \%$ de densificação total por sinterização no estado sólido na temperatura de $1700^{\circ} \mathrm{C}$ (Fig. 3.4).

A formação de uma estrutura "rígida" de partículas, por sinterização no estado sólido (Fig. 3.8), não inibiu a ativação do mecanismo de rearranjo de partículas (Fig. 3.9a). Na temperatura de $1725^{\circ} \mathrm{C}$, o aumento do tempo de sinterização (1 para 60 minutos) causou um aumento significativo de densidade nas amostras de AlN com $\mathrm{Y}_{2} \mathrm{O}_{3}$ (Figs. 3.9a e 3.9b). Isto indicou que a fase sólida teve boa solubilidade na fase líquida, o que resultou na dissolução dos pescoços entre as partículas e, conseqüentemente, no rearranjo das partículas para uma condição de maior empacotamento. As três amostras com $\mathrm{Y}_{2} \mathrm{O}_{3}$ apresentaram um aumento significativo de densidade com o aumento da temperatura de $1700^{\circ} \mathrm{C}$ para $1725^{\circ} \mathrm{C}$ (Fig. 3.4), o 
que indicou um aumento significativo na taxa de densificação com a formação de fase líquida. O aumento das taxas de densificação e crescimento de grão, principalmente acima da temperatura de formação de fase líquida (Figs. 3.4 e 3.9), está relacionado com a ativação do mecanismo de solução-difusão-precipitação da sinterização via fase líquida. Apesar da amostra $2 \mathrm{Y}$ ter apresentado uma densificação mais lenta do que as amostras $05 \mathrm{Y}$ e $4 \mathrm{Y}$ até $1750^{\circ} \mathrm{C}$ (Fig. 3.4), as três amostras sinterizadas a $1800^{\circ} \mathrm{C}$ apresentaram quase completa densificação $(\sim 99 \%$ DT). Estes resultados mostraram que pequenos superaquecimentos $\left(\leq 75^{\circ} \mathrm{C}\right)$, acima da temperatura de formação de líquido, são suficientes para promover quase completa densificação no AlN com até $4 \%$ de $\mathrm{Y}_{2} \mathrm{O}_{3}$.

A fase $\mathrm{YAG}$, presente nas amostras $05 \mathrm{Y}, 2 \mathrm{Y}$ e $4 \mathrm{Y}$ sinterizadas entre $1650^{\circ} \mathrm{C}$ e $1800^{\circ} \mathrm{C}$ (Tabela 3.3), está associada com o ponto eutético $\mathrm{L} \rightarrow \mathrm{YAG}+\alpha-\mathrm{Al}_{2} \mathrm{O}_{3}$, que tem temperatura prevista a $1720^{\circ} \mathrm{C}$ no sistema ternário $\mathrm{AlN}-\mathrm{Y}_{2} \mathrm{O}_{3}-\mathrm{Al}_{2} \mathrm{O}_{3} \cdot{ }^{182} \mathrm{Como}$ as evidências de formação de fase líquida surgiram nas amostras sinterizadas a partir de $1725^{\circ} \mathrm{C}$ (Fig. 3.9a), pode-se dizer que a fase líquida teve uma composição igual ou próxima da fase $\mathrm{YAG},{ }^{186,187}$ pois as fases YAM e YAP são associadas com a fase líquida acima de $1800^{\circ} \mathrm{C}$ (Fig. 3.1). Os resultados das amostras 4Y05C e 4Y1C reforçaram a interpretação de que a fase líquida formada ao redor de $1725^{\circ} \mathrm{C}$ apresentou uma composição igual ou próxima da fase YAG. A adição de $\mathrm{C}$ na amostra $4 \mathrm{Y}$ inibiu a formação da fase YAG (Tabela 3.4), pois a presença de uma atmosfera redutora levou à formação de fases mais refratárias ricas em $\mathrm{Y}_{2} \mathrm{O}_{3}$. As amostras $4 \mathrm{Y} 05 \mathrm{C}$ e $4 \mathrm{Y} 1 \mathrm{C}$ apresentaram microestruturas com poros interconectados até $1750^{\circ} \mathrm{C}$ (Fig. 3.13a). Isto indicou que não ocorreu a formação de fase líquida nestas amostras, pois a presença de poros interconectados é uma característica microestrutural do estágio intermediário da sinterização no estado sólido. Como as amostras 4Y05C e 4Y1C tiveram uma densificação mais lenta do que a amostra $4 \mathrm{Y}$ até $1750^{\circ} \mathrm{C}$ (Fig. 3.12), pode-se dizer que a densificação do $\mathrm{AlN}$ com $\mathrm{Y}_{2} \mathrm{O}_{3}$ foi influenciada pela temperatura de formação da fase líquida. $\mathrm{O}$ aumento do teor de $\mathrm{Y}_{2} \mathrm{O}_{3}$, acima de $5 \%$ em massa, causou um atraso significativo na densificação do AlN. ${ }^{40,183}$ Sabendo que a composição das segundas-fases varia em função dos teores de aditivo de sinterização e de oxigênio presente na superfície do pó de AlN, ${ }^{51,66}$ a adição em excesso de $\mathrm{Y}_{2} \mathrm{O}_{3}$ pode levar à formação de fases mais ricas em $\mathrm{Y}_{2} \mathrm{O}_{3}$, ou seja, mais refratárias (Fig. 3.1). Isto aumenta a temperatura de formação de líquido durante a sinterização, resultando no atraso da densificação, isto é, no aumento da temperatura de sinterização. Estes resultados reforçam a interpretação de que a formação da fase YAG pode levar à formação de fase líquida ao redor de $1725^{\circ} \mathrm{C}$ e, então, promover a completa densificação do AlN em temperaturas tão baixas quanto $1800^{\circ} \mathrm{C}$ (Fig. 3.4). 
Entre $1650^{\circ} \mathrm{C}$ e $1800^{\circ} \mathrm{C}$, as amostras $2 \mathrm{Y}$ e $4 \mathrm{Y}$ apresentaram microestruturas com partículas de segundas-fases (Figs. 3.8d e 3.11a). Outros trabalhos 37-39,54 também evidenciaram partículas grandes de segundas-fases no AlN preparado com $\mathrm{Y}_{2} \mathrm{O}_{3}$ ou óxidos de terras raras. A formação destas partículas de segundas-fases foi associada com a alta viscosidade e/ou baixa molhabilidade da fase líquida presente durante a sinterização. ${ }^{37,39}$ Esta proposição levou à indicação de que as segundas-fases com formato de partículas grandes apresentaram uma melhora no comportamento de viscosidade e/ou molhabilidade somente acima de $1800^{\circ} \mathrm{C}$ (Figs. 3.11a a 3.11c), pois estas segundas-fases mostraram uma tendência para penetrar e espalhar por entre os grãos de AlN. Este comportamento também foi observado em outros trabalhos. ${ }^{39,47,52,180}$ Estes resultados mostraram que a fração de fase líquida com boas características de viscosidade e/ou molhabilidade aumentou somente acima de $1800^{\circ} \mathrm{C}$, ou seja, depois da completa densificação das amostras $2 \mathrm{Y}$ e $4 \mathrm{Y}$ (Fig. 3.4). Sabendo que a amostra $05 \mathrm{Y}$ não apresentou partículas grandes de segundas-fases após a formação de fase líquida (Fig. 3.10), pode-se dizer que as amostras 05Y, 2 Y e 4 Y tiveram quantidades relativamente próximas de fase líquida com boas características de molhamento e espalhamento entre $1725^{\circ} \mathrm{C}$ e $1800^{\circ} \mathrm{C}$. O excesso de aluminatos de ítrio nas amostras com adições acima de $0,5 \%$ de $\mathrm{Y}_{2} \mathrm{O}_{3}$ (amostras $2 \mathrm{Y}$ e $4 \mathrm{Y}$ ), portanto, não participou do processo de densificação por sinterização via fase líquida. Considerando que o aumento da fração de fase líquida presente durante a sinterização favorece a densificação, ${ }^{90,101,188}$ as amostras $05 \mathrm{Y}, 2 \mathrm{Y}$ e 4Y apresentaram comportamentos similares de densificação (Fig. 3.4) porque apresentaram quantidades próximas de fase líquida na faixa de temperatura em que ocorreu a completa densificação $\left(1725^{\circ} \mathrm{C}-1800^{\circ} \mathrm{C}\right)$.

A amostra $05 \mathrm{Y}$ atingiu quase completa densificação a $1750^{\circ} \mathrm{C}$ (Fig. 3.4), indicando que pequenas adições de $\mathrm{Y}_{2} \mathrm{O}_{3}(0,5 \%$ em massa) podem promover a densificação do AlN. Buhr et al. ${ }^{180}$ também relataram que pequenas adições de $\mathrm{Y}_{2} \mathrm{O}_{3}(\sim 1 \%$ em massa) são suficientes para promover a densificação do AIN. No caso das amostras com adição de carbono, observaramse perdas de massa significativamente maiores do que na amostra 4Y (Fig. 3.13), após a sinterização entre $1650^{\circ} \mathrm{C}$ e $1850^{\circ} \mathrm{C}$. Isto indicou que a adição de carbono causou uma evaporação significativa de compostos, que resultou na diminuição da fração de fase líquida presente durante a sinterização. Como as amostras 4Y05C e 4Y1C atingiram densidades próximas daquela observada para a amostra $4 \mathrm{Y}$ após a sinterização na temperatura de $1800^{\circ} \mathrm{C}$ (Figs. 3.12, 3.14b e 3.14c), pode-se dizer que pequenas frações de fase líquida foram suficientes para promover a densificação do AlN com $\mathrm{Y}_{2} \mathrm{O}_{3}$. Embora tenha ocorrido elevada evaporação de compostos com a adição de carbono (Fig. 3.13), as amostras 4Y05C e 4Y1C 
não apresentaram evidências da ocorrência de aprisionamento de gás no interior dos poros fechados, que pode dificultar a densificação em decorrência da estabilização dos poros durante a sinterização em altas temperaturas. Estes resultados indicaram que a densificação do AlN não foi praticamente influenciada pela quantidade de fase líquida presente durante a sinterização e pelo aprisionamento de gás nos poros fechados. Portanto, a densificação do AlN com $\mathrm{Y}_{2} \mathrm{O}_{3}$ foi influenciada, principalmente, pela temperatura de formação de fase líquida, pois as amostras com $\mathrm{C}$ apresentaram pouca densificação abaixo de $1800^{\circ} \mathrm{C}$ em decorrência da formação de segundas-fases mais refratárias do que na amostra sem C (Tabela $3.4)$.

\subsubsection{Formação de partículas grandes de segundas-fases no sistema $\mathrm{AlN}-\mathrm{Y}_{2} \mathrm{O}_{3}$}

As amostras $05 \mathrm{Y}, 2 \mathrm{Y}$ e $4 \mathrm{Y}$ apresentaram partículas grandes de segundas-fases até $1700^{\circ} \mathrm{C}$ (Figs. $3.8 \mathrm{~b}$ e $3.8 \mathrm{~d}$ ). A análise por EDS revelou a presença de oxigênio, alumínio e ítrio nas partículas grandes de segundas-fases (Fig. 3.8e), indicando serem constituídas por fases de aluminato de ítrio. Isto está de acordo com os resultados de DRX (Tabela 3.3), que mostraram somente a presença de fases de aluminato de ítrio nas amostras $05 \mathrm{Y}, 2 \mathrm{Y}$ e $4 \mathrm{Y}$ sinterizadas até $1700^{\circ} \mathrm{C}$. Estes resultados estão de acordo com as observações de Koestler et al. ${ }^{66}$. Eles observaram, por microscopia eletrônica de transmissão, que as partículas primárias de $\mathrm{Y}_{2} \mathrm{O}_{3}$ se transformaram em partículas de aluminato de ítrio por reação no estado sólido a partir de $1125^{\circ} \mathrm{C}$. Estas partículas de aluminato de ítrio ocuparam os mesmos sítios das partículas de $\mathrm{Y}_{2} \mathrm{O}_{3}$ até a temperatura em que ocorreu a formação de fase líquida. No presente trabalho, a formação de partículas grandes de aluminato de ítrio foi atribuída ao uso de $\mathrm{Y}_{2} \mathrm{O}_{3}$ com larga distribuição granulométrica em relação ao AlN (Fig. 3.3). Acima da temperatura de formação de fase líquida, ou seja, acima de $1725^{\circ} \mathrm{C}$, a amostra $05 \mathrm{Y}$ não apresentou partículas grandes de aluminato de ítrio (Fig. 3.10). Estes resultados indicaram que as partículas grandes de segundas-fases fundiram e, então, a fase líquida espalhou por entre os grão de AlN, o que promoveu uma melhora significativa na densificação da amostra 05Y (Figs. 3.4, 3.8a, e 3.10). As partículas grandes, observadas na amostra $05 \mathrm{Y}$ (Fig. 3.8b), fundiram a partir de $1725^{\circ} \mathrm{C}$ porque apresentaram composição igual ou próxima da YAG (Tabela 3.3), que tem temperatura eutética de $1720^{\circ} \mathrm{C} .{ }^{182}$ 
Apesar da boa correlação entre o resultado experimental da amostra 05Y e a proposição apresentada na literatura, os resultados das amostras $2 \mathrm{Y}$ e $4 \mathrm{Y}$ revelaram a presença de partículas grandes de segundas-fases acima da temperatura prevista para formação de fase líquida (Figs. 3.8d e 3.11a). Outros trabalhos também observaram, abaixo de $1850^{\circ} \mathrm{C}$, a formação de partículas grandes de segundas-fases no $\mathrm{AlN}$ com $\mathrm{Y}_{2} \mathrm{O}_{3}$ ou óxidos de terras raras. ${ }^{36-39,54}$ Alguns destes trabalhos ${ }^{37,39}$ sugeriram que a fase líquida apresentou alta viscosidade e/ou baixa molhabilidade no $\mathrm{AlN}$, o que limitou seu espalhamento por entre os grãos de AlN. Isto levou à formação de partículas grandes de segundas-fases, similares às observadas nas amostras $2 \mathrm{Y}$ e $4 \mathrm{Y}$ (Fig. 3.11a). Supondo que a fase líquida teve alta viscosidade e/ou baixa molhabilidade no $\mathrm{AlN}$ até $1800^{\circ} \mathrm{C}$, como proposto, ${ }^{37,39}$ a mudança microestrutural observada nas amostras $2 \mathrm{Y}$ e $4 \mathrm{Y}$ acima desta temperatura (Figs. 3.11a a 3.11c) indicou uma mudança no comportamento de viscosidade ou molhabilidade da fase líquida, baseada na observação de que as segundas-fases com formato de partículas grandes apresentaram tendência para penetrar e espalhar por entre os grãos de AlN. Apesar de admissível esta proposição, no presente trabalho propõe-se um mecanismo alternativo para explicar a formação das partículas grandes de segundas-fases durante a sinterização do AlN.

A amostra $4 \mathrm{Y}$ sinterizada entre $1650^{\circ} \mathrm{C}$ e $1800^{\circ} \mathrm{C}$ apresentou, além da fase YAG, as fases YAM e/ou YAP (Tabela 3.3). Como as fases YAM e YAP são associadas com a fase líquida somente acima de $1800^{\circ} \mathrm{C}$ (Fig. 3.1), pode-se dizer que as partículas grandes de segundas-fases, observadas na amostra $4 \mathrm{Y}$ sinterizada acima de $1725^{\circ} \mathrm{C}$, apresentaram composições próximas das fases YAM ou YAP, ${ }^{186,187}$ o que impediu a fusão destas partículas até $1800^{\circ} \mathrm{C}$. Deste modo, a mudança microestrutural, observada acima de $1800^{\circ} \mathrm{C}$ na amostra 4Y (Figs. 3.11a e 3.11b), indicou que as partículas grandes de segundas-fases fundiram e, então, a fase líquida penetrou por entre os grãos de AlN. Estes resultados reforçaram a interpretação de que a formação da fase YAG levou à formação de fase líquida ao redor de $1725^{\circ} \mathrm{C}$. Já os resultados da amostra $2 \mathrm{Y}$ foram conflitantes com a proposição apresentada acima, pois esta amostra apresentou partículas grandes de segundas-fases até $1800^{\circ} \mathrm{C}$ (Fig. 3.11a), mas seus resultados de DRX mostraram somente a fase YAG em quase toda a faixa de temperatura estudada (Tabela 3.3). Como a fase YAG tem temperatura eutética prevista a $1720^{\circ} \mathrm{C},{ }^{182}$ esperava-se a ausência de partículas grandes de segundas-fases na amostra $2 \mathrm{Y}$ sinterizada acima de $1725^{\circ} \mathrm{C}$, como observado para a amostra 05Y (Fig. 3.10). A presença destas partículas grandes de segundas-fases, acima de $1725^{\circ} \mathrm{C}$, pode estar relacionada com as quantidades de $\mathrm{Y}_{2} \mathrm{O}_{3}$ e $\mathrm{Al}_{2} \mathrm{O}_{3}$ presentes na amostra $2 \mathrm{Y}$. A composição inicial da amostra $2 \mathrm{Y}$ ficou dentro do campo $\mathrm{YAG}+\alpha-\mathrm{Al}_{2} \mathrm{O}_{3}$, mas próximo do campo $\mathrm{YAG}+\mathrm{YAM}$ do diagrama 
de fases do sistema $\mathrm{Y}_{2} \mathrm{O}_{3}-\mathrm{Al}_{2} \mathrm{O}_{3}$ (Fig. 3.1). Como as partículas maiores de $\mathrm{Y}_{2} \mathrm{O}_{3}$ mostraram uma tendência para se transformar em fases mais ricas em $\mathrm{Y}_{2} \mathrm{O}_{3}$ e, sabendo que a composição da amostra $2 \mathrm{Y}$ ficou próxima da interface entre os campos $\mathrm{YAG}+\alpha-\mathrm{Al}_{2} \mathrm{O}_{3}$ e $\mathrm{YAG}+\mathrm{YAM}$ (Fig. 3.1), pode-dizer que durante a sinterização em alta temperatura $\left(\geq 1725^{\circ} \mathrm{C}\right)$ certa fração de partículas grandes de segundas-fases teve uma composição dentro do campo YAG + YAM. Deste modo, as fases YAG e YAM podem ter coexistido durante a sinterização da amostra $2 \mathrm{Y}$ e, portanto, uma fração das partículas grandes de segundas-fases pode ter apresentado uma composição igual ou próxima da fase YAM. Isto impediu a fusão de algumas das partículas grandes de segundas-fases até $1800^{\circ} \mathrm{C}$ (Fig. 3.11a), pois a fase YAM é associada com a fase líquida somente acima desta temperatura (Fig. 3.1). Durante o resfriamento, estas partículas grandes se transformaram na fase YAG, pois a amostra $2 \mathrm{Y}$ sinterizada entre $1650^{\circ} \mathrm{C}$ e $1900^{\circ} \mathrm{C}$ apresentou apenas esta segunda-fase à temperatura ambiente (Tabela 3.3). Provavelmente, a amostra 2Y apresentou certa fração de fase YAM à temperatura ambiente, que ficou abaixo do limite de resolução do equipamento de DRX. Deste modo, pode-se dizer que a formação das partículas de segundas-fases, observadas no AlN com $\mathrm{Y}_{2} \mathrm{O}_{3}$, está relacionada com a formação de aluminatos mais refratários e não com o comportamento de viscosidade e/ou molhabilidade da fase líquida presente durante a sinterização.

\subsection{Conclusões}

Estudou-se o comportamento de densificação do AlN com $0,5 \%$ a $4 \%$ de $\mathrm{Y}_{2} \mathrm{O}_{3}$ sob atmosfera neutra (nitrogênio) entre $1650^{\circ} \mathrm{C}$ e $2000^{\circ} \mathrm{C}$, bem como o efeito da formação in situ de uma atmosfera redutora com carbono (proveniente da adição de $0,5 \%$ e $1 \%$ de C) na densificação do $\mathrm{AlN}$ com $4 \%$ de $\mathrm{Y}_{2} \mathrm{O}_{3}$ entre $1650^{\circ} \mathrm{C}$ e $1850^{\circ} \mathrm{C}$. Os resultados experimentais levaram às seguintes conclusões:

- A densificação do AlN com até 4\% em massa de $\mathrm{Y}_{2} \mathrm{O}_{3}$ ocorre, inicialmente, pela formação de aluminatos de ítrio por sinterização no estado sólido, que induz a retração linear do corpo a partir de aproximadamente $1200^{\circ} \mathrm{C}$. A formação dos aluminatos de ítrio e a subseqüente reação destas segundas-fases com o AlN promove uma significativa densificação por sinterização no estado sólido até cerca de $1700^{\circ} \mathrm{C}(\sim 50 \%$ de densificação total nas condições deste trabalho). A formação de fase líquida ocorre ao redor de $1725^{\circ} \mathrm{C}$ 
com composição igual ou próxima da fase YAG $\left(3 \mathrm{Y}_{2} \mathrm{O}_{3} \cdot 5 \mathrm{Al}_{2} \mathrm{O}_{3}\right)$. Esta fase líquida tem boas características de molhamento e espalhamento, assim como o sólido tem boa solubilidade no líquido, o que favorece a densificação pelo mecanismo de rearranjo de partículas, primeiro estágio da sinterização via fase líquida. Em decorrência das boas propriedades da fase líquida, pequenos superaquecimentos $(\leq 75 \mathrm{C})$, acima da temperatura de formação de fase líquida $\left(\sim 1725^{\circ} \mathrm{C}\right)$, são suficientes para promover completa densificação no AlN com até $4 \%$ de $\mathrm{Y}_{2} \mathrm{O}_{3}$;

- A utilização de $\mathrm{Y}_{2} \mathrm{O}_{3}$ com larga distribuição granulométrica em relação ao AlN induz a formação de partículas grandes de segundas-fases nas amostras de AlN. Estas partículas são compostas por fases mais refratárias $\left(2 \mathrm{Y}_{2} \mathrm{O}_{3} \cdot \mathrm{Al}_{2} \mathrm{O}_{3}, \mathrm{YAM}\right.$ e/ou $\left.\mathrm{Y}_{2} \mathrm{O}_{3} \cdot \mathrm{Al}_{2} \mathrm{O}_{3}, \mathrm{YAP}\right)$ do que a fase $\mathrm{YAG}$, as quais fundem e se espalham pela microestrutura somente acima de $1800^{\circ} \mathrm{C}$;

- A densificação do AlN foi pouco influenciada pelo aumento do teor de $\mathrm{Y}_{2} \mathrm{O}_{3}(0,5 \%$ a $4 \%$ em massa), pois a adição de $\mathrm{Y}_{2} \mathrm{O}_{3}$ acima de $0,5 \%$ causou a formação de aluminatos de ítrio refratários (na forma de partículas grandes), que não participaram do processo de densificação por sinterização via fase líquida, pois fundiram somente acima de $1800^{\circ} \mathrm{C}$, depois da completa densificação do AlN;

- Os aluminatos de ítrio apresentam boa estabilidade durante a sinterização do AlN sob atmosfera inerte (não redutora) até cerca de $1900^{\circ} \mathrm{C}$, mas a formação in situ de uma atmosfera redutora com carbono induz a formação de segundas-fases ricas em $\mathrm{Y}_{2} \mathrm{O}_{3}$, que retarda a densificação do AlN devido ao aumento da temperatura de formação de fase líquida, pois as fases YAM, YAP, $\mathrm{Y}_{2} \mathrm{O}_{3}$ e YN são mais refratárias do que a fase YAG. Já a diminuição da fração de segundas-fases líquidas, causada pela desoxidação com carbono, não influência a densificação do $\mathrm{AlN}$ com $\mathrm{Y}_{2} \mathrm{O}_{3}$. 


\section{Efeito do carbono na densificação do AIN com CaO}

\subsection{Introdução}

A presença de uma atmosfera redutora, produzida pela utilização de cadinho de grafita e/ou de forno com elemento de aquecimento em grafita, pode melhorar significativamente a condutividade térmica do AlN. ${ }^{48-50,54,81-83,180}$ Durante a sinterização, a atmosfera redutora promove a desoxidação das segundas-fases de contorno de grão, o que implica na evaporação significativa de compostos, que resulta na limpeza (cleanness) da microestrutura e, conseqüentemente, no aumento da condutividade térmica. ${ }^{18,47,50,54,82,158}$

Outros trabalhos utilizaram pó de grafita ou de negro de fumo com aditivo de sinterização, visando à formação in situ de uma atmosfera redutora no interior do corpo conformado durante a sinterização. Este tipo de estudo foi realizado para o AlN com $\mathrm{Y}_{2} \mathrm{O}_{3},{ }^{18,49,55,184}$ onde se observou que o uso de carbono (C) até certo valor ( $\sim 0,5 \%$ em massa) aumentou significativamente a condutividade térmica do AlN. ${ }^{49,55}$ Porém, adições acima de 0,5\% de C influenciaram significativamente o comportamento de densificação do AlN devido à formação de fases refratárias, ${ }^{56}$ que retardaram ou inibiram a densificação do AlN com $\mathrm{Y}_{2} \mathrm{O}_{3}$.

O AlN com $\mathrm{CaO}$ apresenta uma evaporação de compostos durante a sinterização, que tem sido observada em atmosfera tanto redutora ${ }^{57-59}$ como inerte ${ }^{60,61}$. Aditivos contendo cálcio e carbono $\left(\mathrm{CaC}_{2}\right.$ e $\left.\mathrm{CaCN}_{2}\right)$ foram utilizados para induzir a formação de uma atmosfera redutora no interior do corpo conformado durante a sinterização, ${ }^{26,62-64}$ visando à melhora da condutividade térmica do AlN. Porém, não se observaram estudos sobre o efeito da formação in situ de uma atmosfera redutora com carbono no comportamento de densificação do AlN com aditivo contendo cálcio. Assim, o presente capítulo teve como objetivo estudar o efeito da adição de carbono na densificação do AlN com aditivo contendo cálcio.

Como base para a compreensão do efeito da adição de $\mathrm{C}$ na densificação do AlN com aditivo contendo cálcio, apresenta-se inicialmente uma revisão sobre o comportamento de densificação do AlN com aditivo contendo cálcio. Esta revisão foi baseada em estudos realizados anteriormente pelo autor. ${ }^{60,61,186}$ 


\subsubsection{Sinterização do AIN com aditivo contendo cálcio}

O aditivo de sinterização à base de cálcio tem sido adicionado na forma de: i) óxido $(\mathrm{CaO})^{48,78,189}$; ii) carbonato $\left(\mathrm{CaCO}_{3}\right)^{40,43,60,61,69,190}$; iii) aluminato $\left[\mathrm{C}_{3} \mathrm{~A}\left(3 \mathrm{CaO} \cdot \mathrm{Al}_{2} \mathrm{O}_{3}\right)^{59,191} \mathrm{e}\right.$ $\mathrm{C}_{12} \mathrm{~A}_{7}\left(12 \mathrm{CaO} .7 \mathrm{Al}_{2} \mathrm{O}_{3}\right){ }^{58}$ ]; iv) cianeto $\left(\mathrm{CaCN}_{2}\right)^{62-64}$; v) fluoreto $\left(\mathrm{CaF}_{2}\right)^{74,75,139,179,192}$; vi) nitreto hidratado $\left(\mathrm{Ca}\left(\mathrm{NO}_{3}\right)_{2} \cdot 4 \mathrm{H}_{2} \mathrm{O}\right)^{37,59}$; e vii) carbeto $\left(\mathrm{CaC}_{2}\right)^{26,193}$.

Análogo ao observado para o AlN preparado com aditivo contendo ítrio, os aluminatos de cálcio se formam durante o aquecimento até a temperatura de sinterização. Os aluminatos de cálcio foram observados a partir de $1100^{\circ} \mathrm{C}$ nas amostras de $\mathrm{AlN}$ com diferentes teores de $\mathrm{CaCO}_{3}\left(0,9 \%\right.$ a $13,5 \%$ em massa). ${ }^{60,61}$ Estes resultados mostraram que a formação dos aluminatos de cálcio ocorre em temperaturas próximas daquelas observadas para a formação dos aluminatos de ítrio $\left(1125^{\circ} \mathrm{C}\right.$ ou $\left.1200^{\circ} \mathrm{C}\right)$.

O comportamento de densificação do AlN com aditivo contendo cálcio foi estudado por dilatometria, ${ }^{26,44,57,60,194}$ utilizando pós comerciais de AlN com área de superfície específica (ASE) próxima de $3,5 \mathrm{~m}^{2} / \mathrm{g}$. Uma ampla faixa de temperatura foi observada para o início de retração linear do $\mathrm{AlN}$ com $\mathrm{CaO}\left(1217^{\circ} \mathrm{C}-1500^{\circ} \mathrm{C}\right) .{ }^{26,44,57,60,194}$ Há trabalhos ${ }^{26,42,44}$ indicando que o início de retração linear do $\mathrm{AlN}$ com $\mathrm{CaO}$ está relacionado com a formação de fase líquida proveniente da fusão dos aluminatos de cálcio com baixa temperatura eutética. Streicher et al. ${ }^{195}$ indicaram que a adição de $\mathrm{CaCO}_{3}$ levou à formação de líquido em temperaturas tão baixas quanto $1400^{\circ} \mathrm{C}$, conforme sugerido pelo diagrama de equilíbrio de fases do sistema $\mathrm{CaO}-\mathrm{Al}_{2} \mathrm{O}_{3}$ (Fig. 4.1).

Komeya et al. ${ }^{69}$ estudaram o efeito do teor de $\mathrm{CaCO}_{3}$ na densificação do AlN. Eles observaram que a densidade aumentou significativamente em função do aumento do teor de $\mathrm{CaCO}_{3}$ e, então, indicaram que este comportamento está relacionado com a composição das segundas-fases formadas durante a sinterização. As amostras com maiores teores de $\mathrm{CaCO}_{3}$ apresentaram a fase $\mathrm{CA}\left(\mathrm{CaO} \cdot \mathrm{Al}_{2} \mathrm{O}_{3}\right)$, enquanto as amostras com menores teores de aditivo apresentaram as fases $\mathrm{CA}_{6}\left(\mathrm{CaO} .6 \mathrm{Al}_{2} \mathrm{O}_{3}\right), \mathrm{CA}_{2}\left(\mathrm{CaO} .2 \mathrm{Al}_{2} \mathrm{O}_{3}\right)$ e pequena quantidade de fase espinélio $\left(\gamma\right.$-AlON). Com base nestes resultados, Komeya et al. ${ }^{69}$ propuseram que as diferenças de densidade estão relacionadas com as diferentes temperaturas liquidus das fases de aluminato de cálcio (Fig. 4.1), pois a diminuição da temperatura de formação de fase líquida favorece a densificação por sinterização via fase líquida. 


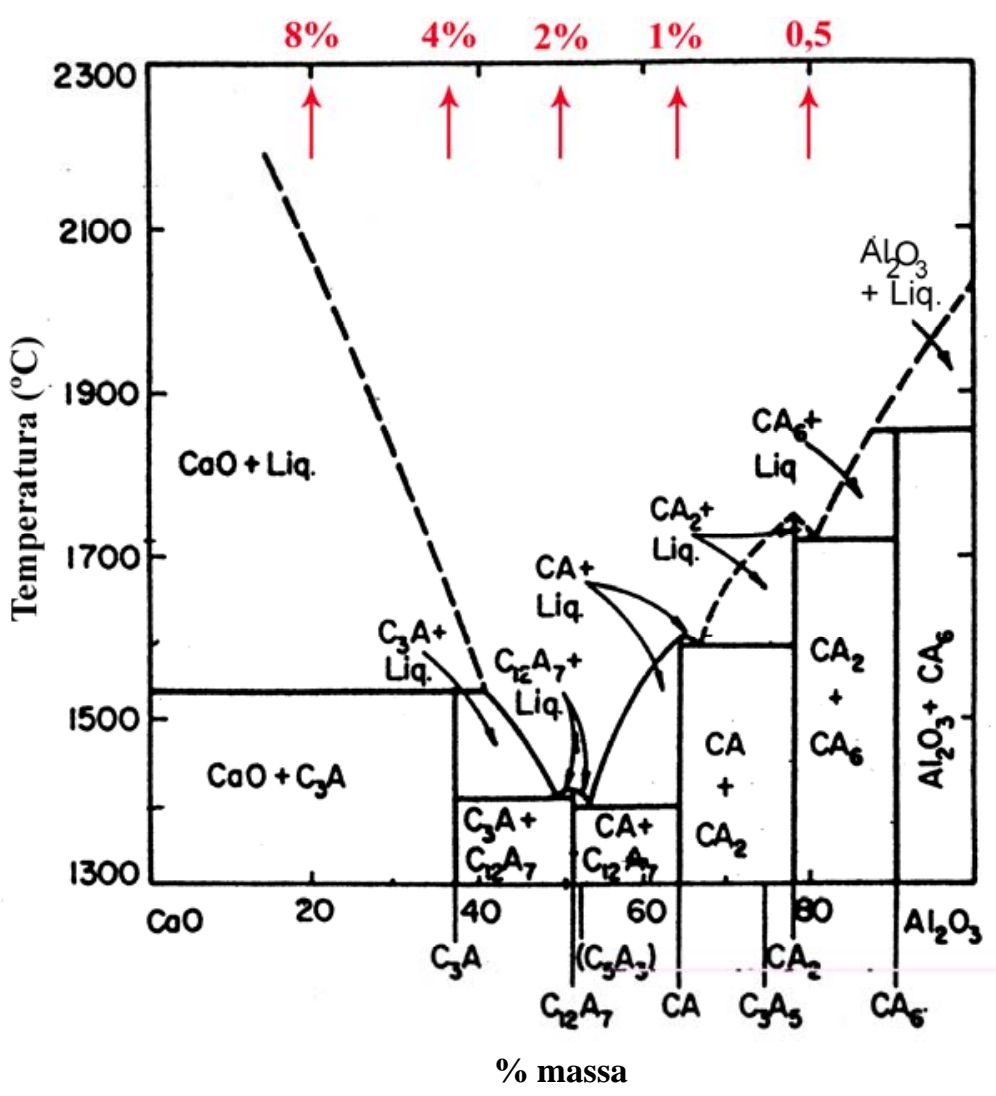

Figura 4.1-Diagrama de equilíbrio de fases do sistema CaO- $\mathrm{Al}_{2} \mathrm{O}_{3} \cdot{ }^{181} \mathrm{C}_{3} \mathrm{~A} \quad\left(3 \mathrm{CaO} . \mathrm{Al}_{2} \mathrm{O}_{3}\right), \mathrm{C}_{12} \mathrm{~A}_{7}$ $\left(12 \mathrm{CaO} .7 \mathrm{Al}_{2} \mathrm{O}_{3}\right), \mathrm{C}_{5} \mathrm{~A}_{3}\left(5 \mathrm{CaO} .3 \mathrm{Al}_{2} \mathrm{O}_{3}\right), \mathrm{CA}\left(\mathrm{CaO} . \mathrm{Al}_{2} \mathrm{O}_{3}\right), \mathrm{CA}_{2}\left(\mathrm{CaO} .2 \mathrm{Al}_{2} \mathrm{O}_{3}\right), \mathrm{C}_{3} \mathrm{~A}_{5}\left(3 \mathrm{CaO} .5 \mathrm{Al}_{2} \mathrm{O}_{3}\right)$ e $\mathrm{CA}_{6}$ $\left(\mathrm{CaO} .6 \mathrm{Al}_{2} \mathrm{O}_{3}\right)$. As setas indicam as composições inicias esperadas nos corpos conformados de pó de AlN com $0,85 \%$ em massa de oxigênio e adição de $0,5 \%$ a $8 \%$ em massa de $\mathrm{CaO}$.

Outros trabalhos observaram o mesmo comportamento de mudança da composição dos aluminatos de cálcio em função do teor de $\mathrm{CaCO}_{3}$. ${ }^{60,61}$ Por exemplo, o AlN com baixo teor de $\mathrm{CaCO}_{3}\left(0,9 \%\right.$ e $1,8 \%$ em massa) apresentou as fases $\mathrm{CA}_{2}$ e/ou $\mathrm{CA}_{6},{ }^{60,61}$ enquanto o AlN com maiores teores de $\mathrm{CaCO}_{3}(3,5 \%$ a 13,5\% em massa) apresentou pelo menos uma das seguintes fases: $\mathrm{C}_{3} \mathrm{~A}\left(3 \mathrm{CaO} . \mathrm{Al}_{2} \mathrm{O}_{3}\right), \mathrm{C}_{12} \mathrm{~A}_{7}\left(12 \mathrm{CaO} .7 \mathrm{Al}_{2} \mathrm{O}_{3}\right)$ e $\mathrm{CA}$. As amostras com alto teor de $\mathrm{CaCO}_{3}$ apresentaram curvas de densificação deslocadas para menores temperaturas em relação às demais amostras com baixo teor de aditivo. Como as fases $\mathrm{C}_{3} \mathrm{~A}, \mathrm{C}_{12} \mathrm{~A}_{7}$ e $\mathrm{CA}$ são relacionadas com a fase líquida a partir de $1390^{\circ} \mathrm{C}$ (Fig. 4.1), concluiu-se que estas segundas-fases ricas em $\mathrm{CaO}$ levaram à formação de líquido em menores temperaturas, ${ }^{60,61}$ o que favoreceu a densificação do AlN por sinterização via fase líquida. Por outro lado, a formação de segundas-fases ricas em $\mathrm{Al}_{2} \mathrm{O}_{3}\left(\mathrm{CA}_{2}\right.$ e $\left.\mathrm{CA}_{6}\right)$, cujas temperaturas eutéticas são previstas a partir de $1589^{\circ} \mathrm{C}$ (Fig. 4.1), atrasou a densificação do $\mathrm{AlN}$ com baixo teor de $\mathrm{CaCO}_{3}$, pois a formação de fase líquida ocorreu em maiores temperaturas de sinterização. 
Como o aumento do teor de aditivo contendo cálcio promoveu a formação de fase líquida em menor temperatura ${ }^{60,61,69}$ e, sabendo que a temperatura de sinterização pode ser diminuída com a diminuição da temperatura de formação de fase líquida, ${ }^{69}$ esperava-se que o AlN com aditivo contendo cálcio alcançasse máxima densidade em menor temperatura do que o AlN com aditivo contendo ítrio, pois a temperatura eutética mais baixa prevista para o sistema $\mathrm{AlN}-\mathrm{Al}_{2} \mathrm{O}_{3}-\mathrm{Y}_{2} \mathrm{O}_{3}$ é $1720^{\circ} \mathrm{C}$. ${ }^{182}$ Porém, o AlN com aditivo contendo cálcio ou ítrio atinge máxima densificação em temperaturas relativamente próximas $\left(\sim 1800^{\circ} \mathrm{C}\right) .{ }^{43,54,61,64,69}$ Estes resultados sugerem que a densificação do AlN com aditivo contendo cálcio é lenta, pois necessita de "grandes" superaquecimentos $\left(>300^{\circ} \mathrm{C}\right)$ acima da menor temperatura eutética prevista no diagrama de fases do sistema $\mathrm{CaO}-\mathrm{Al}_{2} \mathrm{O}_{3}\left(\sim 1390^{\circ} \mathrm{C}\right.$, Fig. 4.1). Há relatos sobre a obtenção de cerâmicas densas de $\mathrm{AlN}$ com aditivo contendo cálcio entre $1550^{\circ} \mathrm{C}$ e $1650^{\circ} \mathrm{C},{ }^{57,58,195}$ mas mesmo nestes casos o superaquecimento usado foi relativamente maior do que o observado para o AlN com aditivo contendo ítrio. ${ }^{186,187}$

Embora tenha sido relatado que o aumento do teor de aditivo contendo cálcio favorece a densificação do AlN em menores temperaturas, ${ }^{62-64,69}$ observou-se, em alguns trabalhos, ${ }^{40,53,60,61,195}$ que o aumento do teor de aditivo contendo cálcio causou uma diminuição significativa de densidade. A Figura 4.2 apresenta dados compilados da literatura, onde se observou tanto o aumento como a diminuição de densidade em função do teor de aditivo contendo cálcio. O termo "teor equivalente de $\mathrm{CaO}$ " na abscissa da Figura 4.2 indica o teor equivalente de $\mathrm{CaO}$ produzido a partir da decomposição do $\mathrm{CaCO}_{3}$ ou $\mathrm{CaCN}_{2}$ usados como aditivo de sinterização. A diminuição de densidade com o aumento do teor equivalente de $\mathrm{CaO}$ (Fig. 4.2) é um indicativo de que a densificação do AlN foi prejudicada pelo aumento do teor de aditivo. Jarrige et al. ${ }^{40}$ observaram que a diminuição de densidade do AlN em função do teor de $\mathrm{CaCO}_{3}$ foi incoerente com a evolução das segundas-fases formadas durante a sinterização. Eles indicaram que as fases de aluminato, tais como $\mathrm{CA}$ e $\mathrm{C}_{12} \mathrm{~A}_{7}$, são líquidas a $1600^{\circ} \mathrm{C}$, mas que apresentam alta viscosidade e/ou baixa molhabilidade sobre os grãos de AlN nesta temperatura, o que resultou na formação de poros e, conseqüentemente, na limitação da densificação do AlN. 


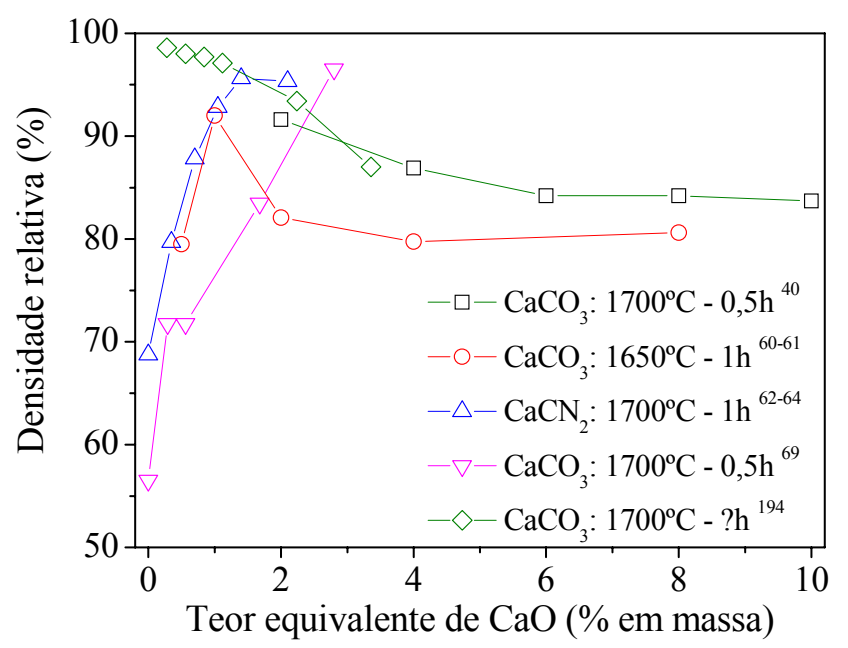

Figura 4.2 - Dados compilados da literatura ${ }^{40,60-64,69,195}$ referente à densidade em função do teor equivalente de $\mathrm{CaO}$ para amostras de $\mathrm{AlN}$ sinterizadas a $1650^{\circ} \mathrm{C}$ e $1700^{\circ} \mathrm{C}$.

A Figura 4.3a apresenta uma imagem de MEV da superfície de fratura do AlN com $13,5 \%$ de $\mathrm{CaCO}_{3}(8 \%$ de $\mathrm{CaO})$ sinterizado a $1500^{\circ} \mathrm{C}$, onde se observou pequenos aglomerados de partículas, assim como partículas grandes de segundas-fases com aspecto coalescido. A presença de aglomerados de partículas é um indicativo de que o mecanismo de rearranjo de partículas da sinterização via fase líquida foi ativado. Porém, o tamanho dos aglomerados foi relativamente pequeno (Fig. 4.3a), sugerindo que o mecanismo de rearranjo de partículas foi pouco efetivo durante a sinterização a $1500^{\circ} \mathrm{C}$. O aspecto coalescido das partículas grandes de segundas-fases (Fig. 4.3a) indicou uma provável fusão das referidas partículas, mas devido à alta viscosidade e/ou baixa molhabilidade destas segundas-fases, a fase líquida não se espalhou pela microestrutura durante a sinterização. Como o $\mathrm{AlN}$ com $13,5 \%$ de $\mathrm{CaCO}_{3}(8 \%$ de $\mathrm{CaO}$ ) apresentou as fases $\mathrm{C}_{3} \mathrm{~A}$ e $\mathrm{C}_{12} \mathrm{~A}_{7}$ entre $1500^{\circ} \mathrm{C}$ e $1700^{\circ} \mathrm{C},{ }^{60,61}$ pode-se dizer que as partículas grandes de segundas-fases (Fig. 4.3a) apresentaram uma composição próxima da fase $\mathrm{C}_{12} \mathrm{~A}_{7}$, pois esta fase pode apresentar alta viscosidade e/ou baixa molhabilidade no AlN em temperaturas tão altas quanto $1600^{\circ} \mathrm{C} .{ }^{40}$

A formação das partículas grandes de segundas-fases foi decorrente da utilização de $\mathrm{CaCO}_{3}$ com larga distribuição granulométrica em relação ao AlN. ${ }^{60,61}$ As partículas grandes de $\mathrm{CaCO}_{3}$ reagiram com as partículas de AlN durante o aquecimento, formando partículas grandes de aluminatos de cálcio (Fig. 4.3a). Estas partículas grandes fundiram com o aumento da temperatura de sinterização $\left(>1500^{\circ} \mathrm{C}\right)$ e, então, a fase líquida migrou por entre as partículas primárias de AIN. Isto causou uma densificação significativa da matriz devido à ativação do mecanismo de rearranjo de partículas da sinterização via fase líquida (Fig. 4.3b), mas os sítios anteriormente ocupados pelas partículas grandes de segundas-fases ficaram 
vazios, o que deu origem aos poros grandes. A eliminação destes poros da microestrutura foi difícil, ${ }^{60,61}$ mesmo usando altas temperaturas de sinterização $\left(>1850^{\circ} \mathrm{C}\right)$. O AlN com aditivo contendo cálcio apresenta significativa evaporação de compostos durante a sinterização em atmosfera tanto redutora ${ }^{40,58}$ como inerte ${ }^{60,61}$. Portanto, o gás proveniente desta evaporação pode ficar aprisionado no interior dos poros fechados durante a sinterização, o que limita a densificação em decorrência da estabilização dos poros em altas temperaturas. ${ }^{60-62}$
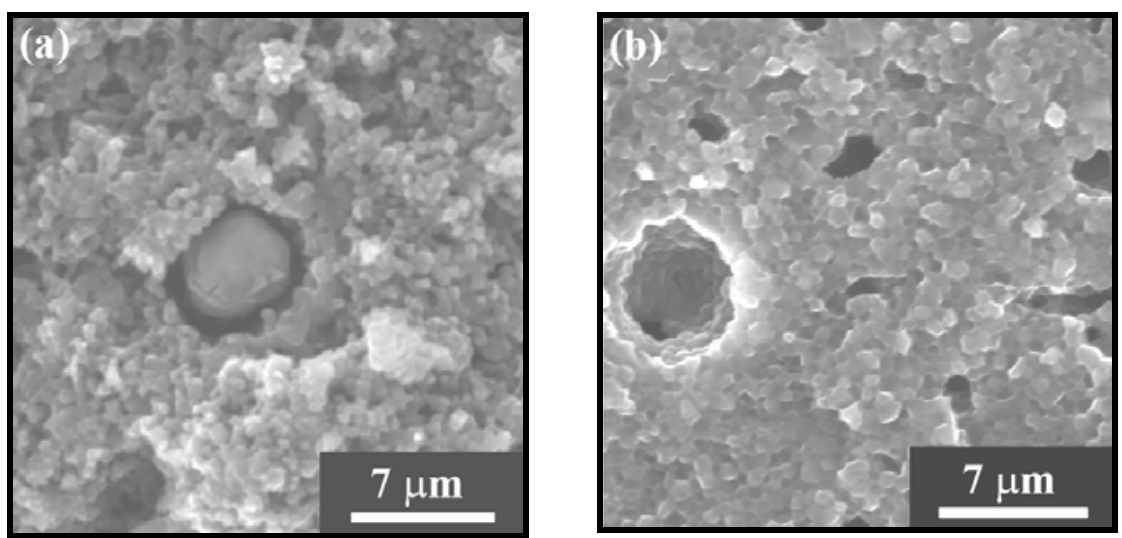

Figura 4.3 - Imagens de MEV da superfície de fratura do AlN com 13,5\% em massa de $\mathrm{CaCO}_{3}$ sinterizado a $1500^{\circ} \mathrm{C}$ (a) e $7 \%$ em massa de $\mathrm{CaCO}_{3}$ sinterizado a $1750^{\circ} \mathrm{C}$ (b). ${ }^{61}$

Em relação ao comportamento de densificação do AlN com aditivo contendo cálcio, os resultados apresentados levaram às seguintes conclusões: i) a formação de aluminatos ricos em $\mathrm{CaO}$ favorece a formação de fase líquida em baixas temperaturas $\left(\leq 1500^{\circ} \mathrm{C}\right),{ }^{60,61}$ mas o espalhamento do líquido pela microestrutura é limitado devido à sua alta viscosidade e/ou baixa molhabilidade abaixo de $1600^{\circ} \mathrm{C} ;{ }^{40,61,196}$ isto diminui a ação efetiva do mecanismo de rearranjo de partículas da sinterização via fase líquida em temperaturas baixas $\left(\leq 1600^{\circ} \mathrm{C}\right)$; ii) pequena adição de composto contendo cálcio promoveu a formação de aluminatos de cálcio mais refratários $\left(\mathrm{CA}_{2}\right.$ e $\left.\mathrm{CA}_{6}\right),{ }^{60,61,69}$ cujas temperaturas eutéticas são previstas a partir de $1589^{\circ} \mathrm{C}$ (Fig. 4.1); isto aumenta a temperatura de formação de fase líquida, o que resulta no atraso da densificação do AlN abaixo de $1600^{\circ} \mathrm{C}$; ${ }^{60,61}$ iii) a utilização de aditivos de sinterização $\left(\mathrm{CaCO}_{3}\right.$ ou $\left.\mathrm{CaO}\right)$ com larga distribuição granulométrica leva à formação de poros grandes, ${ }^{60,61}$ que retarda a densificação do AlN em decorrência da dificuldade para eliminálos da microestrutura, sendo necessário o uso de elevadas temperaturas de sinterização $\left(>1800^{\circ} \mathrm{C}\right)$; e iv) o aprisionamento de gás no interior dos poros fechados pode limitar a densificação do AlN devido à estabilização dos poros durante a sinterização em alta temperatura. ${ }^{60-62}$ Estes fatores contribuem para o aumento da temperatura de sinterização do 
AlN com aditivo contendo cálcio, ${ }^{186,187}$ fazendo com que sua completa densificação aconteça na mesma faixa de temperatura do AlN com aditivo contendo ítrio, que pode apresentar formação de fase líquida somente em altas temperaturas $\left(\geq 1720^{\circ} \mathrm{C}\right)$.

\subsubsection{Evolução das segundas-fases do AIN com aditivo contendo cálcio}

Há poucos estudos sobre o comportamento de evolução das segundas-fases durante a sinterização do AlN com aditivo contendo cálcio. ${ }^{58,60,61}$ Há relatos sobre o efeito da formação in situ de uma atmosfera redutora com $\mathrm{C}$ na densificação e/ou condutividade térmica do AlN com aditivo contendo ítrio, ${ }^{18,49,55}$ mas não se observou este tipo de estudo para o AlN com aditivo contendo cálcio.

Durante a sinterização do AlN com aditivo contendo cálcio, observou-se que o teor de cálcio $(\mathrm{Ca})$ ou $\mathrm{CaO}$ diminuiu significativamente em função do aumento de temperatura e/ou tempo de sinterização, ${ }^{57,59-61}$ sendo este resultado independente da atmosfera de sinterização (redutora ou inerte). Em alguns trabalhos, ${ }^{62-64,80,197}$ a evaporação de segundas-fases foi tão significativa, que a identificação das mesmas ocorreu somente por microscopia eletrônica de transmissão. Estes resultados indicaram uma volatilização significativa de compostos durante a sinterização do AlN com aditivo contendo cálcio. Jarrige et al. ${ }^{40}$ observaram elevada perda de massa em amostras de $\mathrm{AlN}$ com $\mathrm{CaCO}_{3}$ sinterizadas sob atmosfera redutora na temperatura de $1600^{\circ} \mathrm{C}$. Esta perda de massa foi correlacionada com a migração de fase líquida para a camada protetora de pó de AlN colocada no fundo do cadinho de grafita e/ou a evaporação de cálcio durante a sinterização em alta temperatura. Hagen et al. ${ }^{58}$ indicaram que a utilização de uma camada protetora de pó de AlN favorece a evaporação de compostos (aumento da perda de massa), independente da atmosfera existente ao redor das amostras durante a sinterização. Além disso, os autores indicaram que, durante a sinterização em altas temperaturas, pode acontecer uma elevada evaporação de compostos devido às altas pressões de vapor geradas por reações químicas entre o AlN e os aditivos óxidos. Com base em dados termodinâmicos, Hagen et al. ${ }^{58}$ propuseram duas reações químicas, que descrevem a evaporação de compostos durante a sinterização do AlN com aditivo contendo cálcio:

$$
\mathrm{Al}_{2} \mathrm{CaO}_{4}+6 \mathrm{AlN} \leftrightarrow \mathrm{Ca}_{(\mathrm{g})}+4 \mathrm{Al}_{2} \mathrm{O}_{(\mathrm{g})}+\mathrm{N}_{2(\mathrm{~g})}
$$




$$
\mathrm{Al}_{2} \mathrm{CaO}_{4}+\frac{2}{3} \mathrm{AlN} \leftrightarrow \mathrm{Ca}(\mathrm{g})+\frac{4}{3} \mathrm{Al}_{2} \mathrm{O}_{3}+\frac{1}{3} \mathrm{~N}_{2(\mathrm{~g})}
$$

As reações 4.1 e 4.2 mostram que a evaporação de compostos durante a sinterização do AlN com aditivo contendo cálcio não depende da presença de uma atmosfera redutora. Embora a pressão de vapor do $\mathrm{CaO}$ seja maior do que a do $\mathrm{Al}_{2} \mathrm{O}_{3}$ acima de $1400^{\circ} \mathrm{C},{ }^{61}$ a evolução das segundas-fases no AlN com aditivo contendo cálcio não apresentou uma tendência para formar fases mais ricas em $\mathrm{Al}_{2} \mathrm{O}_{3}$. A Figura 4.4 apresenta o diagrama de evolução das segundas-fases no $\mathrm{AlN}$ com $\mathrm{CaCO}_{3}$ sinterizado sob atmosfera não redutora. ${ }^{60,61}$ As amostras foram sinterizadas entre $1100^{\circ} \mathrm{C}$ e $1950^{\circ} \mathrm{C}$ por $1 \mathrm{~h}$ e as segundas-fases foram identificadas por DRX. Este diagrama foi construído com base no diagrama de fases da Figura 4.1. As linhas tracejadas verticais observadas no diagrama correspondem às temperaturas de reação invariante como o líquido, enquanto as linhas tracejadas horizontais demarcam os campos de duas fases. A composição dos corpos compactados foi determinada em função da quantidade de aditivo e do teor de $\mathrm{Al}_{2} \mathrm{O}_{3}$ presente na superfície do pó de $\mathrm{AlN}$.

A composição das fases de aluminato de cálcio variou em função do teor de aditivo de sinterização, sendo observadas duas rotas distintas de evolução das segundas-fases. Entre $1300^{\circ} \mathrm{C}$ e $1600^{\circ} \mathrm{C}$, a evolução das segundas-fases no $\mathrm{AlN}$ com $0,9 \%$ e $1,8 \%$ de $\mathrm{CaCO}_{3}$ (correspondendo a $0,5 \%$ e $1 \%$ em teor equivalente de $\mathrm{CaO}$, respectivamente) mostrou uma tendência para seguir pelo lado mais rico em $\mathrm{Al}_{2} \mathrm{O}_{3}$ no diagrama (Fig. 4.4). Nesta mesma faixa de temperatura, a evolução das segundas-fases no $\mathrm{AlN}$ com 3,5\% a $13,5 \%$ de $\mathrm{CaCO}_{3}$ (correspondendo a $2 \%$ a $8 \%$ em teor equivalente de $\mathrm{CaO}$, respectivamente) mostrou uma tendência para seguir pelo lado mais rico em $\mathrm{CaO}$ no diagrama (Fig. 4.4). Porém, acima de $1600^{\circ} \mathrm{C}$, todas as rotas de evolução das segundas-fases convergiram para uma composição próxima da fase CA (Fig. 4.4). Estes resultados indicaram que, durante a sinterização do AlN com aditivo contendo cálcio, a fase CA é mais estável do que as demais fases de aluminato de cálcio em altas temperaturas, sugerindo que as segundas-fases podem apresentar evaporação tanto de $\mathrm{Al}_{2} \mathrm{O}_{3}$ como de $\mathrm{CaO}$ para atingir uma composição química mais estável em alta temperatura. ${ }^{61}$ 


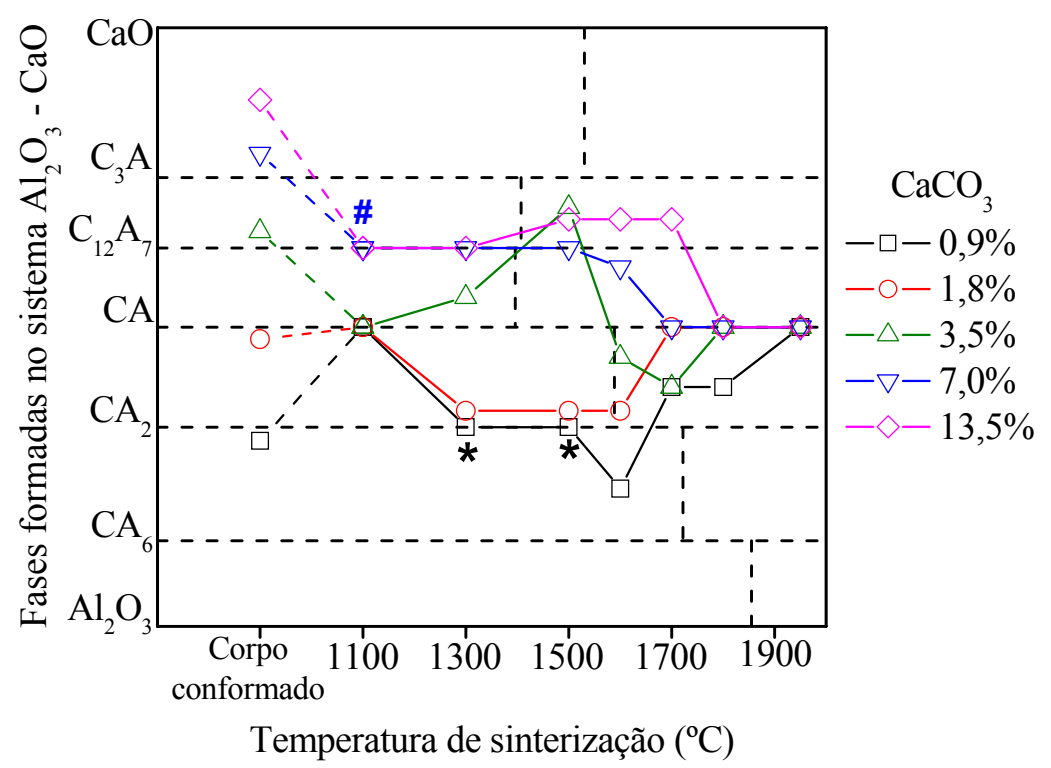

Figura 4.4 - Diagrama esquemático da evolução das segundas-fases no $\mathrm{AlN}$ com $\mathrm{CaCO}_{3}$ sinterizado em várias temperaturas. Os teores $0,9 \%, 1,8 \%, 3,5 \%, 7,0 \%$ e $13,5 \%$ em massa de $\mathrm{CaCO}_{3}$ correspondem a $0,5 \%, 1 \%, 2 \%$, $4 \%$ e $8 \%$ em massa de $\mathrm{CaO}$, respectivamente. $\mathrm{O}$ símbolo \# indica a presença de uma pequena fração da fase $\mathrm{C}_{5} \mathrm{~A}_{3}$, que é metaestável e apresenta composição próxima da fase $\mathrm{C}_{12} \mathrm{~A}_{7}$. $\mathrm{O}$ símbolo * indica a presença de uma pequena fração da fase $\mathrm{Al}_{2} \mathrm{O}_{3}$. As fases $\mathrm{C}_{3} \mathrm{~A}, \mathrm{C}_{12} \mathrm{~A}_{7}, \mathrm{CA}, \mathrm{CA}_{2}$ e $\mathrm{CA}_{6}$ correspondem aos compostos $3 \mathrm{CaO} \mathrm{Al}_{2} \mathrm{O}_{3}$, $12 \mathrm{CaO} .7 \mathrm{Al}_{2} \mathrm{O}_{3}, \mathrm{CaO} . \mathrm{Al}_{2} \mathrm{O}_{3}, \mathrm{CaO} .2 \mathrm{Al}_{2} \mathrm{O}_{3}$ e $\mathrm{CaO} .6 \mathrm{Al}_{2} \mathrm{O}_{3}$, respectivamente. ${ }^{60,61}$

\subsection{Materiais e métodos}

$\mathrm{O}$ aditivo de sinterização usado foi o pó de $\mathrm{CaCO}_{3}$ (Anidrol Produtos Químicos, Brasil). As demais matérias-primas, bem como as metodologias de processamento cerâmico e de caracterização dos materiais foram apresentadas no item 3.2. Os cartões JCPDS utilizados na interpretação dos difratogramas de raios $\mathrm{X}$ das amostras de $\mathrm{AlN}$ sinterizadas entre $1650^{\circ} \mathrm{C}$ e $1850^{\circ} \mathrm{C}$ foram: 25-1133 (AlN), 09-0413 $\left(\mathrm{C}_{12} \mathrm{~A}_{7}, 12 \mathrm{CaO} .7 \mathrm{Al}_{2} \mathrm{O}_{3}\right)$ e $34-0440$ (CA, $\mathrm{CaO} . \mathrm{Al}_{2} \mathrm{O}_{3}$ ). A Tabela 4.1 apresenta as composições e identificações das amostras de AlN estudadas neste capítulo.

Tabela 4.1 - Composições e identificações das amostras de AlN.

\begin{tabular}{l|c}
\hline Composição (\% em massa) & Identificação da amostra \\
\hline $4 \% \mathrm{CaO}^{*}$ & $4 \mathrm{Ca}$ \\
\hline $4 \% \mathrm{CaO}^{*}$ e $0,5 \% \mathrm{C}$ & $4 \mathrm{Ca} 05 \mathrm{C}$ \\
\hline $4 \% \mathrm{CaO}^{*}$ e $1,0 \% \mathrm{C}$ & $4 \mathrm{Ca} 1 \mathrm{C}$ \\
\hline
\end{tabular}

*O aditivo foi adicionado na forma de $\mathrm{CaCO}_{3}$, sendo usada a seguinte relação de massa molecular $\mathrm{M}_{\mathrm{CaO}} / \mathrm{M}_{\mathrm{CaCO}_{3}}=0,55$ para estimar o valor do aditivo na forma de óxido. 


\subsection{Resultados experimentais}

\subsubsection{Caracterização dos pós de partida}

O pó de AIN apresentou estreita distribuição granulométrica em relação ao pó de $\mathrm{CaCO}_{3}$ (Fig. 4.5a). O tamanho médio de partícula do AlN foi $0,9 \mu \mathrm{m}$ (valor referente à $50 \%$ em volume acumulado, Fig. 4.5a), enquanto o pó de $\mathrm{CaCO}_{3}$ apresentou tamanho médio de partícula de 5,7 $\mu \mathrm{m}$. O pó de AlN apresentou partículas com tamanho igual a $2 \mu \mathrm{m}$ para $90 \%$ em volume acumulado (Fig. 4.5a), enquanto o pó de $\mathrm{CaCO}_{3}$ apresentou partículas com tamanho superior a $20 \mu \mathrm{m}$ para a mesma porcentagem em volume. As partículas primárias do pó de AlN tenderam a forma isométrica (Fig. 3.3a), enquanto as partículas do pó de $\mathrm{CaCO}_{3}$ tenderam a forma de pequenos cristais aglomerados (Fig. 4.5b). Já as partículas do pó de grafita (C) tenderam a forma de placas irregulares (Fig. 3.3c), cujo tamanho variou de alguns poucos micrometros até cerca de $20 \mu \mathrm{m}$.
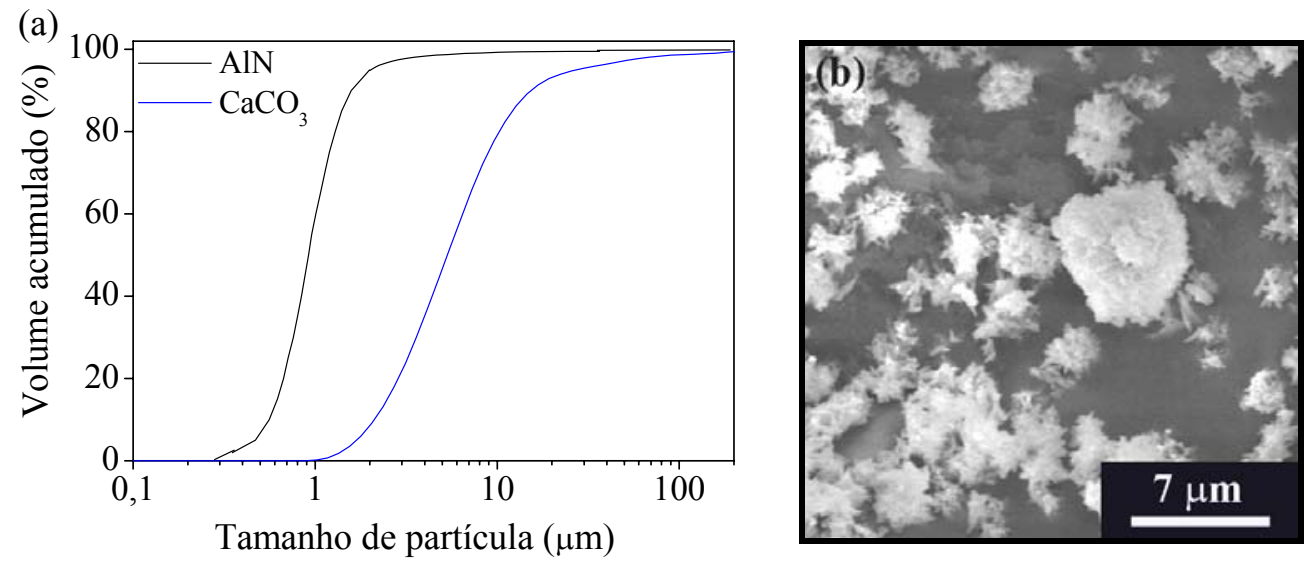

Figura 4.5 - Distribuição granulométrica dos pós de partida de $\mathrm{AlN}$ e $\mathrm{CaCO}_{3}$ (a) e imagem de $\mathrm{MEV}$ das partículas do pó de $\mathrm{CaCO}_{3}$ (b).

\subsubsection{Densificação}

A adição de carbono (C) limitou a densificação da amostra 4Ca (Fig. 4.6), como observado para a amostra 4Y (Fig. 3.12). As diferenças de densidade entre as amostras sem e 
com $\mathrm{C}$ sinterizadas entre $1650^{\circ} \mathrm{C}$ e $1750^{\circ} \mathrm{C}$ (Fig. 4.6) foram, em média, menores do que aquelas observadas para o AlN com $4 \%$ de $\mathrm{Y}_{2} \mathrm{O}_{3}$ (Fig. 3.12). Isto indicou que a adição de $\mathrm{C}$ foi menos prejudicial à densificação do $\mathrm{AlN}$ com $4 \%$ de $\mathrm{CaO}$. As amostras $4 \mathrm{Ca}, 4 \mathrm{Ca} 05 \mathrm{C}$ e 4Ca1C sinterizadas a $1800^{\circ} \mathrm{C}$ atingiram valores próximos de densidade ( 95\% DT, Fig. 4.6), como observado para o AlN com $\mathrm{Y}_{2} \mathrm{O}_{3}$ (Fig. 3.12). O aumento da temperatura de sinterização de $1800^{\circ} \mathrm{C}$ para $1850^{\circ} \mathrm{C}$ causou um leve aumento de densidade para a amostra $4 \mathrm{Ca}(\sim 97 \% \mathrm{DT}$, Fig. 4.6), enquanto as amostras $4 \mathrm{Ca} 05 \mathrm{C}$ e $4 \mathrm{Ca} 1 \mathrm{C}$ não apresentaram praticamente aumento de densidade ( 95\% DT).

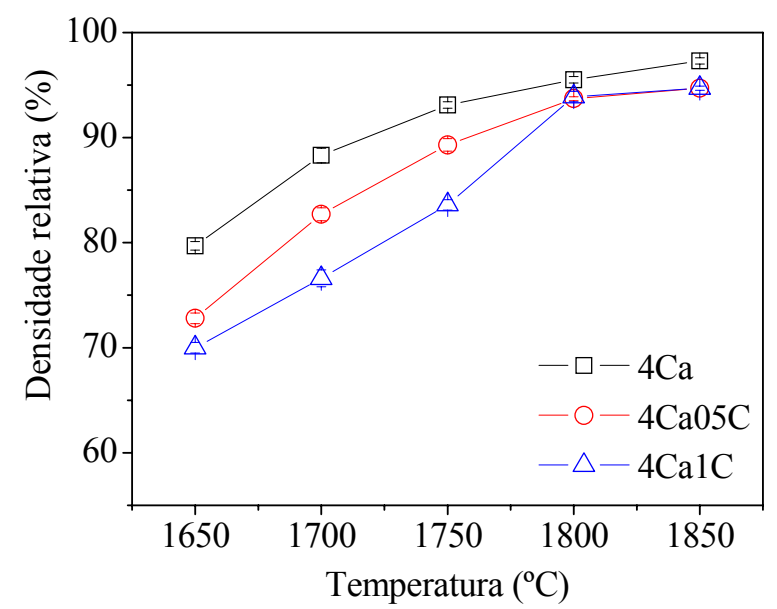

Figura 4.6 - Densidade relativa em função da temperatura de sinterização das amostras 4Ca, 4Ca05C e 4Ca1C.

\subsubsection{Perda de massa e evolução das segundas-fases}

A perda de massa da amostra $4 \mathrm{Ca}$ sinterizada a $1650^{\circ} \mathrm{C}$ foi próxima de $4 \%$ (Fig. 4.7) e, então, aumentou para aproximadamente $4,5 \%$ após a sinterização na temperatura de $1700^{\circ} \mathrm{C}$. $\mathrm{O}$ aumento da temperatura de $1700^{\circ} \mathrm{C}$ para $1750^{\circ} \mathrm{C}$ não mudou o valor de perda de massa da amostra 4Ca (Fig. 4.7). Embora a perda de massa da amostra 4Ca tenha apresentado uma pequena diminuição $(\sim 3,6 \%)$ entre $1750^{\circ} \mathrm{C}$ e $1800^{\circ} \mathrm{C}$ (Fig. 4.7$)$, observou-se um aumentou significativo $(\sim 6 \%)$ de perda de massa entre $1800^{\circ} \mathrm{C}$ e $1850^{\circ} \mathrm{C}$. Desconsiderando a perda esperada de $\mathrm{CO}_{2}(\sim 3 \%)$, oriunda da decomposição do $\mathrm{CaCO}_{3}^{\dagger \dagger}$, pode-se dizer que a perda de massa da amostra $4 \mathrm{Ca}$ sinterizada até $1800^{\circ} \mathrm{C}$ foi, em média, de $1 \%$ e cerca de $3 \%$ após a sinterização na temperatura de $1850^{\circ} \mathrm{C}$. Estes resultados indicaram que a amostra $4 \mathrm{Ca}$

${ }^{\dagger} \mathrm{CaCO}_{3} \leftrightarrow \mathrm{CaO}+\mathrm{CO}_{2}$ 
apresentou evaporação de compostos durante a sinterização sob atmosfera não redutora, principalmente acima de $1800^{\circ} \mathrm{C}$.

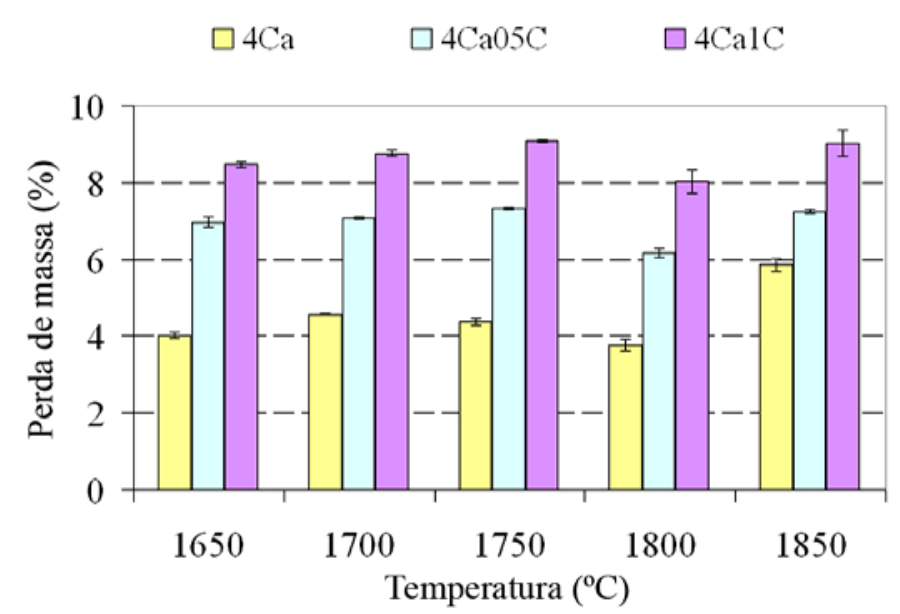

Figura 4.7 - Perda de massa em função da temperatura de sinterização das amostras 4Ca, 4Ca05C e 4Ca1C.

As amostras $4 \mathrm{Ca} 05 \mathrm{C}$ e $4 \mathrm{Ca} 1 \mathrm{C}$ apresentaram perdas de massa significativamente maiores do que a amostra $4 \mathrm{Ca}$ (Fig. 4.7). As perdas de massa esperadas pela oxidação do $\mathrm{C}^{\dagger}$ foram próximas de $2 \%$ e $4 \%$ para as adições de $0,5 \%$ e $1 \%$ de $C$, respectivamente. Somando estes valores de perda de massa com a perda esperada pela decomposição do $\mathrm{CaCO}_{3}(\sim 3 \%)$, pode-se dizer que as perdas de massa decorrentes das decomposições dos aditivos $\left(\mathrm{CaCO}_{3} \mathrm{e}\right.$ C) foram próximas de 5\% e 7\% para as amostras $4 \mathrm{Ca} 05 \mathrm{C}$ e $4 \mathrm{Ca} 1 \mathrm{C}$, respectivamente. A perda de massa variou aproximadamente de $6 \%$ a 7,5\% para a amostra $4 \mathrm{Ca} 05 \mathrm{C}$ e de $8 \%$ a $9 \%$ para a amostra 4Ca1C (Fig. 4.7). Estes resultados mostraram que a adição de C intensificou a evaporação de compostos durante a sinterização entre $1650^{\circ} \mathrm{C}$ e $1850^{\circ} \mathrm{C}$.

Os resultados de DRX das amostras $4 \mathrm{Ca}, 4 \mathrm{Ca} 05 \mathrm{C}$ e $4 \mathrm{Ca} 1 \mathrm{C}$ sinterizadas entre $1650^{\circ} \mathrm{C} \mathrm{e}$ $1850^{\circ} \mathrm{C}$ são apresentados na Tabela 4.2. Os resultados da amostra $4 \mathrm{Ca}\left(7 \%\right.$ de $\mathrm{CaCO}_{3} \approx 4 \%$ de $\mathrm{CaO}$ ) foram compilados da Figura 4.4. A amostra $4 \mathrm{Ca}$ sinterizada a $1650^{\circ} \mathrm{C}$ apresentou em ordem de preponderância as fases $\mathrm{C}_{12} \mathrm{~A}_{7}$ e CA (Tabela 4.2). $\mathrm{O}$ aumento da temperatura de sinterização, acima de $1650^{\circ} \mathrm{C}$, levou somente à formação da fase $\mathrm{CA}$ na amostra $4 \mathrm{Ca}$ (Tabela 4.2). Estes resultados mostraram que a composição das segundas-fases mudou de $\mathrm{C}_{12} \mathrm{~A}_{7}$ para CA com o aumento da temperatura de sinterização, o que sugeriu uma evaporação preferencial de $\mathrm{CaO}$ durante a sinterização da amostra $4 \mathrm{Ca}$ sob atmosfera não redutora. Entretanto, observou-se que, durante a sinterização do AlN com aditivo contendo cálcio, pode ocorrer a evaporação tanto de $\mathrm{CaO}$ como de $\mathrm{Al}_{2} \mathrm{O}_{3},{ }^{61}$ pois as segundas-fases mostraram uma $\mathrm{H}+\mathrm{O}_{2} \leftrightarrow \mathrm{CO}_{2}$ 
tendência para convergir para uma composição próxima da fase CA com o aumento da temperatura de sinterização (Fig. 4.4). Estes resultados sugeriram que a fase CA é mais estável em altas temperaturas $\left(>1600^{\circ} \mathrm{C}\right)$ do que as demais fases de aluminato de cálcio. ${ }^{60,61}$

Tabela 4.2 - Resultados de DRX das segundas-fases nas amostras 4Ca, 4Ca05C e 4Ca1C.

\begin{tabular}{c|c|c|c}
\hline \multirow{2}{*}{ Temperatura $\left({ }^{\circ} \mathbf{C}\right)$} & \multicolumn{3}{|c}{ Segundas-fases em ordem de preponderância } \\
\cline { 2 - 4 } & $\mathbf{4 C a}$ & $\mathbf{4 C a 0 5 C}$ & 4Ca1C \\
\hline $\mathbf{1 6 5 0}$ & $\mathrm{C}_{12} \mathrm{~A}_{7}, \mathrm{CA}$ & $\mathrm{CA}_{12} \mathrm{~A}_{7}$ & $\mathrm{CA}$ \\
\hline $\mathbf{1 7 0 0}$ & $\mathrm{CA}$ & $\mathrm{CA}$ & $\mathrm{CA}$ \\
\hline $\mathbf{1 7 5 0}$ & $\mathrm{CA}$ & $\mathrm{CA}$ & $\mathrm{CA}$ \\
\hline $\mathbf{1 8 0 0}$ & $\mathrm{CA}$ & $\mathrm{CA}$ & $\mathrm{CA}$ \\
\hline $\mathbf{1 8 5 0}$ & $\mathrm{CA}$ & $\mathrm{CA}$ & $\mathrm{CA}$ \\
\hline
\end{tabular}

A amostra $4 \mathrm{Ca} 05 \mathrm{C}$ sinterizada entre $1650^{\circ} \mathrm{C}$ e $1850^{\circ} \mathrm{C}$ apresentou uma evolução de segundas-fases próxima daquela observada para a amostra $4 \mathrm{Ca}$ (Tabela 4.2). Estes resultados indicaram que a formação in situ de uma atmosfera levemente redutora não mudou praticamente a evolução das segundas-fases no $\mathrm{AlN}$ com $4 \%$ de $\mathrm{CaO}$ sinterizado entre $1650^{\circ} \mathrm{C}$ e $1850^{\circ} \mathrm{C}$. Já a amostra $4 \mathrm{Ca} 1 \mathrm{C}$ sinterizada entre $1650^{\circ} \mathrm{C}$ e $1850^{\circ} \mathrm{C}$ apresentou somente a fase CA (Tabela 4.2). Estes resultados mostraram que a formação de uma atmosfera fortemente redutora induziu a formação da fase $\mathrm{CA}$ a partir de $1650^{\circ} \mathrm{C}$, mas não influenciou a evolução das segundas-fases na amostra $4 \mathrm{Ca}$ sinterizada em altas temperaturas $\left(>1650^{\circ} \mathrm{C}\right)$. Porém, os resultados de perda de massa indicaram que as amostras com $\mathrm{C}$ apresentaram maior evaporação de compostos do que a amostra 4Ca (Fig. 4.7). Isto sugeriu que a quantidade de fase líquida presente durante a sinterização diminuiu devido à evaporação de compostos causada pela desoxidação com $\mathrm{C}$ das segundas-fases.

\subsubsection{Análise microestrutural}

A amostra $4 \mathrm{Ca}$ sinterizada a $1650^{\circ} \mathrm{C}$ apresentou uma microestrutura composta por matriz densa e poros grandes (Fig. 4.8a). Estes poros grandes se formaram devido ao uso de $\mathrm{CaCO}_{3}$ com larga distribuição granulométrica em relação ao AlN (Fig. 4.5a). ${ }^{60,61} \mathrm{As}$ partículas grosseiras de $\mathrm{CaCO}_{3}$ reagiram com as partículas finas de $\mathrm{AlN}$ e, então, ocorreu a formação de partículas grandes de aluminatos de cálcio (Fig. 4.3a). Durante a sinterização em 
alta temperatura $\left(\geq 1500^{\circ} \mathrm{C}\right)$, a fase líquida, oriunda da fusão das partículas grandes de segundas-fases, migrou pela matriz de partículas finas, ativando o mecanismo de rearranjo de partículas da sinterização via fase líquida. Isto promoveu uma densificação significativa da matriz do AlN com aditivo contendo cálcio (Figs. 4.3b, 4.8a e 4.8b). Porém, os sítios ocupados pelas partículas grandes de segundas-fases (Fig. 4.3a) ficaram vazios, o que deu origem aos poros grandes (Fig. 4.3b). A presença de fase líquida em baixas temperaturas de sinterização $\left(\sim 1500^{\circ} \mathrm{C}\right)$ se deve a formação de fases ricas em $\mathrm{CaO}$ como, por exemplo, as fases $\mathrm{C}_{12} \mathrm{~A}_{7}$ e CA. ${ }^{60,61} \mathrm{O}$ aumento da temperatura de sinterização diminuiu a fração volumétrica de poros grandes (Fig. 4.8), mas poros residuais relativamente grandes foram observados na amostra $4 \mathrm{Ca}$ sinterizada a $1850^{\circ} \mathrm{C}$ (Fig. $4.8 \mathrm{c}$ ). Estes resultados confirmaram que é difícil eliminar os poros grandes da microestrutura, mesmo usando altas temperaturas de sinterização.
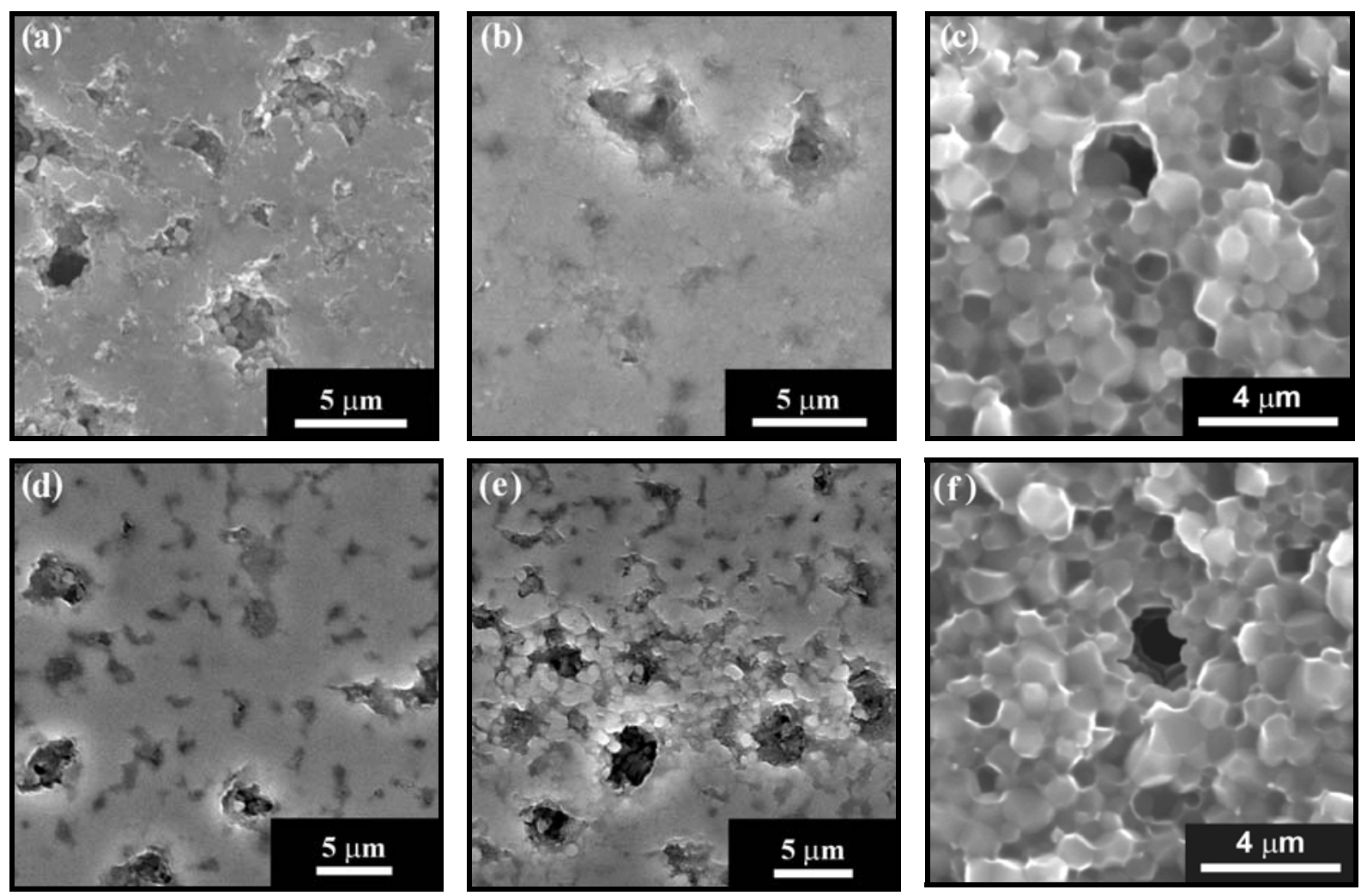

Figura 4.8 - Imagens de MEV: superfícies polidas da amostra $4 \mathrm{Ca}$ sinterizada a $1650^{\circ} \mathrm{C}$ (a) e $1700^{\circ} \mathrm{C}$ (b), e superfície de fratura a $1800^{\circ} \mathrm{C}$ (c); superfícies polidas das amostras $4 \mathrm{Ca} 05 \mathrm{C}$ (d) e $4 \mathrm{Ca} 1 \mathrm{C}$ (e) sinterizadas a $1700^{\circ} \mathrm{C}$, e superfície de fratura da amostra $4 \mathrm{Ca} 1 \mathrm{C}$ sinterizada a $1800^{\circ} \mathrm{C}$ (f).

Além dos poros grandes, que foi pelicular da amostra 4Ca (Figs. 4.8a e 4.8b), as amostras $4 \mathrm{Ca} 05 \mathrm{C}$ e $4 \mathrm{Ca} 1 \mathrm{C}$ sinterizadas abaixo de $1800^{\circ} \mathrm{C}$ apresentaram microestruturas menos densas (Figs. 4.8b, 4.8d e 4.8e). Isto mostrou que adição de $\mathrm{C}$ causou uma diminuição 
significativa na eficácia do $\mathrm{CaO}$ em promover densificação no AlN. Porém, o aumento da temperatura de sinterização minimizou o efeito prejudicial do $\mathrm{C}$ na densificação da amostra $4 \mathrm{Ca}$ (Fig. 4.8), pois ocorreu uma diminuição significativa de porosidade com o aumento de temperatura (Figs. $4.8 \mathrm{e}$ e $4.8 \mathrm{f}$ ).

\subsection{Discussão dos resultados experimentais}

Neste tópico, apresenta-se uma releitura do processo de sinterização do AlN com aditivo contendo cálcio, com base na literatura e nos resultados obtidos no presente trabalho. A formação in situ de uma atmosfera redutora com carbono possibilitou confirmar interpretações sobre a estabilidade das segundas-fases formadas durante a sinterização, bem como sobre o comportamento de densificação.

\subsubsection{Efeito do carbono na evolução das segundas-fases do sistema AIN-CaO}

O AlN com aditivo contendo cálcio sinterizado sob atmosfera redutora apresenta uma evaporação significativa de $\mathrm{CaO}$ ou cálcio com o aumento tanto da temperatura como do tempo de sinterização. ${ }^{57,59-61}$ Outros trabalhos ${ }^{62,64,80,197,198}$ conseguiram identificar as fases de aluminato de cálcio apenas por microscopia eletrônica de transmissão, o que levou à conclusão de o AlN com aditivo contendo cálcio apresenta uma significativa evaporação de compostos durante a sinterização. Para o AlN com $\mathrm{Y}_{2} \mathrm{O}_{3}$, sugeriu-se que, durante a sinterização sob atmosfera redutora, a composição das segundas-fases muda de $\mathrm{xAl}_{2} \mathrm{O}_{3} \cdot \mathrm{yY}_{2} \mathrm{O}_{3}$ para $\mathrm{Y}_{2} \mathrm{O}_{3}$ devido à maior pressão parcial de oxigênio do $\mathrm{Al}_{2} \mathrm{O}_{3}$ em relação ao $\mathrm{Y}_{2} \mathrm{O}_{3}{ }^{49,56}$ Seguindo o mesmo raciocínio, esperava-se que a composição das segundas-fases do AlN com aditivo contendo cálcio mudasse de $\mathrm{xAl}_{2} \mathrm{O}_{3} \cdot \mathrm{yCaO}$ para $\mathrm{Al}_{2} \mathrm{O}_{3}$, visto que o $\mathrm{CaO}$ tem maior pressão de vapor do que o $\mathrm{Al}_{2} \mathrm{O}_{3}$ acima de $1400^{\circ} \mathrm{C}$. ${ }^{61}$ Porém, as evoluções das segundas-fases nas amostras $4 \mathrm{Ca}, 4 \mathrm{Ca} 05 \mathrm{C}$ e $4 \mathrm{Ca} 1 \mathrm{C}$ sinterizadas entre $1650^{\circ} \mathrm{C}$ e $1850^{\circ} \mathrm{C}$ não mostraram uma tendência para formar fases mais ricas em $\mathrm{Al}_{2} \mathrm{O}_{3}$ (Tabela 4.2), o que diferiu da proposição acima. Estes resultados mostraram que o mecanismo proposto ${ }^{49,56}$ para a desoxidação das segundas-fases do AlN com $\mathrm{Y}_{2} \mathrm{O}_{3}$ não se aplica ao AlN com aditivo contendo cálcio. 
No Capítulo 3, sugeriu-se um mecanismo alternativo para explicar a desoxidação com carbono das segundas-fases durante a sinterização do $\mathrm{AlN}$ com $\mathrm{Y}_{2} \mathrm{O}_{3}$. Este mecanismo propõe que, antes da formação dos aluminatos de ítrio, a camada de óxido $\left(\mathrm{Al}_{2} \mathrm{O}_{3}\right)$ presente na superfície do pó de AlN é desoxidada pelo carbono (reação 3.8), o que leva à formação de segundas-fases ricas em $\mathrm{Y}_{2} \mathrm{O}_{3}$ devido à falta de $\mathrm{Al}_{2} \mathrm{O}_{3}$ para reagir com o aditivo $\left(\mathrm{Y}_{2} \mathrm{O}_{3}\right)$ durante a sinterização. Com base nesta proposição e, sabendo que o $\mathrm{Al}_{2} \mathrm{O}_{3}$ é menos estável do que o $\mathrm{CaO},{ }^{44}$ pode-se dizer que a sinterização sob atmosfera redutora com carbono $(\mathrm{C})$ induz a formação de segundas-fases mais ricas em $\mathrm{CaO}$ no $\mathrm{AlN}$ com aditivo contendo cálcio. Embora a perda de massa da amostra $4 \mathrm{Ca}$ tenha aumentado com a adição de C (Fig. 4.7), a utilização de $0,5 \%$ de $C$ não mudou praticamente a evolução das segundas-fases na amostra 4Ca sinterizada entre $1650^{\circ} \mathrm{C}$ e $1850^{\circ} \mathrm{C}$ (Tabela 4.2). Já a adição de $1 \%$ de $\mathrm{C}$ induziu a formação de segundas-fases menos ricas em $\mathrm{CaO}$ na amostra $4 \mathrm{Ca}$ sinterizada a $1650^{\circ} \mathrm{C}$ (Tabela 4.2). Estes resultados foram conflitantes com o mecanismo proposto, pois a composição das segundas-fases não evoluiu para fases mais ricas em $\mathrm{CaO}$ como, por exemplo, as fases $\mathrm{C}_{3} \mathrm{~A}, \mathrm{C}_{12} \mathrm{~A}_{7}$ e $\mathrm{CaO}$ (Fig. 4.1).

As segundas-fases não evoluíram para fases mais ricas em $\mathrm{CaO}$ durante a sinterização do AlN sob atmosfera redutora com carbono em decorrência da maior pressão de vapor do $\mathrm{CaO}$ em relação ao $\mathrm{A}_{2} \mathrm{O}_{3}$ acima de $1400^{\circ} \mathrm{C},{ }^{61}$ o que favoreceu a evaporação tanto do $\mathrm{CaO}$ presente nas segundas-fases como do $\mathrm{CaO}$ não reagido. Outra possibilidade está relacionada com a estabilidade dos aluminatos de cálcio durante a sinterização do AlN. Em trabalhos anteriores, ${ }^{60,61}$ mostrou-se que a evolução das segundas-fases no AlN foi fortemente influenciada pelo do teor de aditivo de sinterização $\left(\mathrm{CaCO}_{3}\right.$ ou $\left.\mathrm{CaO}\right)$, mas as composições das segundas-fases convergiram para uma composição próxima da fase CA com o aumento da temperatura de sinterização (Fig. 4.4). Estes resultados indicaram a ocorrência de evaporação tanto de $\mathrm{Al}_{2} \mathrm{O}_{3}$ como de $\mathrm{CaO}$ das segundas-fases (reações 4.1 e 4.2), ${ }^{60,61}$ visando atingir uma composição mais estável (fase CA) durante a sinterização do AlN em altas temperaturas $\left(>1650^{\circ} \mathrm{C}\right)$. No presente trabalho, a adição de carbono favoreceu a evaporação de compostos durante a sinterização do AlN com aditivo contendo cálcio, mas não influenciou o comportamento de evolução das segundas-fases, pelo menos entre $1700^{\circ} \mathrm{C}$ e $1850^{\circ} \mathrm{C}$. Estes resultados mostraram que, independente da atmosfera de sinterização (redutora ou inerte), a fase CA é mais estável do que as demais fases de aluminato de cálcio durante a sinterização do AlN em altas temperaturas $\left(>1650^{\circ} \mathrm{C}\right)$. 


\subsubsection{Efeito do carbono na densificação do sistema AIN-CaO}

A temperatura de formação de fase líquida do AIN foi fortemente influenciada pelo teor de $\mathrm{CaCO}_{3}$. ${ }^{60,61,69} \mathrm{O}$ aumento do teor de $\mathrm{CaCO}_{3}$ levou à formação de fases como, por exemplo, $\mathrm{C}_{3} \mathrm{~A}, \mathrm{C}_{12} \mathrm{~A}_{7}$ e $\mathrm{CA}$, que resultaram na formação de fase líquida em temperaturas tão baixas quanto $1500^{\circ} \mathrm{C} .{ }^{60,61} \mathrm{Como}$ as amostras $4 \mathrm{Ca}, 4 \mathrm{Ca} 05 \mathrm{C}$ e $4 \mathrm{Ca} 1 \mathrm{C}$ sinterizadas entre $1650^{\circ} \mathrm{C}$ e $1850^{\circ} \mathrm{C}$ apresentaram as fases $\mathrm{C}_{12} \mathrm{~A}_{7}$ e/ou CA (Tabela 4.2), pode-se dizer que a densificação destas amostras foi assistida por sinterização via fase líquida nesta faixa de temperatura. Estes resultados indicaram que a adição de $\mathrm{C}$ não influenciou a temperatura de formação da fase líquida entre $1650^{\circ} \mathrm{C}$ e $1850^{\circ} \mathrm{C}$, pois não induziu a formação de fases refratárias como, por exemplo, as fases $\mathrm{CA}_{2}$ ou $\mathrm{CA}_{6}$ (Fig. 4.1). Estes resultados indicaram que o atraso na densificação da amostra 4Ca em função da adição e do aumento do teor de $\mathrm{C}$ (Fig. 4.6) não foi ocasionado pela mudança na temperatura de formação da fase líquida, como observado para o AlN com adição simultânea de $\mathrm{Y}_{2} \mathrm{O}_{3}$ e C.

Em trabalhos anteriores, ${ }^{60,61}$ estabeleceu-se que a utilização de partículas grosseiras de $\mathrm{CaCO}_{3}$ induziu a formação de poros grandes durante a sinterização do AlN (Fig. 4.3). Como o $\mathrm{CaCO}_{3}$ apresentou larga distribuição granulométrica em relação ao AlN (Fig. 4.5a) e, sabendo que as amostras $4 \mathrm{Ca}, 4 \mathrm{Ca} 05 \mathrm{C}$ e $4 \mathrm{Ca} 1 \mathrm{C}$ sinterizadas abaixo de $1800^{\circ} \mathrm{C}$ foram caracterizadas por apresentarem microestruturas com poros grandes (Figs. 4.8a, 4.8b, 4.8d e 4.8e), pode-se dizer que a densificação das três amostras foi assistida por sinterização via fase líquida entre $1650^{\circ} \mathrm{C}$ e $1850^{\circ} \mathrm{C}$, pois as partículas grandes de segundas-fases (Fig. 4.3a) fundiram e, então, a fase líquida se espalhou por entre as partículas finas de AlN, ativando o mecanismo de rearranjo de partículas da sinterização via fase líquida. Porém, as amostras $4 \mathrm{Ca} 05 \mathrm{C}$ e $4 \mathrm{Ca} 1 \mathrm{C}$ apresentaram microestruturas menos densas do que a amostra 4Ca (Figs. 4.8b, 4.8d e 4.8e). Isto mostrou que a porosidade na amostra $4 \mathrm{Ca}$ aumentou em função da adição e do aumento do teor de carbono $(\mathrm{C})$. A presença de poros grandes atrasou significativamente a densificação do AlN devido à dificuldade para eliminá-los da microestrutura, ${ }^{60,61}$ mesmo utilizando altas temperaturas de sinterização (Figs. 4.8c e 4.8f). Estes resultados indicaram que a formação de poros, quer seja pela adição de partículas grosseiras de $\mathrm{CaCO}_{3}$ e/ou pela adição de $\mathrm{C}$, foi responsável pelo atraso significativo na densificação do AlN.

Embora o AlN com aditivo contendo cálcio apresente uma evaporação significativa de compostos durante a sinterização sob atmosfera redutora ou inerte, ${ }^{57-61}$ a perda de massa da amostra $4 \mathrm{Ca}$ aumentou significativamente em função da adição e do aumento do teor de C 
(Fig. 4.7). Estes resultados indicaram que a adição de $C$ promoveu maior evaporação de compostos durante a sinterização da amostra $4 \mathrm{Ca}$, o que resultou na diminuição da fração de fase líquida presente durante a sinterização. Como o aumento da fração de fase líquida com boas características de molhamento e espalhamento favorece a densificação por rearranjo de

partículas, ${ }^{90,101,188}$ pode-se dizer que a diminuição da fração de fase líquida, causada pela adição de $\mathrm{C}$, diminuiu a eficácia do mecanismo de rearranjo de partículas, pois as amostras 4Ca05C e 4Ca1C apresentaram microestruturas com pouca densificação em relação à amostra 4Ca (Figs. 4.8b, 4.8d e 4.8e). Estes resultados indicaram que a densificação da amostra 4Ca foi influenciada pela diminuição da fração de fase líquida presente durante a sinterização. Porém, o aumento da temperatura de sinterização, acima de $1750^{\circ} \mathrm{C}$, promoveu a densificação das amostras com C (Fig. 4.6), mostrando que o efeito da diminuição da fração de fase líquida na densificação da amostra 4Ca foi minimizado pelo aumento da temperatura de sinterização. Isto indicou que o aumento da temperatura de sinterização promoveu a retração e eliminação de grande parte dos poros grandes. Entretanto, a densidade das amostras com C não aumentou praticamente com o aumento da temperatura de $1800^{\circ} \mathrm{C}$ para $1850^{\circ} \mathrm{C}$ (Fig. 4.6). Isto indicou que o gás proveniente da evaporação dos compostos ficou aprisionado no interior dos poros fechados (Figs. 4.8c e 4.8f), o que dificultou a retração e eliminação dos mesmos durante a sinterização em altas temperaturas $\left(\geq 1800^{\circ} \mathrm{C}\right)$. ${ }^{60,61}$

\subsection{Conclusões}

Estudou-se o efeito da formação in situ de uma atmosfera redutora com carbono (proveniente da adição de $0,5 \%$ e $1 \%$ de carbono) na densificação do $\mathrm{AlN}$ com $4 \%$ de $\mathrm{CaO}$ entre $1650^{\circ} \mathrm{C}$ e $1850^{\circ} \mathrm{C}$. Os resultados experimentais levaram às seguintes conclusões:

- A adição de carbono causa pouca influência na evolução das segundas-fases do AlN com $4 \%$ de $\mathrm{CaO}$ sinterizado entre $1650^{\circ} \mathrm{C}$ e $1850^{\circ} \mathrm{C}$ e, portanto, a temperatura de formação da fase líquida não é modificada pela formação in situ de uma atmosfera redutora com carbono;

- A adição de carbono aumenta significativamente a evaporação de compostos, o que diminui a fração de segundas-fases líquidas durante a sinterização do AlN com 4\% de $\mathrm{CaO}$ e, como conseqüência, ocorre uma diminuição da eficácia dos mecanismos de sinterização via fase líquida, principalmente do estágio de rearranjo de partículas. Isto 
resulta no atraso significativo da densificação do $\mathrm{AlN}$, principalmente entre $1650^{\circ} \mathrm{C}$ e $1750^{\circ} \mathrm{C}$

- O aumento da temperatura de sinterização diminui o efeito prejudicial da adição de carbono na densificação do AlN com 4\% de $\mathrm{CaO}$, o que possibilitou obter amostras com adição de carbono com elevados valores de densidade ( $\sim 95 \%$ da densidade teórica) em temperatura de sinterização acima de $1750^{\circ} \mathrm{C}$;

- A retração e eliminação dos poros é dificultada pela ocorrência de aprisionamento de gás no interior dos poros fechados, que contribuiu, pelo menos em parte, para o atraso na densificação do AlN com adição simultânea de $\mathrm{CaO}$ e carbono;

- A fase CA $\left(\mathrm{CaO} \cdot \mathrm{Al}_{2} \mathrm{O}_{3}\right)$ é mais estável do que as demais fases de aluminato de cálcio durante a sinterização do AlN em altas temperaturas $\left(>1650^{\circ} \mathrm{C}\right)$, independente da atmosfera de sinterização (redutora ou inerte). 


\section{Efeito da adição simultânea de $\mathrm{Y}_{2} \mathrm{O}_{3}$ e $\mathrm{CaO}$ na densificação do $\mathrm{AlN}$}

\subsection{Introdução}

As empresas de microeletrônica estão interessadas em diminuir a temperatura de sinterização do AlN, pois este procedimento implicará na redução dos custos de processamento, otimização das propriedades mecânicas e adequação do AlN ao processo HTCC (High Temperature Cofired Ceramic). ${ }^{61,76,199,200}$ Há duas linhas de pesquisas relacionadas com a diminuição da temperatura de sinterização do AlN. Na primeira linha de pesquisa, utiliza-se pó ultrafino (nanométrico) de AlN com e sem aditivo de sinterização, o que resulta na completa densificação da cerâmica de $\mathrm{AlN}$ entre $1550^{\circ} \mathrm{C}$ e $1650^{\circ} \mathrm{C}{ }^{28,62,65,68}$ Porém, o AlN apresenta baixo valor de condutividade térmica $(\sim 70 \mathrm{~W} / \mathrm{mK})$, pois o pó ultrafino apresenta elevado teor de oxigênio em decorrência da sua elevada área de superfície especifica $\left(>20 \mathrm{~m}^{2} / \mathrm{g}\right)$. Na segunda linha de pesquisa, desenvolveram-se vários sistemas multicomponentes de aditivo de sinterização, onde a mistura simultânea de aditivos contendo ítria e cálcia se destacou, pois promoveu a densificação do $\mathrm{AlN}$ entre $1650^{\circ} \mathrm{C}$ e $1750^{\circ} \mathrm{C},{ }^{40,73-76}$ além de resultar em valores de condutividade térmica superiores a $150 \mathrm{~W} / \mathrm{mK}$. ${ }^{73,75,76}$ Porém, há poucos estudos relacionados com o comportamento de densificação do AlN com adição simultânea de compostos à base de ítrio e cálcio. ${ }^{42-44,75-77}$ Como estes estudos elucidaram parcialmente os mecanismos envolvidos na sinterização do AlN, objetivou-se neste capítulo o estudo do efeito da adição simultânea de $\mathrm{Y}_{2} \mathrm{O}_{3}$ e $\mathrm{CaO}$ na densificação do AlN, bem como o efeito da adição de carbono na densificação do AlN com adição simultânea de $\mathrm{Y}_{2} \mathrm{O}_{3}$ e $\mathrm{CaO}$, que ainda não foi investigado.

\subsubsection{Sinterização do AIN com adição simultânea de $\mathrm{Y}_{2} \mathrm{O}_{3}$ e CaO}

A densificação do AlN com adição simultânea de $\mathrm{Y}_{2} \mathrm{O}_{3}$ e $\mathrm{CaO}$ foi comparada com a densificação do AlN com adições individuais destes aditivos. Os resultados dos ensaios de dilatometria mostraram que o AlN preparado apenas com aditivo contendo cálcio $\left(\mathrm{CaCO}_{3}\right.$ ou $\mathrm{CaF}_{2}$ ) apresentou menor temperatura de início de retração do que o AlN com mistura de 
aditivos $\left(\mathrm{Y}_{2} \mathrm{O}_{3}\right.$ e $\left.\mathrm{CaO}\right) .{ }^{44,76}$ Abaixo de $1600^{\circ} \mathrm{C}$, os valores de retração linear do AlN com aditivo contendo cálcio foram significativamente maiores do que os valores observados para o AlN com mistura de $\mathrm{Y}_{2} \mathrm{O}_{3}$ e CaO. ${ }^{44,76}$ Estes resultados mostraram que o AlN com aditivo contendo cálcio teve maior densificação abaixo de $1600^{\circ} \mathrm{C}$ do que o $\mathrm{AlN}$ com mistura de aditivos. Qiao et al. ${ }^{76}$ indicaram que a adição de $\mathrm{Y}_{2} \mathrm{O}_{3}$ influenciou a formação de compostos do sistema Ca-Al-O, pois parte da alumina $\left(\mathrm{Al}_{2} \mathrm{O}_{3}\right)$ contida no pó de $\mathrm{AlN}$ foi consumida na formação de aluminatos de ítrio. Assim, os autores indicaram que, abaixo de $1650^{\circ} \mathrm{C}$, a menor retração linear das amostras contendo $\mathrm{Y}_{2} \mathrm{O}_{3}$ foi atribuída à diminuição da fração de líquido de aluminato de cálcio presente durante a sinterização do AlN.

A $1600^{\circ} \mathrm{C}$, o AlN com mistura de aditivos apresentou um aumento significativo de retração linear em função do aumento do tempo de sinterização. ${ }^{44}$ Já o AlN com aditivo contendo cálcio apresentou um aumento inexpressivo de retração linear nesta mesma condição de sinterização. ${ }^{44}$ Resultados similares foram observados por Qiao et al. ${ }^{76}$. Jarrige et al. ${ }^{40}$ sugeriram que a fase $\mathrm{C}_{12} \mathrm{~A}_{7}$ levou à formação de líquido em baixa temperatura, mas a composição do líquido mudou para fases mais refratárias durante a sinterização em decorrência do seu enriquecimento com alumina $\left(\mathrm{Al}_{2} \mathrm{O}_{3}\right)$ contida no pó de AlN (Fig. 4.1), o que retardou a densificação do AlN. Quando $\mathrm{Y}_{2} \mathrm{O}_{3}$ ou $\mathrm{CaYAlO}_{4}$ foi adicionado ao AlN com $\mathrm{CaO}$ ou $\mathrm{C}_{12} \mathrm{~A}_{7}$, a fase líquida apresentou um aumento de viscosidade, ${ }^{40}$ bem como sua composição deslocou para o centro do diagrama de equilíbrio de fases do sistema $\mathrm{CaO}-\mathrm{Al}_{2} \mathrm{O}_{3}$ $\mathrm{Y}_{2} \mathrm{O}_{3}$ (Fig. 5.1), onde os domínios vítreos são maiores. A mudança da composição das segundas-fases para o centro do diagrama ternário (Fig. 5.1) melhorou a densificação do AlN em decorrência do atraso na formação de segundas-fases mais refratárias durante a sinterização. ${ }^{40}$ Esta proposição, entretanto, apresenta um dado conflitante, pois indica que a viscosidade da fase líquida aumenta com a adição simultânea de compostos contendo ítrio e cálcio, o que dificulta o espalhamento da fase líquida por entre os grãos de AlN, inibindo a ativação do mecanismo de rearranjo de partículas da sinterização via fase líquida. Já Qiao et al. ${ }^{76}$ observaram que o aumento do teor de $\mathrm{Y}_{2} \mathrm{O}_{3}$ na mistura de aditivos $\left(\mathrm{Y}_{2} \mathrm{O}_{3}\right.$ e $\left.\mathrm{CaO}\right)$ deslocou as curvas de retração para maiores temperaturas. Eles indicaram que as diferentes retrações observadas nas amostras contendo $\mathrm{Y}_{2} \mathrm{O}_{3}$ são comumente atribuídas ao efeito do $\mathrm{Y}_{2} \mathrm{O}_{3}$ na temperatura de formação da fase líquida.

O AlN com mistura de aditivos apresentou curva de retração linear deslocada para menores temperaturas em relação ao $\mathrm{AlN}$ com $\mathrm{Y}_{2} \mathrm{O}_{3} \cdot{ }^{71,76} \mathrm{~A}$ utilização da mistura de $\mathrm{Y}_{2} \mathrm{O}_{3} \mathrm{e}$ $\mathrm{CaO}$ causou uma diminuição de $100^{\circ} \mathrm{C}$ na temperatura de início de sinterização do $\mathrm{AlN}$ com $\mathrm{Y}_{2} \mathrm{O}_{3},{ }^{71}$ mas completa densificação foi alcançada somente a $1800^{\circ} \mathrm{C}$. Já o AlN preparado com 
$\mathrm{CaYAlO}_{4}$ e $\mathrm{CaO}$ atingiu quase completa densificação (97\% da densidade teórica) a $1600^{\circ} \mathrm{C} .{ }^{40}$ Embora os resultados de Jarrige et al. ${ }^{40}$ tenham mostrado uma diminuição significativa na temperatura de sinterização do AlN preparado com aditivo multicomponente $\left(\mathrm{CaYAlO}_{4} \mathrm{e}\right.$ $\mathrm{CaO}$ ), outros trabalhos, ${ }^{43,44}$ que utilizaram uma mistura composta por $\mathrm{CaCO}_{3}$ e $\mathrm{Y}_{2} \mathrm{O}_{3}$, não conseguiram obter $\mathrm{AlN}$ denso a $1600^{\circ} \mathrm{C}$, mesmo usando longos tempos de sinterização (2 a 10 horas). Porém, obteve-se AlN denso, usando $\mathrm{CaF}_{2}$ e $\mathrm{YF}_{3}$ ou $\mathrm{Y}_{2} \mathrm{O}_{3}$, após sinterização por longos tempos ( $>2$ horas) na temperatura de $1650^{\circ} \mathrm{C} .^{73,76}$

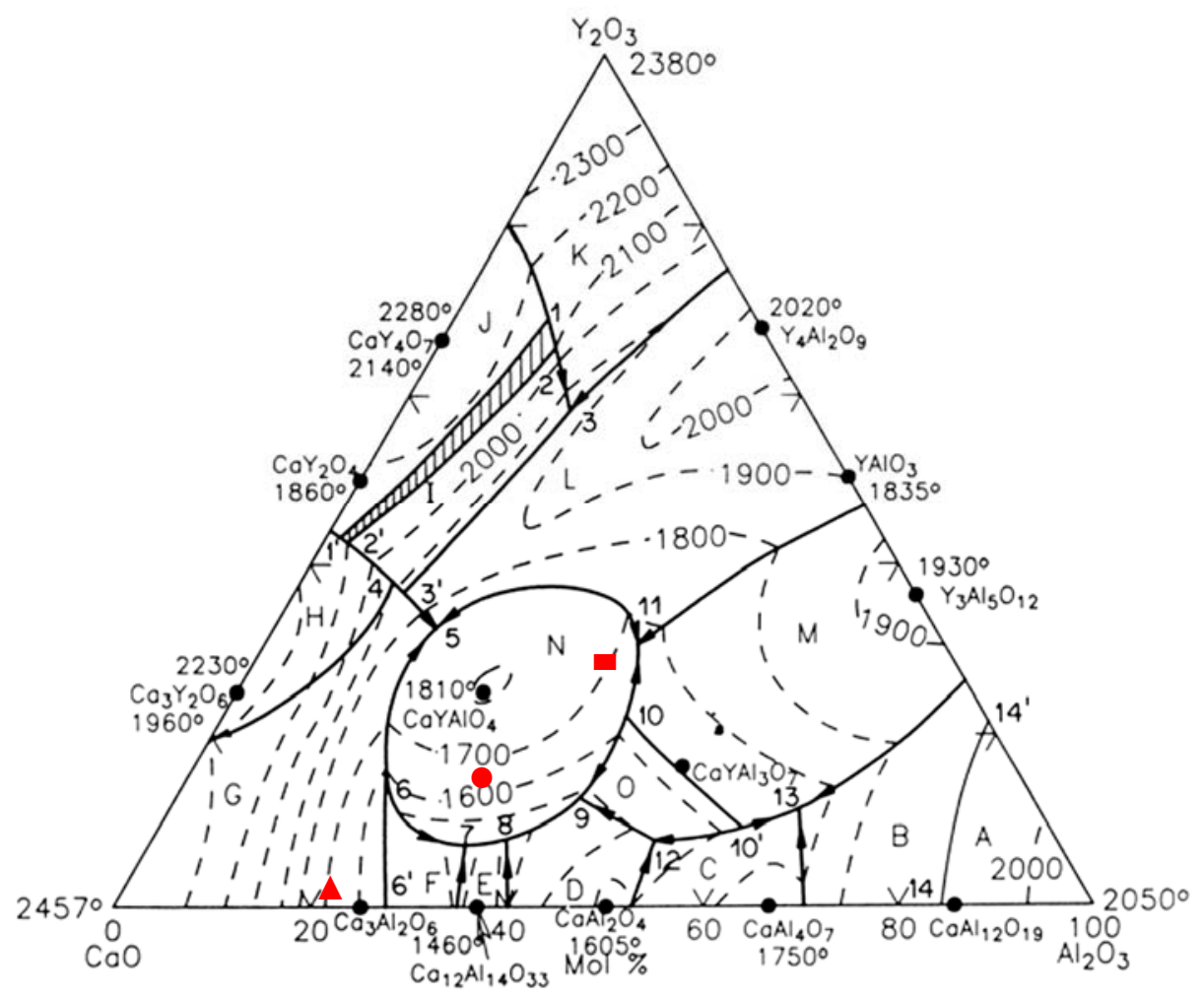

Figura 5.1 - Diagrama de equilíbrio de fases do sistema $\mathrm{CaO}-\mathrm{Al}_{2} \mathrm{O}_{3}-\mathrm{Y}_{2} \mathrm{O}_{3} \cdot{ }^{181}$ As temperaturas eutéticas mais baixas ocorrem a $1375^{\circ} \mathrm{C}\left(\mathrm{n}^{\circ} 8\right), 1395^{\circ} \mathrm{C}\left(\mathrm{n}^{\circ}\right.$ 9), $1420^{\circ} \mathrm{C}\left(\mathrm{n}^{\circ} 7\right)$ e $1535^{\circ} \mathrm{C}\left(\mathrm{n}^{\circ} 6\right.$ e 6 '). Fases de interesse: $\mathrm{CaYAl}_{3} \mathrm{O}_{7}, \mathrm{CaYAlO}_{4}, \mathrm{YAM}\left(\mathrm{Y}_{4} \mathrm{Al}_{2} \mathrm{O}_{9}\right)$, YAP $\left(\mathrm{YAlO}_{3}\right)$, YAG $\left(\mathrm{Y}_{3} \mathrm{Al}_{5} \mathrm{O}_{12}\right), \mathrm{C}_{3} \mathrm{~A}\left(\mathrm{Ca}_{3} \mathrm{Al}_{2} \mathrm{O}_{6}\right), \mathrm{C}_{12} \mathrm{~A}_{7}\left(\mathrm{Ca}_{12} \mathrm{Al}_{14} \mathrm{O}_{33}\right)$, $\mathrm{CA}\left(\mathrm{CaAl}_{2} \mathrm{O}_{4}\right), \mathrm{CA}_{2}\left(\mathrm{CaAl}_{4} \mathrm{O}_{7}\right), \mathrm{CA}_{6}\left(\mathrm{CaAl}_{12} \mathrm{O}_{19}\right)$. Os símbolos indicam as composições iniciais esperadas nos corpos conformados de pó de AlN com $0,85 \%$ em massa de oxigênio e adições, em \% massa, de $1 \% \mathrm{CaO}-3 \%$ $\mathrm{Y}_{2} \mathrm{O}_{3}(\boldsymbol{\bullet}), 2 \% \mathrm{CaO}-2 \% \mathrm{Y}_{2} \mathrm{O}_{3}(\bullet)$ e $3 \% \mathrm{CaO}-1 \% \mathrm{Y}_{2} \mathrm{O}_{3}(\boldsymbol{\Delta})$.

O efeito de diminuição da densidade em função do aumento do teor de aditivo de sinterização (Fig. 4.2) foi observado por Jarrige et al. ${ }^{40}$ para o AlN preparado com aditivo multicomponente $\left(\mathrm{Y}_{2} \mathrm{O}_{3}-\mathrm{CaO}, \mathrm{Y}_{2} \mathrm{O}_{3}-\mathrm{CaYAlO}_{4}\right.$ e $\left.\mathrm{CaO}-\mathrm{CaYAlO}{ }_{4}\right)$. Como a diminuição de densidade foi incoerente com a formação de segundas-fases menos refratárias, os autores indicaram que as fases $\mathrm{CA}, \mathrm{C}_{12} \mathrm{~A}_{7}$ e $\mathrm{CaYAl}_{3} \mathrm{O}_{7}$ identificadas nas amostras sinterizadas, estavam na forma líquida a $1600^{\circ} \mathrm{C}$, mas que apresentaram alta viscosidade e/ou baixa 
molhabilidade no AlN nesta temperatura, o que resultou na formação de poros e, conseqüentemente, na limitação da densificação do AlN. Após a sinterização na temperatura de $1650^{\circ} \mathrm{C}$, Qiao et al. ${ }^{76}$ observaram um ângulo diedro de $120^{\circ}$ no AlN com mistura de aditivos $\left(\mathrm{Y}_{2} \mathrm{O}_{3}\right.$ e $\left.\mathrm{CaF}_{2}\right)$ e, então, indicaram que as segundas-fases de contorno de grão tiveram pouca molhabilidade sobre os grãos de AlN. Com base em resultados de DRX, Qiao et al. ${ }^{76}$ indicaram que a formação de um líquido à base de $\mathrm{CaYAlO}_{4}$ promoveu a densificação do $\mathrm{AlN}$ com mistura de aditivos $\left(\mathrm{Y}_{2} \mathrm{O}_{3}\right.$ e $\left.\mathrm{CaF}_{2}\right)$ sinterizado a $1650^{\circ} \mathrm{C}$. Estes autores também observaram que as segundas-fases de contorno de grão não apresentaram composição homogênea, pois identificaram por microscopia eletrônica de transmissão a presença das fases $\mathrm{CaYAlO}_{4}$ e YAM. Deste modo, Qiao et al. ${ }^{76}$ concluíram que certa quantidade de fase sólida YAM no líquido com composição $\mathrm{CaYAlO}_{4}$ pode diminuir a retração do AlN durante a sinterização abaixo de $1650^{\circ} \mathrm{C}$.

De Baranda et al. ${ }^{37}$ observaram a formação de poças de segundas-fases no AlN com $3 \%$ em massa de $\mathrm{Y}_{2} \mathrm{O}_{3}$ sinterizado a $1825^{\circ} \mathrm{C}$ e, então, indicaram que a fase líquida não apresentou boas características de molhamento e espalhamento durante a sinterização. Eles indicaram que a adição de $\mathrm{CaO}$, acima de $0,15 \%$ em massa, mudou o comportamento de molhamento e espalhamento da fase líquida, pois observaram que as segundas-fases com formato de partículas mostraram uma tendência para penetrar e espalhar por entre os grãos de AlN. Já as amostras contendo alto teor de $\mathrm{CaO}(2 \%$ e $5 \%$ em massa) não apresentaram partículas grandes de segundas-fases, mas ocorreu a formação de poros, que segundo os autores, foi causada pela fusão e posterior redistribuição destas segundas-fases pela microestrutura. Este efeito foi correlacionado com a presença de compostos de baixo ponto de fusão como, por exemplo, a fase $\mathrm{CaYAl}_{3} \mathrm{O}_{7}$, que tem temperatura de fusão a $1630^{\circ} \mathrm{C}$.

\subsubsection{Evolução das segundas-fases do AlN com adição simultânea de $\mathrm{Y}_{2} \mathrm{O}_{3}$ e CaO}

Há poucos relatos sobre a evolução das segundas-fases durante a sinterização do AlN com mistura de aditivos $\left(\mathrm{Y}_{2} \mathrm{O}_{3}\right.$ e $\left.\mathrm{CaO}\right) .{ }^{37,40,76}$ De Baranda et al. ${ }^{37}$ observaram que a adição de $\mathrm{CaO}$ no $\mathrm{AlN}$ com $\mathrm{Y}_{2} \mathrm{O}_{3}$ levou à formação tanto de fases ternárias $\left(\mathrm{CaYAl}_{3} \mathrm{O}_{7}\right.$ e $\left.\mathrm{CaYAlO}_{4}\right)$ como de fases de aluminato de ítrio. Analisando somente as fases ternárias, observou-se somente a fase $\mathrm{CaYAl}_{3} \mathrm{O}_{7}$ nas amostras contendo baixos teores de $\mathrm{CaO}(0,05 \%$ a $1 \%)$. Já a fase $\mathrm{CaYAlO}_{4}$ foi observada, junto com a fase $\mathrm{CaYAl}_{3} \mathrm{O}_{7}$, nas amostras contendo de $2 \%$ a $5 \%$ 
de $\mathrm{CaO}$. Analisando somente as fases de aluminato de ítrio, observou-se que as amostras com adição simultânea de $\mathrm{Y}_{2} \mathrm{O}_{3}$ e $\mathrm{CaO}$ apresentaram fases mais ricas em ítrio (YAP e YAM) do que o AlN preparado apenas com $\mathrm{Y}_{2} \mathrm{O}_{3}$ (YAG e YAP).

Qiao et al. ${ }^{76}$ utilizaram duas misturas de pós $\left(\mathrm{CaF}_{2}-\mathrm{Al}_{2} \mathrm{O}_{3}\right.$ e $\left.\mathrm{CaF}_{2}-\mathrm{Y}_{2} \mathrm{O}_{3}-\mathrm{Al}_{2} \mathrm{O}_{3}\right)$ para estudar a evolução das segundas-fases durante a sinterização do AlN. Após a sinterização na temperatura de $1200^{\circ} \mathrm{C}$, os autores observaram que a mistura $\mathrm{CaF}_{2}-\mathrm{Y}_{2} \mathrm{O}_{3}-\mathrm{Al}_{2} \mathrm{O}_{3}$ apresentou menor quantidade de fases do sistema $\mathrm{Ca}-\mathrm{Al}-\mathrm{O}$ do que a mistura $\mathrm{CaF}_{2}-\mathrm{Al}_{2} \mathrm{O}_{3}$ e, então, indicaram que o $\mathrm{Y}_{2} \mathrm{O}_{3}$ pode limitar a formação de aluminatos de cálcio durante a sinterização do AlN, pois parte da alumina $\left(\mathrm{Al}_{2} \mathrm{O}_{3}\right)$ contida no pó de $\mathrm{AlN}$ deve ser consumida na formação de aluminatos de ítrio. As fases $\mathrm{C}_{3} \mathrm{~A}$ e YAM foram identificadas no AlN com mistura de aditivos $\left(\mathrm{Y}_{2} \mathrm{O}_{3}\right.$ e $\left.\mathrm{CaCO}_{3}\right)$ parcialmente sinterizado a $1200^{\circ} \mathrm{C}$. ${ }^{44}$ Este resultado indicou que os compostos $\mathrm{CaO}$ e $\mathrm{Y}_{2} \mathrm{O}_{3}$ reagiram individualmente com o $\mathrm{Al}_{2} \mathrm{O}_{3}$ presente na superfície do pó de AIN, o que levou à formação tanto de aluminatos de cálcio como de ítrio durante o tratamento térmico em baixas temperaturas $\left(\leq 1200^{\circ} \mathrm{C}\right)$. Porém, o AlN com mistura de aditivos $\left(\mathrm{CaO}\right.$ e $\left.\mathrm{Y}_{2} \mathrm{O}_{3}\right)$, cuja sinterização ocorreu a partir de $1600^{\circ} \mathrm{C}$, foi caracterizado por apresentar fases ternárias e aluminatos de cálcio ${ }^{40,44}$ ou fases ternárias e/ou aluminatos de ítrio. $37,73,75,76,176,200$

As fases de $\mathrm{CaYAl}_{3} \mathrm{O}_{7}$ e $\mathrm{CaYAlO}_{4}$ se mostraram estáveis durante a sinterização do AlN, pois estas segundas-fases, juntamente com outras fases de aluminato de ítrio, foram observadas em amostras de AlN sinterizadas sob atmosfera redutora $\left(\leq 1860^{\circ} \mathrm{C}\right) .{ }^{37}$ Porém, Olhero et al. ${ }^{74}$ observaram que a evolução das segundas-fases do AlN com mistura de

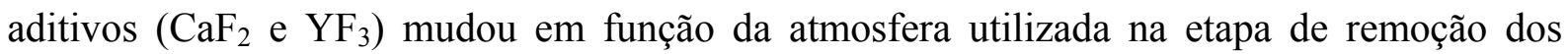
plastificantes por decomposição térmica (burnout). As amostras sinterizadas a $1750^{\circ} \mathrm{C}$, cujo burnout foi realizado em atmosfera inerte (gás nitrogênio), apresentaram somente a fase YAM. Já o burnout realizado em atmosfera oxidante (ao ar) levou à formação das fases YAP e $\mathrm{CaYAl}_{3} \mathrm{O}_{7}$ nas amostras sinterizadas a $1750^{\circ} \mathrm{C}$. A mudança de composição das segundasfases em função da atmosfera de burnout foi correlacionada com a desoxidação das segundasfases durante a sinterização do AlN. Quando o burnout foi realizado em atmosfera inerte (gás nitrogênio), o carbono proveniente da decomposição dos plastificantes não foi oxidado $(\mathrm{C}+$ $\mathrm{O}_{2} \leftrightarrow \mathrm{CO}_{2}$ ). Assim, o carbono livre na superfície das partículas do corpo calcinado promoveu a desoxidação das segundas-fases durante a sinterização, o que levou à formação de segundasfases mais ricas em $\mathrm{Y}_{2} \mathrm{O}_{3}$. Em outro trabalho, quando o AlN com mistura de aditivos $\left(\mathrm{CaF}_{2} \mathrm{e}\right.$ $\mathrm{YF}_{3}$ ) foi sinterizado sob atmosfera redutora na temperatura de $1700^{\circ} \mathrm{C}$, os corpos sinterizados apresentaram as fases $\mathrm{YAM}$ e $\mathrm{CaYAl}_{3} \mathrm{O}_{7}$ na região central (bulk) e somente a fase $\mathrm{Y}_{2} \mathrm{O}_{3}$ na 
superfície. ${ }^{177}$ Estes resultados indicaram que as segundas-fases (aluminatos) próximas da superfície do corpo foram desoxidadas pela atmosfera redutora. A mudança de composição das segundas-fases de $\mathrm{xAl}_{2} \mathrm{O}_{3} \cdot \mathrm{yY}_{2} \mathrm{O}_{3} \cdot \mathrm{zCaO}$ para $\mathrm{Y}_{2} \mathrm{O}_{3}$ sugere a ocorrência de evaporação preferencial de $\mathrm{Al}_{2} \mathrm{O}_{3}$ e $\mathrm{CaO}$ durante a sinterização sob atmosfera redutora do AlN com mistura de aditivos $\left(\mathrm{Y}_{2} \mathrm{O}_{3}+\mathrm{CaO}\right)$.

\subsection{Materiais e métodos}

As matérias-primas utilizadas neste estudo são apresentadas nos itens 3.2 e 4.2, enquanto as metodologias de processamento cerâmico e de caracterização dos materiais são apresentadas no item 3.2. Os cartões JCPDS utilizados na interpretação dos difratogramas de raios $\mathrm{X}$ das amostras de $\mathrm{AlN}$ sinterizadas entre $1650^{\circ} \mathrm{C}$ e $1850^{\circ} \mathrm{C}$ foram: $25-1133$ (AlN), 33 0040 ( $\mathrm{YAG}, 3 \mathrm{Y}_{2} \mathrm{O}_{3} \cdot 5 \mathrm{Al}_{2} \mathrm{O}_{3}$ ), 34-0368 (YAM, 2 $\mathrm{Y}_{2} \mathrm{O}_{3} \cdot \mathrm{Al}_{2} \mathrm{O}_{3}$ ), 33-0041 (YAP, $\mathrm{Y}_{2} \mathrm{O}_{3} \cdot \mathrm{Al}_{2} \mathrm{O}_{3}$ ), 41-1105 $\left(\mathrm{Y}_{2} \mathrm{O}_{3}\right), 49-0605\left(\mathrm{CaYAl}_{3} \mathrm{O}_{7}\right)$ e 81-1588 $\left(\mathrm{CaYAlO}_{4}\right)$.

Este trabalho foi dividido em duas séries experimentais. Na primeira, estudou-se o efeito da adição simultânea de $\mathrm{Y}_{2} \mathrm{O}_{3}$ e $\mathrm{CaO}$ na sinterização do $\mathrm{AlN}$, onde se fixou um teor de 4\% em massa de aditivo de sinterização e, então, prepararam-se três composições distintas de pós em que se variou a fração de $\mathrm{CaO}$ na mistura de aditivos: i) $25 \%$ de $\mathrm{CaO}(1 \% \mathrm{CaO}-3 \%$ $\left.\mathrm{Y}_{2} \mathrm{O}_{3}\right)$; ii) $50 \%$ de $\mathrm{CaO}\left(2 \% \mathrm{CaO}-2 \% \mathrm{Y}_{2} \mathrm{O}_{3}\right)$; e iii) $75 \%$ de $\mathrm{CaO}\left(3 \% \mathrm{CaO}-1 \% \mathrm{Y}_{2} \mathrm{O}_{3}\right) . \mathrm{Na}$ segunda, estudou-se o efeito da formação in situ de uma atmosfera redutora com carbono (C) no interior do corpo conformado de AlN. A composição 2\% $\mathrm{CaO}-2 \% \mathrm{Y}_{2} \mathrm{O}_{3}$, que corresponde a $50 \%$ de $\mathrm{CaO}$ na mistura de aditivos, foi utilizada como base, na qual foram realizadas adições de $0,5 \%$ e $1 \%$ de C. A Tabela 5.1 apresenta as composições e identificações das amostras de AlN estudadas nas duas séries experimentais.

Tabela 5.1 - Composições e identificações das amostras de AlN.

\begin{tabular}{l|l}
\hline Composição (\% em massa) & Identificação da amostra \\
\hline $1 \% \mathrm{CaO}^{*}$ e $3 \% \mathrm{Y}_{2} \mathrm{O}_{3}$ & $1 \mathrm{Ca} 3 \mathrm{Y}$ \\
\hline $2 \% \mathrm{CaO}^{*}$ e $2 \% \mathrm{Y}_{2} \mathrm{O}_{3}$ & $2 \mathrm{Ca} 2 \mathrm{Y}$ \\
\hline $3 \% \mathrm{CaO}^{*}$ e $1 \% \mathrm{Y}_{2} \mathrm{O}_{3}$ & $3 \mathrm{Ca} 1 \mathrm{Y}$ \\
\hline $2 \% \mathrm{CaO}^{*}, 2 \% \mathrm{Y}_{2} \mathrm{O}_{3}$ e $0,5 \% \mathrm{C}$ & $2 \mathrm{Ca} 2 \mathrm{Y} 05 \mathrm{C}$ \\
\hline $2 \% \mathrm{CaO}^{*}, 2 \% \mathrm{Y}_{2} \mathrm{O}_{3}$ e $1 \% \mathrm{C}$ & $2 \mathrm{Ca} 2 \mathrm{Y} 1 \mathrm{C}$ \\
\hline
\end{tabular}

*O aditivo foi adicionado na forma de $\mathrm{CaCO}_{3}$, sendo usada a seguinte relação de massa molecular $\mathrm{M}_{\mathrm{CaO}} / \mathrm{M}_{\mathrm{CaCO}_{3}}=0,55$ para estimar o valor do aditivo na forma de óxido. 


\subsection{Resultados experimentais}

\subsubsection{Efeito da adição simultânea de $\mathrm{Y}_{2} \mathrm{O}_{3}$ e $\mathrm{CaO}$ na densificação do AIN}

Nesta série experimental, os resultados das amostras de $\mathrm{AlN}$ com $4 \%$ de $\mathrm{Y}_{2} \mathrm{O}_{3}(4 \mathrm{Y}, 0 \%$ de $\mathrm{CaO}$ ) e com $4 \%$ de $\mathrm{CaO}$ (4Ca) foram usados como referências. Os resultados da amostra $4 \mathrm{Y}$ foram copilados do Capítulo 3, enquanto os resultados da amostra 4Ca foram compilados do Capítulo 4.

\subsubsection{Densificação}

Os corpos compactados nesta série experimental apresentaram densidades relativas de 55\% DT, independente das composições dos aditivos de sinterização. A amostra 1Ca3Y sinterizada a $1650^{\circ} \mathrm{C}$ atingiu densidade de $98 \%$ DT (Fig. 5.2), enquanto as amostras $2 \mathrm{Ca} 2 \mathrm{Y}$ e $3 \mathrm{Ca} 1 \mathrm{Y}$ sinterizadas na mesma temperatura atingiram densidades de 93\% e 88\% DT, respectivamente. Já as amostras $4 \mathrm{Y}$ e $4 \mathrm{Ca}$ sinterizadas a $1650^{\circ} \mathrm{C}$ atingiram valores menores de densidade do que as amostras com mistura de aditivos (Fig. 5.2), mostrando que a adição simultânea de $\mathrm{Y}_{2} \mathrm{O}_{3}$ e $\mathrm{CaO}$ diminuiu a temperatura de sinterização do AlN.

Desconsiderando os resultados da amostra 4Y, a densidade das amostras sinterizadas entre $1650^{\circ} \mathrm{C}$ e $1850^{\circ} \mathrm{C}$ diminuiu com o aumento da fração de $\mathrm{CaO}$ na mistura de aditivos (Fig. 5.2). Estes resultados mostraram que adições de $\mathrm{CaO}$, acima de $25 \%$ na mistura de aditivos, atrasaram significativamente a densificação do AlN. Porém, o aumento da temperatura de sinterização promoveu uma significativa densificação nas amostras contendo cálcio (Fig. 5.2).

Como relatado no Capítulo 3 , o $\mathrm{AlN}$ com $\mathrm{Y}_{2} \mathrm{O}_{3}$ apresenta uma considerável densificação por sinterização no estado sólido até cerca de $1700^{\circ} \mathrm{C}$, mas completa densificação ocorre somente por sinterização via fase líquida, que é ativada a partir de $1725^{\circ} \mathrm{C}$. Isto explica porque a amostra $4 \mathrm{Y}$ atingiu quase completa densificação somente após a sinterização acima de $1700^{\circ} \mathrm{C}$ (Fig. 5.2). 
Fração de $\mathrm{CaO}$ presente na mistura de aditivos

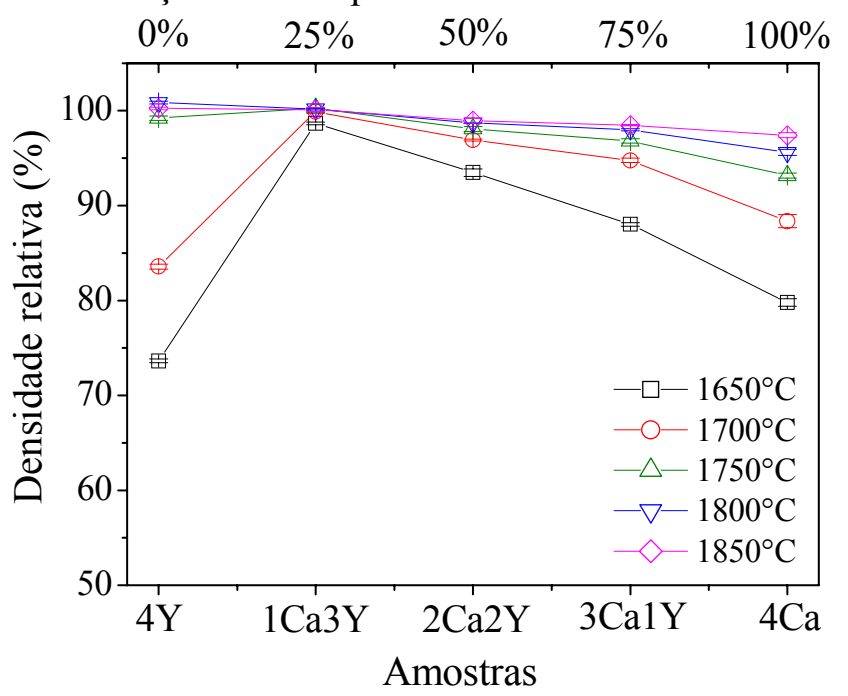

Figura 5.2 - Resultados de densidade relativa das amostras de $\mathrm{AlN}$ com $\mathrm{Y}_{2} \mathrm{O}_{3}$ e/ou CaO. As amostras $4 \mathrm{Y}$ e $4 \mathrm{Ca}$ se referem ao AlN com $4 \%$ de $\mathrm{Y}_{2} \mathrm{O}_{3}$ e $4 \%$ de $\mathrm{CaO}$, respectivamente. Já as amostras $1 \mathrm{Ca} 3 \mathrm{Y}, 2 \mathrm{Ca} 2 \mathrm{Y}$ e $3 \mathrm{Ca} 1 \mathrm{Y}$ se referem ao $\mathrm{AlN}$ com $1 \% \mathrm{CaO}-3 \% \mathrm{Y}_{2} \mathrm{O}_{3}, 2 \% \mathrm{CaO}-2 \% \mathrm{Y}_{2} \mathrm{O}_{3}$ e $3 \% \mathrm{CaO}-1 \% \mathrm{Y}_{2} \mathrm{O}_{3}$, respectivamente.

\subsubsection{Perda de massa e evolução das segundas-fases}

A perda de massa da amostra $1 \mathrm{Ca} 3 \mathrm{Y}$ foi praticamente constante entre $1100^{\circ} \mathrm{C}$ e $1850^{\circ} \mathrm{C}$ (Fig. 5.3). Já a perda de massa da amostra $2 \mathrm{Ca} 2 \mathrm{Y}$ apresentou um pequeno aumento entre $1100^{\circ} \mathrm{C}$ e $1700^{\circ} \mathrm{C}$ e, então, mostrou uma leve tendência para diminuir com a temperatura de sinterização (Fig. 5.3). O mesmo comportamento foi observado para a amostra $3 \mathrm{Ca} 1 \mathrm{Y}$. Estes resultados indicaram que a amostra $1 \mathrm{Ca} 3 \mathrm{Y}$ apresentou evaporação de compostos praticamente em baixas temperaturas de sinterização $\left(\leq 1100^{\circ} \mathrm{C}\right)$, enquanto as amostras 2Ca2Y e 3Ca1Y também apresentaram evaporação de compostos durante a sinterização acima de $1100^{\circ} \mathrm{C}$.

As perdas estimadas de $\mathrm{CO}_{2}$, proveniente da decomposição do $\mathrm{CaCO}_{3}{ }^{\S \S}$, foram próximas de $0,5 \%$ para a amostra $1 \mathrm{Ca} 3 \mathrm{Y}, 0,9 \%$ para a amostra $2 \mathrm{Ca} 2 \mathrm{Y}$ e $1,3 \%$ para a amostra $3 \mathrm{Ca} 1 \mathrm{Y}$. Subtraindo estes valores de perda de $\mathrm{CO}_{2}$ das perdas de massa das respectivas amostras, obtiveram-se os seguintes valores médios de perda de massa entre $1650^{\circ} \mathrm{C}$ e $1850^{\circ} \mathrm{C}: 3 \%$ para a amostra $1 \mathrm{Ca} 3 \mathrm{Y}, 4,5 \%$ para a amostra $2 \mathrm{Ca} 2 \mathrm{Y}$ e $5 \%$ para $3 \mathrm{Ca} 1 \mathrm{Y}$. Como comparação, as amostras $4 \mathrm{Y}$ e $4 \mathrm{Ca}$ sinterizadas entre $1650^{\circ} \mathrm{C}$ e $1850^{\circ} \mathrm{C}$ apresentaram menores valores de perda de massa ( $\sim 0,6 \%$ (Fig. 3.13) e $\sim 1 \%$ (Fig. 4.7), respectivamente) do que as

${ }^{\S} \mathrm{CaCO}_{3} \leftrightarrow \mathrm{CaO}+\mathrm{CO}_{2}$ 
amostras $1 \mathrm{Ca} 3 \mathrm{Y}, 2 \mathrm{Ca} 2 \mathrm{Y}$ e $3 \mathrm{Ca} 1 \mathrm{Y}$ sinterizadas na mesma faixa de temperatura (Fig. 5.3). Portanto, a adição simultânea de $\mathrm{Y}_{2} \mathrm{O}_{3}$ e $\mathrm{CaO}$ favoreceu a evaporação de compostos durante a sinterização do AlN. Além disso, o aumento da fração de $\mathrm{CaO}$ na mistura de aditivos intensificou a evaporação de compostos, pois a amostra 3Ca1Y apresentou os maiores valores de perda de massa entre $1100^{\circ} \mathrm{C}$ e $1850^{\circ} \mathrm{C}$ (Fig. 5.3).

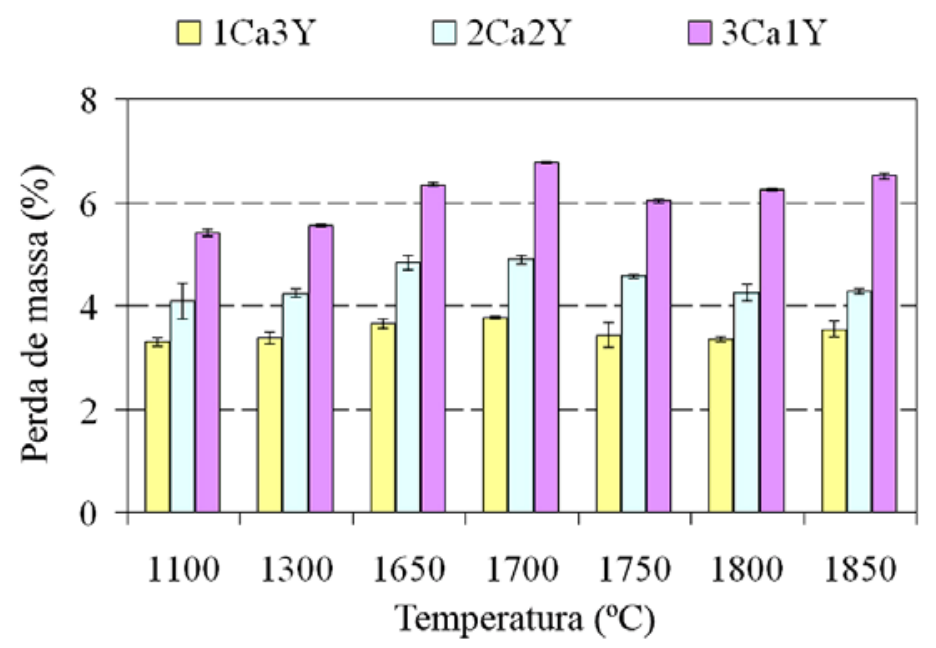

Figura 5.3 - Perda de massa em função da temperatura de sinterização das amostras 1Ca3Y, 2Ca2Y e 3Ca1Y.

Alguns difratogramas de raios $\mathrm{X}$ das amostras de $\mathrm{AlN}$ com adição simultânea de $\mathrm{Y}_{2} \mathrm{O}_{3}$ e $\mathrm{CaO}$ são apresentados na Figura 5.4. Os resultados de DRX das amostras sinterizadas entre $1100^{\circ} \mathrm{C}$ e $1850^{\circ} \mathrm{C}$ são apresentados na Tabela 5.2. As amostras $1 \mathrm{Ca} 3 \mathrm{Y}, 2 \mathrm{Ca} 2 \mathrm{Y}$ e $3 \mathrm{Ca} 1 \mathrm{Y}$ sinterizadas parcialmente a $1100^{\circ} \mathrm{C}$ apresentaram as fases $\mathrm{CaYAl}_{3} \mathrm{O}_{7}$ e/ou $\mathrm{CaYAlO}_{4}(\mathrm{Tabela}$ 5.2), indicando que estas segundas-fases se formaram durante o aquecimento até a temperatura de sinterização. Porém, as três amostras tratadas termicamente a $1100^{\circ} \mathrm{C}$ também apresentaram $\mathrm{Y}_{2} \mathrm{O}_{3}$ (Tabela 5.2), mostrando que parte deste aditivo não reagiu com os demais compostos do corpo conformado. Como o $\mathrm{Y}_{2} \mathrm{O}_{3}$ não foi observado nas três amostras sinterizadas parcialmente a $1300^{\circ} \mathrm{C}$ (Tabela 5.2), e sabendo que a quantidade de aluminatos de ítrio aumentou nestas amostras, pode-se dizer que o $\mathrm{Y}_{2} \mathrm{O}_{3}$ reagiu preferencialmente com a camada de $\mathrm{Al}_{2} \mathrm{O}_{3}$ presente no pó de $\mathrm{AlN}$ durante o tratamento térmico acima de $1100^{\circ} \mathrm{C}$.

$\mathrm{O}$ aumento da temperatura de sinterização, acima de $1300^{\circ} \mathrm{C}$, levou somente à formação de fases ternárias nas amostras $2 \mathrm{Ca} 2 \mathrm{Y}$ e $3 \mathrm{Ca} 1 \mathrm{Y}$ (Tabela 5.2). Após a sinterização entre $1650^{\circ} \mathrm{C}$ e $1850^{\circ} \mathrm{C}$, a amostra $2 \mathrm{Ca} 2 \mathrm{Y}$ apresentou em ordem de preponderância as fases $\mathrm{CaYAl}_{3} \mathrm{O}_{7}$ e $\mathrm{CaYAlO}_{4}$ (Tabela 5.2), enquanto somente a fase $\mathrm{CaYAl}_{3} \mathrm{O}_{7}$ foi identificada na amostra $3 \mathrm{Ca} 1 \mathrm{Y}$. A amostra $1 \mathrm{Ca} 3 \mathrm{Y}$ sinterizada entre $1650^{\circ} \mathrm{C}$ e $1850^{\circ} \mathrm{C}$ apresentou a fase 
$\mathrm{CaYAl}_{3} \mathrm{O}_{7}$ (Tabela 5.2), mas também ocorreu a formação da YAM $\left(\mathrm{Al}_{2} \mathrm{O}_{3} \cdot 2 \mathrm{Y}_{2} \mathrm{O}_{3}\right)$. Estes resultados mostraram que a diminuição da fração de $\mathrm{CaO}$ na mistura de aditivos levou à formação de fases mais ricas em $\mathrm{Y}_{2} \mathrm{O}_{3}$, como indicado por Qiao et al. ${ }^{76}$. O aumento da temperatura de sinterização, entre $1650^{\circ} \mathrm{C}$ e $1850^{\circ} \mathrm{C}$, não causou mudanças na evolução de segundas-fases das amostras $2 \mathrm{Ca} 2 \mathrm{Y}$ e $3 \mathrm{Ca} 1 \mathrm{Y}$ (Tabela 5.2). Porém, observou-se uma mudança na fração das segundas-fases da amostra $1 \mathrm{Ca} 3 \mathrm{Y}$ com o aumento da temperatura de sinterização (Tabela 5.2), sendo observadas, em ordem de preponderância, as fases $\mathrm{CaYAl}_{3} \mathrm{O}_{7}$ e YAM após a sinterização entre $1650^{\circ} \mathrm{C}$ e $1750^{\circ} \mathrm{C}$ e a inversão desta ordem acima desta faixa de temperatura.

(a) $1300^{\circ} \mathrm{C}$

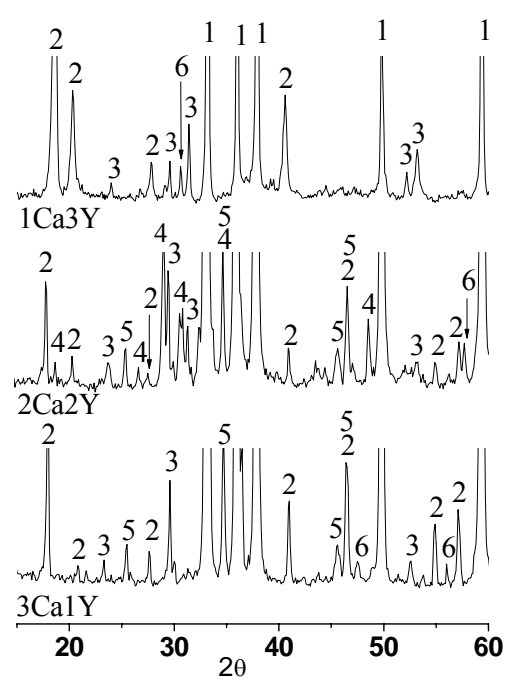

(b) $1750^{\circ} \mathrm{C}$
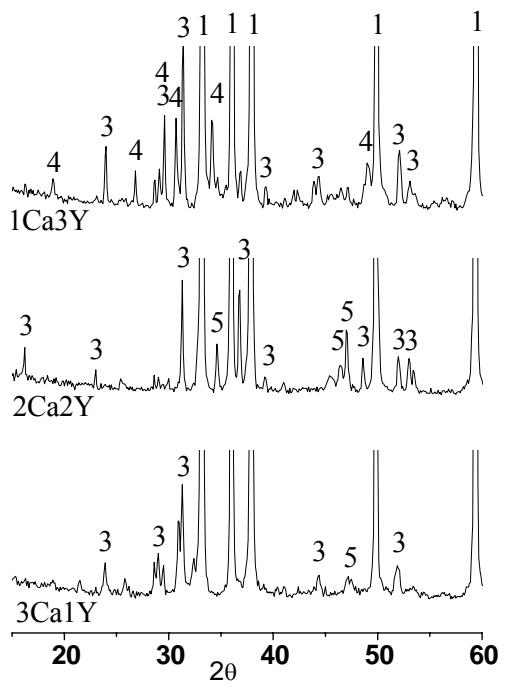

(c) $1850^{\circ} \mathrm{C}$
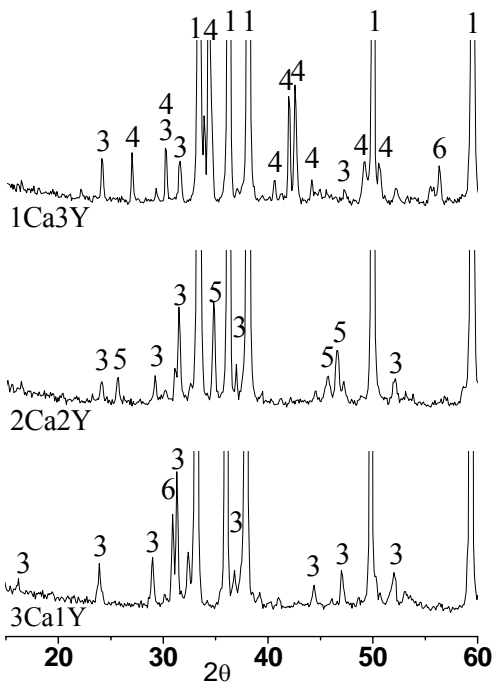

Figura 5.4 - Difratogramas de raios $\mathrm{X}$ das amostras $1 \mathrm{Ca} 3 \mathrm{Y}, 2 \mathrm{Ca} 2 \mathrm{Y}$ e $3 \mathrm{Ca} 1 \mathrm{Y}$. Fases cristalinas: (1) AlN, (2) $\mathrm{YAG}\left[5 \mathrm{Al}_{2} \mathrm{O}_{3} \cdot 3 \mathrm{Y}_{2} \mathrm{O}_{3}\right],(3) \mathrm{CaYAl}_{3} \mathrm{O}_{7}$, (4) YAM $\left[\mathrm{Al}_{2} \mathrm{O}_{3} \cdot 2 \mathrm{Y}_{2} \mathrm{O}_{3}\right]$, (5) $\mathrm{CaYAlO}_{4}$ e (6) não identificada.

Tabela 5.2 - Resultados de DRX das segundas-fases nas amostras 1Ca3Y, 2Ca2Y e 3Ca1Y.

\begin{tabular}{|c|c|c|c|}
\hline \multirow{2}{*}{$\begin{array}{l}\text { Temperatura } \\
\left({ }^{\circ} \mathrm{C}\right)\end{array}$} & \multicolumn{3}{|c|}{ Segundas-fases em ordem de preponderância } \\
\hline & 1Ca3Y & 2Ca2Y & 3Ca1Y \\
\hline 1100 & $\mathrm{Y}_{2} \mathrm{O}_{3}, \mathrm{CaYAl}_{3} \mathrm{O}_{7}$ & $\begin{array}{c}\mathrm{Y}_{2} \mathrm{O}_{3}, \mathrm{CaYAlO}_{4}, \\
\mathrm{CaYAl}_{3} \mathrm{O}_{7}\end{array}$ & $\begin{array}{c}\mathrm{Y}_{2} \mathrm{O}_{3}, \mathrm{CaYAlO}_{4} \\
\mathrm{CaYAl}_{3} \mathrm{O}_{7}\end{array}$ \\
\hline 1300 & $\mathrm{YAG}, \mathrm{CaYAl}_{3} \mathrm{O}_{7}$ & $\begin{array}{c}\text { YAM, YAG, } \\
\mathrm{CaYAlO}_{4}, \mathrm{CaYAl}_{3} \mathrm{O}_{7}\end{array}$ & $\begin{array}{c}\text { YAG, } \mathrm{CaYAlO}_{4}, \\
\mathrm{CaYAl}_{3} \mathrm{O}_{7}\end{array}$ \\
\hline 1650 & $\mathrm{CaYAl}_{3} \mathrm{O}_{7}, \mathrm{YAM}$ & $\mathrm{CaYAl}_{3} \mathrm{O}_{7}, \mathrm{CaYAlO}_{4}$ & $\mathrm{CaYAl}_{3} \mathrm{O}_{7}$ \\
\hline 1700 & $\mathrm{CaYAl}_{3} \mathrm{O}_{7}, \mathrm{YAM}$ & $\mathrm{CaYAl}_{3} \mathrm{O}_{7}, \mathrm{CaYAlO}_{4}$ & $\mathrm{CaYAl}_{3} \mathrm{O}_{7}$ \\
\hline 1750 & $\mathrm{CaYAl}_{3} \mathrm{O}_{7}, \mathrm{YAM}$ & $\mathrm{CaYAl}_{3} \mathrm{O}_{7}, \mathrm{CaYAlO}_{4}$ & $\mathrm{CaYAl}_{3} \mathrm{O}_{7}$ \\
\hline 1800 & $\mathrm{YAM}, \mathrm{CaYAl}_{3} \mathrm{O}_{7}$ & $\mathrm{CaYAl}_{3} \mathrm{O}_{7}, \mathrm{CaYAlO}_{4}$ & $\mathrm{CaYAl}_{3} \mathrm{O}_{7}$ \\
\hline 1850 & $\mathrm{YAM}, \mathrm{CaYAl}_{3} \mathrm{O}_{7}$ & $\mathrm{CaYAl}_{3} \mathrm{O}_{7}, \mathrm{CaYAlO}_{4}$ & $\mathrm{CaYAl}_{3} \mathrm{O}_{7}$ \\
\hline
\end{tabular}




\subsubsection{Análise microestrutural}

A amostra $1 \mathrm{Ca} 3 \mathrm{Y}$ sinterizada a $1650^{\circ} \mathrm{C}$ foi caracterizada por apresentar alguns poros residuais e partículas grandes de segundas-fases (Fig. 5.5a). Uma destas partículas é mostrada em detalhes na Figura 5.5b, onde se observa que a segunda-fase com formato de partícula mostrou uma leve tendência para migrar por entre os grãos de AlN, principalmente nas regiões próximas das junções de suas arestas. Porém, um alto ângulo diedro foi observado na interface entre os grãos de AlN e a partícula grande (Fig. 5.5b). Este resultado indicou que a segunda-fase com formato de partícula grande não fundiu ou teve alta viscosidade e/ou baixa molhabilidade durante a sinterização na temperatura de $1650^{\circ} \mathrm{C}$.
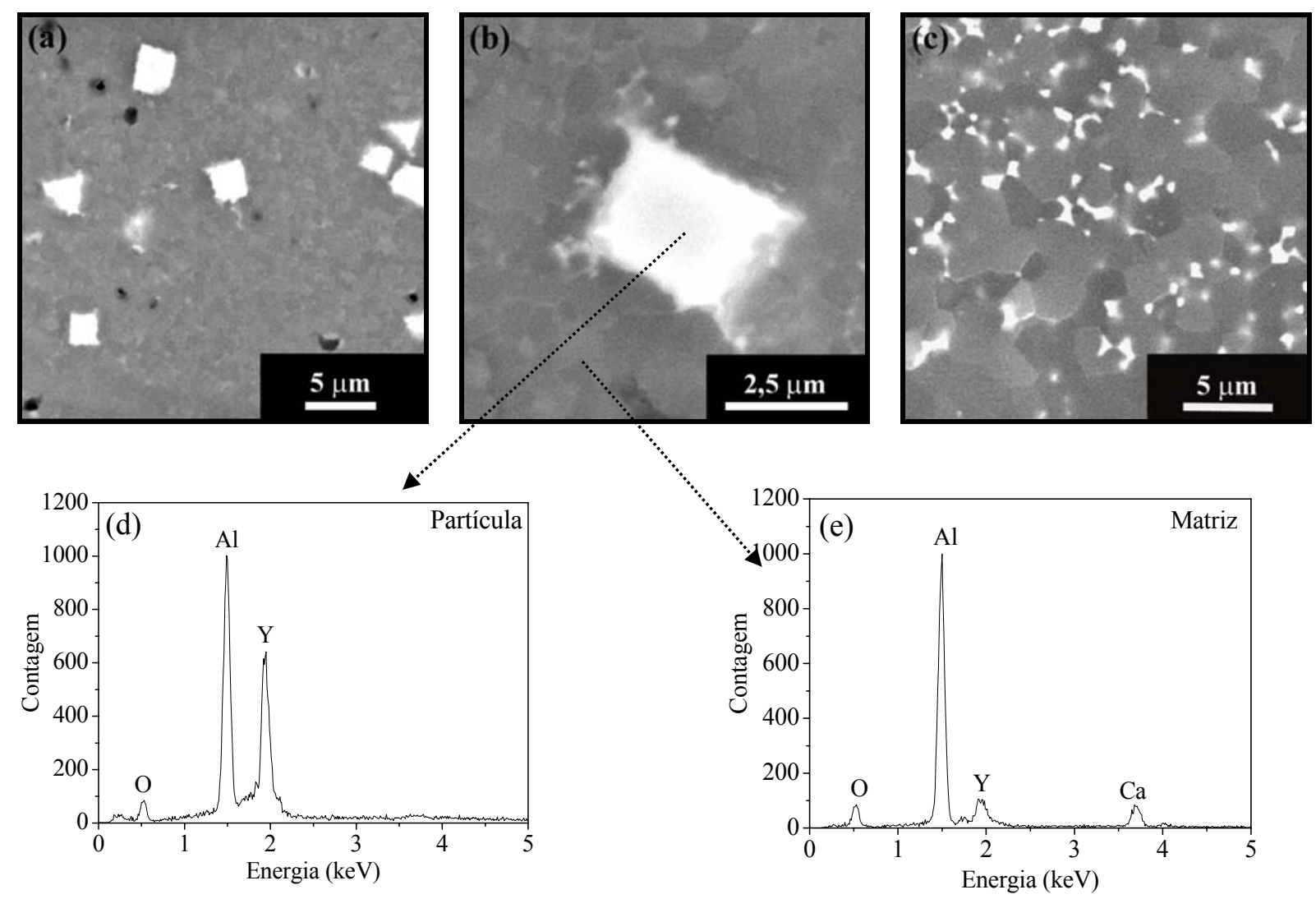

Figura 5.5 - Imagens de MEV da superfície polida da amostra $1 \mathrm{Ca} 3 \mathrm{Y}$ sinterizada a $1650^{\circ} \mathrm{C}$ (a e b) e $1850^{\circ} \mathrm{C}(\mathrm{c})$ por $1 \mathrm{~h}$. As regiões claras observadas nas Figuras 5.5a a 5.5c são partículas de segundas-fases. Resultados das análises por EDS realizadas na partícula grande de segunda-fase (d) e na matriz (e).

A análise por EDS revelou a presença de oxigênio $(\mathrm{O})$, alumínio $(\mathrm{Al})$ e ítrio $(\mathrm{Y})$ na partícula grande de segunda-fase da amostra 1Ca3Y (Fig. 5.5d). Este resultado indicou que as partículas grandes de segundas-fases foram compostas pela fase YAM $\left(\mathrm{Al}_{2} \mathrm{O}_{3} \cdot 2 \mathrm{Y}_{2} \mathrm{O}_{3}\right)$, pois os 
resultados de DRX mostraram a presença desta segunda-fase na amostra $1 \mathrm{Ca} 3 \mathrm{Y}$ sinterizada entre $1650^{\circ} \mathrm{C}$ e $1850^{\circ} \mathrm{C}$ (Tabela 5.2). Estas partículas grandes de segundas-fases foram similares às partículas observadas nas amostras $2 \mathrm{Y}$ e $4 \mathrm{Y}$ sinterizadas até $1800^{\circ} \mathrm{C}$ (Figs. $3.8 \mathrm{~d}$, 3.8e e 3.11a). No Capítulo 3, concluiu-se que estas partículas foram compostas por fases refratárias de aluminato de ítrio, as quais fundiram acima de $1800^{\circ} \mathrm{C}$ e, então, a fase líquida foi redistribuída pela microestrutura (Figs. 3.11a a 3.11c). O mesmo comportamento foi observado para a amostra $1 \mathrm{Ca} 3 \mathrm{Y}$, pois a segunda-fase com formato de partícula mostrou uma tendência para penetrar e espalhar por entre os grãos de $\mathrm{AlN}$ somente acima de $1800^{\circ} \mathrm{C}$ (Fig. $5.5 \mathrm{a}$ e 5.5c). Já a análise por EDS da matriz da amostra $1 \mathrm{Ca} 3 \mathrm{Y}$ sinterizada a $1650^{\circ} \mathrm{C}$ (Fig. 5.5 e) revelou a presença de oxigênio $(\mathrm{O})$, alumínio $(\mathrm{Al})$, ítrio $(\mathrm{Y})$ e cálcio $(\mathrm{Ca})$, indicando que a fase líquida presente durante a sinterização foi composta por uma fase ternária $\left(\mathrm{CaYAl}_{3} \mathrm{O}_{7}\right)$, segundo os resultados de DRX da referida amostra (Tabela 5.2).

As amostras $2 \mathrm{Ca} 2 \mathrm{Y}$ e $3 \mathrm{Ca} 1 \mathrm{Y}$ sinterizadas a $1650^{\circ} \mathrm{C}$ apresentaram microestruturas compostas por matrizes densas e poros relativamente grandes (Figs. 5.6a e 5.6c), cuja fração aumentou em função do aumento da fração de $\mathrm{CaO}$ na mistura de aditivos (Figs. 5.5a, 5.6a e 5.6c). Embora a quantidade de poros tenha aumentado com o aumento da fração de $\mathrm{CaO}$ na mistura de aditivos $\left(\mathrm{CaO}\right.$ e $\left.\mathrm{Y}_{2} \mathrm{O}_{3}\right)$, as amostras $2 \mathrm{Ca} 2 \mathrm{Y}$ e $3 \mathrm{Ca} 1 \mathrm{Y}$ não apresentaram partículas grandes de segundas-fases após a sinterização entre $1650^{\circ} \mathrm{C}$ e $1850^{\circ} \mathrm{C}$ (Fig. 5.6). Isto indicou que a fase líquida teve boas características de molhamento e espalhamento durante a sinterização. A porosidade, observada nas amostras $2 \mathrm{Ca} 2 \mathrm{Y}$ e $3 \mathrm{Ca} 1 \mathrm{Y}$, diminuiu com o aumento da temperatura de sinterização (Fig. 5.6). Porém, alguns poros relativamente grandes ainda permaneceram na microestrutura do AlN (Figs. 5.6e e 5.6f), mesmo depois da sinterização em alta temperatura $\left(\geq 1800^{\circ} \mathrm{C}\right)$. O aumento da temperatura de sinterização promoveu a eliminação da maioria dos poros (Fig. 5.6), o que resultou no aumento significativo de densidade nas amostras com $\mathrm{CaO}$ (Fig. 5.2). Por outro lado, o aumento de temperatura também causou um crescimento de grão significativo (Figs. 5.6a, 5.6c, 5.6e e 5.6f), que pode resultar na diminuição apreciável das propriedades mecânicas do AlN. 

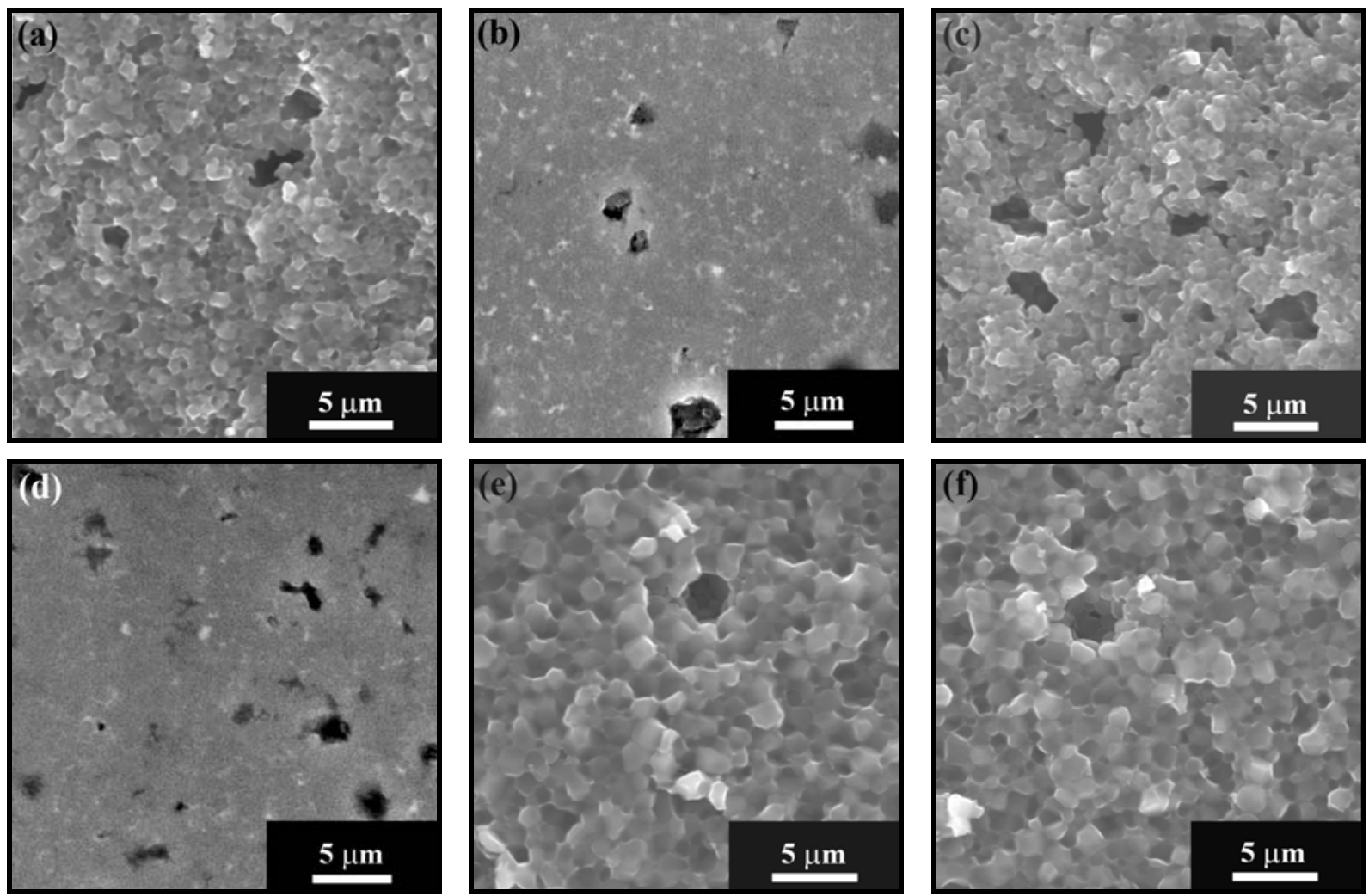

Figura 5.6 - Imagens de MEV das superfícies de fratura das amostras $2 \mathrm{Ca} 2 \mathrm{Y}$ (a) e $3 \mathrm{Ca} 1 \mathrm{Y}$ (c) sinterizadas a $1650^{\circ} \mathrm{C}$, das superfícies polidas das amostras $2 \mathrm{Ca} 2 \mathrm{Y}$ (b) e $3 \mathrm{Ca} 1 \mathrm{Y}$ (d) sinterizadas a $1700^{\circ} \mathrm{C}$ e das superfícies de fratura das amostras $2 \mathrm{Ca} 2 \mathrm{Y}$ (e) e $3 \mathrm{Ca} 1 \mathrm{Y}$ (f) sinterizadas a $1800^{\circ} \mathrm{C}$.

\subsubsection{Efeito do carbono na densificação do AIN com adição simultânea de $\mathrm{Y}_{2} \mathrm{O}_{3}$ e CaO}

\subsubsection{Densificação}

Após a sinterização na temperatura de $1650^{\circ} \mathrm{C}$, a amostra $2 \mathrm{Ca} 2 \mathrm{Y}$ atingiu densidade de 93\% DT (Fig. 5.7), enquanto as amostras 2Ca2Y05C e 2Ca2Y1C atingiram densidades de $78 \%$ e $66 \%$ DT, respectivamente. Em relação aos sistemas $\mathrm{AlN}-\mathrm{Y}_{2} \mathrm{O}_{3}$ (Fig. 3.12) e AlN-CaO (Fig. 4.6), o sistema AlN-CaO- $\mathrm{Y}_{2} \mathrm{O}_{3}$ apresentou as maiores diferenças de densidade entre as amostras sem e com carbono (C) após a sinterização na temperatura de $1650^{\circ} \mathrm{C}$ (Fig. 5.7). No entanto, o $\mathrm{C}$ não inibiu completamente a ação da mistura de aditivos $\left(\mathrm{CaO}\right.$ e $\left.\mathrm{Y}_{2} \mathrm{O}_{3}\right)$ em promover a densificação do AlN durante a sinterização a $1650^{\circ} \mathrm{C}$, pois a amostra $2 \mathrm{Ca} 2 \mathrm{Y} 1 \mathrm{C}$ apresentou maior densidade (66\% DT, Fig. 5.7) do que a amostra 4Y1C (60\% DT, Fig. 3.12), que teve um comportamento de densificação similar ao observado para o AlN sem aditivo 
sinterizado entre $1650^{\circ} \mathrm{C}$ e $1750^{\circ} \mathrm{C}$ (Fig. 3.4). $\mathrm{O}$ aumento da temperatura de $1650^{\circ} \mathrm{C}$ para $1700^{\circ} \mathrm{C}$ causou um aumento significativo de densidade nas amostras com $\mathrm{C}$ (Fig. 5.7). Um comportamento similar foi observado, entre $1750^{\circ} \mathrm{C}$ e $1800^{\circ} \mathrm{C}$, para o sistema $\mathrm{AlN}-\mathrm{Y}_{2} \mathrm{O}_{3}$ (Fig. $3.12)$.

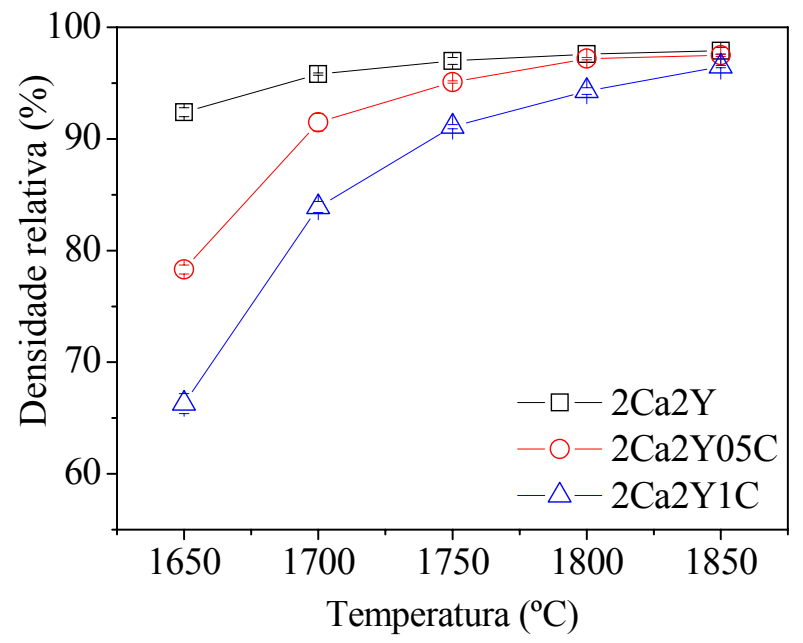

Figura 5.7 - Densidade em função da temperatura de sinterização das amostras 2Ca2Y, 2Ca2Y05C e 2Ca2Y1C.

As densidades das amostras com $\mathrm{C}$ aumentaram moderadamente com o aumento da temperatura de $1700^{\circ} \mathrm{C}$ para $1850^{\circ} \mathrm{C}$ (Fig. 5.7), indicando que o efeito prejudicial do $\mathrm{C}$ na densificação da amostra $2 \mathrm{Ca} 2 \mathrm{Y}$ diminuiu com o aumento da temperatura de sinterização. Entre $1700^{\circ} \mathrm{C}$ e $1850^{\circ} \mathrm{C}$, as amostras $4 \mathrm{Ca} 05 \mathrm{C}$ e $4 \mathrm{Ca} 1 \mathrm{C}$ apresentaram comportamentos de densificação (Fig. 4.6) próximos daqueles observados para as amostras 2Ca2Y05C e 2Ca2Y1C (Fig. 5.7). As amostras $2 \mathrm{Ca} 2 \mathrm{Y}$ e $2 \mathrm{Ca} 2 \mathrm{Y} 05 \mathrm{C}$ sinterizadas a partir de $1800^{\circ} \mathrm{C}$ atingiram densidades próximas ( 97\% DT, Fig. 5.22), como observado para os sistemas AlN$\mathrm{Y}_{2} \mathrm{O}_{3}$ (Fig. 3.12) e AlN-CaO (Fig. 4.6). Porém, a amostra 2Ca2Y1C apresentou uma densificação mais lenta (Fig. 5.7), pois atingiu máxima densidade somente após a sinterização na temperatura de $1850^{\circ} \mathrm{C}$.

\subsubsection{Perda de massa e evolução das segundas-fases}

As amostras $2 \mathrm{Ca} 2 \mathrm{Y}$ e $2 \mathrm{Ca} 2 \mathrm{Y} 05 \mathrm{C}$ sinterizadas entre $1650^{\circ} \mathrm{C}$ e $1850^{\circ} \mathrm{C}$ apresentaram valores próximos de perda de massa (Fig. 5.8), indicando que a adição de $0,5 \%$ de $\mathrm{C}$ não 
aumentou a evaporação de compostos durante a sinterização. Porém, os valores de perda de massa da amostra $2 \mathrm{Ca} 2 \mathrm{Y} 05 \mathrm{C}$ sinterizada entre $1650^{\circ} \mathrm{C}$ e $1850^{\circ} \mathrm{C}$ (Fig. 5.8) foram maiores do que a soma das perdas estimadas de $\mathrm{CO}_{2}(\sim 2,9 \%)$ provenientes das decomposições dos aditivos de sinterização $\left(\mathrm{CaCO}_{3}\right.$ e C). Já a amostra $2 \mathrm{Ca} 2 \mathrm{Y} 1 \mathrm{C}$ apresentou maior perda de massa do que as amostras $2 \mathrm{Ca} 2 \mathrm{Y}$ e $2 \mathrm{Ca} 2 \mathrm{Y} 05 \mathrm{C}$ (Fig. 5.8), bem como maior perda de massa do que a soma das perdas estimadas de $\mathrm{CO}_{2}(\sim 4,9 \%)$ provenientes das decomposições dos aditivos de sinterização $\left(\mathrm{CaCO}_{3}\right.$ e $\left.\mathrm{C}\right)$. Estes resultados indicaram que o aumento do teor de $\mathrm{C}$ aumentou a evaporação de compostos na amostra 2Ca2Y (Fig. 5.8), o que pode ter resultado na diminuição da fração de fase líquida presente durante a sinterização.

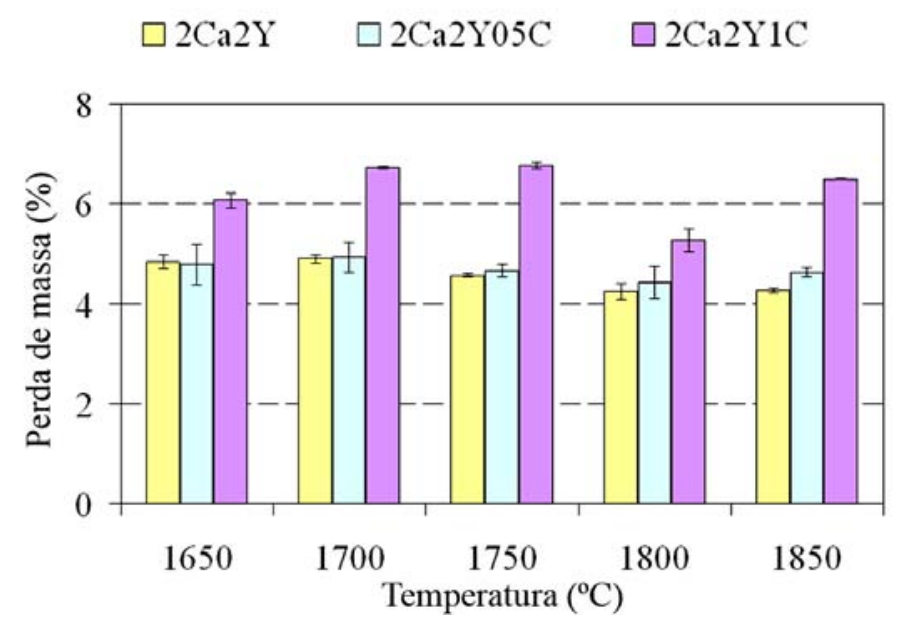

Figura 5.8 - Perda de massa em função da temperatura de sinterização das amostras $2 \mathrm{Ca} 2 \mathrm{Y}, 2 \mathrm{Ca} 2 \mathrm{Y} 05 \mathrm{C}$ e 2Ca2Y1C.

Os resultados de DRX das amostras 2Ca2Y, 2Ca2Y05C e 2Ca2Y1C sinterizadas entre $1650^{\circ} \mathrm{C}$ e $1850^{\circ} \mathrm{C}$ são apresentados na Tabela 5.3. A amostra $2 \mathrm{Ca} 2 \mathrm{Y}$ sinterizada entre $1650^{\circ} \mathrm{C}$ e $1850^{\circ} \mathrm{C}$ apresentou em ordem de preponderância as fases $\mathrm{CaYAl}_{3} \mathrm{O}_{7}$ e $\mathrm{CaYAlO}_{4}(\mathrm{Tabela}$ 5.3), indicando que, nesta faixa de temperatura, as segundas-fases foram estáveis durante a sinterização sob atmosfera inerte. Uma inversão na ordem de preponderância das segundasfases foi observada entre as amostras $2 \mathrm{Ca} 2 \mathrm{Y}$ e $2 \mathrm{Ca} 2 \mathrm{Y} 05 \mathrm{C}$ sinterizadas entre $1650^{\circ} \mathrm{C}$ e $1800^{\circ} \mathrm{C}$ (Tabela 5.3). Acima desta faixa de temperatura, somente a fase $\mathrm{CaYAlO}_{4}$ foi observada na amostra 2Ca2Y05C (Tabela 5.3). Estes resultados indicaram que a utilização de C, bem como o aumento da temperatura de sinterização favoreceu a formação da fase $\mathrm{CaYAlO}_{4}$ durante a sinterização da amostra $2 \mathrm{Ca} 2 \mathrm{Y}$. A amostra $2 \mathrm{Ca} 2 \mathrm{Y} 1 \mathrm{C}$ sinterizada a $1650^{\circ} \mathrm{C}$ e $1700^{\circ} \mathrm{C}$ apresentou em ordem de preponderância as fases $\mathrm{CaYAlO}_{4}$ e YAM e a inversão desta ordem entre $1750^{\circ} \mathrm{C}$ e $1850^{\circ} \mathrm{C}$ (Tabela 5.3). Estes resultados indicaram que a formação in situ de uma 
atmosfera redutora com $\mathrm{C}$, juntamente com o aumento da temperatura de sinterização, causou uma mudança significativa na evolução das segundas fases da amostra $2 \mathrm{Ca} 2 \mathrm{Y}$, que mudou de $\mathrm{CaYAl}_{3} \mathrm{O}_{7}$ para $\mathrm{CaYAlO}_{4}$ e, então, para YAM.

Tabela 5.3 - Resultados de DRX das segundas-fases nas amostras 2Ca2Y, 2Ca2Y05C e 2Ca2Y1C.

\begin{tabular}{c|c|c|c}
\hline \multirow{2}{*}{ Temperatura $\left({ }^{\circ} \mathrm{C}\right)$} & \multicolumn{3}{|c}{ Segundas-fases em ordem de preponderância } \\
\cline { 2 - 4 } & $2 \mathrm{Ca} 2 \mathrm{Y}$ & $2 \mathrm{Ca} 2 \mathrm{Y} 05 \mathrm{C}$ & 2Ca2Y1C \\
\hline 1650 & $\mathrm{CaYAl}_{3} \mathrm{O}_{7}, \mathrm{CaYAlO}_{4}$ & $\mathrm{CaYAlO}_{4}, \mathrm{CaYAl}_{3} \mathrm{O}_{7}$ & $\mathrm{CaYAlO}_{4}, \mathrm{YAM}$ \\
\hline 1700 & $\mathrm{CaYAl}_{3} \mathrm{O}_{7}, \mathrm{CaYAlO}_{4}$ & $\mathrm{CaYAlO}_{4}, \mathrm{CaYAl}_{3} \mathrm{O}_{7}$ & $\mathrm{CaYAlO}_{4}, \mathrm{YAM}$ \\
\hline 1750 & $\mathrm{CaYAl}_{3} \mathrm{O}_{7}, \mathrm{CaYAlO}_{4}$ & $\mathrm{CaYAlO}_{4}, \mathrm{CaYAl}_{3} \mathrm{O}_{7}$ & $\mathrm{YAM}_{4} \mathrm{CaYAlO}_{4}$ \\
\hline 1800 & $\mathrm{CaYAl}_{3} \mathrm{O}_{7}, \mathrm{CaYAlO}_{4}$ & $\mathrm{CaYAlO}_{4}, \mathrm{CaYAl}_{3} \mathrm{O}_{7}$ & $\mathrm{YAM}, \mathrm{CaYAlO}_{4}$ \\
\hline 1850 & $\mathrm{CaYAl}_{3} \mathrm{O}_{7}, \mathrm{CaYAlO}_{4}$ & $\mathrm{CaYAlO}$ & $\mathrm{YAM}, \mathrm{CaYAlO}$ \\
\hline
\end{tabular}

\subsubsection{Análise microestrutural}

As amostras $2 \mathrm{Ca} 2 \mathrm{Y} 05 \mathrm{C}$ e $2 \mathrm{Ca} 2 \mathrm{Y} 1 \mathrm{C}$ sinterizadas a $1650^{\circ} \mathrm{C}$ foram caracterizadas por apresentar uma microestrutura composta por pequenos aglomerados densos de partículas, poros grandes e partículas grandes de segundas-fases (Figs. 5.9a e 5.9c). A presença de pequenos aglomerados densos de partículas indicou que o mecanismo de rearranjo de partículas da sinterização via fase líquida foi ativado durante a sinterização na temperatura de $1650^{\circ} \mathrm{C}$. Porém, a pouca densificação da microestrutura das amostras com $\mathrm{C}$ sinterizadas a $1650^{\circ} \mathrm{C}$ (Figs. 5.9a e 5.9c) indicou que a fase líquida não apresentou boas características de molhamento e espalhamento, o que diminuiu a ação do mecanismo de rearranjo de partículas da sinterização via fase líquida. A presença de partículas grandes de segundas-fases nas amostras com $\mathrm{C}$ sinterizadas a $1650^{\circ} \mathrm{C}$ (Figs. 5.9a e 5.9c) indicou que certa fração de fase líquida apresentou alta viscosidade e/ou baixa molhabilidade, o que dificultou o seu espalhamento pela microestrutura e, como conseqüência, limitou a densificação do AlN.

A análise por EDS revelou a presença de oxigênio (O), alumínio (A1), ítrio (Y) e cálcio (Ca) na partícula grande de segunda-fase da amostra $2 \mathrm{Ca} 2 \mathrm{Y} 05 \mathrm{C}$ sinterizada a $1650^{\circ} \mathrm{C}$ (Figs. 5.9a e 5.9b). Este resultado mostrou que esta partícula foi composta por fases ternárias, pois os resultados de DRX mostraram a presença das fases $\mathrm{CaYAlO}_{4}$ e $\mathrm{CaYAl}_{3} \mathrm{O}_{7}$ na amostra 2Ca2Y05C sinterizada entre $1650^{\circ} \mathrm{C}$ e $1800^{\circ} \mathrm{C}$ (Tabela 5.3). Já a amostra 2Ca2Y1C sinterizada a $1650^{\circ} \mathrm{C}$ apresentou partículas grandes com composições químicas distintas. Uma determinada fração de partículas foi composta por $\mathrm{CaYAlO}_{4}$, segundo os resultados de DRX 
(Tabela 5.3), com morfologia similar às partículas observadas na amostra 2Ca2Y05C sinterizada a $1650^{\circ} \mathrm{C}$ (Figs. 5.9a e 5.9b). A outra fração de partículas foi composta por YAM, como observado nas amostras $2 \mathrm{Y}, 4 \mathrm{Y}$ e $1 \mathrm{Ca} 3 \mathrm{Y}$ sinterizadas até $1800^{\circ} \mathrm{C}$ (Figs. 3.8d, 3.8e, 3.11a, 5.5b e 5.5d). Estes resultados foram confirmados com as análises por EDS e com os resultados de DRX (Tabela 5.3), que mostraram a presença das fases $\mathrm{CaYAlO}_{4}$ e YAM na amostra $2 \mathrm{Ca} 2 \mathrm{Y} 1 \mathrm{C}$ sinterizada entre $1650^{\circ} \mathrm{C}$ e $1850^{\circ} \mathrm{C}$.
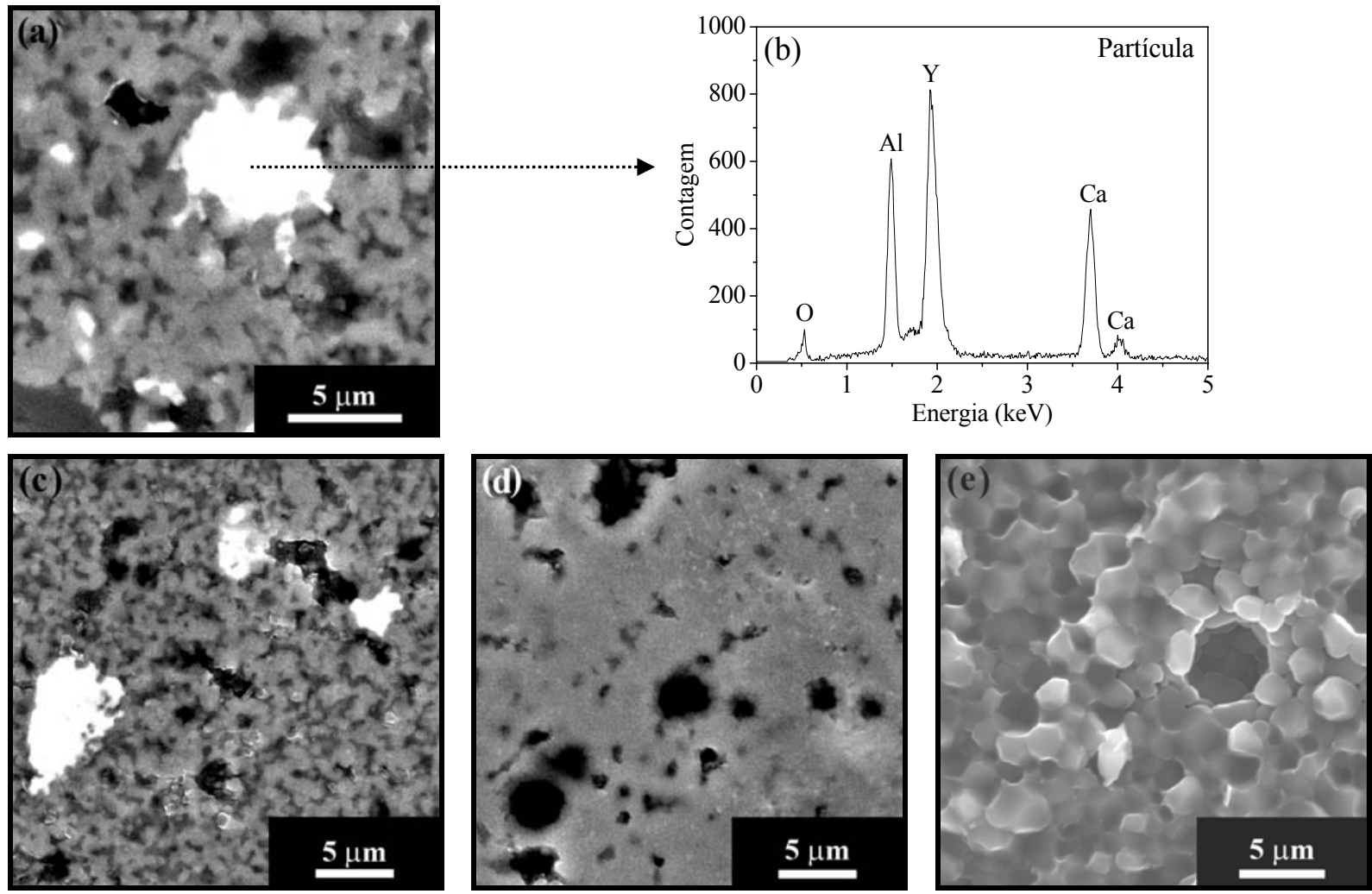

Figura 5.9 - Imagens de MEV da superfície polida das amostras 2Ca2Y05C (a) e 2Ca2Y1C (c) sinterizadas a $1650^{\circ} \mathrm{C}$, e $2 \mathrm{Ca} 2 \mathrm{Y} 05 \mathrm{C}$ (d) sinterizada a $1700^{\circ} \mathrm{C}$. Imagem de $\mathrm{MEV}$ da superfície de fratura da amostra $2 \mathrm{Ca} 2 \mathrm{Y} 1 \mathrm{C}$ (e) sinterizada a $1850^{\circ} \mathrm{C}$. Espectro de EDS (b) de uma partícula grande de segundas-fases observada na amostra 2Ca2Y05C.

$\mathrm{O}$ aumento da temperatura de $1650^{\circ} \mathrm{C}$ para $1700^{\circ} \mathrm{C}$ promoveu a eliminação de todas as partículas de segundas-fases da amostra 2Ca2Y05C (Figs. 5.9a e 5.9d), mas somente uma parte foi eliminada da amostra 2Ca2Y1C. As partículas grandes remanescentes na amostra 2Ca2Y1C permaneceram na microestrutura até $1800^{\circ} \mathrm{C}$ e, então, mostraram uma tendência para penetrar e espalhar por entre os grãos de AlN, similar ao observado nas amostras $2 \mathrm{Y}, 4 \mathrm{Y}$ e 1Ca3Y (Figs. 3.11a, 3.11b, 5.5a e 5.5c). Como as partículas grandes compostas por fases ternárias desapareceram da microestrutura das amostras $2 \mathrm{Ca} 2 \mathrm{Y} 05 \mathrm{C}$ e $2 \mathrm{Ca} 2 \mathrm{Y} 1 \mathrm{C}$ com o aumento da temperatura (Figs. 5.9a e 5.9d), pode-se dizer que os comportamentos de 
viscosidade e/ou molhabilidade destas segundas-fases mudaram acima de $1650^{\circ} \mathrm{C}$, o que aumentou a ação efetiva do mecanismo de rearranjo de partículas da sinterização via fase líquida. Isto causou uma densificação significativa da microestrutura (Figs. 5.9a, 5.9c e 5.9d), que resultou no aumento de densidade nas amostras com carbono sinterizadas entre $1650^{\circ} \mathrm{C}$ e $1700^{\circ} \mathrm{C}$ (Fig. 5.7). Estes resultados mostraram que o aumento da fração de fase líquida, com boas características de molhamento e espalhamento, melhorou a densificação do AlN. Porém, a presença de poros grandes limitou a densificação do AlN em menor temperatura (Fig. 5.7), pois foi difícil eliminá-los da microestrutura, mesmo usando elevadas temperaturas de sinterização (Fig. 5.9).

A amostra $2 \mathrm{Ca} 2 \mathrm{Y} 1 \mathrm{C}$ sinterizada a $1800^{\circ} \mathrm{C}$ apresentou menor densidade do que as amostras 2Ca2Y e 2Ca2Y05C (Fig. 5.7), sendo este resultado diferente daquele observado para os sistemas $\mathrm{AlN}-\mathrm{Y}_{2} \mathrm{O}_{3}$ (Fig. 3.12) e $\mathrm{AlN}-\mathrm{CaO}$ (Fig. 4.6). Provavelmente, esta diferença de densidade está relacionada com a fração de fase líquida presente durante a sinterização. $\mathrm{O}$ aumento do teor de carbono causou maior evaporação de compostos (Fig. 5.8), o que resultou na diminuição da fração de fase líquida presente durante a sinterização. A presença de partículas de fases refratárias (YAM) na amostra $2 \mathrm{Ca} 2 \mathrm{Y} 1 \mathrm{C}$ sinterizada até $1800^{\circ} \mathrm{C}$ indicou que certa fração de fase líquida não apresentou boas características de molhamento e espalhamento, o que contribuiu para diminuir ainda mais a eficácia dos mecanismos de sinterização via fase líquida entre $1650^{\circ} \mathrm{C}$ e $1800^{\circ} \mathrm{C}$. Como a amostra $2 \mathrm{Ca} 2 \mathrm{Y} 1 \mathrm{C}$ apresentou uma densidade próxima das amostras $2 \mathrm{Ca} 2 \mathrm{Y}$ e $2 \mathrm{Ca} 2 \mathrm{Y} 05 \mathrm{C}$ após a sinterização na temperatura de $1850^{\circ} \mathrm{C}$ (Fig. 5.7) e, sabendo que nesta temperatura as partículas de fases refratárias mostraram uma forte tendência para penetrar e espalhar por entre os grãos de AlN, pode-se dizer que a amostra 2Ca2Y1C atingiu quase completa densificação devido ao aumentou da fração de fase líquida com boas características de molhamento e espalhamento.

\subsection{Discussão dos resultados experimentais}

\subsubsection{Evolução das segundas-fases do sistema $\mathrm{AlN}-\mathrm{Y}_{2} \mathrm{O}_{3}-\mathrm{CaO}$}

Os mecanismos de formação das segundas-fases durante a sinterização do AlN preparado com $\mathrm{Y}_{2} \mathrm{O}_{3}$ ou $\mathrm{CaO}$ são conhecidos. Durante o aquecimento até a temperatura de 
sinterização, o aditivo $\left(\mathrm{Y}_{2} \mathrm{O}_{3}\right.$ ou $\left.\mathrm{CaO}\right)$ reage com a camada de $\mathrm{Al}_{2} \mathrm{O}_{3}$ presente na superfície do pó de AlN, formando segundas-fases (aluminato de ítrio ou cálcio) por sinterização no estado sólido. $\mathrm{O}$ AlN com $\mathrm{Y}_{2} \mathrm{O}_{3}$ forma aluminatos de ítrio a partir de $1125^{\circ} \mathrm{C}{ }^{66}$ ou $1200^{\circ} \mathrm{C}{ }^{68}$, enquanto o AlN com $\mathrm{CaO}$ forma aluminatos de cálcio a partir de $1100^{\circ} \mathrm{C}$. ${ }^{60,61} \mathrm{No}$ caso da adição simultânea de $\mathrm{CaO}$ e $\mathrm{Y}_{2} \mathrm{O}_{3}$, observou-se a presença de aluminatos de cálcio $\left(\mathrm{C}_{3} \mathrm{~A}\right)$ e de ítrio (YAM) no AlN sinterizado parcialmente a $1200^{\circ} \mathrm{C} .{ }^{44}$ Qiao et al. ${ }^{76}$ indicaram que a adição de $\mathrm{Y}_{2} \mathrm{O}_{3}$ no $\mathrm{AlN}$ com $\mathrm{CaO}$ influenciou a formação de compostos do sistema Ca-Al-O em baixas temperaturas, pois parte do $\mathrm{Al}_{2} \mathrm{O}_{3}$ contido no pó de $\mathrm{AlN}$ foi consumido na formação dos aluminatos de ítrio. Estes resultados sugeriram que existe uma competição entre os aditivos $\mathrm{CaO}$ e $\mathrm{Y}_{2} \mathrm{O}_{3}$ para reagir com o $\mathrm{Al}_{2} \mathrm{O}_{3}$ contido no pó de AlN, principalmente em baixas temperaturas de sinterização $\left(\leq 1200^{\circ} \mathrm{C}\right)$.

Entretanto, os resultados do presente trabalho mostraram a ocorrência de uma outra rota de evolução das segundas-fases no AlN com mistura de aditivos $\left(\mathrm{CaO}\right.$ e $\left.\mathrm{Y}_{2} \mathrm{O}_{3}\right)$ sinterizado em baixas temperaturas $\left(\leq 1300^{\circ} \mathrm{C}\right.$, Tabela 5.2). As amostras $1 \mathrm{Ca} 3 \mathrm{Y}, 2 \mathrm{Ca} 2 \mathrm{Y}$ e $3 \mathrm{Ca} 1 \mathrm{Y}$ sinterizadas parcialmente a $1100^{\circ} \mathrm{C}$ apresentaram fases ternárias $\left(\mathrm{CaYAl}_{3} \mathrm{O}_{7}\right.$ e/ou $\mathrm{CaYAlO}_{4}$ ) e certa fração de $\mathrm{Y}_{2} \mathrm{O}_{3}$ não reagido. Estes resultados indicaram que os aditivos $\mathrm{CaO}$ e $\mathrm{Y}_{2} \mathrm{O}_{3}$ reagiram simultaneamente com o $\mathrm{Al}_{2} \mathrm{O}_{3}$ contido no pó de $\mathrm{AlN}$, o que levou à formação de fases ternárias durante a sinterização parcial na temperatura de $1100^{\circ} \mathrm{C}$. Como a formação de aluminatos de ítrio ocorreu em maiores temperaturas do que as fases ternárias (Tabela 5.2) e, sabendo que não houve a formação de aluminatos de cálcio entre $1100^{\circ} \mathrm{C} \mathrm{e}$ $1850^{\circ} \mathrm{C}$, pode-se dizer que a reação entre $\mathrm{CaO}, \mathrm{Y}_{2} \mathrm{O}_{3}$ e $\mathrm{Al}_{2} \mathrm{O}_{3}$ foi mais favorável em baixas temperaturas $\left(\leq 1100^{\circ} \mathrm{C}\right)$ do que a reação entre $\mathrm{Y}_{2} \mathrm{O}_{3}$ e $\mathrm{Al}_{2} \mathrm{O}_{3}$ ou $\mathrm{CaO}$ e $\mathrm{Al}_{2} \mathrm{O}_{3}$. Estes resultados corroboram com a proposição de que a adição de $\mathrm{Y}_{2} \mathrm{O}_{3}$ influência a formação de compostos do sistema Ca-Al-O durante a sinterização do AlN. Entretanto, a causa que inibe ou limita a formação destes compostos do sistema Ca-Al-O não pode ser correlacionada com a diminuição da fração de $\mathrm{Al}_{2} \mathrm{O}_{3}$ contido no pó de $\mathrm{AlN}$ devido à formação de aluminatos de ítrio, como sugerido por Qiao et al. ${ }^{76}$. No presente trabalho, propõe-se que o $\mathrm{CaO}$ reagiu com os demais componentes do corpo conformado $\left(\mathrm{Al}_{2} \mathrm{O}_{3}\right.$ e $\left.\mathrm{Y}_{2} \mathrm{O}_{3}\right)$ para formar preferencialmente compostos do sistema Ca-Y-Al-O durante o aquecimento até a temperatura de sinterização.

No Capítulo 3, observaram-se que as composições das segundas-fases do AlN com até $4 \%$ de $\mathrm{Y}_{2} \mathrm{O}_{3}$ sinterizado sob atmosfera inerte se aproximaram das composições estimadas em função do teor de aditivo de sinterização e do teor de oxigênio $\left(\mathrm{Al}_{2} \mathrm{O}_{3}\right)$ presente na superfície do pó de AlN, pelo menos até uma determinada temperatura de sinterização $\left(<1800^{\circ} \mathrm{C}\right)$. Um comportamento similar foi observado para o AlN com aditivo contendo cálcio, conforme 
apresentado no Capítulo 4 (Fig. 4.4). Seguindo o mesmo raciocínio, estimaram-se as composições das amostras $1 \mathrm{Ca} 3 \mathrm{Y}, 2 \mathrm{Ca} 2 \mathrm{Y}$ e $3 \mathrm{Ca} 1 \mathrm{Y}$, que foram indicadas no diagrama de equilíbrio de fases do sistema $\mathrm{CaO}-\mathrm{Al}_{2} \mathrm{O}_{3}-\mathrm{Y}_{2} \mathrm{O}_{3}$ (Fig. 5.1). Nesta figura, observa-se que o aumento da fração de $\mathrm{Y}_{2} \mathrm{O}_{3}$ na mistura de aditivos deslocou as composições das amostras para o lado do diagrama em que são previstas as fases de aluminato de ítrio (Fig. 5.1). Esta tendência foi observada nas amostras sinterizadas entre $1650^{\circ} \mathrm{C}$ e $1850^{\circ} \mathrm{C}$, pois a amostra $1 \mathrm{Ca} 3 \mathrm{Y}$ apresentou as fases $\mathrm{CaYAl}_{3} \mathrm{O}_{7}$ e YAM (Tabela 5.2), enquanto as amostras $2 \mathrm{Ca} 2 \mathrm{Y}$ e $3 \mathrm{Ca} 1 \mathrm{Y}$ apresentaram as fases $\mathrm{CaYAl}_{3} \mathrm{O}_{7}$ e/ou $\mathrm{CaYAlO}_{4}$. Resultados similares foram observados por Qiao et al. ${ }^{76}$. Como o aumento da fração de $\mathrm{Y}_{2} \mathrm{O}_{3}$ na mistura de aditivos induziu a formação de compostos dos sistemas Ca-Y-Al-O e Y-Al-O durante a sinterização do AlN (Tabela 5.2), esperava-se que o aumento da fração de $\mathrm{CaO}$ na mistura de aditivos levasse à formação de compostos dos sistemas Ca-Al-O e Ca-Y-Al-O, como indicado pela composição inicial da amostra 3Ca1Y (Fig. 5.1). Porém, as amostras 1Ca3Y, 2Ca2Y e 3Ca1Y apresentaram frações significativas de fases ricas em $\mathrm{Y}_{2} \mathrm{O}_{3}$ após a sinterização parcial até $1300^{\circ} \mathrm{C}$ (Tabela 5.2), indicando que, mesmo com maior fração de $\mathrm{CaO}$ na mistura de aditivos, grande parte do $\mathrm{CaO}$ evaporou antes de reagir como todo o $\mathrm{Y}_{2} \mathrm{O}_{3}$ e/ou com o $\mathrm{Al}_{2} \mathrm{O}_{3}$ contido no pó de AlN.

Os resultados de perda de massa corroboram com a proposição acima, pois o aumento da fração de $\mathrm{CaO}$ na mistura de aditivos promoveu maior evaporação de compostos durante a sinterização entre $1100^{\circ} \mathrm{C}$ e $1850^{\circ} \mathrm{C}$ (Fig. 5.3). Além disso, as amostras $1 \mathrm{Ca} 3 \mathrm{Y}, 2 \mathrm{Ca} 2 \mathrm{Y}$ e 3Ca1Y (Fig. 5.3) apresentaram maiores valores de perda de massa do que as amostras com adição individual de $\mathrm{Y}_{2} \mathrm{O}_{3}$ (4Y, Fig. 3.13) e $\mathrm{CaO}$ (4Ca, Fig. 4.7). Estes resultados indicaram que a adição simultânea de $\mathrm{CaO}$ e $\mathrm{Y}_{2} \mathrm{O}_{3}$ intensificou a evaporação de compostos durante a sinterização do AlN. Como as amostras 1Ca3Y, 2Ca2Y e 3Ca1Y apresentaram certa quantidade de $\mathrm{Y}_{2} \mathrm{O}_{3}$ não reagido após a sinterização parcial na temperatura de $1100^{\circ} \mathrm{C}$ (Tabela 5.2), pode-se dizer que a estabilidade do $\mathrm{CaO}$ diminuiu na presença de $\mathrm{Y}_{2} \mathrm{O}_{3}$, o que resultou na evaporação significativa de compostos à base de cálcio em baixas temperaturas de sinterização $\left(<1100^{\circ} \mathrm{C}\right)$. Deste modo, não houve $\mathrm{CaO}$ suficiente para reagir com todo o $\mathrm{Y}_{2} \mathrm{O}_{3}$ adicionado, o que levou à formação de compostos mais ricos em $\mathrm{Y}_{2} \mathrm{O}_{3}$ até pelo menos $1300^{\circ} \mathrm{C}$ (Tabela 5.2). Como as fases $\mathrm{CaYAl}_{3} \mathrm{O}_{7}$ e $\mathrm{CaYAlO}_{4}$ são associadas com fase líquida abaixo de $1650^{\circ} \mathrm{C}$ (Fig. 5.1), pode-se dizer que, entre $1300^{\circ} \mathrm{C}$ e $1650^{\circ} \mathrm{C}$, as fases de aluminato de ítrio foram incorporadas à fase líquida com composição próxima das fases $\mathrm{CaYAl}_{3} \mathrm{O}_{7}$ e $\mathrm{CaYAlO}_{4}$, o que levou à formação somente de fases ternárias nas amostras 2Ca2Y e $3 \mathrm{Ca} 1 \mathrm{Y}$ sinterizadas entre $1650^{\circ} \mathrm{C}$ e $1850^{\circ} \mathrm{C}$ (Tabela 5.2). A presença das fases $\mathrm{CaYAl}_{3} \mathrm{O}_{7}$ e YAM na amostra 
$1 \mathrm{Ca} 3 \mathrm{Y}$ sinterizada entre $1650^{\circ} \mathrm{C}$ e $1850^{\circ} \mathrm{C}$ (Tabela 5.2) indicou que, devido à formação em grande quantidade de aluminatos de ítrio, a fase líquida ficou saturada em $\mathrm{Y}_{2} \mathrm{O}_{3}$, o que dificultou a incorporação de todos os aluminatos de ítrio ao líquido presente durante a sinterização acima de $1650^{\circ} \mathrm{C}$.

As evoluções das segundas-fases das amostras 2Ca2Y e 3Ca1Y sinterizadas entre $1650^{\circ} \mathrm{C}$ e $1850^{\circ} \mathrm{C}$ não se alteraram (Tabela 5.2), indicando que, nesta faixa de temperatura, a fase $\mathrm{CaYAl}_{3} \mathrm{O}_{7}$, junta ou não com a fase $\mathrm{CaYAlO}_{4}$, permaneceu estável durante a sinterização sob atmosfera não redutora (Tabela 5.2). Por outro lado, a amostra 1Ca3Y teve sua evolução de segundas-fases modificada entre $1650^{\circ} \mathrm{C}$ e $1850^{\circ} \mathrm{C}$ (Tabela 5.2), indicando que a fase $\mathrm{CaYAl}_{3} \mathrm{O}_{7}$, na presença da fase $\mathrm{YAM}$, teve sua estabilidade diminuída acima de $1750^{\circ} \mathrm{C}$. Já a formação in situ de uma atmosfera redutora com carbono (C) causou mudanças significativas na evolução das segundas-fases da amostra $2 \mathrm{Ca} 2 \mathrm{Y}$ sinterizada entre $1650^{\circ} \mathrm{C}$ e $1850^{\circ} \mathrm{C}$ (Tabela 5.3). A adição de $0,5 \%$ de $\mathrm{C}$, assim como o aumento da temperatura de sinterização, levou à formação preferencial da fase $\mathrm{CaYAlO}_{4}$ (amostra 2Ca2Y05C, Tabela 5.3). O aumento de 0,5\% para $1 \%$ de $\mathrm{C}$ levou à formação das fases $\mathrm{CaYAlO}_{4} \mathrm{e} \mathrm{YAM}(\operatorname{amostra} 2 \mathrm{Ca} 2 \mathrm{Y} 1 \mathrm{C}$, Tabela 5.3). Estes resultados indicaram que, dependendo do grau de redução da atmosfera de sinterização, a composição das segundas-fases pode mudar de $\mathrm{CaYAl}_{3} \mathrm{O}_{7}$ para $\mathrm{CaYAlO}_{4}$ e, então, para YAM. Em alguns trabalhos, ${ }^{74,177}$ observaram-se evoluções de segundas-fases similares, pois a composição das segundas-fases do AlN com mistura de aditivos $\left(\mathrm{CaF}_{2} \mathrm{e}\right.$ $\mathrm{YF}_{3}$ ) mudou de $\mathrm{CaYAl}_{3} \mathrm{O}_{7}$ e YAP para YAM devido ao aumento do grau de redução da atmosfera de sinterização. Estes resultados mostraram a ocorrência de uma evaporação preferencial de $\mathrm{Al}_{2} \mathrm{O}_{3}$ e $\mathrm{CaO}$ das segundas-fases durante a sinterização do AlN sob atmosfera redutora com carbono.

\subsubsection{Densificação do sistema $\mathrm{AlN}-\mathrm{Y}_{2} \mathrm{O}_{3}-\mathrm{CaO}$}

A amostra $1 \mathrm{Ca} 3 \mathrm{Y}$ atingiu o maior valor de densidade após a sinterização na temperatura de $1650^{\circ} \mathrm{C}$ (Fig. 5.2), indicando que esta composição de aditivo foi mais eficiente para promover a densificação do $\mathrm{AlN}$ em baixas temperaturas $\left(\leq 1650^{\circ} \mathrm{C}\right)$. Porém, a microestrutura da amostra $1 \mathrm{Ca} 3 \mathrm{Y}$ sinterizada entre $1650^{\circ} \mathrm{C}$ e $1800^{\circ} \mathrm{C}$ foi caracterizada por apresentar partículas grandes de segundas-fases (Fig. 5.5a). Estas partículas foram constituídas por fases refratárias de aluminato de ítrio (YAM), que fundiram durante a 
sinterização acima de $1800^{\circ} \mathrm{C}$ (Figs. $5.5 \mathrm{a}$ e $5.5 \mathrm{c}$ ). Estes resultados indicaram que pequenas quantidades de fase líquida com boas características de molhamento e espalhamento foram suficientes para promover a densificação do AlN em baixas temperaturas de sinterização $\left(\geq 1650^{\circ} \mathrm{C}\right.$, Fig. 5.2).

As amostras $2 \mathrm{Ca} 2 \mathrm{Y}$ e $3 \mathrm{Ca} 1 \mathrm{Y}$ sinterizadas a partir de $1650^{\circ} \mathrm{C}$ apresentaram microestruturas relativamente densas (Figs. 5.6a e 5.6c), indicando que estas composições de aditivo também foram eficientes para promover a densificação do AlN em baixas temperaturas de sinterização $\left(\leq 1650^{\circ} \mathrm{C}\right)$. Porém, o aumento da fração de $\mathrm{CaO}$ na mistura de aditivos $\left(\mathrm{CaO}\right.$ e $\left.\mathrm{Y}_{2} \mathrm{O}_{3}\right)$ aumentou a fração de poros grandes (Figs. 5.6a e 5.6c), que atrasaram a densificação (Fig. 5.2) devido à dificuldade para eliminá-los da microestrutura, mesmo usando elevadas temperaturas de sinterização (Fig. 5.6f). Em trabalhos anteriores, ${ }^{60,61}$ observou-se que a utilização de $\mathrm{CaCO}_{3}$ com larga distribuição granulométrica em relação ao AlN (Fig. 4.5a) levou à formação de poros grandes durante a sinterização (Fig. 4.3). Como os mesmos pós de partida foram utilizados no presente trabalho, pode-se dizer que, grande parte, dos poros grandes das amostras $2 \mathrm{Ca} 2 \mathrm{Y}$ e $3 \mathrm{Ca} 1 \mathrm{Y}$ foram provenientes da utilização de pó grosseiro de $\mathrm{CaCO}_{3}$.

No Capítulo 3, observou-se que a utilização de $\mathrm{Y}_{2} \mathrm{O}_{3}$ com larga distribuição granulométrica em relação ao AIN (Fig. 3.2) levou à formação de partículas grandes de segundas-fases (Figs. 3.8b, 3.8d), que podem persistir na microestrutura até $1800^{\circ} \mathrm{C}$ (Figs. 3.11a e 3.11b). Como os mesmos pós de partida foram utilizados no presente trabalho, a amostra $1 \mathrm{Ca} 3 \mathrm{Y}$ sinterizada entre $1650^{\circ} \mathrm{C}$ e $1800^{\circ} \mathrm{C}$ apresentou estas partículas grandes de segundas-fases (Figs. 5.5a e 5.5b). Entretanto, as amostras $2 \mathrm{Ca} 2 \mathrm{Y}$ e $3 \mathrm{Ca} 1 \mathrm{Y}$ sinterizadas entre $1650^{\circ} \mathrm{C}$ e $1850^{\circ} \mathrm{C}$ não apresentaram partículas grandes de segundas-fases (Fig. 5.6). Estes resultados indicaram que as partículas grosseiras de $\mathrm{Y}_{2} \mathrm{O}_{3}$ reagiram com os demais componentes do corpo conformado, formando segundas-fases com baixo ponto de fusão. Durante a sinterização em altas temperaturas $\left(\geq 1650^{\circ} \mathrm{C}\right)$, estas partículas grandes de segundas-fases fundiram e, então, a fase líquida migrou por entre as partículas finas de AlN, ativando o mecanismo de rearranjo de partículas da sinterização via fase líquida, que promoveu uma densificação significativa na microestrutura das amostras $2 \mathrm{Ca} 2 \mathrm{Y}$ e $3 \mathrm{Ca} 1 \mathrm{Y}$ (Figs. 5.6a e 5.6c). Porém, os sítios inicialmente ocupados por estas partículas grandes ficaram vazios, o que deu origem aos poros grandes. De Baranda et al. ${ }^{37}$ observaram que a adição de $\mathrm{CaO}$ no $\mathrm{AlN}$ com $\mathrm{Y}_{2} \mathrm{O}_{3}$ induziu a formação de poros durante a sinterização em altas temperaturas $\left(1825^{\circ} \mathrm{C}-1860^{\circ} \mathrm{C}\right)$ e, então, indicaram que a formação de compostos de baixo ponto de fusão como, por exemplo, a fase $\mathrm{CaYAl}_{3} \mathrm{O}_{7}$, causou a formação destes poros. A 
amostra $1 \mathrm{Ca} 3 \mathrm{Y}$ apresentou menor fração de poros do que as amostras $2 \mathrm{Ca} 2 \mathrm{Y}$ e $3 \mathrm{Ca} 1 \mathrm{Y}$ (Figs. 5.5a, 5.6a e 5.6c) devido à formação de partículas com composição mais refratária do que as fases ternárias.

A adição de carbono (C) levou à formação de partículas grandes de segundas-fases na amostra $2 \mathrm{Ca} 2 \mathrm{Y}$ sinterizada a $1650^{\circ} \mathrm{C}$ (Figs. 5.6a, 5.9a e 5.9c). O aumento do teor de $\mathrm{C}$ mudou a composição química destas partículas de segundas-fases, pois a amostra 2Ca2Y05C apresentou apenas partículas compostas por fases ternárias (Figs. 5.9a e 5.9b), enquanto a amostra 2Ca2Y1C apresentou partículas compostas por fases ternárias e por aluminatos de ítrio. As partículas compostas por fases ternárias foram eliminadas da microestrutura das amostras com $\mathrm{C}$ com o aumento da temperatura de $1650^{\circ} \mathrm{C}$ para $1700^{\circ} \mathrm{C}$ (Figs. 5.9a e 5.9d). Já as partículas compostas por aluminatos de ítrio permaneceram na microestrutura da amostra $2 \mathrm{Ca} 2 \mathrm{Y} 1 \mathrm{C}$ até $1800^{\circ} \mathrm{C}$, como observado na amostra $1 \mathrm{Ca} 3 \mathrm{Y}$ (Fig. 5.5a a 5.5d). Estes resultados indicaram que pelo menos uma das fases ternárias apresentou alta viscosidade e/ou baixa molhabilidade abaixo de $1700^{\circ} \mathrm{C}$, o que dificultou o seu espalhamento pela microestrutura, limitando a densificação das amostras $2 \mathrm{Ca} 2 \mathrm{Y} 05 \mathrm{C}$ e $2 \mathrm{Ca} 2 \mathrm{Y} 1 \mathrm{C}$ em relação à amostra $2 \mathrm{Ca} 2 \mathrm{Y}$ (Fig. 5.7).

Como as amostras $2 \mathrm{Ca} 2 \mathrm{Y}$ e $3 \mathrm{Ca} 1 \mathrm{Y}$ sinterizadas a partir de $1650^{\circ} \mathrm{C}$ apresentaram microestruturas relativamente densas (Fig. 5.6), assim como não apresentaram partículas grandes de segundas-fases, pode-se dizer que a fase líquida teve boas características de molhamento e espalhamento durante a sinterização entre $1650^{\circ} \mathrm{C}$ e $1850^{\circ} \mathrm{C}$. Embora tenha ocorrido a formação de partículas grandes de segundas-fases na amostra 1Ca3Y (Fig. 5.5a), esta amostra atingiu quase completa densificação a partir de $1650^{\circ} \mathrm{C}$ (Figs. 5.2 e $5.5 \mathrm{a}$ ). Estes resultados indicaram que a fase líquida presente durante a sinterização da amostra 1Ca3Y apresentou boas características de molhamento e espalhamento, o que favoreceu sua densificação a partir de $1650^{\circ} \mathrm{C}$. Como as amostras $1 \mathrm{Ca} 3 \mathrm{Y}, 2 \mathrm{Ca} 2 \mathrm{Y}$ e $3 \mathrm{Ca} 1 \mathrm{Y}$ sinterizadas até pelo menos $1750^{\circ} \mathrm{C}$ apresentaram a fase $\mathrm{CaYAl}_{3} \mathrm{O}_{7}$ como preponderante (Tabela 5.2), pode-se dizer que a sinterização destas amostras foi assistida por uma fase líquida com composição próxima da fase $\mathrm{CaYAl}_{3} \mathrm{O}_{7}$, principalmente abaixo de $1800^{\circ} \mathrm{C}$. Estes resultados indicaram que a fase $\mathrm{CaYAl}_{3} \mathrm{O}_{7}$ fundiu e que, devido às suas boas características de viscosidade e molhabilidade a partir de $1650^{\circ} \mathrm{C}$, a fase líquida se espalhou por entre os grãos de $\mathrm{AlN}$, ativando o mecanismo de rearranjo de partículas da sinterização via fase líquida.

A adição de carbono atrasou significativamente a densificação da amostra 2Ca2Y (Fig. 5.7), principalmente durante a sinterização na temperatura de $1650^{\circ} \mathrm{C}$. Além dos poros grandes, as microestruturas das amostras $2 \mathrm{Ca} 2 \mathrm{Y} 05 \mathrm{C}$ e $2 \mathrm{Ca} 2 \mathrm{Y} 1 \mathrm{C}$ foram caracterizadas por 
apresentar pequenos aglomerados densos de partículas e partículas grandes de segundas-fases após a sinterização na temperatura de $1650^{\circ} \mathrm{C}$ (Figs. 5.9a e 5.9c). Estas características microestruturais indicaram que a fase líquida não teve boas características de molhamento e espalhamento abaixo de $1700^{\circ} \mathrm{C}$, o que limitou a densificação por rearranjo de partículas da sinterização via fase líquida. Como as amostras $2 \mathrm{Ca} 2 \mathrm{Y} 05 \mathrm{C}$ e $2 \mathrm{Ca} 2 \mathrm{Y} 1 \mathrm{C}$ apresentaram a fase $\mathrm{CaYAlO}_{4}$ como preponderante até pelo menos $1700^{\circ} \mathrm{C}$ (Tabela 5.3), pode-se dizer que a fase líquida com composição próxima da fase $\mathrm{CaYAlO}_{4}$ teve alta viscosidade e/ou baixa molhabilidade no AlN abaixo de $1700^{\circ} \mathrm{C}$, já que a fase $\mathrm{CaYAl}_{3} \mathrm{O}_{7}$ apresentou boas características de molhamento e espalhamento em temperaturas tão baixas quanto $1650^{\circ} \mathrm{C}$.

$\mathrm{O}$ aumento da temperatura de $1650^{\circ} \mathrm{C}$ para $1700^{\circ} \mathrm{C}$ melhorou as características de molhamento e espalhamento da fase $\mathrm{CaYAlO}_{4}$, o que resultou no aumento significativo de densidade para as amostras $2 \mathrm{Ca} 2 \mathrm{Y} 05 \mathrm{C}$ e 2Ca2Y1C (Fig. 5.7, 5.9a e 5.9d). Porém, a amostra $2 \mathrm{Ca} 2 \mathrm{Y} 05 \mathrm{C}$ atingiu uma densidade próxima da amostra $2 \mathrm{Ca} 2 \mathrm{Y}$ somente a $1800^{\circ} \mathrm{C}$ (Fig. 5.7), enquanto a amostra $2 \mathrm{Ca} 2 \mathrm{Y} 1 \mathrm{C}$ atingiu o mesmo valor de densidade somente a $1850^{\circ} \mathrm{C}$. Como a presença da fase sólida YAM no líquido à base de $\mathrm{CaYAlO}_{4}$ pode prejudicar a densificação do AlN em baixas temperaturas de sinterização $\left(<1650^{\circ} \mathrm{C}\right),{ }^{76}$ pode-se dizer que a amostra 2Ca2Y1C apresentou lenta densificação entre $1650^{\circ} \mathrm{C}$ e $1850^{\circ} \mathrm{C}$ devido à formação das fases $\mathrm{CaYAlO}_{4}$ e YAM (Tabela 5.3). Contudo, a amostra 2Ca2Y05C, que apresentou em ordem de preponderância as fases $\mathrm{CaYAlO}_{4} \mathrm{e} \mathrm{CaYAl}_{3} \mathrm{O}_{7}$ até $1800^{\circ} \mathrm{C}$ (Tabela 5.3), também teve uma densificação lenta abaixo de $1800^{\circ} \mathrm{C}$ (Fig. 5.7). Estes resultados indicaram que, mesmo com a melhora das características de viscosidade e molhabilidade da fase $\mathrm{CaYAlO}_{4}$ acima de $1650^{\circ} \mathrm{C}$, a formação de líquido à base de $\mathrm{CaYAlO}_{4}$ não foi eficiente para promover uma rápida densificação no AlN em baixas temperaturas de sinterização. Como a amostra 1Ca3Y atingiu quase completa densificação a $1650^{\circ} \mathrm{C}$ (Figs. 5.2 e 5.5a) e, sabendo que esta amostra apresentou as fases $\mathrm{CaYAl}_{3} \mathrm{O}_{7}$ e YAM entre $1650^{\circ} \mathrm{C}$ e $1850^{\circ} \mathrm{C}$ (Tabela 5.2), pode-se dizer que, mesmo com a presença de certa fração da fase YAM, o líquido à base $\mathrm{CaYAl}_{3} \mathrm{O}_{7}$ promoveu uma rápida densificação no $\mathrm{AlN}$ a partir de $1650^{\circ} \mathrm{C}$. Estes resultados reforçaram a interpretação de que a fase $\mathrm{CaYAl}_{3} \mathrm{O}_{7}$ apresentou boas características de molhamento e espalhamento durante a sinterização do $\mathrm{AlN}$ em baixas temperaturas $\left(\leq 1650^{\circ} \mathrm{C}\right)$.

Além das características de molhamento e espalhamento das segundas-fases, a densificação do AlN com mistura de aditivos $\left(\mathrm{CaO}\right.$ e $\left.\mathrm{Y}_{2} \mathrm{O}_{3}\right)$ também foi influenciada por outros fatores. A amostra $2 \mathrm{Ca} 2 \mathrm{Y} 1 \mathrm{C}$ apresentou maior de perda de massa do que as amostras $2 \mathrm{Ca} 2 \mathrm{Y}$ e $2 \mathrm{Ca} 2 \mathrm{Y} 05 \mathrm{C}$ entre $1650^{\circ} \mathrm{C}$ e $1850^{\circ} \mathrm{C}$ (Fig. 5.8), indicando que, durante a sinterização, a amostra $2 \mathrm{Ca} 2 \mathrm{Y} 1 \mathrm{C}$ teve menor fração de fase líquida do que as demais amostras. Além 
disso, a presença da fase YAM na amostra 2Ca2Y1C (Tabela 5.3) contribuiu para diminuir ainda mais a fração de fase líquida presente durante a sinterização, pois a fase YAM é associada com a fase líquida somente acima de $1800^{\circ} \mathrm{C}$ (Fig. 3.1). Como a amostra $2 \mathrm{Ca} 2 \mathrm{Y} 1 \mathrm{C}$ atingiu o mesmo valor de densidade das amostras $2 \mathrm{Ca} 2 \mathrm{Y}$ e $2 \mathrm{Ca} 2 \mathrm{Y} 05 \mathrm{C}$ a $1850^{\circ} \mathrm{C}$ (Fig. 5.7) e, sabendo que as partículas ricas em aluminato de ítrio fundiram somente durante a sinterização na temperatura de $1850^{\circ} \mathrm{C}$ (Figs. 3.11a, 3.11b, 5.5a e 5.5c), pode-se dizer que o aumento da quantidade de fase líquida, proveniente da fusão das partículas de aluminato de ítrio, levou à densificação da amostra 2Ca2Y1C. Estes resultados indicaram que deve existir uma quantidade mínima de fase líquida presente durante a sinterização para promover a densificação do AlN com adição simultânea de $\mathrm{CaO}$ e $\mathrm{Y}_{2} \mathrm{O}_{3}$. Além disso, o aprisionamento de gás no interior dos poros fechados pode ser atribuído como um dos fatores responsáveis pelo atraso na densificação das amostras 2Ca2Y, 3Ca1Y, 2Ca2Y05C e 2Ca2Y1C, similar ao observado para o AlN com aditivo contendo cálcio. ${ }^{60,61}$

\subsection{Conclusões}

Estudou-se o comportamento de densificação do AlN com mistura de aditivos $(\mathrm{CaO}$ e $\mathrm{Y}_{2} \mathrm{O}_{3}$ ) sob atmosfera inerte (não redutora) entre $1100^{\circ} \mathrm{C}$ e $1850^{\circ} \mathrm{C}$, bem como o efeito da formação in situ de uma atmosfera redutora, gerada pela adição de $0,5 \%$ e $1 \%$ de $C$, na densificação do $\mathrm{AlN}$ com $2 \%$ de $\mathrm{CaO}$ e $2 \%$ de $\mathrm{Y}_{2} \mathrm{O}_{3}$ sinterizado entre $1650^{\circ} \mathrm{C}$ e $1850^{\circ} \mathrm{C}$. Os resultados experimentais levaram às seguintes conclusões:

- A adição simultânea de $\mathrm{CaO}$ e $\mathrm{Y}_{2} \mathrm{O}_{3}$ intensifica a evaporação de compostos durante a sinterização do AlN comparado com as adições individuais destes aditivos;

- As segundas-fases ternárias $\left(\mathrm{CaYAl}_{3} \mathrm{O}_{7}\right.$ e $\left.\mathrm{CaYAlO}_{4}\right)$ se formam em baixas temperaturas, ao redor de $1100^{\circ} \mathrm{C}$. Acima desta temperatura, ocorre formação adicional de aluminatos de ítrio, que foram incorporados às fases ternárias durante a sinterização em altas temperaturas $\left(\geq 1650^{\circ} \mathrm{C}\right)$;

- A densificação do $\mathrm{AlN}$ a partir de $1650^{\circ} \mathrm{C}$ é decorrente principalmente da fase $\mathrm{CaYAl}_{3} \mathrm{O}_{7}$, que apresenta boas características de molhamento e espalhamento. A fase $\mathrm{CaYAlO}_{4}$ tem apresentado pouco efeito na densificação do AlN até cerca de $1700^{\circ} \mathrm{C}$ em decorrência da sua alta viscosidade e/ou baixa molhabilidade no AlN; 
- A adição simultânea de $\mathrm{CaCO}_{3}$ e $\mathrm{Y}_{2} \mathrm{O}_{3}$ com larga distribuição granulométrica em relação ao AlN induz a formação de poros grandes na microestrutura, que são decorrentes da fusão das partículas grandes de aluminatos ternários e do subseqüente espalhamento da fase líquida por entre as partículas finas de AIN. Isto atrasa a densificação devido à dificuldade para eliminá-los da microestrutura, mesmo usando elevadas temperaturas de sinterização $\left(1850^{\circ} \mathrm{C}\right)$;

- Outros fatores que contribuem para atrasar a densificação do AlN são a diminuição da fração de fase líquida presente durante a sinterização e o aprisionamento de gás no interior dos poros fechados;

- A formação in situ de uma atmosfera redutora com carbono modifica a evolução das segundas-fases no AlN, o que leva à formação de segundas-fases refratárias e ricas em $\mathrm{Y}_{2} \mathrm{O}_{3}$ (mudança de $\mathrm{CaYAl}_{3} \mathrm{O}_{7}$ para $\mathrm{CaYAlO}_{4}$ e, então, para $\mathrm{YAM}$ ) com o aumento do teor de carbono (aumento do potencial de redução da atmosfera), o que dificulta a densificação do AlN em baixas temperaturas de sinterização, pois a fase $\mathrm{CaYAlO}_{4}$ apresenta alta viscosidade e/ou baixa molhabilidade no AlN abaixo de $1700^{\circ} \mathrm{C}$. 


\section{Efeito da porosidade nas propriedades elásticas do AIN}

\subsection{Introdução}

Os materiais cerâmicos são produzidos principalmente pela tecnologia do pó e, portanto, podem apresentar uma fração de poros involuntária devido à limitação do processo de sinterização ou à otimização tecnológica de custo/benefício, ou intencional, visando à produção de corpos porosos usados como suporte catalítico ou filtro. ${ }^{201,202}$ Embora haja vários estudos sobre o efeito da porosidade nas propriedades físicas dos materiais, não se sabe com clareza quais são as propriedades que realmente dependem da porosidade. ${ }^{203,204}$ Há uma extensa literatura sobre o efeito da porosidade nas propriedades mecânicas, ${ }^{205}$ pois as constantes elásticas têm um papel chave na determinação do comportamento mecânico dos materiais cerâmicos. No estudo do efeito da porosidade nas constantes elásticas, observaramse duas principais vertentes: ${ }^{204}$ os modelos baseados em geometria ou área da seção transversal que suporta o carregamento e os modelos baseados em micro-mecanismos, que envolvem a concentração de tensão ao redor dos poros.

Os modelos baseados em geometria ou área da seção transversal que suporta o carregamento foram denominados por Rice de modelos de área sólida mínima (ASM). Estes modelos derivam do conceito de que a transmissão do fluxo de tensão (deformação, tenacidade à fratura ou resistência mecânica) ou fluxo condutivo (condutividade térmica ou elétrica) que passa por um corpo é depende da área efetiva de contato entre as partículas. ${ }^{203,204}$ Knudsen ${ }^{206}$ propôs os primeiros modelos de ASM, os quais foram desenvolvidos com base nas seguintes considerações: 1) as partículas apresentam morfologia esférica e têm mesmo tamanho; 2) as partículas esféricas se aproximam em relação aos seus centros durante a densificação, mas sem perder sua orientação angular relativa; 3) as áreas de contato entre as partículas esféricas são achatadas, mas o volume original das partículas é conservado, sendo o material redistribuído sobre as superfícies curvas residuais; e 4) o tamanho da área achatada de contato aumenta com a diminuição da porosidade. As esferas originais se tornam poliedros na condição de completa densificação (ausência de porosidade). Os modelos de Knudsen ${ }^{206}$ foram desenvolvidos supondo que as partículas esféricas estão arranjadas com empacotamento cúbico simples, ortorrômbico e romboédrico. 
Outros autores, partindo das considerações de Knudsen, desenvolveram modelos baseados, não somente na geometria e distribuição das partículas, mas também na morfologia dos poros e na sua disposição em relação ao campo de tensão aplicado. Rice ${ }^{204}$ sugeriu que a combinação de dois ou mais modelos pode resultar em uma boa aproximação da evolução microestrutural dos poros durante a sinterização. A Figura 6.1 mostra um gráfico semi-log em que se observa a representação de alguns dos principais modelos de ASM em função da porosidade.

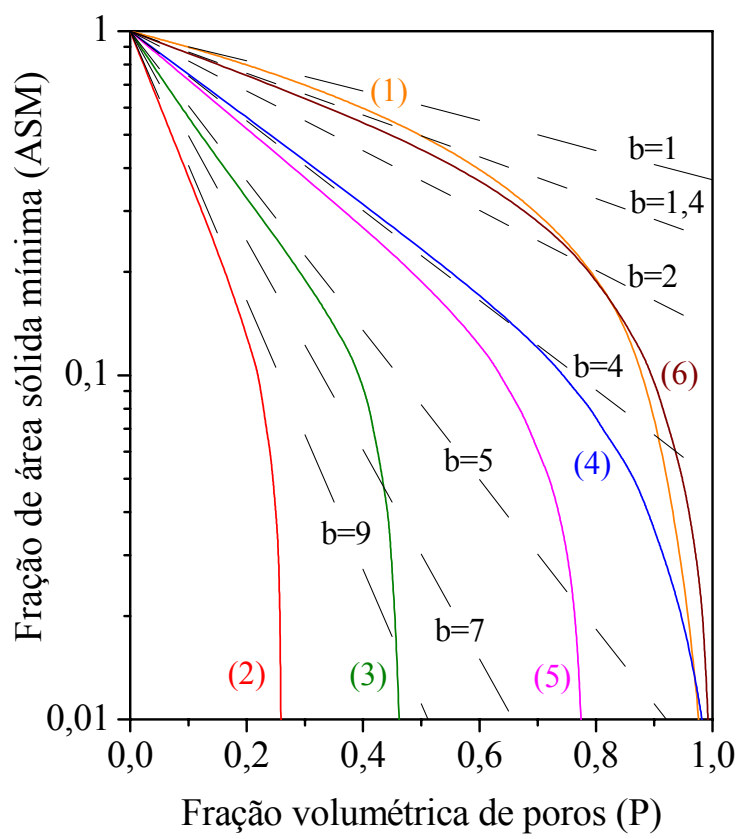

Figura 6.1 - Relação entre fração de área sólida mínima e fração volumétrica de poros determinada para vários tipos de modelo: (1) regra das misturas; (2) partículas esféricas com empilhamento rômbico; (3) partículas esféricas com empilhamento cúbico simples; (4) poros esféricos com empilhamento cúbico simples; (5) poros cilíndricos com empilhamento cúbico simples alinhado transversalmente à tensão aplicada; e (6) poros cilíndricos com empilhamento cúbico simples alinhado paralelamente à tensão aplicada. As linhas tracejadas representam curvas exponenciais $\left(\mathrm{e}^{-\mathrm{bP}}\right)$, que foram ajustadas para diferentes valores de $\mathrm{b} .{ }^{202}$

A característica básica destes modelos é que a fração de área sólida mínima, ou seja, uma determinada propriedade decai de forma aproximadamente linear para baixos valores de porosidade (Fig. 6.1) e, então, decai de forma abrupta até zero para um valor de porosidade considerado crítico $\left(\mathrm{P}_{\text {crit }}\right)$, que é o limite de percolação das partículas. ${ }^{204}$ Para baixos valores de porosidade, as curvas dos modelos de ASM se aproximaram de uma curva exponencial obtida para diferentes valores de b (curvas com linha tracejada na Figura 6.1). A mudança na característica do poro (tamanho, distribuição e morfologia), associada com o método de consolidação das partículas, causa uma variação no valor de b. ${ }^{204}$ Por exemplo, corpos obtidos por prensagem a quente têm maiores valores de b do que corpos obtidos por 
prensagem isostática a frio; corpos obtidos por processamento coloidal podem apresentar maiores valores de $\mathrm{b}$ do que corpos obtidos por prensagem. ${ }^{204}$ Recentemente, várias trabalhos ${ }^{207-210}$ relataram que os parâmetros porosidade e geometria do poro influenciam significativamente as propriedades elásticas.

Alguns trabalhos propuseram modelos analíticos, que são considerados empíricos ou semi-empíricos, pois os parâmetros das equações foram obtidos por ajuste matemático a partir dos resultados experimentais. A Tabela 6.1 apresenta algumas equações semi-empíricas de constantes elásticas em função da porosidade, que são usadas principalmente em estudos do efeito da porosidade nas propriedades elásticas. ${ }^{201-204}$ Segundo Pabst et al. ${ }^{205}$, as equações da Tabela 6.1 são consideradas modelos semi-empíricos pelo fato de que, devido às variações na forma dos poros (forte anisotropia), os coeficientes de primeira ordem não podem ser conhecidos de forma confiável e que, devido à dificuldade de quantificação da distribuição de tamanho e conectividade dos poros, uma estimativa prévia da porosidade crítica não é usualmente obtida. A equação de Phani-Niyogi (eq. 6.7, Tabela 6.1) é muito usada na análise do módulo de elasticidade, ${ }^{210}$ pois este modelo semi-empírico permite avaliar a propriedade de interesse da condição de porosidade igual à zero até um valor de porosidade crítica $\left(\mathrm{P}_{\text {crit }}\right)$, que pode ser considerado o limite de percolação das partículas. A equação de Pabst et al. ${ }^{205}$ (eq. 6.9, Tabela 6.1) também pode avaliar o módulo de Young (E) em uma extensa faixa de porosidade, ou seja, até a condição de porosidade crítica $\left(\mathrm{P}_{\text {crit }}\right)$. Embora Hristopolus \& Demertzi ${ }^{211}$ não tenham explicitado a variável $P_{\text {crit }}$ na equação 6.10 (Tabela 6.1 ), seu modelo pode ser usado em uma extensa faixa de porosidade ( 0 a $40 \%$ ), chegando próximo do limite de percolação das partículas de muitos materiais cerâmicos (40-50\% de porosidade). Em suma, os modelos de Phani-Niyogi, Pabst et al. e Hristopolus-Demertzi podem ser aplicados para uma extensa faixa de porosidade, enquanto os demais modelos da Tabela 6.1 (eq. $6.1 \mathrm{a}$ 6.6) são válidos somente para uma faixa limitada de porosidade. ${ }^{212}$

Rice ${ }^{210}$ observou em diversos trabalhos que a porosidade crítica $\left(\mathrm{P}_{\text {crit }}\right)$, determinada pela equação 6.7, variou em uma extensa faixa de valores $(0,35$ a 0,65$)$, sendo observado o mesmo comportamento para o expoente $\mathrm{n}(0,7$ a 4,1$)$. Ele indicou que os materiais analisados apresentaram provavelmente poros com diferentes morfologias, o que implicou em uma extensa faixa de valores de $\mathrm{P}_{\text {crit. }}$ Além disso, questionou todos os trabalhos, pois os dados experimentais não foram comparados com os modelos de ASM (Fig. 6.1), o que levou à indicação, em alguns casos, de valores de $\mathrm{P}_{\text {crit }}$ sem explicação física $\left(\mathrm{P}_{\text {crit }}>1\right)$. Entretanto, Rice $^{210}$ indicou que a equação de Phani-Niyogi (eq. 6.7, Tabela 6.1) pode ser uma ferramenta valiosa na avaliação dos modelos de porosidade, mas deve ser aplicada de forma mais 
rigorosa, isto é, o valor de $\mathrm{P}_{\text {crit }}$ deve ser determinado e correlacionado com os diversos tipos de modelos de ASM e não ser considerado como um parâmetro arbitrário obtido pelo ajuste de uma equação matemática.

Tabela 6.1 - Equações semi-empíricas de constantes elásticas em função da porosidade. ${ }^{201,202}$

\begin{tabular}{llr}
\hline Autor (ano) & Equação & $(6.1)$ \\
\hline--- & $\mathrm{M}=\mathrm{M}_{0}(1-\mathrm{bP})$ & $(6.2)$ \\
\hline--- & $\mathrm{M}=\mathrm{M}_{0}\left(1-\mathrm{b}_{1} \mathrm{P}+\mathrm{b}_{2} \mathrm{P}^{2}\right)$ & $(6.3)$ \\
\hline Knudsen (1959) & $\mathrm{M}=\mathrm{M}_{0} \exp (-\mathrm{bP})$ & $(6.4)$ \\
\hline Hasselman (1962) & $\mathrm{E}=\mathrm{E}_{0}(1-\mathrm{P}) /(1+\mathrm{bP})$ & $(6.5)$ \\
\hline Martin-Haynes (1971) & $\mathrm{E}=\mathrm{E}_{0}\left(1-\mathrm{b} \mathrm{P}^{2 / 3}\right)$ & $(6.6)$ \\
\hline Wang (1984) & $\mathrm{E}=\mathrm{E}_{0} \exp \left(-\mathrm{b}_{1} \mathrm{P}-\mathrm{b}_{2} \mathrm{P}^{2}\right)$ & $(6.7)$ \\
\hline Phani-Niyogi (1987) & $\mathrm{E}=\mathrm{E}_{0}(1-\mathrm{wP})^{\mathrm{n}} \mathrm{e} \mathrm{w}=1 / \mathrm{P}_{\text {crit }}$ & $(6.9)$ \\
\hline Lam et al. (1994) & $\mathrm{E}=\mathrm{E}_{0}\left(1-\left(\mathrm{P} / \mathrm{P}_{\mathrm{g}}\right)\right)$ & $(6.10)$ \\
\hline Pabst et al. (2006) & $\mathrm{E}=\mathrm{E}_{0}(1-\mathrm{P})\left(1-\left(\mathrm{P} / \mathrm{P}_{\text {crit }}\right)\right)$ & $\mathrm{E}=\mathrm{E}_{0}(1-\mathrm{P})\left(1-\mathrm{b}_{1} \mu_{\chi}^{2}+\mathrm{b}_{2} \mu_{\chi}^{4}\right)$ e $\mu_{\chi}^{2}=(\mathrm{P} /(1-\mathrm{P}))$ \\
\hline Hristopolus-Demertzi (2008) & &
\end{tabular}

Nota: $\mathrm{M}$ pode ser $\mathrm{E}, \mathrm{G}$ ou $\mathrm{K}_{\mathrm{V}}$ (módulos de Young, cisalhamento e volumétrico, respectivamente). O subscrito 0 indica a propriedade do material sem poros. As constantes do material (b, $b_{1}, b_{2}$, e n) são determinadas pelo ajuste dos resultados experimentais. $\mathrm{P}$ é a porosidade, $\mathrm{P}_{\text {crit }}$ é a porosidade crítica na qual o módulo de elasticidade é zero e $\mathrm{P}_{\mathrm{g}}$ é a porosidade do corpo conformado. As equações 6.9 e 6.10 não estão nas referências [201,202].

As equações da Tabela 6.1 não podem ser consideradas equações autoconsistentes ${ }^{213}$ e, portanto, as propriedades elásticas determinadas por estas equações não podem ser usadas para determinar as demais propriedades a partir das relações de autoconsistência:

$$
\begin{aligned}
& E=\frac{9 K_{V} G}{3 K_{V}+G} \\
& v=\frac{3 K_{V}-2 G}{6 K_{V}+2 G}
\end{aligned}
$$

Há controvérsias em relação ao efeito da porosidade no coeficiente de Poisson, ${ }^{208}$ pois alguns autores defendem a idéia de que esta propriedade é independente da porosidade, enquanto outros defendem sua dependência. Algumas relações entre coeficiente de Poisson $(v)$ e porosidade $(\mathrm{P})$ foram observadas na literatura. Com base na teoria de autoconsistência, obteve-se a seguinte relação para a condição de porosidade com morfologia esférica: ${ }^{208}$ 


$$
v=\frac{2 v_{0}\left(5 v_{0}-7\right)+P\left(5 v_{0}-3\right)\left(v_{0}+1\right)}{2\left(5 v_{0}-7\right)+P\left(15 v_{0}-13\right)\left(v_{0}+1\right)}
$$

onde, $v_{0}$ é o coeficiente de Poisson do material livre de poros (este valor deve ser conhecido).

Phani \& Sanyal ${ }^{208}$ utilizaram um valor de $v_{0}$ igual a 0,163 (sílica) e, então, determinaram a curva do coeficiente de Poisson em função da porosidade (eq. 6.13). Eles observaram que esta curva apresentou uma leve tendência para aumentar em função da porosidade, indicando que o coeficiente de Poisson foi praticamente independe da porosidade. Por outro lado, Kovacik ${ }^{207,214}$ indicou que o coeficiente de Poisson em função da porosidade pode ser ajustado a uma equação semi-empírica (eq. 6.14), similar às equações 6.7 e 6.9 (Tabela 6.1).

$$
v=\left(v_{0}+1\right)\left(\frac{\mathrm{P}_{\text {crit }}-\mathrm{P}}{\mathrm{P}_{\text {crit }}}\right)^{\mathrm{n}}-1
$$

onde, $v_{0}$ é o coeficiente de Poisson do material livre de poros, $\mathrm{P}_{\text {crit }}$ é a porosidade crítica, $\mathrm{P}$ é a porosidade, $\mathrm{n}$ é uma constante com valor positivo (valor muito pequeno, $0,06 \leq \mathrm{n} \leq 0,3$ ). A equação 6.14 é válida somente para $\mathrm{P} \leq \mathrm{P}_{\text {crit. }}$.

A curva obtida pela equação 6.14 descreve um comportamento similar aos observados para os modelos de ASM (Fig. 6.1). ${ }^{207,214}$ Os dados de coeficiente de Poisson se ajustaram bem à equação 6.14 no caso do ferro sinterizado e da cerâmica porosa de $\mathrm{Th}_{2} \mathrm{O},{ }^{207,214}$ mas para a cerâmica porosa de $\mathrm{ZnO}$ não houve ajuste, pois esta propriedade permaneceu praticamente constante na faixa de porosidade estudada $(0,37 \leq \mathrm{P} \leq 0)$. Provavelmente, a equação 6.13 deve se ajustar bem aos dados experimentais do $\mathrm{ZnO}$ poroso, pois esta equação indica que o coeficiente de Poisson é independente da porosidade.

De maneira geral, os modelos de ASM se ajustam muito bem às propriedades físicas associadas com fluxo de tensão (deformação, tenacidade à fratura ou resistência mecânica) ou fluxo condutivo (condutividade térmica ou elétrica), ${ }^{203,204}$ mas não são ajustáveis às propriedades físicas que dependem principalmente da quantidade de massa (capacidade térmica, constante dielétrica e índice de refração). As propriedades que dependem da quantidade de massa são influenciadas principalmente pela quantidade de poros e, portanto, 
satisfazem à regra das misturas entre fase sólida e poro. ${ }^{203,204} \mathrm{Na}$ condição de b igual a 1 , a equação 6.1 (Tabela 6.1) é um caso particular da regra das misturas e pode ser usada na análise de propriedades físicas que dependem principalmente da fração volumétrica de sólidos.

Os modelos baseados em micro-mecanismos, que envolvem a concentração de tensão ao redor dos poros, pertencem à outra vertente de modelos usados no estudo do efeito da porosidade nas propriedades mecânicas. A Tabela 6.2 apresenta algumas equações analíticas de constantes elásticas em função da porosidade, que foram determinadas a partir dos conceitos de concentração de tensão ao redor dos poros (micro-mecanismos).

Tabela 3.2 - Equações analíticas de constantes elásticas em função da porosidade. ${ }^{201,202}$

\begin{tabular}{|c|c|c|}
\hline Autor (ano) & Equação & \\
\hline \multirow{2}{*}{ Dewey (1947) } & $\mathrm{G}=\mathrm{G}_{0}\left[1-15 \mathrm{P}\left(1-v_{0}\right) /\left(7-5 v_{0}\right)\right]$ & $(6.15)$ \\
\hline & $\mathrm{K}_{\mathrm{V}}=\mathrm{K}_{\mathrm{v} 0}\left[1-3\left(1-v_{0}\right) \mathrm{P} /\left(2-4 v_{0}\right)\right]$ & $(6.16)$ \\
\hline \multirow{2}{*}{ Mackenzie (1950) } & $\mathrm{G}=\mathrm{G}_{0}\left[1-5 \mathrm{P}\left(3 \mathrm{~K}_{0}+4 \mathrm{G}_{0}\right) /\left(9 \mathrm{~K}_{0}+8 \mathrm{G}_{0}\right)-\varphi_{1} \mathrm{P}^{2}\right]$ & $(6.17)$ \\
\hline & $\mathrm{K}_{\mathrm{V}}=\mathrm{K}_{\mathrm{V} 0}\left\{(1-\mathrm{P})^{-1}+3 \mathrm{PK}_{\mathrm{v} 0} /\left[4 \mathrm{G}_{0}(1-\mathrm{P})\right]+\varphi_{2} \mathrm{P}^{3}\right\}^{-1}$ & $(6.18)$ \\
\hline \multirow{2}{*}{ Kerner (1952) } & $\mathrm{G}=\mathrm{G}_{0}(1-\mathrm{P})\left(7-5 v_{0}\right) /\left[\mathrm{P}\left(8-10 v_{0}\right)+7-5 v_{0}\right]$ & $(6.19)$ \\
\hline & $\mathrm{K}_{\mathrm{V}}=4 \mathrm{~K}_{\mathrm{V} 0} \mathrm{G}_{0}(1-\mathrm{P}) /\left(4 \mathrm{G}_{0}+3 \mathrm{PK}_{\mathrm{V} 0}\right)$ & $(6.20)$ \\
\hline \multirow{3}{*}{ Hashin (1962) } & $\mathrm{E}=\mathrm{E}_{0}(1-\mathrm{P}) /\left\{1+\left(1+v_{0}\right)\left(13-15 v_{0}\right) \mathrm{P} /\left[2\left(7-5 v_{0}\right)\right]\right\}$ & $(6.21)$ \\
\hline & $\mathrm{G}=\mathrm{G}_{0}(1-\mathrm{P}) /\left[1+2\left(4-5 v_{0}\right) \mathrm{P} /\left(7-5 v_{0}\right)\right]$ & $(6.22)$ \\
\hline & $\mathrm{K}_{\mathrm{V}}=\mathrm{K}_{\mathrm{v} 0}(1-\mathrm{P}) /\left\{1+\left(1+\mathrm{v}_{0}\right) \mathrm{P} /\left[2\left(1-2 v_{0}\right)\right]\right\}$ & $(6.23)$ \\
\hline \multirow{2}{*}{ Hashin-Rosen I (1964) } & $\mathrm{E}=\mathrm{E}_{0}(1-\mathrm{P})$ & $(6.24)$ \\
\hline & $\mathrm{G}=\mathrm{G}_{0}(1-\mathrm{P}) /(1+\mathrm{P})$ & $(6.25)$ \\
\hline \multirow{3}{*}{ Hashin-Rosen II (1964) } & $\mathrm{E}=4 \mathrm{GK}\left\{\mathrm{K}_{\mathrm{V}}+\mathrm{G}+\mathrm{K}_{\mathrm{V}} \mathrm{Gv}_{0}^{2} /\left[\mathrm{E}_{0}(1-\mathrm{P})\right]\right\}$ & $(6.26)$ \\
\hline & $\mathrm{G}=\mathrm{G}_{0}\left\{1-4 \mathrm{P}\left(1-\mathrm{v}_{0}\right) /\left[1+2 \mathrm{P}\left(1-2 \mathrm{v}_{0}\right)\right]\right\}$ & $(6.27)$ \\
\hline & $\mathrm{K}_{\mathrm{V}}=2 v_{0}\left(\mathrm{~K}_{\mathrm{v} 0}+\mathrm{G}_{0} / 3\right)(1-\mathrm{P}) /\left(\mathrm{P}+2 \mathrm{v}_{0}\right)$ & $(6.28)$ \\
\hline \multirow{2}{*}{ Budianski (1970) } & $\mathrm{G}=\mathrm{G}_{0}[1-15 \mathrm{P}(1-v) /(7-5 v)]$ & $(6.29)$ \\
\hline & $\mathrm{K}_{\mathrm{V}}=\mathrm{K}_{\mathrm{V} 0}[1-3(1-v) \mathrm{P} /(2-4 v)]$ & $(6.30)$ \\
\hline
\end{tabular}

Nota: Módulos de Young (E), cisalhamento $(\mathrm{G})$ e volumétrico $\left(\mathrm{K}_{\mathrm{V}}\right)$, v é o coeficiente de Poisson, P é a porosidade e $\varphi 1$ e $\varphi 2$ são constantes. $\mathrm{O}$ subscrito 0 indica a propriedade do material sem poros.

Os modelos de Dewey, Mackenzie, Kerner, Hashin e Budiansky consideram corpos com concentração limitada de poros esféricos. Os demais modelos consideram corpos com 
concentração limitada de poros cilíndricos alinhados, cuja direção de carregamento é paralela (Hashin-Rosen I) ou perpendicular (Hashin-Rosen II) à direção do eixo dos poros cilíndricos. Todos os modelos da Tabela 6.2 são severamente questionados porque apresentam várias limitações em relação aos modelos de ASM. ${ }^{122,204}$ Estes modelos baseados em micromecanismos negligenciam a diversidade de características que o poro pode apresentar durante a densificação, ${ }^{203}$ pois fixam um tipo específico de poro que permanece invariável em toda sua faixa de aplicabilidade. Embora tenha ocorrido uma diminuição significativa de algumas propriedades físicas em decorrência da presença de poros cilíndricos (curvas 5 e 6, Fig. $6.1),{ }^{122,204}$ os modelos baseados em micro-mecanismos não identificam a presença de concentração de tensão em poro cilíndrico com seu eixo alinhado paralelamente ao eixo de tensão (tração ou compressão). ${ }^{122}$ Os modelos baseados em micro-mecanismos também mostram que a concentração de tensão ao redor dos poros diminui com o aumento do número de poros, isto é, com a diminuição do espaçamento entre os poros. ${ }^{122}$ Outra limitação destes modelos foi considerar que o coeficiente de Poisson é um parâmetro dependente da porosidade, ${ }^{204}$ sendo tratado na maioria das vezes como um parâmetro de ajuste matemático.

Apesar do extenso estudo sobre a influencia da porosidade nas propriedades mecânicas dos materiais cerâmicos, observaram-se poucos estudos ${ }^{215,216}$ para a cerâmica de AlN. Boch et al. ${ }^{215}$ observaram que as propriedades elásticas ( $E, G$ e $v$ ) do AlN sem aditivo variaram linearmente em função da porosidade (0-20\%), conforme previsto pela equação 6.1 ( $b=1$, Tabela 6.1). Já De With \& Hattu ${ }^{216}$ observaram que o módulo de Young (E) apresentou um comportamento não linear entre 0 e $40 \%$ de porosidade para o AIN sem aditivo. Em decorrência do pouco estudo sobre o efeito da porosidade nas propriedades elásticas do AlN, objetivou-se neste capítulo o estudo do efeito da porosidade nas propriedades elásticas do AIN com adição individual de $\mathrm{Y}_{2} \mathrm{O}_{3}$ e $\mathrm{CaO}$.

\subsection{Materiais e métodos}

As matérias-primas utilizadas nesta série experimental, bem como as metodologias de processamento cerâmico e caracterização dos materiais foram apresentadas nos itens 3.2 e 4.2. A Tabela 6.3 apresenta as composições e identificações das amostras de AlN, que foram sinterizadas entre $1650^{\circ} \mathrm{C}$ e $2000^{\circ} \mathrm{C}$ por 1 hora. 
Tabela 6.3 - Composições e identificações das amostras de AlN.

\begin{tabular}{l|c}
\hline Composição (\% em massa) & Identificação da amostra \\
\hline $0,5 \% \mathrm{CaO}^{*}$ & $05 \mathrm{Ca}$ \\
\hline $1 \% \mathrm{CaO}^{*}$ & $1 \mathrm{Ca}$ \\
\hline $2 \% \mathrm{CaO}^{*}$ & $2 \mathrm{Ca}$ \\
\hline $4 \% \mathrm{CaO}^{*}$ & $4 \mathrm{Ca}$ \\
\hline $8 \% \mathrm{CaO}^{*}$ & $8 \mathrm{Ca}$ \\
\hline $0,5 \% \mathrm{Y}_{2} \mathrm{O}_{3}$ & $05 \mathrm{Y}$ \\
\hline $2 \% \mathrm{Y}_{2} \mathrm{O}_{3}$ & $2 \mathrm{Y}$ \\
\hline $4 \% \mathrm{Y}_{2} \mathrm{O}_{3}$ & $4 \mathrm{Y}$ \\
\hline
\end{tabular}

*O aditivo foi adicionado na forma de $\mathrm{CaCO}_{3}$, sendo usada a seguinte relação de massa molecular $\mathrm{M}_{\mathrm{CaO}} / \mathrm{M}_{\mathrm{CaCO}_{3}}=0,55$ para estimar o valor do aditivo na forma de óxido.

O método não destrutivo denominado pulso-eco ultra-sônico foi usado para determinar as constantes elásticas do corpo sinterizado. Este método se baseia na determinação da velocidade de propagação do pulso ultra-sônico que percorre um corpo de espessura conhecida. Os pulsos ultra-sônicos longitudinal e transversal ou de cisalhamento gerados com auxílio de dois transdutores de onda de $20 \mathrm{MHz}$ (longitudinal, V208-RM, Panametrics, Waltham, MA, USA e transversal, V222-RM, Panametrics, Waltham, MA, USA), que foram ligados individualmente ao dispositivo emissor-receptor de pulso ultra-sônico de $200 \mathrm{MHz}$ (pulser-receiver 5900 PR, Panametrics, Waltham, MA, USA). Um material acoplante (Couplant SWC, Panametrics) foi aplicado na superfície do corpo para garantir um bom contanto com o transdutor. As velocidades longitudinal $\left(\mathrm{v}_{\mathrm{L}}\right)$ e transversal $\left(\mathrm{v}_{\mathrm{T}}\right)$ foram calculadas pela razão entre o dobro da espessura do corpo, determinada com micrômetro digital (156-101, Mitutoyo, Japão), e o tempo de vôo do pulso ultra-sônico que percorre o corpo, determinado com osciloscópio (Tektronix, Beaverton, OR, USA). Dez corpos-de-prova de cada amostra de AIN foram usados para determinação do tempo de vôo do pulso ultrasônico e, então, as constantes elásticas foram determinadas com base nas Normas JISR1602:1981 “Testing methods for elastic modulus of high performance ceramics” e ASTME494:2002 "Standard practice for measuring ultrasonic velocity in materials", usando as seguintes equações.

$$
\begin{aligned}
& E=\left[\rho\left(\frac{3 v_{T}^{2} v_{L}^{2}-4 v_{T}^{4}}{v_{L}^{2}-v_{T}^{2}}\right)\right] \\
& G=\left(\rho v_{T}^{2}\right)
\end{aligned}
$$




$$
\begin{aligned}
& \mathrm{K}_{\mathrm{V}}=\left[\frac{\rho}{3}\left(3 \mathrm{v}_{\mathrm{L}}^{2}-4 \mathrm{v}_{\mathrm{T}}^{4}\right)\right] \\
& v=0,5\left(\frac{\mathrm{v}_{\mathrm{L}}^{2}-2 \mathrm{v}_{\mathrm{T}}^{2}}{\mathrm{v}_{\mathrm{L}}^{2}-\mathrm{v}_{\mathrm{T}}^{2}}\right)
\end{aligned}
$$

onde, E é o módulo de Young, G é o módulo de cisalhamento, $\mathrm{K}_{\mathrm{V}}$ é o módulo volumétrico, $\mathrm{v}$ é o coeficiente de Poisson, $\rho$ é a densidade e $v_{L}$ é a velocidade da onda longitudinal e $v_{T}$ é a velocidade da onda transversal. As velocidades ultra-sônicas são determinadas por: $\mathrm{v}_{\mathrm{L}}=2 \mathrm{w} / \mathrm{t}_{\mathrm{L}}$ e $\mathrm{v}_{\mathrm{T}}=2 \mathrm{w} / \mathrm{t}_{\mathrm{T}}$, onde $\mathrm{w}$ é a espessura da amostra e $\mathrm{t}_{\mathrm{L}}$ e $\mathrm{t}_{\mathrm{T}}$ são os tempos de vôo do pulso ultrasônico na direção longitudinal e transversal, respectivamente.

\subsection{Resultados experimentais}

\section{Análise microestrutural}

Os corpos conformados apresentaram, em média, uma fração volumétrica de poros $\left(f_{\mathrm{P}}\right)$ de $45 \%(0,45)$, independente do tipo e teor de aditivo de sinterização. Após a sinterização na temperatura de $1650^{\circ} \mathrm{C}$, as amostras com $\mathrm{CaO}$ apresentaram menor porosidade do que as amostras com $\mathrm{Y}_{2} \mathrm{O}_{3}$ (Fig. 6.2). Nesta temperatura, as amostras $05 \mathrm{Ca}$ e $1 \mathrm{Ca}$ apresentaram poros $(\leq 1 \mu \mathrm{m})$ com morfologia isométrica (poros esféricos, Fig. 6.3a), enquanto as amostras $2 \mathrm{Ca}$, 4Ca e $8 \mathrm{Ca}$ apresentaram poros grandes isométricos $(1-5 \mu \mathrm{m})$ e poros pequenos alongados e tortuosos distribuídos homogeneamente na microestrutura relativamente densa (Fig. 6.3b). Embora tenha ocorrido um aumento significativo no valor de $f_{\mathrm{P}}$ em função do teor de $\mathrm{CaO}$ (Fig. 6.3a e 6.3b), o aumento de temperatura causou a retração e eliminação de grande parte dos poros (Fig. 6.3c), sendo apenas observados poros isométricos em todas as amostras sinterizadas acima de $1700^{\circ} \mathrm{C}$. Já as amostras com $\mathrm{Y}_{2} \mathrm{O}_{3}$ sinterizadas até $1700^{\circ} \mathrm{C}$ apresentaram poros pequenos $(\leq 1 \mu \mathrm{m})$ com morfologia alongada e tortuosa (Fig. 6.3d). O aumento da temperatura de sinterização diminuiu a porosidade e mudou a morfologia dos poros para isométrica nas amostras com $\mathrm{Y}_{2} \mathrm{O}_{3}$ (Figs. 6.3e e 6.3f). Estes resultados mostraram que, independente do tipo de aditivo de sinterização, a morfologia dos poros mudou de alongada e tortuosa para isométrica com o aumento da temperatura de sinterização $\left(\geq 1650^{\circ} \mathrm{C}\right)$. 


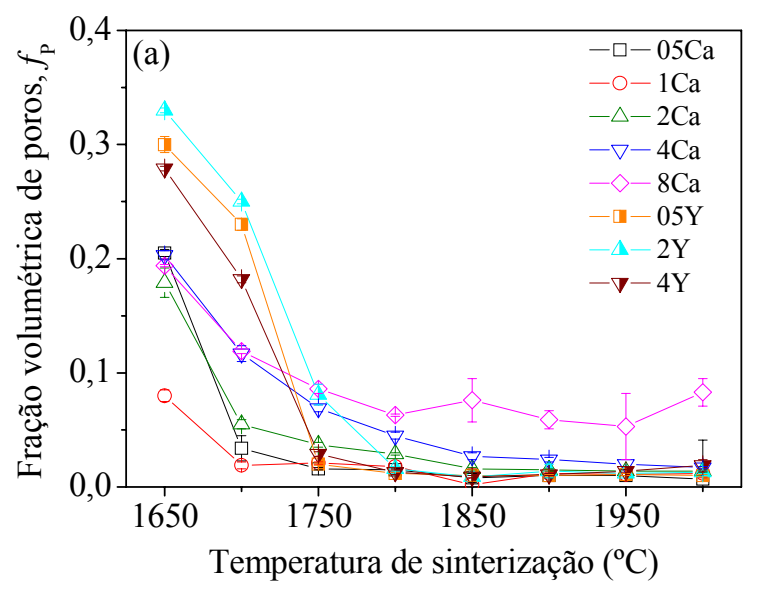

Figura 6.2 - Resultados de fração volumétrica de poros em função da temperatura de sinterização. O coeficiente de variação foi menor do que $0,3 \%$.
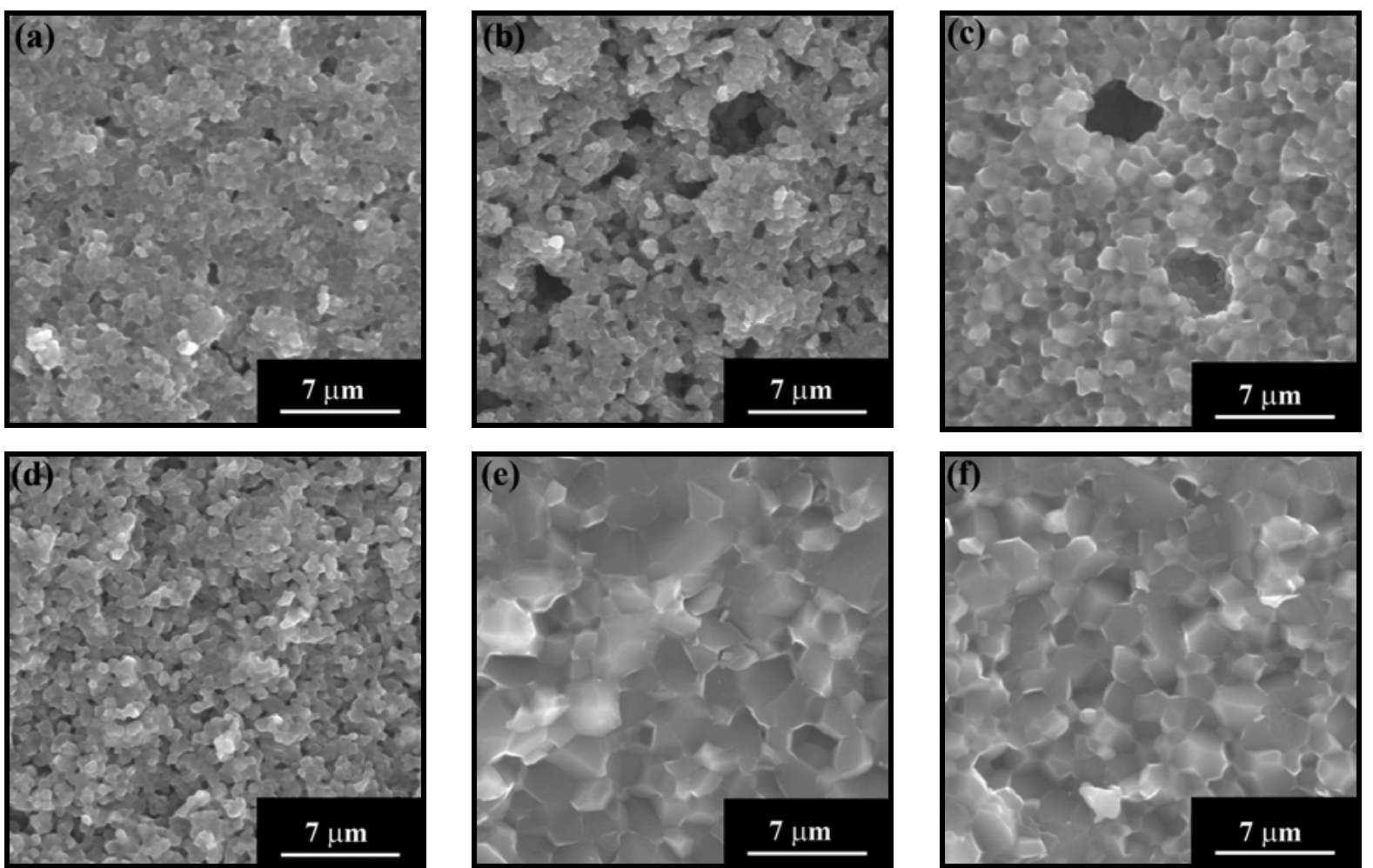

Figura 6.3 - Imagens de MEV da superfície de fratura das amostras de AlN. Amostras 1Ca (a) e 4Ca (b) sinterizadas a $1650^{\circ} \mathrm{C}$ e amostra $2 \mathrm{Ca}$ sinterizada a $1800^{\circ} \mathrm{C}$. Amostra $4 \mathrm{Y}$ (d) sinterizada a $1700^{\circ} \mathrm{C}$ e amostras $05 \mathrm{Y}$ e 2 Y sinterizadas a $1800^{\circ} \mathrm{C}$.

\section{Constantes elásticas}

A Figura 6.4a apresenta os resultados de módulo de Young (E) em função da temperatura de sinterização, onde se observa que E aumentou significativamente com o aumento da temperatura de sinterização, independente do tipo $\left(\mathrm{CaO}\right.$ e $\left.\mathrm{Y}_{2} \mathrm{O}_{3}\right)$ e teor $(0,5 \%$ a 
$8 \%$ em massa) de aditivo de sinterização. Como $f_{\mathrm{P}}$ diminuiu com o aumento da temperatura de sinterização (Fig. 6.2), pode-se dizer que o módulo de Young diminuiu devido à diminuição de $f_{\mathrm{P}}$. As demais propriedades $\left(\mathrm{G}, \mathrm{K}_{\mathrm{V}}, v, \mathrm{v}_{\mathrm{L}}\right.$ e $\left.\mathrm{v}_{\mathrm{T}}\right)$ apresentaram comportamentos similares ao observado para o módulo de Young (E), ou seja, aumentaram com a diminuição de $f_{\mathrm{P}}$. A Figura $6.4 \mathrm{~b}$ apresenta os resultados das constantes elásticas $\left(\mathrm{E}, \mathrm{G}\right.$ e $\left.\mathrm{K}_{\mathrm{V}}\right)$ em função de $f_{\mathrm{P}}$, onde se observa que as referidas propriedades elásticas não foram influenciadas pelo tipo e teor de aditivo de sinterização, mas foram fortemente influenciadas pelo aumento de porosidade. O mesmo comportamento foi observado para o coeficiente de Poisson $(v)$ e as velocidades sônicas longitudinal $\left(\mathrm{v}_{\mathrm{L}}\right)$ e transversal $\left(\mathrm{v}_{\mathrm{T}}\right)$.
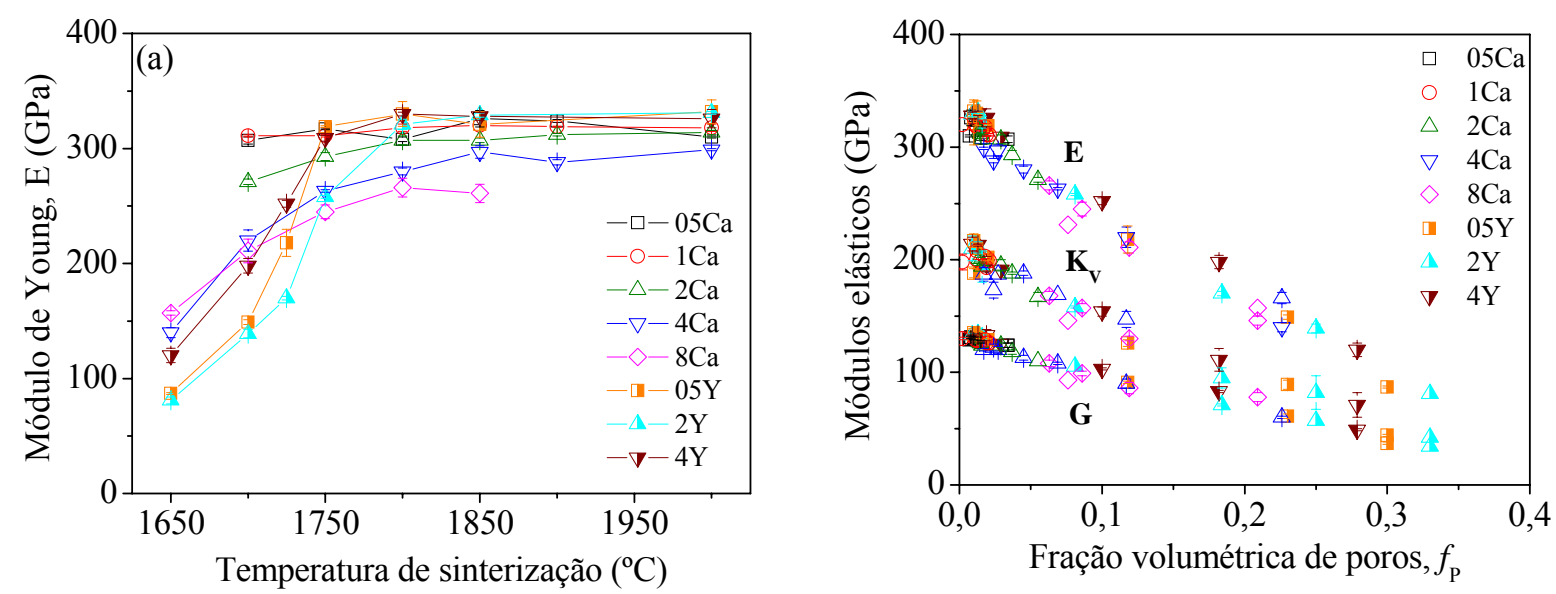

Figura 6.4-Resultados de módulo de Young (E) em função da temperatura de sinterização (a) e módulos elásticos $\left(\mathrm{E}, \mathrm{G}\right.$ e $\left.\mathrm{K}_{\mathrm{V}}\right)$ em função da fração volumétrica de poros, $f_{\mathrm{P}}(\mathrm{b})$. Módulos de cisalhamento $(\mathrm{G}) \mathrm{e}$ geométrico $\left(\mathrm{K}_{\mathrm{V}}\right)$. Os coeficientes de variação das constantes elásticas foram menores do que $5 \%$.

\section{Modelos semi-empíricos}

Como as propriedades $\mathrm{E}, \mathrm{G}, \mathrm{K}_{\mathrm{V}}, \mathrm{v}, \mathrm{v}_{\mathrm{L}}$ e $\mathrm{v}_{\mathrm{T}}$ não foram influenciadas pelo tipo e teor de aditivo de sinterização, todos os resultados de cada uma das propriedades analisadas foram apresentados em função da fração volumétrica de poros (Fig. 6.5) e, então, foram ajustados às equações semi-empíricas da Tabela 6.1. Os melhores ajustes, ou seja, os resultados com menor valor de $\chi^{2}$ e maior valor de $\mathrm{R}^{2}$, foram obtidos para as equações 6.2 e 6.7 (Tabela 6.4). Porém, todas as equações semi-empíricas, com exceção da equação 6.8 , se ajustam bem aos dados experimentais de $\mathrm{E}, \mathrm{G}, \mathrm{K}_{\mathrm{V}}, \mathrm{v}_{\mathrm{L}} \mathrm{e} \mathrm{v}_{\mathrm{T}}$ (Tabela 6.4), pois os ajustes apresentaram, em média, $\mathrm{R}^{2}>0,970$. Já os dados experimentais de coeficiente de Poisson ( $v$ ) não se ajustaram 
bem às equações semi-empíricas da Tabela 6.1 , pois os valores de $\mathrm{R}^{2}$ variaram de 0,887 a 0,913 (Tabela 6.4).

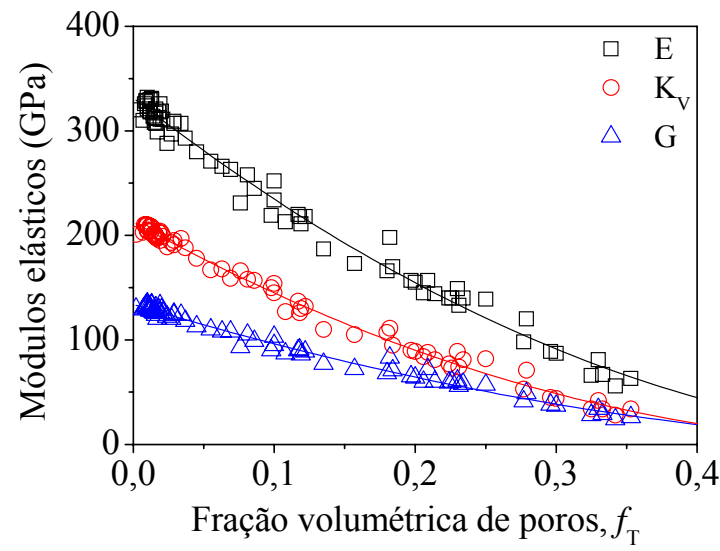

(a)

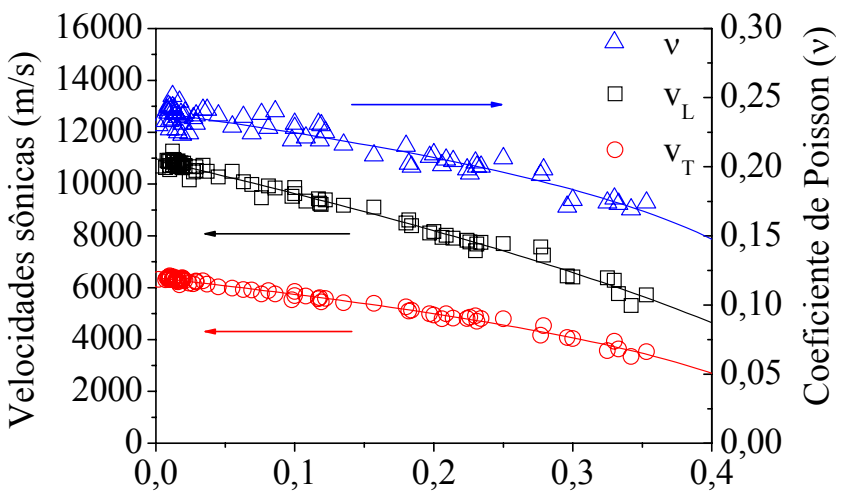

(b)

Fração volumétrica de poros, $f_{\mathrm{T}}$

Figura 6.5 - Módulos elásticos (a) e velocidades sônicas e coeficiente de Poisson (b) em função da fração volumétrica de poros $\left(f_{\mathrm{P}}\right)$ para todas as amostras sinterizadas entre $1650^{\circ} \mathrm{C}$ e $2000^{\circ} \mathrm{C}$. As curvas foram obtidas a partir do ajuste dos dados experimentais a equação de Phani-Niyogi (eq. 6.7, Tabela 6.1).

Quando se utilizou a porosidade do corpo conformado $\left(\mathrm{P}_{\mathrm{g}}=0,45\right)$ na equação 6.8 (Tabela 6.1), as curvas ajustadas aos resultados dos módulos E e G apresentaram baixos valores de $\mathrm{R}^{2}(<0,82)$ e não houve ajuste para as demais propriedades avaliadas. Embora a equação 6.9 (Tabela 6.1) tenha sido desenvolvida apenas para determinar o módulo E, esta equação apresentou bons ajustes para os módulos $\mathrm{G}$ e $\mathrm{K}_{V}$ (Tabela 6.4), além de apresentar ajustes razoáveis para as velocidades sônicas $\left(\mathrm{v}_{\mathrm{L}} \mathrm{e} \mathrm{v}_{\mathrm{T}}\right)$. Já os resultados de coeficiente de Poisson (v) não se ajustaram à equação 6.9 (Tabela 6.4). 
Tabela 6.4 - Resultados do ajuste matemático dos resultados de módulos elásticos $\left(\mathrm{E}, \mathrm{G}\right.$ e $\left.\mathrm{K}_{\mathrm{V}}\right)$, coeficiente Poisson ( $\left.\mathrm{v}\right)$ e velocidades sônicas $\left(\mathrm{v}_{\mathrm{L}} \mathrm{e} \mathrm{v}_{\mathrm{T}}\right)$. $\mathrm{O}$ índice 0 se refere à propriedade de interesse na condição de porosidade igual a zero. VE é a variável b para as equações $6.1,6.3,6.4$ e 6.5 (Tabela 6.1$)$, $b_{1} / b_{2}$ para as equações 6.2 e $6.6, \mathrm{P}_{\text {crit }} / \mathrm{n}$ para a equação 6.7 e $\mathrm{P}_{\text {crit }}$ para equação 6.9. Os melhores ajustes, ou seja, os resultados com maior valor de $\mathrm{R}^{2}$ foram obtidos para as equações 6.2 e 6.7 .

\begin{tabular}{|c|c|c|c|c|c|c|c|c|}
\hline Resultados & eq. 6.1 & eq. 6.2 & eq. 6.3 & eq. 6.4 & eq. 6.5 & eq. 6.6 & eq. 6.7 & eq. 6.9 \\
\hline $\mathrm{E}_{0}(\mathrm{GPa})$ & 323 & 331 & 338 & 343 & 353 & 331 & 331 & 330 \\
\hline VE & 2,5 & $3,1 / 2,4$ & 4,0 & 4,0 & 1,6 & $3,1 / 3,8$ & $0,63 / 2,0$ & 0,49 \\
\hline$\chi^{2} / \mathbf{R}^{2}$ & $156 / 0,980$ & $100 / 0,987$ & $136 / 0,982$ & $197 / 0,975$ & $103 / 0,986$ & $106 / 0,986$ & $101 / 0,987$ & $100 / 0,987$ \\
\hline $\mathrm{G}_{0}(\mathrm{GPa})$ & 131 & 134 & 137 & 139 & 143 & 134 & 134 & 134 \\
\hline VE & 2,4 & $3,0 / 2,1$ & 3,9 & 3,7 & 1,6 & $3,0 / 3,7$ & $0,62 / 1,9$ & 0,51 \\
\hline$\chi^{2} / \mathbf{R}^{2}$ & $24 / 0,980$ & $17 / 0,986$ & $23 / 0,981$ & $32 / 0,974$ & $18 / 0,985$ & $18 / 0,985$ & $17 / 0,986$ & $17 / 0,986$ \\
\hline $\mathrm{K}_{\mathrm{V} 0}(\mathrm{GPa})$ & 206 & 213 & 218 & 222 & 226 & 212 & 213 & 211 \\
\hline VE & 2,6 & $3,5 / 3,0$ & 4,5 & 4,8 & 1,7 & $3,3 / 5,2$ & $0,58 / 2,0$ & 0,44 \\
\hline$\chi^{2} / \mathbf{R}^{2}$ & $71 / 0,980$ & 33 / 0,991 & $54 / 0,985$ & $97 / 0,973$ & $38 / 0,989$ & 35 / 0,990 & 33 / 0,991 & 35 / 0,990 \\
\hline$v_{0}$ & 0,241 & 0,238 & 0,242 & 0,241 & 0,247 & 0,238 & 0,239 & \multirow{3}{*}{$\begin{array}{c}\text { não } \\
\text { ajustou }\end{array}$} \\
\hline VE & 0,8 & $0,4 / 1,2$ & 0,9 & $-0,3$ & 0,5 & $0,3 / 1,8$ & $0,48 / 0,3$ & \\
\hline$\chi^{2} / \mathbf{R}^{2}$ & $5 \times 10^{-5} / 0,897$ & $4 \times 10^{-5} / 0,913$ & $5 \times 10^{-5} / 0,887$ & $5 \times 10^{-5} / 0,903$ & $7 \times 10^{-5} / 0,852$ & $4 \times 10^{-5} / 0,912$ & $4 \times 10^{-5} / 0,913$ & \\
\hline $\mathrm{v}_{\mathrm{L} 0}(\mathrm{GPa})$ & 11006 & 10926 & 11101 & 11049 & 11505 & 10904 & 10932 & 11041 \\
\hline VE & 1,3 & $1,1 /-0,7$ & 1,6 & 0,5 & 0,9 & $1,0 / 2,4$ & $0,53 / 0,6$ & 2,28 \\
\hline$\chi^{2} / \mathbf{R}^{2}$ & $4 \times 10^{4} / 0,983$ & $4 \times 10^{4} / 0,985$ & $7 \times 10^{4} / 0,971$ & $6 \times 10^{4} / 0,977$ & $1 \times 10^{5} / 0,975$ & $4 \times 10^{4} / 0,984$ & $4 \times 10^{4} / 0,985$ & $5 \times 10^{4} / 0,979$ \\
\hline $\mathrm{v}_{\mathrm{T} 0}$ (GPa) & 6452 & 6377 & 6495 & 6461 & 6716 & 6366 & 6383 & 6461 \\
\hline VE & 1,2 & $0,9 /-1,2$ & 1,4 & 0,3 & 0,8 & $0,7 / 2,5$ & $0,46 / 0,4$ & 3,67 \\
\hline$\chi^{2} / \mathbf{R}^{2}$ & $1 \times 10^{4} / 0,978$ & $1 \times 10^{4} / 0,985$ & $3 \times 10^{4} / 0,965$ & $2 \times 10^{4} / 0,974$ & $4 \times 10^{4} / 0,948$ & $1 \times 10^{4} / 0,983$ & $1 \times 10^{4} / 0,987$ & $2 \times 10^{4} / 0,974$ \\
\hline
\end{tabular}


A equação 6.10 (Tabela 6.1) também foi desenvolvida somente para determinar o módulo $\mathrm{E}$, mas se observaram bons ajustes para os módulos $\mathrm{G}$ e $\mathrm{K}_{\mathrm{V}}$, sendo os resultados de $\mathrm{E}$, $\mathrm{G}, \mathrm{K}_{\mathrm{V}}, \chi^{2}$ e $\mathrm{R}^{2}$ próximos dos valores observados para a equação 6.9 (Tabela 6.4). Os coeficientes empíricos $b_{1}$ e $b_{2}$ da equação 6.10 (Tabela 6.1) devem ser sempre positivos devido às condições de contorno impostas para o desenvolvimento do modelo, ${ }^{211}$ mas podem variar em função das mudanças microestruturais. No presente trabalho, os dados de velocidades sônicas $\left(\mathrm{v}_{\mathrm{L}}\right.$ e $\left.\mathrm{v}_{\mathrm{T}}\right)$ se ajustaram bem a equação $6.10\left(\mathrm{R}^{2} \approx 0,986\right)$, mas pelo menos um dos coeficientes empíricos $\left(b_{1}\right.$ e $\left.b_{2}\right)$, obtidos com os ajustes matemáticos, foram negativos e, portanto, os resultados foram desconsiderados.

Além das equações semi-empíricas da Tabela 6.1, os resultados de coeficiente de Poisson (v) foram ajustados às equações 6.13 e 6.14 . A Figura 6.6 mostra os resultados de $v$ em função de $f_{\mathrm{P}}$, onde se observa que a equação 6.13 se ajustou bem somente na região com baixa porosidade $(<0,05)$ e, então, os resultados apresentaram um desvio significativo do comportamento previsto por esta equação analítica. Os resultados de $v$ seguiram $o$ comportamento previsto pela equação 6.14 na faixa de porosidade avaliada (Fig. 6.6), sendo que os valores de $v_{0}, \chi^{2}$ e $\mathrm{R}^{2}$ foram praticamente os mesmos obtidos com a equação de PhaniNiyogi (eq. 6.7, Tabela 6.4).

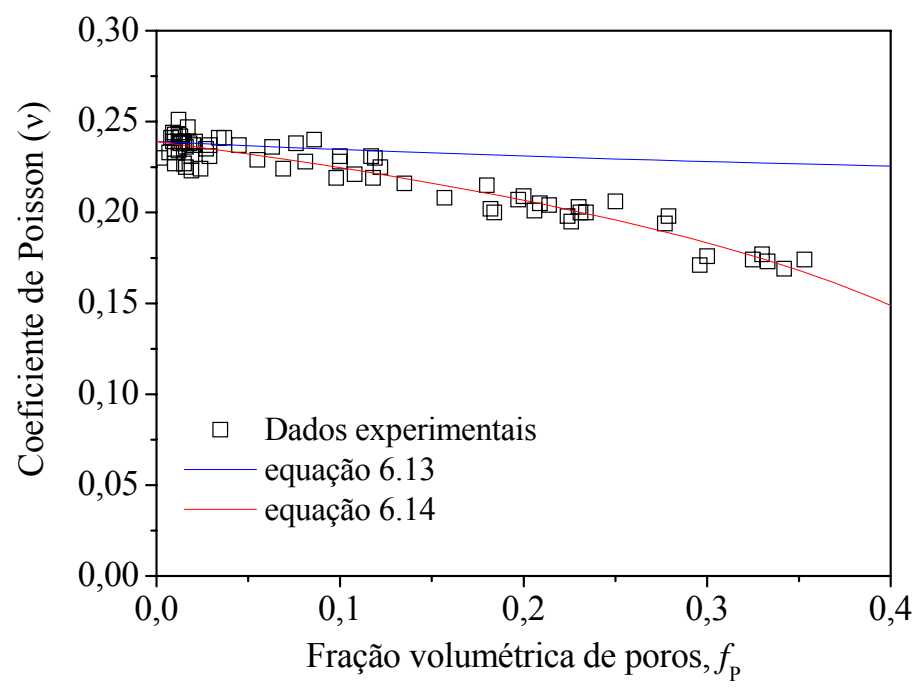

Figura 6.6 - Dados experimentais de coeficiente de Poisson (v) em função da fração volumétrica de poros. 


\section{Modelos de Área Sólida Mínima (ASM)}

A equação de Phani-Niyogi ${ }^{212}$, uma das mais usadas no estudo do efeito da porosidade nas propriedades elásticas, ${ }^{210}$ foi a que apresentou os melhores ajustes para todas as propriedades avaliadas (eq. 6.7, Tabela 6.4). Deste modo, os valores de $\mathrm{E}_{0}, \mathrm{G}_{0}, \mathrm{~K}_{\mathrm{V} 0}, \mathrm{v}_{0}, \mathrm{v}_{\mathrm{L} 0} \mathrm{e}$ $\mathrm{v}_{\mathrm{T} 0}$ determinados por esta equação foram considerados os valores destas propriedades para o material livre de poros $\left(f_{\mathrm{P}}=0\right)$. Os resultados de módulos elásticos $\left(\mathrm{E}, \mathrm{G}\right.$ e $\left.\mathrm{K}_{\mathrm{V}}\right)$, coeficiente de Poisson $(v)$ e velocidades sônicas $\left(v_{L}\right.$ e $\left.v_{T}\right)$ foram normalizados pelos respectivos valores obtidos pelos ajustes matemáticos $\left(\mathrm{E}_{0}, \mathrm{G}_{0}, \mathrm{~K}_{\mathrm{V} 0}, v_{0}, \mathrm{~V}_{\mathrm{L} 0}\right.$ e $\left.\mathrm{V}_{\mathrm{T} 0}\right)$. Os resultados das propriedades normalizadas $\left(\mathrm{M} / \mathrm{M}_{0}\right)$ em função de $f_{\mathrm{P}}$ são apresentados na Figura 6.7. Estes resultados foram comparados com os modelos da regra das misturas e de ASM (curvas 1 a 6, Fig. 6.7). A taxa de diminuição do coeficiente de Poisson $(v)$ em função de $f_{\mathrm{P}}$ foi menor do que a prevista pelo modelo da regra das misturas (Fig. 6.7). Para $f_{\mathrm{P}} \leq 0,2$, as velocidades sônicas $\left(\mathrm{v}_{\mathrm{L}}\right.$ e $\mathrm{v}_{\mathrm{T}}$ ) tiveram um comportamento próximo daquele previsto para o modelo da regra das misturas (Fig. 6.7). Porém, as duas velocidades sônicas tiveram uma diminuição mais significativa com o aumento de $f_{\mathrm{P}}\left(0,2<f_{\mathrm{P}}<0,3\right.$, Fig. 6.7), desviando tanto do modelo da regra das misturas (curva 1) como do modelo de poros cilíndricos em empilhamento cúbico simples alinhado paralelamente à tensão aplicada (curva 6). Para $f_{\mathrm{P}} \geq 0,3$, as velocidades sônicas mostraram uma tendência para se aproximar do modelo de poros esféricos em empilhamento cúbico simples (curva 4, Fig. 6.7).

Para $f_{\mathrm{P}} \leq 0,2$ (Fig. 6.7), os módulos elásticos (E, $\mathrm{G}$ e $\mathrm{K}_{\mathrm{v}}$ ) apresentaram um comportamento próximo daqueles previstos para os modelos de poros esféricos em empilhamento cúbico simples (curva 4) e poros cilíndricos em empilhamento cúbico simples alinhado transversalmente à tensão aplicada (curva 5). Para $f_{\mathrm{P}}>0,2$, os módulos elásticos (E, $\mathrm{G}$ e $\mathrm{K}_{\mathrm{V}}$ ) apresentaram diminuições mais significativas do que aquelas previstas por estes modelos (curvas 4 e 5, Fig. 6.7). Estas três propriedades elásticas apresentaram, acima de $f_{\mathrm{P}}=$ 0,2 , um comportamento próximo daquele previsto para o modelo de partículas esféricas em empilhamento cúbico simples (curva 3, Fig. 6.7). Como indicado por Rice ${ }^{203}$, os dados experimentais se aproximaram de um ou mais modelos teóricos apresentados na Figura 6.7, o que indicou a ocorrência de mudanças microestruturais durante a densificação, conforme observado na análise microestrutural do AlN preparado com $\mathrm{CaO}$ ou $\mathrm{Y}_{2} \mathrm{O}_{3}$ (Fig. 6.3). 


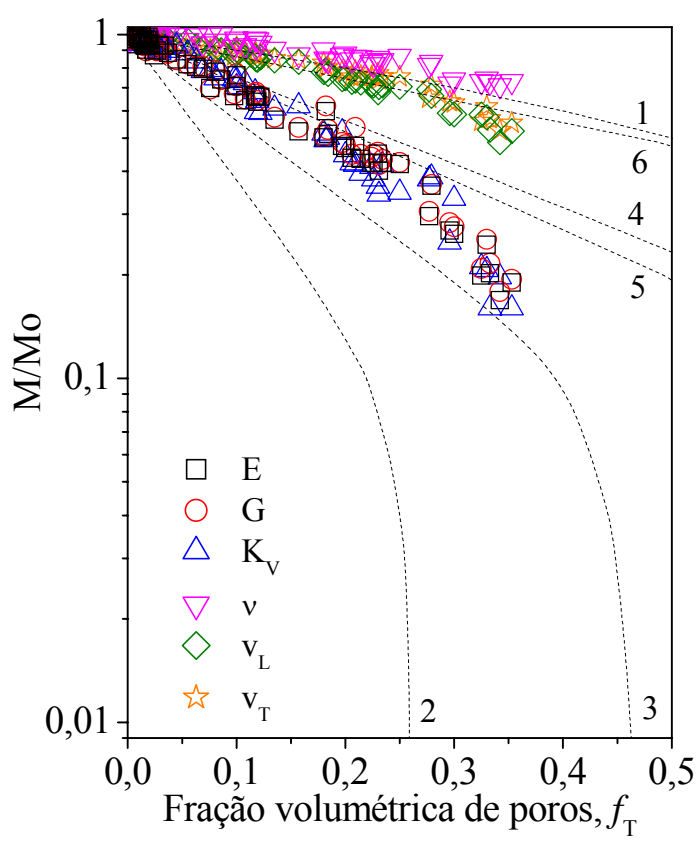

Figura 6.7 - Propriedades relativas $\left(M / M_{0}=E / E_{0}, G / G_{0}, K_{V} / K_{V 0}, v / v 0, v_{L} / v_{L 0}\right.$ e $\left.v_{T} / v_{T 0}\right)$ em função da fração volumétrica de poros. As curvas tracejadas indicadas com número se referem aos vários tipos de modelos. A curva 1 se refere ao modelo de regra das misturas. As demais curvas se referem aos modelos de área sólida mínima (ASM): (2) partículas esféricas com empilhamento rômbico; (3) partículas esféricas com empilhamento cúbico simples; (4) poros esféricos com empilhamento cúbico simples; (5) poros cilíndricos com empilhamento cúbico simples alinhado transversalmente à tensão aplicada; e (6) poros cilíndricos com empilhamento cúbico simples alinhado paralelamente à tensão aplicada.

\section{Modelos analíticos}

As propriedades normalizadas $\left(\mathrm{E} / \mathrm{E}_{0}, \mathrm{G} / \mathrm{G}_{0}\right.$ e $\left.\mathrm{K}_{\mathrm{V}} / \mathrm{K}_{\mathrm{V} 0}\right)$ em função de $f_{\mathrm{P}}$, juntamente com as curvas dos modelos analíticos de concentração de tensão ao redor dos poros (Tabela 6.2), são apresentadas na Figura 6.8. Algumas condições foram estabelecidas para determinar as curvas dos modelos analíticos da Tabela 6.2: i) os termos de segunda ordem das equações de Mackenzie (eq. 6.17 e 6.18) foram desprezados, o que pode influenciar os resultados na região com elevada porosidade; ${ }^{213}$ ii) o coeficiente de Poisson (v), obtido a partir do ajuste matemático dos dados experimentais (Fig. 6.5b), foi usado nas equações de Budianski (eq. 6.29 e 6.30); e iii) quando os modelos analíticos apresentaram soluções para determinar apenas dois módulos elásticos (Tabela 6.2), o terceiro módulo foi determinado com a equação 6.11 .

A Figura 6.8 mostra que os dados experimentais se ajustaram melhor ao modelo de Hashin-Rosen II (Tabela 6.2), que foi desenvolvido para corpos com poros cilíndricos alinhados transversalmente à tensão aplicada. Este resultado não foi coerente com os resultados da análise microestrutural, que mostrou a presença de poros alongados e tortuosos 
não alinhados nas amostras com alta porosidade e poros isométricos nas amostras com baixa porosidade (Fig. 6.3).
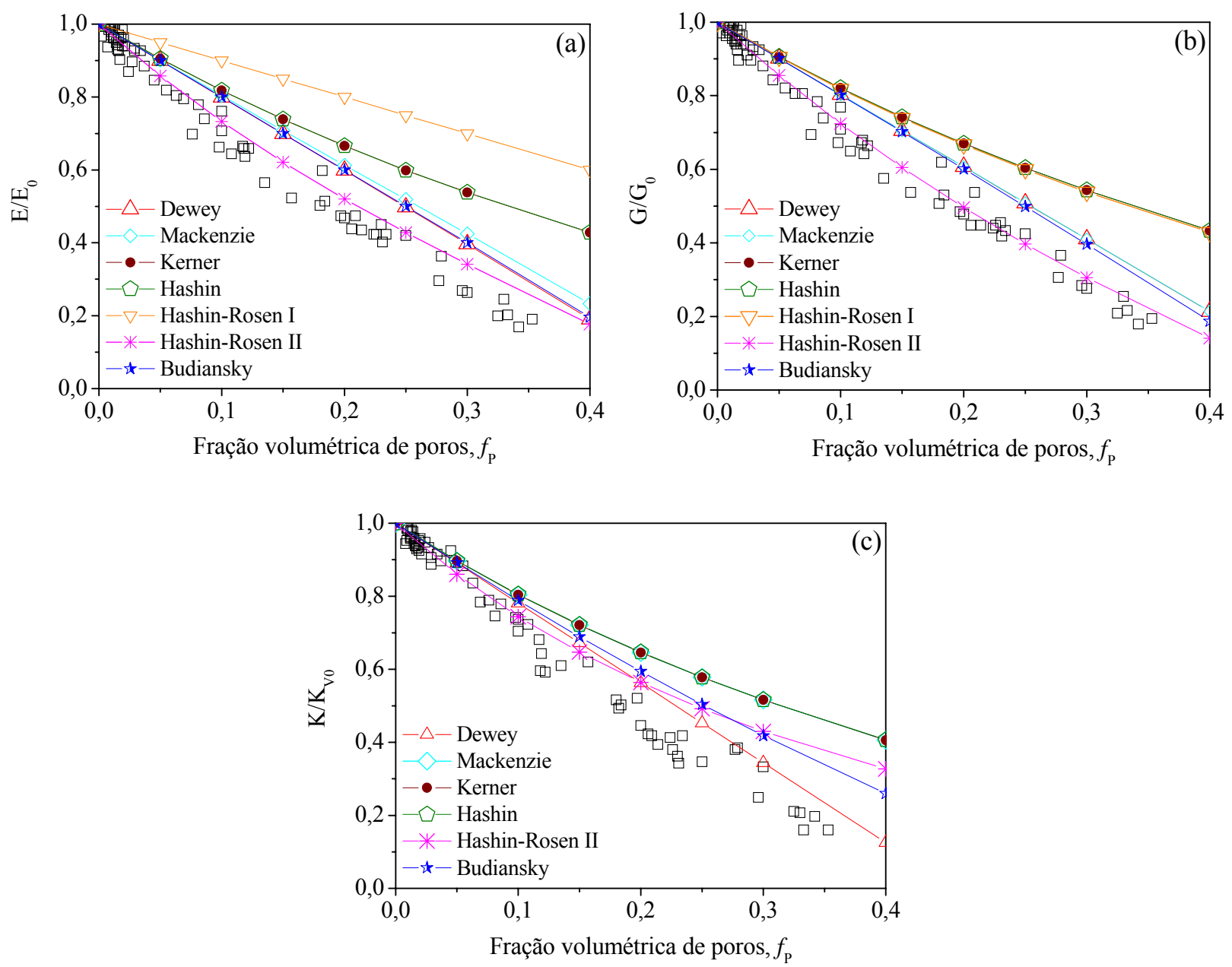

Figura 6.8 - Módulos elásticos normalizados em função da fração volumétrica de poros: (a) módulo de Young (E), (b) módulo de cisalhamento $(\mathrm{G})$ e (c) módulo volumétrico $\left(\mathrm{K}_{\mathrm{V}}\right)$. As curvas se referem aos modelos analíticos baseados em concentração de tensão ao redor dos poros (Tabela 6.2).

Os resultados de $G$ se ajustaram ao modelo de Hashin-Rosen II até cerca de $f_{\mathrm{P}}=0,3$ (Fig. 6.8b). Já os resultados de $\mathrm{E}$ e $\mathrm{K}_{\mathrm{V}}$ se ajustaram bem ao modelo de Hashin-Rosen II até cerca de $f_{\mathrm{P}}=0,1$ (Figs. 6.7a e 6.7c, respectivamente). As curvas do modelo de Hashin-Rosen II desviaram dos resultados de $\mathrm{E}, \mathrm{G}$ e $\mathrm{K}_{\mathrm{V}}$ com o aumento de $f_{\mathrm{P}}$ (Fig. 6.8), indicando que este modelo analítico superestimou os módulos elásticos, principalmente na região com elevada porosidade. Os resultados de E e G ficaram relativamente próximos das curvas referentes aos modelos de Dewey, Mackenzie e Budiansky em toda a faixa de porosidade estudada (Figs. 6.8a e 6.8b). Porém, os três modelos analíticos superestimaram os valores de E e G nesta faixa de porosidade. A curva do modelo de Dewey se aproximou mais dos resultados de $\mathrm{K}_{V}$ (Fig. 
6.8c) do que as curvas dos modelos de Mackenzie e Budiansky. No entanto, o modelo de Dewey também superestimou os valores de $\mathrm{K}_{\mathrm{V}}$ na faixa de porosidade estudada (Fig. 6.8c). Os modelos analíticos de Kerner, Hashin e Hashin-Rosen I (Tabela 6.2) não se ajustaram aos resultados de E, G e $\mathrm{K}_{\mathrm{V}}$ (Fig. 6.8).

\subsection{Discussão dos resultados experimentais}

\section{Análise dos modelos semi-empíricos}

As equações semi-empíricas da Tabela 6.1, com exceção da equação 6.8, se ajustaram bem $\left(R^{2}>0,970\right)$ aos resultados das constantes elásticas $\left(E, G\right.$ e $\left.K_{V}\right)$, como observado na Tabela 6.4. Porém, as equações de Phani-Niyogi e Pabst et al. (eq. 6.7 e 6.9, Tabela 6.1), que consideram a variável $\mathrm{P}_{\text {crit }}$ (porosidade crítica), apresentaram resultados mais consistentes, pois $\mathrm{P}_{\text {crit }}$ pode ser associado com a porosidade inicial do corpo conformado. No presente trabalho, os valores de $\mathrm{P}_{\text {crit, }}$ obtidos a partir dos ajustes dos resultados de $\mathrm{E}, \mathrm{G}$ e $\mathrm{K}_{\mathrm{V}}$, foram próximos de 0,60, segundo a equação de Phani-Niyogi (eq. 6.7, Tabela 6.4). Estes valores de $\mathrm{P}_{\text {crit }}$ foram significativamente maiores do que o valor de $f_{\mathrm{P}}$ do corpo conformado $(0,45)$, mostrando que a equação de Phani-Niyogi superestimou o limite de percolação das partículas. Quando os dados de E, G e $\mathrm{K}_{\mathrm{V}}$ foram ajustados ao modelo de Pabst et al. (eq. 6.9, Tabela 6.1), os valores de $\mathrm{P}_{\text {crit }}\left(0,44-0,51\right.$, Tabela 6.4) foram próximos do valor de $f_{\mathrm{P}}$ do corpo conformado $(0,45)$, mostrando que esta equação se ajustou melhor aos resultados das constantes elásticas, principalmente na região com elevada porosidade $\left(\sim \mathrm{P}_{\text {crit }}\right)$. Porém, os valores de $\mathrm{E}_{0}, \mathrm{G}_{0}$ e $\mathrm{K}_{\mathrm{V} 0}$ obtidos com as equações 6.7 e 6.9 foram praticamente os mesmos $\left(\mathrm{E}_{0}\right.$ $=331 \mathrm{GPa}, \mathrm{G}_{0}=134 \mathrm{GPa}$ e $\mathrm{K}_{\mathrm{V} 0}=213 \mathrm{GPa}$, Tabela 6.4), sendo estes valores relativamente próximos dos valores de literatura para o AlN sem aditivo $(\mathrm{E} \approx 306-335 \mathrm{MPa}, \mathrm{G} \approx 125-130$ $\mathrm{MPa}$ e $\left.\mathrm{K}_{\mathrm{V}} \approx 200 \mathrm{MPa}\right)^{215,217-220}$ e para o AlN com aditivo de sinterização $(\mathrm{E} \approx 312-323 \mathrm{MPa}$, $\mathrm{G} \approx 131 \mathrm{MPa}$ e $\left.\mathrm{K}_{\mathrm{V}} \approx 205 \mathrm{MPa}\right)^{87,221}$. 


\section{Análise dos modelos de Área Sólida Mínima (ASM)}

$\mathrm{Na}$ região com baixa porosidade $\left(f_{\mathrm{P}} \leq 0,1\right.$, Fig. 6.7), as constantes elásticas normalizadas $\left(\mathrm{E} / \mathrm{E}_{0}, \mathrm{G} / \mathrm{G}_{0}\right.$ e $\left.\mathrm{K}_{\mathrm{V}} / \mathrm{K}_{\mathrm{V} 0}\right)$ apresentaram um comportamento próximo dos modelos de poros esféricos em empilhamento cúbico simples (curva 4) e poros cilíndricos em empilhamento cúbico simples alinhado transversalmente à tensão aplicada (curva 5), mas ocorreu um desvio no comportamento destas propriedades acima de $f_{\mathrm{P}}=0,2$, fazendo com que o mesmo se aproximasse do modelo de partículas esféricas em empilhamento cúbico simples (curva 3). Durante a sinterização do corpo conformado, a evolução microestrutural mais consistente para ser associada com a densificação é a mudança de um arranjo de partículas esféricas em empilhamento cúbico simples (curva 4, Fig. 6.7) para um arranjo de poros esféricos em empilhamento cúbico simples (curva 3, Fig. 6.7), pois as amostras sinterizadas não apresentaram poros cilíndricos ou alongados alinhados de forma paralela ou perpendicular à tensão aplicada (Fig. 6.3). Na Figura 6.7, observa-se que a maioria dos resultados de módulos elásticos $\left(\mathrm{E}, \mathrm{G}\right.$ e $\left.\mathrm{K}_{\mathrm{V}}\right)$ se situou entre as curvas 3 e 4, mostrando que, na faixa de porosidade estudada $(\mathrm{P}<0,38)$, estes módulos elásticos foram influenciados pelos dois modelos geométricos de ASM.

Quando uma determinada propriedade é influenciada por dois ou mais modelos geométricos de ASM, como observado no presente trabalho, pode-se estimar a fração relativa do efeito de cada um dos modelos na referida propriedade por meio da regra das misturas. ${ }^{204}$ Para verificar a influência de cada um dos modelos de ASM (curvas 3 e 4, Fig. 6.7) nas constantes elásticas do AIN, os dados normalizados de $E / E_{0}, G / G_{0}$ e $K_{V} / K_{V 0}$ foram ajustados à equação de Phani-Nioygi (eq. 6.7, Tabela 6.1) e, então, as curvas determinas por ajuste matemático foram comparadas com as curvas dos modelos de ASM. Com base na regra das misturas, as frações relativas dos modelos de ASM (curvas 3 e 4, Fig. 6.7) foram estimadas e, então, apresentadas na Figura 6.9, como realizado em trabalho anterior. ${ }^{201}$

$\mathrm{Na}$ região com alta porosidade $\left(f_{\mathrm{P}}>0,3\right)$, o modelo de partículas esféricas em empilhamento cúbico simples (curva 3) apresentou maior fração relativa (Fig. 6.9). Esta proposição é admissível, pois as partículas de AlN apresentaram estreita distribuição granulométrica (Fig. 3.2) e morfologia isométrica (Fig. 3.3a), o que pode favorecer a ocorrência de empilhamento cúbico simples de partículas no corpo conformado. Uma transição quase linear entre os modelos 3 e 4 foi observada com a diminuição de $f_{\mathrm{P}}$ (Fig. 6.9). Os dois modelos apresentaram frações relativas praticamente iguais $(\sim 50 \%)$ ao redor de $f_{\mathrm{P}}=$ 0,2 (Fig. 6.9). Estes resultados sugeriram que a microestrutura deve ser composta por poros 
tanto alongados e tortuosos como isométricos. Os poros alongados e tortuosos são provenientes da condição de empilhamento cúbico simples de partículas (modelo 3), enquanto os poros isométricos são provenientes da condição de empilhamento cúbico simples de poros esféricos (modelo 4). Esta proposição é possível, pois as amostras de AlN apresentaram esta transição de geometria de poros com a diminuição da porosidade (Fig. 6.3). Já na região com baixa porosidade $\left(f_{\mathrm{P}} \leq 0,5\right)$ o modelo de poros esféricos em empilhamento cúbico simples (modelo 4) se tornou predominante (Fig. 6.9), como observado na análise microestrutural (Fig. 6.3). Resultados similares foram observados para o AlN sem aditivo e com $2 \%$ em massa de aditivo $\left(\mathrm{CaCO}_{3}, \mathrm{CaO}\right.$ e $\left.\mathrm{Y}_{2} \mathrm{O}_{3}\right)$. ${ }^{201}$

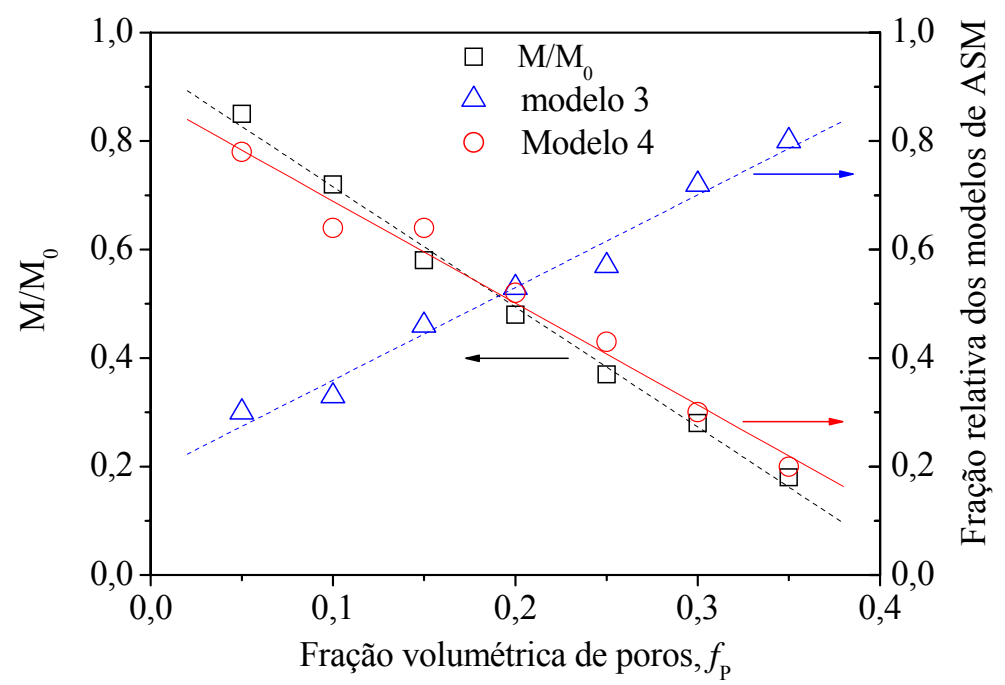

Figura 6.9 - Módulo elástico relativo $\left(\mathrm{M} / \mathrm{M}_{0}\right)$ e fração relativa dos modelos de ASM em função da fração volumétrica de poros. Os modelos 3 e 4 se referem aos respectivos modelos de partículas esféricas em empilhamento cúbico simples (curva 3, Fig. 6.7) e poros esféricos em empilhamento cúbico simples (curva 4, Fig. 6.7).

Os dados normalizados de coeficiente de Poisson $\left(v / v_{0}\right)$ não se ajustaram aos modelos de ASM (curvas 2 a 6, Fig. 6.7), mas seguiram um comportamento próximo do modelo da regra das misturas (curva 1). Além disso, os resultados de $v$ não se ajustaram bem às equações semi-empíricas da Tabela 6.1, pois os melhores ajustes apresentaram $\mathrm{R}^{2}=0,913$ (eq. $6.2 \mathrm{e}$ 6.7, Tabela 6.4). Estes resultados indicaram que $v$ foi pouco dependente da área efetiva de contato entre as partículas (modelos de ASM), isto é, quase independente da morfologia e distribuição dos poros na microestrutura. Portanto, pode-se dizer que $v$ foi praticamente dependente da quantidade de massa, isto é, da fração volumétrica de sólidos, o que satisfaz a regra da misturas entre fase sólida e poro. Apesar dos resultados de $v$ não se ajustarem bem às equações semi-empíricas da Tabela 6.1, o valor determinado de $v_{0}=0,239$ ficou dentro da 
faixa de valores de literatura para o AlN com e sem aditivo de sinterização $(v \approx 0,234$ $0,245) .{ }^{87,215,218,219,221}$

Já os dados normalizados das velocidades sônicas $\left(\mathrm{v}_{\mathrm{L}}\right.$ e $\left.\mathrm{v}_{\mathrm{T}}\right)$ apresentaram um comportamento próximo do modelo da regra das misturas entre $0 \leq f_{\mathrm{P}} \leq 0,2$ (curva 1, Fig. 6.7). Nesta faixa de porosidade, pode-se dizer que as velocidades sônicas foram praticamente independentes da área efetiva de contato entre as partículas (modelos de ASM). Entretanto, para $f_{\mathrm{P}} \geq 0,2$, as velocidades sônicas mostraram uma tendência para seguir o modelo de poros cilíndricos em empilhamento cúbico simples alinhado paralelamente à tensão aplicada (curva 6, Fig. 6.7), mas logo ocorreu um desvio no seu comportamento, fazendo com que se aproximasse do modelo de poros esféricos em empilhamento cúbico simples (curva 4, Fig. 6.7). Os dados de velocidades sônicas se ajustaram relativamente bem às equações semiempíricas 6.2 e 6.7 (Tabela 6.4), mostrando que esta propriedade pode ser correlacionada com os modelos de ASM e, portanto, são dependentes das características dos poros. Embora não haja um modelo plausível de ASM para descrever o comportamento das velocidades sônicas na região com elevada porosidade (Fig. 6.7), os resultados mostraram que as velocidades sônicas foram menos sensíveis às características dos poros na região com baixa porosidade (0 $\leq f_{\mathrm{P}} \leq 0,2$, Fig. 6.7). Isto indicou que existe um valor limite de porosidade $\left(f_{\mathrm{P}} \approx 0,2\right)$ abaixo do qual as velocidades sônicas se tornam quase independente da área efetiva de contato entre as partículas. Os valores das velocidades sônicas $\mathrm{v}_{\mathrm{L} 0}$ e $\mathrm{v}_{\mathrm{T} 0}$ foram $10932 \mathrm{~m} / \mathrm{s}$ e $6383 \mathrm{~m} / \mathrm{s}$, respectivamente. Estes valores foram próximos dos valores de literatura para o AlN com e sem aditivo de sinterização ( $\mathrm{v}_{\mathrm{L}} \approx 10127-10700 \mathrm{~m} / \mathrm{s}$ e $\left.\mathrm{v}_{\mathrm{T}} \approx 6220-6333 \mathrm{~m} / \mathrm{s}\right){ }^{201,219,221,222}$

\section{Análise dos modelos analíticos}

Os modelos analíticos baseados na concentração de tensão ao redor dos poros (Tabela 6.2) superestimaram os valores de $E, G$ e $K_{V}$ (Fig. 6.7), principalmente na região com elevada porosidade. Portanto, pode-se dizer que os modelos analíticos baseados em micromecanismos foram inconsistentes para determinar as constantes elásticas do $\mathrm{AlN}$, o que reforçou a interpretação de que os conceitos de concentração de tensão ao redor dos poros têm pouca ou praticamente nenhuma base fundamental para determinar as constantes elásticas de materiais porosos, conforme proposto por Rice ${ }^{203}$. 


\subsection{Conclusões}

Estudou-se o efeito da porosidade nas propriedades elásticas do AlN com adição individual de $\mathrm{Y}_{2} \mathrm{O}_{3}(0,5 \%$ a $4 \%$ em massa) e $\mathrm{CaO}(0,5 \%$ a $8 \%$ em massa) sinterizado entre $1650^{\circ} \mathrm{C}$ e $2000^{\circ} \mathrm{C}$. Os resultados experimentais levaram às seguintes conclusões:

- As propriedades elásticas analisadas $\left(\mathrm{E}, \mathrm{G}, \mathrm{K}_{\mathrm{V}}, \mathrm{v}, \mathrm{v}_{\mathrm{L}} \mathrm{e} \mathrm{v}_{\mathrm{T}}\right)$ não são influenciadas pelo tipo e teor de aditivo de sinterização, mas são influenciadas pela porosidade;

- Em geral, as equações semi-empíricas se ajustaram bem aos resultados das constantes elásticas $\left(\mathrm{E}, \mathrm{G}\right.$ e $\left.\mathrm{K}_{\mathrm{V}}\right)$. Porém, as equações de Phani-Niyogi e Pabst et al., que consideram a variável $\mathrm{P}_{\text {crit }}$ (porosidade crítica), apresentaram resultados mais consistentes, pois $\mathrm{P}_{\text {crit }}$ pode ser associado com a porosidade inicial do corpo conformado;

- A diminuição dos módulos de elasticidade (E, G e $\mathrm{K}_{\mathrm{V}}$ ) com a porosidade pode ser explicada por dois modelos de Área Sólida Mínima (ASM). O modelo de partículas com empilhamento cúbico simples prevaleceu na região com elevada porosidade, enquanto o modelo de poros esféricos com empilhamento cúbico simples prevaleceu na região com baixa porosidade. Estes modelos são condizentes com a evolução microestrutural das amostras de AlN durante o processo de densificação;

- As equações semi-empíricas se ajustaram razoavelmente aos resultados de coeficiente de Poisson (v), que mostraram pouca dependência pela área efetiva de contato entre as partículas (modelos de ASM). Esta propriedade mostrou maior tendência para apresentar uma dependência pela quantidade de massa, isto é, pela fração volumétrica de sólidos, o que satisfaz a regra das misturas entre fase sólida e poros;

- As equações semi-empíricas se ajustaram bem aos resultados das velocidades sônicas $\left(\mathrm{v}_{\mathrm{L}} \mathrm{e}\right.$ $\left.\mathrm{v}_{\mathrm{T}}\right)$. Porém, observou-se um valor limite de porosidade $\left(f_{\mathrm{P}} \approx 0,2\right)$ abaixo do qual as velocidades sônicas se tornaram quase independente da área efetiva de contato entre as partículas (modelos de ASM);

- Os modelos analíticos baseados na concentração de tensão ao redor dos poros superestimaram os valores de $\mathrm{E}, \mathrm{G}$ e $\mathrm{K}_{\mathrm{V}}$, principalmente na região com elevada porosidade, o que mostra uma inconsistência para determinar as propriedades elásticas do AlN. 


\section{Efeito do teor de $\mathrm{Y}_{2} \mathrm{O}_{3}$ ou CaO nas propriedades mecânicas do AIN}

\subsection{Introdução}

A cerâmica de AlN, além de ser utilizada como substrato e/ou material de encapsulamento para dispositivos eletrônicos, também pode ser utilizada como material estrutural de baixa ou alta temperatura. ${ }^{88,171,201,219,223}$ Porém, o estudo sobre o comportamento mecânico do AlN é limitado em comparação com os estudos observados para outras cerâmicas estruturais $\left(\mathrm{Al}_{2} \mathrm{O}_{3}, \mathrm{SiC}\right.$ e $\left.\mathrm{Si}_{3} \mathrm{~N}_{4}\right) .{ }^{219}$ Os primeiros estudos sobre o comportamento mecânico do AlN sem aditivo surgiram no final da década de $70,{ }^{24,224}$ mas poucos estudos ${ }^{19,88,217,219,225-227}$ foram realizados nos últimos trinta anos, quando ocorreram avanços significativos no processo de sinterização via fase líquida. $O$ aumento do teor de oxigênio, presente inerentemente na superfície do pó de AlN, pode aumentar significativamente a resistência mecânica da cerâmica de AlN sem aditivo preparada por prensagem a quente. ${ }^{224} \mathrm{~A}$ resistência à flexão do AlN sem aditivo atingiu cerca de $500 \mathrm{MPa}$ com 2,7\% em massa de oxigênio e, então, apresentou uma diminuição significativa com o aumento do teor de oxigênio (<300 MPa para 12\% em massa de oxigênio). A diminuição da resistência mecânica com o aumento do teor de oxigênio foi atribuída à formação dos politipóides $27 \mathrm{R}\left(\mathrm{Al}_{9} \mathrm{O}_{3} \mathrm{~N}_{7}\right) \mathrm{e}$ $12 \mathrm{H}\left(\mathrm{Al}_{6} \mathrm{O}_{3} \mathrm{~N}_{4}\right) .{ }^{224}$ Já o aumento do teor de $\mathrm{Al}_{2} \mathrm{O}_{3}(8,6 \%$ a $32,6 \%$ em massa $)$, no AlN preparado com $1,5 \%$ em massa de $\mathrm{Y}_{2} \mathrm{O}_{3}$, aumentou tanto a dureza Vickers como a tenacidade à fratura determinada pelo método IF (Indentation Fracture). ${ }^{175} \mathrm{O}$ aumento do teor de $\mathrm{Al}_{2} \mathrm{O}_{3}$ levou à formação de grãos alongados, ${ }^{175} \mathrm{o}$ que indicou a formação de fases politipóides do sistema $\mathrm{AlN}-\mathrm{Al}_{2} \mathrm{O}_{3}$ (Fig. 2.10). Embora tenha ocorrido um aumento na tenacidade à fratura do AlN com adição simultânea de $1,5 \%$ de $\mathrm{Y}_{2} \mathrm{O}_{3}$ e até cerca de $20 \%$ de $\mathrm{Al}_{2} \mathrm{O}_{3},{ }^{175}$ a análise microestrutural não evidenciou a ocorrência de tenacificação por deflexão de trinca causada pela presença de grãos alongados, pois a propagação da trinca ocorreu de forma transgranular. Neste caso, a tenacificação foi atribuída a uma deflexão mais suave causada pela propagação da trinca por planos de clivagem preferenciais nos grãos tanto de AlN como das fases politipóides. ${ }^{175}$

Ichimaru \& Pezzotti ${ }^{228}$ observaram que o AlN sem aditivo, sinterizado por prensagem a quente nas temperaturas de $1800^{\circ} \mathrm{C}$ e $2000^{\circ} \mathrm{C}$, apresentou um comportamento de curva $\mathrm{R}$ pouco significativo. Alguns trabalhos ${ }^{68,79}$ têm sugerido que a presença de oxigênio dissolvido 
na rede cristalina do AlN causa o enfraquecimento do grão devido à formação de defeitos cristalinos (lacunas de alumínio e falhas de empilhamento). Porém, a resistência do grão de AlN pode aumentar consideravelmente com a utilização de aditivos de sinterização, ${ }^{79}$ que reagem com o oxigênio da superfície do pó de partida, formado segundas-fases de contorno de grão, o que evita a entrada desta impureza na rede cristalina do AlN durante a sinterização. A Tabela 7.1 apresenta dados de algumas propriedades do AlN sem aditivo de sinterização.

Tabela 7.1 - Propriedades do AlN sem aditivo de sinterização.

\begin{tabular}{l|c|c|c|c|c|c}
\hline \multirow{2}{*}{ Propriedades } & \multicolumn{7}{|c}{ Referências } \\
\cline { 2 - 7 } & {$[219]$} & {$[217]$} & {$[220]$} & {$[229]$} & {$[215]$} & {$[218]$} \\
\hline$\sigma_{\text {f-3pontos }}(\mathbf{M P a})$ & n.a. & n.a. & n.a. & n.a. & 370 & n.a. \\
\hline$\sigma_{\text {f-4pontos }}(\mathbf{M P a})$ & 295 & n.a. & 280 & 283 & n.a. & n.a. \\
\hline $\mathbf{H}_{\mathbf{V}}(\mathbf{G P a})$ & 11,4 & 13 & 10,5 & 11,5 & 11,5 & n.a. \\
\hline $\mathbf{K}_{\text {Ic-IF }}\left(\mathbf{M P a} \mathbf{m}^{\mathbf{1 / 2}}\right)$ & n.a. & 4 & n.a. & n.a. & n.a. & n.a. \\
\hline $\mathbf{K}_{\text {Ic-SEPB }}\left(\mathbf{M P a} \cdot \mathbf{m}^{\mathbf{1 / 2}}\right)$ & 2,8 & n.a. & 3,4 & n.a. & n.a. & n.a. \\
\hline $\mathbf{E ~ ( G P a ) ~}$ & 320 & 335 & 306 & 320 & 315 & 320 \\
\hline$\rho\left(\mathbf{g} / \mathbf{c m}^{\mathbf{3}}\right)$ & 3,25 & 3,24 & 3,25 & 3,25 & $3,26$. & 3,26 \\
\hline Tamanho de grão $(\mu \mathbf{m})$ & 3,0 & n.a. & 6,0 & n.a. & 20,0 & 4,2 \\
\hline
\end{tabular}

Nota: As amostras de AlN foram produzidas por sinterização via prensagem a quente ${ }^{215,217-219,229}$ ou sem aplicação de pressão ${ }^{220}$. Resistência à flexão em três pontos $\left(\sigma_{\mathrm{f}-3 \text { pontos }}\right)$ e quatro pontos $\left(\sigma_{\mathrm{f}-4 \text { pontos }}\right)$, dureza Vickers $\left(\mathrm{H}_{\mathrm{V}}\right)$, tenacidade à fratura $\left(\mathrm{K}_{\mathrm{Ic}}\right)$ determinada pelos métodos IF (Indentation Fracture) e SEPB (Single Edge Precracked Beam), módulos de Young (E) e densidade ( $\rho)$. A notação n.a. indica propriedade não avaliada.

Após a sinterização na temperatura de $1800^{\circ} \mathrm{C}$, o AlN com $5 \%$ em massa de $\mathrm{Y}_{2} \mathrm{O}_{3}$ (com grãos equiaxiais com tamanho médio de $10 \mu \mathrm{m}$ ) apresentou um comportamento de curva $\mathrm{R}$ mais significativo do que o material sem aditivo. ${ }^{228}$ A melhora no comportamento de curva $\mathrm{R}$ do $\mathrm{AlN}$ com $\mathrm{Y}_{2} \mathrm{O}_{3}$ foi atribuída à presença de segundas-fases, ${ }^{228}$ que gerou campos de tensão de tração na região de contorno de grão devido à diferença de coeficiente de expansão térmica entre o AlN e as segundas-fases. Isto aumentou significativamente a fração de fratura intergranular no $\mathrm{AlN} \operatorname{com} \mathrm{Y}_{2} \mathrm{O}_{3}(\sim 70 \%)$, o que levou os autores à conclusão de que a tenacificação ocorreu pela ativação dos mecanismos de engastamento (interlocking) mecânico e/ou escorregamento com atrito das superfícies de fratura na zona de processo da cauda da trinca. Huang \& Jih ${ }^{230}$ também indicaram que a deflexão de trinca, em compósitos de $\mathrm{SiC}-\mathrm{AlN}$, ocorreu devido à presença de tensões residuais geradas por diferenças tanto no módulo de elasticidade como no coeficiente de expansão térmica entre as duas fases, sendo que a formação de uma camada de solução sólida entre as partículas de $\mathrm{SiC}$ e $\mathrm{AlN}$ pode diminuir esta tensão residual. 
Witek et al. ${ }^{80}$ observaram que, em comparação com uma amostra sem aditivo, a adição de $2 \%$ em massa de $\mathrm{CaO}$ causou uma diminuição significativa na resistência à flexão do AlN ( 17\%), quando se comparou amostras com tamanho de grão próximo $(\sim 3 \mu \mathrm{m})$. Eles observaram que a adição de $\mathrm{CaO}$ mudou o modo de fratura do AlN de transgranular para intergranular e, então, indicaram que a segunda-fase de contorno de grão foi menos resistente do que o grão de $\mathrm{AlN}$, o que resultou na diminuição da tenacidade à fratura $(\sim 19 \%)$. Entretanto, o aumento do tamanho de grão de $3 \mu \mathrm{m}$ para $20 \mu \mathrm{m}$ aumentou em cerca de $6 \%$ a tenacidade à fratura do $\mathrm{AlN}$ com $\mathrm{CaO}$, em decorrência da ativação do mecanismo de tenacificação por deflexão de trinca, ${ }^{80}$ mas isto causou uma diminuição na resistência à flexão. Komeya et al. ${ }^{41}$ estudaram o efeito do teor de $\mathrm{CaCO}_{3}$ na resistência à flexão do AlN. Em relação ao AlN sem aditivo $\left(\sigma_{\mathrm{f}-3 \text { pontos }} \approx 264 \mathrm{MPa}\right)$, os autores observaram que a adição de $1 \%$ em massa de $\mathrm{CaCO}_{3}$ causou um aumento significativo na resistência à flexão $\left(\sigma_{\mathrm{f}-3 \text { pontos }} \approx\right.$ $358 \mathrm{MPa}$ ). Acima de $1 \%$ de $\mathrm{CaCO}_{3}$, o aumento do teor de aditivo causou uma diminuição significativa na resistência à flexão, sendo observado um valor de $298 \mathrm{MPa}$ para o AlN com $10 \%$ de $\mathrm{CaCO}_{3}$.

Abe et al. ${ }^{84}$ observaram que a presença de defeitos de processamento (poros grandes) diminuiu drasticamente a resistência à flexão do $\mathrm{AlN}$ com $\mathrm{Y}_{2} \mathrm{O}_{3}$. Narita ${ }^{87}$ observou que a presença de inclusões orgânicas $(\sim 50 \mu \mathrm{m})$ no corpo conformado, cuja fração volumétrica foi de $0,01 \%$, causou a formação de poros grandes no corpo sinterizado de AlN com $\mathrm{Y}_{2} \mathrm{O}_{3}$. Mesmo em pequena quantidade, estes poros grandes foram responsáveis pela fratura em pelo menos 50\% dos corpos-de-prova analisados. Por outro lado, observou-se em cerâmicas de alumina $\left(\mathrm{Al}_{2} \mathrm{O}_{3}\right)$ que a resistência à flexão não foi dependente do tamanho de defeito (poros grandes). ${ }^{135}$ Mesmo introduzindo poros artificiais de diferentes tamanhos, os corpos sinterizados de $\mathrm{Al}_{2} \mathrm{O}_{3}$ falharam predominantemente devido a defeitos superficiais não identificados (unidentified surface flaws).

A Tabela 7.2 apresenta dados de algumas propriedades do AIN com adição individual de $\mathrm{Y}_{2} \mathrm{O}_{3}$ e $\mathrm{CaO}$. Estes resultados mostram apenas uma tendência do comportamento mecânico do AlN com adição de $\mathrm{Y}_{2} \mathrm{O}_{3}$ ou $\mathrm{CaO}$, já que é difícil correlacionar estes resultados devido ao emprego de diferentes métodos tanto de determinação das propriedades mecânicas como de processamento cerâmico. Na literatura, observou-se que o aumento do teor de aditivo de sinterização, até certo valor ( $3 \%$ a $5 \%$ em massa), melhora a condutividade térmica do AIN com $\mathrm{Y}_{2} \mathrm{O}_{3}$ ou $\mathrm{CaO}$, mas poucos trabalhos ${ }^{41}$ estudaram o efeito do teor destes aditivos nas 
propriedades mecânicas destes materiais. Assim, o presente capítulo teve como objetivo estudar o efeito do teor de $\mathrm{Y}_{2} \mathrm{O}_{3}$ ou $\mathrm{CaO}$ nas propriedades mecânicas do AlN.

Tabela 7.2 - Propriedades do AlN com adição individual de $\mathrm{Y}_{2} \mathrm{O}_{3}$ ou $\mathrm{CaO}$.

\begin{tabular}{|c|c|c|c|c|c|c|}
\hline \multirow{2}{*}{ Propriedades } & \multicolumn{6}{|c|}{ Referências } \\
\hline & [87] & [79] & {$[221]$} & [226] & {$[84]$} & [80] \\
\hline Teor de aditivo (\% massa) & 5 & 5 & 4 & 3 & $\sim 2$ & 2 \\
\hline Aditivo de sinterização & $\mathrm{Y}_{2} \mathrm{O}_{3}$ & $\mathrm{Y}_{2} \mathrm{O}_{3}$ & $\mathrm{Y}_{2} \mathrm{O}_{3}$ & $\mathrm{Y}_{2} \mathrm{O}_{3}$ & $\mathrm{Y}_{2} \mathrm{O}_{3}$ & $\mathrm{CaO}$ \\
\hline$\sigma_{\mathrm{f}-3 p o n t o s}(\mathrm{MPa})$ & 386 & 353 & n.a. & 416 & n.a. & n.a. \\
\hline$\sigma_{\mathrm{f}-4 \text { pontos }}(\mathrm{MPa})$ & 277 & n.a. & n.a. & n.a. & 343 & n.a. \\
\hline$\sigma_{\text {f-biaxial }}(\mathbf{M P a})$ & n.a. & n.a. & n.a. & n.a. & n.a. & 313 \\
\hline $\mathrm{H}_{\mathrm{V}}(\mathrm{GPa})$ & 10,2 & n.a. & n.a. & 10,8 & n.a. & 10,8 \\
\hline $\mathrm{K}_{\text {Ic-IF }}\left(\mathrm{MPa.m^{1/2 }}\right)$ & 2,1 & n.a. & n.a. & n.a. & n.a. & 1,8 \\
\hline $\mathrm{K}_{\text {Ic-IS }}\left(\mathrm{MPa} \cdot \mathrm{m}^{1 / 2}\right)$ & n.a. & n.a. & n.a. & n.a. & n.a. & 3,1 \\
\hline $\mathrm{K}_{\text {Ic-SEPB }}\left(\mathrm{MPa} \mathrm{m}^{1 / 2}\right)$ & n.a. & n.a. & n.a. & n.a. & 4 & n.a. \\
\hline $\mathrm{K}_{\text {Ic-SCF }}\left(\mathrm{MPa} \mathrm{m}^{1 / 2}\right)$ & 3,0 & 2,9 & n.a. & n.a. & n.a. & n.a. \\
\hline E (GPa) & 323 & n.a. & 312 & n.a. & n.a. & n.a. \\
\hline$\rho\left(\mathrm{g} / \mathrm{cm}^{3}\right)$ & 3,33 & 3,25 & 2,29 & n.a. & 3,33 & n.a. \\
\hline Tamanho de grão $(\mu \mathrm{m})$ & 5 & 4 & 4 & n.a. & n.a. & 3 \\
\hline
\end{tabular}

Nota: as amostras de AlN com aditivo foram produzidas por sinterização via prensagem a quente ${ }^{221}$ ou sem aplicação de pressão ${ }^{79,80,84,87,226}$. Resistência à flexão $\left(\sigma_{\mathrm{f}}\right)$, dureza Vickers $\left(\mathrm{H}_{\mathrm{V}}\right)$, tenacidade à fratura $\left(\mathrm{K}_{\mathrm{Ic}}\right)$ determinada pelos métodos IF (Indentation Fracture), IS (Indentation Strength), SEPB (Single Edge Precracked Beam) e SCF (Surface Crack in Flexure), módulos de Young (E) e densidade ( $\rho)$. A notação n.a. indica propriedade não avaliada.

\subsection{Materiais e métodos}

As matérias-primas utilizadas nesta série experimental, bem como a metodologia de processamento cerâmico foram apresentadas nos itens 3.2 e 4.2, só que nesta série os corpos foram conformados na forma de cilindros (altura e diâmetro próximos de $30 \mathrm{~mm}$ e $15 \mathrm{~mm}$, respectivamente) e sinterizados a $1800^{\circ} \mathrm{C}$ por $1 \mathrm{~h}$. A quantidade de amostras (cilindros) variou de 3 a 4 para cada composição estudada (Tabela 6.3).

A densidade dos corpos sinterizados foi determinada conforme procedimento apresentado no item 3.2. Após a sinterização e determinação da densidade, o corpo-de-prova cilíndrico foi cortado em fatias com espessura ao redor de $2 \mathrm{~mm}$ em uma cortadeira de alta rotação (Buehler, Isomet-2000) com disco de corte adiamantado. Os discos cerâmicos foram usinados em retificadora plana (Mitutoyo, MSG-600) com rebolos adiamantados denominados grosso (Winter, D15c-K+888NY-B-C75), médio (Winter, D46-K+1313NY-B- 
C75) e fino (Winter, D151-K+1313NY-B-C75). As duas faces do disco cerâmico foram retificadas até o corpo atingir uma espessura próxima de $1 \mathrm{~mm}$, utilizando a seguinte rotina: 1) desbaste com rebolo grosso, com avanço de $20 \mu \mathrm{m}$ até remover pelo menos $60 \mu \mathrm{m}$ de material; 2) usinagem com rebolo médio, com avanço de $6 \mu \mathrm{m}$ até remover $60 \mu \mathrm{m}$ de material; e 3) acabamento final com rebolo fino, com avanço de $4 \mu \mathrm{m}$ até remover $60 \mu \mathrm{m}$ de material. A face do disco usinado, que foi submetida à tensão de tração durante o ensaio de resistência à flexão, foi polida em politriz semi-automática (Buehler, Ecomet 3) com suspensões aquosas de diamante $(45 \mu \mathrm{m}$ a $1 \mu \mathrm{m})$ e sílica coloidal para acabamento final.

O módulo de Young (E) foi determinado conforme procedimento apresentado no item 6.2. Já a resistência à fratura foi determinada pelo teste de flexão biaxial do tipo pistão sobre três esferas, usando o dispositivo de ensaio apresentado na Figura 7.1a. O porta-amostra apresenta três esferas metálicas com diâmetros de $1,58 \mathrm{~mm}$ eqüidistantes (separada de um ângulo de $120^{\circ}$ ) entre si (Fig. 7.1b), formado um círculo "imaginário" com diâmetro de $8 \mathrm{~mm}$. O diâmetro do pistão de aplicação de carga foi de 1,65 mm (Fig. 7.1b). O corpo na forma de disco foi colocado no porta-amostra (Fig. 7.1c) com a superfície polida voltada para baixo, isto é, em contato com as esferas metálicas.
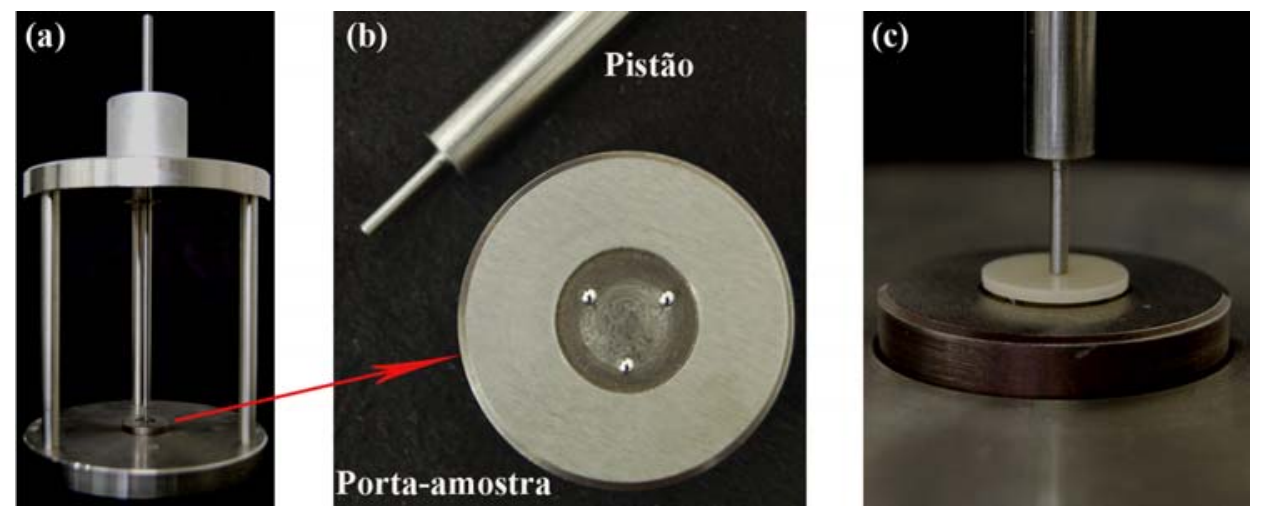

Figura 7.1 - Dispositivo de teste de resistência à flexão biaxial do tipo pistão sobre três esferas (a), imagem do pistão de aplicação de carga com diâmetro de $1,65 \mathrm{~mm}$ e do porta-amostra com esferas metálicas (diâmetro = $1,58 \mathrm{~mm}$ ) arranjadas de tal modo a formar ângulos de $120^{\circ}$ (b), e imagem de um disco cerâmico colocado no porta-amostra para realização do ensaio (c).

Dez corpos-de-prova de cada amostra de AlN foram ensaiados em um equipamento universal de ensaios mecânicos com capacidade de 2,5 toneladas (Sintech 5G, MTS Sistemas do Brasil Ltda.), utilizando célula de carga de $5.000 \mathrm{~N}$ e velocidade de avanço da travessa de $0,5 \mathrm{~mm} / \mathrm{min}$. A temperatura e umidade relativa do meio ambiente foram, em média, de $28^{\circ} \mathrm{C} \mathrm{e}$ $50 \%$, respectivamente. A resistência à flexão foi determinada conforme Norma ASTM F394- 
78:1991 "Standard test method for biaxial flexure strength (module of rupture) of ceramic substrates", usando as seguintes equações:

$$
\begin{aligned}
& \sigma_{\mathrm{f}, \mathrm{b}}=\frac{-0,2387 \mathrm{C}_{\text {rup }}(\Pi-\mathrm{Z})}{\mathrm{w}^{2}} \\
& \Pi=(1+v) \ln \left(\frac{\mathrm{B}}{\mathrm{C}}\right)^{2}+\left(\frac{1-v}{2}\right)\left(\frac{\mathrm{B}}{\mathrm{C}}\right)^{2} \\
& Z=(1+v)\left[1+\ln \left(\frac{\mathrm{A}}{\mathrm{C}}\right)^{2}\right]+(1-v)\left(\frac{\mathrm{A}}{\mathrm{C}}\right)^{2}
\end{aligned}
$$

onde, $\sigma_{\mathrm{f}, \mathrm{b}}$ é a resistência à flexão biaxial, $\mathrm{C}_{\text {rup }}$ é a carga de ruptura, $v$ é o coeficiente de Poisson, A é o raio do círculo formado pelas esferas do porta-amostra, B é o raio da área de carregamento ou do pistão, $C$ é o raio do corpo-de-prova e w é a espessura da amostra na região da origem da fratura.

Fragmentos do corpo ensaiado no teste de resistência à flexão foram usados para determinar tanto a dureza Vickers com a tenacidade à fratura pelo método de fratura por indentação (IF, Indentation Fracture). A superfície polida do fragmento cerâmico foi indentada em um microdurômetro (Mitutoyo, MVK-3) com penetrador Vickers e carga de 0,5 kgf. Três indentações foram realizadas em cada fragmento cerâmico, retirado de corpos-deprova distintos, sendo totalizado um número de 10 indentações para cada amostra de AlN. A dureza Vickers foi determinada com base na Norma ASTM C1327:1999 "Standard test method for Vickers indentation hardness of advanced ceramics", usando a seguinte equação:

$$
\mathrm{H}_{\mathrm{V}}=\left(\frac{1,8544 \mathrm{C}_{\mathrm{ap}}}{(2 \mathrm{u})^{2}}\right) \times 10^{-3}
$$

onde, $\mathrm{H}_{\mathrm{V}}$ é a dureza Vickers [GPa], $\mathrm{C}_{\mathrm{ap}}$ é a carga aplicada $[\mathrm{N}]$ e $(2 \mathrm{u})$ é o comprimento da diagonal da indentação [mm].

Logo em seguida à realização da indentação Vickers com carga de 0,5 kgf, as duas trincas radial-medianas (2c, Fig. 7.2), formadas nas direções x e y, foram medidas em um 
microscópio óptico acoplado ao microdurômetro e, então, determinou-se a tenacidade à fratura pelo método IF, usando a equação de Anstis et al. ${ }^{231}$ :

$$
\mathrm{K}_{\mathrm{Ic}}=\left[0,016\left(\frac{\mathrm{E}}{\mathrm{C}_{\mathrm{ap}} / 2 \mathrm{u}^{2}}\right)^{\frac{1}{2}}\left(\frac{\mathrm{C}_{\mathrm{ap}}}{\mathrm{c}_{0}^{3 / 2}}\right)\right]
$$

onde, $\mathrm{K}_{\mathrm{Ic}}$ é a tenacidade à fratura, $\mathrm{C}_{\mathrm{ap}}$ é carga de indentação, $2 \mathrm{u}$ é o comprimento da diagonal de indentação Vickers, E é o módulo de Young, e $\mathrm{c}_{0}$ é a metade do comprimento da trinca radial-mediana logo após a indentação.
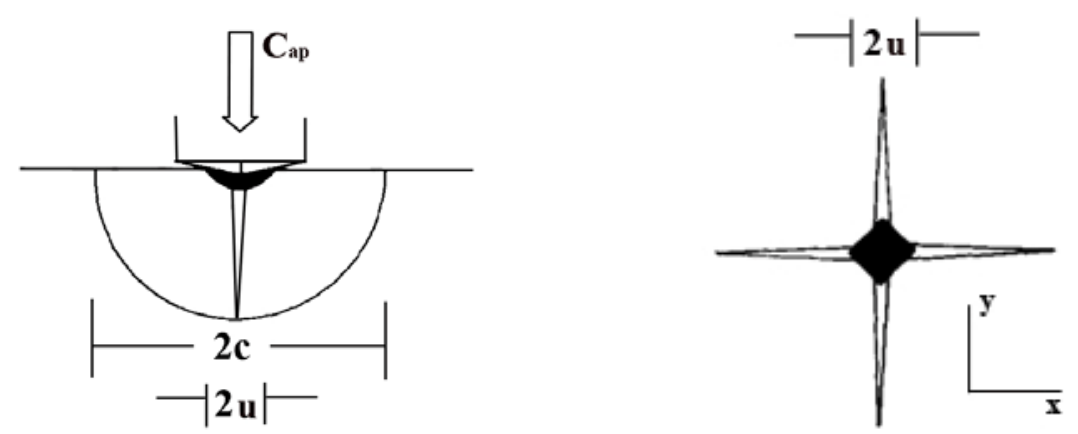

Figura 7.2 - Esquema do sistema de fratura produzido por indentação Vickers, onde $C_{a p}$ é a carga aplicada e 2c é o comprimento da trinca radial-mediana (a), e vista de topo da região indentada, onde $2 u$ é o comprimento da diagonal da indentação Vickers (região de deformação plástica) (b). ${ }^{231}$

A tenacidade à fratura também foi determinada pelo método IS (Indentation Strength) proposto por Chantikul et al. ${ }^{232}$. Amostras na forma de disco, similares às usadas no ensaio de resistência à flexão biaxial, foram indentadas com penetrador Vickers, objetivando formar trincas radial-medianas (2c, Fig. 7.2) no centro do disco cerâmico com superfície polida. Neste método, a carga aplicada na indentação deve ser o suficiente para introduzir um defeito (trinca) maior do que os defeitos existentes no material. ${ }^{232}$ Porém, a trinca radial-mediana deve apresentar um tamanho menor do que 1/10 da espessura do corpo-de-prova, ${ }^{232}$ assim como a razão entre o comprimento da trinca (2c) e o comprimento da diagonal da indentação $(2 \mathrm{u})$ deve ser maior ou igual a 2. No presente trabalho, a indentação Vickers foi realizada com carga de $0,5 \mathrm{kgf}$. Uma gota de óleo de silicone foi colocada sobre a indentação para evitar a possível ocorrência de crescimento subcrítico de trinca devido à entrada de umidade na ponta da trinca radial-mediana. Cinco corpos-de-prova de cada amostra de AlN foram ensaiados em um equipamento universal de ensaio mecânico com capacidade de 2,5 toneladas (Sintech 5G, 
MTS Sistemas do Brasil Ltda.), utilizando célula de carga de 5.000 N e velocidade de avanço da travessa de $0,5 \mathrm{~mm} / \mathrm{min}$. A temperatura e umidade relativa do meio ambiente foram, em média, de $28^{\circ} \mathrm{C}$ e $50 \%$, respectivamente. A tenacidade à fratura $\left(\mathrm{K}_{\mathrm{Ic}}\right)$ foi determina com a equação proposta por Chantikul et al. ${ }^{232}$ :

$$
\mathrm{K}_{\mathrm{IC}}=\eta\left(\frac{\mathrm{E}}{\mathrm{C}_{\mathrm{ap}} /(2 \mathrm{u})^{2}}\right)^{\frac{1}{8}}\left(\sigma_{\mathrm{f}} \mathrm{C}_{\mathrm{ap}}^{1 / 3}\right)^{\frac{3}{4}}
$$

onde, $\eta$ é uma constante geométrica, $E$ é o módulo de Young, $\mathrm{C}_{\mathrm{ap}}$ é a carga de indentação, $2 \mathrm{u}$ é o comprimento da diagonal de indentação Vickers e $\sigma_{\mathrm{f}}$ é a tensão de fratura obtida no ensaio de resistência à flexão biaxial.

O tamanho de grão das amostras de AlN foi estimado por meio da análise da superfície de fratura dos corpos submetidos ao ensaio de resistência à flexão biaxial, pois é difícil revelar os contornos de grãos por tratamento térmico ou químico. ${ }^{138,192,198,221}$ As imagens de microscópio eletrônico de varredura (MEV) das superfícies de fratura foram tratadas em um programa de edição de imagens para delimitar os contornos de grãos, como apresentado na Figura 7.3. Os grãos não completos, localizados na borda das imagens digitalizadas, e os poros foram descartados na análise do tamanho de grão. Estas imagens foram analisadas em um programa de análise de imagens (Image J), onde se realizou a determinação do tamanho de grão.

As superfícies de fratura das amostras de AlN apresentaram uma mistura de modos de fratura: transgranular e intergranular. Deste modo, determinou-se, a partir das imagens de MEV das superfícies de fratura, a fração de grãos com fratura transgranular $\left(f_{\mathrm{T}}\right)$ por meio da seguinte equação: ${ }^{79}$

$$
f_{\mathrm{T}}=\frac{\mathrm{N}_{\mathrm{GFT}}}{\mathrm{N}_{\mathrm{G}}}
$$

onde, $f_{\mathrm{T}}$ é a fração de grãos com fratura transgranular, $\mathrm{N}_{\mathrm{GFT}}$ é o numero de grãos com fratura transgranular observados na imagem da superfície de fratura e $\mathrm{N}_{\mathrm{G}}$ é o numero total de grãos observados na imagem da superfície de fratura. Duas imagens das superfícies de fratura foram 
analisadas para cada amostra de AlN, o que resultou em pelo menos 300 grãos analisados por amostra.
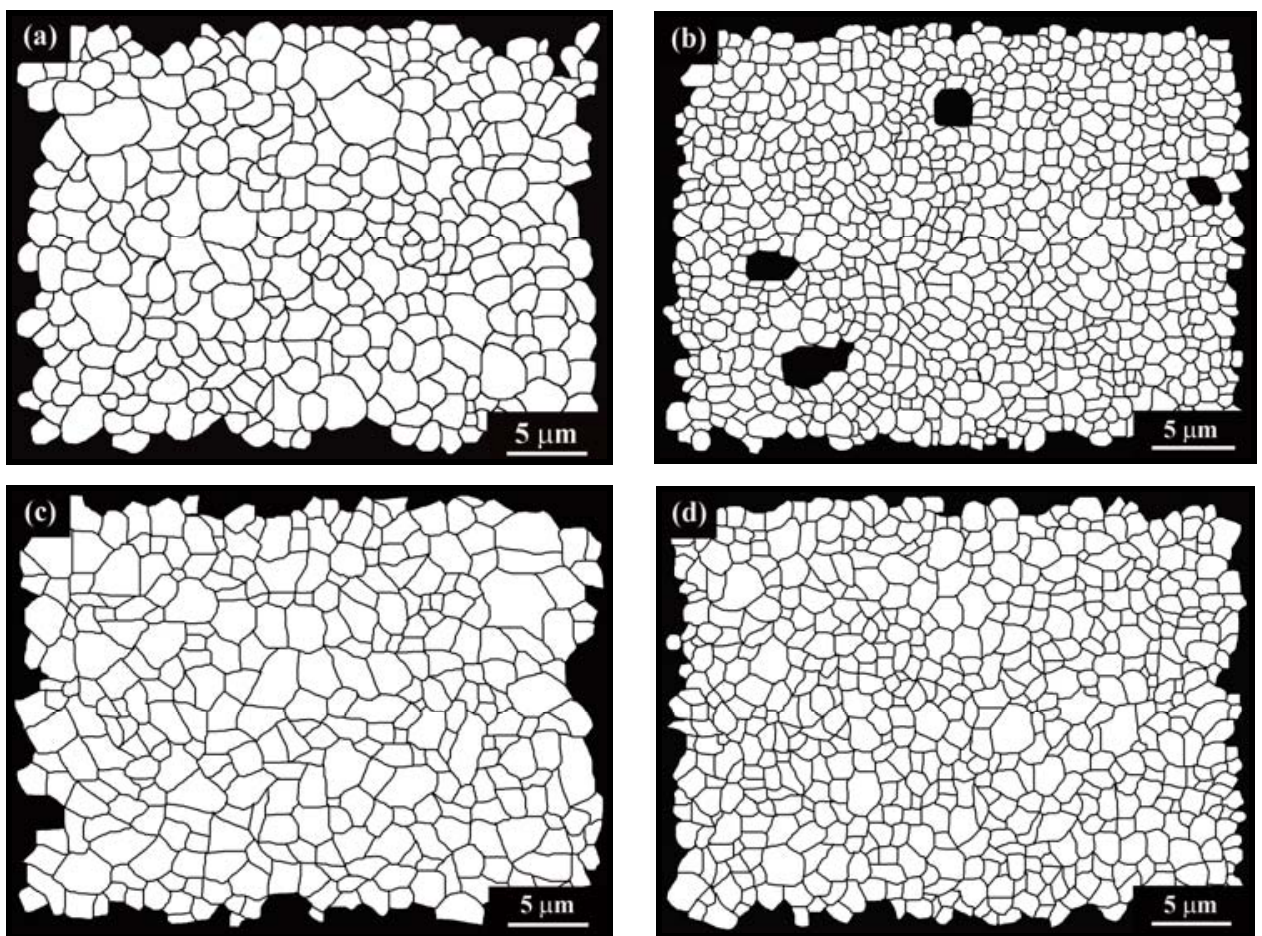

Figura 7.3 - Imagens replicadas da superfície de fraturas das amostras de AlN sinterizadas a $1800^{\circ} \mathrm{C}$, onde se delimitou os contornos de grão para determinação do tamanho de grão por meio de análise de imagens: (a) AlN$0,5 \% \mathrm{CaO}$, (b) AlN-4\% CaO, (c) AlN-0,5\% $\mathrm{Y}_{2} \mathrm{O}_{3}$ e (d) $\mathrm{AlN}-4 \% \mathrm{Y}_{2} \mathrm{O}_{3}$.

A análise fractográfica é freqüentemente usada para identificar o defeito que originou a fratura. Em materiais com fratura frágil, a área percorrida pela trinca é caracterizada por três regiões distintas (Fig. 7.4), que são concêntricas e apresentam formato semi-elíptico. A região com aspecto relativamente plano, isto é, sem muita mudança no plano de propagação da trinca, e que está nas adjacências da origem da fratura é denominada mirror (Fig. 7.4). Esta região corresponde à aceleração da frente da trinca, que passa da condição de repouso para velocidades da ordem da velocidade do som. Em seguida, pode ocorrer à formação de uma estreita região denominada mist (Fig. 7.4), que representa uma região de transição entre as regiões mirror e hackle. Esta última (hackle) tem aspecto mais rugoso (Fig. 7.4), que é um indicativo de maior ocorrência de mudança no plano de propagação da fratura. A região hackle, quando visualizada com baixa ampliação, pode auxiliar na identificação tanto da região mirror como do defeito que ocasionou a fratura. $\mathrm{O}$ tamanho crítico do defeito foi determinado pela medida dos parâmetros a e c do defeito semi-elíptico apresentado no esquema da Figura 7.4. Neste trabalho, a análise fractográfica foi realizada na superfície de 
fratura do corpo submetido aos ensaios de resistência à flexão biaxial, usando microscópio óptico (MO, Leica, DMRXE) e microscópio eletrônico de varredura (MEV, Jeol, JSM 6300).

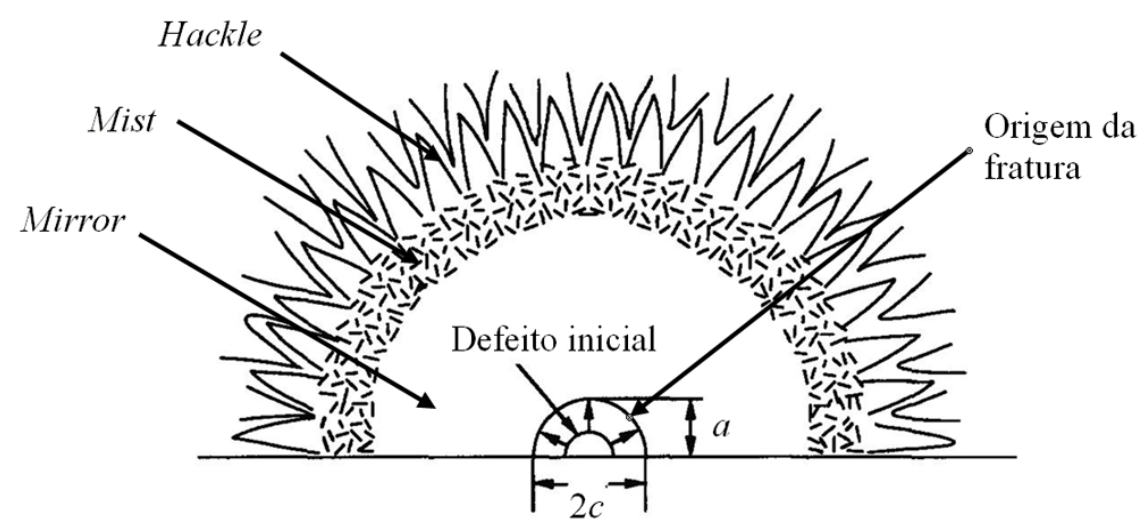

Figura 7.4 - Ilustração esquemática da superfície de fratura mostrando as três regiões características da propagação da trinca (mirror, mist e hackle), bem como a origem da fratura, profundidade do defeito (a) e comprimento do defeito (2c). ${ }^{233}$

\subsection{Resultados experimentais}

\subsubsection{Módulo de Young}

Os resultados de módulo de Young e de porosidade do AlN em função do teor de aditivo de sinterização são apresentados na Figura 7.5. As amostras de AlN com 0,5\% e 1\% de $\mathrm{CaO}$ apresentaram valores próximos de módulo de Young (Fig 7.5a). Porém, o aumento do teor de $\mathrm{CaO}$, acima de $1 \%$, causou uma diminuição significativa no módulo de Young do AlN (Fig. 7.5a). Já a porosidade do AlN aumentou significativamente com o aumento do teor de $\mathrm{CaO}$ (Fig. 7.5a). No caso das amostras de $\mathrm{AlN}$ com $0,5 \%$ a 4\% de $\mathrm{Y}_{2} \mathrm{O}_{3}$, o módulo de Young apresentou uma pequena diminuição $(\sim 3 \%)$ com o aumento do teor de aditivo de sinterização, mas a porosidade destas amostras permaneceu praticamente constante $(\sim 1,6 \%)$.

As amostras de AlN com adição de $0,5 \%$ e $1 \%$ de $\mathrm{CaO}$ e com adição de $0,5 \%$ a $4 \%$ de $\mathrm{Y}_{2} \mathrm{O}_{3}$, que apresentaram valores próximos de porosidade $(<2 \%$, Figs. 7.5a e $7.5 \mathrm{~b})$, tiveram valores relativamente próximos de módulo de Young. Estes resultados indicaram que a presença de até cerca de $2 \%$ de porosidade no AlN causou pouca influência no módulo de 
Young. Porém, esta propriedade elástica diminuiu significativamente com o aumento de porosidade decorrente do aumento do teor de $\mathrm{CaO}$ (Fig. 7.5a).
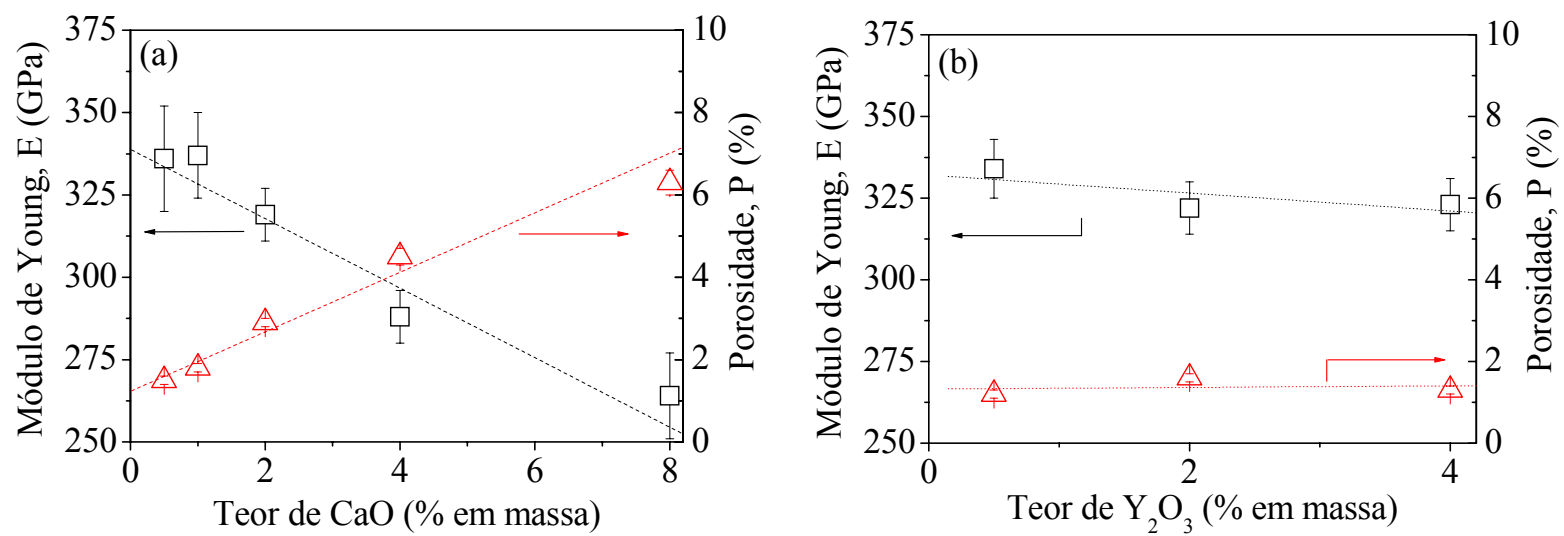

Figura 7.5 - Módulo de Young (E) e porosidade (P) em função do teor de aditivo de sinterização: (a) $\mathrm{CaO}$ e (b) $\mathrm{Y}_{2} \mathrm{O}_{3}$. As amostras de AlN foram sinterizadas a $1800^{\circ} \mathrm{C}$ por $1 \mathrm{~h}$.

\subsubsection{Resistência à flexão}

Os resultados de resistência à flexão biaxial $\left(\sigma_{\mathrm{f}, \mathrm{b}}\right)$ do AlN em função do teor de aditivo de sinterização são apresentados na Figura 7.6. A resistência à flexão do AlN diminuiu cerca de $30 \%$ com o aumento de $0,5 \%$ para $1 \%$ de $\mathrm{CaO}$ (Fig. 7.6) e, então, permaneceu praticamente constante com o aumento do teor de $\mathrm{CaO}(1 \%$ a $8 \%)$. Komeya et al. ${ }^{41}$ observaram que a resistência à flexão do AlN diminuiu 17\% com o aumento de 1\% para 10\% em massa de $\mathrm{CaCO}_{3}(\sim 0,5 \%$ para $\sim 5 \%$ de $\mathrm{CaO})$. Estes resultados mostraram que a resistência à flexão do $\mathrm{AlN}$ é influenciada pelo teor de $\mathrm{CaO}$ adicionado. De modo geral, os valores de literatura ${ }^{41,80}$ para a resistência à flexão do $\mathrm{AlN}$ com $\mathrm{CaO}$ foram próximos dos valores determinados para as amostras de $\mathrm{AlN}$ com $1 \%$ a $8 \%$ de $\mathrm{CaO}$ (Fig. 7.6). Já o comportamento de resistência à flexão das amostras de $\mathrm{AlN}$ com $\mathrm{Y}_{2} \mathrm{O}_{3}$ foi diferente daquele observado para as amostras de $\mathrm{AlN}$ com $\mathrm{CaO}$ (Fig. 7.6). O aumento de $0,5 \%$ para $2 \%$ de $\mathrm{Y}_{2} \mathrm{O}_{3}$ causou um aumento de 10\% na resistência à flexão do AlN (Fig. 7.6) e, então, ocorreu uma diminuição abrupta nesta propriedade $(\sim 23 \%)$ com o aumento de $2 \%$ para $4 \%$ de $\mathrm{Y}_{2} \mathrm{O}_{3}$. $\mathrm{O}$ valor de $\sigma_{\mathrm{f}, \mathrm{b}}$ da amostra de $\mathrm{AlN}$ com $4 \%$ de $\mathrm{Y}_{2} \mathrm{O}_{3}$ foi próximo dos valores de $\sigma_{\mathrm{f}, \mathrm{b}}$ determinados para as amostras de $\mathrm{AlN}$ com $1 \%$ a $8 \%$ de $\mathrm{CaO}$ (Fig. 7.6). Os resultados da Tabela 7.2 mostram que a resistência à flexão em três pontos $\left(\sigma_{\mathrm{f}, 3 \text { pontos }}\right)$ do AlN diminuiu com 
o aumento de $3 \%$ para $5 \%$ de $\mathrm{Y}_{2} \mathrm{O}_{3}$, o que sugere a diminuição da resistência mecânica do AlN em função do teor de aditivo de sinterização.

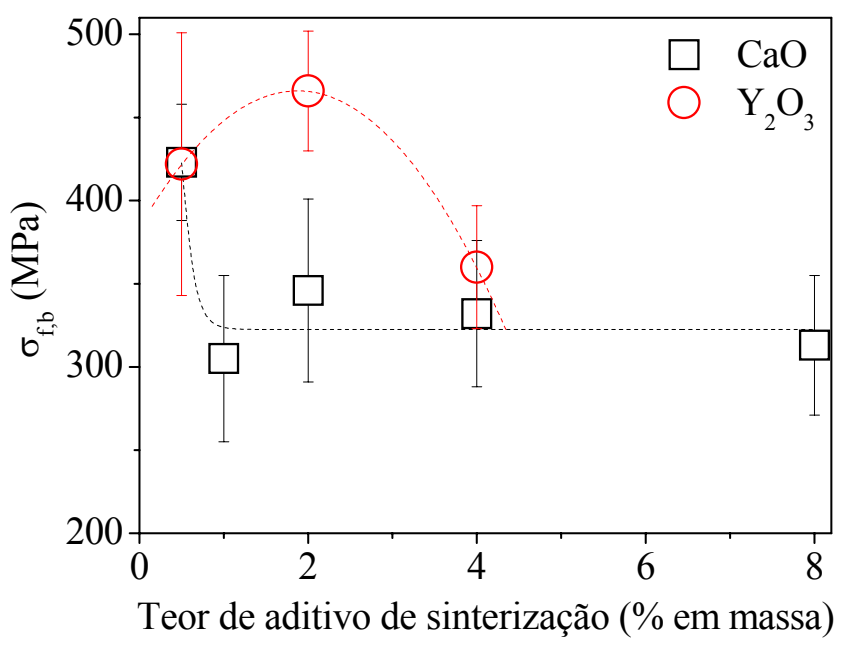

Figura 7.6 - Resistência à flexão biaxial $\left(\sigma_{\mathrm{f}, \mathrm{b}}\right)$ do AlN em função do teor de aditivo de sinterização. As amostras de AlN foram sinterizadas a $1800^{\circ} \mathrm{C}$ por $1 \mathrm{~h}$.

A Figura 7.7 apresenta imagens de MEV da superfície de fratura das amostras de AlN sinterizadas a $1800^{\circ} \mathrm{C}$ e submetidas ao ensaio de resistência à flexão biaxial. As amostras de AlN com adição tanto de $\mathrm{CaO}$ como de $\mathrm{Y}_{2} \mathrm{O}_{3}$ apresentaram microestruturas densas com grãos de AlN facetados e isométricos (Fig. 7.7). Porém, o aumento do teor de $\mathrm{CaO}$ levou à formação de poros residuais relativamente grandes na cerâmica de AlN (Figs. 7.7a a 7.7c). A Figura 7.8a apresenta os resultados de tamanho médio de grão (TG) em função do teor de aditivo de sinterização. O tamanho médio de grão do AlN diminuiu como o aumento de $0,5 \%$ para $2 \%$ de $\mathrm{CaO}$, mas acima deste teor, permaneceu praticamente constante. No caso do AlN com $\mathrm{Y}_{2} \mathrm{O}_{3}$, o tamanho médio de grão diminuiu com o aumento do teor de aditivo de sinterização (Fig. 7.8a). As amostras de $\mathrm{AlN}$ com $0,5 \%$ e $4 \%$ de $\mathrm{Y}_{2} \mathrm{O}_{3}$ apresentaram tamanhos de grãos próximos daqueles observados para as amostras de $\mathrm{AlN}$ com 0,5\% e 4\% de $\mathrm{CaO}$ (Fig. 7.8a), o que indicou uma pequena variação na cinética de crescimento de grão do AlN em função do tipo de aditivo de sinterização $\left(\mathrm{CaO}\right.$ ou $\left.\mathrm{Y}_{2} \mathrm{O}_{3}\right)$. Entretanto, o tamanho de grão da amostra de $\mathrm{AlN}$ com $2 \%$ de $\mathrm{Y}_{2} \mathrm{O}_{3}$ foi maior do que o da amostra de $\mathrm{AlN}$ com $2 \%$ de $\mathrm{CaO}$ (Fig. 7.8a), o que indicou uma menor eficiência das segundas-fases em restringir o crescimento de grão do AlN com o aumento do teor de $\mathrm{Y}_{2} \mathrm{O}_{3}$, pelo menos para adições de até cerca de $2 \%$ em massa. 

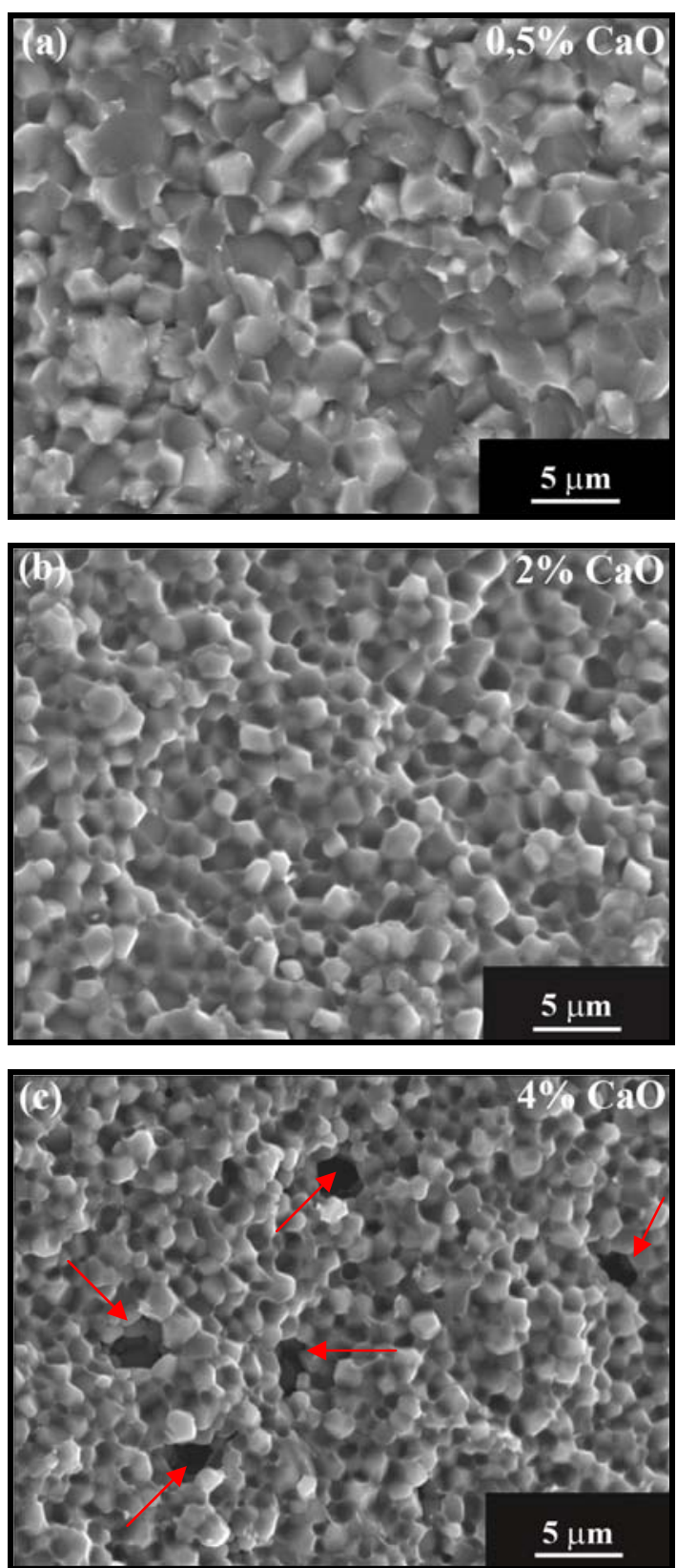
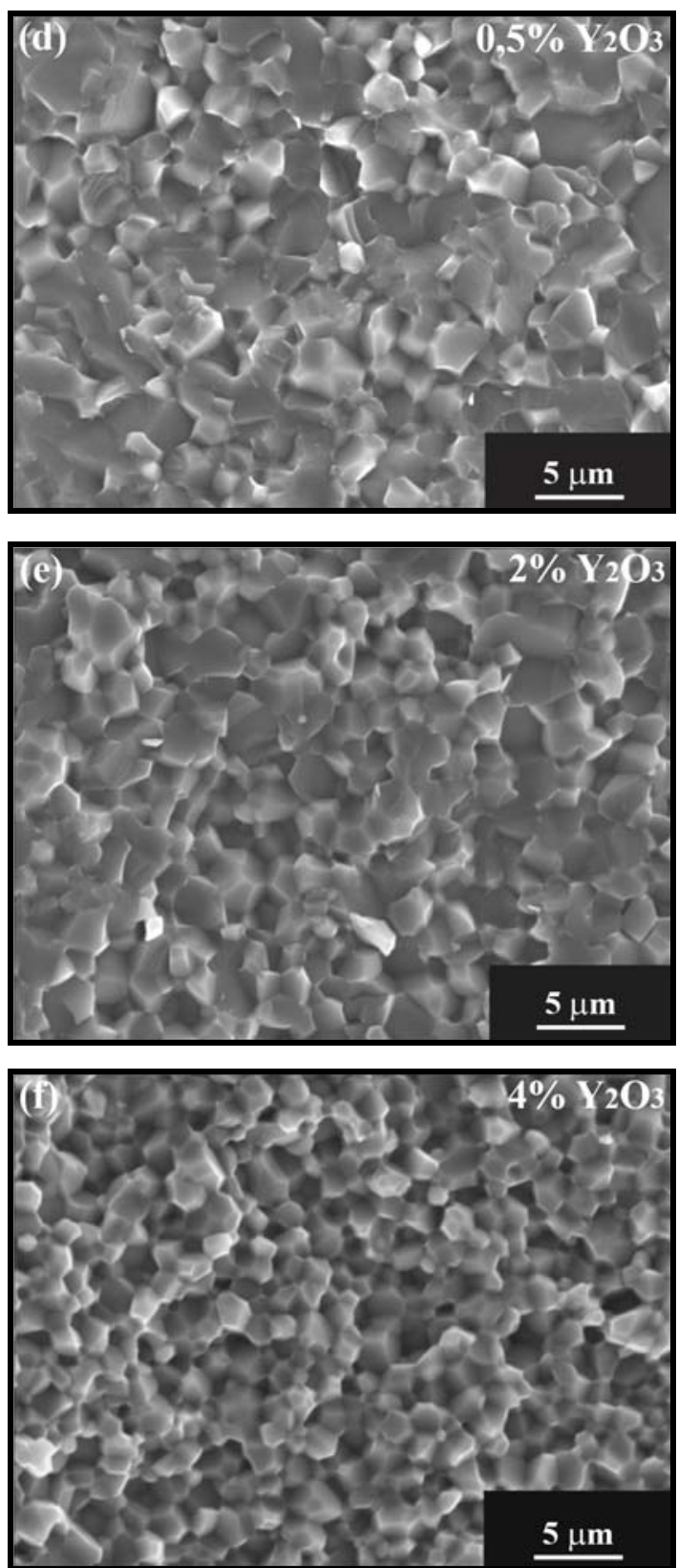

Figura 7.7 - Imagens de MEV da superfície de fratura das amostras de $\mathrm{AlN}$ sinterizadas a $1800^{\circ} \mathrm{C}$ e submetidas ao ensaio de resistência à flexão biaxial. As setas indicam poros grandes residuais. 


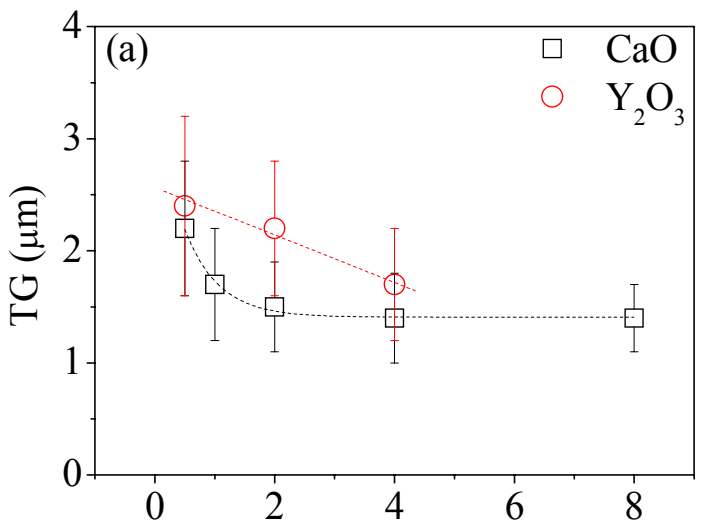

Teor de aditivo de sinterização (\% em massa)

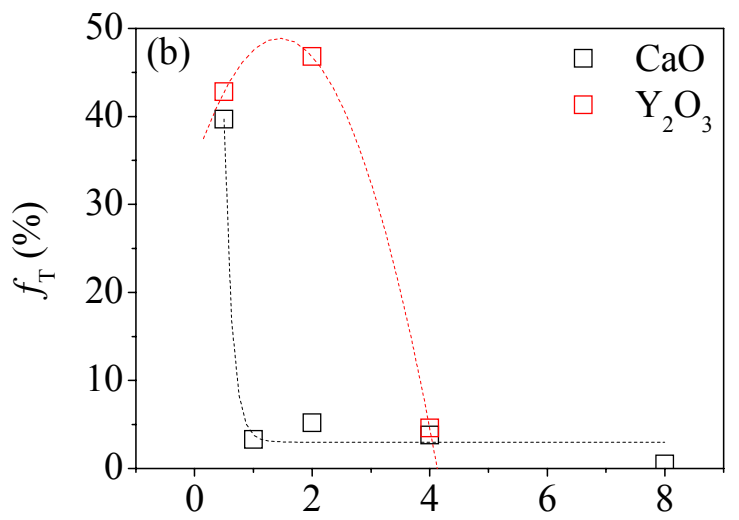

Teor de aditivo de sinterização (\% em massa)

Figura 7.8 - Tamanho médio de grão (a) e fração de grãos com fratura transgranular (b) em função do teor de aditivo de sinterização. As amostras de AlN foram sinterizadas a $1800^{\circ} \mathrm{C}$ por $1 \mathrm{~h}$.

A Figura $7.8 \mathrm{~b}$ apresenta os resultados de fração de grãos com fratura transgranular $\left(f_{\mathrm{T}}\right)$ em função do teor de aditivo de sinterização. No caso das amostras com $\mathrm{CaO}$, a fração de grãos com fratura transgranular $\left(f_{\mathrm{T}}\right)$ diminuiu abruptamente com o aumento de $0,5 \%$ para $1 \%$ de $\mathrm{CaO}$ (Fig. 7.8b) e, então, permaneceu praticamente constante com o aumento do teor de $\mathrm{CaO}(1 \%$ a $8 \%)$. Esta tendência de comportamento foi próxima da observada para a resistência à flexão (Fig. 7.6) e o tamanho de grão (Fig. 7.8a) do $\mathrm{AlN}$ com CaO. Isto mostrou que pode existir uma correlação entre resistência à flexão, tamanho de grão e fração de grãos com fratura transgranular para o AlN com CaO. No caso das amostras de AlN com $\mathrm{Y}_{2} \mathrm{O}_{3}$, a fração de grãos com fratura transgranular aumentou com o aumento de $0,5 \%$ para $2 \%$ de $\mathrm{Y}_{2} \mathrm{O}_{3}$ (Fig. 7.8b) e, então, diminuiu abruptamente com o aumento de $2 \%$ para $4 \%$ de $\mathrm{Y}_{2} \mathrm{O}_{3}$. Este comportamento foi similar ao observado para a resistência à flexão das amostras de AlN com $\mathrm{Y}_{2} \mathrm{O}_{3}$ (Fig. 7.6). Estes resultados mostraram que pode existir uma correlação entre $\sigma_{\mathrm{f}, \mathrm{b}}$ e $f_{\mathrm{T}}$, onde se observou que o aumento de $f_{\mathrm{T}}$ (Fig. 7.8b) resultou no aumento de $\sigma_{\mathrm{f}, \mathrm{b}}$ do AlN com $\mathrm{Y}_{2} \mathrm{O}_{3}$ (Fig. 7.6). Além disso, a diminuição do tamanho de grão (Fig. 7.8a), principalmente entre $0,5 \%$ e $2 \%$ de $\mathrm{Y}_{2} \mathrm{O}_{3}$, também pode ter contribuído para o aumento da resistência à flexão do AlN, como tem sido observado para outras cerâmicas estruturais.

\subsubsection{Dureza Vickers}

Os resultados de dureza Vickers ( $\left.\mathrm{H}_{\mathrm{V}-0,5 \mathrm{kgf}}\right)$ em função do teor de aditivo de sinterização são apresentados na Figura 7.9a. A dureza Vickers do AlN permaneceu praticamente 
constante entre $0,5 \%$ e $2 \%$ de $\mathrm{CaO}(\sim 11,4 \mathrm{GPa}$, Fig. $7.9 \mathrm{a})$ e, então, diminuiu em função do aumento do teor de $\mathrm{CaO}(\sim 9 \mathrm{GPa}$ para $8 \%$ de $\mathrm{CaO})$. Já o aumento de $0,5 \%$ para $4 \%$ de $\mathrm{Y}_{2} \mathrm{O}_{3}$ não mudou praticamente a dureza Vickers do $\mathrm{AlN}(\sim 11,4 \mathrm{GPa}$, Fig. 7.9a), cujos valores foram iguais ou próximos dos valores determinados para as amostras de AlN com $0,5 \%$ a $2 \%$ de $\mathrm{CaO}$. Os resultados de literatura para a dureza Vickers (Tabelas 7.1 e 7.2) mostraram que os valores medidos neste trabalho com adição de $0,5 \%$ a $4 \%$ de $\mathrm{CaO}$ ou de $\mathrm{Y}_{2} \mathrm{O}_{3}$ (Fig. 7.9a) foram próximos dos valores reportados para o AlN sem aditivo e levemente maiores do que os valores reportados para o AlN com adição tanto de $\mathrm{CaO}$ como de $\mathrm{Y}_{2} \mathrm{O}_{3}$.
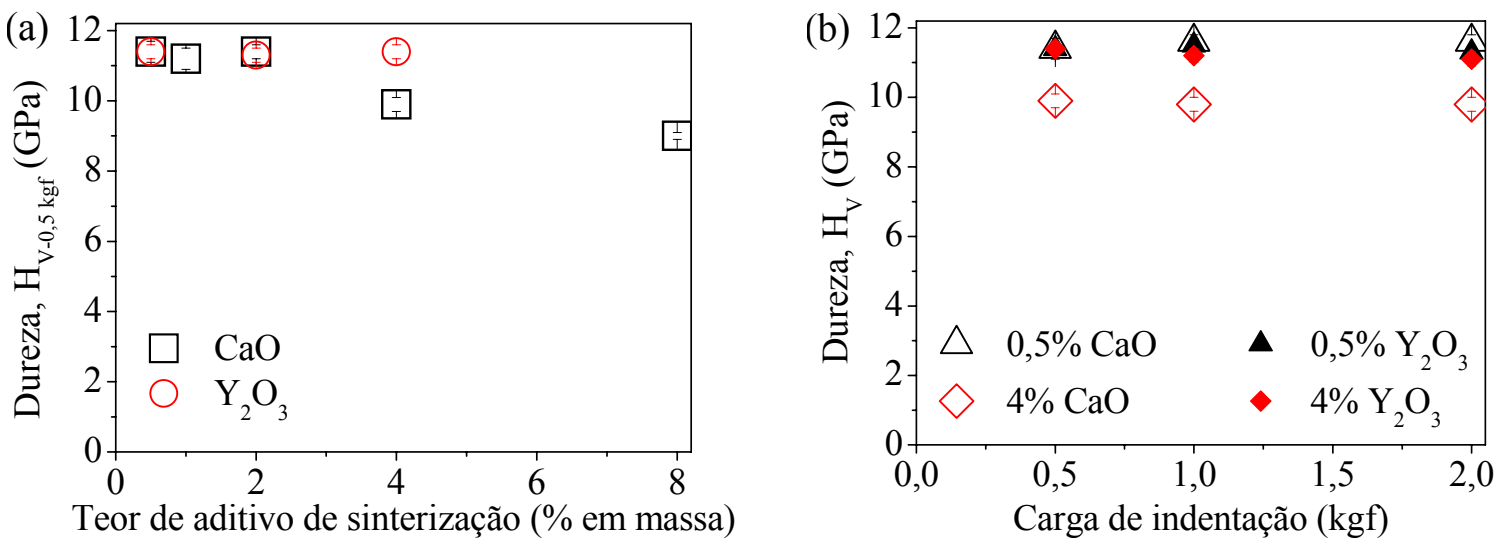

Figura 7.9 - Dureza Vickers ( $\left.\mathrm{H}_{\mathrm{V}-0,5 \mathrm{kgf}}\right)$ em função do teor de aditivo de sinterização (a) e da carga de indentação (b). As amostras de AlN foram sinterizadas a $1800^{\circ} \mathrm{C}$ por $1 \mathrm{~h}$.

A Figura 7.9b apresenta os resultados de dureza Vickers do AlN em função da carga de indentação, onde se observa que a dureza não mudou com a variação da carga entre $0,5 \mathrm{kgf}$ e 2,0 kgf. Os menores valores de dureza Vickers da amostra de AlN com 4\% de CaO está relacionado com a porosidade, que aumentou significativamente com o aumento do teor de $\mathrm{CaO}$ (Figs. 7.5a e 7.7a a 7.7c).

\subsubsection{Tenacidade à fratura}

Os resultados de tenacidade à fratura determinada pelo método Indentation Fracture $\left(\mathrm{K}_{\mathrm{Ic}-\mathrm{IF}}\right)$ do AlN em função do teor de aditivo de sinterização são apresentados na Figura 7.10. As amostras de $\mathrm{AlN}$ com $0,5 \%$ e $1 \%$ de $\mathrm{CaO}$ apresentaram valores iguais de $\mathrm{K}_{\text {Ic-IF }}(1,8$ MPa.m ${ }^{1 / 2}$, Fig. 7.10). Porém, o valor de $K_{\text {Ic-IF }}$ do AlN aumentou com o aumento do teor de 
$\mathrm{CaO}$ (Fig, 7.10). As amostras de $\mathrm{AlN}$ com $0,5 \%$ e $1 \%$ de $\mathrm{CaO}$ apresentaram valores de $\mathrm{K}_{\text {Ic-IF }}$ iguais ao valor determinado por Witek et al. ${ }^{80}$ para o AlN com $2 \%$ em massa de CaO. Já as amostras de $\mathrm{AlN}$ com $0,5 \%$ a $4 \%$ de $\mathrm{Y}_{2} \mathrm{O}_{3}$ apresentaram valores de $\mathrm{K}_{\text {Ic-IF }}$ próximos entre si (Fig. 7.10), o que mostrou pouca influência da adição de $\mathrm{Y}_{2} \mathrm{O}_{3}$ na tenacidade à fratura do AlN, pelo menos nesta faixa de teor de aditivo de sinterização. Os valores de $\mathrm{K}_{\mathrm{Ic}-\mathrm{IF}}$ das amostras de $\mathrm{AlN}$ com $\mathrm{Y}_{2} \mathrm{O}_{3}\left(\sim 1,4 \mathrm{MPa} . \mathrm{m}^{1 / 2}\right.$, Fig. 7.10) foram menores do que o valores determinados para as amostras de $\mathrm{AlN}$ com $\mathrm{CaO}$. Além disso, os valores de $\mathrm{K}_{\mathrm{Ic}-\mathrm{IF}}$ das amostras de $\mathrm{AlN}$ com 0,5\% a $4 \%$ de $\mathrm{Y}_{2} \mathrm{O}_{3}$ foram menores do que o valor reportado para o AlN com 5\% em massa de $\mathrm{Y}_{2} \mathrm{O}_{3}{ }^{87}\left(2,1 \mathrm{MPa} \cdot \mathrm{m}^{1 / 2}\right.$, Tabela 7.2$)$.

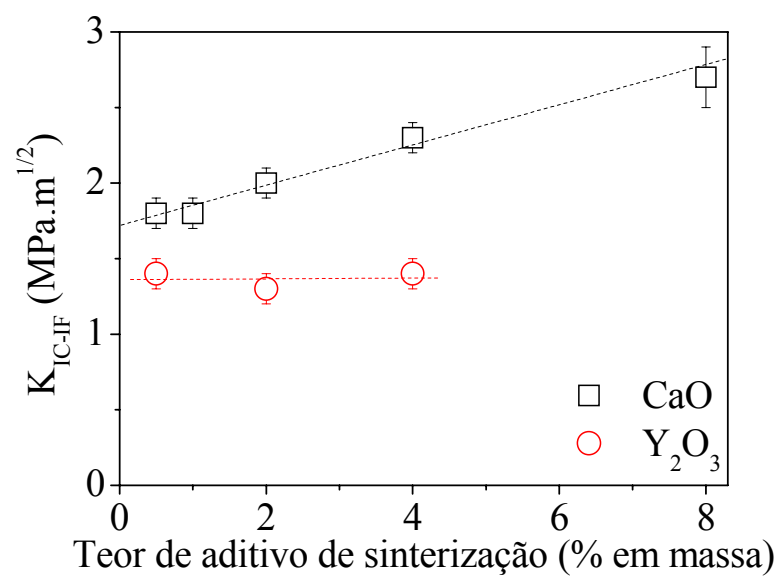

Figura 7.10 - Tenacidade à fratura determinada pelo método IF - Indentation Fracture $\left(\mathrm{K}_{\mathrm{Ic}-\mathrm{IF}}\right)$ do AlN em função do teor de aditivo de sinterização. As amostras de $\mathrm{AlN}$ foram sinterizadas a $1800^{\circ} \mathrm{C}$ por $1 \mathrm{~h}$.

A Figura 7.11 apresenta imagens de MEV do perfil de trincas geradas pela indentação Vickers na superfície polida das amostras de AlN com CaO. Estas trincas foram caracterizadas por apresentar superfícies de fratura irregulares (tortuosas), onde se observaram alguns indícios da ocorrência de mecanismos de tenacificação. As amostras de AlN com 0,5\% e $1 \%$ de $\mathrm{CaO}$ apresentaram evidências da ocorrência do mecanismo de engastamento (interlocking) mecânico e escorregamento (sliding) com atrito das superfícies de fratura na zona de processo da cauda da trinca (indicação 1, Fig. 7.11a), similar ao observado para as cerâmicas de alumina (Figs. 2.8a e 2.8b). As demais amostras de AlN com CaO apresentaram um mecanismo adicional de tenacificação (indicação 2, Figs. 7.11b e 7.11c), que corresponde ao mecanismo de ponteamento de trinca (crack bridging), o qual é caracterizado pela ocorrência de algumas pequenas interrupções no caminho de propagação da trinca. 

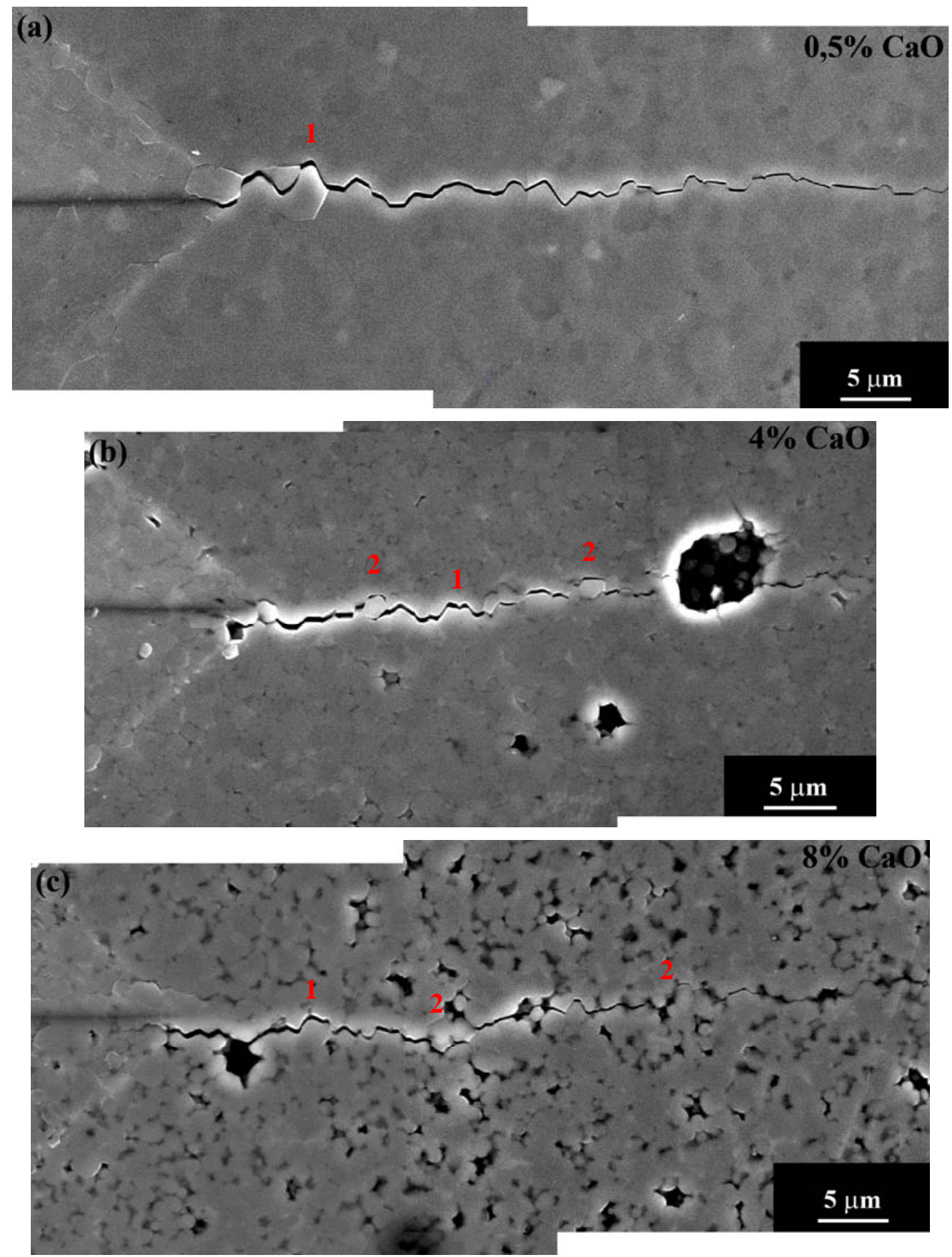

Figura 7.11 - Imagens de MEV do perfil da trinca gerada por indentação Vickers (carga de 0,5 kgf) na superfície polida de amostras de $\mathrm{AlN}$ com CaO sinterizadas a $1800^{\circ} \mathrm{C}$ por $1 \mathrm{~h}$. As indicações referem-se aos mecanismos de tenacificação: (1) engastamento (interlocking) mecânico e escorregamento (sliding) com atrito das superfícies de fratura e (2) ponteamento de trinca (crack bridging). 
A Figura 7.12 apresenta imagens de MEV do perfil de trincas geradas pela indentação Vickers na superfície polida das amostras de $\mathrm{AlN}$ com $\mathrm{Y}_{2} \mathrm{O}_{3}$. As amostras de AlN com 0,5\% e $2 \%$ de $\mathrm{CaO}$ apresentaram menor tortuosidade nas superfícies de fratura (Figs. 7.12a e 7.12b) do que as amostras de AlN com $\mathrm{CaO}$ (Fig. 7.11). A tortuosidade da superfície de fratura está relacionada com a ocorrência de fratura intergranular. Apesar das amostras de AIN com adição de $0,5 \%$ de $\mathrm{CaO}$ e com $0,5 \%$ e $2 \%$ de $\mathrm{Y}_{2} \mathrm{O}_{3}$ terem apresentado valores próximos de fração de grãos com fratura transgranular (Fig. 7.8b), a amostra com 0,5\% de $\mathrm{CaO}$ (Fig. 7.11a) apresentou uma superfície de fratura mais tortuosa do que as amostras com $0,5 \%$ e $2 \%$ de $\mathrm{Y}_{2} \mathrm{O}_{3}$ (Figs. 7.12a e 7.12b). Já a amostra de $\mathrm{AlN}$ com 4\% de $\mathrm{Y}_{2} \mathrm{O}_{3}$ apresentou um perfil de trinca (Fig. 7.12c) próximo daqueles observados para as amostras de $\mathrm{AlN}$ com $\mathrm{CaO}$ (Fig. 7.11) em decorrência da diminuição de $f_{\mathrm{T}}$ com o aumento do teor de $\mathrm{Y}_{2} \mathrm{O}_{3}$ (Fig. 7.8b). A tortuosidade da superfície de fratura pode aumentar com o aumento do tamanho de grão, o que pode explicar as mudanças do grau de tortuosidade das superfícies de fratura do AlN em função do tipo de aditivo de sinterização $\left(\mathrm{CaO}\right.$ e $\left.\mathrm{Y}_{2} \mathrm{O}_{3}\right)$. No entanto, o tamanho médio de grão do AlN variou pouco em função do tipo de aditivo de sinterização utilizado (Fig. 7.8a), além de ter apresentado uma pequena diminuição com o aumento do teor de aditivo, o que não justificou a diferença entre os perfis de fratura das amostras de AlN com adição de $\mathrm{CaO}$ (Fig. 7.11) e com adição de $0,5 \%$ e $2 \%$ de $\mathrm{Y}_{2} \mathrm{O}_{3}$ (Figs. 7.12a e 7.12b).

As amostras de AlN com 0,5\% a 4\% de $\mathrm{Y}_{2} \mathrm{O}_{3}$ também apresentaram evidências da ocorrência de alguns mecanismos de tenacificação (indicações 1 e 2, Fig. 7.12), tais como: 1) engastamento mecânico e escorregamento com atrito das superfícies de fratura e 2) ponteamento de trinca. A presença de partículas grandes de aluminatos de ítrio nas amostras de AlN com 2\% e 4\% de $\mathrm{Y}_{2} \mathrm{O}_{3}$ (indicação P, Figs. 7.12b e 7.12c) não induziram a ocorrência de tenacificação por deflexão de trinca, pois estas partículas de segundas-fases não causaram desvios significativos na trajetória de propagação da trinca. Na literatura, observou-se que o AlN com $2 \%$ de $\mathrm{CaO}$ apresentou tenacificação por deflexão de trinca quando o tamanho de grão aumentou de $3 \mu \mathrm{m}$ para $20 \mu \mathrm{m} .{ }^{80}$ Como as amostras de $\mathrm{AlN}$ com adição tanto de $\mathrm{CaO}$ como de $\mathrm{Y}_{2} \mathrm{O}_{3}$ apresentaram tamanhos médios de grão abaixo de $3 \mu \mathrm{m}$ (Fig. 7.8a), pode-se dizer que o mecanismo de tenacificação por deflexão de trinca não foi ativado nestas amostras. 

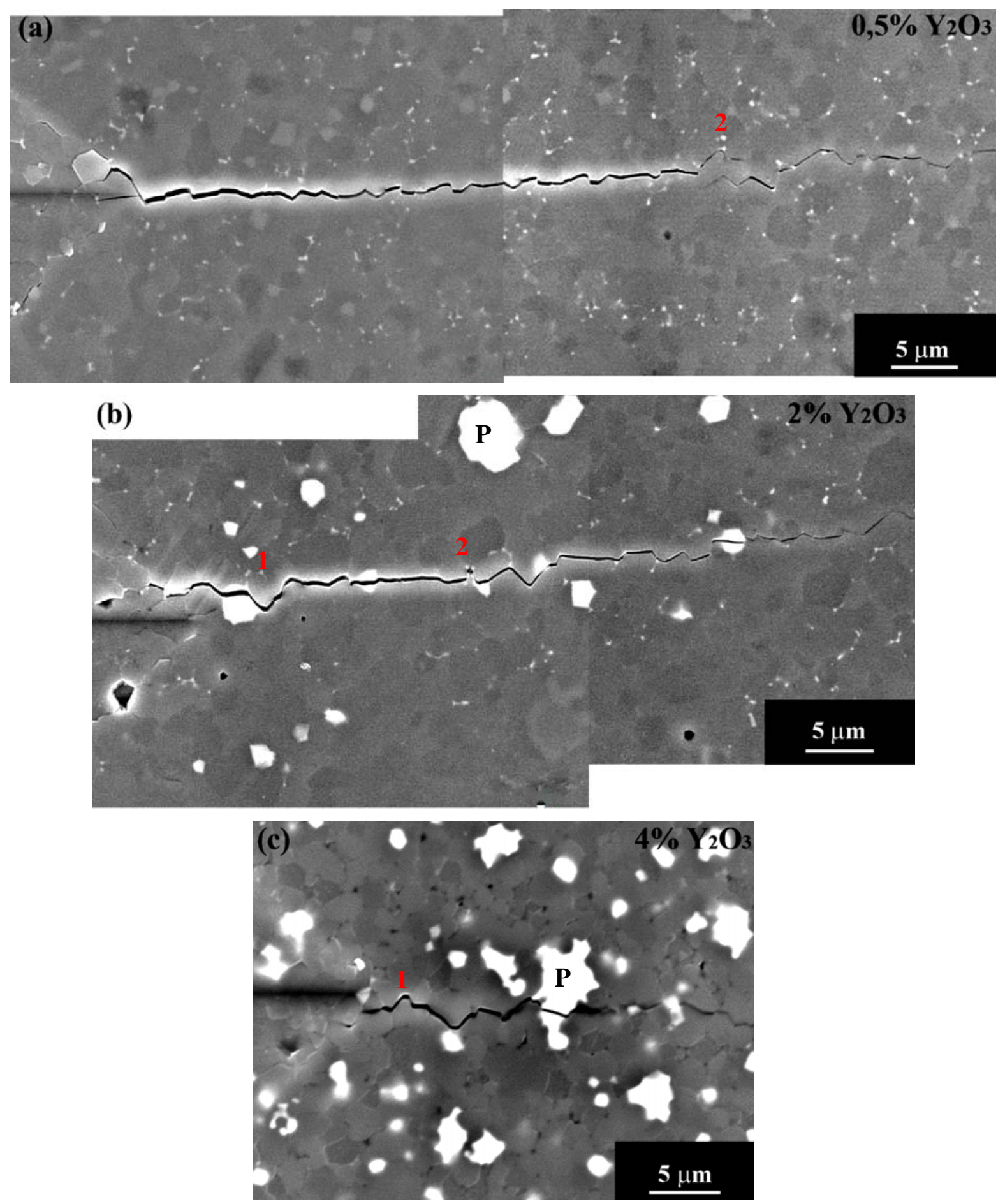

Figura 7.12 - Imagens de MEV do perfil da trinca gerada por indentação Vickers (carga de 0,5 kgf) na superfície polida de amostras de $\mathrm{AlN}$ com $\mathrm{Y}_{2} \mathrm{O}_{3}$ sinterizadas a $1800^{\circ} \mathrm{C}$ por $1 \mathrm{~h}$. As indicações 1 e 2 referem-se aos mecanismos de tenacificação: (1) engastamento (interlocking) mecânico e escorregamento (sliding) com atrito das superfícies de fratura e (2) ponteamento de trinca (crack bridging). Já a indicação P refere-se às partículas grandes de aluminatos de ítrio. 
A Figura 7.13 apresenta os resultados de tenacidade à fratura determinada pelo método Indentation Strength $\left(\mathrm{K}_{\mathrm{Ic}-\mathrm{IS}}\right)$ do AlN em função do teor de aditivo de sinterização, onde se observa que $\mathrm{K}_{\mathrm{Ic}-\mathrm{IS}}$ não variou praticamente com o tipo e teor de aditivo de sinterização $(\sim 2,8$ $\mathrm{MPa} \cdot \mathrm{m}^{1 / 2}$ ). Estes resultados mostraram que a tenacidade à fratura do AlN não foi influenciada pelo tipo $\left(\mathrm{CaO}\right.$ ou $\left.\mathrm{Y}_{2} \mathrm{O}_{3}\right)$ e teor $(0,5 \%$ a $4 \%$ em massa) de aditivo de sinterização. Além disso, os valores de $\mathrm{K}_{\mathrm{Ic}-\mathrm{IS}}$ (Fig. 7.13) foram significativamente maiores do que os valores de $\mathrm{K}_{\mathrm{Ic}-\mathrm{IF}}$ (Fig. 7.10), principalmente em relação aos valores determinados para as amostras de AlN com $\mathrm{Y}_{2} \mathrm{O}_{3}\left(\sim 1,4 \mathrm{MPa}^{1 / 2}\right)$. O mesmo comportamento foi observado por Witek et al. ${ }^{80}$, que determinaram $\mathrm{K}_{\text {Ic-IF }}$ de 1,8 $\mathrm{MPa}^{1 / 2}$ e $_{\text {Ic-IS }}$ de 3,1 $\mathrm{MPa}^{1 / 2}$ para o AlN com $2 \%$ em massa de $\mathrm{CaO}$. Os resultados de literatura (Tabela 7.2) mostraram que os valores de $\mathrm{K}_{\mathrm{Ic}-\mathrm{IF}}$ são usualmente menores do que os valores de $\mathrm{K}_{\mathrm{Ic}}$ determinados por outros métodos. Estes resultados mostraram que o valor de tenacidade à fratura do AlN pode variar significativamente com o método de determinação utilizado.

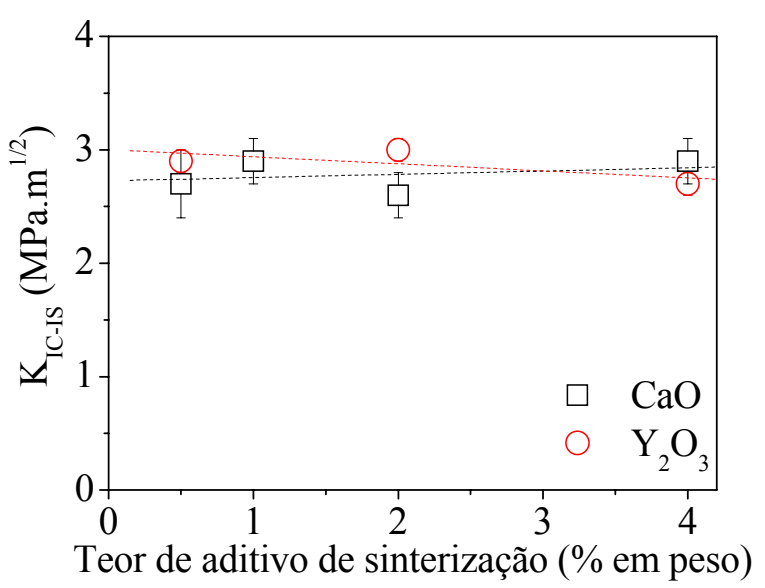

Figura 7.13 - Tenacidade à fratura determinada pelo método IS - Indentation Strength $\left(\mathrm{K}_{\mathrm{Ic}-\mathrm{IS}}\right)$ do AlN em função do teor de aditivo de sinterização. As amostras de AlN foram sinterizadas a $1800^{\circ} \mathrm{C}$ por $1 \mathrm{~h}$.

\subsubsection{Análise fractográfica}

A Figura 7.14 apresenta os principais padrões macroscópicos de fratura das amostras de AlN submetidas ao ensaio de resistência à flexão biaxial. A maioria dos corpos-de-prova foi caracterizada por apresentar de 3 a 5 fragmentos de fratura, independentemente do tipo e teor de aditivo de sinterização. Porém, alguns corpos-de-prova foram constituídos por 2, 6 ou 7 fragmentos de fratura. A Figura 7.15 apresenta os resultados de resistência à flexão biaxial 
$\left(\sigma_{\mathrm{f}, \mathrm{b}}\right)$ em função do número de fragmentos de fratura $\left(\mathrm{N}_{\mathrm{ff}}\right)$. Estes resultados mostraram que a resistência à flexão apresentou tendência para aumentar com o aumento do número de fragmentos de fratura.

(a)

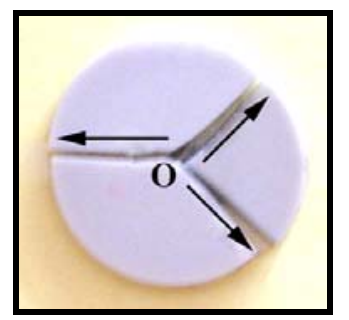

(b)

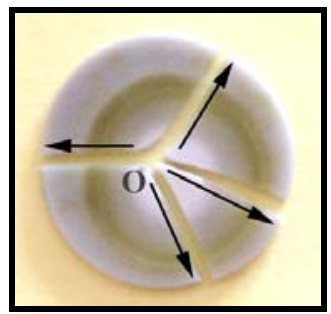

(c)

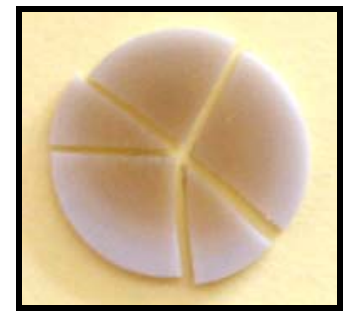

Figura 7.14-Imagens dos principais padrões macroscópicos de fratura das amostras de AlN submetidas ao ensaio de resistência à flexão biaxial. As setas nas Figuras 7.14a e 7.14b indicam a direção de propagação da trinca e o ponto $\mathrm{O}$ indica a região em que se localiza provavelmente a origem da fratura. Os diâmetros dos corpos-de-prova foram próximos de $11 \mathrm{~mm}$.

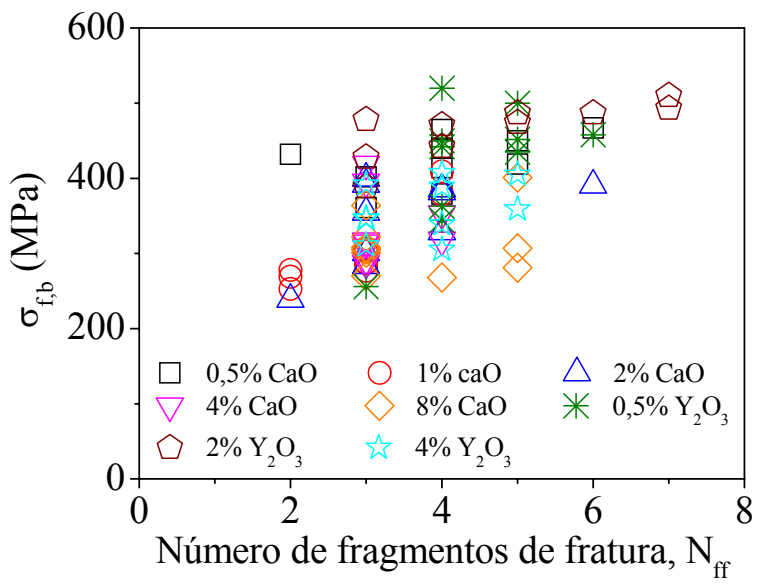

Figura 7.15 - Relação entre resistência à flexão biaxial $\left(\sigma_{\mathrm{f}, \mathrm{b}}\right)$ e número de fragmentos de fratura $\left(\mathrm{N}_{\mathrm{ff}}\right)$ das amostras de AlN sinterizadas a $1800^{\circ} \mathrm{C}$ por $1 \mathrm{~h}$.

As regiões denominadas mirror, mist e hackle (Fig. 7.4) não foram claramente evidenciadas nas superfícies de fratura das amostras de AlN submetidas ao ensaio de resistência à flexão biaxial, mesmo realizando a análise fractográfica por MEV. Assim, a origem de fratura foi identificada somente em alguns corpos-de-prova constituídos por 2 ou 3 fragmentos de fratura, pois a região em que ocorreu a falha foi inicialmente identificada pela análise do padrão macroscópico de fratura do corpo-de-prova (Figs. 7.14a e 7.14b) e, então, o fragmento contendo a origem da fratura foi analisado por MEV. A maioria das origens de fratura identificadas foi defeito superficial associado com a superfície polida solicitada em tração (Figs. 7.16a a 7.16c). Como estas origens de fratura não foram associadas, em grande parte, com defeitos de processamento (poros ou aglomerados de partículas), pode-se dizer que 
o defeito iniciador da fratura foi oriundo de trincas superficiais. Porém, a análise por MEV da superfície polida solicitada em tração não revelou a presença de defeitos superficiais causados pelas etapas de usinagem e polimento.
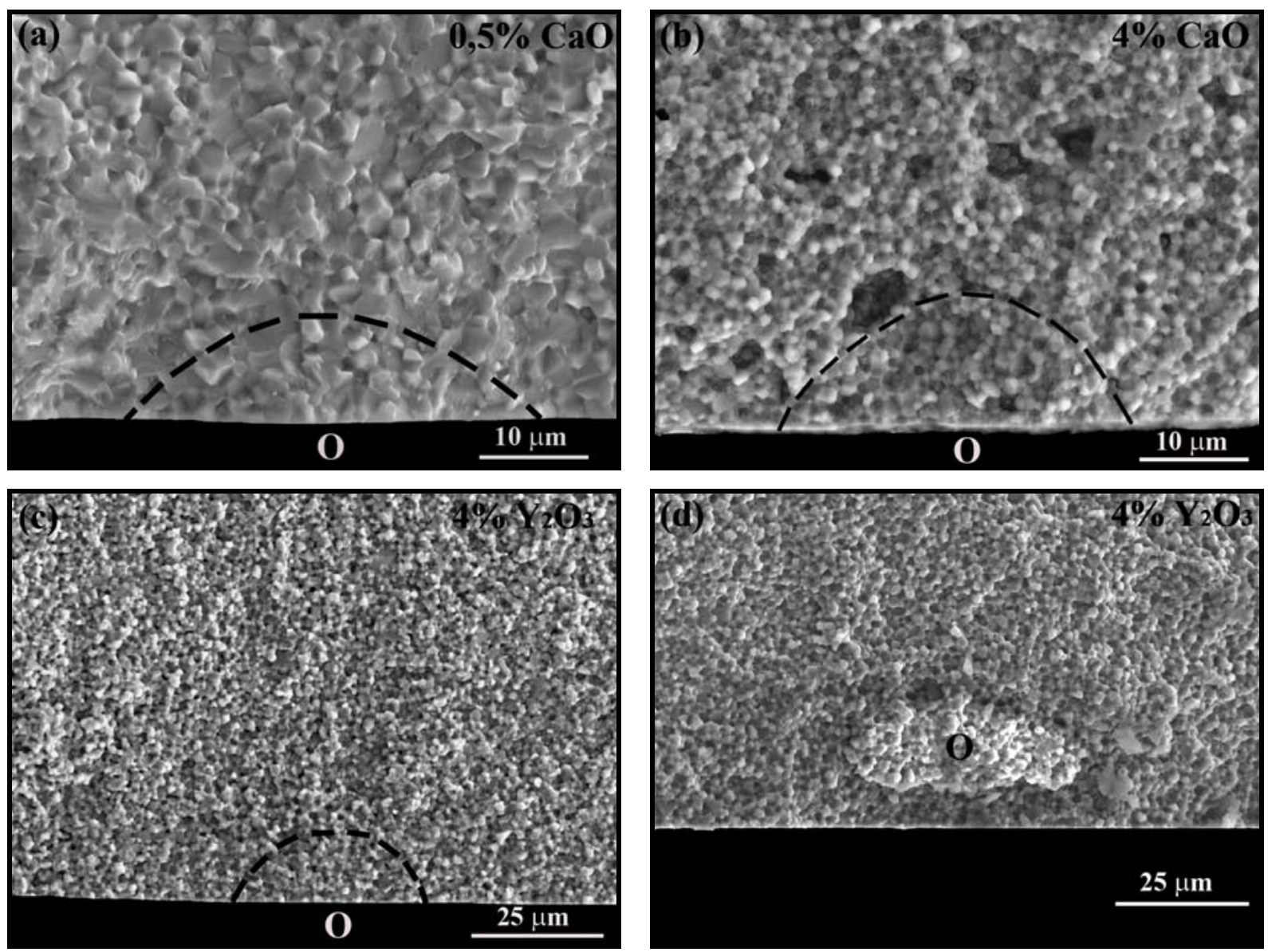

Figura 7.16 - Imagens de MEV mostrando a origem de fratura (O) dos corpos-de-prova de AlN submetidos ao ensaio de resistência à flexão biaxial. As regiões demarcadas nas imagens indicam o tamanho do defeito iniciador da fratura.

Uma das origens de fratura foi correlacionada com um defeito volumétrico próximo da superfície de tração (Fig. 7.16d). Este defeito volumétrico foi introduzido durante o processamento cerâmico. Uma das possibilidades de formação deste defeito está relacionada com a etapa de produção do pó granulado, que pode ter levado à formação de alguns aglomerados grandes de partículas, que durante a sinterização apresentaram maior retração do que a matriz, o que resultou na formação de vazios (poros) na microestrutura. Outra possibilidade está relacionada com a ativação do mecanismo de rearranjo de partículas da sinterização via fase líquida. Este mecanismo pode induzir a formação de poros e de defeitos volumétricos similares ao observado na Figura 7.16d, quando a fração de fase líquida presente durante a sinterização é significativamente baixa. ${ }^{90,99}$ Porém, as amostras de AlN com baixos 
teores de $\mathrm{CaO}$ ou de $\mathrm{Y}_{2} \mathrm{O}_{3}(0,5 \%$ em massa $)$ não foram caracterizadas por apresentar este tipo de defeito volumétrico (Fig. 7.16d) e, portanto, este defeito deve ter sido decorrente da formação de aglomerados grandes de partículas na etapa de granulação do pó.

Além dos poros residuais grandes decorrentes da adição de partículas grosseiras de $\mathrm{CaCO}_{3}$ nas amostras de $\mathrm{AlN}$ com $\mathrm{CaO}$ (Figs. 7.7a a 7.7c), várias amostras de AlN com adição tanto de $\mathrm{CaO}$ como de $\mathrm{Y}_{2} \mathrm{O}_{3}$ apresentaram poros grandes de processamento localizados no interior (volume) do corpo sinterizado (Fig. 7.17). Estes poros podem ser cavidades formadas pela decomposição de inclusões orgânicas. ${ }^{87}$ Muitos poros de processamento apresentaram grandes dimensões, com comprimentos de dezenas de micrometros (Figs. 7.17a e 7.17b). Esta característica torna-os potenciais iniciadores (origens) de fratura. Porém, estes defeitos não foram correlacionados com as origens de fratura dos corpos-de-prova analisados.
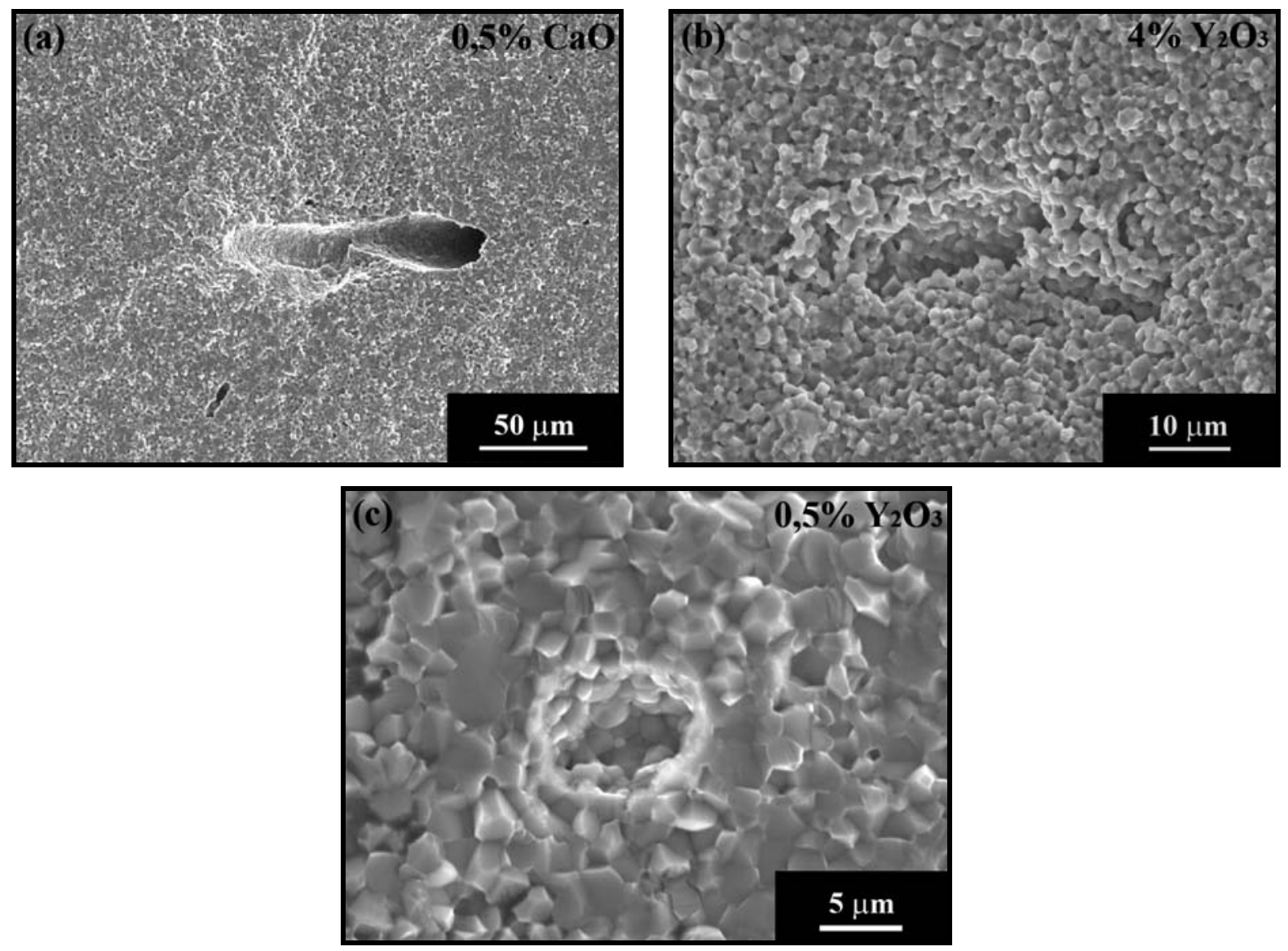

Figura 7.17 - Imagens de MEV mostrando defeitos (poros grandes) de processamento nas superfícies de fratura de amostras de AlN submetidas ao ensaio de resistência à flexão biaxial. Os defeitos foram localizados no interior (volume) do corpo. 
A Figura 7.18 mostra a relação entre o comprimento de trinca $\left(\mathrm{c}_{\text {calc }}\right)$ calculado pelo critério de falha de Irwin-Griffith (eq. 2.22), considerando os valores de $\mathrm{K}_{\mathrm{Ic}}$ determinados tanto pelo método IF como pelo método IS, e o comprimento de trinca $\left(\mathrm{c}_{\mathrm{det}}\right)$ determinado por análise fractográfica. $\mathrm{O}$ fator de forma (Y, eq. 2.22) utilizado nos cálculos foi de 1,29, ${ }^{233}$ que corresponde ao padrão da trinca semi-elíptica superficial observada comumente na análise fractográfica das amostras de AlN (Fig. 7.16). Os valores de $\mathrm{c}_{\text {calc }}$ calculados com os resultados de $\mathrm{K}_{\mathrm{Ic}-\mathrm{IF}}$ foram quase todos subestimados em relação aos valores de $\mathrm{c}_{\mathrm{det}}$ (Fig. 7.18). Estes resultados sugerem que os baixos valores determinados de $\mathrm{K}_{\mathrm{Ic}}$ pelo método IF foram subestimados (Fig. 7.10). Já parte dos valores de $\mathrm{c}_{\text {calc }}$ calculados a partir de $\mathrm{K}_{\mathrm{Ic}-\mathrm{IS}}$ foi próxima dos valores de $c_{\text {det }}$ (Fig. 7.18), o que mostrou boa correlação entre os valores medidos de resistência à flexão biaxial e tenacidade à fratura pelo método IS, segundo previsto pela equação do critério de falha de Irwin-Griffith (eq. 2.22). Parte dos valores de $c_{\text {calc }}$ calculados com os resultados de $\mathrm{K}_{\mathrm{Ic}-\mathrm{IS}}$, entretanto, foi superestimada em relação aos tamanhos de defeitos determinados por análise fractográfica $\left(\mathrm{c}_{\mathrm{det}}\right)$. Estas diferenças podem estar relacionadas, por um lado, com a dificuldade para se determinar o contorno (tamanho) do defeito no momento da fratura pela análise fractográfica e, por outro lado, com a dificuldade para se conhecer o valor exato do fator de forma (Y) utilizado nos cálculos com a equação 2.22.

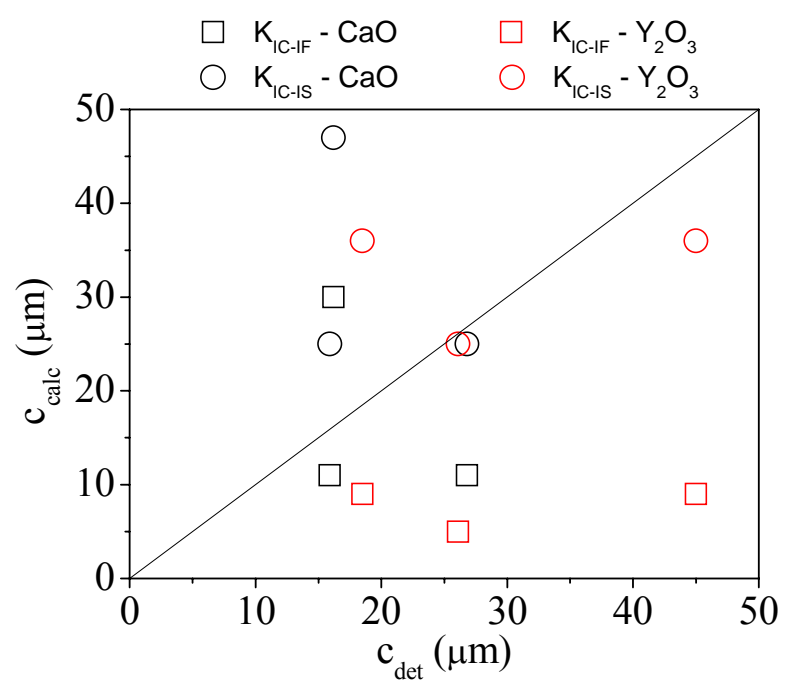

Figura 7.18 - Comprimento de trinca calculado ( $\mathrm{c}_{\text {calc }}$ ) pela equação 2.22 a partir dos dados de $\mathrm{K}_{\text {Ic-IF }}$ e $\mathrm{K}_{\text {Ic-IS }}$ em função do comprimento de trinca determinado $\left(\mathrm{c}_{\mathrm{det}}\right)$ pela análise fractográfica. A curva linear corresponde à condição $\mathrm{c}_{\mathrm{calc}}=\mathrm{c}_{\mathrm{det}}$.

Para facilitar a comparação de resultados, as propriedades das diferentes amostras de AlN com adição tanto de $\mathrm{CaO}$ como de $\mathrm{Y}_{2} \mathrm{O}_{3}$ sinterizadas a $1800^{\circ} \mathrm{C}$ são apresentadas na Tabela 7.3. 
Tabela 7.3 - Propriedades (média \pm desvio-padrão) das amostras de $\mathrm{AlN}$ com adição tanto de $\mathrm{CaO}$ como de $\mathrm{Y}_{2} \mathrm{O}_{3}$ sinterizadas a $1800^{\circ} \mathrm{C}$.

\begin{tabular}{|c|c|c|c|c|c|c|c|c|}
\hline \multirow{2}{*}{ Propriedades } & \multicolumn{5}{|c|}{ Fração em massa de CaO } & \multicolumn{3}{|c|}{ Fração em massa de $\mathrm{Y}_{2} \mathrm{O}_{3}$} \\
\hline & $0,5 \%$ & $1 \%$ & $2 \%$ & $4 \%$ & $8 \%$ & $0,5 \%$ & $2 \%$ & $4 \%$ \\
\hline E (GPa) & $336 \pm 16$ & $337 \pm 17$ & $319 \pm 8$ & $288 \pm 8$ & $264 \pm 13$ & $333 \pm 9$ & $322 \pm 7$ & $323 \pm 5$ \\
\hline$\sigma_{\mathrm{f}, \mathrm{b}}(\mathbf{M P a})$ & $423 \pm 35$ & $305 \pm 50$ & $346 \pm 55$ & $332 \pm 44$ & $313 \pm 42$ & $422 \pm 79$ & $466 \pm 36$ & $360 \pm 37$ \\
\hline $\mathrm{H}_{\mathrm{V}-05 \mathrm{kgf}}(\mathrm{GPa})$ & $11,4 \pm 0,3$ & $11,2 \pm 0,3$ & $11,4 \pm 0,2$ & $9,9 \pm 0,2$ & $9,0 \pm 0,2$ & $11,4 \pm 0,2$ & $11,3 \pm 0,2$ & $11,4 \pm 0,2$ \\
\hline $\mathrm{K}_{\text {Ic-IF }}\left(\mathrm{MPa} . \mathrm{m}_{1 / 2}\right)$ & $1,8 \pm 0,1$ & $1,8 \pm 0,1$ & $2,0 \pm 0,1$ & $2,3 \pm 0,1$ & $2,7 \pm 0,2$ & $1,3 \pm 0,1$ & $1,4 \pm 0,1$ & $1,4 \pm 0,1$ \\
\hline $\mathrm{K}_{\mathrm{Ic}-\mathrm{IS}}\left(\mathrm{MPa} . \mathrm{m}_{1 / 2}\right)$ & $2,7 \pm 0,3$ & $2,9 \pm 0,3$ & $2,6 \pm 0,2$ & $2,9 \pm 0,2$ & n.a. & $2,9 \pm 0,1$ & $3,0 \pm 0,1$ & $2,7 \pm 0,1$ \\
\hline TG $(\mu \mathbf{m})$ & $2,2 \pm 0,6$ & $1,7 \pm 0,5$ & $1,5 \pm 0,4$ & $1,4 \pm 0,4$ & $1,4 \pm 0,4$ & $2,4 \pm 0,8$ & $2,2 \pm 0,6$ & $1,7 \pm 0,5$ \\
\hline$f_{\mathrm{T}}(\%)$ & 39,7 & 3,3 & 5,2 & 3,8 & 0,5 & 42,8 & $46,, 8$ & 4,6 \\
\hline P (\%) & $1,5 \pm 0,1$ & $1,8 \pm 0,1$ & $2,9 \pm 0,1$ & $4,5 \pm 0,1$ & $6,3 \pm 0,1$ & $1,2 \pm 0,3$ & $1,6 \pm 0,1$ & $1,3 \pm 0,1$ \\
\hline
\end{tabular}

Notas: módulo de Young $(\mathrm{E})$, resistência à flexão biaxial $\left(\sigma_{\mathrm{f}, \mathrm{b}}\right)$, dureza Vickers com carga de indentação de $0,5 \mathrm{kgf}\left(\mathrm{H}_{\mathrm{V}-0,5 \mathrm{~kg}}\right)$, tenacidade à fratura determinada pelo método Indentation Fracture $\left(\mathrm{K}_{\mathrm{Ic}-\mathrm{IF}}\right)$ e pelo método Indentation Strength $\left(\mathrm{K}_{\mathrm{Ic}-\mathrm{IS}}\right)$, tamanho médio de grão $(\mathrm{TG})$, fração de grãos com fratura transgranular $\left(f_{\mathrm{T}}\right)$, porosidade $(\mathrm{P})$ e amostra não analisada (n.a.). 


\subsection{Discussão dos resultados experimentais}

\subsubsection{Módulo de Young}

As amostras de AlN com adição de $0,5 \%$ e $1 \%$ de $\mathrm{CaO}$ e com adição de $0,5 \%$ a $4 \%$ de $\mathrm{Y}_{2} \mathrm{O}_{3}$ apresentaram valores próximos de módulo de Young (Fig. 7.5). Já as amostras de AlN com 2\% a $8 \%$ de $\mathrm{CaO}$ apresentaram valores significativamente menores de módulo de Young do que as demais amostras de AlN (Fig. 7.5). Como o módulo de Young diminuiu significativamente com o aumento de $1 \%$ para $8 \%$ de $\mathrm{CaO}$ (Fig. 7.5a) e, sabendo que a porosidade do AlN aumentou significativamente nesta faixa de teor de aditivo de sinterização, pode-se dizer que o módulo de Young foi fortemente influenciado pelo aumento de porosidade. Porém, esta propriedade elástica apresentou uma pequena diminuição ( 3\%) com o aumento do teor de $\mathrm{Y}_{2} \mathrm{O}_{3}$ (Fig. 7.5b), o que indicou uma pequena influência do teor de $\mathrm{Y}_{2} \mathrm{O}_{3}$ no módulo de Young do AlN. No Capítulo 6, constatou-se que o módulo de Young do AlN foi fortemente influenciado pela porosidade (Fig. 6.4a), mas pouca influência foi observada em relação ao tipo $\left(\mathrm{CaO}\right.$ ou $\left.\mathrm{Y}_{2} \mathrm{O}_{3}\right)$ e teor $(0,5 \%$ a $8 \%$ em massa $)$ de aditivo de sinterização. Deste modo, pode-se dizer que o módulo de Young do AlN não foi praticamente influenciado pelo tipo e teor de aditivo de sinterização.

\subsubsection{Resistência à flexão biaxial}

O comportamento de resistência à flexão biaxial $\left(\sigma_{\mathrm{f}, \mathrm{b}}\right)$ do AlN mudou em função do tipo de aditivo de sinterização (Fig. 7.6). $\mathrm{O}$ aumento de $0,5 \%$ para $1 \%$ de $\mathrm{CaO}$ causou uma diminuição abrupta $(\sim 30 \%)$ em $\sigma_{f, b}$ (Fig. 7.6), mas pouca variação no valor de $\sigma_{f, b}$ ocorreu entre $1 \%$ e $8 \%$ de $\mathrm{CaO}$. Já o aumento de $0,5 \%$ para $2 \%$ de $\mathrm{Y}_{2} \mathrm{O}_{3}$ causou um pequeno aumento $(\sim 10 \%)$ em $\sigma_{\mathrm{f}, \mathrm{b}}$ (Fig. 7.6), mas uma diminuição significativa de $\sigma_{\mathrm{f}, \mathrm{b}}(\sim 23 \%)$ ocorreu com o aumento de $2 \%$ para $4 \%$ de $\mathrm{Y}_{2} \mathrm{O}_{3}$. Embora o comportamento de $\sigma_{\mathrm{f}, \mathrm{b}}$ tenha mudado com o tipo de aditivo de sinterização (Fig. 7.6), os valores de $\sigma_{\mathrm{f}, \mathrm{b}}$ das amostras de AlN com adição de $0,5 \%$ de $\mathrm{CaO}$ e com adição de $0,5 \%$ e $2 \%$ de $\mathrm{Y}_{2} \mathrm{O}_{3}$ foram próximos ( $\left.440 \mathrm{MPa}\right)$, enquanto as 
demais amostras com adição tanto de $\mathrm{CaO}$ como de $\mathrm{Y}_{2} \mathrm{O}_{3}$ apresentaram valores menores de $\sigma_{\mathrm{f}, \mathrm{b}}$, mas próximos entre si $(\sim 330 \mathrm{MPa})$. Estes resultados indicaram a existência de um valor crítico de teor de aditivo de sinterização, acima do qual $\sigma_{\mathrm{f}, \mathrm{b}}$ diminui de forma significativa e, então, permanece praticamente constante para maiores teores de aditivos de sinterização. No presente trabalho, este valor crítico ocorreu próximo de $0,5 \%$ para o $\mathrm{AlN}$ com adição de $\mathrm{CaO}$ e $2 \%$ para o AlN com adição de $\mathrm{Y}_{2} \mathrm{O}_{3}$ (Fig. 7.6). Estes resultados mostraram que cerâmicas de AlN com elevada resistência à flexão biaxial (> $420 \mathrm{MPa})$ podem ser obtidas com adições de até $0,5 \%$ de $\mathrm{CaO}$ ou de até $2 \%$ de $\mathrm{Y}_{2} \mathrm{O}_{3}$. Acima destes teores, a resistência mecânica do AlN diminui fortemente e tende a estabilizar em torno de 300 a $360 \mathrm{MPa}$.

Como o AlN sem aditivo de sinterização apresenta praticamente modo de fratura transgranular (Fig. 3.7c), pode-se dizer que sua resistência mecânica é controlada pela resistência do grão de $\mathrm{AlN}$. Porém, a adição tanto de $\mathrm{CaO}$ como de $\mathrm{Y}_{2} \mathrm{O}_{3}$ modificou o modo de fratura dos grãos de AlN de transgranular para intergranular (Fig. 7.7), só que esta mudança ocorreu gradativamente com o aumento do teor de aditivo de sinterização (Fig. 7.8b). Análogo ao observado para $\sigma_{f, b}$ (Fig. 7.6), a fração de grãos com fratura transgranular $\left(f_{\mathrm{T}}\right)$ mudou com o tipo e teor de aditivo de sinterização (Fig. 7.8b). Os comportamentos de $f_{\mathrm{T}}$ (Fig. 7.8b) apresentaram tendências próximas dos comportamentos de $\sigma_{\mathrm{f}, \mathrm{b}}$ (Fig. 7.6) em função do tipo e teor de aditivo de sinterização. Estes resultados mostraram a ocorrência de boa correlação entre $\sigma_{\mathrm{f}, \mathrm{b}}$ e $f_{\mathrm{T}}$, onde se observou que a diminuição de $f_{\mathrm{T}}$ implicou na diminuição de $\sigma_{\mathrm{f}, \mathrm{b}}$ (Figs. 7.6 e 7.8b). Portanto, a mudança do modo de fratura de transgranular para intergranular causou uma diminuição significativa na resistência mecânica do AlN.

A ocorrência de modo de fratura intergranular indica que a trinca propagou pela região de contorno de grão. Como a utilização de aditivos de sinterização modificou o modo de fratura do AlN de transgranular para intergranular, pode-se dizer que a resistência mecânica do AlN com aditivo de sinterização foi controlada pela resistência da segunda-fase de contorno de grão, como sugerido por Terao et al. ${ }^{79}$ Com base nesta proposição, verificou-se o efeito da composição das segundas-fases na resistência à flexão das amostras de AlN com adição tanto de $\mathrm{CaO}$ como de $\mathrm{Y}_{2} \mathrm{O}_{3}$ sinterizadas a $1800^{\circ} \mathrm{C}$. Em relação ao AlN com $\mathrm{CaO}$, observou-se a presença das fases $\mathrm{CA}_{2}\left(\mathrm{CaO} \cdot 2 \mathrm{Al}_{2} \mathrm{O}_{3}\right)$ e $\mathrm{CA}\left(\mathrm{CaO} \cdot \mathrm{Al}_{2} \mathrm{O}_{3}\right)$ na amostra com $0,5 \%$ de $\mathrm{CaO}$ e somente da fase $\mathrm{CA}$ nas amostras com $1 \%$ a $8 \%$ de $\mathrm{CaO}$ (Fig. 4.4). Estes resultados mostraram que a amostra de $\mathrm{AlN}$ com $0,5 \%$ de $\mathrm{CaO}$ apresentou uma segunda-fase adicional $\left(\mathrm{CA}_{2}\right)$ em relação às demais amostras com $\mathrm{CaO}$. Como a amostra com $0,5 \%$ de $\mathrm{CaO}$ apresentou elevada fração de grãos com fratura transgranular (Fig. 7.8b) e, sabendo que as 
demais amostras com $\mathrm{CaO}$ apresentaram baixos valores de $f_{\mathrm{T}}$, pode-se inferir que a resistência do contorno de grão com a presença das fases $\mathrm{CA}$ e $\mathrm{CA}_{2}$ foi maior do que a resistência do grão de AlN, o que induziu a ocorrência de elevada fração de grãos de AlN com fratura transgranular. Já a resistência do contorno de grão com a presença apenas da fase CA foi menor do que a resistência do grão de AIN, o que induziu a ocorrência de fratura intergranular nas amostras de AlN com $\mathrm{CaO}$. Como a amostra de $\mathrm{AlN}$ com $0,5 \%$ de $\mathrm{CaO}$ apresentou elevada resistência à flexão $\left(\sigma_{\mathrm{f}, \mathrm{b}}\right)$ em relação às demais amostras com $\mathrm{CaO}$ (Fig. 7.6), pode-se inferir que a formação adicional da fase $\mathrm{CA}_{2}$ foi responsável pelo aumento de $\sigma_{\mathrm{f}, \mathrm{b}} \mathrm{em}$ decorrência do aumento da resistência do contorno de grão.

Em relação ao AlN com $\mathrm{Y}_{2} \mathrm{O}_{3}$, observou-se a presença da fase YAG $\left(3 \mathrm{Y}_{2} \mathrm{O}_{3} .5 \mathrm{Al}_{2} \mathrm{O}_{3}\right)$ nas amostras com $0,5 \%$ e $2 \%$ de $\mathrm{Y}_{2} \mathrm{O}_{3}$ e das fases YAP $\left(\mathrm{Y}_{2} \mathrm{O}_{3} \cdot \mathrm{Al}_{2} \mathrm{O}_{3}\right)$ e YAG na amostra com $4 \%$ de $\mathrm{Y}_{2} \mathrm{O}_{3}$ (Tabela 3.3). Estes resultados indicaram que a amostra de AlN com 4\% de $\mathrm{Y}_{2} \mathrm{O}_{3}$ apresentou uma segunda-fase adicional (YAP) em relação às demais amostras com $\mathrm{Y}_{2} \mathrm{O}_{3}$. Provavelmente, a presença majoritária da fase YAP na amostra de AlN com 4\% de $\mathrm{Y}_{2} \mathrm{O}_{3}$ induziu a ocorrência preferencial de fratura intergranular (Fig. 7.8b), pois as demais amostras com $\mathrm{Y}_{2} \mathrm{O}_{3}$, que apresentaram somente a fase $\mathrm{YAG}$, exibiram elevada fração de grãos com fratura transgranular. Estes resultados indicaram que a resistência do contorno de grão contendo apenas a fase YAG foi maior do que a resistência do grão de AlN, que, por sua vez, foi maior do que a resistência do contorno de grão contendo as fases YAP e YAG. Portanto, a formação apenas da fase YAG pode aumentar consideravelmente a resistência à flexão $\left(\sigma_{\mathrm{f}, \mathrm{b}}\right)$ do AlN, devido ao aumento da resistência do contorno de grão.

Embora a fração de poros grandes tenha aumentado com o aumento do teor de $\mathrm{CaO}$ (Figs. 7.16a a 7.16c), a resistência à flexão $\left(\sigma_{\mathrm{f}, \mathrm{b}}\right)$ das amostras de $\mathrm{AlN}$ com $1 \%$ a $8 \%$ de $\mathrm{CaO}$ foram próximas (Fig. 7.6). Estes resultados indicaram que $\sigma_{\mathrm{f}, \mathrm{b}}$ foi pouco influenciado pelo aumento de porosidade. Já o aumento do teor de $\mathrm{Y}_{2} \mathrm{O}_{3}$ levou à formação de partículas grandes de segundas-fases nas amostras de AlN (Fig. 7.12), mas não ocorreu a formação de poros grandes. Estas partículas grandes também não influenciaram os valores de $\sigma_{\mathrm{f}, \mathrm{b}}$ do $\mathrm{AlN}$, pois a amostra com $0,5 \%$ de $\mathrm{Y}_{2} \mathrm{O}_{3}$, que não apresentou este tipo de partícula (Fig. 7.12a), teve um valor de $\sigma_{\mathrm{f}, \mathrm{b}}$ próximo do valor determinado para a amostra com $2 \%$ de $\mathrm{Y}_{2} \mathrm{O}_{3}$ (Fig. 7.6), que exibiu uma quantidade considerável de partículas grandes de segundas-fases (Fig. 7.12b). Já a análise fractográfica mostrou que a origem de fratura foi decorrente da presença de defeitos tanto superficiais (Figs. 7.16a a 7.16c) como volumétricos (Fig. 7.16d), que foram introduzidos durante as etapas de processamento cerâmico, usinagem e polimento. 
Provavelmente, estes defeitos diminuíram os valores máximos de resistência à flexão obtidos para as amostras de $\mathrm{AlN}$ com adição tanto de $\mathrm{CaO}$ como de $\mathrm{Y}_{2} \mathrm{O}_{3}$, mas não foram responsáveis pela diminuição desta propriedade mecânica em função do teor de aditivo de sinterização, pois este comportamento foi correlacionado com a mudança do modo de fratura dos grãos de AlN.

\subsubsection{Dureza Vickers}

$\mathrm{Na}$ literatura, verificou-se que a dureza Vickers diminui com o aumento tanto do tamanho de grão ${ }^{234}$ como da porosidade ${ }^{192}$. No presente trabalho, o aumentou do teor de $\mathrm{CaO}$ ou de $\mathrm{Y}_{2} \mathrm{O}_{3}$ diminuiu o tamanho médio de grão do $\mathrm{AlN}(\sim 2,4 \mu \mathrm{m}$ para 1,5 $\mu \mathrm{m}$, Fig. 7.8a), o que deveria resultar no aumento da dureza Vickers. Porém, esta propriedade mecânica diminuiu com a adição de $\mathrm{CaO}$ e permaneceu praticamente constante com a adição de $\mathrm{Y}_{2} \mathrm{O}_{3}$ (Fig. 7.9a). Estes resultados mostraram que, devido à pequena diminuição do tamanho de grão com o aumento do teor de aditivo de sinterização, a dureza Vickers do AlN não foi praticamente influenciada pela variação do tamanho de grão. Em relação à porosidade, observou-se que a porosidade do $\mathrm{AlN}$ aumentou com o aumento do teor de $\mathrm{CaO}$ (Figs. 7.5a e 7.7a a 7.7c) e permaneceu praticamente constante com o aumento do teor de $\mathrm{Y}_{2} \mathrm{O}_{3}$ (Figs. 7.5b e 7.7d a 7.7f). Como a dureza Vickers e a porosidade do AlN não variaram com o aumento do teor de $\mathrm{Y}_{2} \mathrm{O}_{3}$ e, sabendo que as referidas propriedades diminuíram com o aumento do teor de $\mathrm{CaO}$, pode-se dizer que a dureza Vickers do AlN diminuiu devido ao aumento de porosidade causado pelo aumento do teor de $\mathrm{CaO}$. Com base nos resultados de porosidade das amostras de $\mathrm{AlN}$ com adição tanto de $\mathrm{CaO}$ como de $\mathrm{Y}_{2} \mathrm{O}_{3}$ (Fig. 7.5) e, sabendo que as amostras de $\mathrm{AlN}$ com adição de $0,5 \%$ a $2 \%$ de $\mathrm{CaO}$ e com adição de $0,5 \%$ a $4 \%$ de $\mathrm{Y}_{2} \mathrm{O}_{3}$ apresentaram valores próximos de dureza Vickers (Fig. 7.9a), pode-se dizer que a presença de até cerca de 3\% de porosidade no AlN causou pouca influência nesta propriedade mecânica.

O aumento da carga de indentação de $0,5 \mathrm{kgf}$ para $2 \mathrm{kgf}$ não mudou os valores de dureza Vickers do AlN (Fig. 7.9b), independente do tipo e teor de aditivo de sinterização. Porém, a utilização de uma carga de indentação de $20 \mathrm{kgf}$ levou à determinação de valores de dureza Vickers de 8,9 GPa para o AlN com 2\% em massa de $\mathrm{CaO}$ e de 9,5 GPa para o AlN com 4\% em massa de $\mathrm{Y}_{2} \mathrm{O}_{3} .{ }^{78}$ Estes valores de dureza Vickers foram significativamente menores do que os valores determinados com menores cargas de indentação (Tabela 7.2 e Fig. 
7.9), o que sugeriu que a dureza Vickers pode ser influenciada pela aplicação de elevadas cargas de indentação.

\subsubsection{Tenacidade à fratura}

Os perfis das trincas geradas por indentação Vickers nas amostras de AlN com adição tanto de $\mathrm{CaO}$ como de $\mathrm{Y}_{2} \mathrm{O}_{3}$ mostraram evidências da ocorrência de dois mecanismos de tenacificação (indicações 1 e 2, Figs. 7.11 e 7.12): 1) engastamento (interlocking) mecânico e escorregamento (sliding) com atrito das superfícies de fratura na zona de processo da cauda da trinca e 2) ponteamento de trinca (crack bridging). Estes resultados sugeriram que as amostras de $\mathrm{AlN}$ com adição tanto de $\mathrm{CaO}$ como de $\mathrm{Y}_{2} \mathrm{O}_{3}$ podem apresentar comportamento de curva R (Fig. 2.7), ou seja, a tenacidade à fratura pode aumentar significativamente com o aumento do tamanho da trinca devido à ativação dos dois mecanismos de tenacificação associados com a zona de processo da cauda da trinca.

Os resultados de literatura (Tabela 7.2) mostraram que os valores de $\mathrm{K}_{\mathrm{Ic}}$ das amostras de AlN com adição tanto de $\mathrm{CaO}$ como de $\mathrm{Y}_{2} \mathrm{O}_{3}$ variaram em função do método de determinação. Por exemplo, o AlN com 5\% em massa de $\mathrm{Y}_{2} \mathrm{O}_{3}$ apresentou os seguintes valores de tenacidade à fratura $\left(\mathrm{K}_{\mathrm{Ic}}\right):{ }^{87} 2,1 \mathrm{MPa} \cdot \mathrm{m}^{1 / 2}$ pelo método IF (Indentation Fracture), 3,0 MPa.m ${ }^{1 / 2}$ pelo método SCF (Surface Crack in Flexure) e 4,2 $\mathrm{MPa}^{1 / 2}$ pelo método SENB (Single Edge Noched Beam). Como o tamanho da pré-trinca aumentou em função do método de determinação de $\mathrm{K}_{\mathrm{Ic}}(\sim 173 \mu \mathrm{m}$ para IF, $\sim 648 \mu \mathrm{m}$ para $\mathrm{SCF}$ e $\sim 1,76 \mathrm{~mm}$ para SENB), Narita ${ }^{87}$ indicou que a tenacidade à fratura do AlN com $\mathrm{Y}_{2} \mathrm{O}_{3}$ aumentou em função do aumento do tamanho da pré-trinca e, então, sugeriu que este material apresentou comportamento de curva R. Ichimaru \& Pezzotti ${ }^{228}$ constataram que o AlN com 5\% em massa de $\mathrm{Y}_{2} \mathrm{O}_{3}$ apresentou comportamento de curva $\mathrm{R}$ devido à ativação do mecanismo de engastamento mecânico e escorregamento com atrito das superfícies de fratura. Estes resultados corroboram com a interpretação de que as amostras de AlN com adição tanto de $\mathrm{CaO}$ como de $\mathrm{Y}_{2} \mathrm{O}_{3}$ podem apresentar comportamento de curva $\mathrm{R}$, pois estas amostras mostraram indícios de tenacificação por (indicações 1 e 2, Figs. 7.11 e 7.12): 1) engastamento mecânico e escorregamento com atrito das superfícies de fratura e 2) ponteamento de trinca.

$\mathrm{Na}$ Figura 7.18, verificou-se que os tamanhos dos defeitos iniciadores de fratura calculados $\left(\mathrm{c}_{\text {calc }}\right)$ a partir dos resultados de $\mathrm{K}_{\mathrm{Ic}-\mathrm{IF}}$ foram menores do que os tamanhos de 
defeitos determinados $\left(\mathrm{c}_{\mathrm{det}}\right)$ por análise fractográfica, o que indicou a não ocorrência de boa correlação entre os valores medidos de $\mathrm{K}_{\mathrm{Ic}-\mathrm{IF}}$ e $\sigma_{\mathrm{f}, \mathrm{b}}$ para as amostras de AlN com adição tanto de $\mathrm{CaO}$ como de $\mathrm{Y}_{2} \mathrm{O}_{3}$. Estes resultados indicaram que os valores de $\mathrm{K}_{\text {Ic-IF }}$ foram subestimados para as amostras de $\mathrm{AlN}$ com aditivos de sinterização $\left(\mathrm{CaO}\right.$ e $\left.\mathrm{Y}_{2} \mathrm{O}_{3}\right)$, segundo a equação do critério de falha de Irwin-Griffith (eq. 2.22). Por outro lado, observou-se que parte dos tamanhos dos defeitos iniciadores de fratura calculados $\left(\mathrm{c}_{\text {calc }}\right)$ a partir dos resultados de $\mathrm{K}_{\mathrm{Ic}-\mathrm{IS}}$ se aproximaram dos tamanhos dos defeitos determinados $\left(\mathrm{c}_{\mathrm{det}}\right)$ por análise fractográfica (Fig. 7.18), o que mostrou uma boa correlação entre os valores medidos de $\mathrm{K}_{\mathrm{Ic}-\mathrm{IS}} \mathrm{e} \sigma_{\mathrm{f}, \mathrm{b}}$ das amostras de $\mathrm{AlN}$ com adição tanto de $\mathrm{CaO}$ como de $\mathrm{Y}_{2} \mathrm{O}_{3}$. Portanto, os valores de $\mathrm{K}_{\text {Ic-IS }}$ foram considerados os valores de tenacidade à fratura das amostras de $\mathrm{AlN}$ com adição tanto de $\mathrm{CaO}$ como de $\mathrm{Y}_{2} \mathrm{O}_{3}$.

Os resultados de $\mathrm{K}_{\mathrm{Ic}-\mathrm{IS}}$ mostraram que a tenacidade à fratura do $\mathrm{AlN}$ não foi praticamente influenciada pelo tipo $\left(\mathrm{CaO}\right.$ e $\left.\mathrm{Y}_{2} \mathrm{O}_{3}\right)$ e teor $(0,5 \%$ a $4 \%$ em massa) de aditivo de sinterização (Fig. 7.13), pois a tenacidade à fratura determinada pelo método IS apresentou um valor médio próximo de 2,8 $\mathrm{MPa}^{1 / 2}$. Este valor de tenacidade foi considerado admissível para o AlN com adição tanto de $\mathrm{CaO}$ como de $\mathrm{Y}_{2} \mathrm{O}_{3}$, pois foi próximo dos valores de tenacidade à fratura reportados para a cerâmica de AlN (Tabelas 7.1 e 7.2). Witek et al. ${ }^{80}$ indicaram que o valor de tenacidade à fratura determinada pelo método IS foi cerca de duas vezes maior do que o valor de tenacidade à fratura determinada pelo método IF, similar ao observado para o AlN com 0,5\% e 1\% de $\mathrm{CaO}$ e com 0,5\% a 4\% de $\mathrm{Y}_{2} \mathrm{O}_{3}$ (Figs. 7.10 e 7.13). A ocorrência de valores de $\mathrm{K}_{\text {Ic-IF }}$ próximos de $1,4 \mathrm{MPa}^{1 / 2}$ (Fig. 7.10) foi considerada incompatível com a cerâmica de $\mathrm{AlN}$, pois valores de tenacidade à fratura próximos de 1 MPa.m ${ }^{1 / 2}$ são observados freqüentemente em alguns materiais vítreos. ${ }^{115}$ Estes resultados reforçam a interpretação de que os resultados de $\mathrm{K}_{\mathrm{Ic}-\mathrm{IS}}$ foram mais condizentes para expressar a tenacidade à fratura do $\mathrm{AlN}$ com adição de $0,5 \%$ a $4 \%$ de $\mathrm{CaO}$ ou de $\mathrm{Y}_{2} \mathrm{O}_{3}$.

A relação entre resistência à flexão $\left(\sigma_{f}\right)$ e tenacidade à fratura $\left(K_{I c}\right)$ do AlN com adição tanto de $\mathrm{CaO}$ como de $\mathrm{Y}_{2} \mathrm{O}_{3}$ apresentou certa inconsistência com os resultados de literatura, que mostram duas tendências de comportamento para a relação entre $\sigma_{\mathrm{f}}$ e $\mathrm{K}_{\mathrm{Ic}}$. Na primeira, $\sigma_{\mathrm{f}}$ diminui com a diminuição de $\mathrm{K}_{\mathrm{Ic}}{ }^{202} \mathrm{e}$, na segunda, $\sigma_{\mathrm{f}}$ aumenta com a diminuição de $\mathrm{K}_{\mathrm{Ic}}{ }^{80,123}$ No presente trabalho, os resultados experimentais foram inconsistentes em relação aos resultados de literatura, pois $\sigma_{\mathrm{f}, \mathrm{b}}$ diminuiu sem ocorrer variação de $\mathrm{K}_{\mathrm{Ic}-\mathrm{IS}}$ entre $0,5 \%$ e $1 \%$ de $\mathrm{CaO}$ e entre $2 \%$ e $4 \%$ de $\mathrm{Y}_{2} \mathrm{O}_{3}$ (Figs. 7.6 e 7.13 , respectivamente). Os resultados de $\mathrm{K}_{\text {Ic-IF }}$ foram desconsiderados no presente trabalho porque subestimaram os valores de tenacidade à 
fratura do AlN, mas também apresentaram certa inconsistência em relação aos resultados de literatura, como, por exemplo: i) na condição entre $1 \%$ e $8 \%$ de $\mathrm{CaO}$, onde o aumento de $\mathrm{K}_{\mathrm{Ic}-}$ IF (Fig. 7.10) não resultou em mudanças significativas em $\sigma_{f, b}$ (Fig. 7.6) e ii) na condição entre $2 \%$ e $4 \%$ de $\mathrm{Y}_{2} \mathrm{O}_{3}$, onde $\sigma_{\mathrm{f}, \mathrm{b}}$ diminuiu (Fig. 7.6) sem ocorrer variação significativa nos valores de $K_{\text {Ic-IF }}$ (Fig. 7.10). Estas inconsistências tanto de $K_{\text {Ic-IS }}$ e $\sigma_{f, b}$ como de $K_{\text {Ic-IF }}$ e $\sigma_{f, b}$ em relação aos resultados de literatura não puderam ser explicadas com bases nos resultados experimentais apresentados no presente trabalho. Porém, parte dos resultados do presente trabalho mostrou uma boa correlação entre $\mathrm{K}_{\mathrm{Ic}-\mathrm{IS}}$ e $\sigma_{\mathrm{f}, \mathrm{b}}$ entre $1 \%$ e $8 \%$ de $\mathrm{CaO}$ e entre $0,5 \%$ e $2 \%$ de $\mathrm{Y}_{2} \mathrm{O}_{3}$ (Figs. 7.13 e 7.6, respectivamente), pois se observou que as duas propriedades mecânicas não apresentaram variações significativas em função do aumento do teor de aditivo de sinterização. Entretanto, os valores de $\sigma_{f, b}$ do AlN com 0,5\% e 2\% de $\mathrm{Y}_{2} \mathrm{O}_{3}$ foram significativamente maiores do que os valores de $\sigma_{\mathrm{f}, \mathrm{b}}$ do $\mathrm{AlN}$ com $1 \%$ a $4 \%$ de $\mathrm{CaO}$ (Fig. 7.6), o que deveria resultar em diferentes valores de $\mathrm{K}_{\mathrm{Ic}-\mathrm{IS}}$, o que não aconteceu nestas faixas de teores de aditivos de sinterização (Fig. 7.13). Estes resultados mostraram que os resultados de tenacidade à fratura determinada pelo método IS $\left(\mathrm{K}_{\mathrm{Ic}-\mathrm{IS}}\right)$ foram conflitantes com os resultados de resistência à flexão $\left(\sigma_{\mathrm{f}, \mathrm{b}}\right)$ do $\mathrm{AlN}$ com adição tanto de $\mathrm{CaO}$ como de $\mathrm{Y}_{2} \mathrm{O}_{3}$. Contudo, os valores de $\mathrm{K}_{\mathrm{Ic}-\mathrm{IS}}\left(\sim 2,8 \mathrm{MPa} \cdot \mathrm{m}^{1 / 2}\right)$ foram considerados admissíveis para as cerâmicas de AlN com aditivos de sinterização $\left(\mathrm{CaO}\right.$ e $\left.\mathrm{Y}_{2} \mathrm{O}_{3}\right)$, quando comparados com os valores de tenacidade à fratura da cerâmica de alumina com resistência à flexão equivalente.

\subsection{Conclusões}

As amostras de AlN com adição de $0,5 \%$ a $8 \%$ de $\mathrm{CaO}$ e com adição de $0,5 \%$ a $4 \%$ de $\mathrm{Y}_{2} \mathrm{O}_{3}$ foram sinterizadas a $1800^{\circ} \mathrm{C}$ e, então, verificou-se o efeito do teor de aditivo de sinterização nas propriedades mecânicas do AlN, o que possibilitou obter as seguintes conclusões:

- O módulo de Young do AlN não foi praticamente influenciado pelo tipo e teor de aditivo de sinterização, mas foi influenciado fortemente pela porosidade;

- A resistência à flexão do AlN foi influenciada pelo tipo e teor de aditivo de sinterização; observou-se um valor crítico de teor de aditivo, acima do qual a resistência à flexão diminuiu significativamente e, então, mostrou uma tendência a permanecer constante com 
o aumento do teor de aditivo. Este valor crítico de teor de aditivo de sinterização foi próximo de $0,5 \%$ para o $\mathrm{AlN}$ com $\mathrm{CaO}$ e próximo de $2 \%$ para o $\mathrm{AlN}$ com $\mathrm{Y}_{2} \mathrm{O}_{3}$. A diminuição da resistência à flexão foi atribuída à mudança do modo de fratura do AlN de transgranular para intergranular, o que mostrou que esta propriedade mecânica foi controlada pela resistência contorno de grão, que por sua vez foi influenciada pela natureza das segundas-fases;

- A Dureza Vickers não foi praticamente influenciada pelo tipo e teor de aditivo de sinterização, mas foi influenciada pelo aumento de porosidade. A variação na carga de indentação de 0,5 kgf para 2 kgf não influenciou a dureza Vickers, independente do tipo e teor de aditivo de sinterização;

- Os resultados de tenacidade à fratura determinada tanto pelo método IF (Indentation Fracture) como pelo método IS (Indentation Strength) foram conflitantes com os resultados de resistência à flexão biaxial, independente do tipo de aditivo de sinterização empregado. Entretanto, os valores de tenacidade à fratura determinados pelo método IS foram mais condizentes com os resultados de resistência mecânica. $\mathrm{O}$ valor médio de tenacidade à fratura do $\mathrm{AlN}$ com $0,5 \%$ a $4 \%$ de $\mathrm{CaO}$ ou de $\mathrm{Y}_{2} \mathrm{O}_{3}$ foi próximo de 2,8 MPa.m ${ }^{1 / 2}$, o que mostrou que esta propriedade mecânica não foi praticamente influenciada pelo tipo e teor de aditivo de sinterização. 


\section{Comentários finais}

A cerâmica de AlN com $0,5 \%$ a $4 \%$ em massa de $\mathrm{Y}_{2} \mathrm{O}_{3}$ apresenta temperatura de formação da fase líquida ao redor de $1725^{\circ} \mathrm{C}$, que é próxima da temperatura eutética $\left(\sim 1720^{\circ} \mathrm{C}\right)$ mais baixa prevista no diagrama de fases do sistema ternário $\mathrm{AlN}-\mathrm{Y}_{2} \mathrm{O}_{3}-\mathrm{Al}_{2} \mathrm{O}_{3}$. Em decorrência da elevada temperatura de formação da fase líquida, o AlN com $\mathrm{Y}_{2} \mathrm{O}_{3}$ apresenta uma significativa densificação $(\sim 50 \%$ da densificação total) por sinterização no estado sólido até cerca de $1700^{\circ} \mathrm{C}$. Já a temperatura de formação da fase líquida do AlN com aditivo contendo cálcio $\left(\mathrm{CaCO}_{3}\right.$ ou $\left.\mathrm{CaO}\right)$ varia em função do teor de aditivo de sinterização. Pequenas quantidades de $\mathrm{CaO}(0,5 \%$ a $1 \%$ em massa) promovem a formação de fase líquida ao redor de $1600^{\circ} \mathrm{C}$, enquanto adições acima desta faixa de teor de aditivo $(2 \%$ a $8 \%$ em massa) promovem a formação de fase líquida em menores temperaturas $\left(\leq 1500^{\circ} \mathrm{C}\right)$. Estes resultados indicam que o AlN com aditivo contendo cálcio atinge completa densificação em menor temperatura de sinterização do que o AlN com $\mathrm{Y}_{2} \mathrm{O}_{3}$. Porém, as cerâmicas de $\mathrm{AlN}$ com adição tanto de $\mathrm{CaO}$ como de $\mathrm{Y}_{2} \mathrm{O}_{3}$ apresentam temperaturas de sinterização relativamente próximas. Estes resultados indicam que o AlN com aditivo contendo cálcio tem uma densificação mais lenta do que o $\mathrm{AlN}$ com $\mathrm{Y}_{2} \mathrm{O}_{3}$.

$\mathrm{O}$ AlN com $\mathrm{Y}_{2} \mathrm{O}_{3}$ precisa de pequenos superaquecimentos $\left(\leq 75^{\circ} \mathrm{C}\right)$, acima da temperatura de formação da fase líquida $\left(\sim 1725^{\circ} \mathrm{C}\right)$, para atingir completa densificação. Isto mostra que a fase líquida tem boas características de molhamento e espalhamento durante a sinterização, o que maximiza a ação dos mecanismos de sinterização via fase líquida. Já o AlN com aditivo contendo cálcio $\left(\mathrm{CaCO}_{3}\right.$ ou $\left.\mathrm{CaO}\right)$ precisa de elevados superaquecimentos $\left(\geq 300^{\circ} \mathrm{C}\right)$ para atingir completa densificação. Isto ocorre porque os aluminatos de cálcio com baixo ponto de fusão $\left(\sim 1400^{\circ} \mathrm{C}\right)$ apresentam alta viscosidade e/ou baixa molhabilidade no AlN até cerca de $1600^{\circ} \mathrm{C}$, o que dificulta a densificação do $\mathrm{AlN}$ em baixas temperaturas de sinterização. Embora o AlN com mistura de $\mathrm{Y}_{2} \mathrm{O}_{3}$ e $\mathrm{CaO}$ tenha apresentado lenta densificação em relação ao $\mathrm{AlN}$ com $\mathrm{CaO}$ em baixas temperaturas de sinterização $\left(\leq 1600^{\circ} \mathrm{C}\right)$, sua completa densificação ocorre a partir de $1650^{\circ} \mathrm{C}$, o que indica uma melhora significativa nas características de molhamento e espalhamento da fase líquida acima de $1600^{\circ} \mathrm{C}$ com a coadição de $\mathrm{Y}_{2} \mathrm{O}_{3}$ e $\mathrm{CaO}$. Estes resultados mostram que o comportamento de densificação do AlN é pouco influenciado pela temperatura de formação da fase líquida, pois é fortemente dependente das características de molhamento e espalhamento da fase líquida presente durante a sinterização. 
A utilização de grafita como aditivo de sinterização leva à formação in situ de uma atmosfera redutora no interior do corpo conformado durante a sinterização. Este procedimento tem sido utilizado para melhorar a condutividade térmica do AlN com $\mathrm{Y}_{2} \mathrm{O}_{3}$. Porém, o comportamento de densificação do $\mathrm{AlN}$ com $\mathrm{Y}_{2} \mathrm{O}_{3}$ é fortemente influenciado pela adição de grafita, que muda as composições das segundas-fases de $\mathrm{xY}_{2} \mathrm{O}_{3} \cdot \mathrm{yAl}_{2} \mathrm{O}_{3}$ para $\mathrm{Y}_{2} \mathrm{O}_{3}$ durante a sinterização, o que aumenta significativamente a temperatura de formação da fase líquida, ou seja, atrasa a densificação. Aparentemente não há relatos na literatura sobre o efeito da adição de grafita na condutividade térmica ou na densificação do AlN com adição tanto de $\mathrm{CaO}$ como da mistura de $\mathrm{Y}_{2} \mathrm{O}_{3}$ e $\mathrm{CaO}$. No presente trabalho, constatou-se que a evolução das segundas-fases do $\mathrm{AlN}$ com $\mathrm{CaO}$ não é influenciada pela adição de grafita, pois as composições das segundas-fases apresentam tendência para mudar de $\mathrm{xCaO}^{\mathrm{yAl}} \mathrm{Al}_{2} \mathrm{O}_{3}$ para $\mathrm{CA}$ $\left(\mathrm{CaO} \cdot \mathrm{Al}_{2} \mathrm{O}_{3}\right)$ durante a sinterização acima de $1650^{\circ} \mathrm{C}$, independente da atmosfera de sinterização (inerte ou redutora). Isto mostra que a temperatura de formação da fase líquida do AlN com $\mathrm{CaO}$ não é influenciada pela adição da grafita, pelo menos durante a sinterização em altas temperaturas $\left(\geq 1650^{\circ} \mathrm{C}\right)$. Já a evolução das segundas-fases do AlN com mistura de $\mathrm{Y}_{2} \mathrm{O}_{3}$ e $\mathrm{CaO}$ é influenciada pela adição de grafita, pois as composições das segundas-fases mudam para fases mais ricas em $\mathrm{Y}_{2} \mathrm{O}_{3}\left(\mathrm{CaYAl}_{3} \mathrm{O}_{7} \rightarrow \mathrm{CaYAlO}_{4} \rightarrow \mathrm{YAM}, 2 \mathrm{Y}_{2} \mathrm{O}_{3} \cdot \mathrm{Al}_{2} \mathrm{O}_{3}\right)$ com o aumento do grau de redução da atmosfera de sinterização. Neste caso, o comportamento de densificação do AlN é fortemente influenciado pela adição de grafita, pois a fase $\mathrm{CaYAlO}_{4}$ apresenta alta viscosidade e/ou baixa molhabilidade no $\mathrm{AlN}$ abaixo de $1700^{\circ} \mathrm{C}$ e a fase YAM apresenta alta refratariedade, isto é, funde somente acima de $1800^{\circ} \mathrm{C}$.

O AlN atinge elevada resistência mecânica (420-460 MPa) com adições de até 0,5\% em massa de $\mathrm{CaO}$ ou com adições de até $2 \%$ em massa de $\mathrm{Y}_{2} \mathrm{O}_{3}$. Estes resultados mostram a existência de um antagonismo entre resistência mecânica e condutividade térmica, pois o AlN atinge elevada condutividade térmica (140-180 W/mK) somente com adições de 3\% a 5\% em massa de $\mathrm{CaO}$ ou de $\mathrm{Y}_{2} \mathrm{O}_{3}$. Nestas faixas de teores de aditivos, a resistência mecânica do AlN apresenta tendência para permanecer constante em torno de 300 a $360 \mathrm{MPa}$, o que mostra que o AlN com elevada condutividade térmica pode apresentar apenas valores moderados de resistência mecânica. A variação do teor de $\mathrm{CaO}$ ou de $\mathrm{Y}_{2} \mathrm{O}_{3}$, entre $0,5 \%$ e $4 \%$ em massa, causa pouca influência no comportamento de densificação do AlN, o que mostra que a otimização da resistência mecânica ou da condutividade térmica por meio da variação do teor de aditivo não atrasa a densificação do AlN. 


\section{Referências}

1) HOAGLAND, R.W. Switchmode power supply miniaturization with emphasis on integrated passive components on prefired high performance ceramic substrates. 1999. 248 p. Doctor of Philosophy - Faculty of the Virginia Polytechnic Institute and State University, Blacksburg, 1999.

2) ROY, R. Ceramic packaging for electronics. Key Engineering Materials, v. 123-124, p. 17-34, 1996.

3) DESCAMPS, M.; MOREAU, G.; MASCART, M.; THRENV, B. Processing of aluminum nitride powder by the tape-casting process. Journal of the European Ceramics Society, v. 13, p. 221-228, 1994.

4) LOSTETTER, A.B.; BARLOW, F.; ELSHABINI, A. An overview to integrated power module design for high power electronics packaging. Microelectronics Reliability, v. 40, p. 365-379, 2000.

5) BAILEY, A.E. Cap. 3: Ceramics and Glasses. In: Electronic Materials and Processes Handbook. The McGraw-Hill Companies, 2004 - Disponível em: www.digitalengineeringlibrary.com. Acesso em: 09/maio/2006.

6) ENTEZARIAN, M.; DREW, R.A.L. Direct bonding of copper to aluminum nitride. Materials Science and Engineering, v. A212, p. 206-212, 1996.

7) GROVENOR, C.R.M. Microelectronic Materials. IOP Publishing Ltda, 1989. Cap. 7.3: Substrate materials, p. 326-332.

8) JARRIGE, J.; JOYEUX, T.; LECOMPTE, J.P.; LABBE, J.C. Influence of oxygen on the joining between copper and aluminium nitride. Journal of the European Ceramic Society, v. 27, n. 1, p. 337-341, 2007.

9) JARRIGE, J.; JOYEUX, T.; LECOMPTE, J.P.; LABBE, J.C. Comparison between two processes using oxygen in the $\mathrm{Cu} / \mathrm{AlN}$ bonding. Journal of the European Ceramic Society, v. 27, n. 2-3, p. 855-860, 2007.

10) BOURSAT, B.; DUTARDE, E.; MARTIN, N.; SOLOMALALA, P.; SAIZ, J. Substrate for an electronic power circuit, and an electronic power module using such a substrate. US 6,586,783, July 12003. 
11) KUNEMAN, J.E.; DICKSON, J.F. Direct bond copper ceramic substrate for electronic applications. US 4,563,383, January 7, 1986.

12) NING, H.; MA, J.; HUANG, F.; WANG, Y.; LI, Q.; LI, X. Pre-oxidation of the Cu layer in direct bonding technology, Applied Surface Science, v. 211, p. 250-258, 2003.

13) NING, H.; MA, J.; HUANG, F.; WANG, Y.; ZHU, J.; ZHITING, G. Investigation of the interface of the DBC substrate. Surface Review and Letters, v. 10, n. 1, p. 95-99, 2003.

14) YI, S.; TRUMBLE, K.P.; GASKELL, D.R. Thermodynamic analysis of aluminate stability in the eutectic bonding of copper with alumina. Acta Materialia, v. 47, n. 11, p. 3221-3226, 1999.

15) BAIK, Y.; DREW, R.A.L. Aluminum nitride: processing and applications. Key Engineering Materials, v. 122-124, p. 553-570, 1996.

16) KNUDSEN, A.K. Aluminum nitride. American Ceramic Society Bulletin, v. 74, n. 6, p. 97-98, 1995.

17) SHEPPARD, L.M. Aluminum nitride: a versatile but challenging material. American Ceramic Society Bulletin, v. 69, n. 11, p. 1801-1812, 1990.

18) LEE, R.-R. Development of high thermal conductivity aluminum nitride ceramic. Journal of the American Ceramic Society, v. 74, n. 9, p. 2242-2249, 1991.

19) SCHWETZ, K.A.; KNOCH, H.; LIPP, A. Sintering of aluminum nitride with low oxide addition. In: Progress In Nitrogen Ceramics, 1981, University of Sussex, Falmer, UK, p. 245-252.

20) JARRIGE, J.; LECOMPTE, J.P.; MULLOT, J.; MULLER, G. Effect of oxygen on the thermal conductivity of aluminium nitride ceramics. Journal of the European Ceramic Society, v. 17, n. 15-16, p. 1891-1895, 1997.

21) SLACK, G.A. Nonmetallic crystals with high thermal conductivity. Journal Phys. Chem. Solids, v. 34, p. 321-335, 1973.

22) SLACK, G.A.; TANZILLI, R.A.; POHL, R.O.; VANDERSANDE, J.W. The intrinsic thermal conductivity of AlN. Journal Phys. Chem. Solids, v. 48, n. 7, p. 641-647, 1987. 
23) VIRKAR, A.V.; JACKSON, T.B.; CUTLER, R.A. Thermodynamic and kinetic effects of oxygen removal on the thermal conductivity of aluminum nitride. Journal of the American Ceramic Society, v. 72, n. 11, p. 2031-2042, 1989.

24) SAKAI, T.; IWATA, M. Effect of oxygen on sintering of AlN. Journal of Materials Science, v. 12, n. 8, p. 1659-1665, 1977.

25) SAKAI, T.; KURIYAMA, M.; INUKAI, T.; KIZIMA, T. Effect of the oxygen impurity on the sintering and the thermal conductivity of AlN polycrystal. Yogyo-Kyokai-Shi, v. 86, n. 4, p. 174-179, 1978.

26) KUROKAWA, Y.; UTSUMI, K.; TAKAMIZAWA, H. Development and microstructural characterization of high-thermal-conductivity aluminum nitride ceramics. Journal of the American Ceramic Society, v. 71, n. 7, p. 588-594, 1988.

27) PARK, Y.-W.; CHOI, S.-C. Sintering behavior and microstructural morphology of AlN system. In: Third Euro-Ceramic, 1993, San Vicente, Spain, p. 955-960.

28) DA CRUZ, A.C.; MUNZ, R.J.; VALI, H. The densification and microstructure development os sintered aluminum nitride ultrafine powder produced in a two-stage transferred-arc plasma reactor. Journal of Materials Science Letters, v. 17, p. 1255-1261, 1998.

29) IDE, T.; KOMEYA, K.; MEGURO, T.; TATAMI, J. Synthesis of AlN powder by carbothermal reduction-nitridation of various $\mathrm{Al}_{2} \mathrm{O}_{3}$ powders with $\mathrm{CaF}_{2}$. Journal of the American Ceramic Society, v. 82, n. 11, p. 2993-2998, 1999.

30) IDE, T.; KOMEYA, K.; TATAMI, J.; MEGURO, T.; NAITO, M.; HOTTA, T. Effect of $\mathrm{Y}_{2} \mathrm{O}_{3}$ addition on synthesis of AIN powder by carbothermal reduction-nitridation of $\mathrm{Al}_{2} \mathrm{O}_{3}$. Journal of the Ceramic Society of Japan, v. 109, n. 4, p. 372-375, 2001.

31) KAMESHIMA, Y.; IRIE, M.; YASUMORI, A.; OKADA, K. Mechanochemical effect on low temperature synthesis of AIN by direct nitridation method. Solid State Ionics, v. 172, n. 1-4, p. 185-190, 2004.

32) KAMESHIMA, Y.; IRIE, M.; YASUMORI, A.; OKADA, K. Low temperature synthesis of AlN by addition of various Li-salts. Journal of the European Ceramic Society, v. 24, n. 15-16, p. 3801-3806, 2004.

33) SELVADURAY, G.; SHEET, L. Aluminum nitride - Review of synthesis methods. Materials Science and Technology, v. 9, n. 6, p. 463-473, 1993. 
34) KOMEYA, K.; KITAGAWA, I.; MEGURO, T. Effect of Ca-compound addition on synthesis of AlN powder by carbothermal reduction-nitridation method. Journal of the Ceramic Society of Japan, v. 102, n. 7, p. 670-674, 1994.

35) KOMEYA, K.; MITSUHASHI, E.; MEGURO, T. Synthesis of AlN powder by carbothermal reduction-nitridation method - Effect of additives on reaction rate. Journal of the Ceramic Society of Japan, v. 101, n. 4, p. 377-382, 1993.

36) DE BARANDA, P.S.; KNUDSEN, A.K.; RUH, E. Effect of silica on the thermal conductivity of aluminum nitride. Journal of the American Ceramic Society, v. 76, n. 7, p. 1761-1771, 1993.

37) DE BARANDA, P.S.; KNUDSEN, A.K.; RUH, E. Effect of $\mathrm{CaO}$ on the thermal conductivity of aluminum nitride. Journal of the American Ceramic Society, v. 76, n. 7, p. 1751-1760, 1993.

38) DE BARANDA, P.S.; KNUDSEN, A.K.; RUH, E. Effect of yttria on the thermal conductivity of aluminum nitride. Journal of the American Ceramic Society, v. 77, n. 7, p. 1846-1850, 1994.

39) JACKSON, T.B.; VIRKAR, A.; MORE, K.L.; DINWIDDIE, R.B., JR.; CUTLER, R.A. High-thermal-conductivity aluminum nitride ceramic: The effect of thermodynamic, kinetic, and microstructural factors. Journal of the American Ceramic Society, v. 80, n. 6, p. 1421$1435,1997$.

40) JARRIGE, J.; BOUZOUITA, K.; DORADOUX, C.; BILLY, M. A new method for fabrication of dense aluminum nitride bodies at temperatures as low as $1600^{\circ} \mathrm{C}$. Journal of the European Ceramic Society, v. 12, n. 4, p. 279-285, 1993.

41) KOMEYA, K.; INOUE, H.; TSUGE, A. Effect of various additives on sintering of aluminum nitride. Yogyo-Kyokai-Shi, v. 89, n. 6, p. 330-336, 1981.

42) WATARI, K.; HWANG, H.J.; TORIYAMA, M.; KANZAKI, S. Low-temperature sintering and high thermal conductivity of $\mathrm{YLiO}_{2}$ doped AlN ceramics. Journal of the American Ceramic Society, v. 79, n. 7, p. 1979-1981, 1996.

43) WATARI, K.; HWANG, H.J.; TORIYAMA, M.; KANZAKI, S. Effective sintering aids for low-temperature sintering of AIN ceramics. Journal of Materials Research, v. 14, n. 4, p. 1409-1417, 1999.

44) WATARI, K.; VALECILLOS, M.C.; BRITO, M.E.; TORIYAMA, M.; KANZAKI, S. Densification and thermal conductivity of AlN doped with $\mathrm{Y}_{2} \mathrm{O}_{3}, \mathrm{CaO}$, and $\mathrm{Li}_{2} \mathrm{O}$. Journal of the American Ceramic Society, v. 79, n. 12, p. 3103-3108, 1996. 
45) BUHR, H.; MULLER, G. Microstructure and thermal-conductivity of AlN $\left(\mathrm{Y}_{2} \mathrm{O}_{3}\right)$ ceramics sintered in different atmospheres. Journal of the European Ceramic Society, v. 12, n. 4, p. 271-277, 1993.

46) EINARSRUD, M.-A.; HUNDERE, A.M. Influence of carbon reducing atmosphere on the sintering of aluminum nitride (AIN). In: Third Euro-Ceramic, 1993, San Vicente, Spain, p. 919-924.

47) HUNDERE, A.M.; EINARSRUD, M.A. Effects of reduction of the Al-Y-O containing secondary phases during sintering of AlN with $\mathrm{YF}_{3}$ additions. Journal of the European Ceramic Society, v. 16, n. 8, p. 899-906, 1996.

48) ICHINOSE, N. Effect of carbon-reducing atmosphere on the properties of aluminum nitride (AIN). Materials Chemistry and Physics, v. 42, n. 3, p. 176-180, 1995.

49) NAKAMATSU, T.; POMAR, F.; ISHIZAKI, K. The effect of carbon coating of AlN powder on sintering behavior and thermal conductivity. Journal of Materials Science, v. 34, p. 1553-1556, 1999.

50) WATARI, K.; KAWAMOTO, M.; ISHIZAKI, K. Sintering chemical reactions to increase thermal conductivity of aluminium nitride. Journal of Materials Science, v. 26, p. 4727-4732, 1991.

51) MITRA, S.; DUTTA, G.; DUTTA, I. Effect of heat-treatment on the microstructure and properties of dense AlN sintered with $\mathrm{Y}_{2} \mathrm{O}_{3}$ additions. Journal of the American Ceramic Society, v. 78, n. 9, p. 2335-2344, 1995.

52) PEZZOTTI, G.; NAKAHIRA, A.; TAJIKA, M. Effect of extended annealing cycles on the thermal conductivity of $\mathrm{AlN} / \mathrm{Y}_{2} \mathrm{O}_{3}$ ceramics. Journal of the European Ceramic Society, v. 20, p. 1319-1325, 2000.

53) RAGHAVAN, N.S. Pressureless sintering of aluminium nitride: Effect of concentration of additives and sintering conditions on properties. Material Science and Engineering A, v. 148, p. 307-317, 1991.

54) KASORI, M.; UENO, F. Thermal-conductivity improvement of YAG added AlN ceramics in the grain-boundary elimination process. Journal of the European Ceramic Society, v. 15, n. 5, p. 435-443, 1995.

55) LAI, G.-C.; NAGAI, Y. Effect of oxygen on sintering of Aluminum Nitride with $\mathrm{Y}_{2} \mathrm{O}_{3}$ Sintering Aid. Journal of the Ceramic Society of Japan, v. 103, n. 1, p. 6-10, 1995. 
56) YAN, H.; CANNON, W.R.; SHANEFIELD, D.J. Evolution of carbon during burnout and sintering of tape-cast aluminum nitride. Journal of the American Ceramic Society, v. 76, n. 1, p. 166-172, 1993.

57) GEITH, A.; KULIG, M.; HOFMANN, T.; RÜSSEL, C. Thermal conductivity of calciumdoped aluminum nitride ceramics: I. Conventionally produced ceramics. Journal of Materials Science, v. 28, p. 865-869, 1993.

58) HAGEN, E.; YU, Y.D.; GRANDE, T.; HOIER, R.; EINARSRUD, M.A. Sintering of AIN using $\mathrm{CaO}-\mathrm{Al}_{2} \mathrm{O}_{3}$ as a sintering additive: Chemistry and microstructural development. Journal of the American Ceramic Society, v. 85, n. 12, p. 2971-2976, 2002.

59) KURAMOTO, N.; TANIGUCHI, H.; ASO, I. Development of translucent aluminum nitride ceramics. American Ceramic Society Bulletin, v. 68, n. 4, p. 883-887, 1989.

60) MOLISANI, A.L. Sinterização de nitreto de alumínio com compostos contendo cálcio. 2004. 113 p. Dissertação (Mestrado) - Universidade de São Paulo, São Paulo, 2004.

61) MOLISANI, A.L.; YOSHIMURA, H.N.; GOLDENSTEIN, H.; WATARI, K. Effects of $\mathrm{CaCO}_{3}$ content on the densification of aluminum nitride. Journal of the European Ceramic Society, v. 26, n. 15, p. 3431-3440, 2006.

62) WANG, M.C.; HONG, C.K.; TSAI, M.S.; WU, N.C. Sintering of ultrafine aluminum nitride powder added with calcium cyanamide. Journal of the Ceramic Society of Japan, v. 108, n. 10, p. 869-875, 2000.

63) WANG, M.C.; YANG, C.C.; WU, N.C. Densification and structural development in the sintering of AlN ceramics with $\mathrm{CaCN}_{2}$ additives. Journal of the European Ceramic Society, v. 21, n. 12, p. 2185-2192, 2001.

64) WANG, M.C.; YANG, C.C.; WU, N.C. Grain growth and electric properties of liquid phase sintered $\mathrm{AlN}$ ceramics with $\mathrm{CaCN}_{2}$ additives. Materials Science and Engineering A, v. 343, n. 1-2, p. 97-106, 2003.

65) HASHIMOTO, N.; YODEN, H. Sintering behavior of fine aluminum nitride powder synthesized from aluminum polynuclear complexes. Journal of the American Ceramic Society, v. 75, n. 8, p. 2098-2106, 1992.

66) KOESTlER, C.; BeStGEN, H.; ROOSEN, A.; BOECKER, W. Microstrutural development during sintering of AlN ceramics. In: Third Euro-Ceramic, 1993, San Vicente, Spain, p. 913-918. 
67) TAJIKA, M.; RAFANIELLO, W.; NIIHARA, K. Sintering behavior of direct nitrided AlN powder. Materials Letters, v. 46, p. 98-104, 2000.

68) WATARI, K.; BRITO, M.E.; YASUOKA, M.; VALECILLOS, M.C.; KANZAKI, S. Influence of powder characteristics on sintering process and thermal-conductivity of aluminum nitride ceramics. Journal of the Ceramic Society of Japan, v. 103, n. 9, p. 891900, 1995.

69) KOMEYA, K.; TSUGE, A.; INOUE, H.; OHTA, H. Effect of $\mathrm{CaCO}_{3}$ addition on the sintering of AlN. Journal of Materials Science Letters, v. 1, p. 325-326, 1982.

70) BROWN, W.; ANG, S.; BARLOW, F.; RAILKAR, T. Chapter 3: Advance Packaging. In: Printed circuits handbook. The McGraw-Hill Companies, 2004 - Disponível em: www.digitalengineeringlibrary.com. Acesso em: 09/maio/2006.

71) TROCZYNSKI, T.B.; NICHOLSON, P.S. Effect of additive on the pressureless sintering of aluminum nitride between 1500 and $1800^{\circ} \mathrm{C}$. Journal of the American Ceramic Society, v. 72, n. 8, p. 1488-1491, 1989.

72) Aluminum nitride substrate manufactured by low-temperature sintering. Techno Japan, v. 32, n. 2, p. 70, 1999.

73) LIU, Y.C.; ZHOU, H.; QIAO, L.; WU, Y. Low-temperature sintering of aluminum nitride with $\mathrm{YF}_{3}-\mathrm{CaF}_{2}$ binary additive. Journal of Materials Science Letters, v. 18, p. 703-704, 1999.

74) OLHERO, S.M.; MIRANZO, P.; FERREIRA, J.M.F. Influence of the de-waxing atmosphere on the properties of AlN ceramics processed from aqueous media. Journal of the European Ceramic Society, v. 26, n. 13, p. 2475-2483, 2006.

75) QIAO, L.; ZHOU, H.P.; FU, R.L. Thermal conductivity of AIN ceramics sintered with $\mathrm{CaF}_{2}$ and $\mathrm{YF}_{3}$. Ceramics International, v. 29, n. 8, p. 893-896, 2003.

76) QIAO, L.A.; ZHOU, H.P.; XUE, H.; WANG, S.H. Effect of $\mathrm{Y}_{2} \mathrm{O}_{3}$ on low temperature sintering and thermal conductivity of AlN ceramics. Journal of the European Ceramic Society, v. 23, n. 1, p. 61-67, 2003.

77) QIAO, L.; ZHOU, H.P.; CHEN, K.X.; FU, R.L. Effects of $\mathrm{Li}_{2} \mathrm{O}$ on the low temperature sintering and thermal conductivity of AIN ceramics. Journal of the European Ceramic Society, v. 23, n. 9, p. 1517-1524, 2003. 
78) ASAI, H.; TAKAHASHI, T. Influence of the grain boundary phase on the mechanical strength at aluminum nitride substrate surfaces. IEEE Transactions on Advanced Packaging, v. 23, n. 3, p. 452-460, 2000.

79) TERAO, R.; TATAMI, J.; MEGURO, T.; KOMEYA, K. Fracture behavior of AlN ceramics with rare earth oxides. Journal of the European Ceramic Society, v. 22, n. 7, p. 1051-1059, 2002.

80) WITEK, S.R.; MILLER, G.A.; HARMER, M.P. Effects of $\mathrm{CaO}$ on the strength and toughness of AlN. Journal of the American Ceramic Society, v. 72, n. 3, p. 469-473, 1989.

81) NAKANO, H.; WATARI, K.; HAYASHI, H.; URABE, K. Microstructural characterization of high-thermal-conductivity aluminum nitride ceramic. Journal of the American Ceramic Society, v. 85, n. 12, p. 3093-3095, 2002.

82) NAKANO, H.; WATARI, K.; URABE, K. Grain boundary phase in AlN ceramics fired under reducing $\mathrm{N}_{2}$ atmosphere with carbon. Journal of the American Ceramic Society, v. 23, n. 10, p. 1761-1768, 2003.

83) WATARI, K.; NAKANO, H.; URABE, K.; ISHIZAKI, K.; CAO, S.X.; MORI, K. Thermal conductivity of AIN ceramic with a very low amount of grain boundary phase at 4 to 1000 K. Journal of Materials Research, v. 17, n. 11, p. 2940-2944, 2002.

84) ABE, H.; SATO, K.; NAITO, M.; NOGI, K.; HOTTA, T.; TATAMI, J.; KOMEYA, K. Effects of granule compaction procedures on defect structure, fracture strength and thermal conductivity of AIN ceramics. Powder Technology, v. 159, n. 3, p. 155-160, 2005.

85) DESFONTAINES, M.; JORAND, Y.; GONON, M.; FANTOZZII, G. Characterization of the green machinability of AIN powder compacts. Journal of the European Ceramic Society, v. 25, p. 781-791, 2005.

86) SUZUKI, T.S.; SAKKA, Y. Preparation of oriented bulk $5 \mathrm{wt} \% \mathrm{Y}_{2} \mathrm{O}_{3}$-AlN ceramics by slip casting in a high magnetic field and sintering. Scripta Materialia, v. 52, n. 7, p. 583-586, 2005.

87) NARITA, N.E. Efeito da temperatura na resistência e tenacidade à fratura do AlN sinterizado com $\mathbf{Y}_{2} \mathbf{O}_{3}$. 2006. 58 p. Trabalho de conclusão de curso - Universidade de São Paulo, São Paulo, 2006.

88) AZZAZ, M.; GEORGE, A. High temperature plastic deformation of aluminum nitride with a lower-oxygen content. Materials Science and Engineering, v. A364, p. 84-93, 2004. 
89) TAMAI, H.; HAMAUZU, T.; RYUMON, A.; AOKI, K.; ODA, K.; YOSHIO, T. Hydrothermal corrosion and strength degradation of aluminum nitride ceramics. Journal of the American Ceramic Society, v. 83, n. 12, p. 3216-18, 2000.

90) GERMAN, R.M. Liquid phase sintering. Plenum Press, 1985.

91) GERMAN, R.M. Sintering Theory and Practice. John Wiley \& Sons, Inc., 1996. Cap. 1: Introduction to sintering, p. 1-22.

92) RAHAMAN, M.N. Ceramic Processing and Sintering. Marcel Dekker, Inc., 1995. Cap. 7: Sintering of ceramics: Fundamentals, p. 331-373.

93) COBLE, R.L. Sintering crystalline solids. I. Intermediate and final state diffusion models. Journal of Applied Physics, v. 32, n. 5, p. 787-792, 1961.

94) COBLE, R.L. Sintering crystalline solids. II. Experimental test of diffusion models in powder compacts. Journal of Applied Physics, v. 32, n. 5, p. 793-799, 1961.

95) GERMAN, R.M. Sintering Theory and Practice. John Wiley \& Sons, Inc., 1996. Cap. 3: Solid-state sintering fundamentals, p. 67-137.

96) RAHAMAN, M.N. Ceramic Processing and Sintering. Marcel Dekker, Inc., 1995. Cap. 8: Theory of solid-state and viscous sintering, p. 374-444.

97) CHIANG, W.Y.; BIRNIE III, D.; KINGERY, W.D. Physical Ceramics. John Wileyn \& Sons, Inc., 1997. Cap. 5: Microstructure, p. 351-496.

98) ASHBY, M.F. A first report on sintering diagrams. Acta metallurgica, v. 22, p. 275-289, 1974.

99) GERMAN, R.M. Sintering Theory and Practice. John Wiley \& Sons, Inc., 1996. Cap. 6: Liquid-phase sintering, p. 226-307.

100) DONG, W.M.; JAIN, H.; HARMER, M.P. Liquid phase sintering of alumina, I. Microstructure evolution and densification. Journal of the American Ceramic Society, v. 88, n. 7, p. 1702-1707, 2005.

101) KINGERY, W.D. Densification during sintering in the presence of a liquid phase. 1. Theory. Journal of Applied Physics, v. 30, n. 3, p. 301-306, 1959. 
102) KINGERY, W.D.; NARASIMHAN, M.D. Densification during sintering in the presence of a liquid phase. 2. Experimental. Journal of Applied Physics, v. 30, n. 3, p. 307-310, 1959.

103) RAHAMAN, M.N. Ceramic Processing and Sintering. Marcel Dekker, Inc., 1995. Cap. 10: Liquid-phase sintering, p. 515-582.

104) KNOW, O.-J.; YOON, D.N. Closure of isolated pores in liquid phase sintering of W-Ni. The International Journal of Powder Metallurgy \& Powder Technology, v. 17, n. 2, p. 127-133, 1981.

105) MORTENSEN, A. Kinetics of densification by solution-reprecipitation. Acta Materialia, v. 45, n. 2, p. 749-758, 1997.

106) KANG, S.-J.L. Effect of entrapped and external gas pressure on densification during liquid phase sintering. In: Proceedings of the 4th International Symposium on Science and Technology of Sintering, 1987, Japan, p. 471-474.

107) KANG, S.-J.L.; KIM, K.-H.; YOON, D.N. Densification and shrinkage during liquidphase sintering. Journal of the American Ceramic Society, v. 74, n. 2, p. 425-427, 1991.

108) LEE, S.-M.; KANG, S.-J.L. Theoretical analysis of liquid-phase sintering: Pore filling theory. Acta Materialia, v. 46, n. 9, p. 3191-3202, 1998.

109) DONG, W.M.; JAIN, H.S.; HARMER, M.P. Liquid phase sintering of alumina, II. Penetration of liquid phase into model microstructures. Journal of the American Ceramic Society, v. 88, n. 7, p. 1708-1713, 2005.

110) DONG, W.M.; JAIN, H.S.; HARMER, M.P. Liquid phase sintering of alumina, III. Effect of trapped gases in pores on densification. Journal of the American Ceramic Society, v. 88, n. 7, p. 1714-1719, 2005.

111) KIM, J.-J.; KIM, B.-M.; SONG, B.-M.; KIM, D.-Y.; YOON, D.N. Effect of sintering atmosphere on isolated pores during the liquid-phase sintering of $\mathrm{MgO}_{-} \mathrm{CaMgSiO}_{4}$. Journal of the American Ceramic Society, v. 70, n. 10, p. 734-737, 1987.

112) WACHTMAN, J.B. Mechanical properties of ceramics. John Wiley \& Sons, Inc, 1996. Cap. 4: Strength of defect-free solids, p. 28-43.

113) ANDERSON, T.L. Fractures mechanics: fundamentals and applications. CRC Press, Inc., 1991. Cap. 2: Linear elastic fracture mechanics, p. 37-107. 
114) GREEN, D.J. An introduction to the mechanical properties of ceramics. Cambridge University Press, 1998. Cap. 8: Brittle fracture, p. 210-283.

115) BARSOUM, M.W. Fundamentals of ceramics. McGraw-Hill International, 1997. Cap. 11: Mechanical properties: fast fracture, p. 391-433.

116) LANGE, F.F. Powder processing science and technology for increased reliability. Journal of the American Ceramic Society, v. 72, n. 1, p. 3-15, 1989.

117) WACHTMAN, J.B. Mechanical properties of ceramics. John Wiley \& Sons, Inc, 1996. Cap. 5: Linear elastic fracture mechanics, p. 43-63.

118) MUNZ, D. What can we learn from R-curve measurements? Journal of the American Ceramic Society, v. 90, n. 1, p. 1-15, 2007.

119) LAWN, B.R. Fracture of brittle solids. Cambridge University Press, 1993.

120) WACHTMAN, J.B. Highlights of progress in the science of fracture of ceramics and glass. Journal of the American Ceramic Society, v. 57, n. 12, p. 509-519, 1974.

121) OLAGNON, C.; CHEVALIER, J.; PAUCHARD, V. Global description of crack propagation in ceramics. Journal of the European Ceramic Society, v. 26, n. 15, p. 30513059, 2006.

122) RICE, R.W. Limitations of pore-stress concentrations on the mechanical properties of porous materials. Journal of Materials Science, v. 32, n. 17, p. 4731-4736, 1997.

123) KRUZIC, J.J.; SATET, R.L.; HOFFMANN, M.J.; CANNON, R.M.; RITCHIE, R.O. The utility of R-curves for understanding fracture toughness-strength relations in bridging ceramics. Journal of the American Ceramic Society, v. 91, n. 6, p. 1986-1994, 2008.

124) CHANTIKUL, P.; BENNISON, S.J.; LAWN, B.R. Role of grain size in the strength and R-curve properties of alumina. Journal of the American Ceramic Society, v. 73, n. 8, p. 2419-2427, 1990.

125) RICE, R.W.; FREIMAN, S.W.; BRECHER, P.F. Grain-size dependence of fracture energy in ceramics: I, Experimental. Journal of the American Ceramic Society, v. 64, n. 6, p. 345-350, 1981. 
126) RICE, R.W.; POHANKA, R.C.; MCDONOUGH, W.J. Effect of stresses from thermal expansion anisotropy, phase transformation, and second phases on the strength of ceramics. Journal of the American Ceramic Society, v. 63, n. 11-12, p. 703-710, 1980.

127) TOMASZEWSKI, H.; BONIECKI, M.; WEGLARZ, H. Effect of grain size on R-curve behaviour of alumina ceramics. Journal of the European Ceramic Society, v. 20, p. 25692574, 2000.

128) BRAUN, L.M.; BENNISON, S.J.; LAWN, B.R. Objective evaluation of short-crack toughness curves using indentation flaws: case study on alumina-based ceramics. Journal of the American Ceramic Society, v. 75, n. 11, p. 3049-3057, 1992.

129) EVANS, A.G.; FABER, K.T. Crack-growth resistance of microcracking brittle materials. Journal of the American Ceramic Society, v. 67, n. 4, p. 255-260, 1984.

130) COOK, R.F. Effect changes in grain boundary toughness on the strength of alumina. In: Advanced Structural Ceramics, 1987, Massachusetts, USA, p. 199-206.

131) NISHIDA, T.; KAMEYAMA, I. R-curve properties of alumina. In: Fracture Mechanics of Ceramics, 1992, Nagoya, Japan, p. 277-288.

132) STEINBRECH, R.W. R-curve behavior of ceramics. In: Fracture Mechanics of Ceramics, 1992, Nagoya, Japan, p. 187-208.

133) STEINBRECH, R.W.; REICHL, A.; SCHAARWÄCHTER, W. R-curve behavior of long cracks in alumina. Journal of the American Ceramic Society, v. 73, n. 7, p. 20092015, 1990.

134) SWANSON, P.L.; FAIRBANKS, C.J.; LAWN, B.R.; MAI, Y.-W.; HOCKEY, B.J. Crack-interface grain bridging as a fracture resistance mechanism in ceramics: I, experimental study on alumina. Journal of the American Ceramic Society, v. 70, n. 4, p. 279-289, 1987.

135) IGHODARO, O.L.; OKOLI, O.I. Fracture toughness enhancement for alumina systems: a review. International Journal of Applied Ceramic Technology, v. 5, n. 3, p. 313-323, 2008.

136) KHAN, A.A.; LABBE, J.C. Aluminium nitride molybdenum ceramic matrix composites: influence of molybdenum concentration on the mechanical properties. Journal of Materials Science, v. 32, n. 14, p. 3829-3833, 1997. 
137) LANGE, F.F. Transformation-toughened $\mathrm{ZrO}_{2}$ - correlations between grain-size control and composition in the system $\mathrm{ZrO}_{2}-\mathrm{Y}_{2} \mathrm{O}_{3}$. Journal of the American Ceramic Society, v. 69 , n. 3, p. 240-242, 1986.

138) DU, X.L.; QIN, M.L.; FARID, A.; HUMAIL, I.S.; QU, X.H. Study of rare-earth oxide sintering aid systems for AIN ceramics. Materials science and engineering A-structural materials properties microstructure and processing, v. 460, p. 471-474, 2007.

139) KHOR, K.A.; YU, L.G.; MURAKOSHI, Y. Spark plasma sintering of $\mathrm{Sm}_{2} \mathrm{O}_{3}$-doped aluminum nitride. Journal of the European Ceramic Society, v. 25, n. 7, p. 1057-1065, 2005.

140) JANG, S.A.; CHOI, G.M. Electrical-conduction in aluminum nitride. Journal of the American Ceramic Society, v. 76, n. 4, p. 957-960, 1993.

141) YOUNGMAN, R.A.; HARRIS, J.H. Luminescence studies of oxygen-related defects in aluminum nitride. Journal of the American Ceramic Society, v. 73, n. 11, p. 3238-3246, 1990.

142) FRANCO, A.; SHANAFIELD, D.J. The use of yttrium(III) isopropoxide to improve thermal conductivity of polycrystalline aluminum nitride (AIN) ceramics. Journal of Materials Science: Materials in Electronics, v. 16, n. 3, p. 139-144, 2005.

143) WANG, M.C.; TSAI, M.S.; WU, N.C. Effect of process parameters on synthesis of aluminum nitride powder prepared by chemical vapor deposition. Journal of Materials Science, v. 36, n. 13, p. 3283-3289, 2001.

144) WU, N.C.; TSAI, M.S.; WANG, M.C.; LIU, H.S. The morphology and formation mechanism of aluminum nitride nanocrystals synthesized by chemical vapor deposition. Journal of Crystal Growth, v. 208, n. 1-4, p. 189-196, 2000.

145) KIM, K. Plasma synthesis and characterization of nanocrystalline aluminum nitride particles by aluminum plasma jet discharge. Journal of Crystal Growth, v. 283, n. 3-4, p. 540-546, 2005.

146) OH, S.M.; PARK, D.W. Preparation of AlN fine powder by thermal plasma processing. Thin Solid Films, v. 316, n. 1-2, p. 189-194, 1998.

147) HAO, X.P.; YU, M.Y.; CUI, D.L.; XU, X.G.; BAI, Y.J.; WANG, Q.L.; JIANG, M.H. Synthesize AlN nanocrystals in organic solvent at atmospheric pressure. Journal of Crystal Growth, v. 242, n. 1-2, p. 229-232, 2002. 
148) KROKE, E.; LOEFFLER, L.; LANGE, F.F.; RIEDEL, R. Aluminum nitride prepared by nitridation of aluminum oxide precursors. Journal of the American Ceramic Society, v. 85, n. 12, p. 3117-3119, 2002.

149) KUANG, J.C.; ZHANG, C.R.; ZHOU, X.G.; WANG, S.Q. Influence of processing parameters on synthesis of nano-sized AlN powders. Journal of Crystal Growth, v. 263, n. $1-4$, p. 12-20, 2004.

150) LEFORT, P.; BILLY, M. Mechanism of AlN formation through the carbothermal reduction of $\mathrm{Al}_{2} \mathrm{O}_{3}$ in a flowing $\mathrm{N}_{2}$ atmosphere. Journal of the American Ceramic Society, v. 76, n. 9, p. 2295-2299, 1993.

151) GU, Z.; EDGAR, J.H.; WANG, C.M.; COFFEY, D.W. Thermal oxidation of aluminum nitride powder. Journal of the American Ceramic Society, v. 89, n. 7, p. 2167-2171, 2006.

152) LI, J.W.; NAKAMURA, M.; SHIRAI, T.; MATSUMARU, K.; ISHIZAKI, C.; ISHIZAKI, K. Mechanism and kinetics of aluminum nitride powder degradation in moist air. Journal of the American Ceramic Society, v. 89, n. 3, p. 937-943, 2006.

153) BOWEN, P.; HIGHFIELD, J.G.; MOCELLIN, A.; RING, T.A. Degradation of aluminum nitride powder in an aqueous environment. Journal of the American Ceramic Society, v. 73, n. 3, p. 724-728, 1990.

154) GANESH, I.; THIYAGARAJAN, N.; SUNDARARAJAN, G.; OLHERO, S.M.; FERREIRA, J.M.F. A non-aqueous processing route for phosphate-protection of AlN powder against hydrolysis. Journal of the European Ceramic Society, v. 28, p. 2281-2288, 2008.

155) GROAT, E.A.; MROZ, T. Aqueous slip casting of stabilized AlN powders. American Ceramic Society Bulletin, v. 73, n. 11, p. 75-78, 1994.

156) KOCJAN, A.; KRNEL, K.; KOSMAC, T. The influence of temperature and time on the AlN powder hydrolysis reaction products. Journal of the European Ceramic Society, v. 28, n. 5, p. 1003-1008, 2008.

157) SUEHIRO, T.; HIROSAKI, N.; TERAO, R.; TATAMI, J.; MEGURO, T.; KOMEYA, $\mathrm{K}$. Synthesis of aluminum nitride nanopowder by gas-reduction-nitridation method. Journal of the American Ceramic Society, v. 86, n. 6, p. 1046-1048, 2003.

158) WATARI, K. High thermal conductivity non-oxide ceramics. Journal of the Ceramic Society of Japan, v. 109, n. 1, p. S7-S16, 2001. 
159) BERGER, A. Nucleation and growth of inversion domains in AlN: 1. Study of fundamental processes. Journal of the American Ceramic Society, v. 78, n. 1, p. 153-160, 1995.

160) HARRIS, J.H.; YOUNGMAN, R.A.; TELLER, R.G. On the nature of the oxygenrelated defect in aluminum nitride. Journal of Materials Research, v. 5, n. 8, p. 1763-1773, 1990.

161) WESTWOOD, A.D.; NOTIS, M.R. Inversion domain boundaries in aluminum nitride. Journal of the American Ceramic Society, v. 74, n. 6, p. 1226-1239, 1991.

162) GORZAWSKI, G.; STERNITZKE, M.; MULLER, W.F.; BERGER, A.; MULLER, G. Oxygen enrichment at inversion domain boundaries in aluminum nitride - influence on thermal-conductivity. Journal of the European Ceramic Society, v. 15, n. 1, p. 95-99, 1995.

163) WATARI, K.; ISHIZAKI, K.; TSUCHIYA, F. Phonon scattering and thermal conduction mechanisms of sintered aluminium nitride ceramics. Journal of Materials Science, v. 28, p. 3709-3714, 1993.

164) WERDECKER, W.; ALDINGER, F. Aluminum nitride - an alternative ceramic substrate for high-power applications in microcircuits. IEEE Transactions on Components Hybrids and Manufacturing Technology, v. 7, n. 4, p. 399-404, 1984.

165) MEDRAJ, M.; BAIK, Y.; THOMPSON, W.T.; DREW, R.A.L. Understanding AIN sintering through computational thermodynamics combined with experimental investigation. Journal of Materials Processing Technology, v. 161, n. 3, p. 415-422, 2005.

166) DREW, R.A.L.; BAIK, Y.; ENTEZARIAN, M. Effect of $\mathrm{Y}_{2} \mathrm{O}_{3}$ content on sintering of Aluminum nitride. Materials Science Forum, v. 325-326, p. 249-254, 2000.

167) KOMEYA, K.; INOUE, H. Sintering of aluminium nitride: particle size dependence of sintering kinetics. Journal of Materials Science, v. 4, p. 1045-1050, 1969.

168) KURAMOTO, N.; TANIGUCHI, H. Transparent AIN ceramics. Journal of Materials Science Letters, v. 3, p. 471-474, 1984.

169) TANIGUSHI, H.; KIKUTANI, S.; KURAMOTO, N. Sinterability of aluminum nitride. In: Proceedings of the International Institute for the Science of Sintering (IISS) Symposium Held in Tokyo, 1987, Japan, p. 956-961. 
170) McCAULEY, J.W.; CORBIN, N.D. High Temperature Reactions and Microstructures in the $\mathrm{Al}_{2} \mathrm{O}_{3}$-AlN System. In: Progress in Nitrogen Ceramics, 1981, University Sussex, Falmer, UK, p. 111-118.

171) KOMEYA, K.; INOUE, H.; TSUGE, A. Role of $\mathrm{Y}_{2} \mathrm{O}_{3}$ and $\mathrm{SiO}_{2}$ additions in sintering of AlN. Journal of the American Ceramic Society, v. 57, n. 9, p. 411-412, 1974.

172) PROCHAZKA, S.; BOBIK, C.F. Sintering of aluminium nitride. In: Proceedings of the Fifth International Conference on Sintering and Related Phenomena, 1979, University of Notre Dame, Indiana, $\mathrm{p}$.

173) CHEN, C.-F.; PERISSE, M.E.; RAMIREZ, A.F.; PADTURE, N.P.; CHAN, H.M. Effect of grain boundary phase on the thermal conductivity of aluminium nitride ceramics. Journal of Materials Science, v. 29, p. 1595-1600, 1994.

174) KUME, S.; YASUOKA, M.; OMURA, N.; WATARI, K. Annealing effect on dielectric property of AIN ceramics. Journal of the European Ceramic Society, v. 26, n. 10-11, p. 1831-1834, 2006.

175) TANGEN, I.L.; YU, Y.D.; GRANDE, T.; HOIER, R.; EINARSRUD, M.A. Phase relations and microstructural development of aluminum nitride-aluminum nitride polytypoid composites in the aluminum nitride-alumina-yttria system. Journal of the American Ceramic Society, v. 87, n. 9, p. 1734-1740, 2004.

176) YU, Y.D.; HUNDERE, A.M.; HOIER, R.; DUNIN-BORKOWSKI, R.E.; EINARSRUD, M.A. Microstructural characterization and microstructural effects on the thermal conductivity of $\mathrm{AlN}\left(\mathrm{Y}_{2} \mathrm{O}_{3}\right)$ ceramics. Journal of the European Ceramic Society, v. 22, n. 2, p. 247-252, 2002.

177) FU, R.; CHEN, K.; AGATHOPOULOUS, S.; FERRO, M.C.; TULYAGANOV, D.U.; FERREIRA, J.M.F. Migration of liquid phase in low temperature sintering of AIN. Journal of Materials Science, v. 40, n. 9-10, p. 2425-2429, 2005.

178) ICHINOSE, N. The Thermal Conductivity of Sintered AlN-YF 3 System. In: Proceedings of the International Institute for the Science of Sintering (IISS) Symposium Held in Tokyo, 1987, Japan, p. 950-955.

179) OLHERO, S.M.; JENSEN, Z.S.; EINARSUD, M.A.; GRANDE, T.; FERREIRA, J.M.F. Thermodynamic studies on the AIN sintering powders treated with phosphate species. Journal of the American Ceramic Society, v. 90, n. 11, p. 3589-3595, 2007. 
180) BUHR, H.; MÜLLER, G.; WIGGERS, H.; ALDINGER, F.; FOLEY, P.; ROOSEN, A. Phase composition, oxygen content, and thermal conductivity of $\operatorname{AlN}\left(\mathrm{Y}_{2} \mathrm{O}_{3}\right)$ ceramic. Journal of the American Ceramic Society, v. 74, n. 4, p. 718-723, 1991.

181) LEVIN, E.M.; ROBBINS, C.R.; MCMURDIE, H.F. Phase diagrams for ceramists. The American Ceramic Society, Inc., 1969.

182) SHINOZAKI, K.; SAWADA, Y.; MIZUTANI, N. Liquid phase formation and its migration in aluminum nitride ceramics. In: Mass and Charge Transport in Ceramics, 1996, Nagoya, Japan, p. 307-321.

183) KIM, N.H.; FUN, Q.D.; KOMEYA, K.; MEGURO, T. Phase reaction and sintering behavior in the pseudoternary system $\mathrm{AlN}-\mathrm{Y}_{2} \mathrm{O}_{3}-\mathrm{Al}_{2} \mathrm{O}_{3}$. Journal of the American Ceramic Society, v. 79, n. 10, p. 2645-2651, 1996.

184) LIN, K.-H.; LIN, Y.-C.; LIN, S.-T. Effects of reduction atmosphere and nano carbon powder addition on the deoxidization of injection molded aluminum nitride parts. Journal of materials processing technology, v. 201, p. 701-705, 2008.

185) LAM, D.C.C.; LANGE, F.F.; EVANS, A.G. Mechanical properties of partially dense alumina produced from powder compacts. Journal of the American Ceramic Society, v. 77, n. 8, p. 2113-2117, 1994.

186) MOLISANI, A.L.; YOSHIMURA, H.N.; GOLDENSTEIN, H. Sintering mechanisms in aluminum nitride with $\mathrm{Y}$ or Ca-containing additive. Journal of Materials Science: Materials in Electronics, v. 20, p. 1-8, 2009.

187) MOLISANI, A.L.; YOSHIMURA, H.N.; GOLDENSTEIN, H. Efeito do teor de $\mathrm{Y}_{2} \mathrm{O}_{3}$ na sinterização do nitreto de alumínio. Cerâmica, v. 52, p. 151-160, 2006.

188) KWON, O.-H.; MESSING, G.L. Kinetic analysis of solution-precipitation during liquidphase sintering of alumina. Journal of the American Ceramic Society, v. 73, n. 2, p. 275$281,1990$.

189) LIU, Y.; WU, Y.; ZHOU, H. Microstruture of low-temperature sintered AlN. Materials Letters, v. 35, p. 232-235, 1998.

190) ENLOE, J.H.; RICE, R.W.; LAU, J.W.; KUMAR, R.; LEE, S.Y. Microstrutural effects on the thermal conductivity of polycrystalline aluminum nitride. Journal of the American Ceramic Society, v. 74, n. 9, p. 2214-2219, 1991. 
191) HONMA, T.; KUROKI, Y.; OKAMOTO, T.; TAKATA, M.; KANECHIKA, Y.; AZUMA, M.; TANIGUCHI, H. Transmittance and cathodoluminescence of AlN ceramics sintered with $\mathrm{Ca}_{3} \mathrm{Al}_{2} \mathrm{O}_{6}$ as sintering additive. Ceramics International, v. 34, n. 4, p. 943-946, 2008 .

192) XIONG, Y.; FU, Z.Y.; WANG, H.; WANG, Y.C.; ZHANG, Q.J. Microstructure and IR transmittance of spark plasma sintering translucent $\mathrm{AlN}$ ceramics with $\mathrm{CaF}_{2}$ additive. Materials Science and Engineering, v. B 123, p. 57-62, 2005.

193) KUROKAWA, Y.; TOY, C.; SCOT, W.D. Characterization of the AIN-W interface in a cofired multilayer AIN substrate. Journal of the American Ceramic Society, v. 72, n. 4, p. 612-616, 1989.

194) ZAHNEISEN, R.; RÜSSEL, C. Thermal conductivity of calcium-doped aluminum nitride ceramics. Part II: Polymer-derived ceramics. Journal of Materials Science, v. 28, p. 870-874, 1993.

195) STREICHER, E.; CHARTIER, T.; BOCH, P. Influence of organic-components on properties of tape-cast aluminum nitride substrates. Ceramics International, v. 16, n. 4, p. 247-252, 1990.

196) HAFIDI, A.; BILLY, M.; LECOMPTE, J.P. Influence of microstructural parameters on thermal diffusivity of aluminum nitride-based ceramics. Journal of Materials Science, v. 27, p. 3405-3408, 1992.

197) SURNEV, S.; LEPKOVA, D.; YOLEVA, A. Influence of the sintering additives on the phase composition and the thermal conductivity of aluminum nitride ceramics. Materials Science and Engineering B, v. 10, n. 1, p. 35-40, 1991.

198) HORVATH, S.F.; WITEK, S.R.; HARMER, M.P. Effects of carbon and calcium oxide on the sintering behavior of aluminum nitride. Advances in Ceramics, v. 26, p. 121-132, 1989.

199) FANG, Z.Y.; LIU, Y.C.; WU, Y.; ZHOU, H.P. Microstructure and dielectric dispersion of low-temperature sintered AlN. Journal of Materials Science Letters, v. 19, n. 2, p. 95-97, 2000 .

200) MIAO, W.G.; WU, Y.; ZHOU, H.P. Low temperature co-fired AlN multilayer substrates. Journal of Materials Science: Materials in Electronics, v. 8, n. 4, p. 233-238, 1997. 
201) YOSHIMURA, H.N.; MOLISANI, A.L.; NARITA, N.E.; CESAR, P.F.; GOLDENSTEIN, H. Porosity dependence of elastic constants in aluminum nitride ceramics. Materials Research, v. 10, n. 2, p. 127-133, 2007.

202) YOSHIMURA, H.N.; MOLISANI, A.L.; SIQUEIRA, G.R.; DE CAMARGO, A.C.; NARITA, N.E.; CESAR, P.F.; GOLDENSTEIN, H. Efeito da porosidade nas propriedades mecânicas de uma alumina de elevada pureza. Cerâmica, v. 51, n. 319, p. 239-251, 2005.

203) RICE, R.W. Comparison of physical property porosity behaviour with minimum solid area models. Journal of Materials Science, v. 31, n. 6, p. 1509-1528, 1996.

204) RICE, R.W. Evaluation and extension of physical property-porosity models based on minimum solid area. Journal of Materials Science, v. 31, n. 1, p. 102-118, 1996.

205) PABST, W.; GREGOROVÁ, E.; TICHÁ, G. Elasticity of porous ceramics: a critical study of modulus-porosity relations. Journal of the European Ceramic Society, v. 26, p. 1085-1097, 2006.

206) KNUDSEN, F.P. Dependence of mechanical strength of brittle polycrystalline specimens on porosity and grain size. Journal of the American Ceramic Society, v. 42, n. 8, p. 376-387, 1959.

207) KOVACIK, J. Correlation between elastic Modulus, shear modulus, Poisson's ratio and porosity in porous materials. Advanced Engineering Materials, v. 10, n. 3, p. 250-252, 2008.

208) PHANI, K.K.; SANYAL, D. Critical reevaluation of the prediction of effective Poisson's ratio for porous materials. Journal of Materials Science, v. 40, n. 21, p. 5685-5690, 2005.

209) PHANI, K.K.; SANYAL, D. The relation between the shear modulus, the bulk modulus and Young's modulus for porous isotropic ceramic materials. Material Science Engineering A, v. 490, p. 305-312, 2008.

210) RICE, R.W. Use of normalized porosity in models for the porosity dependence of mechanical properties. Journal of Materials Science, v. 40, n. 4, p. 983-989, 2005.

211) HRISTOPULOS, D.; DEMERTZI, M. A semi-analytical equation for the Young's modulus of isotropic ceramic materials. Journal of the European Ceramic Society, v. 28, p. 1111-1120, 2008.

212) PHANI, K.K.; NIYOGI, S.K. Elastic modulus-porosity relation in polycrystalline rareearth oxides. Journal of the American Ceramic Society, v. 70, n. 12, p. C362-C366, 1987. 
213) RICE, R.W. Microstructure dependence of mechanical behaviour of ceramics. In: Properties and microstructures, 1977, New York, p. 199-381.

214) KOVACIK, J. Correlation between Poisson's ratio and porosity in porous materials. Journal of Materials Science, v. 41, p. 1247-1249, 2006.

215) BOCH, P.; GLANDUS, J.C.; JARRIGE, J.; LECOMPTE, J.P.; MEXMAIN, J. Sintering, oxidation and mechanical properties of hot pressed aluminum nitride. Ceramics International, v. 8, n. 1, p. 34-40, 1982.

216) DE WITH, G.; HATTU, N. High-temperature fracture of hot-pressed AlN ceramics. Journal of Materials Science, v. 18, p. 503-507, 1983.

217) DAGDAG, S.; ALEXIS, J.; BEGUIN, J.-D.; PETIT, J.-A.; FERRATO, M. Relation between microstructure and mechanical properties of spark plasma sintered aluminum nitride. In: Sintering 05, 2005, Grenoble, France, p. 168-171.

218) DODD, S.P.; SAUNDERS, G.A.; CANKURTARAN, M.; JAMES, B. Ultrasonic study of the elastic and nonlinear acoustic properties of ceramic aluminum nitride. Journal of Materials Science, v. 36, p. 723-729, 2001.

219) SUBHASH, G.; RAVICHANDRAN, G. Mechanical behaviour of a hot pressed aluminum nitride under uniaxial compression. Journal of Materials Science, v. 33, p. 19331939, 1998.

220) TANGEN, I.L.; YU, Y.D.; GRANDE, T.; HOIER, R.; EINARSRUD, M.A. Preparation and characterization of aluminium nitride-titanium nitride composites. Ceramics International, v. 30, p. 931-938, 2004.

221) BRULS, R.J.; HINTZEN, H.T.; DE WITH, G.; METSELAAR, R. The temperature dependence of the Young's modulus of $\mathrm{MgSiN}_{2}, \mathrm{AlN}$ and $\mathrm{Si}_{3} \mathrm{~N}_{4}$. Journal of the European Ceramic Society, v. 21, p. 263-268, 2001.

222) GERLICH, D.; DOLE, S.L.; SLACK, G.A. Elastic properties of aluminum nitride. Journal Phys. Chem. Solids, v. 47, n. 5, p. 437-441, 1986.

223) PALIT, D.; MEIER, A.M. Reaction kinetics and mechanical properties in the reactive brazing of copper to aluminum nitride. Journal of Materials Science, v. 41, p. 7197-7209, 2006.

224) SAKAI, T. Effect of oxygen composition on flexural strength of hot-pressed AIN. Journal of the American Ceramic Society, v. 61, n. 9, p. 460-461, 1978. 
225) LECOMPTE, J.P.; JARRIGE, J.; MEXMAIN, J. Hot Pressing of Aluminum Nitride. In: Progress in Nitrogen Ceramics, 1981, University SSussex, Falmer, UK, p. 293-299.

226) ROULET, F.; TRISTANT, P.; DESMAISON, J.; REZAKHANLOU, R.; FERRATO, M. Corrosion behaviour of aluminium nitride in liquid aluminium: Influence of the microstructure. Journal of the European Ceramic Society, v. 17, n. 15-16, p. 1877-1883, 1997.

227) SAKAI, T. Hight-temperature strength of $\mathrm{AlN}$ hot-pressed with $\mathrm{Al}_{2} \mathrm{O}_{3}$ additions. Journal of the American Ceramic Society, v. 64, n. 3, p. 135-137, 1981.

228) ICHIMARU, H.; PEZZOTTI, G. Raman microprobe mapping of residual and bridging stress fields in AlN ceramics. Materials Science and Engineering, v. A 326, n. 2, p. 261269, 2002.

229) LUBIS, A.H.; HECHT, N.L.; GRAVES, G.A., JR.; RUH, R. Microstruture-property relations of hot-pressed silicon carbide-aluminum nitride compositions at room and elevated temperatures. Journal of the American Ceramic Society, v. 82, n. 9, p. 2481-2489, 1999.

230) HUANG, J.-L.; JIH, J.-M. Investigation of SiC-AlN: Part II, mechanical properties. Journal of the American Ceramic Society, v. 79, n. 5, p. 1262-1264, 1996.

231) ANSTIS, G.R.; CHANTIKUL, P.; LAWN, B.R.; MARSHALL, D.B. A criticalevaluation of indentation techniques for measuring fracture-toughness: 1. Direct crack measurements. Journal of the American Ceramic Society, v. 64, n. 9, p. 533-538, 1981.

232) CHANTIKUL, P.; ANSTIS, G.R.; LAWN, B.R.; MARSHALL, D.B. A critical evaluation of indentation techniques for measuring fracture toughness: II, strength method. Journal of the American Ceramic Society, v. 64, n. 9, p. 539-543, 1981.

233) QUINN, G.D. Fractography of ceramics and glasses. U.S. Government Print Office Washington, 2006. Cap. 7: Quantitative analysis, p. 7-27.

234) LI, M.; REECE, M.J. Influence of grain size on the indentation-fatigue behavior of alumina. Journal of the American Ceramic Society, v. 83, n. 4, p. 967-970, 2000. 